\title{
Impact of Whole-School Education for Sustainability on Upper-Primary Students and their Families
}

\author{
Zarín Táj Salter \\ BSc. (UNSW) Hons. (UWA)
}

This thesis is presented for the degree of Doctor of Philosophy at The University of Western Australia

Graduate School of Education

2013

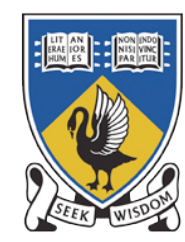

THE UNIVERSITY OF

WESTERN AUSTRALIA 


\section{DECLARATION}

I declare that this dissertation is my own work and that no part of it has been submitted for a degree or diploma in any university. To the best of my knowledge, this thesis does not contain any materials previously published or written by another author other than those that have been referenced appropriately in the text and reproduced with permission. This thesis has been referenced in accordance with the American Psychological Association (2010) publication guidelines.

I have the permission of each of my co-authors, Winthrop Professor Grady Venville and Associate Professor Nancy Longnecker, to include work from the following publication in my thesis. Sections from this publication appear in Chapters 2 and 5 of this thesis.

Salter, Z., Venville, G., Longnecker, N. (2011). An Australian story: School sustainability education in the lucky country. Australian Journal of Environmental Education - Special Issue. 27 (1): p. 149-159.

Signatures:

Zarin Salter

Winthrop Professor

Grady Venville
Associate Professor

Nancy Longnecker

July 2013 


\section{List of Publications ANd PRESENTATIONS FROM this ReSEARCH}

Salter, Z., Venville, G., Longnecker, N. (2011). An Australian story: School sustainability education in the lucky country. Australian Journal of Environmental Education - Special Issue. 27 (1): p. 149-159.

Salter, Z., Longnecker, N., Venville, G. (2012, May). Using mind maps to assess student environmental knowledge. A seminar presented to the Centre for Science and the Schools Research Group at the Pennsylvania State University. USA.

Salter, Z., Longnecker, N., Venville, G. (2011, October). A summary of research on sustainability education at two Perth primary schools. Two papers presented at the UWA Postgraduate Fogarty Forum. Perth, WA.

Salter, Z., Longnecker, N., Venville, G. (2011, September). Sustainability education at school and home: Intergenerational influence and proenvironmentalism. A poster presented at the European Science Education Research Association annual conference. Lyon, France.

Salter, Z., Longnecker, N., Venville, G. (2011, August). Sustainability education at school and home: AuSSI - WA and Intergenerational influence. Presented as part of a symposium on AuSSI - WA at the 26th annual Western Australian Institute of Educational Research forum. Fremantle, WA.

Salter, Z., Longnecker, N., Venville, G. (2011, July). Sustainability education at a Perth primary school: What difference does it make anyway? A roundtable presented at the 6th biennial World Environmental Education Congress. Brisbane, QLD.

Salter, Z., Longnecker, N., Venville, G. (2010, September). Tapestry of relationships: The Millennium Kids' approach to sustainability facilitation. A paper presented at the Australian Association for Environmental Education biennial conference. Canberra, ACT.

Salter, Z., Longnecker, N., Venville, G. (2009, August). Greening behaviour: Impact of whole school sustainability education on students and families. A paper presented at the 24th annual Western Australian Institute for Educational Research annual conference. Perth, WA.

Salter, Z., Longnecker, N., Venville, G. (2009, May). Impact of whole-school approaches to education for sustainability on adoption of environmentally responsible behaviours by upper-primary students and their families. A paper presented at the UWA Postgraduate Fogarty Forum. Perth, WA. 


\begin{abstract}
This doctoral research explored the impact of whole-school education for sustainability on upper-primary students and their families. More specifically, it examined: organisational factors that foster or impede the establishment of school sustainability programs; the environmental knowledge, attitudes and behaviours of upper-primary school students; the family dynamics that influence intergenerational transfer of pro-environmental behaviours between students and their families; and identified factors that potentially maximised the impact of whole-school education for sustainability.

A multiple comparative case study approach was utilised, involving three primary schools with populations of similar socio-economic status in Perth, Western Australia. Two of these schools were connected with the Australian Sustainable Schools Initiative - Western Australia (AuSSI - WA) and the third was not involved with any sustainability or environmental education providers. The case study design included mixed methods of data collection, triangulated for analysis. Methods included surveys, mind maps, interviews, observations and document searches.

Results indicated that effective whole-school sustainability education requires: visionary, committed school leadership; collaborative governance that invites participation from all staff; a few core staff to spearhead projects; contextualised professional learning opportunities; and authentic engagement of student voice. When these elements are prioritised, school sustainability programs can have a positive impact on students' knowledge about ways they can care for the environment and attitudes towards school environmental activities. Furthermore, when sustainability facilitators work closely with schools these outcomes can be maximised. The degree to which pro-environmental behaviours carry into students' home lives, however, is mediated by complexity of the behaviour, family norms and parents' willingness to encourage their child's enthusiasm.

Environmental educators and school sustainability coordinators can foster willingness to act and action competence in students by creating meaningful leadership opportunities that can turn a student's knowledge and interest into enthusiasm and empowerment. They can also influence a parent's responsiveness to their child's environmental interest by fostering collaborative parent and school relationships. These relationships provide opportunities for students and their parents to learn ways of simplifying complex pro-environmental behaviours, integrate them into their family life and ultimately create social norms and communities of practice.
\end{abstract}




\section{ACKNOWLEDGEMENTS}

This thesis is dedicated to my brother Adam, who was taken tragically from this world on 18 November 2009. Adam always encouraged me to achieve excellence in whatever I put my energies towards and I know he is proud of me now. The following lyrics, from of one of Adam's favourite songs by José González, have given me hope and peace of mind during the difficult hours of writing this thesis:

Don't you know that I'll be around to guide you? Through your weakest moments to leave them behind you. Returning nightmares, only shadows.

We'll cast some light and you'll be alright...

I would like to thank many people for their constant love and support in my life. I thank my husband Shamim, for he is my rock - with him in my life I am stronger, more joyful and content. I thank my parents, Lynne and Adrian, for their guidance, love, encouragement, for helping to edit my thesis and for their patience in waiting for grandchildren. I thank my brothers, Adam and Noah, for always looking out for me. I thank my closest girlfriends, Katie, Janey, Luki and Kate, for their authenticity, love and inspiration in my life - friendships like these come once in a life and are deeply treasured. I thank my parents-in-law, Rouha and Heshmat, and siblings-in-law, Shabnam and Erfan, for their overwhelming love, compassion and support. I thank my chiropractor and cousin-in-law, Soroush, for keeping me thinking straight. And I thank many other friends and family who are too many to name here. Without the support of each of these people, writing this thesis would have been a momentous struggle. It was, nonetheless, a difficult task, but one made easier because of the support and love of so many close friends and family.

I would also like to thank my research colleagues from the Science Communication Research Group at The University of Western Australia and from the Environmental Education Research Group at Murdoch University for their friendships, their assistance with data analysis, and our many interesting discussions.

Finally, I would like to thank my supervisors, Nancy Longnecker and Grady Venville, for their ongoing support, understanding and compassion shown towards me through the rough patches I have traversed over the past four years. I also thank them for: their wise advice; meeting regularly with me amidst their busy teaching, research, supervision and professional schedules; and their encouragement of my research practice and thesis writing. I am a better researcher now for their guidance and mentoring. 


\section{TABLE OF CONTENTS}

$\begin{array}{lll}\text { LIST OF FIGURES } & \text { IX }\end{array}$

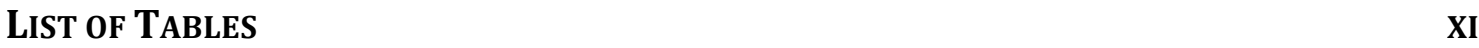

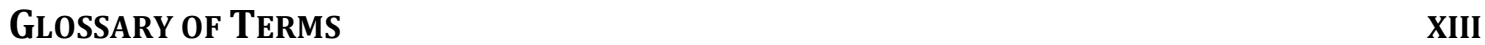

ChAPTER 1: InTroduction, BACKground AND ConteXt 1

Research Rationale $\quad 2$

Aim of the Research 6

$\begin{array}{lr}\text { Significance of the Research } & 7\end{array}$

$\begin{array}{lr}\text { Research Paradigm } & 10\end{array}$

Western Australian Context 12

$\begin{array}{ll}\text { Thesis Outline } & 19\end{array}$

$\begin{array}{ll}\text { Chapter Conclusion } & 20\end{array}$

Chapter 2: Literature ReVIEW AND THEORETICAL FrameWORK $\quad \mathbf{2 1}$

Environmental Education, Education for Sustainability or Environmental Education for Sustainability? $\quad 22$

Key Elements of School Sustainability Education $\quad 28$

$\begin{array}{ll}\text { Pro-Environmental Behaviour } & 39\end{array}$

Intergenerational Influence and Family Dynamics $\quad 52$

Research Methods $\quad 54$

Theoretical Framework and Propositions $\quad 62$

$\begin{array}{ll}\text { Chapter Conclusion } & 65\end{array}$

Chapter 3: Research Design ANd Methodology 67

$\begin{array}{ll}\text { Research Design } & 67\end{array}$

$\begin{array}{ll}\text { Instrument Design, Data Collection and Data Analysis } & 79\end{array}$

$\begin{array}{lr}\text { Research Rigour } & 98\end{array}$

$\begin{array}{lr}\text { Ethical Considerations } & 107\end{array}$

$\begin{array}{ll}\text { Chapter Conclusion } & 109\end{array}$

Chapter 4: A Pioneering Push - Lighthouse Primary School 111

Research Question 1: What Organisational Factors Fostered or Impeded the Establishment of Whole-School Sustainability at Lighthouse Primary School?

Research Question 2: What was the Environmental and Sustainability Knowledge of Upper-Primary Students at Lighthouse Primary School?

Research Question 3: What were the Environmental Behaviours of Upper-Primary

Students at Lighthouse Primary School?

$\begin{array}{ll}\text { Chapter Conclusion } & 149\end{array}$

\section{Chapter 5: Small Steps ANd Giant Leaps - River's Edge Primary SchOol 151}

Research Question 1: What Organizational Factors Fostered or Impeded the Establishment of Sustainability Initiatives at River's Edge Primary School?

Research Question 2: What was the Environmental and Sustainability Knowledge of Upper-Primary Students at River's Edge Primary School?

Research Question 3: What were the Environmental Behaviours of Upper-Primary Students at River's Edge Primary School? 
Research Question 1: What Organisational Factors Fostered or Impeded the Establishment of Sustainability Initiatives at Fertile Ground Primary School?

Research Question 2: What was the Environmental and Sustainability Knowledge of Upper-Primary Students at Fertile Ground Primary School?

Research Question 3: What were the Environmental Behaviours of Upper-Primary Students at Fertile Ground Primary School?

Chapter Conclusion

Chapter 7: Student Environmental AtTitudes AND Behaviours - Lighthouse AND RIVER's Edge Primary SCHOOLS

Research Question 4: What was the Relationship Between the Environmental Attitudes and Behaviours of Upper-Primary Students?

Chapter Conclusion

ChAPTER 8: FAMILY DYNAMICS AND INTERgENERATIONAL INFLUENCE - LigHTHOUSE AND River's Edge Primary Schools

Research Question 5: What Were the Family Dynamics that Contributed to Intergenerational Influence and the Uptake of New Environmental Behaviours in the Homes of Students at Lighthouse and River's Edge Primary Schools?

Chapter 9: UnPaCking Sustainability - Synthesis ANd Conclusions

Organisational Factors that Foster or Impede Whole-School Sustainability Education 245 Environmental Knowledge, Attitudes and Behaviours of Students 260

$\begin{array}{ll}\text { Family Dynamics and Intergenerational Influence } & 278\end{array}$

$\begin{array}{ll}\text { Limitations } & 283\end{array}$

$\begin{array}{ll}\text { Recommendations } & 285\end{array}$

Advocacy for AuSSI - WA 287

$\begin{array}{ll}\text { Future Research } & 288\end{array}$

$\begin{array}{ll}\text { Conclusion } & 288\end{array}$

$\begin{array}{lr}\text { REFERENCES } & 291\end{array}$

$\begin{array}{ll}\text { APPENDIX } 1 \text { - InTERVIEW Protocols } & \mathbf{3 0 7}\end{array}$

APPEndix 2 - Mind MaP Templates and Coding Materials $\quad 317$

$\begin{array}{ll}\text { APPENDIX } 3 \text { - SURVEY QUESTIONNAIRES } & 323\end{array}$

AppendiX 4 - Detailed Student Behaviour Results from Lighthouse Primary $\begin{array}{ll}\text { SCHOOL } & 329\end{array}$

ApPendix 5 - Detailed Student Behaviour Results from River's Edge Primary SCHOOL

APPENDIX 6 - DETAILED STUDENT BEHAVIOUR RESULTS FROM FERTILE GROUND PRIMARY SCHOOL

ApPendix 7 - Correlation Matrices, Scree Plots And Tests of Configural INVARIANCE 


\section{LIST OF FigURES}

Figure 1.1: 'Ecological footprint' and 'social handprint' visual tools provided to participating AuSSI - WA schools. Reproduced with permission from DoE, $2012 \mathrm{~b}$.

Figure 2.1: $\quad$ UNESCO's model of the interlocking dimensions of sustainability (C) UNESCO. All rights reserved. Reproduced with permission from UNESCO (2002).

Figure 2.2: $\quad$ Two dominant conceptualisations of sustainability that inform debates on education for sustainability.

Figure 2.3: $\quad$ AuSSI - WA Key Elements Rubric. Reproduced with permission from DoE, $2012 \mathrm{~b}$.

Figure 2.4: $\quad$ Model of Responsible Environmental Behaviour. Redrawn from Hines, Hungerford and Tomera, 1987.

Figure 2.5: Theoretical framework that guided this research.

Figure 3.1: $\quad$ Illustration of the research paradigm and theoretical lens adopted for this research and the mixed method multiple case study design considered most suitable to address the research questions.

Figure 3.2: $\quad$ Example of a student's mind map showing hierarchies sketched from each of the two constructs.

Figure 3.3: $\quad$ Example of a student's mind map showing ideas sketched from one construct.

Figure 3.4: The nested hierarchical design of this research, showing number of students surveyed within classrooms and within schools.

Figure 4.1: Large sustainability themed mosaic, contributed to by many dedicated staff, students, administrators and parents. Completed in 2006.

Figure 4.2: $\quad$ Top left: Green Envirokids sashes on display in Mrs Brolga's classroom. Top right: Envirokids lining up for the weekly weighing of paper recycling boxes collected from every classroom and office in the school. Bottom left: Envirokids removing contamination from schoolyard recycling bins before tipping the contents into the yellow-topped recycling bins. Bottom right: The three bin waste sorting system at Lighthouse Primary School - compost bucket, blue recycling bin, green general waste bin.

Figure 4.3: $\quad$ Top left: Carbon material (paper, dried leaves, etcetera) for adding into compost. Bottles of worm juice fertiliser and bags of compost stored for later sale. Top right: Girl from Year 6 composting team chopping-up the daily fruit and vegetable scraps. Bottom left: Closer look at how the fruit and vegetable scraps are chopped. Bottom right: Year 6 composting team turning the compost tumblers.

Figure 4.4: $\quad$ Depth of knowledge for each construct, $n_{S}=161, n_{H E}=161$.

Figure 4.5: $\quad$ Volume of knowledge for each construct, $n_{S}=161, n_{H E}=161$.

Figure 4.6: $\quad$ Breadth of knowledge for each construct, $n_{S}=161, n_{H E}=161$.

Figure 4.7: $\quad$ Percent response per theme per construct, $n_{S}=161, n_{H E}=161$.

Figure 4.8: $\quad$ Percent of year group response per theme per construct, $n_{4}=54, n_{5}=52, n_{6}=55$.

Figure 4.9: $\quad$ Percentage of students that reported they undertook each of the seven proenvironmental behaviours in 2009 and 2010 'never', 'less than weekly' or 'more than weekly'. $\mathrm{n}_{2009}=161, \mathrm{n}_{2010}=157$.

Figure 5.1: Timeline of sustainability activities at River's Edge Primary School before their partnership with AuSSI - WA and Millennium Kids.

Figure 5.2: $\quad$ Examples of student work created after Grandparents' Day and references made to the "eight pillars of sustainability".

Figure 5.3: Left: Examples of Millennium Kids' student conferences. Right: Dolls made for student art activities that were donated to a Millennium Kids development project in South Africa.

Figure 5.4: $\quad$ Examples of the Year 5 focus on water conservation.

Figure 5.5: $\quad$ Depth of knowledge for each construct, $n_{S}=154, n_{H E}=154$.

Figure 5.6: $\quad$ Volume of knowledge for each construct, $n_{S}=154, n_{H E}=154$.

Figure 5.7: $\quad$ Breadth of knowledge for each construct, $n_{S}=154, n_{H E}=154$. 
Figure 5.8: $\quad$ Percent response per theme per construct, $n_{S}=154, n_{H E}=154$.

Figure 5.9: $\quad$ Percent of year group response per theme per construct, $n_{4}=42, n_{5}=55, n_{6}=57$.

Figure 5.10: Percentage of students that reported they undertook each of the seven proenvironmental behaviours in 2009 and 2010 'never', 'less than weekly' or 'more than weekly'. $\mathrm{n}_{2009}=155, \mathrm{n}_{2010}=128$.

Figure 6.1: $\quad$ The tomatoes in a wheelbarrow being grown by a Year 1 class.

Figure 6.2: $\quad$ Examples of Year 5 students' work on environmental footprints, energy reduction and renewable energies.

Figure 6.3: $\quad$ Examples of Year 4 students' work on the theme of water conservation.

Figure 6.4: $\quad$ Depth of knowledge for each construct, $n_{S}=26, n_{H E}=26$.

Figure 6.5: $\quad$ Volume of knowledge for each construct, $n_{S}=26, n_{H E}=26$.

Figure 6.6: $\quad$ Breadth of knowledge for each construct, $n_{S}=26, n_{H E}=26$.

Figure 6.7: $\quad$ Percent response per theme per construct, $n_{S}=26, n_{H E}=26$.

Figure 6.8: $\quad$ Percent of year group response per theme per construct, $n_{5}=8, n_{6}=16$.

Figure 6.9: Percentage of students that reported they undertook each of the seven proenvironmental behaviours in 2009 either 'never', 'less than weekly' or 'more than weekly', $\mathrm{n}_{2009}=26$.

Figure 7.1: The nested hierarchical design of this research, showing number of students surveyed within classrooms and within schools. Originally shown in Chapter 3, but replicated here for the benefit of the reader.

Figure 7.2: $\quad$ Standardised coefficients for the attitude-behaviour structural equation model and their standard errors in parentheses $(n=281)$. Latent constructs are shown in ellipses and observed variables are shown in rectangles.

Figure 8.1: $\quad$ Simplification of the spectrum of intergenerational dynamics.

Figure 9.1: $\quad$ Illustrations in a children's colouring book titled 'Daddy you can save the planet', produced for the UNECE (Jakobowicz \& Dabas, 2007). Reproduced with permission from UNECE (2007).

Figure 9.2: $\quad$ The Model of Responsible Environmental Behaviour (Hines et al., 1987) and Jensen's (1993) action competence approach overlayed. Two constellations of behaviours that are impacted by different factors are also illustrated. Pathway A represents a constellation of simple household water saving behaviours, and pathway $\mathrm{B}$ represents a constellation of simple household recycling and energy saving behaviours.

Figure 9.3: $\quad$ Front and inside covers of a children's colouring book titled 'Daddy you can save the planet', produced for the UNECE (Jakobowicz \& Dabas, 2007). Reproduced with permission from UNECE (2007). 


\section{LIST OF TABLES}

Table 3.1: Summary of data collection methods, sources and analyses used to provide information about the variables of interest and answer each of the research questions that guided this research.

Table 3.2: $\quad$ Number of interviews, mind maps and surveys collected from each data source at each case study school in 2009 and 2010.

Table 3.3: $\quad$ Scales to estimate student environmental attitudes.

Table 3.4: $\quad$ Audit trail of validation of the survey instrument, data collection and data analysis.

Table 4.1: Annual account of sustainability activities at Lighthouse Primary School since beginning its focus in 2001 and prior to joining AuSSI - WA in 2006.

Table 4.2: Annual account of sustainability activities at Lighthouse Primary School from joining AuSSI - WA in 2006 to 2007.

Table 4.3: $\quad$ Annual account of sustainability activities at Lighthouse Primary School from 2008 to the time of data collection in 2009.

Table 4.4: $\quad$ Statistical results from Kruskal-Wallis tests of Ideas compared across year groups and constructs.

Table 4.5: $\quad$ Statistical results from Kruskal-Wallis tests of Scope of Themes compared across year groups and constructs.

Table 4.6: $\quad$ Significant results from Kruskal-Wallis tests of percent response compared across constructs.

Table 4.7: $\quad$ Significant results from Kruskal-Wallis tests of percent response compared across year groups per construct.

Table 4.8: $\quad$ Results from post hoc Mann-Whitney U tests of percent response compared across year groups.

Table 4.9: Summary of the dominant relationships between seven pro-environmental behaviours that students could practice in their homes and the three variables: Learning, Importance and Participation.

Table 5.1: $\quad$ Detailed timeline of sustainability initiatives at River's Edge Primary School since beginning the partnerships with AuSSI - WA and Millennium Kids.

Table 5.2: $\quad$ Statistical results from Kruskal-Wallis tests of Hierarchies compared across year groups and constructs.

Table 5.3: $\quad$ Statistical results from post hoc Mann-Whitney U tests of Hierarchies compared across year groups.

Table 5.4: $\quad$ Statistical results from Kruskal-Wallis tests of Ideas compared across year groups and constructs.

Table 5.5: $\quad$ Statistical results from post hoc Mann-Whitney $U$ tests of Ideas compared across year groups.

Table 5.6: $\quad$ Statistical results from Kruskal-Wallis tests of Scope of Themes compared across year groups and constructs.

Table 5.7: $\quad$ Statistical results from post hoc Mann-Whitney $U$ tests of Scope of Themes compared across year groups.

Table 5.8: $\quad$ Significant results from Kruskal-Wallis tests of percent response compared across constructs.

Table 5.9: $\quad$ Significant results from Kruskal-Wallis tests of percent response compared across year groups per construct.

Table 5.10: $\quad$ Results from post hoc Mann-Whitney U tests of percent response compared across year groups.

Table 5.11: Summary of the dominant relationships between seven pro-environmental behaviours that students could practice in their homes and the three variables: Learning, Importance and Participation.

Table 6.1: $\quad$ Statistical results from Kruskal-Wallis tests of Ideas compared across year groups and constructs. 
Table 6.2: $\quad$ Statistical results from Kruskal-Wallis tests of Scope of Themes compared across year groups and constructs.

Table 6.3: $\quad$ Significant results from Kruskal-Wallis tests of percent response compared across constructs.

Table 6.4: Summary of the dominant relationships between seven pro-environmental behaviours that students could practice in their homes and the three variables: Learning, Importance and Participation.

Table 7.1: $\quad$ Summary of standardised factor loadings, communalities, eigenvalues and percent explained variance for the attitudes to school environmental activities scale $(n=$ 278).

Table 7.2: $\quad$ Summary of standardised factor loadings on each of two factors, communalities, eigenvalues and percent of explained variance for the environmental worldviews scale $(n=278)$.

Table 7.3: $\quad$ Continued summary of standardised factor loadings, communalities, eigenvalues and percent explained variance for the environmental worldviews scale $(n=278)$.

Table 7.4: $\quad$ Summary of standardised factor loadings, eigenvalues, chi-square and goodness-offit indices for the pro-environmental behaviours scale $(n=281)$.

Table 8.1: $\quad$ Table of interview excerpts that illustrate different family dynamics - Lighthouse Primary School.

Table 8.2: $\quad$ Table of interview excerpts that illustrate different family dynamics - River's Edge Primary School.

Table 8.3: $\quad$ Number of each family type identified at each school $\left(n_{\text {Lighthouse }}=9, n_{\text {River's Edge }}=9\right)$.

Table 9.1: $\quad$ Cross-case analysis of the case study schools compared across the five key elements investigated and themes that emerged from the data.

Table 9.2: $\quad$ Cross-case analysis of Year 4, 5 and 6 students survey responses from the case study schools showing students' prevalence of environmental behaviours and the degree of students' participation within their families that was associated with their weekly practice of each behaviour. 


\section{GLOSSARY OF TERMS}

ABS:

ACARA:

ACF:

AESA:

ARIES:

ASG:

AuSSI:

AuSSI - WA:

BIC:

CEO:

DCCEE:

DESD:

DEWHA:

DoE:

DPC:

DSEWPC:

EE:

EfS:

Environment:

Gonski Report:

IPCC:

IUCN:

My Schools Website:

NAPLAN:

NGO:

NHMRC:

Ning:

OECD:

P\&C:

PISA:

RRT:

SCEW:
Australian Bureau of Statistics

Australian Curriculum, Assessment and Reporting Authority

Australian Conservation Foundation

Australian Education for Sustainability Alliance

Australian Research Institute in Education for Sustainability

Australian Scholarships Group

Australian Sustainable Schools Initiative

Australian Sustainable Schools Initiative - Western Australia

Bahá'í International Community

Chief Executive Officer

The Australian Government's Department of Climate Change and Energy Efficiency

The Decade of Education for Sustainable Development

The Australian Government's Department of Environment, Water, Heritage and the Arts (currently DSEWPC)

The Western Australian Government's Department of Education

The Western Australian Government's Department of the Premier and Cabinet

The Australian Government's Department of Sustainability, Environment, Water, Population and Communities (formerly DEWHA)

Environmental Education

Education for Sustainability

The Western Australian Government's Department of Environment

Review of Funding for Schooling prepared for the federal Minister of School Education, Early Childhood and Youth

Intergovernmental Panel on Climate Change (a scientific body of the United Nations)

International Union for the Conservation of Nature and Natural Resources

An Australian Curriculum, Assessment and Reporting Authority (ACARA) information service about all Australian schools

Australia's National Assessment Program - Literacy and Numeracy

Non-Government Organisation

National Health and Medical Research Council

An online platform that enables individuals or organisations to create their own social networking website. Members of the Ning can create their own profile and upload photos, videos, blogs, and timelines, and can interact with each other via forums and comments.

Organisation for Economic Cooperation and Development

Parents and Citizen's Committee of a school

The Programme for International Student Assessment

Resource Recovery Team (RRT) for the Bankstown City Council

Schools Council of England and Wales 
SCSA:

UNDESA:

UNECE:

UNESCO:

UNICEF:

WACOSS:
The Western Australian Government's School Curriculum and Standards Authority

United Nations Department of Economic and Social Affairs

United Nations Economic Commission for Europe

United Nations Educational Scientific and Cultural Organisation

United Nations Children's Fund

Western Australian Council of Social Service 


\section{CHAPTER 1: INTRODUCTION, BACKGROUND AND CONTEXT}

\section{Our biggest challenge in this new century is to take an idea that seems abstract - sustainable development - and turn it into a daily reality for all the world's people. \\ (Kofi Annan, former Secretary General of the United Nations)}

The environmental, social and economic implications of complex global issues, such as climate change, are becoming increasingly apparent and demanding of humanity's attention (IPCC, 2007). Identifying the issues and seeing the implications, however, are not enough to change the behaviour of individuals or governments towards averting environmental, social or economic crises (Norgaard, 2009). For example, as the science of climate change is becoming widely accepted there is a growing awareness among the Australian public that human actions are the major contributor (ABS, 2010; Buys, Miller, \& Megen, 2012; Leviston, Leitch, Greenhill, Leonard, \& Walker, 2011). There is awareness among the Australian public that the situation will continue to decline if ignored; but most people remain reticent about changing their personal behaviours beyond adopting simple recycling and water or energy saving measures. Ultimately, making changes to one's behaviour requires more than being aware of the issues; it requires taking responsibility for the problem, being aware of what actions can be taken and a willingness to act (Jensen \& Schnack, 2006; Norgaard, 2009).

Changing human behaviour is challenging, because complex issues such as climate change are difficult to conceptualise, difficult to relate to one's life and consequently, difficult to take responsibility for (Buys et al., 2012; Fritze, Blashki, Burke, \& Wiseman, 2008; Norgaard, 2009). Further, the factors are various, the implications are vast and seemingly distant, and messages fuelled by 'merchants of doubt' (Oreskes \& Conway, 2010) and conveyed by public media are convoluted and confusing (Buys et al., 2012; Fritze et al., 2008; Norgaard, 2009). This confusion is magnified by differences in individuals' perception of the issues. For example, individuals' perception of global warming is malleable such that individuals report global warming is more of a serious problem when they experience higher outdoor temperatures (Li, Johnson, \& Zaval, 2011; Risen \& Critcher, 2011) or, higher embodied temperatures induced by chewing gum (Lewandowski, Ciarocco, \& Gately, 2012).

Many educators, scientists, psychologists, policy makers and other motivated individuals have attempted to confront these challenges by communicating and clarifying the facts (Norgaard, 2009; Oreskes \& Conway, 2010). But research also 
shows that as people continue to learn about the issues and hear only negative reports they feel increasingly disillusioned about humanity's capacity to overcome these problems and disempowered in their ability to contribute to lasting change in the world (Fritze et al., 2008; Norgaard, 2009).

\section{Research Rationale}

Environmental education has traditionally focused on increasing peoples' awareness of environmental issues as a method of encouraging people to adopt proenvironmental behaviours (Heimlich \& Ardoin, 2008). Many programs and initiatives have arisen that attempt to trigger within people a desire to adopt and sustain proenvironmental behaviours in all aspects of their lives. A majority of these initiatives and environmental messages are focused on children (R. Ballantyne, S. Connell, \& J. Fien, 1998b; Duvall \& Zint, 2007; Uzzell et al., 1994), because children have traditionally been seen as "tomorrow's leaders and stewards of the Earth" (Ballantyne et al., 1998a, p. 285).

Since the global issues that society faces require immediate action, many environmental educators acknowledge that these initiatives also need to focus on adults who are better positioned than children to take urgent and effective action, both individually and by influencing others (Duvall \& Zint, 2007; Sutherland \& Ham, 1992; Uzzell, 1999). Reaching time-poor adults across the community, however, is a difficult task compared with the captive audience of school students (Ballantyne et al., 1998b; Duvall \& Zint, 2007). Moreover, school students are targeted because their attitudes are considered more malleable than those of adults (Sutherland \& Ham, 1992). Many environmental educators hope that adult behaviour will be affected through a process of intergenerational influence (Ballantyne et al., 1998b; Ballantyne, Fien, \& Packer, 2001b; Duvall \& Zint, 2007; Uzzell et al., 1994), where young people can "act as catalysts for environmental change among their parents and other adult members of the community" (Ballantyne et al., 2001a, p. 9).

Campaigns designed to increase awareness of environmental issues must be bolstered with sufficient knowledge of what actions can be taken and skills in undertaking them (henceforth referred to as action-based knowledge). Providing knowledge of devastating global issues alone contributes to the phenomenon of disillusion and despair, especially among children (Ojala, 2011; Tucci, Mitchell, \& Goddard, 2007) and has been described as causing 'action paralysis' (Jensen \& Schnack, 2006; Uzzell \& Rutland, 1993). Action paralysis involves feelings of guilt and 
powerlessness, and needs to be replaced by collective action and feelings of shared responsibility. Research shows that through ongoing programs at school, it is possible to turn a child's anxiety into optimistic, action-based concern (Alimahomed \& Keeler, 1995; Jensen \& Schnack, 2006; Uzzell, 1999; Uzzell et al., 1994).

There is evidence that Australian school students are aware of the precarious future of the world's environment and yet they show little concern about the potential impact on them and their families (Thomson \& De Bortoli, 2008; Tucci et al., 2007). They also show a low sense of responsibility towards the issues of sustainable development. The Programme for International Student Assessment (PISA), an initiative of the Organisation for Economic Cooperation and Development (OECD), conducts regular large-scale international surveys of 15 year old students' scientific, reading and mathematical literacy (Thomson \& De Bortoli, 2008). The major focus of the PISA 2006 assessment was scientific literacy, which included a section of questions about students" "responsibility towards resources and environments" (Thomson \& De Bortoli, 2008, p. 135). Data showed when asked how aware they were about various environmental issues, of the 57 countries surveyed, Australian youth ranked $16^{\text {th }}(.10$ above the OECD average). In spite of a relatively high awareness of the issues, Australia's youth rated $47^{\text {th }}$ for concern about the ramifications to them and their families of major environmental issues (-.19 below the OECD average) and $47^{\text {th }}$ for responsibility towards sustainable development (-.24 below the OECD average). Australia's result in these domains of concern and responsibility was similar to those of Sweden, Norway, Denmark, United Kingdom, and New Zealand, all countries with affluent and well-educated populations.

In the same survey, youth were asked how optimistic they were that environmental issues, such as air pollution, water shortages, and species extinction, would improve over the next 20 years (Thomson \& De Bortoli, 2008). Many of the countries from which youth ranked lowest for concern and responsibility were higher in the optimism scale and vice-versa, a pattern one might expect if youth expect solutions to these issues to be developed. Australian youth, however, differed by being similarly at the low end of the scale for concern and responsibility as well as for optimism, rated $48^{\text {th }}$ for the latter ( -.13 below OECD average).

The patterns identified from the PISA 2006 survey suggest that Australian youth had sufficient issues-based knowledge of environmental problems, but were lacking in action-based knowledge and a connection to the issues in locally relevant contexts. Increasing action-based knowledge could engage Australian students to take more 
responsibility for choices that contribute to sustainable development, which may in turn help them feel more optimistic about the world's future environmental state, and more able to see the inextricable links between local and global issues.

\section{The Australian Sustainable Schools Initiative}

Efforts have been made to include more sustainability focussed education in Australian schools. For example, in recent years, the Australian Sustainable Schools Initiative (AuSSI) has brought education for sustainability to the forefront of school teaching (DSEWPC, 2012a, 2012b) and schools involved with AuSSI are amongst those examined in this thesis. AuSSI is described by the Australian Government as a federal partnership with all state and territory governments, and the Catholic and Independent school sectors, which promotes whole-school, whole-system approaches to sustainability education (DEWHA, 2008; DSEWPC, 2012b). AuSSI aims to tackle an apparent lack of environmental concern, responsibility and optimism among young Australians by promoting holistic and locally relevant approaches to environmental action.

AuSSI became nationally adopted in 2004 after initial trials in New South Wales and Victoria. Different approaches have been taken in each state in response to the demands of existing networks and local education systems (Davis \& Ferreira, 2009; Gough, 2006b; Larri, 2006). The national establishment of AuSSI was influenced through: 1) momentum developed by the long-running work of environmental educators in Australia, together with 2) increased governmental willingness to back the initiative following the December 2002 resolution adopted by the United Nations (UN) General Assembly to make 2005 - 2014 the Decade of Education for Sustainable Development (Davis \& Ferreira, 2009; Gough, 2006b; Henderson \& Tilbury, 2004; UNESCO, 2005a, 2005b, 2007). The United Nations Educational Scientific and Cultural Organisation (UNESCO) describes the goals of the decade stating,

Sustainable development, a constantly evolving concept, is thus the will to improve everyone's quality of life, including that of future generations, by reconciling economic growth, social development and environmental protection. ... Throughout the Decade, education for sustainable development will contribute to enabling citizens to face the challenges of the present and future, and leaders to make relevant decisions for a viable world. (UNESCO, 2005a, pp. $2 \& 3)$

These two influences have caused some debate about the purpose of AuSSI and the goals of education for sustainability (Gough, 2006a, 2006b; Jickling \& Wals, 2012; McKeown \& Hopkins, 2003; Wals, 2009). It is relevant here to note that 'education for 
sustainability' is often used interchangeably in Australia with 'education for sustainable development' (Tilbury, 2004). Some educators have seen AuSSI and education for sustainability as a framework through which they can legitimately help schools build initiatives across varied yet interconnected pursuits of environmental, social and economic justice (Fien, 2001; Pepper \& Wildy, 2008; Tilbury, Coleman, \& Garlick, 2005). There also are educators who see education for sustainability as having evolved from environmental education, and use this rationale to justify a focus on environmental initiatives that draw links to the social and economic implications of negative environmental choices (Gough, 2006b; Larri, 2006; Tilbury, 1995, 2004). This approach is sometimes framed as 'environmental education for sustainability' (Gough \& Sharpley, 2005; Tilbury, 1995; Wals, 2009), and in some instances has seen the continuation or expansion of what are fundamentally environmental initiatives in schools (Armstrong \& Bottomley, 2003; Gough, 2006b; Larri, 2006; Wals, 2009). There are yet other educators who argue that environmental education has always included an exploration of the interconnection between environmental, social and economic issues (Dillon \& Huang, 2010; Gough, 2006a; Jickling \& Spork, 1998), and that sustainable development is a "conceptually flawed and internally inconsistent concept" (Jickling \& Wals, 2012, p. 53). These perspectives have been extensively debated and will be explored further in the review of the literature in Chapter 2.

Despite continuing debates, AuSSI is described by the Australian Government's Department of Sustainability, Environment, Water, Population and Communities (DSEWPC, formerly DEWHA) as a federal and state partnership that "fosters a wholeschool approach to change for sustainability with measurable environmental, educational, social and financial outcomes" (DSEWPC, 2010b, para. 1). This is in concord with UNESCO's definition of education for sustainability. Furthermore, DSEWPC states the purpose of AuSSI is to "build sustainability knowledge, skills and motivation", using an approach that "integrates [multiple] activities with teaching and learning across the curriculum" (DSEWPC, 2010b, paras. 2 \& 3).

Whole-school cross-curricula approaches to education for sustainability have been increasingly recognised as a successful means of engaging students, staff, parents and local community in a process of behaviour change for sustainability (Henderson \& Tilbury, 2004; Kennelly, Taylor, \& Serow, 2011; Lewis, 2012). A key aspect of an effective whole-school approach to education for sustainability is the depth of collaboration between the school, parents and local community groups, and commitment to work together as agents for environmental change (ARTD, 2010; 
Henderson \& Tilbury, 2004). Further, research suggests that when AuSSI schools collaborate with an established community organisation or network of organisations, the school is better able to access resources, and create authentic and transformative learning opportunities, which can lead to substantial and long-term behavioural change (Davis \& Ferreira, 2009; Flowers \& Chodkiewicz, 2009; Taylor, 2010).

\section{Scope of the Research}

The research reported in this thesis acknowledges that environmental education is only one sphere of education for sustainability and that the implications of climate change and the goals of education for sustainability equally encompass environmental, socio-cultural and economic factors. However, the research primarily focussed on the environmental sphere of the global issues currently before humanity for several reasons: 1) environmental education is directly relevant to the researcher's background, skills and interests, 2) it was more acceptable to the case study schools for the researcher to measure environmental knowledge, attitudes and behaviours, and easier for participants to conceptualise, and 3) it was necessary to provide a boundary for the scope of the research. Thus it was determined that the environmental aspect of sustainability was an appropriate focus for this research.

\section{Aim of the Research}

The broad aim of this research was to explore the impacts of whole-school education for sustainability initiatives supported by the Australian Sustainable Schools Initiative in Western Australia (AuSSI - WA) on upper-primary school students and their families. More specific aims were to: examine organisational factors related to the establishment of school sustainability programs; determine the environmental knowledge, attitudes and behaviours of upper-primary school students; explore the dynamics of intergenerational transfer between students and their families; and identify factors that may maximise the impact of education for sustainability. To achieve these aims, this study was situated within a pragmatic research paradigm and given direction from a transformative theoretical lens. Adopting a transformative lens allowed recommendations to be provided to the case study schools, and permitted advocacy of whole-school sustainability education and AuSSI - WA. 


\section{Research Questions}

The overarching research question addressed in this research was 'what is the impact of whole-school education for sustainability on upper-primary students and their families?' In order to answer the overarching research question, five questions were addressed at case study schools:

1) What organisational factors foster or impede the establishment of whole-school education for sustainability programs?

2) What is the environmental and sustainability knowledge of upper-primary students?

3) What are the environmental behaviours of upper-primary students?

4) What is the relationship between environmental attitudes and behaviours of upperprimary students?

5) What are the family dynamics that contribute to intergenerational influence and the uptake of new environmental behaviours in students' homes?

\section{Significance of the Research}

The significance of this research is threefold: 1) education for sustainability has been deemed a global priority by UNESCO and a national priority by the Australian Federal Government, 2) there have been few comprehensive studies that have investigated the impact of the Australian Sustainable Schools Initiative in Western Australia, and 3) there have been few studies worldwide that have investigated the impact of education programs on the intergenerational transfer of pro-environmental behaviours from schools to homes via students.

Education for sustainability is a movement that attempts to confront the challenge of shifting human behaviour towards adopting responsible environmental, social and economic choices. The urgent need outlined by UNESCO (2005a, 2005b, 2007, 2009) to educate and encourage shifts in human behaviour, and the challenge of achieving this through efforts beyond the limited and sometimes paralysing approach of issues-based education have been outlined in previous paragraphs. As discussed, the Australian Sustainable Schools Initiative (AuSSI) was established to specifically foster the appropriate attitudes, knowledge and behaviours among school students by encouraging schools to adopt a multi-faceted educational approach that utilises principles of youth empowerment and authentic stakeholder engagement. All new 
initiatives should be evaluated to determine if they have achieved their goals and, identify areas that require more attention and improvement.

The purpose of this research was to document, analyse and evaluate the impact of education for sustainability efforts at two schools working with AuSSI in Western Australia and compare them with a school that had no association with AuSSI - WA. Research has been undertaken in New South Wales (e.g. Larri, 2006; Smith, 2006), Victoria (e.g. Larri, 2006; Gough 2005; Armstrong \& Bottomley, 2003), and Queensland (e.g Davis \& Ferreira, 2006, cited in Davis \& Ferreira, 2009) to evaluate the impact of AuSSI on schools in each of those states, however, only one other comprehensive research project, recently completed by Lewis (2012), has investigated the impact of AuSSI in Western Australia. Lewis (2012) conducted a longitudinal, qualitative case study of one school's experience with AuSSI - WA, whereas this research conducted multiple comparative case studies of three Western Australian schools using mixed methods data collection, carried out over a shorter time frame.

Recommendations for future research identified by Lewis (2012) included: exploring student understandings and assessment of whole-systems thinking, and conducting comparative studies of a range of WA schools. Lewis (2012, p. 293) also recommended investigating the depth of school engagement with education for sustainability because, "such research is necessary to examine the depth of behaviour change in AuSSI schools as an outcome of initiatives implemented". The research reported in this thesis examines issues raised in these recommendations and contributes to the body of research about the impact of AuSSI on school engagement with education for sustainability, pro-environmental behaviour adoption, student understandings and assessment of whole-systems thinking. The findings have ramifications for education for sustainability programs globally.

Pepper (2007) also conducted research into AuSSI - WA. The focus of her research was particular to one aspect of sustainability education - school leadership. Pepper (2007, p. 169) proposed, "a similar but separate study to compare secondary schools not involved in the initiative with a number who are involved has merit". The research reported in this thesis has adopted the approach suggested by Pepper (2007) with primary schools, and sees the comparison of schools engaged with AuSSI - WA with those not engaged, as an important means of authenticating the impact of AuSSI WA and differentiating its impact from standard school practices. Lewis (2012, p. 294) also proposed that, "similar research could be conducted comparing AuSSI - WA schools in terms of student, teacher and community outcomes in education for 
sustainability". The research reported in this thesis specifically involved the comparison of two AuSSI - WA schools to determine the effectiveness of different modes of school operation on education for sustainability outcomes.

Research of whole-school sustainability education has shown that behaviour change among students and teachers increases as the adopted programs become integrated across the whole school, into classroom activities and school life (Gough, 2005; Henderson \& Tilbury, 2004; Ilich, 2008; Lewis, 2012). However, there is a paucity of research about the impact of whole-school sustainability education on intergenerational influence of students on their parents and the potential for transfer of specifically pro-environmental behaviours into homes because of the school's influence. To this effect, Gough (2005, p. 349) has called for research to "investigate the impact of the school embodying sustainable practices on the practices of the students and parents at home”. Moreover, in a recent evaluation of AuSSI by DEWHA (2010, p. vii), it was argued that, "in some schools, parents have been engaged in the EfS activities, although there is little evidence about whether student learnings are transferring to the home environment".

This research also will contribute to the literature about the effect of environmental education on intergenerational influence. Duvall and Zint (2007, p. 23) investigated intergenerational influence in environmental education and identified that "designing intergenerational learning strategies into environmental education, is an issue that, to date, researchers have explored in only a handful of studies". They further advocate that,

In light of the potentially devastating environmental problems facing us today, it is important to continue to investigate ways in which children can act as catalysts for promoting environmental knowledge, attitudes, and changed behaviors in their parents and throughout their communities. (Duvall \& Zint, 2007, p. 23)

Several methodological and program limitations were identified in the review paper by Duvall and Zint (2007), of which three were investigated in this thesis. First, time frame and integration was addressed in this research through the long running involvement of two participating schools with AuSSI - WA. Second, quality of teaching and cooperation of teachers was addressed in this research through the wholeschool approach to sustainability education encouraged by AuSSI. Third, consideration of school-community relationships was addressed in this research through in-depth interviews with parents and teachers that included questions about school-community relationships. 
The challenge currently faced by whole-school sustainability programs is finding ways of fostering awareness and empowerment among the extended school community including parents, caregivers and families (ARTD, 2010; Gough, 2005). The research reported in this thesis contributes to the body of research on the role of family dynamics and intergenerational influence on adoption of pro-environmental behaviours among families at schools that have implemented whole-school education for sustainability. This research also identifies approaches that environmental educators and school sustainability coordinators could utilise in their efforts to meaningfully engage with parents and, to encourage parent participation and support for school sustainability initiatives.

Calls for environmental, social and economic sustainability to be taught in schools, for more community-school partnerships, and for parents to be active participants in the behaviour change process all emphasise the need for rigorous studies such as this to assess the results of new endeavours and to help identify paths for future action.

\section{Research Paradigm}

Creswell (2009, p. 15) explains that the paradigm of a research project "provides a framework for topics of interest, methods for collecting data, and outcomes or changes anticipated by the study". In this research, a pragmatic research paradigm with a transformative theoretical lens were adopted (detailed in Chapter 3, Methods) to achieve the following purposes: 1) to describe the impact of whole-school education for sustainability on the environmental knowledge, attitudes and behaviour of upperprimary students and their families, 2) to document and provide feedback to the participating schools and the management body of AuSSI - WA, 3) to determine whether it was appropriate to advocate for increased recognition of the effectiveness of whole-school sustainability education and increased funding to AuSSI - WA and its partners. The pragmatic paradigm and transformative lens guiding this research led to the development of the five research questions (p. 7), which were investigated using multiple comparative case studies and mixed methods data collection.

Utilising a transformative lens often leads to recommendations for action or advocacy being offered at the conclusion of the study (Cohen, Manion, \& Morrison, 2011; Creswell, 2009; Creswell \& Plano Clark, 2011; Mertens, 2009). In this study, recommendations (see Chapter 9, Synthesis and Conclusions) include strategies that AuSSI - WA can adopt to better support schools, strategies for schools to inform and 
engage parents, teachers and students towards adopting environmental practices in the short and long term, and identifying factors that will increase receptiveness towards environmental practices among parents and improve effectiveness of intergenerational transfer.

\section{The Researcher}

The transformative lens adopted in this research obliges that some information be provided about the researcher's background, skills, motivations and resources. Information is provided here as a personal account.

The areas of environmental education and education for sustainability have interested me since my undergraduate study at the University of New South Wales. My interests were spread across the social sciences and biological sciences. Although I ultimately chose the path of biological sciences, specifically marine science, I took as many units in sociology and psychology as I was allowed.

During my undergraduate degree I found casual work as a marine education guide at the Marine Discovery Centre - Bondi Beach, which I continued until leaving Australia in 2004 to volunteer in social development projects with the Bahá 'i Community in Yukon, Canada. Upon returning ten months later, I moved to Western Australia, commenced my Honours research and found another position working as a marine education guide. After one year I was promoted to Marine Programs Officer for the environmental excursion provider, Nearer to Nature - an initiative of the Department of Environment and Conservation in Western Australia.

Being the Marine Programs Officer involved designing and refining Nearer to Nature's marine excursion activities, linking their activities to the WA primary school curriculum, coordinating and training new guides, collecting and caring for the marine organisms used during the touch-pool activity and regularly running activities with classes of primary school children. This role perfectly catered for my love of the ocean, the outdoors, marine conservation, engaging with and informing young people about their precious marine environment and my desire to foster a deep sense of responsibility for our environment in young people.

This experience, however, also caused me to question the pre and post excursion learning that students were receiving in their classrooms. I was aware that some classes seemed more prepared for their marine excursion than others. Their teachers were also more organised, asked relevant questions, and in some cases, months later, sent examples of student work back to Nearer to Nature with their class' enthusiastic thanks. By contrast, other schools were less organised or engaged, and gave the overwhelming impression they were only interested in a fun day at the beach. This observation prompted me to investigate the services available to assist teachers in weaving the environmental messages their students received on class excursions with their regular teaching content. I soon discovered the whole-school sustainability education movement and the inspiring work being undertaken by AuSSI - WA, which led me to develop a research interest in this area. 
It is also relevant that I have volunteered regularly on various youth and community engagement projects through the Baha' $i$ Community, Millennium Kids, and the Western Australian branch of the Australian Association for Environmental Education (AAEE-WA). My volunteer work with the Baha' 'i Faith has involved teaching weekly religious education classes at several Perth primary schools and working as a group leader for the Baha''i junior youth empowerment program. My volunteer work with Millennium Kids has included working as a leader and support person for many of their youth led environmental projects, and being a member of their annually elected adult board of administration. My volunteer work with AAEE - WA has included assisting with the annual community science fair held during National Science Week, and helping with the annual Catchments, Corridors and Coasts three-day excursion for environmental educators. These volunteer roles have deepened my belief in the positive potential of empowered youth who are supported and encouraged by their community. I also have become more confident and skilled in working with children, youth and other environmental educators.

Through involvement with these community organisations, workplaces and academic institutions, I have made valuable personal connections with other knowledgeable people that work, research or volunteer in the field of education for sustainability, environmental education and youth empowerment. These connections have made useful resources available for me to draw upon throughout my PhD research.

\section{Western Australian Context}

For many Australians 'the lucky country' has become a celebrated phrase used to describe Australia's bountiful natural resources, weather, lifestyle, history, and distance from problems elsewhere in the world. This phrase, though originally intended to be an indictment of Australia (Horne, 1964), has become an affirmation of the Australian way of life and reflected a 'she'll be right' mentality (AG, 2012). In school halls across Australia this ethos is developed and honed through the mantra of the national anthem, in particular the line, "our land abounds with nature's gifts of beauty, rich and rare". So it is not surprising that Australians have come to rely not only economically, but perhaps also emotionally, on the mineral resources industry.

Western Australia has come to be characterised as the 'cash cow' state of Australia, because of the massive mineral resources industry that is projected to continue thriving beyond 2020 (Chung, 2012, June 26; Korporaal, 2012, June 1; Sheehan, 2012, August 22). This characterisation has become sorely apparent in recent years, with demand for Western Australia's mineral resources attributed as playing an important role in keeping Australia's economy afloat during the uncertain years following the global financial crisis of 2008 (Allen, 2011; Priestley, 2010).

Along with a thriving resources industry, however, have come increased pressures associated with rising costs of living (WACOSS, 2011) and a widening 
disparity between the wealthiest and poorest Australians (Neal, Norton, \& Ariely, April 2011). This widening gap has become particularly apparent in Western Australia with an inflated Australian dollar and the booming Western Australian economy (Trenwith, 2012, April 18; WACOSS, 2011). The current West Australian Premier, Mr Colin Barnett was quoted saying,

I am conscious that the strength of the mining industry in this state certainly brings a lot of benefits and prosperity to those who work in or service the mining industry but other sectors ... are facing it tough, and of course right across the community people on pensions or low or fixed incomes are finding life difficult with rising cost of living pressures. (Barnett in Trenwith, 2012, April 18, para. 21)

The widening gap between rich and poor in Australia has implications for decreased life expectancy, mental illness, drug and alcohol abuse, and educational underperformance (Lawrence, 2012, August 24). In the recently tabled Gonski Report (Review of Funding for Schooling prepared for the federal Minister of School Education, Early Childhood and Youth) it was noted that in one third of all Australian schools, the average socioeconomic background of students is below the national average, and that concentrations of students from disadvantaged backgrounds is growing (Gonski et al., 2011). Without appropriate support and resources for teachers who work in these challenging schools, an atmosphere of educational underperformance can become the norm, which can lead to decreased teacher morale and an increased drift towards private education among those who can afford it. The report states,

Concentrations of disadvantage have been demonstrated not only to impact on student performance, but also to impact on teacher morale and community alienation from the school, and result in difficulties in attracting and retaining good teachers and students. As a school's reputation worsens, it is argued that more parents send their children elsewhere, and hence the cycle continues. (Gonski et al., December 2011, p. 124)

These challenges are further compounded by pressures on schools to churn out high performing students because of recently introduced nationalised testing. Australia's National Assessment Program - Literacy and Numeracy (NAPLAN) was introduced in 2008, and provides a measure of students' academic performance in Years 3, 5, 7 and 9 (ACARA, 2012c). Whilst it is argued that nationalised testing serves the useful purpose of providing baseline comparable data on student performance (ACARA, 2012c), it has received criticism for losing sight of the whole child, their creativity, wellbeing, citizenship, language diversity and other holistic merits (Lawrence, 2012, August 24; Polesel, Dulfer, \& Turnbull, 2012; Wigglesworth, 
Simpson, \& Loakes, 2011). Furthermore, critics argue NAPLAN testing puts undue pressure on teachers to perform and has already led to the adoption of reductionist pedagogies that focus on learning of facts and issues-based knowledge at the expense of other holistic pursuits (Polesel et al., 2012; Smeed, Spiller, \& Kimber, 2009).

Another educational challenge currently faced by all Australian schools is the introduction of the first-ever Australian Curriculum, aspects of which began to be implemented by schools in Western Australia from July 2012 (SCSA, 2012). The Australian Curriculum espouses a focus on building general capabilities (including literacy, numeracy and ethical behaviour) across all subject areas, and a focus on crosscurricula priorities (including sustainability) as a means of contemporising and contextualising student learning (ACARA, 2012d). In light of the advocacy of wholesystem sustainability education, these curriculum priorities can be seen as a positive step (Lewis, 2012). Many educators and researchers, however, are uncertain about the impact that a centralised curriculum will have on teachers' agency to mediate and interpret content, the ultimate learning of students, and the increased potential for politicisation of education (Briant \& Doherty, 2012). Some critics argue that a centralised national curriculum may only place further pressure on teachers and students to perform within an increasingly reductionist educational paradigm associated with nationalised testing (Brennan, 2009).

In this economic and educational climate, environmental and sustainability education in Western Australia has been battling for attention. Despite the booming Western Australian economy, which has brought with it large and increased tax revenues (Burrell, 2012, May 19), state and federal government funding for AuSSI and programs that complement and support AuSSI have faced significant budget cuts and financial uncertainty in recent years (AESA, 2012; Sandell, 2012, June 22). Furthermore, the typical Australian 'she'll be right' mentality combined with economic reliance on the mining and resources industry is an obstacle to discussing the implications of human induced climate change and encouraging pro-environmental behaviour. These, together with a renewed emphasis on issues-based, factual knowledge among school students, create unique challenges for environmental and sustainability education in Western Australia. The combination of these dynamics has shaped environmental education in Western Australia through their influence on the structure and availability of resources, and the political support for environmental education in the state. 


\section{Environmental Education in Western Australia}

Western Australia (WA) hosts a wide variety of environmental education experiences that are offered by government agencies, commercial operators, faith groups, scout groups, friendship groups and not-for-profit organisations. These educational experiences address a range of environmental problems that our society is currently facing (e.g. management of water, energy, air, waste and biodiversity) through interactive, informative and empowering approaches. The experiences available to schools in Western Australia can be broadly classified into three categories: 1) excursions/incursions, 2) teacher-driven programs and 3) whole-school programs supported by AuSSI - WA and other agencies. There are differences in their longevity and integration into school and community life.

Excursions and incursions are usually a one-off experience that might have relevance to a unit of study on which the classroom teacher is focusing. For example, a classroom unit on sea life might prompt the teacher to organise an excursion to an aquarium or another marine education provider. Developing pre- and post-excursion classroom activities often depends purely on the teacher's initiative, making it difficult to track the content and quality of messages conveyed to the children (Rennie, 2007). Furthermore, excursions and incursions, whilst having the potential to raise awareness and provide real-world contexts, are limited by minimal contact time to provoke thoughtful discussion about the social, cultural or economic contexts of the issues, or to provoke children to develop and undertake solutions to local environmental problems (Uzzell, 1999).

The differences between teacher driven and whole-school adopted programs are obvious. When one or more of the above programs are adopted by a whole school, their integration into school and community life is more penetrating and their potential to effect lasting pro-environmental behaviour changes in children is far greater than if they were only adopted by one dedicated class teacher (Gough, 2005; Henderson \& Tilbury, 2004; Ilich, 2008; Lewis \& Baudains, 2007). This influence is most apparent in primary schools as compared with high schools, where a smaller teacher body, each working with only one class, is able to collaborate more easily towards a whole-school approach to education for sustainability (Dow \& Prabawa, 2012; Henderson \& Tilbury, 2004). In schools that adopt a whole-school approach, there is often one dedicated teacher that initially drives the implementation of a particular program, but once the program is established as a way of life in the daily school routine that teacher's leadership is devolved to other staff and the students (Henderson \& Tilbury, 2004; Lewis, 2012; 
Pepper \& Wildy, 2008; Wooltorton, 2004). With such an approach to leadership the school's program is far less likely to collapse if the dedicated teacher moves on or burns out.

By their nature, whole-school programs are better able to promote youth empowerment, capacity development, assistance to teachers in the field and, ultimately, 'action competence' into the vision of the program (Jensen, 2004; Uzzell, 1999). Another hallmark of a successfully implemented and tracked environmental action project is collaboration between the school and various community participants (Henderson \& Tilbury, 2004; Lewis, Mansfield, \& Baudains, 2008; Uzzell, 1999). Programs that are supported by other agencies are often tailored to the school curriculum, well coordinated, and results are tracked over a certain time period (months to years). Examples of such programs currently offered to Perth schools include 'Waste Wise', 'Waterwise', 'Travel Smart, and 'Ribbons of Blue', which are funded and coordinated by the State Department of Environment and Conservation (DEC).

\section{Relevant Educational Organisations}

This research was conducted with case study schools that had varying degrees of association with the Australian Sustainable Schools Initiative in Western Australia (AuSSI - WA) and Millennium Kids. Schools were selected for their association (or not) with AuSSI - WA because the sustainable schools movement underpinned the rationale of this research. One school was selected for its association with Millennium Kids in addition to AuSSI - WA, because Millennium Kids had worked closely with the school to assist them with implementing and embedding sustainability priorities in all areas of school life. Furthermore, research has shown that whole-school sustainability initiatives accompanied by external agencies that act as facilitators are better able to promote youth empowerment, develop capacity among staff, assistance to teachers and ultimately to build sustainability knowledge, skills and motivation in all stakeholders (Davis \& Ferreira, 2009; Flowers \& Chodkiewicz, 2009; Taylor, 2010).

AuSSI - WA. AuSSI - WA was established in 2005 after pilot programs had been conducted in New South Wales and Victoria (Lewis, 2012). In Western Australia, AuSSI advocates an holistic, integrated vision of education for sustainability, by placing equal emphasis on environmental, socio-cultural, and economic perspectives and facilitating explicit links across the curriculum (DoE, 2012a; Lewis, Baudains, \& Mansfield, 2009). This focus, on a broad definition of sustainability, was pre-empted by earlier publications from the Western Australian Government that described sustainability as "meeting the needs of current and future generations through an 
integration of environmental protection, social advancement and economic prosperity" (DPC, 2003, p. 4; Environment, 2004, p. 6). These documents also described the important role that whole-school education for sustainability must play in working toward these goals (DPC, 2003; Environment, 2004).

AuSSI - WA has adopted a framework approach to implementing the national and state education for sustainability goals (Ilich, 2008). The framework approach is different to the approaches adopted by AuSSI in other states (Davis \& Ferreira, 2009). It encourages schools to tailor a sustainability journey appropriate to the school community, while still drawing on AuSSI - WA for access to networks, tools and resources (Ilich, 2008). This approach fosters bottom-up driven implementation of education for sustainability goals in schools. AuSSI - WA recognises that most schools in Western Australia already practice many elements of sustainability, though usually in a disconnected way and driven by a handful of staff. AuSSI - WA thus supports schools to adopt sustainability as a key context for teaching and learning across the whole school (DoE, 2012a).

Similar to other states AuSSI - WA provides schools with professional development, access to an alliance of key education providers and case studies of school experiences to foster resource sharing (Davis \& Ferreira, 2009; Gough, 2005; Ilich, 2008). In addition, AuSSI - WA provides a detailed rubric self-assessment tool (displayed in Chapter 2), a basic step-by-step guide to help schools get started, and visual tools termed the 'ecological footprint' and 'social handprint' (Figure 1.1) that emphasise the three key areas of sustainability (DoE, 2012a, 2012d; Ilich, 2008). Currently more than four hundred schools across Western Australia are registered as participating AuSSI - WA schools (DoE, 2012c). Due to federal government funding and policy constraints, however, AuSSI - WA faces challenges in their support of schools (AESA, 2012; Sandell, 2012, June 22), which could be mitigated by working with a team of dedicated sustainability facilitators (Ilich, 2008). 

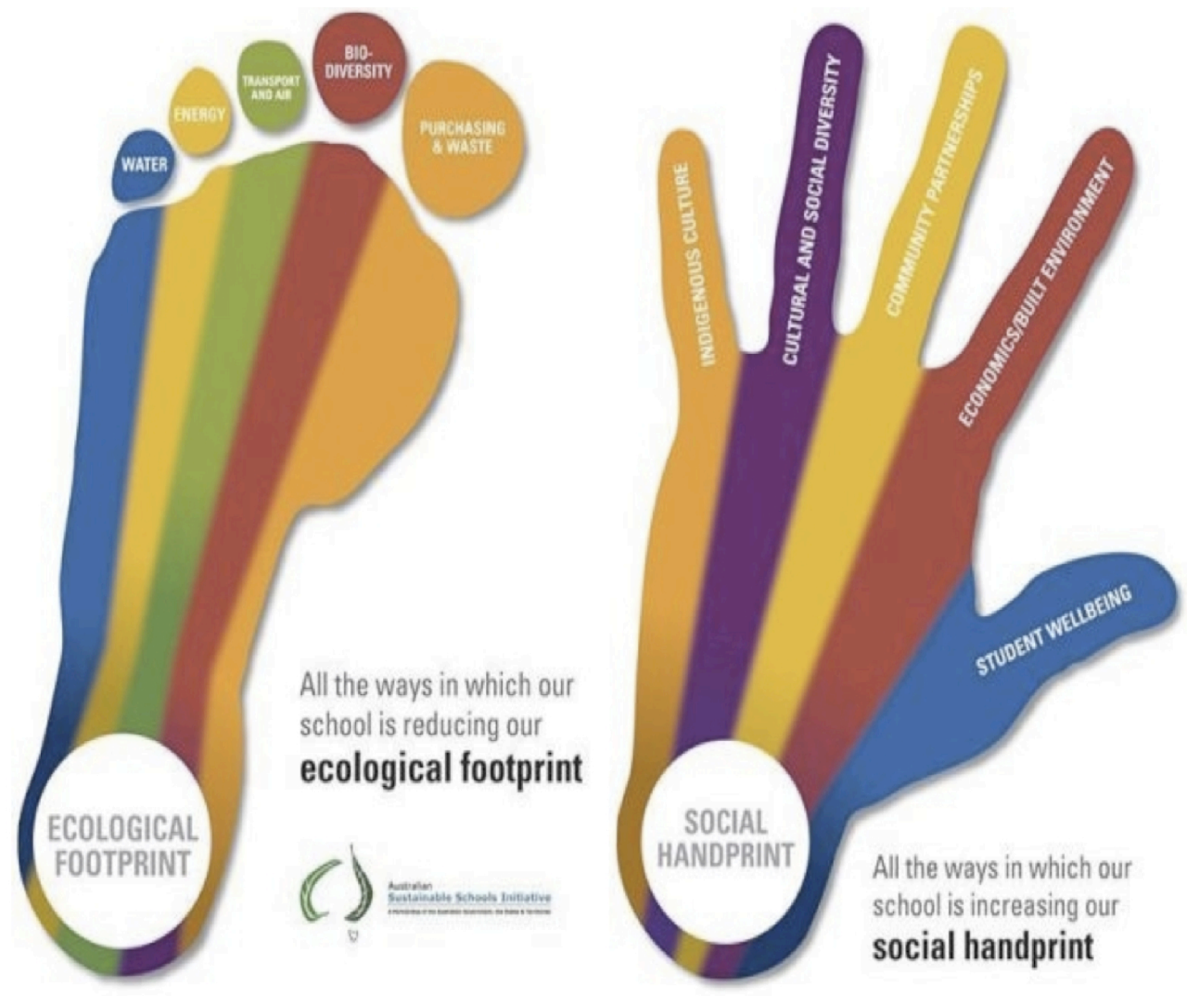

Figure 1.1. 'Ecological footprint' and 'social handprint' visual tools provided to participating AuSSI - WA schools. Reproduced with permission from DoE, $2012 \mathrm{~b}$.

Millennium Kids. Millennium Kids Inc. is a Perth based non-profit, nongovernment environmental organisation for young people aged 10-25 years old that promotes youth empowerment and supports youth led environment and sustainability initiatives (MK, 2012). Millennium Kids has worked as a privately contracted school sustainability facilitator for over 40 schools in Western Australia (Salter, Venville, \& Longnecker, 2011; Taylor, 2010).

Millennium Kids' origins date back to 1995 when four young West Australians attended the United Nations 'Leave it to Us' Children's Conference on the Environment in the United Kingdom (Johnson, 2001; La Mar, 2006). A key theme of the conference was based on the United Nations Declaration for Sustainable Development, Agenda 21 (section 3, chapter 25), which states that national governments "should take measures to ensure that the interests of children are taken fully into account in the participatory process for sustainable development and environmental improvement" (UNDESA, 1992, section 3, chapter 25). After returning, these young people were disheartened at the inadequate level of youth involvement in environmental decision making in Western Australia, and in 1996, with the support of their class teacher, the students established 
their own youth-run environmental organisation, which later adopted the name Millennium Kids (Johnson, 2001; La Mar, 2006).

Millennium Kids are well placed to work as a school sustainability facilitator because of direct networks they have developed with schools, indigenous groups, local and international not-for-profit organizations, government and non-government educational program providers, universities, small and large corporations, religious groups and many like-minded individuals (Salter, Venville, et al., 2011; Taylor, 2010). Chief among these relationships is an association with AuSSI - WA. Millennium Kids support the work of AuSSI - WA and when working with schools, often utilise the AuSSI - WA framework (Salter, Venville, et al., 2011).

\section{Thesis Outline}

This thesis is organised across nine chapters. Chapter 2 summarises and discusses the literature relevant to each research question and the theoretical framework in which this research was situated. Chapter 3 describes the methodology, methods of data collection, analysis and instrument validation that were used in the research.

The five research questions (p. 7) provide a framework for the results chapters. Each Chapter 4, 5 and 6 focuses on one of the three case study schools, presenting findings for Research Questions 1, 2 and 3. Each chapter begins with a qualitative description of the school and discussion of the organisational factors that fostered or impeded the school's sustainability initiatives. Each chapter continues with an exploration of the quantitative trends observed in the students' environmental and sustainability knowledge in that school. Following this is a presentation of the quantitative trends observed in students' self-reported environmental behaviours and a detailed exploration of the relationship between behaviours and certain situational factors. Each of these chapters concludes with a summary and discussion of the school's distinctive characteristics.

Chapter 4 presents findings from Lighthouse Primary School, which had been a participating AuSSI - WA school for eight years at the time of data collection. Chapter 5 presents findings from River's Edge Primary School, which at the time of data collection had been a participating AuSSI - WA school for two years and had been closely accompanied on its sustainability journey by the community organisation Millennium Kids. Chapter 6 presents findings from Fertile Ground Primary School, which was selected as a comparison school because it did not have a relationship with 
AuSSI - WA, nor did it have any whole-school sustainability initiatives in operation at the time of data collection.

Chapter 7 presents findings for Research Question 4, exploring relationships between students' attitudes and behaviours from the two AuSSI-connected case study schools: Lighthouse and River's Edge. This chapter explains results from factor analyses and structural equation models that were used to interrogate those relationships.

Chapter 8 presents findings for Research Question 5 from case study schools: Lighthouse and River's Edge. This chapter details the qualitative examination of family dynamics that contributed to or created challenges for the uptake of environmental behaviours in family homes resulting from the school's influence.

Chapter 9 synthesises and critically discusses the findings of each research question as they were compared across case study schools, and concludes by postulating recommendations that may maximise stakeholder support and the permeating impact of sustainable schools.

\section{Chapter Conclusion}

This chapter has presented the context and research agenda that framed and motivated this research. The following chapter will provide a detailed discussion of the literature as it relates to each of the five research questions, and will conclude with a presentation of the theoretical framework that guided this research. 


\title{
CHAPTER 2: LITERATURE REVIEW AND THEORETICAL FRAMEWORK
}

\author{
Education must be lifelong. It should help people to develop the \\ knowledge, values, attitudes and skills necessary to earn a \\ livelihood and to contribute confidently and constructively to \\ shaping communities that reflect principles of justice, equity and \\ unity. It should also help the individual develop a sense of place and \\ community, grounded in the local, but embracing the whole world.
}

(Bahá ’i International Community, 1998, V.2.3)

This chapter is structured around the literature that underpinned development of the research questions, data collection methods and theoretical framework presented in this thesis. First, key elements of school sustainability education are presented and five elements are discussed in detail. Next, factors that affect pro-environmental behaviour and dominant theories about their interactions are presented. Following this, the factors: knowledge, attitudes and behaviour, are discussed in detail. Next, theories about intergenerational influence and the role of family dynamics in transfer of proenvironmental behaviours between children and their parents is presented and discussed. Finally, literature relevant to the data collection approaches adopted in this research is presented and discussed. The chapter concludes with a presentation of the theoretical framework and a restatement of the propositions that directed the research.

Before exploring literature relevant to the research questions, however, due focus must be paid to the debate surrounding environmental education and education for sustainability. As outlined in Chapter 1, there are differing perspectives regarding the definition and purpose of these two related fields. This debate is summarised in the following paragraphs and the researcher's chosen perspective clarified and justified.

The term 'education for sustainability' has come to be used in Australia interchangeably with 'education for sustainable development' (Tilbury, 2004). Consequently, education for sustainability will be used throughout this thesis rather than education for sustainable development unless specific reference is made to the UNESCO Decade of Education for Sustainable Development. 


\section{Environmental Education, Education for Sustainability or Environmental Education for Sustainability?}

There is no unanimously agreed definition for education for sustainability and its relationship with environmental education (Gough, 2006b; Jickling \& Wals, 2012; McKeown \& Hopkins, 2003). The following sections summarise the different perspectives and close with a description of the definition that guided this research.

\section{Education for Sustainability: An Overarching Modus Operandi}

On one side of the debate are international governing bodies such as UNESCO and the International Union for the Conservation of Nature and Natural Resources (IUCN), and a body of researchers who argue that environmental education is but one of three spheres that must interact and combine towards the overarching pursuit of education for sustainability (Fien, 2001; Pepper \& Wildy, 2008; UNESCO, 2005b; Wals, 2009).

In UNESCO's descriptions of the Decade of Education for Sustainable Development, the pursuits of education for sustainability are carefully and eloquently distinguished from a narrower focus on environmental education (UNESCO, 2002, 2005a, 2005b; Wals, 2009). They describe that an education for sustainability modus operandi should equally pursue issues of environmental, social-cultural and economic justice, as illustrated in Figure 2.1, and make the statement,

Education for Sustainable Development must be seen as a comprehensive package for quality education and learning within which key issues such as poverty reduction, sustainable livelihoods, climate change, gender equality, corporate social responsibility and protection of indigenous cultures, to name a few, are found. (Wals, 2009, p. 26)

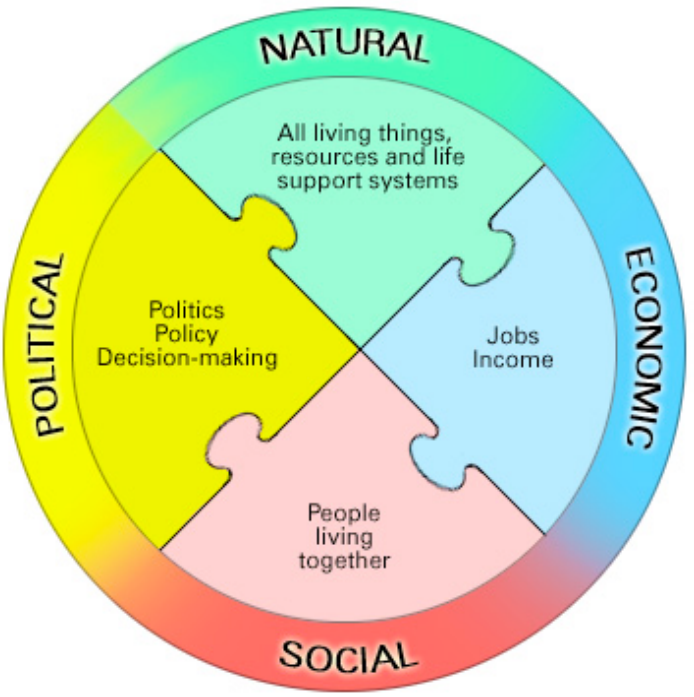

Figure 2.1. UNESCO's model of the interlocking dimensions of sustainability $\mathbb{C}$ UNESCO. All rights reserved. Reproduced with permission from UNESCO (2002). 
The term sustainable development arose out of a realisation in the 1980s of the great threat of excessive economic development to the needs and rights of the world's poorest people and the world's environmental health (Brundtland, 1987; Fien \& Tilbury, 2002). The concept of sustainable development, as an overarching goal under which principles of economic development, social development and environmental protection were merged, began appearing in United Nations documents in the 1980s but was notably reinforced in the Brundtland Report (1987) (Fien \& Tilbury, 2002). The report states (Foreword, p. 2), “...the 'environment' is where we all live; and 'development' is what we all do in attempting to improve our lot within that abode. The two are inseparable", and,

Humanity has the ability to make development sustainable to ensure that it meets the needs of the present without compromising the ability of future generations to meet their own needs. (Brundtland, 1987, section I.3.27)

The role of education in achieving the goals of sustainable development was also prioritised in the Brundtland Report (1987). The report argued (Foreword, p. 4), "the world's teachers will have a crucial role to play in bringing this report to them [the world's youth]", whose wellbeing, they argue, "is the ultimate goal of all environment and development policies".

International agreement for education for sustainable development goals was notably articulated at the 1992 United Nations Conference on Environment and Development (the Earth Summit) held in Rio de Janeiro, where Agenda 21, the global action plan for environmental protection, was first proposed (Fien \& Tilbury, 2002; Gough, 2006a; UNDESA, 1992). Chapter 36 (para. 3) states, "education is critical for promoting sustainable development and improving the capacity of the people to address environment and development issues". It is difficult in this document, however, to find clear distinction between environmental education and education for sustainability. Chapter 36 (para. 1) of Agenda 21 also states that the "recommendations of the Tbilisi Intergovernmental Conference on Environmental Education ... held in 1977, have provided the fundamental principles for the proposals in this document".

It is precisely these kinds of statements that indicate education for sustainability grew alongside and possibly evolved from certain concepts found in the international environmental education movement (Tilbury, 1995). Ten years after the Rio Earth Summit, the United Nations General Assembly adopted a resolution to make 2005 2014 the Decade of Education for Sustainable Development (Davis \& Ferreira, 2009; Gough, 2006b; Henderson \& Tilbury, 2004; UNESCO, 2005a, 2005b, 2007). In their 
Implementation Scheme for the Decade, UNESCO frankly addresses the relationship between environmental education and education for sustainability stating,

The concept of sustainable development being closely related throughout its evolution to the question of the protection of the planet ... is widely known and practiced. The Decade is not limited, however, to environmental education. Developing adequate teaching contents is, thus, a challenge to take up immediately. (UNESCO, 2005a, p. 7)

It is entirely understandable, however, that some countries have pursued education for sustainability as simply another facet of environmental education. In a mid-term review of the Decade, Wals (2009) stated,

...the inter-relationship with environmental education (EE) is emphasized in nearly all regional reports. This is no surprise as in many countries around the world EE is firmly established, particularly in formal education systems. The simultaneous existence and development of EE and ESD has given rise in some countries to questions about the relationships between the two and the call for distinctions by some or for convergence by others. The resulting confusion or stalemate in some cases can hinder policy implementation. Also, it appears that in countries with a strong EE tradition, ESD tends to build upon EE structures and policies already in place, particularly in countries that have interpreted EE broadly to include social, economic and political dimensions. (Wals, 2009, p. 28)

\section{Environmental Education: An Overarching Modus Operandi}

On the other side of the debate is a body of researchers who argue that environmental education has, since its emergence in the 1960s and 70s, encompassed and upheld the same goals that education for sustainability now asserts (Dillon \& Huang, 2010; Jickling, 2006; Jickling \& Wals, 2012). Pivotal publications in the emergence and international recognition of the importance of environmental education, such as Carson's Silent Spring (1962), the Belgrade Charter (1975) and the Tbilisi Declaration (1977), all included references to the social and economic implications of negative environmental decisions (Gough, 2006b; Jickling, 2006). Consequently, critics of education for sustainability argue that environmental education has essentially included sustainability education as one facet of an overarching objective, and question the relevance of the newcomer (Hesselink, van Kempen, \& Wals, 2000; Jickling, 2006; Robottom, 2007).

An international online debate conducted between June 1999 and March 2000 with 50 invited environmental education experts from 25 countries found that more than half of the respondents agreed the concept of education for sustainable development should be abolished (Hesselink et al., 2000). In principle alone, this finding indicated 
there was strong scepticism and concern about moving from an environmental education focus towards an education for sustainability agenda. Some proponents of this case fear that moving towards an education for sustainability modus operandi will subsume and dilute the hard-won validity of environmental education in the public eye and on governmental agendas (González-Gaudiano, 2006; Jickling, 2006; Jickling \& Wals, 2008; Robottom, 2007). González-Gaudiano (2006, p. 292) describes the concern as, "a chill in the air as environmental matters steadily lose their own vitality and relevance within these discourses".

Perhaps one of the most disconcerting observations cited by critics is that environmental education is in many places being 'converted' into education for sustainability to conform with new governmental agendas and funding requirements (Gough, 2006b; Jickling \& Wals, 2008). Jickling and Wals (2008) argue that the international prioritisation of an education for sustainability modus operandi has caused, whether intentionally or otherwise, many environmental educators around the globe to try to 'convert' environmental education into education for sustainability. This move towards conversion, they argue (p. 18), is "problematic" because "this globalising agenda [education for sustainable development] has instrumental and deterministic tendencies that favour transmissive arrangements for teaching and learning over more transformative ones". The transmissive teaching arrangements Jickling and Wals (2008) refer to is a misuse of the emphasis on educating for sustainability, which they argue ( $\mathrm{p}$. 7) can lead to "implanting a particular agenda", where "education inculcates the preferred message, agenda, ideology, or consumer preference".

\section{Environmental Education for Sustainability: An Evolution}

Somewhere in the middle of this debate sit another group of researchers who embrace the move towards education for sustainability and see it as an evolution of environmental education (Gough \& Sharpley, 2005; Lewis, 2012; Tilbury, 1995, 2004). This evolutionary perspective has seen emergence of the term 'environmental education for sustainability' (Wals, 2009). The adoption of this term appears to have been used in some government documents (e.g. Gough \& Sharpley, 2005) as an attempt at reconciling confusion about the purposes of environmental education and education for sustainability by encouraging sustainability education to be viewed through a predominantly environmental lens.

This evolutionary perspective also has seen an emphasis on the for as symbolic of education that empowers and motivates students to take action rather than education 
that simply informs students about issues or teaches them skills couched in experiences (Tilbury, 1995).

In an analysis of environmental education in the 1970s, the Schools Council of England and Wales (1974) described three classes of education. These have become characterised as education about the environment, education in the environment, and education for the environment (Lucas, 1979; Palmer \& Neal, 1994; Tilbury, 1995; Uzzell, 1999). Education about the environment has been described as a process of building knowledge about issues, facts and concepts, education in the environment as a process of developing skills and actions specific to environmental contexts, and education for the environment as a process of cultivating pro-environmental attitudes, motivation and willingness to act. Lucas (1979) proposed that these three classifications of environmental education are not mutually exclusive and should work together in a cyclical way to foster environmental behaviour change, where participation in environmental education,

...will influence attitudes and increase knowledge. The changed attitude and increased knowledge are then assumed to generate new activities, directed towards related goals, or more effective versions of the original actions. (Lucas, 1979, p. 74)

Though overly simple compared with models such as The Model of Responsible Environmental Behaviour (Hines, Hungerford, \& Tomera, 1987), these classifications of environmental education specifically served to identify that more attention should be directed to education for the environment (Tilbury, 1995). The classifications also highlighted a dearth of the kind of education that fosters motivation in children to act in ways that are beneficial for the environment, and triggered research to identify how this could be accomplished (e.g. Jensen, 1993; Uzzell et al. 1994). Furthermore, the characterisation of education for the environment ultimately helped to conceptualise the definition and purpose of education for sustainability (Fien, 2001; Tilbury, 1995, 2004).

\section{Definitional Definition: A Guide for this Research}

Despite attempts at providing clear definitions for education for sustainability, it is precisely the breadth of possibilities claimed to be encompassed by the term that have caused it to be considered ambiguous, 'fuzzy' and 'conceptually flawed' (Fien \& Tilbury, 2002; Jickling \& Wals, 2012). It is perhaps also for this reason that diverse interest groups, such as environmental educators, have each conceptualised a different arrangement of attributes to this one vast term that are, not surprisingly, aligned with their original worldviews. 
Figure 2.2 illustrates the two competing perspectives of education for sustainability. McKeown and Hopkins (2003) highlighted that the debate boils down to whether environmental education or education for sustainability is perceived as being the bigger umbrella. McKeown and Hopkins (2003, p. 124) argue that the answer to this quandary depends entirely on the perspective of those engaged in the debate, and to ask, “Which umbrella is larger?' becomes an inflammatory yet unimportant question". Using this logic, it can be argued that getting on with the job of educating for a sustainability agenda, whether one focuses on sustainability as a feature of environmental action or vice versa, is more important than fighting over definitions. Nonetheless, it is important to specify the definition of education for sustainability that guided this research for the purpose of providing context and meaning.

a)

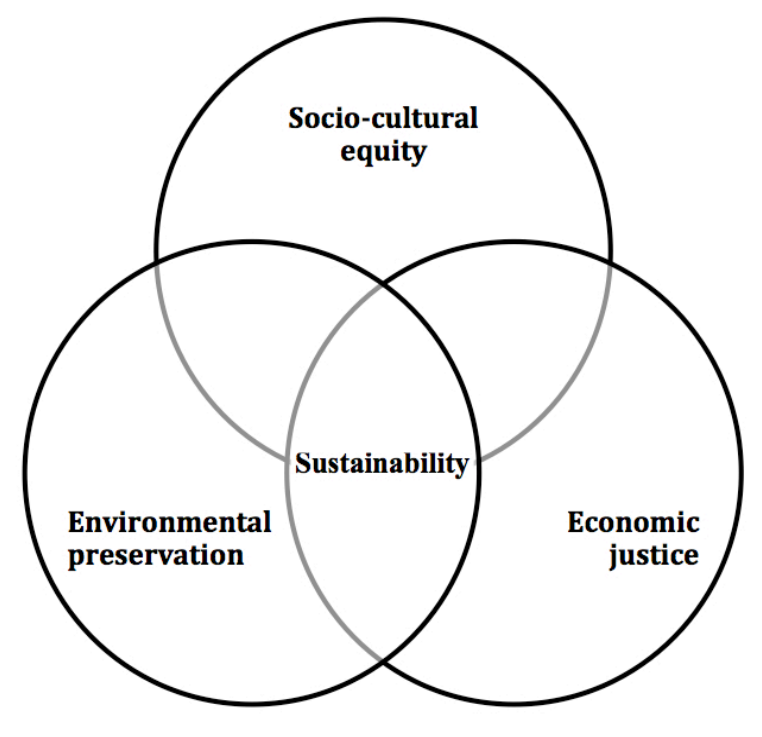

b)

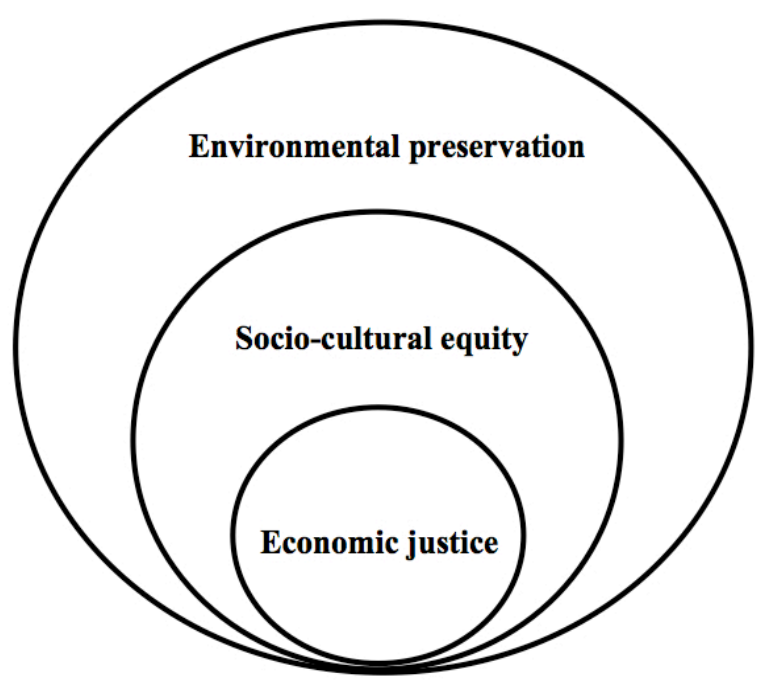

Figure 2.2. Two dominant conceptualisations of sustainability that inform debates on education for sustainability: a) interlocking spheres of economic justice, socio-cultural equity and environmental preservation, b) economic and social concerns as part of a greater pursuit of environmental preservation. 
Summary. This research was undertaken with the view that environmental education is one facet of an overarching goal of education for sustainability (Figure 2.2). Where sustainability, also sustainable development, refers to "meet[ing] the needs of the present without compromising the ability of future generations to meet their own needs" (Brundtland, 1987, section I.3.27) and is underpinned by "the three spheres of sustainable development - environment, society and economy" (UNESCO, 2005b, p. 7) as adopted by UNESCO in their descriptions of the Decade of Education for Sustainable Development (UNESCO, 2005a, 2005b). The researcher accepts the view that the concept of education for sustainability is ambiguous, but embraces this ambiguity as an opportunity for the concept to continue its evolution by taking on new meanings.

The researcher also embraces the emphasis on education for sustainability as an opportunity for educators to use transformative pedagogies to cultivate proenvironmental attitudes, motivation and willingness to act among students. Finally, the researcher acknowledges the inherent limitation of focussing this research primarily on the environmental sphere of education for sustainability, but justifies this decision based on the need for focus inherent in postgraduate research combined with the researcher's pre-existing experience in environmental education.

\section{Key Elements of School Sustainability Education}

The first research question (p. 7) investigated through this research explored the organisational dynamics that foster or impede the establishment of whole-school school sustainability education. Five of twelve key elements were selected from the Key Elements Rubric developed by AuSSI - WA for interrogation in this research.

The AuSSI - WA Key Elements Rubric is a self-assessment resource for schools that outlines twelve elements considered essential to the establishment and longevity of school sustainability education programs (DoE, 2012b). The twelve key elements cover important dynamics that span the areas of: school leadership, community and student engagement, and teaching and learning (Figure 2.3). Administrative and teaching staff are encouraged to use this resource to assess their school's progress in some or all of the twelve elements, and across four levels of achievement: starting, establishing, achieving and excelling.

The five key elements selected for interrogation in this research and described in the following sections were: 1) school governance, 2) school planning, 3) community networks and partnerships, 4) student voice and engagement, and 5) curriculum integration (Figure 2.3). These five elements were considered sufficient to capture 
important organisational dynamics that foster or impede the establishment of wholeschool sustainability education programs.

Many of the twelve elements (Figure 2.3) share common activities, however, and some of the other twelve elements may be touched upon in the discussion of the five selected elements. For example, school planning has been focussed on in this research, but the process of reviewing and evaluating is necessary to creating school plans and is consequently mentioned as part of the key element school planning. Another example is the focus on curriculum integration in this research, which requires mention of teachers' competence for using a cross-curricula approach and thus involves some discussion of professional learning.

\section{School Governance}

Governance, in this context, refers to the system of management established within a school to support and develop whole-school sustainability goals (Tilbury, 2004). Successful whole-school sustainability programs are those in which governance is collaborative and inviting of participation across all levels of the school body, administrators, teachers, parents and students (Gough \& Sharpley, 2005; Pepper \& Wildy, 2008; Tilbury, 2004; Wooltorton, 2004).

Collaborative governance contributes to successful whole-school sustainability programs because it allows every stakeholder to share responsibility and feel ownership of the initiatives that result from the group's discussions (Higgs \& McMillan, 2006; Tilbury, 2004; Wooltorton, 2004). And shared responsibility helps to ensure the longevity of a whole-school sustainability program, which otherwise could be compromised if the principal or key sustainability champions leave the school (Lewis, 2012). Furthermore, commitment and support from a school's governing body are required for a whole-school sustainability program to be successful and long lasting. Without this it can "lose momentum and fail to become embedded in the school culture" (Henderson \& Tilbury, 2004, p. 35). To achieve this sense of shared responsibility, leadership should be distributed and all collaborators engaged in participative, democratic decision-making (Henderson \& Tilbury, 2004; O'Donoghue \& Clarke, 2010; Wooltorton, 2004).

Because of their administrative authority, the principal plays an important role in how a school's governing body is managed and whether leadership is distributed (O'Donoghue \& Clarke, 2010; Pepper \& Wildy, 2008; Wooltorton, 2004). Depending on the principal's leadership style, they can take actions that enable sustainability initiatives to become embedded, create tensions in the process of meeting whole-school 


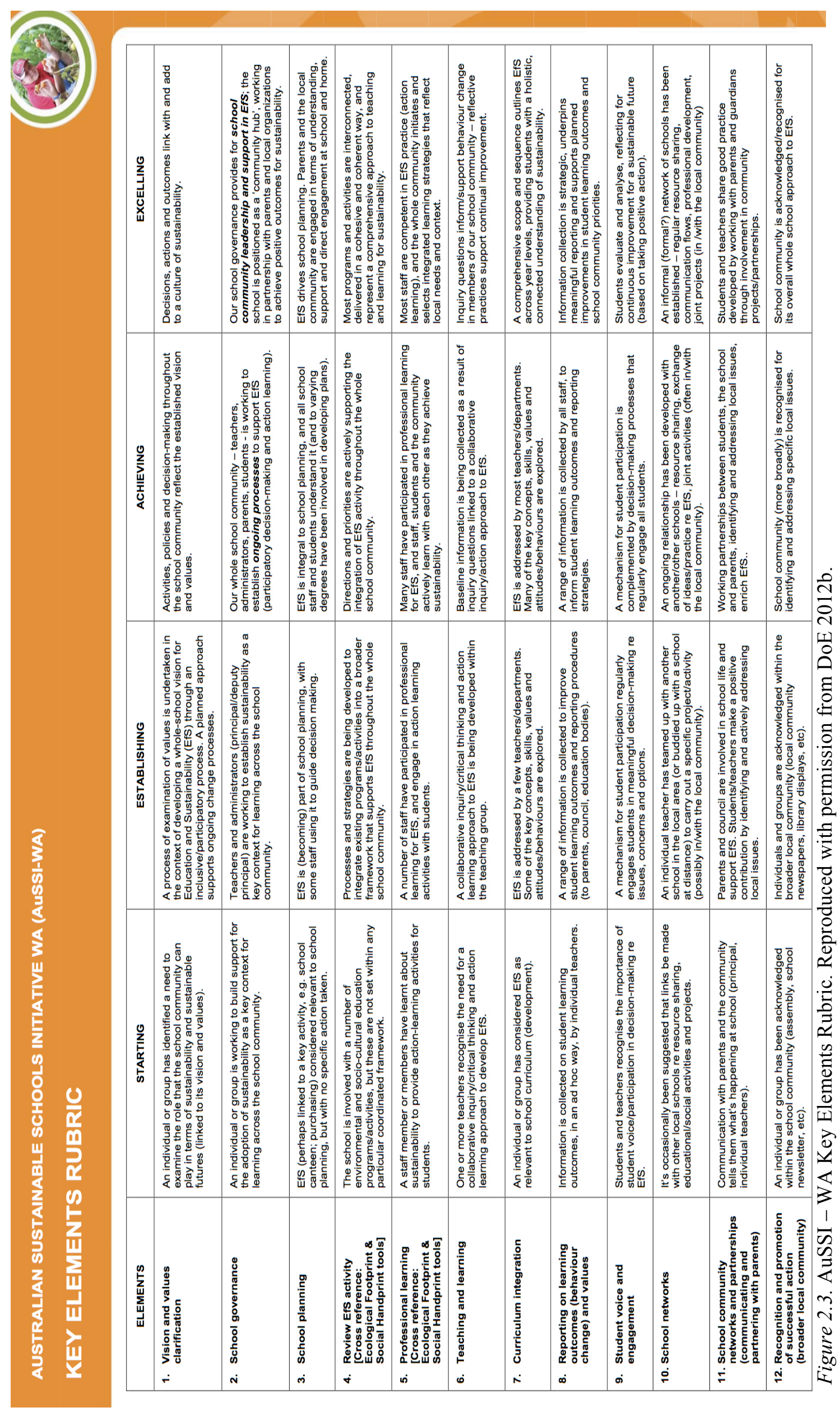


sustainability goals, or not provide the support necessary for initiatives to be sustained (N. S. Evans, Whitehouse, \& Gooch, 2012; Wooltorton, 2004).

Common leadership styles could be summarised as managerial, transactional, transformational and distributed (O'Donoghue \& Clarke, 2010). Managerial leadership "focuses on functions, tasks and the behaviours of people", and leaders exert their influence "through positions of authority within the organisational hierarchy" (O’Donoghue \& Clarke, 2010, p. 57). Transactional leadership "is based on exchange relationships between leader and follower", and can be viewed as a kind of bartering where rewards are given in exchange for good performance and high outcomes (O’Donoghue \& Clarke, 2010, p. 58). Transformational leadership is where a new vision is provided to the school community that "inspires and transforms followers from higher levels of morality [making] the promise of reward unnecessary" (O’Donoghue \& Clarke, 2010, p. 58). Distributed leadership, by contrast, is where leaders "establish a framework for collaborative action and involve the school community in developing and supporting shared beliefs, values, mission and goals for the school" (O'Donoghue \& Clarke, 2010, p. 61). Successful whole-school sustainability initiatives are those where school principals provide leadership that is distributed, where they are at once immersed in the processes and also encouraging of input and collaboration from every stakeholder, together with a shared overarching vision to guide the process (Pepper \& Wildy, 2008).

\section{School Planning}

Sustainability policies embedded into school action plans are necessary for whole-school integration of sustainability education initiatives (Henderson \& Tilbury, 2004; Tilbury, 2004). Building sustainability policies into school plans often serves to encourage every staff member, regardless of their particular level of interest, to begin introducing sustainability concepts into their teaching practice (Henderson \& Tilbury, 2004; Lewis et al., 2009; Salter, Venville, et al., 2011). Policies and plans can also help to maintain the longevity of programs by keeping sustainability on the school agenda, which becomes increasingly important if champions and decision makers leave the school (Henderson \& Tilbury, 2004; Lewis, 2012; Pepper \& Wildy, 2008; Wooltorton, 2004). In some established sustainable schools, new staff are hired based on their interest in the environment or sustainability and their vision of how they can contribute to the school's sustainability goals (Pepper \& Wildy, 2008; Salter, Venville, et al., 2011). 
The process of writing school sustainability policies and plans enables the school administration and teaching staff to define what sustainability will look like within their school and the outcomes they would collectively like to achieve (Henderson \& Tilbury, 2004; Tilbury, 2004). This process is sometimes described as 'visioning' or the development of 'mission statements'. Henderson and Tilbury (2004, section 3.6.4) describe, "the process of visioning ways forward for sustainability is aligned with core principles of EFS: futures thinking".

Together with visioning, it is important that school sustainability policies define how their achievements will be evaluated (Henderson \& Tilbury, 2004). Regular audits of the breadth and quality of the school's sustainability achievements are necessary. Such audits become most effective and empowering when they invite feedback from all stakeholders - teachers, students, parents and administrators (Henderson \& Tilbury, 2004; Lewis, 2012; Lewis et al., 2009). AuSSI - WA suggests that policies and plans should be reviewed regularly and encourages schools to use the Key Elements Rubric to assist with their self-assessment and evaluation (DoE, 2012d). Evaluation provides opportunities for staff to reflect on how well they are achieving their goals and operates as a platform to refine the school's policies accordingly (DoE, 2012d; Lewis et al., 2009; Pepper \& Wildy, 2008). Lewis, Baudains and Mansfield (2009), documented the use of the Key Elements Rubric across three years of staff meetings at one Perth primary school. The rubric was found to have helped staff recognise the systematic connections between activities that had developed as a result of the school's involvement with AuSSI - WA and to identify areas of focus for the following year (Lewis et al., 2009).

\section{Community Networks and Partnerships}

The potential for widespread adoption of environmental behaviours and attitudes is greatest when a sustainable school is valued as the centre of community life (Flowers \& Chodkiewicz, 2009; Gough, 2005; Henderson \& Tilbury, 2004; Lewis, 2012; Uzzell, 1999). Henderson and Tilbury (2004, p. 6) defined a sustainable school as the focus of learning in the community, saying, "It involves all stakeholders in contributing to but also gaining from a partnership approach to Education for Sustainability". Links to community groups, partnerships with program providers and networks with other schools all help to nurture and strengthen a whole-school approach to sustainability education (Davis \& Ferreira, 2009; Eames \& Bolstad, 2004; Tilbury et al., 2005).

Sustainable schools are encouraged to build links with community organisations to enhance their local relevance and increase multi-stakeholder involvement (Davis \& Ferreira, 2009; Eames \& Bolstad, 2004; Flowers \& Chodkiewicz, 2009; Tilbury et al., 
2005). Community groups include parent groups such as the school parents and citizens committee (P\&C), local businesses, non-government organisations (NGOs) or volunteer nature-care groups. For example, in some sustainable schools parent groups will actively coordinate working-bees, prepare grants for additional resources or skilled parents will donate their time for specific tasks (Flowers \& Chodkiewicz, 2009; Lewis et al., 2008; Potter, 2007). As a consequence, schools involved in sustainability initiatives have reported greater involvement in the life of the school by parents and the community as a whole (Flowers \& Chodkiewicz, 2009; Gough, 2005; Henderson \& Tilbury, 2004; Lewis, 2012).

Partnerships with program providers and government agencies are seen as critical to the effectiveness of whole-school sustainability initiatives because they enable schools to seek advice and access resources whenever necessary and can help to promote support for sustainability priorities across the whole school (Henderson \& Tilbury, 2004; Ilich, 2008; Salter, Venville, et al., 2011; Tilbury, 2004). Because of the nature of large agencies, however, it can often be difficult for teachers to know where to look for resources or who to ask for certain advice (Eames \& Bolstad, 2004; Ilich, 2008). For this reason, facilitators can contribute to the effectiveness of partnerships by operating as a bridge between the school and the external agency (Davis \& Ferreira, 2009; Ilich, 2008; Salter, Venville, et al., 2011).

Davis and Ferreira (2009, p. 67) place particular emphasis on the creation of a dynamic relationship between schools and sustainability facilitators, calling it the "webbed network approach", in which they explain that "All participants are recognised as 'knowing experts', learning and acting together around contextualised issues and problems". With collaboration, capacity-building and power-sharing as an ideal dynamic, Davis and Ferreira (2009) debate that advances in the school's sustainability agendas will be driven more by the needs and interests of participants within the school than the facilitator alone, and that because of this dynamic approach, outcomes may, at times, be difficult to clearly identify.

In Western Australia, Millennium Kids have adopted a similar dynamic in their approach as a school sustainability facilitator. Millennium Kids utilise the framework provided by AuSSI - WA and build on their other relationships with various organisations to act as a conduit for a school's connection to resources relevant to a project's needs (Salter, Venville, et al., 2011; Taylor, 2010). Millennium Kids do this by "advertising the diversity of groups and people out there who care about the environment and with which young people could participate", and then based on the 
school's priorities they "call in the people with expertise in other areas, rather than overlapping or competing” (Taylor, 2010, p. 79). Millennium Kids also provide a variety of important facilitation tools when working with a school (Ilich, 2008), such as vision and perspective, mentoring the 'sustainability champions' within the teaching staff, creating relevant professional development opportunities for teachers, helping to link projects with curriculum objectives, and raising understanding within school administration (Salter, Venville, et al., 2011; Taylor, 2010). Using this collaborative, power-sharing approach helps to build capacity in school staff members, and often sees projects emerge that are unique to the interests of school participants (staff and students), the school's location or resources available to the school.

Consequently, it is argued that the Millennium Kids approach to sustainability facilitation is congruent with the webbed network approach (Davis \& Ferreira, 2009), as well as research that shows facilitating a school's connection with education providers and helping staff develop a rapport with key individuals within each education provider is more effective for the successful implementation of the school's sustainability goals than simply providing contact information (Eames \& Bolstad, 2004; Ilich, 2008). Moreover, the Millennium Kids approach is congruent with research showing that whole-school approaches to education for sustainability are most successful when they build on the school's existing priorities and values (Bolstad, Baker, Barker, \& Keown, 2004; Lewis, 2012), and are allowed to evolve from the bottom up, out of the concerns and interests of the whole-school community, especially those of the students (Ilich, 2008; Johnson, 2001; Potter, 2007). Whilst Millennium Kids try to make their services available to as many schools as possible, they are, nevertheless, a not-for-profit organisation that relies on grant funding and sponsorships (Taylor, 2010). Thus, if they have no funds to subsidise a school workshop, it will be up to the school to find the means, which could be a disincentive to some schools that might otherwise wish to employ Millennium Kids as a sustainability facilitator.

Networks between sustainable schools allow learning to flow between school administrators, parent groups, teachers and students, and often begin with more accomplished schools acting as a lighthouse or role model for neighbouring schools (Eames \& Bolstad, 2004; Henderson \& Tilbury, 2004). Networks can also help to build continuity between students' primary and secondary schooling, without which it is suspected that many students' concern for issues of sustainability or interest in acting for the environment decline, as interest in many science topics do (Bennett \& Hogarth, 2009). 
A sustainable school that is valued as central to community life is one where community members are present in the school and students are active in the local community (Gough, 2005; Henderson \& Tilbury, 2004; Lewis et al., 2008; Uzzell, 1999). This interaction develops action competence within all participants that can propel them to continue their sustainability actions at home and showcases concrete actions in the local community that can raise the interest of other community and family members (Armstrong, Sharpley, \& Malcolm, 2003; Henderson \& Tilbury, 2004; Shallcross \& Robinson, 2008; Uzzell, 1999). Whole-school approaches to sustainability have considerable potential to play an important role in shifting whole communities towards sustainability.

\section{Student Voice and Engagement}

The AuSSI - WA Key Elements Rubric describes student voice and engagement as "a mechanism for student participation [that] regularly engages students in meaningful decision-making regarding issues, concerns and options" and that ideally "students evaluate and analyse, reflecting for continuous improvement for a sustainable future - based on taking positive action" (Figure 2.3). How to meaningfully achieve these goals is an important consideration for a sustainable school and one that can present challenges to conservative pedagogies (Eames et al., 2006; Higgs \& McMillan, 2006; Jensen \& Schnack, 2006; Lewis, 2012).

Student engagement requires a move away from the traditional notion of children as helpless dependents and a re-conceptualisation of adult/child relationships (Jensen \& Schnack, 2006; Lansdown, 2001; Uzzell, 1999). Advocates of student engagement often refer to Article 12 of the United Nations Convention on the Rights of the Child, which states,

Parties shall assure to the child who is capable of forming his or her own views the right to express those views freely in all matters affecting the child, the views of the child being given due weight in accordance with the age and maturity of the child. (UNICEF, 20 November 1989)

By extrapolation, Article 12 recommends a move towards listening to children's views, recognising the value of their experiences and insights, seeing them as partners in projects that involve their participation, offering them authentic opportunities for engagement, and encouraging their participation in democratic decision-making (Barratt-Hacking, Barratt, \& Scott, 2007; Eames, Barker, Wilson-Hil, \& Law, 2010; Jensen \& Schnack, 2006; Lansdown, 2001; Uzzell, 1999; Uzzell et al., 1994). In the context of whole-school sustainability education, this requires more than giving students 
opportunities to be part of a school committee or working group. It requires allowing students to take the lead on certain initiatives, which may see those initiatives take a different direction than had been expected by the teachers or administrators (BarrattHacking et al., 2007; Higgs \& McMillan, 2006; Jensen \& Schnack, 2006; Lewis, 2012; Uzzell, 1999). The Millennium Kids Green Team's Ten Steps is one approach that was developed to value children's views and foster their development and continues to be used in every Millennium Kids project (Taylor, 2010).

Millennium Kids youth representatives designed the Ten Step Methodology in 2001 (La Mar, 2006). Ten Steps is an inquiry methodology that helps youth look at an area of concern and develop a practical plan of action in response (La Mar, 2006; Taylor, 2010). It engages young people throughout the project development process from an audit of their concerns, to idea development, research, goal setting, planning, consulting with stakeholders, enacting the project according to their plan, evaluating and reporting. It also develops a young person's capacity for leadership by giving them control of project design, implementation, management and troubleshooting. This tool has been used successfully with young people in many settings, including workshops with school students, environmental camps, or youth conferences (La Mar, 2006; Levett, 2005; Taylor, 2010). When used in schools, teachers are encouraged to "let go of the leading role, and run projects where there are real deadlines and pressures and which teach students about the real world" (Taylor, 2010, p. 80). Projects that utilised the Ten Steps methodology have found that as students see their ideas or the ideas of their peers take shape they express a greater sense of ownership of the overall program and a sense that their ideas have credit in an adult world (Johnson, 2001; La Mar, 2006; Levett, 2005; Taylor, 2010).

Creating authentic and meaningful opportunities for student engagement is a primary goal of the action competence approach to environmental education, which is described in more detail later in this chapter. In short, however, the action competence approach is built on the combination of: 1) issues-based education, 2) action-based education, and 3) cultivating a willingness to act (Jensen \& Schnack, 2006). The argument for this approach is that by combining knowledge and willingness, students become empowered to take up new pro-environmental actions and to contribute to school or family decision-making processes (Fontes, 2004; Jensen, 2004). In a review of research on action competence, Fontes (2004) argued that this approach establishes a confidence in students to continue adopting pro-environmental behaviours throughout 
their lives, stating, "experiences of empowerment increase one's competence for future actions through their mobilising energy" (2004, p. 158).

\section{Curriculum Integration}

As discussed in an earlier section, the importance of understanding the interconnectedness of global sustainability issues was emphasised by UNESCO in its International Implementation Scheme for the UN Decade of Education for Sustainable Development,

Understanding and addressing these global issues of sustainability that affect individual nations and communities are at the heart of Education for Sustainable Development. These issues come from the three spheres of sustainable development - environment, society and economy. (UNESCO, 2005b, p. 7)

Consequently, AuSSI - WA advocates a holistic, integrated vision of education for sustainability, to be achieved by placing emphasis on environmental, economic and socio-cultural perspectives and facilitating explicit links across the curriculum (DoE, 2012a; Lewis et al., 2009). However, issues often arise for teachers when planning and teaching sustainability such as: making links to the curriculum, using whole-systems thinking, depth of personal understanding, and teacher time (N. S. Evans et al., 2012; Summers, Corney, \& Childs, 2003; Tilbury et al., 2005). Furthermore, some teachers have expressed frustration that they are expected to teach a host of different skills and content, above and beyond their training. To adopt this integrated approach schools require mentoring, resource materials, professional learning and time (Carter \& Smith, 2010; Ferreira, Ryan, \& Tilbury, 2007; Tilbury et al., 2005; Wooltorton, 2004).

In whole-school sustainability education, effective integration of curriculum areas, whilst also meeting all learning objectives, requires whole-system thinking (Sterling, 2003; Tilbury et al., 2005). Whole-systems thinking requires a move beyond disseminating knowledge and involves a focus on building capacity, skills, knowledge and motivation in all participants to respond to the complex sustainability issues they encounter (Gough, 2005; Lewis et al., 2009; Potter, 2007; Sterling, 2003; Tilbury, 2004). Whole-systems thinking is an encouraged approach to teaching sustainability because it focuses on an holistic understanding of the interconnections and interdependence between all things and helps foster action competence, rather than teaching separate subjects which the students may not connect with the bigger picture (Lewis \& Baudains, 2007; Lewis et al., 2008; Sterling, 2003). A whole-systems approach should ideally be coupled with a whole-school approach, which aims to ensure 
continuity of the learning experience by encouraging integrated learning across teachers and year levels (Gough, 2005; Henderson \& Tilbury, 2004; Lewis, 2012).

Such a whole-system cross-curricula approach requires teachers to think outside of the silos that currently define learning areas or subjects, such as mathematics, English literacy, social studies or society and environment, science and arts, to see that certain topics can be woven across each of these learning areas when programming a unit of study (Lewis, 2012; Lewis \& Baudains, 2007; Sterling, 2003; Tilbury et al., 2005). Doing so often makes class lessons more relevant for students because learning can be focused around contexts they are familiar with and the theory reinforced by practical hands-on action in the school arena.

Integrating sustainability principles, concepts and actions in a whole-school whole-system way that fosters student empowerment and community engagement, requires preparation time, adequate conceptual understanding of sustainability and flexibility in pedagogy, all of which can seem a daunting challenge, even for motivated teachers (Carter \& Smith, 2010; Ferreira et al., 2007; Henderson \& Tilbury, 2004; Hopkins \& McKeown, 2005; Lewis, 2012; Summers et al., 2003). Consequently, adequate pre-service training and regular, relevant professional learning in education for sustainability are critical to the successful implementation and longevity of school sustainability initiatives. Such training is necessary for teachers not to see sustainability as 'just another thing to teach' and for school administrators not to simply 'tick off' sustainability accomplishments.

Even when teachers are willing to adopt an integrated curriculum and use whole-systems thinking, there are certain barriers they must face, in particular, issues of credibility and pressure to perform (Polesel et al., 2012; Rennie, Venville, \& Wallace, 2012). Venville, Sheffield and Rennie (2008, p. 16) discuss issues of credibility that teachers face in attempting to build integration into their science lessons, stating, "the kind of learning observed in this case study could also be considered to be 'soft' that is, difficult to test in an objective way". Issues of credibility arise because traditional conceptualisations of the science discipline state that students should learn 'hard' or fact based knowledge, which is discipline specific (Rennie et al., 2012; Venville, Sheffield, Rennie, \& Wallace, 2008). Consequently, newer conceptualisations of integrated knowledge that crosses disciplines, is, by certain critics, considered 'soft', 'everyday' or 'weakly framed'. Similar issues of credibility arise for other discipline areas and are most pronounced in secondary schools where each discipline is taught by a different teacher (Pepper \& Wildy, 2008). By contrast, class teachers in primary schools have 
more flexibility to teach an integrated curriculum should they wish to or feel confident to do so (Henderson \& Tilbury, 2004).

Pressure to perform is another barrier to adopting an integrated curriculum. Introduction of the National Assessment Program for Literacy and Numeracy (NAPLAN) in 2008 (ACARA, 2012c) has placed extra pressure on primary and secondary teachers in Australian schools to meet or exceed certain performance targets in mathematics, English and science (Polesel et al., 2012; Smeed et al., 2009; Wigglesworth et al., 2011). This focus on content knowledge in specific disciplines has seen NAPLAN testing receive criticism for reducing the onus on teachers to pursue other holistic pursuits such as an integrated curriculum. It has been established that high stakes testing narrows the curriculum down to what is tested ( $\mathrm{Au}, 2007)$ and limits pedagogies to traditional chalk and talk.

\section{Summary}

The five key elements of whole-school sustainability education discussed here: 1) school governance, 2) school planning, 3) community networks and partnerships, 4) student voice and engagement, and 5) curriculum integration, were examined in each case study school involved in this research.

\section{Pro-Environmental Behaviour}

To adequately investigate the research questions posed in this thesis (p. 7), it is necessary to discuss and frame the factors that contribute to pro-environmental behaviour and develop definitions for the concepts of knowledge, attitudes and behaviour to be used throughout this thesis. Research Question 2 focused on the environmental and sustainability knowledge of students; Research Question 3 probed students' pro-environmental behaviours; and Research Question 4 assessed the relationship between students' pro-environmental attitudes and pro-environmental behaviours. A summary of the literature dedicated to the theories of pro-environmental behaviour, and its theoretical relationship with knowledge and attitudes is provided.

\section{Theories of Pro-Environmental Behaviour}

Identifying and measuring the factors that contribute to changes in human behaviour is a complex task that psychologists have explored for many years (Heimlich \& Ardoin, 2008; Kollmuss \& Agyeman, 2002). Multiple theories and models have been proposed by researchers in their attempts to understand the factors that drive behaviour change. These range from linear theories of causality from the 1970's, where affect and 
knowledge led to behaviour, to later, more complex theories of causality, where various contributing and mediating factors led to different degrees of behaviour.

Researchers in environmental education have benefitted from and contributed to the development of these theories (Heimlich \& Ardoin, 2008; Kollmuss \& Agyeman, 2002). Among the theories and models most widely used in environmental education research are: The Communication-Persuasion model (McGuire, 1964); The Diffusion of Innovation model (Rogers, 1995); The Theory of Reasoned Action (I. Ajzen \& Fishbein, 1980; Fishbein \& Ajzen, 1975); The Theory of Planned Behaviour (Icek Ajzen, 1991), which grew out of the Theory of Reasoned Action; and, The Model of Responsible Environmental Behaviour (Hines, Hungerford \& Tomera, 1987).

Various other models have been proposed by researchers in attempts to encapsulate the complex interplay of factors that can lead to pro-environmental behaviour, however, these models risk becoming convoluted and layered with assumptions (e.g. Kollmuss and Agyeman's, 2002, Theory of Pro-Environmental Behaviour) (Heimlich \& Ardoin, 2008). In selecting a behaviour change theory or combination of theories to guide their research, researchers should consider the context, the individual motivations and the specific behaviours being targeted (De Young, 2000; Heimlich \& Ardoin, 2008; Kollmuss \& Agyeman, 2002; Stern, 2000). Heimlich and Ardoin (2008, p. 231) argue,

If environmental education is to produce a citizenry capable of making sound decisions and acting on those decisions in a way that is environmentally and personally sustainable, it is imperative that the field avoids unilateral assumptions. It is necessary to understand that, related to behaviours, individuals are not all alike; they are not motivated by the same things nor are they equally capable of altering routines. People may act in ways we believe are not environmentally appropriate and yet believe themselves to be committed to the environment. (Heimlich \& Ardoin, 2008, p. 231)

Context was an important consideration when deciding on a model of behaviour change to use in this research. Lighthouse and River's Edge Primary Schools had been undertaking their whole-school sustainability program for eight and two years respectively and the researcher was not in a position to experiment with behaviour change by building on an existing program at either school. In addition, Fertile Ground Primary School, at the time of making contact, had no intention of establishing a wholeschool sustainability education program. Consequently, change in behaviour during the course of this research could not be tested, and the research was limited to exploration and inference. 
Due to these contextual constraints and because human behaviour is profoundly complex, the selection of a theory to guide this research was a difficult task. Nonetheless, it was decided to adopt Hines et al.'s (1987) Model of Responsible Environmental Behaviour because it is a concisely articulated theory that builds on previous research about environmental behaviour and includes contingency for contextual variation in observed behaviours. This model also encapsulates concepts that emerged from the 1970's characterisation of education about, in and for the environment, and Jensen's (1993) action competence approach.

Model of Responsible Environmental Behaviour. Hines et al. (1987) developed The Model of Responsible Environmental Behaviour following a metaanalysis of 128 studies that investigated the behaviour research literature in environmental education. Similar to Jensen's (1993) action competence approach and the 1970's characterisation of education about, in and for the environment, The Model of Responsible Environmental Behaviour (Hines et al., 1987) recognises the importance of issues-based knowledge, action-based knowledge, and willingness to act. The Model of Responsible Environmental Behaviour (Hines et al., 1987), however, incorporates some important differences, which include a rigorous definition of the factors that contribute to a person's willingness to act, and recognition of certain factors that may intervene between a willing, knowledgeable person and their actual behaviour (Figure 2.4). This section explores the components of The Model of Responsible Environmental Behaviour and describes how they have been conceptualised in this research.

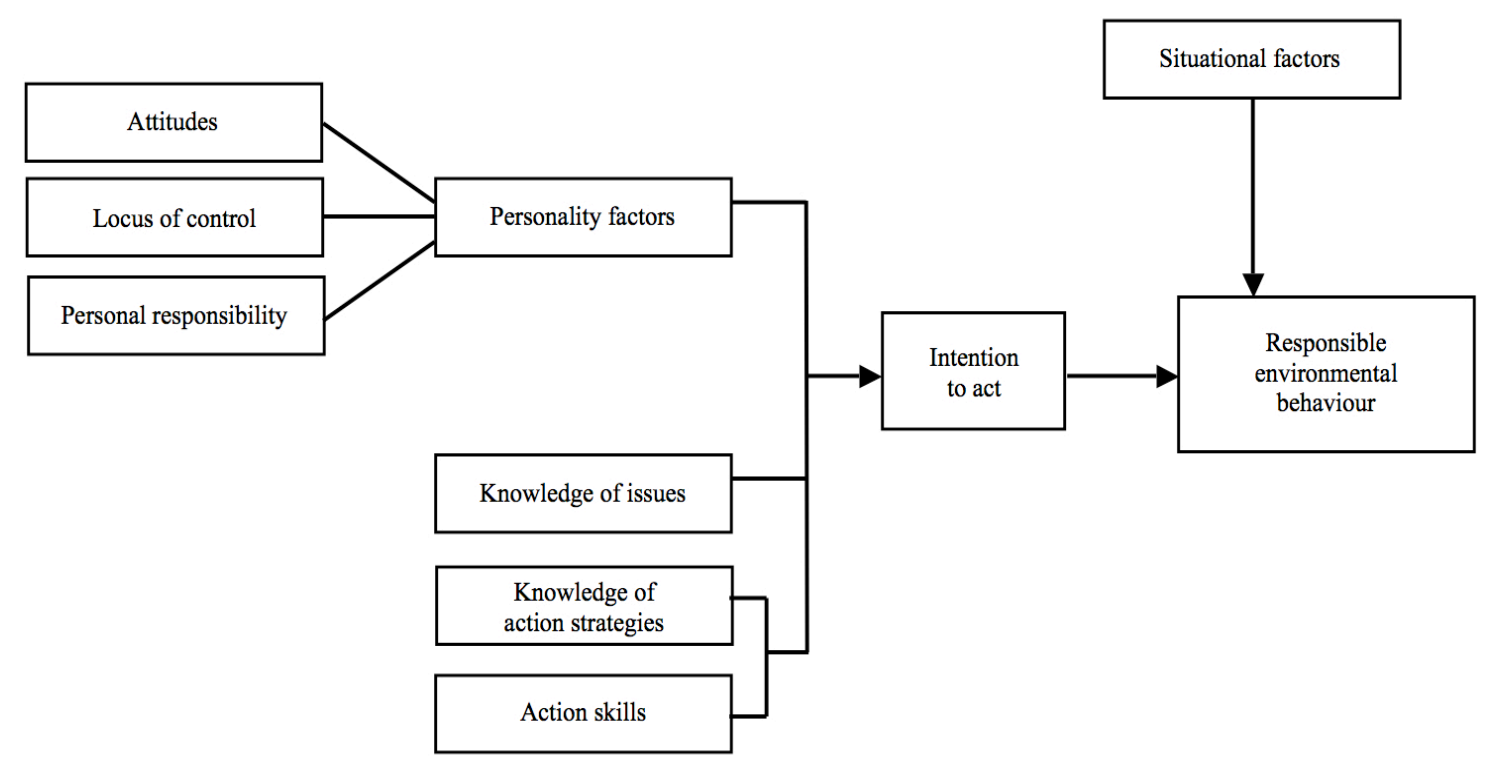

Figure 2.4. The Model of Responsible Environmental Behaviour. Redrawn from Hines, Hungerford \& Tomera (1987). 
Hines et al.'s (1987) Model of Responsible Environmental Behaviour differentiates between issues-based and action-based knowledge,

Before an individual can intentionally act on a particular environmental problem, that individual must be cognizant of the existence of the problem. Thus, knowledge of the problem appears to be a prerequisite to action. However, an individual must also possess knowledge of those courses of action which are available and which will be most effective in a given situation. (Hines et al., 1987, p. 6)

It should also be noted that Hines et al.'s (1987) model differentiates between knowledge of action strategies and action skills (Figure 2.4). Hines et al. (1987) argue that a person's knowledge of 'what' can be done is only powerful if a person also has the skill to consider 'how' certain strategies can be appropriately applied to given situations. For example, it is not enough to know that planting a tall-growing tree will provide shade and reduce the energy used to cool household air temperatures in summer. An individual must also have the skill to determine the most appropriate tree to plant, choose the best place to plant it, and decide how best to fulfil the ongoing commitment required to care for the tree.

In this research, The Model of Responsible Environmental Behaviour (Hines et al., 1987) is considered to not only encapsulate Jensen's (1993) action competence approach and the 1970's characterisation of education about, in and for the environment, but also includes further important details that these two conceptualisations do not. The Model of Responsible Environmental Behaviour (Hines et al., 1987) not only acknowledges the contribution of issues-based and action-based knowledge, but describes the factors that contribute to 'education for the environment' or a person's 'willingness to act' in accordance with psychological concepts that are commonly described in the literature about behaviour change. Hines et al. (1987) describe these factors as a person's 'personality factors', which include attitudes, locus of control and sense of personal responsibility (Figure 2.4):

In addition, an individual must possess a desire to act. One's desire to act appears to be affected by a host of personality factors. These include locus of control, attitudes, and personal responsibility. Thus, an individual with an internal locus of control, positive attitudes toward the environment and toward taking action, and with a sense of obligation toward the environment will likely develop a desire to take action. (Hines et al., 1987, p. 7)

Another distinction between The Model of Responsible Environmental Behaviour (Hines et al., 1987) and, the action competence approach (Jensen, 1993) and education about, in and for the environment, is that the former accounts for the effects 
of moderating factors. Hines et al. (1987) describe the interaction between personality factors and the two knowledge types saying, "If the requisite abilities to act are also present, action will likely follow. If these abilities are absent, action will not be likely to follow" (1987, p. 7). Even so, they included in their model the moderating factor, 'intention to act', which accounts for any discrepancy between an individual's intended and actual behaviour. Other models of behaviour change, including the widely accepted Theory of Planned Behaviour (Ajzen, 1991), have incorporated 'intention' as a variable that mediates between an individual's intended and actual behaviour. This is because the path between knowledge, willingness and actual behaviour can be interrupted by other variables, which Hines et al. (1987) describe as 'situational factors'.

Situational factors can contribute to differences in behaviours that are unrelated to a person's issues-based or action-based knowledge, willingness to act or intention to act (Hines et al., 1987). Situational factors include social norms, family norms, availability of infrastructure, access to resources, and time. The widely used Theory of Planned Behaviour (Ajzen, 1991) specifically incorporated social norms as a key feature of the model, and also referred to it as a moderating factor that intervenes between a person's behavioural intention and their observed behaviour. Ajzen's (1991) inclusion of this concept propelled a large number of studies into the influence of social norms on a person's behaviour, particularly in recent years (Cialdini \& Goldstein, 2004; Lapinski \& Rimal, 2005; P. W. Schultz, Nolan, Cialdini, Goldstein, \& Griskevicius, 2007). In an environmental education context, however, the broader description of situational factors, provided by Hines et al. (1987), allows wider scope for other relevant influential factors to be considered, such as access to infrastructure, resources and time.

In contrast with Ajzen's (1991) Theory of Planned Behaviour, The Model of Responsible Environmental Behaviour (Hines et al., 1987) incorporates issues-based and action-based knowledge as factors that contribute to behaviour change (for reasons already discussed) (Heimlich \& Ardoin, 2008; Kollmuss \& Agyeman, 2002). Consequently, The Model of Responsible Environmental Behaviour (Hines et al., 1987) can be considered more sophisticated and appropriate to use in environmental education research than the widely used and, conceptually concise Theory of Planned Behaviour (Ajzen, 1991).

The use of the The Model of Responsible Environmental Behaviour (Hines et al., 1987) in this research was justified to investigate: 1) the depth, volume and breadth of issues-based and action-based knowledge of students at each school; 2) students' 
self-reported frequency of undertaking certain pro-environmental behaviours in their homes, while also considering situational factors that may have affected their frequency of undertaking each behaviour; and 3) the relationship between students' attitudes towards environmental world-views and attitudes towards school environmental education and, students' self-reported pro-environmental behaviours.

\section{Factors that Affect Pro-Environmental Behaviour}

Factors that affect pro-environmental behaviour can be split into three broad categories: demographic factors, external factors and internal factors (Kollmuss \& Agyeman, 2002). Demographic factors include gender, years of education and socioeconomic status. External factors include financial incentives, access to resources, institutional support, available infrastructure, and social or cultural norms. Internal factors include motives, values, risk perception, awareness, emotional connectedness, locus of control, knowledge and attitudes. Extensive research has been conducted on each of these factors and their relationships with pro-environmental behaviour, with earlier research being well summarised in a review paper by Kollmuss and Agyeman (2002).

In this research, the focus was on the internal factors of knowledge and attitudes, and their relationships with behaviour. These factors were selected because many studies suggest that knowledge and attitudes do impact environmental behaviour, despite continuing debates about their precise relationship with behaviour (G. W. Evans et al., 2007; Gralton, Sinclair, \& Purnell, 2004; Heimlich \& Ardoin, 2008; Jensen, 2002; Kollmuss \& Agyeman, 2002). Knowledge and attitudes also feature in many theories of behaviour change.

Knowledge. Knowledge can be defined as "any internal information, understanding, or capacity to accomplish tasks which has been learned" (Matsumoto, 2009 , p. 274), and is sometimes divided into three types: declarative, procedural and acquaintanceship (Matsumoto, 2009). In this definition, declarative knowledge is associated with learned facts, procedural knowledge is associated with a learned ability or skill, and acquaintanceship knowledge is associated with recognition of people with whom one has any kind of relationship.

Types of knowledge. In the field of environmental education, some authors have also differentiated between types of knowledge. They describe these as knowledge of issues, which can be likened to declarative knowledge, and knowledge of action strategies, which can be likened to procedural knowledge (Hines et al., 1987; Hungerford \& Volk, 1990; Jensen, 2002). 
Many environmental education researchers have been critical of the contribution of knowledge towards pro-environmental behaviour, describing the link between them as spurious (Kollmuss \& Agyeman, 2002; McKenzie-Mohr, 2000; Stern, 2000). However, authors that differentiate between issues-based and action-based knowledge, argue that the reason many studies have found a spurious connection between knowledge and behaviour change is because of the dominant focus on issues-based knowledge in environmental education (Hines et al., 1987; Jensen, 2002; Monroe, 2003). Jensen (2002, p. 329) argued that school based environmental education "has traditionally focused on passing on knowledge to pupils, who have not been afforded the possibility of actively appropriating and internalising that knowledge", and advocated "an action oriented approach that involves an interdisciplinary connection between environment, people, culture and society". Similarly, in a meta-analysis of research on environmental behaviour change, Hines et al. (1987, p. 7) reported,

...treatments employing both knowledge and cognitive skill components resulted in significant increases in the numbers of actions reported as compared to those programs which employed only cognitive knowledge components. (Hines et al., 1987, p. 7)

These traditional, issues-based approaches to environmental education continue to be used by some researchers, and were originally influenced by superseded theories from communication and media studies which assumed knowledge of information leads to the desired cognitive and attitudinal outcomes, and consequently to the desired behaviours (Heimlich \& Ardoin, 2008; Hungerford \& Volk, 1990; Kollmuss \& Agyeman, 2002; Ramsey \& Rickson, 1976). This approach was also known as the deficit model of communication (Trench, 2008). A widely accepted model from the 1970's stated, “increased knowledge leads to favourable attitudes ... which in turn lead to action promoting better environmental quality" (Ramsey \& Rickson, 1976, p. 1). Interestingly, however, Ramsey and Rickson themselves found that "not all knowledge offered the public within the environmental context leads to favourable attitudes" (1976, p. 17). In recognising that this linear model of causality was too simplistic, researchers began to propose a variety of different models in their attempts to capture the complex interrelationships of factors that may lead to pro-environmental behaviour (Heimlich \& Ardoin, 2008; Hungerford \& Volk, 1990; Kollmuss \& Agyeman, 2002). While a basic knowledge of environmental issues may be necessary for people to be cognizant of the need to act environmentally, it is not enough on its own to cause an increase in proenvironmental behaviour. 
In fact, it has been found that knowledge of environmental issues, such as climate change, without knowledge of actions or skills that enable pro-environmental behaviour, can lead to anxiety and worry in children (Jensen \& Schnack, 2006; Ojala, 2011; Tucci et al., 2007), which can further lead to a sense of hopelessness, distress and despair about the world's environmental state (Fritze et al., 2008). Some children have described unwillingness towards taking actions to care for the environment if their despair and anxiety remain unchallenged by activities that foster hope, ownership and empowerment (Ojala, 2011). This despair, anxiety and unwillingness could be an underlying reason why Australian youth have been shown to have high awareness of environmental issues, relative to OECD countries, but low optimism, concern and responsibility, as found in the PISA 2006 assessment (Thomson \& De Bortoli, 2008). Jensen (2002, 2004) and Jensen and Schnack (2006) describe this despair and unwillingness to act as 'action paralysis', and suggest that by fostering 'action competence' this scenario can be averted.

Action competence. The term action competence was first coined by Jensen in 1993 and quickly adopted by other researchers (Fontes, 2004). Jensen first suggested the term in an attempt to differentiate between activity oriented environmental education (one-off visits to a science centre, or water testing in a local creek) and action oriented environmental education (community based environmental interventions, such as those promoted by the current Australian Sustainable Schools Initiative). The action competence approach in environmental education has come to be understood as a cohesion of: 1) knowledge about environmental issues, 2) knowledge of how to act for the environment and 3) a willingness to act, which together contribute to a person's ability to act (Eames et al., 2010; Eames et al., 2006; Fontes, 2004; Jensen, 2004; Jensen $\&$ Schnack, 2006). These goals of the action competence approach grew out of the earlier characterisations of education about the environment, education in the environment, and education for the environment.

A key feature of the action competence approach in environmental education is about cultivating within students the desire to take actions that are based on thoughtful informed choices as opposed to indoctrinating students to undertake behaviours of which they may not understand the relevance (Jensen, 1993, 2004; Jensen \& Schnack, 2006). To achieve action competence, educators are encouraged to foster students' capacities for democratic decision making, critical investigation and problem solving, and to provide socially relevant contexts in which to centre the learning experience (Eames et al., 2006; Fontes, 2004; Jensen \& Schnack, 2006). All of these capacities can 
be considered examples of developing locus of control, personal responsibility, contextual learning and social norms, which are psychological concepts commonly used in the scholarly discussion of behaviour change (Hines et al., 1987; Kollmuss \& Agyeman, 2002).

Although Jensen (1993) first described the term 'action competence' and has continued to write extensively on the topic, Jensen was not the first to describe the important interaction of issues-based knowledge, action-based knowledge and a person's willingness to take action. The Schools Council of England and Wales' (1974) description of education about, in and for the environment opened the gateway for seeing environmental education through this lens. This interaction was more rigorously described in the Model of Responsible Environmental Behaviour, proposed by Hines, Hungerford and Tomera (1987), after reporting a meta-analysis of 128 studies that investigated the behaviour research literature in environmental education (Hines et al., 1987; Hungerford \& Volk, 1990). The Model of Responsible Environmental Behaviour was examined in more detail in an earlier section.

Integrated knowledge. Knowledge can also be described as breadth of knowledge or an understanding of integrated concepts, as is advocated in the literature about whole-systems thinking. Earlier in this chapter the concept of whole-systems thinking was introduced with respect to a pedagogical approach to curriculum integration. A desired outcome of integrating sustainability concepts across curriculum learning areas is to develop aspects of whole-systems thinking, including social and environmental responsibility, in the students being taught (Lewis, 2012; Lewis \& Baudains, 2007; Sterling, 2003).

Whole-systems thinking in students may be expressed as an understanding of the interconnected nature of complex social and environmental issues, such as an understanding of the cyclical connection between personal energy consumption, global warming, rising living costs and urban poverty. It may also be expressed as knowledge of a breadth of issues or actions that are all connected to one central concept, such as identifying many different kinds of actions that could contribute to pro-environmental behaviour.

Knowledge - in this research. The descriptions of integrated knowledge and whole-systems thinking, action competence, and action-based knowledge as different from issues-based knowledge, are referred to throughout this thesis. Data collection and analysis is discussed in Chapter 3, but later in this chapter, literature about estimating knowledge is presented and discussed with reference to the tool used in this research. 
Attitudes. Attitudes can be defined as "a general and relatively lasting evaluation an individual holds regarding another person, object, or idea" that "can be positive, negative, or neutral and can range from moderate to quite extreme" (Matsumoto, 2009, p. 60). Identifying the components that contribute to the formation of an individual's attitudes has been a point of debate in the literature for many years (Fishbein \& Ajzen, 1975), with researchers debating the inclusion of concepts such as motivation, self-esteem, feelings and enjoyment (Heimlich \& Ardoin, 2008; Kind, Jones, \& Barmby, 2007). Through this debate, a common definition evolved that describes attitudes in relation to cognition, affect and behaviour, where cognition refers to understanding and affect refers to feelings (Kind et al., 2007; Reid, 2006). The Cambridge Dictionary of Psychology (Matsumoto, 2009, p. 59) defines the components that contribute to the formation of an individual's attitudes saying, "attitudes can be influenced by and can influence beliefs, affect, and behaviour in relation to the attitude object". The term "attitude object" is often used to refer to the "person, object or idea" towards which the attitude is directed (Crano \& Prislin, 2006; Matsumoto, 2009).

These discussions of how to conceptualise attitudes have also influenced the perception and definition of environmental attitudes, as they are understood in an environmental education context (Heimlich \& Ardoin, 2008; Milfont \& Duckitt, 2004; P. W. Schultz, Shriver, Tabanico, \& Khazian, 2004). Environmental attitudes can be defined as "the collection of beliefs, affect and behavioural intentions a person holds regarding environmentally related activities or issues" (Schultz et al., 2004, p. 31).

Beliefs can be described as an individual's knowledge, ideas or propositions about an attitude object that are regarded as true, whether factually correct or not (Matsumoto, 2009; Reid, 2006). Take for example the statement, '97 percent of climate scientists agree that humans are causing global warming', versus the statement, 'There is no consensus among climate scientists that humans are causing global warming'. The first statement is factually correct and the second is not, yet both represent beliefs common among the general public today (ScepticalScience, 2012).

Affect refers to peoples' feelings about an attitude object (like or dislike, fear or hope, etcetera), which can be influenced by their beliefs of what they think to be true, and can also be influenced by their mood at the time of expressing their attitude (Matsumoto, 2009; Reid, 2006). For example, a sample of Australian children, aged 10 - 14 years old, surveyed in 2007 found that 44 percent were worried about the future impact of climate change and 25 percent were so worried about the state of the world that they thought it would come to an end before they grew older (Tucci et al., 2007). 
This collective sense of worry would likely be influenced by what these children believed to be true about climate change and world affairs, and would consequently have influenced their attitudes (positive or negative) towards taking action on issues such as climate change.

Conceptualising attitudes as influenced by beliefs and affect in these ways, allows a clearer definition to emerge that sees attitudes as evaluative judgements towards attitude objects that are influenced by "the feelings that a person has about an object, based on his or her knowledge and belief about that object" (Barmby et al., 2008, p. 1076). Moreover, these evaluative judgements may have some influence on the actions that a person takes for or against the attitude object (Barmby, Kind, \& Jones, 2008; Glasman \& Albarracín, 2006; Matsumoto, 2009).

Attitude-behaviour link. The link between behaviour and attitude has been explored in many studies with the intention of determining attitude-behaviour consistency and causality. Attitude-behaviour consistency is "the degree to which an attitude toward an object predicts behaviour toward this object", which can be estimated by looking for associations or correlations between a group of peoples' attitudes and behaviours (Matsumoto, 2009, p. 60). Several factors have been identified that increase attitude-behaviour consistency, including: valid and reliable measurement, knowledge about the attitude object, and having direct experience with the attitude object (Glasman \& Albarracín, 2006; Matsumoto, 2009).

In 1987, Hines et al. conducted a meta-analysis of 128 studies to explore the relationship between pro-environmental behaviours and a number of sociopsychological variables. From a subset of nine studies that reported correlations between environmental attitudes and behaviours the mean correlation was .35, with a standard error of .08 (Hines et al., 1987). This result indicated that positive environmental attitudes were moderately related with a propensity for engaging in proenvironmental behaviours, and the sizeable standard deviation indicated that other factors were responsible for the low and high variation. Twenty years later, Bamberg and Möser (2007) conducted a meta-analysis of 46 studies with the same intention as their predecessors. From a subset of seventeen studies they found a correlation between attitudes and behaviours of .42 , with a standard error of .07 , which, because they fell within one standard error, could be described as not significantly different to the results of Hines et al. (1987) (Bamberg \& Möser, 2007).

Further research has found that broad environmental attitudes have low predictability of a person's propensity to engage in specific pro-environmental 
behaviours, whereas attitudes towards specific issues have greater predictive value (Corraliza \& Berenguer, 2000; Guagnano, Stern, \& Dietz, 1995; Heimlich \& Ardoin, 2008). In these studies, researchers found that correlation between attitudes and behaviours were more than double the finding from Hines et al. (1987) when, the attitudes estimated reflected participants' direct experience and knowledge of the attitude object, and the behaviours estimated were relevant to circumstances and opportunities available to the participants (e.g. Corraliza \& Berenguer, 2000; Guagnano, Stern \& Dietz, 1995).

For these reasons, it was decided to create an attitude scale specifically designed to suit the context of this research. As the context of the research was whole-school education for environmental sustainability, it was considered appropriate for the second attitude scale to include questions about students' beliefs and feelings towards school environmental activities. The creation of this scale involved validation and reliability testing, prior to modelling its relationship with students' pro-environmental behaviours (as discussed later in this chapter and in Chapter 3).

Attitudes - in this research. In this research, attitudes will continue to be defined as being influenced by an individual's beliefs and affect towards an attitude object. Two scales were used to estimate students' environmental attitudes, one that estimates general attitudes towards environmental worldviews and another that estimates specific attitudes towards school environmental experiences. Data collection and analysis is discussed in Chapter 3, but later in this chapter, literature about the specific attitude scales used in this research is presented and discussed.

Behaviour. Behaviour can be broadly defined as, "all the activities that living organisms exhibit" (Matsumoto, 2009, p. 78). The study of human behaviour, behaviourism, has long debated a definition of human behaviour and the factors that influence it (Heimlich \& Ardoin, 2008). Behaviourism broadly postulates that, individuals exhibit behaviours in response to environmental stimuli. Types of behavioural responses have been debated; with classical behaviourists describing behaviour as solely overt, physical and observable (e.g. Watson, 1913; Skinner, 1957 as cited in Epstein, 1991; Heimlich \& Ardoin, 2008; Hineline, 1992), and other behaviourists widening the definition of behaviour to include cognitive or affective processes (e.g. Dewey, 1896; James, 1912; as cited in Garrison, 1995; Heimlich \& Ardoin, 2008).

In environmental education, behaviour commonly refers to this wider definition that includes overt, physically observable behaviours and covert behaviours such as 
thoughts or intentions (Heimlich \& Ardoin, 2008). Furthermore, that these behaviours are potentially influenced by messaging, educational strategies or a variety of other stimuli (Heimlich \& Ardoin, 2008; Monroe, 2003). Despite this broad definition, it is recognised that an analysis of environmental behaviours requires looking for discernable behaviours or specific actions. McKenzie-Mohr and Smith (1999) state that 'most environmental activities are made up of several discernible behaviours' (cited in Monroe, 2003, p. 115).

The overarching goal of environmental education is to employ effective stimuli that will encourage environmentally responsible citizenship and the regular practice of pro-environmental behaviours (Heimlich \& Ardoin, 2008; Hines et al., 1987; Hungerford \& Volk, 1990; Kollmuss \& Agyeman, 2002). Consequently, volumes of studies have been devoted to investigating the factors that influence pro-environmental behaviour, and multiple theories have been proposed by researchers in their attempts to understand the interaction of these factors, as discussed earlier in this chapter.

Behaviour - in this research. In this research, behaviour refers to overt, physically observable behaviours as well as covert behaviours such as thoughts or intentions, and was investigated by looking for discernable, specific behaviours. Behaviour was estimated using a self-report questionnaire with items that covered a variety of behaviours, from simple to complex, that are actionable by upper-primary student respondents. Students' motivations and circumstances as they relate to patterns of behavioural responses would also be considered. Data collection and analysis is discussed in Chapter 3, but later in this chapter, literature about estimating behaviour is presented and discussed with reference to the questionnaire developed for this research.

\section{Summary}

These descriptions of knowledge, attitudes and behaviours, and the adoption of Hines et al.'s (1987) Model of Responsible Environmental Behaviour, provide meaning and purpose to the investigation carried out in this research. These will be referred to in the discussion of student mind maps and survey results from each case study school. 


\section{Intergenerational Influence and Family Dynamics}

The fifth question being investigated in this research explores the role that intergenerational influence and family dynamics play on the transfer of proenvironmental behaviours from school to home via the child. This investigation is informed by theories of intergenerational influence and family dynamics.

\section{Intergenerational Influence}

Intergenerational influence in environmental education refers to the effect children have on the environmental knowledge, attitudes and behaviour choices of their parents and other adults (Ballantyne et al., 1998b; Ballantyne, Fien, \& Packer, 2001a; Ballantyne et al., 2001b; Duvall \& Zint, 2007; Larsson, Andersson, \& Osbeck, 2010). It can of course, also refer to the influence that parents have on the environmental knowledge, attitudes and behaviours of their children (G. W. Evans et al., 2007; Grøhøj \& Thøgersen, 2009, 2012; Leppänen, Haahla, Lensu, \& Kuitunen, 2012), however, the focus of this research is on the potential influence that children can have on their parents. Many environmental education programs have been specifically designed with the intention of fostering the influential potential of children (Ballantyne et al., 2001b; Duvall \& Zint, 2007; Uzzell et al., 1994). These programs often harbour the vision that children will 'transfer' some of what they have learned to their parents.

Theories of intergenerational influence and knowledge transfer operate on the premise that the global issues facing society require immediate action and parents are better placed in society than their children to effect change through the power of their vote, purchasing choices, industrial practices and, in some cases, as community leaders and educators (Sutherland \& Ham, 1992; Uzzell, 1999). Parents are also primarily responsible for instituting changes to household practices, which can contribute to social norms at the neighbourhood-level and thereby influence a collective approach to environmental action (Henderson \& Tilbury, 2004; Uzzell, 1999). Parental support is also considered necessary to enhance the effectiveness of their children's proenvironmental efforts at home (Uzzell, 1999).

Intergenerational influence and knowledge transfer is thought to be an effective way of reaching parents who are typically time-poor and difficult to reach via traditional forms of communication, whereas children are essentially a captive audience (Ballantyne et al., 1998b; Duvall \& Zint, 2007). School children are also targeted because their attitudes are considered more malleable than adults' (Sutherland \& Ham, 1992). Consequently, environmental educators hope that adult behaviour will be 
affected through a process of intergenerational influence (Ballantyne et al., 1998b; Duvall \& Zint, 2007; Uzzell et al., 1994), where young people can "act as catalysts for environmental change among their parents and other adult members of the community" (Ballantyne et al., 2001a, p. 9).

The role of family dynamics. Some research has found that children are more informed than their parents about global environmental issues (Ballantyne et al., 2001b; S. M. Evans, Gill, \& Marchant, 1996), thus indicating that efforts to raise the environmental knowledge and attitudes of children may well be affecting children but may not be directly impacting their parents' knowledge and attitudes. Other research has found that parents with high pre-existing environmental interest actively encourage their children's interest in environmental topics and engage with them about school environmental experiences (Payne, 2005), which begs the question about how other parents respond to their child's interest in environmental topics. Consequently, researchers have questioned whether it is reliable to assume that the innocent enthusiasm with which children passively carry environmental messages to parents, will naturally stimulate awareness and enthusiasm for adopting sustainable practices in the home lives of families (Duvall \& Zint, 2007; Eilam \& Trop, 2012b; Larsson et al., 2010; Uzzell et al., 1994).

It has been suggested that the success of intergenerational transfer depends on the kinds of interpersonal dynamics that operate within the family (Duvall \& Zint, 2007; Larsson et al., 2010; Payne, 2005). Larsson et al. (2010, p. 140), argue that "children should not be seen as "intermediaries", and assert that they would better be considered "'mediators', who interpret and negotiate environmental discourses and practices in complex intergenerational learning processes". It is also suggested that environmental programs should be tailored in such a way that encourages democratic decision-making in families and for the status roles of parents and children to be redefined (Larsson et al., 2010; Payne, 2005; Uzzell et al., 1994). Payne (2005, p. 92) argues that educators need to adopt a process of "co-constructing family involvement in a social and ecological direction", where parents and children are reciprocally engaged in the learning process.

Recently, research has found that the environmental behaviours of parents are more easily influenced than their environmental attitudes by the influence of messages transmitted from school to home via their children (Eilam \& Trop, 2012b). This is not surprising given that attitudes are influenced by beliefs and affective processes, and can often take a long time to form. It is, however, further evidence that school 
environmental programs have the potential to influence the behaviours of parents. Nonetheless, for this reason, this research focussed solely on whether new behaviours were adopted in households as a result of intergenerational influence from the school via the child.

These findings indicate that in a school environmental education program, the dynamics between parents and their children together with an engagement of students that utilises principles of empowerment and action competence, play important mediating roles in the potential for intergenerational influence and the resulting uptake of new environmental behaviours in households.

\section{Summary}

The descriptions of intergenerational influence in the literature and the potential role that family dynamics play in mediating the effectiveness of knowledge transfer, inform the discussion of results from interviews with parents and their children at the two sustainability focussed case study schools.

\section{Research Methods}

The following paragraphs discuss literature that informed the selection, refinement and validation of the quantitative data collection methods used in this research to estimate students' knowledge, attitudes and behaviours. Lessons from research into intergenerational influence and family dynamics also are described because these informed the approach adopted in this research. Specific details of instrument design, data collection and data analysis are discussed in Chapter 3.

Literature relating to methods for exploring organisational dynamics that foster or impede the establishment of whole-school sustainability education programs is not discussed here because few studies have detailed their data collection approaches. Furthermore, the multi-dimensional quality of sustainability education lends itself to a variety of data collection methods.

\section{Estimating Knowledge}

Many studies have used multiple choice survey questions and concept maps to measure the accuracy or correctness of student knowledge because these can easily be compared with an answer sheet or teacher expert concept map (Gerstner \& Bogner, 2009; Îngeç, 2009; Rye \& Rubba, 2002; Shavelson, Ruiz-Primo, \& Wiley, 2005). In this research, it was considered more relevant to elicit unprompted, non-linear responses from children that would provide an indication of the volume and depth of their action- 
based and issues-based knowledge of the environment and sustainability, and would capture the breadth of their thinking across multiple themes. To meet this purpose, mind maps were selected as a data collection tool.

While mind maps are distinct from concept maps, both are hierarchical and the resulting structure of each is unique to the map's author (Eppler, 2006). Mind maps are semantic organisation tools that provide a concise overview of hierarchical ideas radiating from one central concept (Budd, 2004; Buzan \& Buzan, 1996; Eppler, 2006; Willis \& Miertschin, 2006). Mind maps often use colours and pictures to represent multiple ideas and to aid recall, and are easy to learn and apply. Concept maps provide a systematic overview of hierarchical propositions that connect concepts starting from one main concept at the top of the page (Budd, 2004; Eppler, 2006; Kinchin, Hay, \& Adams, 2000; Zipp, Maher, \& D'Antoni, 2009). Concept maps focus on the relationships among sub-concepts, do not involve colours or pictures, and are not as easy to learn or apply as mind maps. Mind maps have been used in education for a variety of purposes including to organise information, to aid memory, to summarise ideas from several students, to introduce new information or concepts that are connected with previous knowledge, and to foster creativity (Brinkmann, 2003; Buzan \& Buzan, 1996).

Mind maps are tools that teachers, researchers and evaluators can administer with minimal effort or training (Brinkmann, 2003; Buzan \& Buzan, 1996). In assessing mind maps, however, it can be difficult to maintain consistency and guard against bias, because mind maps are non-linear and freely structured (Brinkmann, 2003; Buzan \& Buzan, 1996; Eppler, 2006). Consequently, in using mind maps to collect data for this research, it was necessary to validate a mind map coding scheme and determine its usefulness as an assessment tool (described in Chapter 3).

An assessment rubric. The assessment tool developed in this research differs from the only published assessment tool to compare student mind maps, developed by D'Antoni, Zipp and Olson (2009). Because of the non-linear composition of mind maps, they can be difficult to interpret (Brinkmann, 2003; Buzan \& Buzan, 1996; Eppler, 2006) and few studies have attempted to develop an assessment rubric or coding scheme (D'Antoni, Zipp, \& Olson, 2009; Evrekli, İnel, \& Balım, 2010). D’Antoni et al. (2009) used mind maps to estimate content knowledge with a group of first-year medical students after they attended a 30 minute mind map training session. D'Antoni, et al. (2009) designed and tested an assessment rubric to score students' results, which was adapted from a scoring system used to assess concept maps. The mind map assessment 
rubric was further developed and tested by Evrekli, İnel and Balım (2010) for use with pre-service teachers. The assessment rubric allocates points to six features of the mind map (concept-links, cross-links, hierarchies, examples, pictures and colours) which are then translated into a total numeric score, thus enabling mind maps to be compared. Invalid responses are given zero points.

The assessment rubric developed by D'Antoni et al. (2009) accounts well for the freely structured responses that are generated from mind maps, which cannot be compared against an expert-teacher map (Brinkmann, 2003; Buzan \& Buzan, 1996; Eppler, 2006). But it does not account for the diversity of themes that are often generated in mind maps, especially those that radiate from a complex central construct, such as sustainability. For this reason it was considered robust, when developing and validating the coding scheme used in this research, to identify emergent themes using content analysis and to assess students' breadth of knowldege by counting the number of ideas within each theme per mind map.

The assessment rubric developed by D'Antoni et al. (2009) also gives grades for a student's use of pictures and colours, which are described by Buzan and Buzan (1996) as important features of a mind map. This approach, however, can be biased towards students who are more inclined towards drawing and expressing themselves using colours. Thus, it was decided not to analyse students' use of pictures or colours in this research.

Another difference between the two assessment approaches is related to the grading of individual mind maps. The assessment rubric developed by D'Antoni et al. (2009) was designed for teachers to grade individual students' mind maps, whereas the coding scheme developed in this research was designed for evaluators and researchers to explore trends and compare groups of students.

The specific method of estimating student knowledge using mind maps and the validation of a mind map coding scheme and assessment tool is discussed further in Chapter 3.

\section{Estimating Attitudes}

Attitudes are not observable, outward or obvious, and are consequently described as a latent construct (Glasman \& Albarracín, 2006; Kraus, 1995). Because of their complex character, attitudes have predominantly been measured using quantitative, multiple-item scales, conducted with large sample sizes (200 participants or more) that are refined over several iterations (Worthington \& Whittaker, 2006). 
In the field of environmental education several scales have been proposed, but the New Environmental Paradigm Scale is a measure widely used to investigate environmental attitudes (Dunlap, Van Liere, Mertig, \& Jones, 2000; G. W. Evans et al., 2007; Hawcroft \& Milfont, 2010; Milfont \& Duckitt, 2010). The New Environmental Paradigm scale was first created by Dunlap and Van Liere (1978), and later refined by Dunlap and Van Liere together with Mertig and Jones (2000). The New Environmental Paradigm Scale became popularly applied and continues to be widely used, because: 1) it was rigorously developed, through validation and replication over multiple iterations; and 2) it was generaliseable because the items within the scale were relevant across a broad range of contexts (Boeve-de Pauw, Donche, \& Van Petegem, 2011; G. W. Evans et al., 2007; Hawcroft \& Milfont, 2010; Manoli, Johnson, \& Dunlap, 2007). Many of Dunlap and Van Liere's contemporaries developed attitude scales relevant to a specific context, which did not allow for broad application, replication and validation.

The original New Environmental Paradigm Scale was created to measure people's environmental worldviews, which the authors described as the degree to which people view humans as a part of nature rather than dominant over it (Dunlap \& Van Liere, 1978). It consists of three sets of items designed to measure: 1) the balance of nature, 2) anthropocentrism and 3) limits to growth (Dunlap \& Van Liere, 1978). The revised New Environmental Paradigm Scale integrated two new sets of items to measure, 4) human exemptionalism and 5) ecocrisis (Dunlap et al., 2000). The revised scale includes fifteen questions; three questions for each dimension being measured. This revised scale was renamed the New Ecological Paradigm Scale, but in this thesis it will continue to be referred to as the New Environmental Paradigm Scale for the purpose of continuity.

The New Environmental Paradigm Scale has been criticised for inconsistency in its dimensionality with some researchers finding five dimensions (as suggested by the authors), and others finding only one dimension (Boeve-de Pauw et al., 2011; Hawcroft $\&$ Milfont, 2010). Despite some criticism of the dimensionality of the original and revised New Environmental Paradigm Scale, it has been "used in a variety of contexts, by an equally diverse array of scientists ... [who] have shown the scale to be valid and useful" (Boeve-de Pauw et al., 2011, p. 110).

The research into adults' environmental attitudes and the wide application of the New Environmental Paradigm Scale (Dunlap \& Van Liere, 1978; Dunlap et al., 2000) inspired many researchers to develop scales appropriate for use with children (G. W. Evans et al., 2007; Manoli et al., 2007). Prior to the 1990's empirical research on 
children's attitudes and behaviour had not received the same attention as adults' attitudes, with some researchers claiming it was time for that balance to shift, because "early attitudes and knowledge shape the later thinking of adolescents and adults" (Leeming et al. 1995, p. 23).

Various scales have been developed to examine children's environmental attitudes; some have appropriated the New Environmental Paradigm Scale (Dunlap \& Van Liere, 1978; Dunlap et al., 2000) and others have attributed their rationale to other origins (Boeve-de Pauw et al., 2011; G. W. Evans et al., 2007; Manoli et al., 2007). Among the most commonly used of these scales are: The Children's Environmental Response Inventory (CERI) (Bunting \& Semple, 1979), the Children's Attitudes Toward the Environment Scale (CATES) (Musser \& Malkus, 1994), The Children's Environmental Attitudes and Knowledge Scale (CHEAKS) (Leeming, Bracken, \& Dwyer, 1995), the Environmental Values Short Form (CERI - short form) (Zimmermann, 1996), the Environmental Attitudes Questionnaire (EAQ) (Eagles \& Demare, 1999), and the New Environmental Paradigm Scale for Children (NEP - for children) (Manoli et al., 2007).

The New Environmental Paradigm Scale for Children (Manoli et al., 2007) was developed and refined over several iterations of testing and analysis. Questions from the original New Environmental Paradigm Scale (Dunlap \& Van Liere, 1978; Dunlap et al., 2000) were adjusted to suit the comprehension of upper-primary school aged children (Manoli et al., 2007). This shorter fifteen-item scale was further revised over three years with three different groups of children, aged $10-12$ years old; $n_{\text {year } 1}=84, n_{\text {year } 2}=672$, $n_{\text {year3 }}=515$ (Manoli et al., 2007). The first year of revision included interviews with 30 children to determine comprehension and revise wording of the scale items, and a pilot test with 54 students to determine if the five point Likert scale, with middle score 'not sure', was adequate. The second year of revision included exploratory and confirmatory factor analysis on responses from 672 children's surveys, which led to the deletion of four items and a consequent eleven-item scale that revealed three factors and explained 49 percent of the variance. The third year of revision involved confirmatory factor analysis on responses from 515 children's surveys, which led to the deletion of one item and a consequent ten-item scale that supported the three factor solution extracted in the previous year's testing. The final scale included ten questions, which were proposed to capture attitudes across the three dimensions of: 1) human exemptionalism, 2) rights of nature, and 3) ecocrisis. The authors acknowledged, however, the possibility that 
replications of the scale by other researchers may reveal the presence of only one dimension (Manoli et al., 2007).

In this research, the New Environmental Paradigm Scale for Children (Manoli et al., 2007) was selected over other attitude scales for children, because of the rigour, prestige and wide application of the original New Environmental Paradigm Scale, together with the well-justified validation process described by Manoli et al. (2007). Nonetheless, it was necessary to validate the scale for use in a Western Australian context, before using it to model its relationship with students' pro-environmental behaviours (described in Chapter 3).

\section{Estimating Behaviours}

When deciding on an approach to estimate behaviour, consideration should be given to the intended use of the information, the accuracy of data collected, the appropriateness of questions posed, and selecting behaviours that represent levels of complexity; from easy to enact behaviours to those that require more time or skills to carry out.

Pro-environmental behaviours are primarily estimated through: self-reporting by individuals in response to a questionnaire or interview or, direct observations of an individual's behaviour or their records including household bills, metre readings, etc. (Corral-Verdugo, 1997; Gralton et al., 2004). The advantage of collecting self-reports over direct observations, is that questionnaires and interviews are relatively inexpensive and easily obtained (Corral-Verdugo, 1997). In particular, questionnaires enable a large quantity of diverse behavioural information to be ascertained that can be statistically compared with other variables estimated via the survey, such as attitudes. In this research, a self-reporting approach was adopted because it was intended that information about students' behaviours would be statistically compared with the two student attitudes scales.

The accuracy of using self-reports has been questioned, however, with many researchers finding discrepancies in the attitude-behaviour correlations of self-reported and directly observed behaviours (see reviews by: Hines et al., 1987; Kraus, 1995). For example, in a review of 88 studies, Kraus (1995) found a strong attitude-behaviour correlation $(\mathrm{r}=.51)$ when behaviours were self-reported, and a weaker attitudebehaviour correlation $(r=.32)$ when behaviours were directly observed. These results suggest that people tend to over-estimate their behaviours when self-reporting. Environmental researchers have suggested this discrepancy could be linked to: respondents wishing to appear socially responsible, lack of time or knowledge, or flaws 
in an individual's memory that may lead them to over or under represent the true situation (Corral-Verdugo, 1997; Milfont, 2009).

The usefulness of estimated behaviours is also affected by the kinds of behaviours of interest and the way that questions are asked. Measured behaviours should be appropriate to the age, ability and opportunities available to respondents (Corraliza \& Berenguer, 2000; G. W. Evans et al., 2007; Guagnano et al., 1995). For example, in the questionnaire developed for this research and designed to measure upper-primary students' behaviours, it would not have been appropriate to include an item that asked students to rate the frequency that they purchased locally grown produce or phosphate-free cleaning products, because they had no control over these behaviours. Instead, behavioural options were used that were potentially available to upper-primary students, such as the frequency that they ate home grown produce or saved water by taking short showers (described in Chapter 3).

In building a questionnaire to estimate behaviours, thought can also be given to selecting a variety of behaviours that potentially represent levels of complexity or degrees of difficulty (Cleveland, Kalamas, \& Laroche, 2005; Heimlich \& Ardoin, 2008; Kollmuss \& Agyeman, 2002). Research has found that often people will undertake certain groups of pro-environmental behaviours and not others, depending on their motivations. Heimlich and Ardoin (2008, p. 223) refer to these as, "constellations of behaviours that may be expected to occur together". For example, a person who is motivated primarily by economic concerns might frequently undertake money-saving behaviours such as turning off lights and conserving water, but not be engaged in growing produce at home or composting. In contrast, a person who is motivated by selfidentity and sees themselves as 'an environmentalist' might undertake an array of proenvironmental behaviours from simple to complex.

The concept that a person's motivations or circumstances may lead them to undertake certain groups of behaviours, from simple to complex, has not been welldescribed for primary-school aged students, and for this reason formed part of this research. To achieve this, specific options were included in the questionnaire that represented common motivations or circumstances shared by all students, which could then be compared with their self-reported behaviours.

\section{Researching Intergenerational Influence and Family Dynamics}

A small number of studies have investigated the effectiveness of environmental education programs in fostering intergenerational learning. Duvall and Zint (2007) collated the learning from all studies available at the time of their review and surmised 
that environmental education programs offered from Kindergarten to Year 12 have only a modest potential to influence parental knowledge, attitudes and behaviours. However, they acknowledged these conclusions were confounded by various limitations in the methodological approaches of the studies and deficiencies in the environmental programs being studied, together with the small number of studies in their review.

Duvall and Zint's (2007) review found that intergenerational learning was most successful when the following social conditions and program factors were in place:

1. The perceived status of children in a family included children and their parents as partners in the processes of learning and action (Uzzell et al., 1994).

2. National, state and local policies existed that encouraged and supported schools to be a source of environmental information in their community and to take action on local issues alongside adults in the community (Uzzell, 1999).

3. Parents were involved in student activities through homework, research activities and class presentations (R. Ballantyne, S. Connell, \& J. Fien, 1998a; Uzzell et al., 1994).

4. Community members were involved in school programs, which promoted information transfer throughout the larger community (Uzzell et al., 1994; Vaughan, Gack, Solorazano, \& Ray, 2003).

5. Hands-on and action oriented activities that encouraged children to develop solutions to environmental problems were embedded into the programs. Programs with this element were more likely to enthuse and captivate the interest of children, who were then more likely to engage in discussions with their parents (Ballantyne, Fien, \& Packer, 2001c).

6. Programs were integrated into regular classroom learning and sufficient time was spent on exploring issues in depth (Ballantyne et al., 2001c).

7. Programs focused on local issues, which made the environmental issues more relevant and encouraged a sense of ownership within children and their parents (Ballantyne et al., 2001c; Sutherland \& Ham, 1992).

8. Teachers were interested in and committed to the programs. These kinds of teachers were more likely to create enthusiasm in their students, who were then more likely to engage in environmental discussions with their parents (Ballantyne et al., 2001a; Legault \& Pelletier, 2000).

Duvall and Zint's (2007) comprehensive literature review provides useful considerations for researchers designing studies in this under-explored field. They also 
presented recommendations for future research, including a careful choice of what factors to measure and a consideration of how to integrate environmental education programs into regular classroom activities with the intention to increase the transfer and durability of outcomes in children and parents.

This research adopted Duvall and Zint's (2007) suggestions by assessing the success of well-integrated programs using a carefully chosen methodological design. In this research, integration of programs into classroom activities was addressed through involvement with AuSSI - WA.

\section{Theoretical Framework and Propositions}

The overarching theoretical proposition of this research was that students who attended a primary school with whole-school sustainability programs in operation, were likely to practice pro-environmental behaviours more often at home, and have greater and broader environmental knowledge than students at a school without sustainability education programs in place. In addition, students who attended a primary school with sustainability programs would have attitudes that correlated with their behaviours and parents who were receptive to environmental messages.

The theoretical framework that guided this research is summarised in the following paragraphs and in Figure 2.5. The theoretical framework was informed by the literature reviewed and presented throughout this chapter, which will not be restated here, and was used to inform the methodology presented in the following chapter.

In this research, the inputs and activities of sustainability education programs at three Perth primary schools were explored through Research Question 1, and were directly related to the literature about key elements of sustainability education (Figure 2.5). The proposition underlying this research question was that schools with sustainability education programs would have more strategies, policies and practices that support sustainability education, than a school without sustainability education.

In this research, the outcomes of sustainability education programs at three Perth primary schools were split into: Outcomes for students, and outcomes for families. Outcomes for students were explored through Research Questions 2, 3 and 4, and were directly related to the literature about the conceptualisation and interaction of knowledge, attitudes and behaviours (Figure 2.5). The proposition underlying Research Question 2 was that students at schools with sustainability education would have deeper, greater and broader issues-based and action-based knowledge of the environment and sustainability, than students at a school without sustainability 
education. The proposition underlying Research Question 3 was that a greater proportion of students at schools with sustainability education would practice proenvironmental behaviours on a weekly basis, than students at a school without sustainability education. The proposition underlying Research Question 4 was that the attitudes of students at schools with sustainability education would be positively correlated with their behaviours.

Outcomes for families were explored through Research Question 5, and were directly related to the literature about family dynamics and intergenerational influence (Figure 2.5). The proposition underlying Research Question 5 was that the parents of students at schools with sustainability education would report being encouraging of their child's interest in environmental actions and being receptive of adopting new environmental behaviours in their homes as a result of the school's influence.

The theoretical framework illustrated in Figure 2.5 also depicts the potential influence on outcomes, of two variables: Level of implementation and accompaniment. These variables were included in the framework to account for differences in the two sustainability schools. Lighthouse Primary School had implemented their sustainability programs to a greater depth than River's Edge Primary School. Whereas, River's Edge Primary School had experienced close accompaniment, from an external sustainability facilitator, along the beginning stages of implementing their sustainability programs, while Lighthouse Primary School had never been closely accompanied by an external agency.

Figure 2.5 is expressed using logic model terminology: Inputs, activities and outcomes. Logic models are regularly used in the evaluation of social change programs, such as health education or intervention programs, and enable evaluators or researchers to present a concise visualisation of the program's goals and objectives with respect to the inputs and activities that have been implemented to achieve them (Funnell \& Rogers, 2011). 

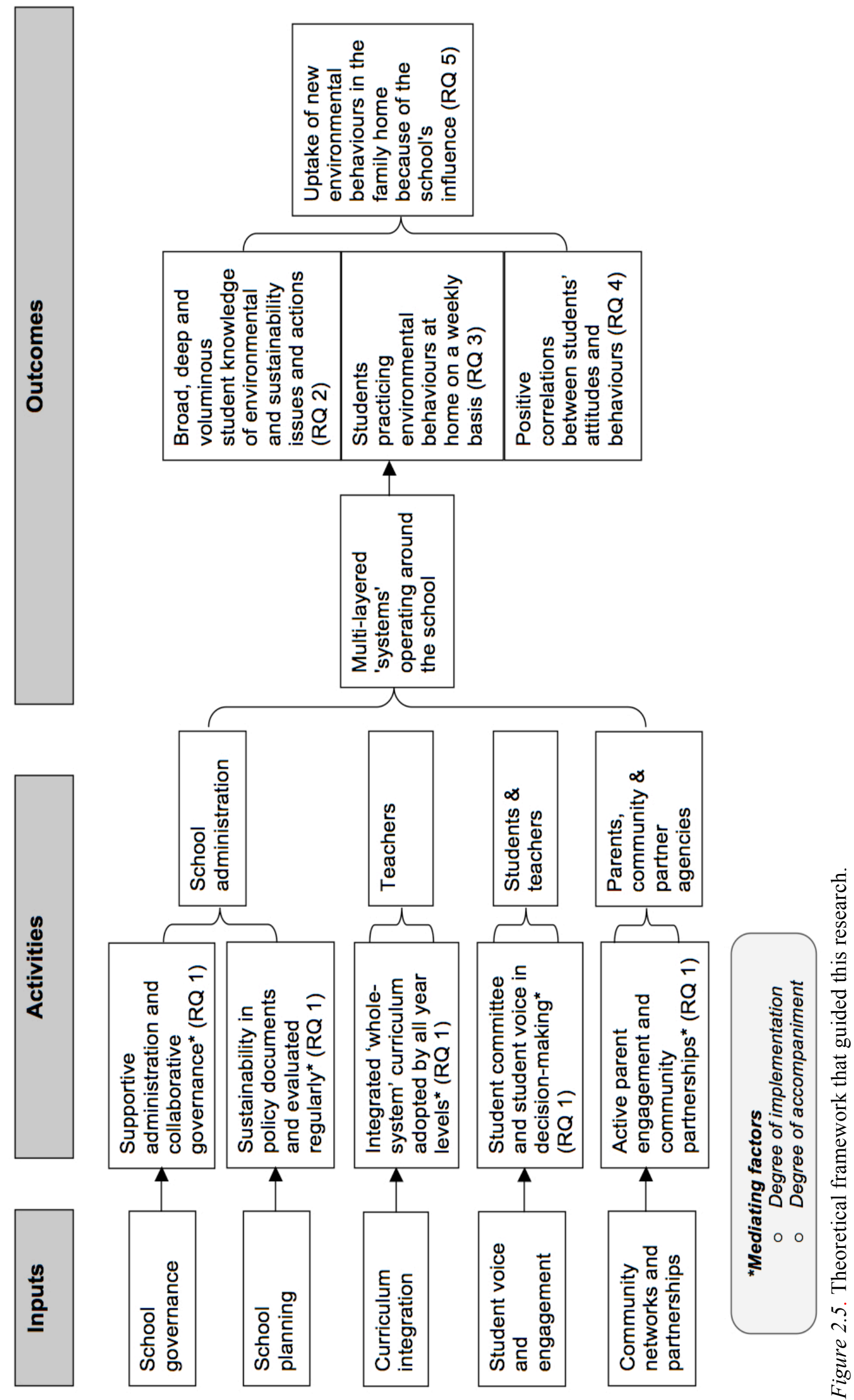


\section{Chapter Conclusion}

This chapter explored the literature surrounding: 1) definitions of education for sustainability, 2) key elements for assessing effectiveness of management structures and implementation strategies of whole-school sustainability education programs, 3) research on knowledge, attitudes and behaviours, 4) the goals of intergenerational influence and the interactions of family dynamics, and 5) methods for estimating school organisation, student knowledge, attitudes and behaviours, and family dynamics and intergenerational influence. This chapter concluded with a re-statement of the propositions that underpinned this research and presentation of the theoretical framework that guided this research.

The next chapter will discuss the mixed-method multiple comparative case study methodology that framed this research and will describe in more detail the methods utilised to collect data. It will also explore issues of ethics and rigour, and will explain the processes employed to validate the data collection methods. 
THIS PAGE HAS PURPOSELY BEEN LEFT BLANK 


\title{
CHAPTER 3: ReseARCH Design AND Methodology
}

\author{
The case study: ' ... an empirical inquiry that investigates a \\ contemporary phenomenon in depth and within its real-life \\ context, especially when the boundaries between phenomenon \\ and context are not clearly evident.'
}

$$
\text { (Yin, 2009, p. 18) }
$$

This research involved multiple comparative case studies of three primary schools in Perth, Western Australia: 1) Lighthouse Primary School, 2) River's Edge Primary School, and 3) Fertile Ground Primary School. The five research questions (p. 7) were explored using specifically designed and validated qualitative and quantitative data collection tools.

This chapter begins by outlining the pragmatic research paradigm and transformative theoretical lens that underpinned this research, and the mixed method, multiple case study research design. Details are then provided about the design of each data collection instrument (interviews, observations, document searches, mind maps and surveys) and the collection and analysis of data to address each of the five research questions. The chapter concludes with sections on research rigour and ethical considerations.

\section{Research Design}

The purpose of this research was to describe the impact of whole-school education for sustainability on the environmental knowledge, attitudes and behaviour of upper-primary school students and their families. The research was situated within a pragmatic research paradigm and utilised a transformative lens as outlined in the following paragraphs. The case study methodology involved literal and theoretical replication across multiple cases and the boundaries of each case were defined by the school context. Units of analysis were clearly definable and embedded within each case. The research utilised a convergent mixed method design where qualitative and quantitative data were collected concurrently from multiple sources, and triangulated during analysis to address each of the research questions. Figure 3.1 illustrates the paradigmatic and methodological choices that framed this research. 


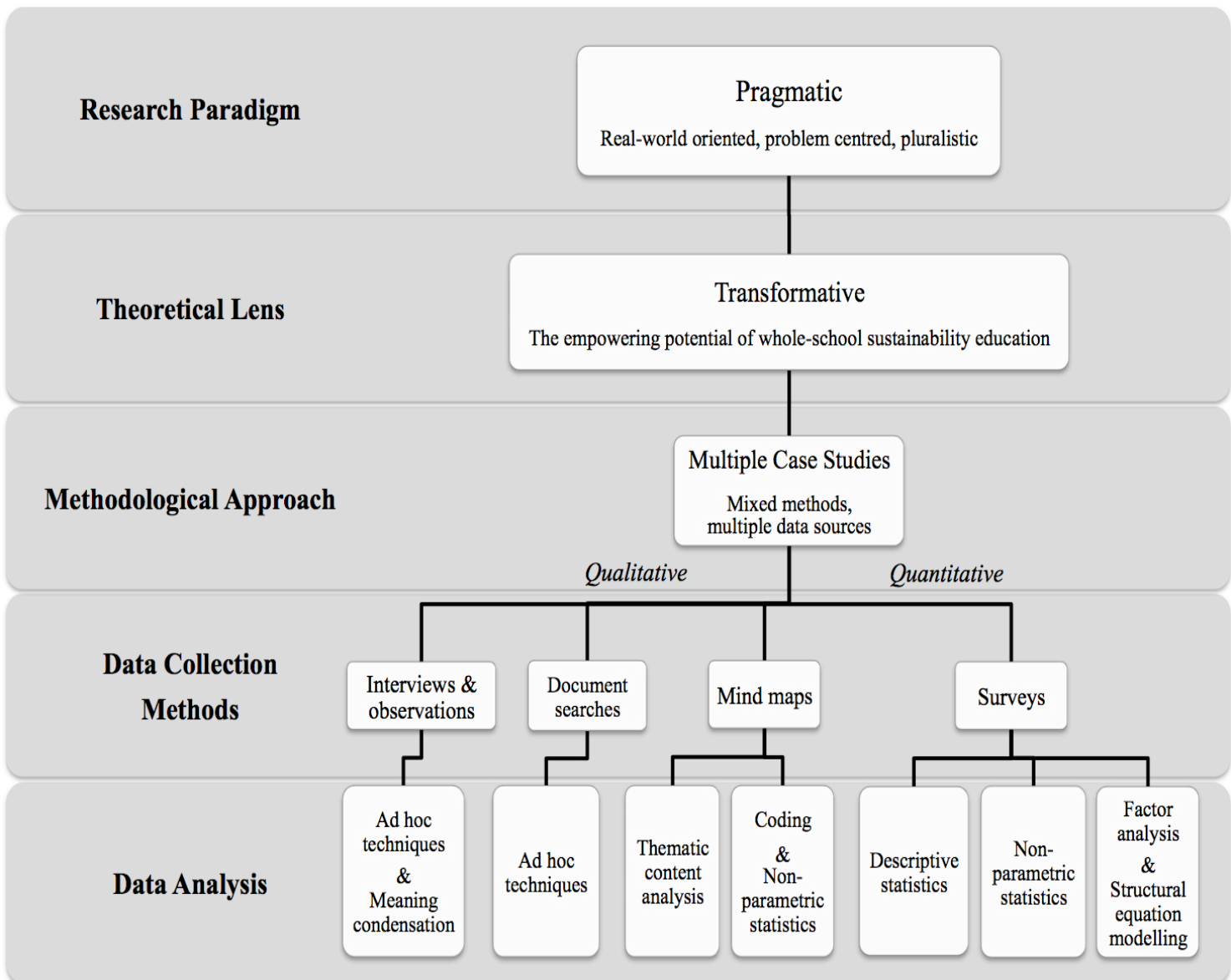

Figure 3.1. Illustration of the research paradigm and theoretical lens adopted for this research and the mixed method multiple case study design considered most suitable to address the research questions.

\section{Research Paradigm and Theoretical Lens}

This research was situated within a pragmatic research paradigm with a transformative theoretical lens, as introduced in Chapter 1. A paradigm can be described as a worldview (Creswell \& Plano Clark, 2011) or a set of philosophical assumptions that guide inquiries (Guba \& Lincoln, 2005). By describing the paradigm within which this research was placed, the researcher acknowledges that her beliefs and assumptions about education for sustainability, whole-school sustainability education, behaviour change and intergenerational influence informed the research (Creswell \& Plano Clark, 2011). A pragmatic paradigm was selected to guide this research, because it enabled the researcher to: 1) focus on consequences and descriptions of real-world practice in whole-school sustainability education rather than testing or generating theory, 2) place chief importance on the research questions rather than methods, and 3) use a pluralistic, mixed methods approach to data collection.

A theoretical lens can be used to provide direction to certain phases of the research and operates within the overarching framework provided by the research paradigm (Creswell \& Plano Clark, 2011; Mertens, 2009). A transformative theoretical 
lens (also referred to as an emancipatory theoretical lens) involves taking a stance in favour of an underrepresented group or cause. A transformative lens was utilised for this research because it enabled acknowledgement of the potential of whole-school sustainability education, supported by AuSSI - WA, to influence increased adoption of pro-environmental knowledge, attitudes and behaviours among students and their parents. It has been asserted that this potential can be realised when sustainability is integrated across curriculum learning areas, into school policies and throughout school daily life, when the school is valued at the centre of a community, and when all stakeholders are given fair opportunities to contribute towards visioning, planning, enacting and evaluating initiatives (Henderson \& Tilbury, 2004).

The purpose of this research was to describe the impact of whole-school education for sustainability on the environmental knowledge, attitudes and behaviour of upper-primary students and their families. The foremost intention of this research was to document and provide feedback to the participating schools and the management body of the Australian Sustainable Schools Initiative - Western Australia (AuSSI - WA). Another intention was to determine whether it was appropriate to advocate for increased recognition of the effectiveness of whole-school sustainability education and increased funding to AuSSI - WA and its partners. Consequently, a pragmatic research paradigm with a transformative theoretical lens was considered the most appropriate approach to achieve these purposes.

Using a pragmatic paradigm allowed the researcher to adopt a pluralistic mixedmethod approach that focussed on investigating the real-world practice of whole-school sustainability education (Creswell \& Plano Clark, 2011). In a pragmatic paradigm there is no 'preferred' methodology or data type, rather these are based on an assessment of the most appropriate approach to answer the research questions. Thus, the pragmatic paradigm used in this research allowed findings to be informed by singular realities where assertions were built from tested hypotheses (e.g. quantitative survey results), or informed by multiple realities where assertions reflected the perspectives of multiple individuals (e.g. qualitative interview data). The pragmatic paradigm used in this research also allowed weight to be given to biased and unbiased interpretations of the data such that the researcher could propose assertions that were potentially biased by her own background or were crosschecked through rigorous validation techniques.

Utilising a transformative lens often leads to recommendations for action or advocacy being offered at the conclusion of the study (Cohen et al., 2011; Creswell, 2009; Creswell \& Plano Clark, 2011; Mertens, 2009). In this study, recommendations 
(see Chapter 9, Synthesis and Conclusions) include strategies that AuSSI - WA can adopt to better support schools, strategies for schools to inform and engage parents, teachers and students towards adopting environmental practices in the short and long term, and identifying factors that will increase receptiveness towards environmental practices among parents and improve effectiveness of intergenerational transfer.

\section{Case Study Methodology}

A case study is a process of empirical inquiry that focuses on revealing and understanding a multiplicity of factors and dynamics present within one or a small number of cases (Corcoran, Walker, \& Wals, 2004; Eisenhardt, 1989; Mertens, 2009; Punch, 2010; Stake, 2005; Yin, 1989, 2008). Case study methodology is flexible and adaptive, complementary to a variety of research aims, data collection methods, disciplinary perspectives and theoretical paradigms. Case studies are an appropriate research methodology when the overarching objective is to develop a full understanding of the case or cases involved and not to conduct a large scale survey or experiment that might otherwise provide only superficial insight into the study population (Punch, 2010). A case study design that involves multiple cases, multiple data sources and mixed qualitative and quantitative methods can make an important contribution to a deep understanding of a certain context and study population.

For the reasons stated in the above paragraph, Corcoran et al. (2004) assert that case study methodology is an ideal approach for investigating sustainability programs in tertiary education. Similarly, case study methodology was considered an ideal approach for this research to investigate sustainability programs in primary education, in particular, when an external sustainability facilitator was employed to assist a school establish a whole-school sustainability focus.

Important features. The features discussed in the following paragraphs outline important characteristics that were considered when designing this case study research. First, the purpose of the study and the boundaries of each case were identified (Corcoran et al., 2004; Punch, 2010; Yin, 2008). Second, the type of case study was delineated and the number of cases required to answer the research questions was determined. Third, ways of maintaining the overall integrity of each case was considered while also focussing on the key points of interest as determined in the research questions. Fourth, data sources and data collection methods were selected, which included combinations of quantitative and qualitative methods. Fifth, the balance of each data type and the timing of data collection were considered. Sixth, the role of the researcher was considered. 
1) Purpose and Boundaries. Case studies can be exploratory, descriptive or explanatory (Corcoran et al., 2004; Yin, 2008). Descriptive case studies are undertaken with a purpose of describing the context of a case, whereas exploratory approaches often involve theory development and explanatory approaches involve theory testing. Each of these approaches can be used to investigate why and how certain elements function within each case, and results can be used to provoke consideration of elements that might be transferrable to similar contexts.

This research adopted a descriptive approach, where pre-existing theories about the potential for youth empowerment and behaviour change that can come as a result of whole-school sustainability education (described in Chapter 1), guided the development of research questions and data collection methods. Consistent with a descriptive approach, it was anticipated that the research would conclude by forming hypotheses of cause-effect relationships that might contribute to greater understanding of the wholeschool sustainability movement (Corcoran et al., 2004; Yin, 2008).

The boundaries of a case study are defined whilst considering the purpose of the study and developing the research questions that will guide the study (Yin, 2008). Because the purpose of this research was to examine the effect of whole-school sustainability education on adoption of pro-environmental behaviours in upper-primary students and their families, the school context and students' year levels defined the boundaries of each case. The school context included school grounds, administrative staff, teaching and support staff, student committees, parent committees and other forms of community engagement with the school, yearbooks, newsletters and other school publications. Upper-primary students, Years 4, 5 and 6, were selected as a target group because the researcher was interested in discerning the sense of volition, of children in this age group, towards undertaking pro-environmental behaviours in their homes and participating in school sustainability activities. It was also considered that gauging the volition of pre-adolescents might provide a firm foundation for follow-up studies of adolescents' willingness to undertake pro-environmental behaviours. Other research has shown that the transition from primary to secondary school is a tumultuous time with considerable changes in students' attitudes towards various aspects of school-related work (Bennett \& Hogarth, 2009; Speering \& Rennie, 1996).

2) Types and Replication. Different types of case studies have been defined: for example, the intrinsic case study and instrumental case study, both focus on a single case; and the multiple case study, in which the focus is both within and across cases (Punch, 2010; Stake, 2005). 
This research adopted a multiple case study approach because conclusions are more powerful and generalisable when the patterns and complexities that emerge during analysis of each case are compared and contrasted during meta-analysis and the common elements are discussed (Corcoran et al., 2004; Punch, 2010; Yin, 2008). It was also considered important that such comparisons might highlight practices that work and those that do not, as this kind of information could be valuable for institutional reform, useful feedback for funding bodies, and provide important considerations for future educational program design (Corcoran et al., 2004).

When planning a multiple case study, researchers must consider the issue of replication versus sampling (Yin, 2008). Selection of cases in multiple case study research is guided by conditions defined in the theoretical framework and is quite different to the sampling logic commonly used in survey design. A few cases must be carefully selected to either predict similar results (literal replication) or predict contrasting results based on theoretical reasons (theoretical replication).

This research had a multiple case study design that incorporated both literal and theoretical replication. Lighthouse and River's Edge Primary Schools were chosen for their emphasis on whole-school sustainability education and Fertile Ground Primary School was chosen as a comparison case because the school did not have whole-school sustainability or environmental education initiatives in operation.

3) Maintaining holistic integrity. The units of analysis within multiple case studies can be either holistic or embedded (Yin, 2008). A holistic design is chosen when individual units of analysis are difficult to define and the overarching organisational structure of each case is of most interest. An embedded design is chosen when separate units of analysis are definable within each case. The units of analysis in this research were: 1) organisational factors that impact school sustainability initiatives, 2) impact on student knowledge, attitudes and behaviours, and 3) impact of family dynamics on intergenerational influence and the adoption of pro-environmental behaviours in homes.

This research involved an embedded design because separate units of analysis were clearly definable, and this approach enabled greater depth in addressing the research questions (Yin, 2008). It was acknowledged by the researcher, however, that a common pitfall when using an embedded design is to focus only on the individual units of analysis. Thus, it was considered important to triangulate results from each unit of analysis so as to appreciate the interconnection of factors that define each case.

4) Data sources and methods. Embedded multiple case studies often rely on a mixture of qualitative and quantitative data collection methods, collected from a variety 
of sources, to investigate each of the units of analysis (Mertens, 2009; Yin, 2008). The data sources in this research were: 1) principals, 2) teachers, 3) school documents, 4) students, 5) parents and 6) the chief executive officer (CEO) of Millennium Kids.

The mixed methods approach enabled the collection of both qualitative and quantitative data from each case study, thus providing a richer array of evidence that, when triangulated, gave a comprehensive account of the whole-school sustainability education context (Mertens, 2009; Yin, 2008). In particular, the mixed methods design enabled the researcher to glean specific background understanding of the school context through interviews, observations and document searches, coupled with generalisable information about broad relationships between variables of interest estimated using surveys and mind maps (Creswell \& Plano Clark, 2011).

The methods of data collection utilised in this multiple case study research were surveys, mind-maps, interviews, observations and document searches. Surveys and mind maps were used to explore the relationship between sustainability programs undertaken by the schools being studied (or not, as in the comparison school) and the pro-environmental knowledge, attitudes and behaviours of students who attended these schools. Interviews and observations were used to gather more fine grained and detailed information with regard to the values, attitudes, behavioural intentions and self-reported pro-environmental behaviours in selected students, their parents, several teachers and the principal at the case study schools. Document searches were used to explore the history of school sustainability priorities and initiatives. Specific details of instrument design, data collection and data analysis are discussed in later sections of this chapter.

5) Managing data types, collection and comparison. Researchers who utilise mixed methods of data collection must consider the balance of each data type that is required to answer the research questions, the order in which they will be collected and how they will be compared (Creswell \& Plano Clark, 2011; Mertens, 2009; Yin, 2008).

This research used a convergent design, in which qualitative and quantitative data were collected concurrently, analysed independently of each other, given equal weighting throughout the study and converged during the overall interpretation of results to highlight or dispel patterns found in the results of either data collection method (Cohen et al., 2011; Creswell \& Plano Clark, 2011; Hammersley, 2008). Triangulation was used to enhance the rigour of the research by checking the validity of the interpretations of each data type against the other.

Comparison and triangulation of results from multiple case studies often occurs in the form of a cross-case synthesis at the end of the research report, after having 
already presented and discussed results from each case (Yin, 2008). In this research, a cross-case synthesis was created, which included word tables to display data from each case and these were used to develop strong, plausible arguments as a basis for recommendations and advocacy.

6) The researcher. In case study research, the researcher is commonly an outside evaluator or privileged observer who sets out to critique and provide important feedback that could help those involved within the case to reflect and improve on their practices (Corcoran et al., 2004). A privileged observer is known to the participants but only observes and does not actively participate in classroom activities (Creswell, 2009; Punch, 2010). This outside perspective enables objectivity and allows critical findings to be shared and transferred to other contexts (Corcoran et al., 2004). Case studies may also be conducted by people involved within the case, such as a self-study. In these instances the ability to provide critical external feedback is reduced because of potential for bias, but this approach can still be a valuable way of improving practices.

A privileged observer, the doctoral candidate, conducted the research reported in this doctoral thesis. Furthermore, consistent with a transformative theoretical lens, this research had the intention of providing critique and feedback that might stimulate reflection and transformation within the schools involved. Feedback also was intended to be transferrable to other schools and contexts.

Summary. In this research, qualitative and quantitative data were collected concurrently by a privileged observer, and, all data preparation, collection, analysis and interpretation were centred within a pragmatic paradigm and the transformative theoretical lens of whole-school sustainability education. Each method of data collection was used to provide data on a number of variables to answer each research question as displayed in Table 3.1. The qualitative and quantitative data were triangulated, in the cross-case synthesis, to compare and contrast qualitative and quantitative data collected separately (Creswell \& Plano Clark, 2011). This produced valid, substantiated results about a single phenomenon, which, in this research was the effect of whole-school sustainability education on participants' attitudes about and adoption of pro-environmental behaviours. 
Table 3.1. Summary of data collection methods, sources and analyses used to provide information about the variables of interest and answer each of the research questions that guided this research.

\begin{tabular}{|c|c|c|c|}
\hline & Variables of Interest & $\begin{array}{l}\text { Data Collection } \\
\text { Methods and Sources }\end{array}$ & Analysis \\
\hline $\begin{array}{l}\text { Research } \\
\text { Question } 1\end{array}$ & $\begin{array}{l}\text { 1. School governance } \\
\text { 2. School planning } \\
\text { 3. Community networks \& } \\
\text { partnerships } \\
\text { 4. Student voice \& engagement } \\
\text { 5. Curriculum integration }\end{array}$ & $\begin{array}{l}\text { - Principal interviews } \\
\text { - Teacher interviews } \\
\text { - Document searches }\end{array}$ & $\begin{array}{l}\text { 1. Ad hoc analysis } \\
\text { techniques } \\
\text { 2. Triangulation }\end{array}$ \\
\hline $\begin{array}{l}\text { Research } \\
\text { Question } 2\end{array}$ & $\begin{array}{l}\text { 1. Depth, breadth and volume of } \\
\text { knowledge about actions } \\
\text { students can do to help the } \\
\text { environment. } \\
\text { 2. Depth, breadth and volume of } \\
\text { knowledge about } \\
\text { sustainability }\end{array}$ & - Student mind maps & $\begin{array}{l}\text { 1. Inductive thematic } \\
\text { content analysis } \\
\text { 2. Intercoder } \\
\text { reliability testing } \\
\text { 3. Coding } \\
\text { 4. Non-parametric } \\
\text { statistical analysis }\end{array}$ \\
\hline $\begin{array}{l}\text { Research } \\
\text { Question } 3\end{array}$ & $\begin{array}{l}\text { 1. Frequency of environmental } \\
\text { behaviours undertaken at } \\
\text { home, related with: } \\
\text { a. Participation } \\
\text { b. Importance } \\
\text { c. Learning }\end{array}$ & $\begin{array}{ll}\text { - } & \text { Student surveys } \\
\text { - } & \text { Student interviews }\end{array}$ & $\begin{array}{l}\text { 1. Descriptive } \\
\text { statistics } \\
\text { 2. Triangulation }\end{array}$ \\
\hline $\begin{array}{l}\text { Research } \\
\text { Question } 4\end{array}$ & $\begin{array}{l}\text { 1. Attitudes to school } \\
\text { environmental activities } \\
\text { 2. Environmental worldviews } \\
\text { 3. Pro-environmental behaviours }\end{array}$ & - Student surveys & $\begin{array}{l}\text { 1. Exploratory factor } \\
\text { analysis } \\
\text { 2. Structural equation } \\
\text { modelling }\end{array}$ \\
\hline $\begin{array}{l}\text { Research } \\
\text { Question } 5\end{array}$ & $\begin{array}{l}\text { 1. Family dynamics and } \\
\text { intergenerational influence }\end{array}$ & $\begin{array}{l}\text { - Parent interviews } \\
\text { - Student interviews }\end{array}$ & $\begin{array}{l}\text { 1. Meaning } \\
\text { condensation } \\
\text { 2. Triangulation }\end{array}$ \\
\hline
\end{tabular}

\section{Selection of Cases}

Three case study schools were selected for the main body of this research. A fourth school, School X, was chosen to pilot the data collection instruments. The main body of research involved literal and theoretical replication of cases. Lighthouse and River's Edge Primary Schools were selected because of their involvement with AuSSI WA and their whole-school approach towards embedding sustainability initiatives. In contrast, Fertile Ground Primary School was selected because it was not involved, at the time of data collection, with AuSSI - WA or, the Waste Wise or Water Wise Schools programs offered by the Department of Environment and Conservation (DEC). 
It was anticipated that Lighthouse and River's Edge Primary Schools would yield informative, contrasting findings, despite both being involved with AuSSI - WA. River's Edge Primary School had worked closely with an external sustainability facilitator, Millennium Kids, to assist them in embedding sustainability principles into their policies, teaching and learning. In contrast, Lighthouse Primary School had not been closely accompanied by an external facilitator but had been working for many years on creating a successful whole-school program and was widely acclaimed for the depth and integration of their initiatives. These different approaches were considered to be of relevance to the research questions, in particular because it was suspected that the facilitation provided to River's Edge Primary School may have assisted them in creating a firm foundation of certain key elements that could easily be built upon and contribute to quick advances in their whole-school programs.

Socio-economic demographics. It was considered important for purposes of comparison in the cross-case analysis to ensure as much as possible that all three schools had certain factors in common. For this reason, schools that were located in upper-middle to high socioeconomic suburbs of Perth were selected, which ensured that students were drawn from similar socio-economic suburban demographics. It was anticipated that these schools would have low rates of behaviour management issues and student achievement scores above the national average, which may indicate that the schools had sufficient time and energy to potentially devote to whole-school sustainability education. Lighthouse, River's Edge and Fertile Ground Primary Schools all were located in upper-middle to high socioeconomic status neighbourhoods in Perth's south, western and northern suburbs respectively. Their student achievement scores were all above average, as indicated on the My School's website (ACARA, 2012a).

Steps involved in the selection of schools. There were several steps involved in selecting each of the schools, including School X. First, the project manager of AuSSI WA was consulted and provided a full list of participating AuSSI - WA schools (200 at the time). The AuSSI - WA project manager also provided a shortlist of schools that had become closely involved with the sustainable schools initiative. These schools were considered to be 'lighthouse' schools and among the top ten schools at embedding sustainability principles into their policies, teaching and learning. Next, the manager of DEC's Community Education Branch, was consulted and provided a full list of schools that were participating in DEC's Waste Wise or Water Wise Schools programs. This 
information provided the basis for investigation and selection of potential schools, outlined below.

Lighthouse Primary School. The researcher visited Lighthouse Primary School during a celebration of their school's sustainability achievements that was open to the public, and noted the scope and depth of the school's sustainability initiatives. After informal discussions with teachers at the school, it became apparent that, although one teacher was driving the process, staff from across the whole school were undertaking sustainability initiatives. After an introduction by the AuSSI - WA project manager, their principal was approached and took great interest in the research being conducted at his school.

River's Edge Primary School. Other schools on the shortlist provided by The AuSSI - WA project manager were considered for the purpose of literal replication with Lighthouse Primary School. It was considered important, however, to explore the role of an external sustainability facilitator in assisting a school to establish a whole-school sustainability focus. Because of the researcher's involvement with Millennium Kids (described in Chapter 1), their CEO was consulted and suggested River's Edge Primary School. River's Edge Primary School was found to fit all the requirements: 1) being an AuSSI school, 2) operating with a whole-school approach towards embedding sustainability initiatives, and 3) being closely accompanied by an external facilitator. Their principal was approached and took great interest in the research being conducted at her school.

Fertile Ground Primary School. Choosing a comparison school was more time consuming. A shortlist of schools was created by comparing the complete list of government primary schools with the lists of AuSSI, Waste Wise and Water Wise schools, and identifying schools in upper-middle to high socioeconomic Perth neighbourhoods that did not have sustainability or environmental programs in operation. This process yielded three possible comparison schools.

The researcher scrutinised each school's profile on the My Schools website (ACARA, 2012a) to determine their student achievement scores and read descriptions of their school's demographic, focus, and initiatives. Two schools were identified as possibilities. After asking friends and colleagues for any information they knew about these schools and speaking to the office staff at each school, Fertile Ground Primary School, was considered preferable because it appeared to have the most stable demographic and friendly staff of the two schools. The principal was approached and, 
like the other principals, expressed his interest in the research and willingness for the research to be conducted at his school.

School $X$. This school was on the shortlist provided by The AuSSI - WA project manager. Following an introduction by The AuSSI - WA project manager, the principal was approached and was amenable to the research being conducted at his school.

Summary. A multiple case study design was used in this study to add rigour and richness to the results and interpretations. Three case study schools were selected to enable triangulation. Moreover, variation from school to school was considered to add richness to the cross-case analysis.

\section{Case Study Research in Sustainability Education}

In a review of case studies that investigated sustainability in higher education, Corcoran et al. (2004) identified four critical considerations for planning and conducting the research. These considerations are: 1) having a clear purpose and adequately addressing that purpose, 2) representing and exploring the role played by each protagonist within a case, 3) capturing the tension between unique contextual elements and abstract transferable elements that can promote transformation both within and across institutions, and 4) challenging transformation within an institution or community of learners through considered feedback of information that will foster discourse and trigger rethinking of ideas and practices.

The research presented in this doctoral thesis was designed and implemented to address each of the considerations suggested by Corcoran et al. (2004). The purpose was clear (to assess the impact of whole-school school sustainability education) and guided the development of each research question and the research design. All protagonists in the primary school institutional structure were incorporated into the research and their role in whole-school school sustainability education explored. The multiple case study approach with literal and theoretical replication was used to capture the unique and transferable elements of each case. These are explored in each data chapter and synthesised in Chapter 9, the cross-case analysis.

Furthermore, the process of transformation has already been encouraged through considered feedback in the form of a journal publication, a poster, several conference presentations, and informal meetings with the project manager of AuSSI - WA. Direct feedback to each case study school and a formal presentation to the project manager of AuSSI - WA will be provided in the coming months. 


\section{Instrument Design, Data Collection and Data Analysis}

Qualitative and quantitative data were collected concurrently in each of the three case study schools across two years with one intensive data collection period per year. The intensive data collection period took place during school terms three and four each year and spanned six weeks. In September and October 2009, students from Years 4, 5 and 6 at the three case study schools $\left(n_{\text {Lighthouse }}=161, n_{\text {River's Edge }}=155, n_{\text {Fertile Ground }}=\right.$ 26) created mind maps and completed surveys. A few weeks later, at each school, interviews were conducted with the school principal and several teachers. At Lighthouse and River's Edge Primary Schools interviews also were conducted with nine children and one or both of their parents.

In October 2010 a second round of surveys was conducted with students from Years 5, 6 and 7 at Lighthouse Primary School $(n=157)$ and with students from Years 5 and 6 at River's Edge Primary School $(n=128)$. It was not possible to survey the Year 7 students at River's Edge Primary School in 2010, as they had already progressed to the senior school. It was decided not to re-visit Fertile Ground Primary School in 2010 because the number of participants after attrition would have been too low $(n<$ 20) and not representative across year groups. Table 3.2 shows a summary of the data collected from each school in 2009 and 2010.

Table 3.2. Number of interviews, mind maps and surveys collected from each data source at each case study school in 2009 and 2010.

\begin{tabular}{|c|c|c|c|c|c|c|}
\hline & \multicolumn{2}{|c|}{$\begin{array}{l}\text { Lighthouse } \\
\text { P.S. }\end{array}$} & \multicolumn{2}{|c|}{$\begin{array}{l}\text { River's Edge } \\
\text { P.S. }\end{array}$} & \multicolumn{2}{|c|}{$\begin{array}{l}\text { Fertile Ground } \\
\text { P. S. }\end{array}$} \\
\hline & 2009 & 2010 & 2009 & 2010 & 2009 & 2010 \\
\hline Principals Interviewed & 1 & & 1 & & 1 & \\
\hline $\begin{array}{c}\text { Lead } \\
\text { Sustainability Coordinators } \\
\text { Interviewed }\end{array}$ & 1 & & 1 & & N/A & \\
\hline $\begin{array}{l}\text { Deputy Principals } \\
\text { Interviewed }\end{array}$ & 1 & & 1 & & 1 & \\
\hline Other Teachers Interviewed & 2 & & 3 & & 2 & \\
\hline $\begin{array}{c}\text { Sustainability Facilitators } \\
\text { Interviewed }\end{array}$ & & & 1 & & & \\
\hline Parents Interviewed & 10 & & 11 & & & \\
\hline Students Interviewed & 9 & & 9 & & & \\
\hline $\begin{array}{l}\text { Student Mind maps } \\
\text { collected }\end{array}$ & 161 & & 154 & & 26 & \\
\hline Student Surveys collected & 161 & 157 & 155 & 128 & 26 & \\
\hline
\end{tabular}




\section{Interviews and Observations}

Interviews and observations were used to collect information about five key elements of whole-school sustainability education in order to answer Research Question 1 (p. 7). Interviews and observations also were used to collect information about family dynamics that contribute to intergenerational influence and the uptake (or non-uptake) of environmental behaviours in students' homes in an effort to answer Research Question 5. Five different interview protocols were developed for use with principals, lead sustainability coordinators, teachers, parents and students (Appendices 1.1, 1.2, 1.3, 1.4 and 1.5). Each protocol underwent a process of verification prior to use (Morse, Barrett, Mayan, Olson, \& Spiers, 2008) and was checked for trustworthiness during analysis (Creswell \& Plano Clark, 2011; Guba \& Lincoln, 1989), as described later in this chapter.

Design. Interviews followed a semi-structured protocol where interviewees were asked a series of pre-determined questions, some directly answerable and others openended to allow for in-depth and variable responses (Barbour, 2008; Kvale \& Brinkmann, 2009; Punch, 2010). This enabled systematic analysis and gave flexibility for the interviewees to provide responses about their particular interests and behaviours. Observations were used to triangulate with data collected from interviews. Observations of participants, conducted in the school or in a family home, followed an unstructured protocol where patterns and categories of behaviour emerged during analysis of the data.

To facilitate comparison, several interview questions were asked consistently of all participants (Creswell \& Plano Clark, 2011; Guba \& Lincoln, 1989). These included: knowledge of climate change and attitudes towards the complex issues surrounding climate change. Other interview questions were tailored for each participant group (Appendices 1.1, 1.2, 1.3, 1.4 and 1.5). Principals and deputy principals were asked about the history of sustainability initiatives (or lack thereof) at their school, their approach to governance and policies to support the initiatives, their perspective of the whole-school response and the interaction with AuSSI - WA, and the relationship between the school and the parent body. Teachers were asked specifically about whether they planned lessons across multiple learning areas, how they integrated sustainability concepts into their teaching and learning, and their perspective of the whole-school response and the interaction with AuSSI - WA. Lead sustainability coordinators were asked all of the questions asked of principals and teachers. Parents were asked about their interest in environmental topics, their encouragement of their 
child(ren)'s interest in environmental topics and practices, and whether they supported the school's sustainability education program. Students were asked about their interest in environmental topics, their experience of environmental activities at school, and whether their family undertook many environmental initiatives at home.

Collection. Interviews with principals, deputy principals, teachers, parents and students were conducted at the three case study schools between September and October 2009 (Table 3.2). Parent and student interviews were conducted with participants from Lighthouse and River's Edge Primary Schools only (Table 3.2), because Research Question 5 was specific to schools with a sustainability program in operation.

In total, fifty-five face-to-face interviews were conducted (Table 3.2), each of which was audio recorded to assist with data analysis (Creswell \& Plano Clark, 2011; Kvale \& Brinkmann, 2009; Punch, 2010). Interviews with principals, teachers and parents ranged from 30-60 minutes in duration and interviews with children ranged from 20-35 minutes in duration. Efforts were made to select participants who would represent a range of views, opinions and levels of interest in school sustainability programs (Kvale \& Brinkmann, 2009).

Interviews were conducted, where possible, with one teacher of Years 4, 5 and 6 , who may or may not have had a specific interest in sustainability education. At Lighthouse Primary School, however, it was not possible to interview a teacher of Year 5 because none gave their consent to be interviewed. As an alternative, the music teacher was interviewed because she: 1) volunteered, 2) was teaching the students from Year 5, and 3) had insight into the school's sustainability program and interactions among relevant staff in the school. Teacher interviews at Lighthouse and River's Edge Primary Schools also included the teacher within each school who had chiefly been responsible for setting up and driving their school's sustainability initiatives, referred to in this thesis as the lead sustainability coordinator.

One interview was also conducted with the CEO of Millennium Kids who was employed by River's Edge Primary School to facilitate and provided guidance to their sustainability initiatives.

Visible sustainable features or initiatives around the school grounds were observed and documented with photographs and reflective journaling written immediately after each school visit (Creswell \& Plano Clark, 2011; Punch, 2010).

Nine students and at least one of their parents were interviewed at Lighthouse and River's Edge Primary Schools. Three criteria were used to create a shortlist of 
students for interviews: 1) the student and the student's parent/s had consented to be interviewed, 2) the student expressed a positive, negative or neutral response to a survey question that asked them to rate importance of school environmental activities, and 3) the student's mind map was either extensive or minimal in scope. To make the final selection of students for interviews, the lead sustainability coordinator at the school was consulted for their suggestions. These teachers were able to provide insight about a student's confidence in speaking, the student's familiarity with the school's sustainability program, and their parents' interaction with the school's sustainability program, which helped to narrow the selections. Where possible, a balance of genders and representation across year groups was maintained.

Through this process, nine students with a spread of positive, negative or neutral levels of expressed importance towards school environmental activities, and from across Years 4, 5 and 6 were selected for interviews at both schools. It was anticipated that selecting students with a spread of expressed importance towards school environmental activities, would enable access to a wide variety of parent attitudes. One week after student interviews, interviews were conducted with one or both of the parents, either at the school or at the family's home. When invite0d into a family home, household environmental behaviours were observed and, if allowed, photographs were taken of environmental features in or around the home (Punch, 2010).

Analysis. The data from interviews and observations were explored using a combination of analytic approaches that focussed on finding patterns and meaning in the data. Such an exploratory approach lends itself to the use of qualitative methods (Larsson et al., 2010; Punch, 2010), triangulated where appropriate with patterns discovered through examining quantitative data from the same population (Yin, 2008). Analysis of principal and teacher interviews, and school observations, followed an ad hoc process of qualitative analysis (Kvale \& Brinkmann, 2009; Miles \& Huberman, 1994), where the theory about key elements of whole-school sustainability education (described in Chapter 2) guided the identification of themes and multiple approaches were used to interrogate the data. Analysis of parent and child interviews, and home observations, followed a process of meaning condensation (Kvale \& Brinkmann, 2009), where meaning units and themes emerged from the data through a process of reading, note taking, interrogation and reflection. Ad hoc techniques and meaning condensation were used in preference to other techniques, such as content analysis, because these methods allowed wider, contextualised interpretations of the rich, complex information 
found in the many lengthy multiple-participant interviews collected in this research (Kvale \& Brinkmann, 2009).

All interviews were audio recorded and in the months following data collection they were repeatedly listened to and partially transcribed (Barbour, 2008; Halcomb \& Davidson, 2006). Partial transcription involved making notes of themes that emerged, indexing sections of the recordings to go back to, and transcribing verbatim sections that were considered important for reporting. Partial transcription enabled the researcher to go back to the recordings during data analysis for more detailed information as and when necessary. Particular attention was paid to contradictions or exceptions that emerged from the data (Barbour, 2008; Guba \& Lincoln, 1989). The researcher chose not to employ a transcription service or use a computer software package designed for coding because it was considered more beneficial for the depth of analysis if the researcher became intimately familiar with the data by transcribing and coding by hand (Kvale \& Brinkmann, 2009; Punch, 2010).

Organisational factors of whole-school sustainability programs. Ad hoc techniques in analysis of principal and teacher interviews allowed multiple approaches to be used in conjunction with each other so as to build a logical chain of evidence that is theoretically coherent (Kvale \& Brinkmann, 2009; Miles \& Huberman, 1994). The combination of approaches used in this research to analyse principal and teacher interviews included: 1) theoretical reading and interpretation, 2) noting themes and patterns, 3) seeing plausibility in the patterns, and 4) clustering and making contrasts/comparisons between themes. Specifically, the interviews from each school were listened to multiple times and notes were made of themes that were relevant to the literature about five key elements of whole-school sustainability education: 1) school governance, 2) school planning, 3) community networks and partnerships, 4) student voice and engagement, and 5) curriculum integration. If similar themes emerged across several interviews these were considered to build plausible patterns that further informed the overall interpretation. Whenever contrasting opinions were identified these were noted.

Individual case reports were written for each school addressing each of the five key elements identified as important organisational factors for whole-school sustainability programs. In addition, relevant background information to the school's sustainability initiatives (or lack thereof) was presented at the beginning of each case report, which was further informed by document searches. Case reports highlighted patterns in the themes emerging from interview data, and used verbatim quotations to 
accentuate certain points. Contrasting opinions were included in the case reports to enhance richness and contribute to trustworthiness. Finally, a cross-case synthesis, showing common and divergent themes, was created and assertions postulated, as discussed in Chapter 9.

Family dynamics. Analysis of parent and child interviews from Lighthouse and River's Edge Primary Schools used meaning condensation analysis involving five stages (Kvale \& Brinkmann, 2009):

1) First, each interview was listened to multiple times to get a sense of the whole.

2) Second, sections of each interview (also called 'meaning units') that demonstrated themes relevant to family dynamics, intergenerational influence and uptake or nonuptake of environmental behaviours were noted, and the central theme of each meaning unit was identified and restated in simple terms.

3) Third, each meaning unit and theme was interrogated to determine if patterns existed between parent and child interviews that might indicate the role of family dynamics in uptake or non-uptake of pro-environmental behaviours in homes. Interrogation involved exploring patterns, postulating theories, reflecting on the strength of assertions by looking for alternative themes or patterns, and doing this repeatedly until simple, plausible connections were identified. Interrogation also involved noting the range of positive and negative responses that emerged from each theme to assist with defining typologies of family dynamics.

4) Fourth, a figure was created that illustrated the plausible connections between parent and child interviews, including positive and negative typologies, and a table was created with examples of interview excerpts that elucidated each of the typologies identified.

5) Fifth, the dominant themes and plausible connections between parent and child interviews that were judged as indicating the role of family dynamics in uptake or non-uptake of pro-environmental behaviours in homes, were woven together in a descriptive account of the whole data set of eighteen interviews from each school.

\section{Document Searches}

Document searches were used to supplement the rich data collected through interviews to answer Research Question 1 (p. 7). From each of the three case study schools, physical and web-based documents that contained information about the school's sustainability or environmental initiatives were collected during school visits. These documents were triangulated with the interview data during analysis using ad hoc 
techniques that allowed patterns and themes to be compared or contrasted between both data types (Kvale \& Brinkmann, 2009; Miles \& Huberman, 1994).

Yearbooks, dating back to 2002, were collected from Lighthouse Primary School, together with the school's sustainability policy and action plans from 2008 and 2009 provided by the principal. Newsletters, dating back to 2008, were collected from River's Edge Primary School, together with the school's sustainability policy from 2009 , and other detailed information available online through the school's profile on the Millennium Kids schools networking website referred to as a 'Ning' ("Timeline", 2010). An information booklet, containing only general information, was collected from Fertile Ground Primary School.

\section{Mind maps}

Mind maps were used to collect information about students' environmental and sustainability knowledge to answer Research Question 2 (p. 7). As discussed in Chapter 2 , it was anticipated that mind maps would provide an indication of the volume and depth of students' knowledge of environmental behaviours and sustainability, and would capture the breadth of their thinking across multiple themes. Mind maps are an ideal method for collecting data on students' knowledge and whole-systems thinking, for several reasons. Mind maps: 1) provide an unprompted, concise, and non-linear overview of students' thinking on a particular topic, 2) are easy to learn and often already familiar to students, 3) can be used to engage students with varying levels of literacy skills, and 4) encourage creativity and self-expression (Brinkmann, 2003; Buzan \& Buzan, 1996; Eppler, 2006).

Students at the three case study schools produced mind maps in 2009, immediately prior to completing the surveys. Pilot testing with students at School X, one month before collecting data from the three case study schools, enabled minor refinement of the mind mapping data collection and provided insight into how it should be conducted. Analysis of mind map data required the development and validation of a coding scheme (described later in this chapter), which helped to develop the mind map assessment tool.

The assessment tool developed in this research is an innovative approach that converts qualitative mind map data to quantitative data which can be statistically analysed to explore trends and compare groups of students (Salter, Longnecker, \& Venville, 2011). Only one published assessment tool is currently available to compare student mind maps, which focuses on grading mind maps to compare individual student results (D'Antoni et al., 2009). The assessment tool developed in this research differs 
from the tool developed by D'Antoni, Zipp and Olson (2009) and used by Evrekli, Inel and Balim (2010), as discussed in Chapter 2.

Design. Mind maps were used to estimate students' general knowledge of proenvironmental behaviours and to determine if there was a difference in the depth, volume and breadth of their responses to the two constructs: sustainability and things I can do to help the environment. The two constructs were juxtaposed on the same page and students were asked to write as many things they could think of for each of them (e.g. Figures 3.2 and 3.3). Their responses also were compared statistically across year groups to determine if relationships existed between responses from students in Years 4, 5 and 6 , and the depth, volume and breadth of students' pro-environmental knowledge.

Sustainability as a concept is ambiguous to many adults (Jickling \& Wals, 2012; Kagawa, 2007), let alone children, so it was considered important in researching the effect of school sustainability education to assess students' knowledge about sustainability. Furthermore, it was considered important to assess students' knowledge about behaviours they can do to help the environment. Estimates of this second construct provided an indication of the main kinds of pro-environmental behaviours students associated with themselves, which could be descriptively compared with survey results about frequency of pro-environmental behaviours.

It was acknowledged that having both constructs juxtaposed on the same page might cause bias in students' responses towards sustainability. However, this approach had two benefits: 1) the ability to assess any links that students drew between the two constructs, and 2) saving paper and time during data collection.

Collection. Mind maps were collected from students in all three case study schools in 2009 (Table 3.2). The mind map collection procedure was piloted with students at School $\mathrm{X}$ one month before the main data collection in the case study schools. The mind mapping was completed immediately prior to administering the surveys, which ensured that students' mind maps were not influenced by content from the surveys. The collection of mind map data required 15 minutes with each group of students.

Piloting the mind maps with students at School $\mathrm{X}$ highlighted two important changes required to the instrument and the process of collecting the mind maps. In the pilot test, students were given blank sheets of paper and asked to write their class and name details at the top, and to draw two bubbles on the page with the words sustainability and things I can do to help the environment inside them. Although examples were written on the board students struggled with setting up the page as 
requested, often taking a long time to copy the words with the correct spelling. Following the pilot test, a template was created with each of the required fields and constructs ready to facilitate students writing their name and class details before commencing their mind map (Appendix 2.1).

The pilot test also highlighted the need to train students how to build mind maps in case they were not familiar with the technique. Training ensured consistency in the general structure of students' mind maps. Training involved showing students how to make hierarchical branches from general to complex ideas and to generate ideas across a diversity of themes. To facilitate training, an example mind map with ideas from an unrelated topic was provided on the back of the answer template (Appendix 2.2). This example was then worked through with the students on a white board. Training also involved providing the students with a general definition of the word sustainability, which was defined for all students as "helping the world stay healthy for a long time". A general definition had to be provided because the pilot test showed that most students had little, if any, idea of what sustainability meant.

Analysis. Analysis of the mind maps involved using inductive thematic content analysis to code students' responses and required the development and validation of a detailed coding scheme (Hsieh \& Shannon, 2005; Krippendorff, 2004; Neuendorf, 2002) (described later in this chapter). Coding generated the following categories: links, hierarchies, ideas and themes. Unlike other studies to assess mind map data (D'Antoni et al., 2009; Evrekli et al., 2010), this study coded emergent textual themes but did not code colours or pictures.

Nine themes were identified through the coding process:

1) Waste management

2) Water conservation

3) Biodiversity conservation

4) Energy reduction

5) Air pollution and transport choices

6) Values, advocacy and philanthropy

7) Social and cultural wellbeing

8) Complex

9) Simple 
An idea was considered complex if it could be coded into more than one theme. For example, "have very little mines" could be coded into waste management, water conservation, biodiversity conservation, energy reduction and air pollution and transport choices. Or, "use non-toxic chemicals" could be coded into waste management, biodiversity conservation and social and cultural wellbeing.

The theme simple represented responses that were primarily simple nouns with no associated action and could not be coded into the other themes. For example, "tree", "alive" and "sun" were considered simple. For this reason, the theme simple was excluded from analyses of volume and breadth of knowledge. It was, however, represented graphically alongside the other themes to depict the percent of student response per year group, thus giving an indication of the proportion of students who gave simple responses.

Depth of pro-environmental knowledge was estimated by counting the maximum number of hierarchies that students sketched from each construct (Figure 3.2). Volume of pro-environmental knowledge was estimated, for each construct, by counting the total number of ideas that students generated (Figure 3.3). Breadth of proenvironmental ideas was estimated, for each construct, by counting the total number of themes about which a student generated ideas.

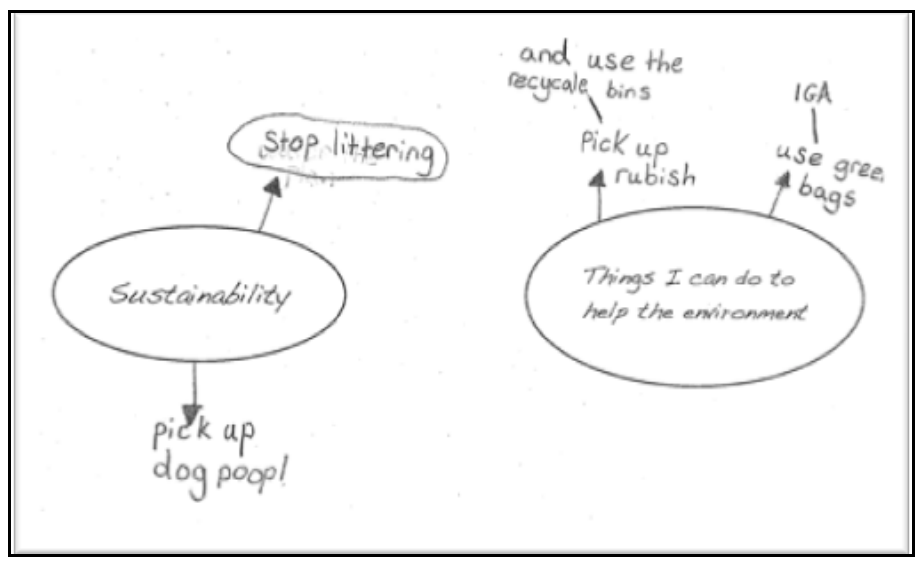

Figure 3.2. Example of a student's mind map showing hierarchies sketched from each of the two constructs. In this example Sustainability has one hierarchy, two ideas and one theme, and Things I can do to help the environment has two hierarchies, four ideas and one theme. 


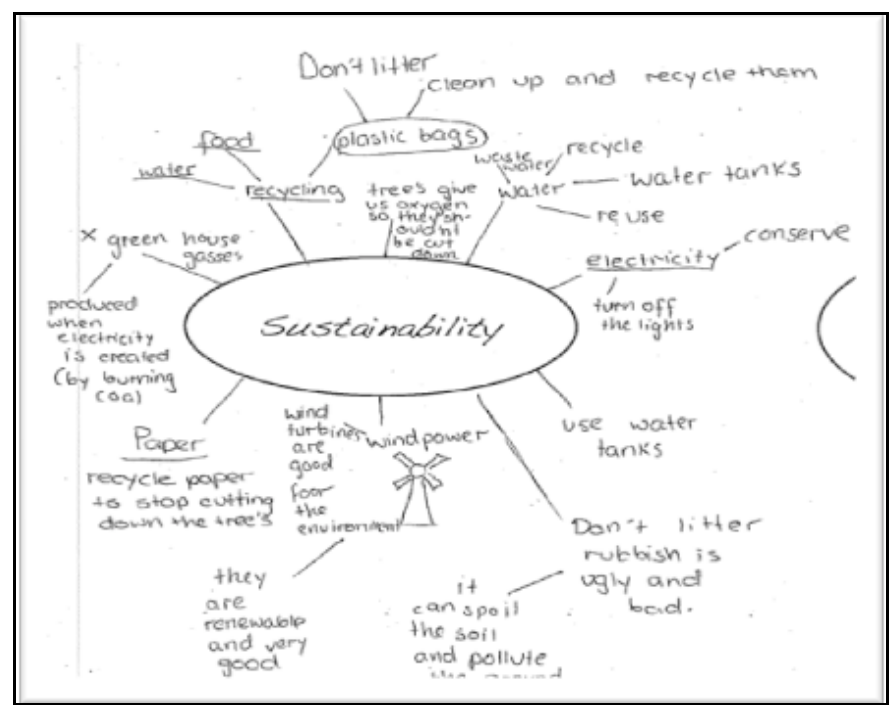

Figure 3.3. Example of a student's mind map showing ideas sketched from one construct. This example has twenty-four ideas, five themes and a maximum of three hierarchies.

Interconnected thinking of pro-environmental knowledge was intended to be estimated by counting the total number of links that students sketched between the two constructs. Very few students sketched links, however, which indicated either this was not a useful estimate or there were problems with the training.

The coded data from mind maps were examined with descriptive statistics and non-parametric analyses using SPSS. Before data analysis progressed, normality was assessed using SPSS by looking at the Kolmogorov-Smirnov statistic, and values of skewness and kurtosis for all data collected from each school (Pallant, 2007). Influence from extreme outliers also was inspected using SPSS by comparing the difference between the mean and the five percent trimmed mean for each variable. Results from these analyses indicated that the mind map data from each school did not conform to normality and that it was not necessary to remove or recode outliers. The influence of classrooms within year groups also was investigated and few small classroom differences were found among the variables estimated. It was consequently decided to treat classes within year groups as equal.

Kruskal-Wallis tests were used to look for differences in the median number of hierarchies (depth), ideas (volume) and themes (breadth) generated by students from Years 4, 5 and 6. Kruskal-Wallis tests were used to look for differences in students' responses to the constructs sustainability and things I can do to help the environment. If differences were found, post hoc Mann-Whitney U tests were used to determine where they were located. The percent of student responses from each year group for each theme also were compared using Kruskal-Wallis tests to determine if there were specific year group related differences in the proportion of responses towards the nine 
themes. All findings were presented as column graphs for ease of comparison and any differences between year groups or constructs were highlighted.

\section{Surveys}

Surveys were designed to collect information about students' pro-environmental attitudes and behaviours to answer Research Questions 3 and 4 (p. 7). After several iterations and validation testing including piloting the survey at School X (described later in this chapter), the 2009 survey instrument was used to collect data from students at the three case study schools. During data analysis the instrument's validity was further evaluated and led to development of the instrument for use in 2010.

Design. The 2009 survey included thirteen closed questions, on a five-point Likert scale (Appendix 3.1). It also included a set of seven open response questions about which family member/s were most responsible for certain environmental behaviours at home. The open response questions were later coded into four categories and used in quantitative analyses. The 2010 survey was revised to include additional closed questions (Appendix 3.2). The length of the survey was limited to four pages with questions spaced to increase readability and suitability of format for a print survey (Rea \& Parker, 1997). The Likert scale questions were formatted for students to circle their response rather than tick a box or put a line on a scale. This approach was chosen to minimise potential confusion caused by a scale and to minimise the frequency of accidentally missed questions (Fowler, 2009).

The 2009 survey was designed to explore student behaviours using exploratory data analysis. Some questions required direct answers about frequency of certain proenvironmental behaviours undertaken in their homes, and other supplementary questions were included to shed light on factors that may influence or be related to students' frequency of undertaking certain pro-environmental behaviours. These questions included how often they perceived they learned about certain topics at school, the importance of environmental experiences to them, and which of their family members were most active in undertaking certain environmental behaviours.

The 2010 survey retained the existing Likert scale questions to enable comparisons between 2009 and 2010 data on student behaviours. It was anticipated that comparisons would be general and simply look for similar or different patterns in the two data sets. Consequently, while most of the same students were surveyed in 2009 and 2010 exact continuity of participants was not a relevant concern.

In addition, the 2010 survey included nineteen new Likert scale questions to estimate a range of student attitudes, including attitudes to school environmental 
activities and environmental worldviews. The ten-item New Environmental Paradigm (NEP) Scale for Children (Manoli et al., 2007) was used with permission (Manoli, personal communication, 14 December 2010) to assess students' environmental worldviews. Nine additional questions were created to investigate student attitudes towards school environmental activities. The questions that estimated student attitudes, together with the set of questions that estimated student pro-environmental behaviours, were validated using factor analysis before exploring relationships using structural equation modelling (Cunningham, 2010; Pallant, 2007). They are explained in more detail below.

Collection. Surveys were administered with students from the three case study schools in 2009 and students from Lighthouse and River's Edge Primary Schools in 2010 (Table 3.2). In each school the researcher was the person responsible for administering the surveys (and mind maps) - a method which, although time consuming, ensured consistency and quality of results (Punch, 2010). The collection of survey data required 10-20 minutes with each group of students. Before administering the surveys (and mind maps), students were reminded about the purpose and context of the research, the confidentiality and anonymity of their results, and what would be done with their data (as described later in this chapter).

Results from piloting the survey with students from School $\mathrm{X}$ showed that students needed to be familiarised with each page of the survey before commencing the survey to ensure that items or whole pages were not accidentally skipped. The pilot also revealed that some students lagged behind because of their reading ability, which prompted the researcher to adopt a flexible lockstep method of reading the survey questions aloud. This helped the slower students to keep up with the majority of students and allowed the faster students to move ahead at their own pace, and also helped the researcher to keep on schedule.

Analysis. Analysis of the 2009 and 2010 behaviour data involved descriptive statistics and chi-square tests for independence (Pallant, 2007). Analysis of the 2010 attitude-behaviour data involved factor analysis and structural equation modelling (Cunningham, 2010; Pallant, 2007).

Behaviours. The 2009 and 2010 surveys (Appendices 3.1 and 3.2) included a set of questions to estimate students' self-reported frequency of undertaking certain proenvironmental behaviours at home. The set included seven questions, beginning with 'at home I':

1) Save power by turning off lights 
2) Recycle paper and plastic

3) Have short showers and use a four minute shower timer to help keep on time

4) Save water in other ways

5) Walk, ride my bike or take the bus to school

6) Eat fruit and vegetables that my family has grown in our home garden

7) Put food scraps in a worm farm or compost bin

A five-point categorical scale, with definitions for each response option, was used to assess frequency. The options were: never, rarely (once a year or more), sometimes (once a term or more), often (once a week or more), every day. During analysis these were reduced to three categories to assist with chi-square comparisons and graphing of results. The three categories were: never, less than weekly, more than weekly. Reduction of responses for categorical analyses is a common practice that can help to simplify results but involves some loss of detail (Punch, 2010).

It was considered a robust way of investigating pro-environmental behaviour to estimate the frequency that students undertook specific behaviours and to compare their relationships with other estimated variables to infer reasons for possible variation in those frequencies. For example, it was expected that recycling would be more frequently practiced by students than composting, and might be positively related with the importance students place on school environmental experiences whereas composting might not be related. A result such as this would suggest that students who place great importance on environmental experiences would recycle at home more frequently than other students. However, they would not be more likely to compost, which could indicate that other factors such as time, parent support, skills or infrastructure have greater association with frequency of composting than importance alone.

Before data analysis progressed, normality was assessed using a process similar to that already described for coded mind map responses. Results from these analyses indicated that survey data from each school did not conform to normality and that it was not necessary to remove or recode outliers.

Relationships with other variables. The behaviour questions were examined through a combination of descriptive statistics and non-parametric analyses using SPSS. Chi square tests for independence were conducted to look for relationships between students' self-reported frequency of performing each behaviour at home and: 1) students' perceived frequency of learning about each pro-environmental behaviour at school, 2) students' expressed importance of school environmental experiences, and, 3) students' degree of participation in each behaviour at home. These three comparison 
variables were given the abbreviated titles: 'Learning', 'Importance' and 'Participation' (discussed further below). If significant associations were found, box plots were performed to observe and infer the patterns.

Chi-square tests for independence $\left(\chi^{2}\right)$ were chosen to explore relationships between each of the seven environmental behaviours and the three comparison variables because chi-square tests are able to accurately explore relationships between variables in a non-normal data set (Pallant, 2007). Chi-square tests compare observed frequencies with theoretically expected frequencies. However, when more than 20 percent of cells had expected frequencies of less than five, Fisher's exact test of significance (FET) was used in place of chi-square. Fisher's exact test of significance gives a more robust estimate of the strength of relationships when there are a high proportion of cells with low frequencies. Results quoted either $\chi^{2}$ or FET, in addition to the probability value at .05 significance level (p) and a measure of effect size, Cramer's V (V). Cramer's V effect size range is: $.07=$ small, $.21=$ medium, $.35=$ large.

Box plots were chosen to illustrate patterns because this type of graph is simple to understand and is suitable for use with non-parametric data. Box plots visually indicate variability in scores within a group and allow examination of differences between groups (McGill, Tukey, \& Larsen, 1978; Pallant, 2007). Box plots clearly depict five summary features for each group: 1) smallest observation, 2) lower quartile, 3) median, 4) upper quartile, and 5) largest observation. The distance between the lower and upper quartile, the interquartile range, contains 50 percent of cases. Box plots can also indicate which observations might be considered outliers or extreme points. In SPSS, outliers are shown using little circles and extreme points are shown using asterisks (Pallant, 2007).

A variation of box plots called, 'variable width box plots', were used in this research to depict the size of groups on the $x$ axis plotted against a variable on the $y$ axis. In this approach, the box widths for each group are proportional to the size of the group. Variable width box plots provide a clear illustration of the overall median for all groups and indicate which group has greater influence on the observed trends (McGill et al., 1978).

Learning. Students' perceived frequencies of learning environmental topics at school were estimated using the same five point categorical response format as those used to estimate frequency of behaviour and were also reduced to three categories during analysis. The set included five questions (Appendices 3.1 and 3.2), beginning with 'at school I learn about': 
1) Reducing household power use

2) Using transport other than cars

3) Recycling and composting

4) Growing and eating fruits and vegetables from a home or school garden

5) Reducing household water use

Item 3, at school I learn about recycling and composting, was designed to be compared with Items 2 and 7 in the behaviour scale. Item 5, at school I learn about reducing household water use, was designed to be compared with Items 3 and 4 in the behaviour scale.

Importance. Students' expressed importance of school environmental experiences was estimated using a five point Likert response format. The five options were: not at all, a little, average, a lot, very important. During analysis these were reduced to three categories to assist with chi-square comparisons and graphing of results. The three categories were:

1) Not important

2) Average

3) Important

Participation. Students' degree of participation in each behaviour at home was estimated by using open response questions about which family member/s were most responsible for each behaviour at home. These open responses were later coded and reduced to four categories. Students were asked to write in boxes adjacent to each of the frequency of behaviour questions, which of their family members did this behaviour most often. This provided an estimate of which family members, if anyone, were the main drivers of each behaviour at home. Responses were coded initially into 16 categories and further reduced to four categories for analysis:

1) $\mathrm{Me}$

2) Me and other family

3) Parents or siblings

4) No one

These four categories were selected to represent four modes of self-reported student participation in the home: 1) the student as the main driver of a behaviour, 2) the student equally with any combination of other family members as the main drivers of a behaviour, 3) parents or siblings as the main drivers of a behaviour, and 4) no family members driving the behaviour. 
Summary. Whenever significant relationships between behaviour variables and the three comparison variables - Learning, Importance, and Participation - were found, they were presented graphically using box plots and discussed. Discussion included inferring logical reasons for such relationships and triangulation with open response survey and interview data.

Attitude-Behaviour. Student attitudes to the environment were estimated in the 2010 survey with students at Lighthouse and River's Edge Primary Schools using two scales (Table 3.3 and Appendix 3.2). As described in Chapter 2, one scale was adapted by researchers in the United States (Manoli et al., 2007), based on the widely used New Environmental Paradigm survey (Dunlap \& Van Liere, 1978; Dunlap et al., 2000), to estimate children's environmental worldviews (Table 3.3). The other scale was designed specifically for this research to estimate students' attitudes to school environmental activities (Table 3.3).

Table 3.3. Scales to estimate student environmental attitudes.

\begin{tabular}{|c|c|}
\hline & Item \\
\hline $\begin{array}{l}\text { Attitudes to } \\
\text { school } \\
\text { environmental } \\
\text { activities }\end{array}$ & $\begin{array}{l}\text { 1. It is important for everyone to do things that help care for the natural environment } \\
\text { 2. I am proud of what my school is doing to help care for the environment } \\
\text { 3. I think my school should do more to help care for the environment } \\
\text { 4. I would like more opportunities at school to do things that help care for the } \\
\text { environment } \\
\text { 5. I'm only young and it's not my responsibility to care for the environment } \\
\text { (reversed) } \\
\text { 6. I sometimes get tired of learning about environmental topics at school (reversed) } \\
\text { 8. I know a lot about different ways people can look after the environment } \\
\text { 9. Adults listen to my opinions about the environment }\end{array}$ \\
\hline & $\begin{array}{l}\text { 1. Plants and animals have as much right as people do to live } \\
\text { 2. There are too many (or almost too many) people on earth } \\
\text { 3. People are clever enough to keep from ruining the Earth (reversed) } \\
\text { 4. People must still obey the laws of nature } \\
\text { 5. When people mess with nature it has bad results } \\
\text { 6. Nature is strong enough to handle the bad effects of our modern lifestyle } \\
\text { 7. People are supposed to rule over the rest of nature (reversed) } \\
\text { 8. People are treating nature badly } \\
\text { 9. People will someday know enough about how nature works to be able to control it } \\
\text { 10. If things don't change, we will have a big disaster in the environment soon }\end{array}$ \\
\hline
\end{tabular}


Both scales followed a five point Likert scale response format, with response options: 'strongly disagree', 'disagree', 'not sure', 'agree', and 'strongly agree'. Use of 'not sure' or 'don't know' as a middle score is controversial (Kline, 2011; Young, 2012). However, it was decided to keep 'not sure' as a middle response option to be consistent with the New Environmental Paradigm (NEP) Scale for Children (Manoli et al., 2007). Investigation of other commonly used environmental attitude scales for children, such as CHEAKS (Leeming et al., 1995), CERI (Bunting \& Semple, 1979; Zimmermann, 1996), EABS (Bogner, 1996) and EAQ (Eagles \& Demare, 1999), supported this decision.

Existence of relationships between student attitudes and pro-environmental behaviours were tested using structural equation modelling. Before relationship models could be tested, the internal consistency of the two attitude scales and the behaviour scale had to be validated and latent constructs had to be identified through factor extraction using exploratory factor analysis. This validation process is described in more detail later in this chapter.

Structural equation modelling. Structural equation modelling is used to determine the strength of relationships between latent variables (Cunningham, 2010; Kline, 2011). In this research, modelling was conducted between the attitude and behaviour latent variables that were determined through exploratory factor analysis. Modelling was conducted using Mplus and greatly assisted by comprehensive course notes and email advice from a renowned professor and expert in structural equation modelling. Mplus was chosen for structural equation modelling because it can sufficiently deal with ordinal categorical data, skewed data and data that might otherwise be confounded by differences in hierarchical groups as with school settings that involve students within year groups within schools (Cunningham, 2010).

The data presented in this thesis were collected from students, within classrooms, within schools, and thus considered a nested hierarchical design (Figure 3.4) Data from the two schools were pooled for the factor analyses to bring the total sample size above the minimum required for exploratory factor analyses of continuous and categorical data (described later in this chapter). It was considered reasonable to pool the data sets on the assumption that students from schools with a sustainability program would respond similarly. It was of course, possible that students from each school responded differently to the attitude and behaviour questions. Therefore, to accurately estimate the relationship between latent variables using structural equation modelling, it was determined whether the hierarchical structure of the data had 
sufficient measurement invariance for the data to be considered as one population (Cunningham, 2010), as described below.
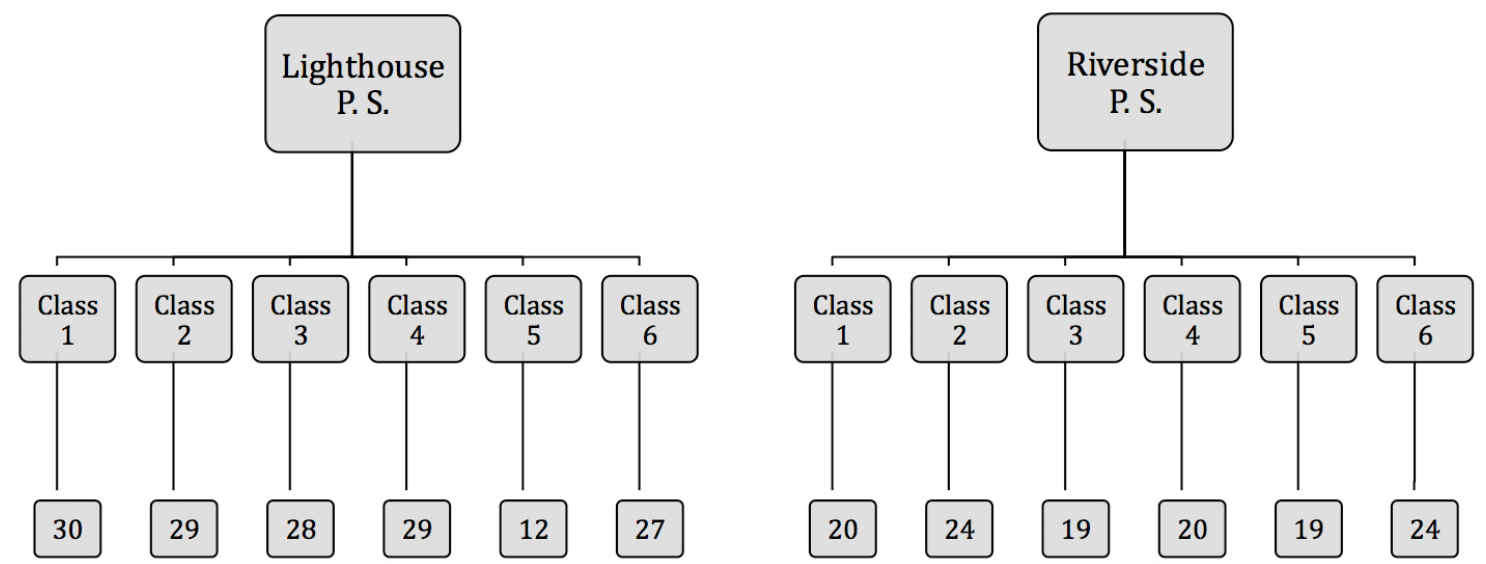

Figure 3.4. The nested hierarchical design of this research, showing number of students surveyed within classrooms and within schools.

To determine the measurement invariance a series of tests were conducted. Cunningham (2010, ch. 5, p. 1) explains, "measurement invariance or measurement equivalence involves using multiple-group CFA [confirmatory factor analysis] to test whether the relations of latent variables with their indicators are identical for different groups". The prerequisite tests to determine invariance before proceeding to structural equation modelling are: 1) invariant invariance (omnibus test), 2) configural invariance, and 3) metric invariance (Cunningham, personal communication, 30 August 2012). The results of invariance testing (presented in Chapter 7) were used to determine the most appropriate modelling technique, which in this research had to account for variance due to the nested hierarchical design (Figure 3.4).

The aggregated approach to modelling was selected for this purpose because it accounts for variance at the clustering level (i.e. classroom), and gives information about the overall relationship of latent variables while also providing correct chi-square and goodness-of-fit statistics, and an appropriate (albeit often larger) standard error (Cunningham, 2010). The aggregated approach, which uses the Huber-White (Sandwich) estimator, is robust to non-normality, and is appropriate when the goal of the research is to make inferences at the lowest level of a hierarchical design, which in this research was at the level of individual. Thus, using the aggregated approach in this research gave a result for the overall relationship between attitudes and behaviours.

The results of structural equation modelling between attitudes and behaviours were assessed by comparing the chi-square and goodness-of-fit statistics with the recommended values (described later in this chapter), and by noting the value of the regression co-efficient and the standard error. The value of the regression co-efficient 
gives an indication of the strength of the relationship between latent variables (as a percentage) by estimating how much of the variance in the endogenous latent variable being regressed onto (i.e. behaviours) is explained by the exogenous latent variable that is regressing onto it (i.e. attitudes). Consequently, a regression co-efficient of .65 with standard error of .10 would indicate that attitudes explain 65 percent of the relationship with behaviours within a 10 percent degree of confidence. Such a relationship would indicate a very strong relationship between attitudes and behaviour, as discussed in Chapter 2.

\section{Research Rigour}

Mixed methods research projects must consider the rigour of the research design, which involves consideration of the validity and reliability of the instruments used, the process of analysis and the interpretation of results (Creswell, 2009; Creswell \& Plano Clark, 2011). In qualitative research, validity refers both to building in strategies that enhance rigour (Morse et al., 2008) and an assessment of whether the information obtained can be trusted as accurate and credible, and reliability often refers to the coding of qualitative data compared among several coders (Creswell \& Plano Clark, 2011). In quantitative research, validity refers to the quality of the instrument and the quality of the interpretations that can be made from the data collected, and reliability refers to the consistency of the participants' scores (Creswell \& Plano Clark, 2011; Punch, 2010).

A mixed method study must also be transferable and easily replicable when other researchers wish to further test or develop the research findings (Cohen et al., 2011; Creswell \& Plano Clark, 2011; Punch, 2010). It must involve a thorough, wellplanned research design that considers the methods and suggestions of previous research and can be generalised to fit other settings and contexts.

Triangulation of various methods and data sources is a robust approach to enhance rigour that is especially apparent in a mixed method study (Cohen et al., 2011; Creswell \& Plano Clark, 2011; Punch, 2010). Triangulation has been used extensively throughout this research to enhance the rigour of each of the five research questions. For example, the investigation of students' pro-environmental behaviours triangulated data from surveys and interviews. In this research, triangulation also features in the crosscase analysis, Chapter 9, where data from each case study school is compared, pooled, categorised and discussed. 
The following paragraphs discuss how different processes of achieving validation and reliability for quantitative and qualitative methods were applied to each of the methods used in this research.

\section{Validity in Qualitative Methods}

Validation of qualitative data collection approaches such as the interviews, mind maps and documents that were collected in this research requires the use of verification techniques that are monitored throughout the course of data collection (Morse et al., 2008), and the use of post-hoc analyses that assess the trustworthiness of the data collected (Creswell \& Plano Clark, 2011; Guba \& Lincoln, 1989). In this research, the design of interview protocols and data collection regimens benefitted from consideration of the verification techniques of methodological coherence, sampling adequacy and theory development (Morse et al., 2008). The analysis of interviews, observations and documents benefitted from assessments of trustworthiness, including triangulation of data sources and reporting disconfirming evidence (Creswell \& Plano Clark, 2011; Guba \& Lincoln, 1989; Kvale \& Brinkmann, 2009).

Methodological coherence, which refers to consistently ensuring that data sampling plans and analyses are relevant to the research questions (Morse et al., 2008), helped to expand the scope of data sources. As data were collected about school organisational approaches, it became apparent that school documents were necessary to bolster and provide context to the findings from interviews, so it was decided to include documents in the data collection and modify the data analysis to include these findings.

Sampling adequacy, which refers to ensuring that participants are representative of the range of opinions towards the phenomenon of interest and requires the researcher to look for negative cases to balance the likely abundance of positive cases (Morse et al., 2008), was built into the participant sample. Interviews were conducted, where possible, with one teacher of Years 4, 5 and 6. Interviews also were conducted with nine students from each school who were selected because they represented a spread of positive, negative or neutral levels of expressed importance towards school environmental activities. It was anticipated that this process would also yield a range of parent interests.

Theory development as a verification technique refers to moving between a micro intimate perspective of the data and a macro conceptual perspective, which allows the researcher to continually inform the data collection and analysis with broader theoretical understandings (Morse et al., 2008). This approach was particularly drawn upon when analysing student mind maps where previous research and theories about 
issues-based and action-based knowledge and whole-systems thinking helped to inform the interpretations of mind map results.

Triangulation of data refers to identifying patterns using data from several sources or individuals, and using these to develop strong, plausible arguments (Creswell \& Plano Clark, 2011; Guba \& Lincoln, 1989; Yin, 2008). Triangulation was built into the qualitative investigations of Research Questions 1 and 5 by ensuring that data were collected from multiple stakeholders as well as in the form of observations and relevant documents. Triangulation was built into investigations of Research Question 2 by ensuring that mind maps were collected from students across three year groups and three schools, and by requiring students to draw mind maps for both constructs: sustainability and things I can do to help the environment.

Reporting disconfirming evidence that is contrary to the bulk of evidence collected enhances the trustworthiness of the data by capturing elements of complexity that exist in real life (Creswell \& Plano Clark, 2011; Guba \& Lincoln, 1989; Kvale \& Brinkmann, 2009). Throughout data analysis and writing of the case reports the researcher attempted to elucidate various perspectives, including those that were contrary to the bulk of evidence, providing that they added relevant information.

\section{Reliability in Qualitative Methods}

When qualitative methods utilise coding strategies, as was the case for the analysis for mind maps in this research, issues of reliability must be considered. Reliability in qualitative analysis refers to intercoder assessment of emergent themes or codes in the data as a means of validating and refining a coding scheme, which once validated is considered reliable to use for coding the whole data set (Creswell \& Plano Clark, 2011; Krippendorff, 2004; Neuendorf, 2002). The validation process ensures that the coding scheme can be used by more than one person and yield similar results. Development of a coding scheme requires clear instructions in the form of a coding guide, sheet, and manual (Krippendorff, 2004; Neuendorf, 2002). Validation of a coding scheme requires clear criteria for the selection of individual coders and that coders work independently of each other.

Comparing results between two or more coders requires achievement of a certain level of agreement (Neuendorf, 2002). A minimum of 80 percent agreement between coders, for every measured variable, is required to indicate the coding scheme is valid. Neuendorf (2002) explains that coders should be given a 10 percent subsample of the data that has been systematically randomly sampled with some cases purposively 
included to ensure the presence of key characteristics. This subsample should be different for each round of intercoder reliability testing until agreement is achieved.

There are multiple ways to assess intercoder agreement, which depend on the type of data being coded and the number of coders involved (Neuendorf, 2002). Simple percent agreement of categorical measures by two coders was used in this research. Percent agreement looks at the total number of agreements divided by the total number of measures, and does this for each variable. After 80 percent agreement is achieved for each variable the coding scheme is considered reliable for the principal coder to use for coding the whole data set.

Mind map coding scheme. Validation of a coding scheme for students' mind map data involved several rounds of intercoder reliability testing and several iterations of the coding scheme. Development of the coding scheme first involved inductive thematic content analysis of the data, which identified the emergent themes. Once the major themes were identified a coding guide was developed that illustrated examples of each theme and helped to clarify coding of items (Appendix 2.3). A coding sheet was also developed to streamline coding (Appendix 2.4). The categories and themes for coding were: Links, Hierarchies, Ideas, Waste, Water, Biodiversity, Energy, Air and Transport, Values Advocacy and Philanthropy, Social and Cultural, Simple or Confused, and Complex.

With a coding guide and sheet developed, eight potential coders were invited to participate in the first round of intercoder testing. The principal researcher did not participate in this round of coding so as to be free to answer questions and assess coders' capacities for coding. Coders were given clear verbal instructions, a 10 percent systematically randomly selected subsample of the data (34 out of a total of 342 mind maps, selected in a spaced pattern of two cases per class group) and asked to work independently.

This first round of intercoder testing highlighted potential ambiguities in the data, for example, how to code the response 'turn off' when it has two or more different ideas branching from it, such as 'taps' and 'lights', which could be coded into different themes. It also served to identify two coders that showed greater capacity and reliability in their coding. Following this, a comprehensive coding manual was developed that gave clear instructions for all coding, especially for coding of ambiguous or difficult items (Appendix 2.5).

Another round of intercoder testing between the principal researcher and one of the shortlisted coders, with a different 10 percent of the data, highlighted further 
ambiguities and caused another iteration of the coding manual and coding guide. This round of intercoder testing only saw greater than 80 percent agreement for Links, Hierarchies, Ideas and one theme, Air and Transport. A final round of intercoder testing between the principal researcher and the other shortlisted coder, with another different 10 percent of the data, achieved 80 percent reliability for all variables and themes.

\section{Validity in Quantitative Surveys}

Validation of survey instruments in quantitative research requires consideration of content validity, criterion-related validity and construct validity (Creswell \& Plano Clark, 2011; Punch, 2010).

Content validity refers to making an assessment of whether the survey instrument will adequately capture a variety of ideas and concepts from within the conceptual definition that the researcher has set out to estimate (Punch, 2010). Content validity was achieved for the 2009 and 2010 survey through literature searches, reviews from teacher experts, peer reviews, and trials of the instrument with students from School $\mathrm{X}$ and small samples of similar aged students who were the children of colleagues.

Criterion-related validity refers to comparisons of the participants' scores with an external criterion that is related to the concept of interest and a reliable estimate of that concept (Corbetta, 2003; Creswell \& Plano Clark, 2011; Punch, 2010). One type of concurrent criterion-related validity is 'validity for known groups' where a survey scale is applied to groups of known difference to see if there are expected differences in responses (Corbetta, 2003). In this research, criterion-related validity was achieved because the survey items measuring pro-environmental behaviours were administered to students from schools that had adopted different approaches to administering their sustainability programs and another school that did not have a program in operation. It was expected that a greater proportion of students from the two sustainability schools would frequently practice pro-environmental behaviours in their homes than students from the school without such a program in place.

Construct validity refers to making a determination of whether the data fits the theoretical model it was intended to measure, which can be determined by statistically analysing relationships between the measured constructs and / or with other constructs that can be predicted and interpreted within that context (Pallant, 2007; Punch, 2010). In this research, construct validation of the survey instrument designed to estimate student's pro-environmental behaviours involved statistically comparing students' selfreported frequency of practicing certain behaviours with their expressed importance 
towards environmental activities, their frequency of learning about environmental topics at school and their degree of participation in each behaviour within their families.

The 2009 and 2010 survey instruments were validated across several stages: 1) the initial design stage, 2) the piloting stage, and 3) analysis of collected data (Table $3.4)$.

\section{Reliability in Quantitative Surveys}

Reliability of a survey instrument refers to the internal consistency of the measurement items (Creswell \& Plano Clark, 2011; Punch, 2010). Internal consistency is the ability of the instrument to account for common variance between items and to minimise the remaining error variance (Pallant, 2007; Punch, 2010). The better the items relate to each other and are estimating the same latent construct, the smaller the error variance, which shows good internal consistency in the measurement instrument. Chronbach's coefficient alpha is a commonly used statistic for internal consistency for which a minimum level of .7 is recommended on a range from 0 to 1 (Pallant, 2007).

Internal consistency of the three scales from the 2010 survey: attitudes to school environmental activities, environmental worldviews and pro-environmental behaviours, were assessed using exploratory factor analysis, the results of which are reported in Chapter 7. The process of exploratory factor analysis is quite involved and is outlined here.

The two attitude scales, school environmental activities and environmental worldviews, were analysed for internal consistency and factorability using exploratory factor analyses performed in SPSS. The scales were analysed separately because they had been developed independently of each other and were designed to estimate theoretically different constructs (Hair, Black, Babin, \& Anderson, 2010). The categorical behaviour scale, pro-environmental behaviour, was analysed using exploratory factor analyses performed in the statistical package, Mplus, which can sufficiently deal with ordinal categorical data (Cunningham, 2010).

Responses from Lighthouse and River's Edge Primary Schools were analysed together providing a total data set of 285 responses, which is above the recommended minimum sample size of 150 required for exploratory factor analysis with continuous variables (Worthington \& Whittaker, 2006) and 200 required for exploratory factor analysis with ordinal categorical variables (Cunningham, 2010).

Exploratory factor analyses using maximum likelihood and oblique rotation (direct oblimin) were performed separately on the two continuous attitude scales. Maximum likelihood was chosen as the extraction method because it allows correlations 
Table 3.4. Audit trail of validation of the survey instrument, data collection and data analysis.

\begin{tabular}{|c|c|c|c|}
\hline \multicolumn{2}{|c|}{ SURVEY INSTRUMENT } & Actions & Date \\
\hline \multicolumn{2}{|c|}{ Development } & $\begin{array}{l}\text { Development, with reference to literature, of a } \\
\text { quantitative survey questionnaire }\end{array}$ & $\begin{array}{l}\text { May - June } \\
2009\end{array}$ \\
\hline \multirow[t]{2}{*}{$\begin{array}{l}\text { Iteration } \\
\quad 1\end{array}$} & Validation & $\begin{array}{l}\text { Content validity: Supervisors and peer researchers } \\
\text { reviewed the survey }\end{array}$ & \multirow{2}{*}{ June 2009} \\
\hline & $\begin{array}{l}\text { Changes } \\
\text { made }\end{array}$ & Wording alterations and re-arrangement of questions & \\
\hline \multirow[t]{2}{*}{$\begin{array}{l}\text { Iteration } \\
\quad 2\end{array}$} & Validation & $\begin{array}{l}\text { Content validity and construct validity: Four volunteer } \\
\text { children of similar ages to the sample population } \\
\text { completed the survey and immediately afterwards } \\
\text { participated in interviews about their survey responses }\end{array}$ & \multirow[t]{2}{*}{ July 2009} \\
\hline & $\begin{array}{l}\text { Changes } \\
\text { made }\end{array}$ & $\begin{array}{l}\text { Clarification and simplification of terms, exclusion of } \\
\text { some items and inclusion of new items }\end{array}$ & \\
\hline \multirow[t]{2}{*}{$\begin{array}{l}\text { Iteration } \\
\quad 3\end{array}$} & Validation & $\begin{array}{l}\text { Content validity: Teacher experts from the study schools } \\
\text { reviewed the survey }\end{array}$ & \multirow{2}{*}{ August 2009} \\
\hline & $\begin{array}{l}\text { Changes } \\
\text { made }\end{array}$ & Clarification and simplification of terms & \\
\hline \multirow[t]{2}{*}{$\begin{array}{l}\text { Iteration } \\
4\end{array}$} & Validation & $\begin{array}{l}\text { Content validity and construct validity: Pilot test at } \\
\text { School X }\end{array}$ & \multirow{2}{*}{ September 2009} \\
\hline & $\begin{array}{l}\text { Changes } \\
\text { made }\end{array}$ & $\begin{array}{l}\text { Decided to read the survey aloud for all students and } \\
\text { allow fast workers to move ahead at their own pace }\end{array}$ & \\
\hline \multicolumn{2}{|c|}{ Data Collection } & $\begin{array}{l}\text { Surveys conducted with students at The Lighthouse, } \\
\text { River's Edge and Fertile Ground Schools }\end{array}$ & $\begin{array}{l}\text { October and } \\
\text { November } 2009\end{array}$ \\
\hline \multicolumn{2}{|c|}{ Data Analysis } & $\begin{array}{l}\text { Construct validity and criterion-related validity assessed } \\
\text { during analysis }\end{array}$ & $\begin{array}{l}\text { April } 2010 \text { to } \\
\text { November } 2011\end{array}$ \\
\hline \multicolumn{2}{|c|}{ Development } & $\begin{array}{l}\text { - Nine new items generated to assess student attitudes } \\
\text { to school environmental activities. Items were } \\
\text { generated following consideration of student } \\
\text { interview data (content validity) } \\
\text { - Ten new items included from the 'New } \\
\text { Environmental Paradigm Scale for Children' to } \\
\text { assess children's environmental worldviews } \\
\text { (Manoli, Johnson and Dunlap, 2007) }\end{array}$ & June 2010 \\
\hline \multirow[t]{2}{*}{$\begin{array}{l}\text { Iteration } \\
\quad 5\end{array}$} & Validation & $\begin{array}{l}\text { Content validity: Supervisors and peer researchers } \\
\text { reviewed the survey }\end{array}$ & \multirow{2}{*}{ July 2010} \\
\hline & $\begin{array}{l}\text { Changes } \\
\text { made }\end{array}$ & $\begin{array}{l}\text { Clarification of terms for the newly generated student } \\
\text { attitude questions only }\end{array}$ & \\
\hline \multicolumn{2}{|c|}{ Data Collection } & $\begin{array}{l}\text { Surveys conducted with students at Lighthouse and } \\
\text { River's Edge Primary Schools }\end{array}$ & October 2010 \\
\hline \multicolumn{2}{|c|}{ Data Analysis } & $\begin{array}{l}\text { Construct validity, criterion-related validity and internal } \\
\text { consistency were assessed during analysis }\end{array}$ & $\begin{array}{l}\text { November } 2010 \\
\text { to November } \\
2011\end{array}$ \\
\hline
\end{tabular}


among factors to be determined and a range of model fit indices to be calculated for the purpose of understanding the latent factors or constructs that account for the shared variance among items (Fabrigar, Wegener, MacCallum, \& Strahan, 1999; Hair et al., 2010; Preacher \& MacCallum, 2003; Worthington \& Whittaker, 2006). An oblique rotation method was chosen because it was assumed that factors would be correlated. These extraction and rotation methods were inconsistent with those used to develop the New Environmental Paradigm Scale for Children (termed in this research as the environmental worldviews scale), which instead used principal components analysis (PCA) and orthogonal rotation (Manoli et al., 2007). It was decided to depart from their chosen extraction and rotation methods because although PCA is often termed as factor analysis, its purpose and mathematical underpinnings are quite different from true factor analysis (Preacher \& MacCallum, 2003; Worthington \& Whittaker, 2006). For the purpose of scale development and identifying shared variance among items, factor analysis is preferred over PCA, because "PCA can overestimate factor loadings and result in erroneous decisions about the number of factors or items to retain" (Worthington and Whittaker, 2006, p. 819).

The inter-item correlation matrix and Chronbach's alpha were consulted to determine if the scale was internally consistent and to help decide if items should be deleted from the scale prior to running the factor analysis. The minimum recommended Chronbach's alpha, above which the scale is considered sufficiently internally consistent, is .70 (Pallant, 2007). Following this, the Kaiser-Meyer-Olikin measure of sampling adequacy and Bartlett's Test of Sphericity were used to determine if factor analysis could be run on the scale. If the Kaiser-Meyer-Oklin value was above the recommended value of .60 and the Bartlett's Test of Sphericity was significant, factor analysis was conducted (Tabachnick \& Fidell, 2007). To determine the most appropriate factor solution and whether items should be removed to improve the model fit the correlation matrix, eigenvalues, scree plot, factor loadings, cross-loadings and communalities were checked (Worthington \& Whittaker, 2006).

It is recommended that factors with eigenvalues above 1.0 should be retained, but this should be interpreted in conjunction with the scree plot, factor loadings and cross-loadings (Hair et al., 2010; Pallant, 2007; Worthington \& Whittaker, 2006). Scree plots graph eigenvalues against factors. Sharp decreases between values on a scree plot indicate that the factors prior to the drop should be retained. Ideally, the factors to be retained should have simple structure, wherein several items load strongly on a single factor and have zero correlation with other factors in the solution (Worthington \& 
Whittaker, 2006). If factors share items that cross-load above .32 on each factor then the item is considered complex, and suggests that either the item or factor should be deleted.

Once the factor solutions were determined for each scale, the number of items to retain could be determined (Pallant, 2007; Worthington \& Whittaker, 2006). Two criteria for deleting items are to investigate: 1) the factor loadings and cross-loadings, and 2) the rotated item communalities. Worthington and Whittaker (2006) suggest that items should be deleted when they have factor loadings below .32, cross-loadings less than .15 difference from the item's highest factor loading, and loadings higher than .32 on two or more factors. Rotated item communalities less than .30 indicate the item is not highly correlated with other items within a factor, and should be deleted (Pallant, 2007; Worthington \& Whittaker, 2006). Removing scale items can increase the proportion of explained variance and improve the factor solution. For a scale that measures educational data, Kline (2011) recommends 30 percent of explained variance as a reasonable minimum.

The categorical behaviour scale was analysed with an exploratory factor analysis using robust weighted least squares (WLSMV) and oblique rotation (geomin) in Mplus, as recommended by Cunningham (2010). The correlation matrix, eigenvalues, scree plot, factor loadings, cross-loadings, chi-square statistic and goodness-of-fit indices were checked to determine the most appropriate factor solution and whether items should be removed to improve the model fit (Cunningham, 2010).

The process of determining factor solution and item deletion for the categorical behaviour scale was similar to the process described for the two continuous attitude scales. The first step is to consider the correlations between items and make note of those below .30, which gives an indication of the internal consistency of a categorical scale (Cunningham, 2010). If few coefficients are found above .30, factor analysis should be reconsidered (Tabachnick \& Fidell, 2007), and if one item is found to have no correlations above .30 it should be removed (Cunningham, 2010).

Next is to consider the eigenvalues, scree plot, factor loadings and crossloadings to determine the most appropriate factor solution, as has already been described. The chi-square statistic and goodness-of-fit indices give added information about the stability of different factor solutions. Goodness-of-fit indices include: comparative fit index (CFI), Tucker Lewis index (TLI), standardised root-mean-square residual (SRMR). Chi-square should not be significant at .05, CFI and TLI should be above .995, and SRMR should be below .05 (Cunningham, 2010; Rodebaugh, Woods, 
\& Heimberg, 2007). These are all ideal thresholds, and debate in the literature highlights that when determining the most suitable factor solution, the researcher must take into account the goodness-of-fit indices together with information from eigenvalues, factor loadings and the overall interpretability of the factor (Cunningham, 2010; Worthington \& Whittaker, 2006). As such, when results are close to the recommended thresholds on some fit indices and are within the acceptable range for other indices, it is allowable to retain the factor solution.

Once it has been decided how many factors to extract, items can be deleted oneat-a-time as required. Identifying items to be deleted should be done by consulting the factor loadings and estimated residual variances. Items with factor loadings below 30 and large estimated residual variances should be considered for deletion. It is important to note that choosing items for deletion should also be guided by a theoretical reason for retaining or excluding that item (Cunningham, 2010; Worthington \& Whittaker, 2006). After deleting the suspected problem item/s the chi-square and goodness-of-fit indices should improve (Cunningham, 2010).

Following extraction of univariate factors (latent constructs) from each of the scales, the relationships between constructs could be analysed using structural equation modelling in Mplus, the results of which are reported in Chapter 7.

\section{Summary}

All approaches to enhancing validity and reliability of data collection instruments have limitations and the approaches chosen should depend on the situation and the research methodology selected (Creswell \& Plano Clark, 2011; Punch, 2010; Zeller, 1997). For this reason many researchers advocate a validation strategy that triangulates the results from quantitative and qualitative methods. This was the approach adopted for this research.

\section{Ethical Considerations}

\section{Approvals and Consent}

This research required ethics approvals from the University of Western Australia (UWA) and the Western Australian Department of Education (DoE) to ensure no adverse effect on the health or wellbeing of any participating child or their family members, and that teachers and schools would be appropriately represented. The research was designed in concord with the National Statement on Ethical Conduct in Human Research published by the National Health and Medical Research Council 
(NHMRC, 2007). The ethics approval process required the researcher to supply multiple documents, including copies of the original research proposal, the researcher and her coordinating supervisor's Working With Children Certifications, the survey instruments and interview protocols that would be used, and the consent letters that would be provided to each group of participants.

Approvals were granted within two months and did not require any changes to the research approach. The UWA Ethics Committee required annual reports on the research progress, and both the UWA and DoE offices required that a copy of the research findings be provided to them upon completion of the research. The reference number given to this research by the Policy and Planning Office of DoE was D09/0364469. The reference number given to this research by the Human Research Ethics Committee of UWA was RA/4/1/2345.

Informed consent was required from the case study and pilot school principals before any information could be provided to staff, students or parents. Following this, information letters were provided to the teachers, students and parents of Years 4, 5 and 6 from each case study and pilot school to ensure they were all aware of the study taking place, and aware of their choice to participate.

In Lighthouse and River's Edge Primary Schools, the two sustainability schools, the principals were interested in the surveys and mind maps being conducted with as many students as possible because the research aligned with the schools' priorities and policy for self-assessment. In these two schools, the principals authorised for anonymous surveys and mind maps to be collected from all students in the year groups of interest, as concordant with their reporting responsibilities (DoE, 2012e, 2012f) and the conditions of 'standing parental consent' described in item 4.2.11 of the NMHRC National Guidelines (NHMRC, 2007). In Fertile Ground Primary School the principal gave authority for surveys and mind maps to be collected only from students that had been granted specific parental permission to participate in the research. All interviews were conducted with students, parents, principals and teachers who had themselves consented to participate.

\section{Anonymity}

Anonymity was considered important for the schools and for all participants, as per items 3.1.10 and 4.2.11 of the NMHRC National Guidelines (NHMRC, 2007). The schools were given pseudonyms and all participants remained unidentified throughout the research and when presenting research findings at conferences or in publications. Where notable participants such as the school principals and lead sustainability 
coordinators could possibly become identifiable at some later stage, their consent to be identified was obtained, but their identities were still given pseudonyms throughout the research.

All principals gave permission for photographs to be taken around the school grounds, providing no children were identifiable in the photographs. If any students were potentially identifiable in a photograph that the researcher wanted to use for conference presentations or this thesis, the researcher used Adobe Photoshop to blur the faces.

\section{Feedback to Schools and Dissemination of Findings}

Findings have already been disseminated in the form of a journal publication, a poster, several conference presentations (as listed at the beginning of this thesis), and informal meetings with the project manager of AuSSI - WA. Direct feedback to each case study school, including copies of research results relevant to their school, and a formal presentation to the project manager of AuSSI - WA will be provided in the coming months. Furthermore, copies of the research findings will be provided to the UWA and DoE research ethics committees upon completion and approval of this thesis.

\section{Chapter Conclusion}

This chapter introduced the mixed method multiple case study design that was utilised in this research and outlined the rationale for selection of cases, data collection instruments and participants. Detail was then provided about the instrument design, data collection and data analysis, followed by discussion of the validation process applied to each instrument and analytic technique. The chapter concluded with an exploration of the ethical considerations that underpinned this research.

The following three chapters present data collected at each of the three case study schools to answer Research Questions 1, 2 and 3 (p. 7). Chapter 4 explores data from Lighthouse Primary School, Chapter 5 examines River's Edge Primary School, and Chapter 6 investigates Fertile Ground Primary School. Research Questions 4 and 5 are probed in Chapters 7 and 8 respectively. 
THIS PAGE HAS PURPOSELY BEEN LEFT BLANK 


\title{
CHAPTER 4: A PiONEERING PUSH - Lighthouse PRIMARY SCHOOL
}

\begin{abstract}
The success of each initiative came from applying the core education for sustainability skills: taking a holistic view of the current situation; challenging the assumptions that underpin day-today practices; and drawing on the strengths of collaboration and action learning.
\end{abstract}

(ARIES, 2009, p. 5)

This chapter presents a case study framed within whole-school, whole-system approaches to environmental education for sustainability. Lighthouse Primary School's sustainability program was supported by the Australian Sustainable Schools Initiative in Western Australia (AuSSI - WA). In 2001 Lighthouse Primary School began to implement waste minimisation initiatives, pioneered by one enthusiastic teacher. At the time of data collection in 2009 this school had: 1) multiple and diverse teacher supported and student led environmental systems and social wellbeing programs operating within the school, 2) broad staff support for the program, 3) sustainability goals written into school plans and reviewed annually by all staff, and 4) an open, inviting atmosphere for parents to contribute ideas and become involved in any initiative of their choice. This case study was characterised by the school's deeply embedded emphasis on sustainability education, the tensions these mounting priorities had created among some staff members and resolutions proffered by AuSSI - WA.

Lighthouse Primary School is a government public school located in an uppermiddle to high socioeconomic suburb of Perth, roughly 15 kilometres south of the city. On the Index of Community Socio-Educational Advantage (ACARA, 2012b), Lighthouse Primary School was rated 1129 in 2009. The national average ICSEA score is $1000-100$ points either side of this average is equal to one standard deviation.

Surveys and mind maps with students, interviews with teachers, the school principal, parents and students, observations of the school grounds, and document searches, were carried out at Lighthouse Primary School in 2009 and surveys were conducted with students once more in 2010. Seventy three percent of the 161 students surveyed in 2009 and the 157 students surveyed in 2010 lived within 2 kilometres of the school. 


\section{Research Question 1: What Organisational Factors Fostered or Impeded the}

Establishment of Whole-School Sustainability at Lighthouse Primary School?

This section explores the organisational outcomes and challenges that Lighthouse Primary School encountered since their sustainability focus began and whether being aligned with AuSSI - WA influenced their focus. Results are presented across six themes, first, the history of sustainability education at the case study school and obstacles to its establishment, followed by five organisational elements important to the establishment of sustainability education: 1) school governance, 2) school planning, 3) community networks and partnerships, 4) student voice and engagement, and 5) curriculum integration.

This section presents a discussion of the school's sustainability focus, as reported by school staff. The main protagonists presented here are: Mr Honeyeater, the principal; Mr Magpie, the deputy principal; Mrs Brolga, the lead sustainability coordinator and teacher of Year 4; Mrs Osprey, a Year 6 teacher, and Mrs Mallard, the music teacher. Where relevant to support patterns in the data, quotations also are presented from student interviews.

It is relevant to note that at the time of data collection in 2009, the Lighthouse Primary School $(\mathrm{K}-7)$ had been operating for 23 years, since 1986, and Mr Honeyeater had been principal at the school for 20 years. Mr Magpie had been teaching at the school for nine years, Mrs Brolga for 18 years, Mrs Osprey for three years and Mrs Mallard for two years.

\section{History of Sustainability Education at Lighthouse Primary School}

Tables 4.1, 4.2 and 4.3 provide summaries of the annual sustainability initiatives (initially all environmental) in operation at Lighthouse Primary School, from when the school commenced its focus in 2001 to the time of data collection in 2009. These tables will be referred to throughout this qualitative analysis of organisational outcomes and challenges encountered by Lighthouse Primary School.

The sustainability focus of the school began in 2001 (Table 4.1) when Mrs Brolga challenged her Year 7 class to set up a recycling system within the school as a project relevant to the Technology and Enterprise learning area of the Western Australian Curriculum Framework (SCSA, 1998). In less than one year, the class' efforts reaped large cost savings across many areas of the school's utilities budgets and significant positive environmental impacts. Mr Honeyeater stated, 
That was their maths. They'd go out and have a look and see what's in there and over time built a case up, and said we can save some money. And then by saving money they've also got less going into landfill. ... That money that was saved was reinvested in the next bit of our program as we moved through it. ...you buy the compost tumblers and you use that money. So it became, nobody could say that it was taking up too much of our budget, it wasn't. It was using it's own savings.

Mrs Brolga's class' efforts saw expansion of the existing aluminium can recycling program to include plastics and drink bottles, and establishment of a worm farm and compost bin. These waste wise initiatives required a new three-bin system to be adopted around the school grounds for compostable waste, recyclable waste and general rubbish. The class' efforts in monitoring paper waste across the school also saw one less collection per week of the two skip rubbish bins provided to the school, which saved money that could be diverted to other sustainability projects. Mr Honeyeater explained,

...plus you've got utilities management savings. Of which, the skip bin is that. We get money for that, so if we don't get the bin taken away as many times as they feel a school of this size should, that's good for us. And then that goes into [Mrs Brolga's] account. She'll buy worm farms, she can buy buckets, she can buy - whatever it is. That's her budget. And some of the other ones, utilities management savings and power, water savings, they also go there.

In 2002 Mrs Brolga became affiliated with the Department of Environment and Conservation's Waste Wise program and attended the inaugural Waste Wise in-service. She described the collaboration as an opportunity to feel part of something larger than their school,

I had already initiated with my Year $7 s$ a recycling program. They were already doing the paper, the cardboard, the compost and the worms and suddenly this initiative came about and I thought "oh that's good it would be nice to fit into something that we're doing".

The success of the recycling initiatives in 2001 was so inspiring to Mrs Brolga and the principal that Mrs Brolga built on those initiatives with her Year 7 class the following year and the principal provided support every step of the way. Mrs Brolga encouraged other teachers to create similar opportunities for their students and to take up responsibility for some of the systems already in place. Mrs Brolga described her motivation saying, "I realised that for teachers to take on ownership and to be part of it then they also had to have responsibility".

Mrs Brolga was passionate about making sustainability a priority across the whole school. She described the reason for her motivation to start the initiatives within 
the school as about creating opportunities for children to learn through involvement. She explained,

I had always been teaching environmental responsibility to kids over the years what you should do what you shouldn't do in your caring for the environment and that sort of thing - but it was actually through the action and through the involvement that we're going to be able to get kids to demonstrate environmental responsibility. ... If we don't give them the opportunity to do that then we're not doing what we're supposed to do.

Money continued to be saved through the efficiencies adopted around the school and the savings continued to be diverted to Mrs Brolga's sustainability fund. Over the years, this fund, together with grants applied for by Mrs Brolga, paid for the installation of many new sustainability resources. Some of these resources included a school recycling facility (SRF), two large tumbling compost bins, several small blue wheelie bins to collect schoolyard recyclables, solar panels on top of the library, a 28,000 litre water tank plumbed into the toilet blocks, and raised permaculture garden beds for use by each classroom.

Mrs Brolga was the school's waste wise coordinator from 2002 - 2006, and from 2006 onwards, when the school joined the Australian Sustainable Schools Initiative for Western Australia (AuSSI - WA), she became the school's sustainability coordinator. Joining AuSSI - WA in 2006 provided a new focus to the school's initiatives and increased the sense of collective ownership among staff members, as discussed in more detail in the following paragraphs. Mrs Brolga described the significance of joining AuSSI - WA saying,

It gives you a purpose for what you are doing. It makes you feel like you're part of a whole system, where it's an organised system that you know what you're doing is worthwhile and it's valued. ... It also gives more credibility to yourself because when you try to sell it within a school then you've got some big system or initiative behind you. ... Because it's also an Education Department initiative then obviously then it has more significance and more importance to teachers. 


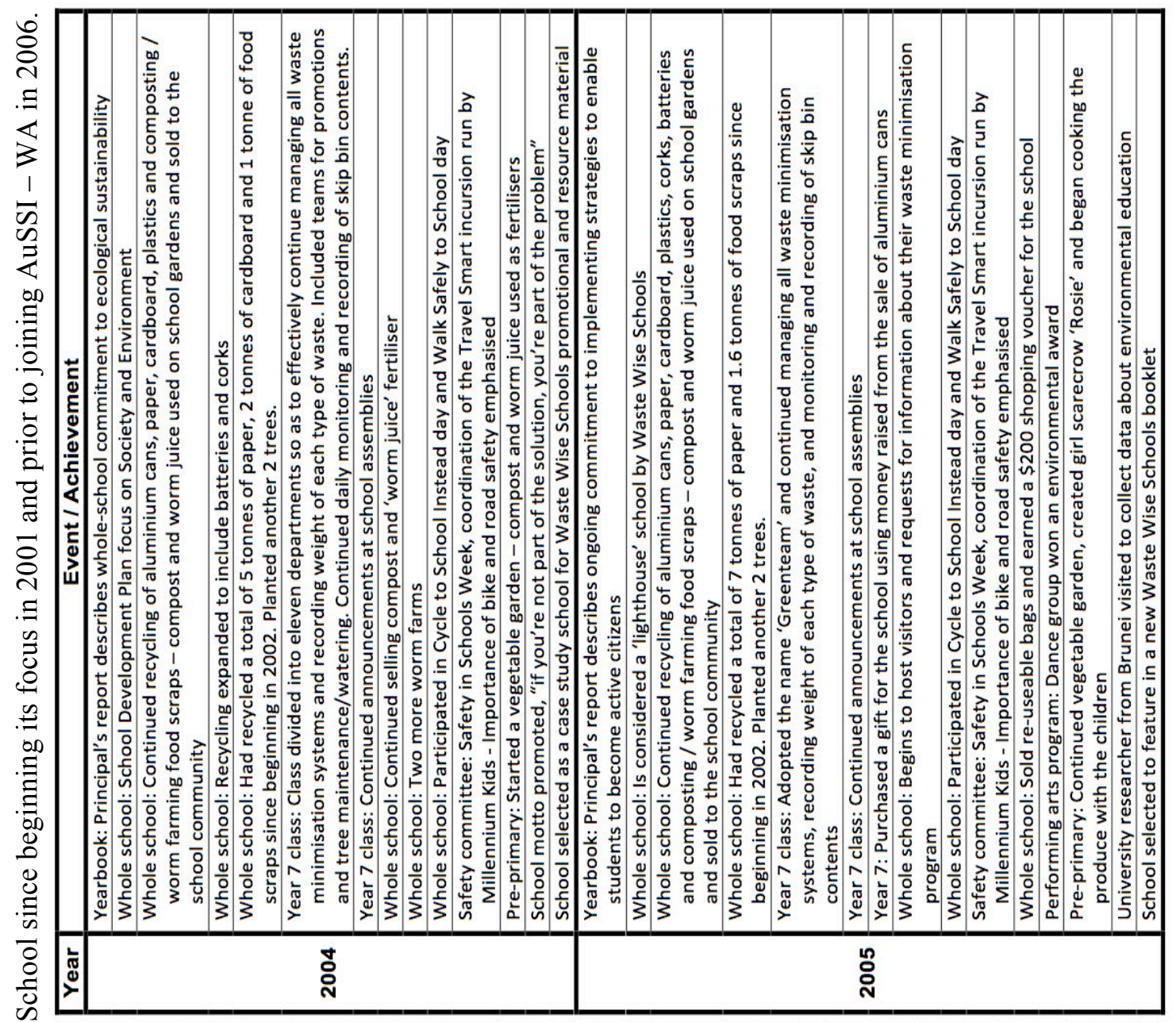

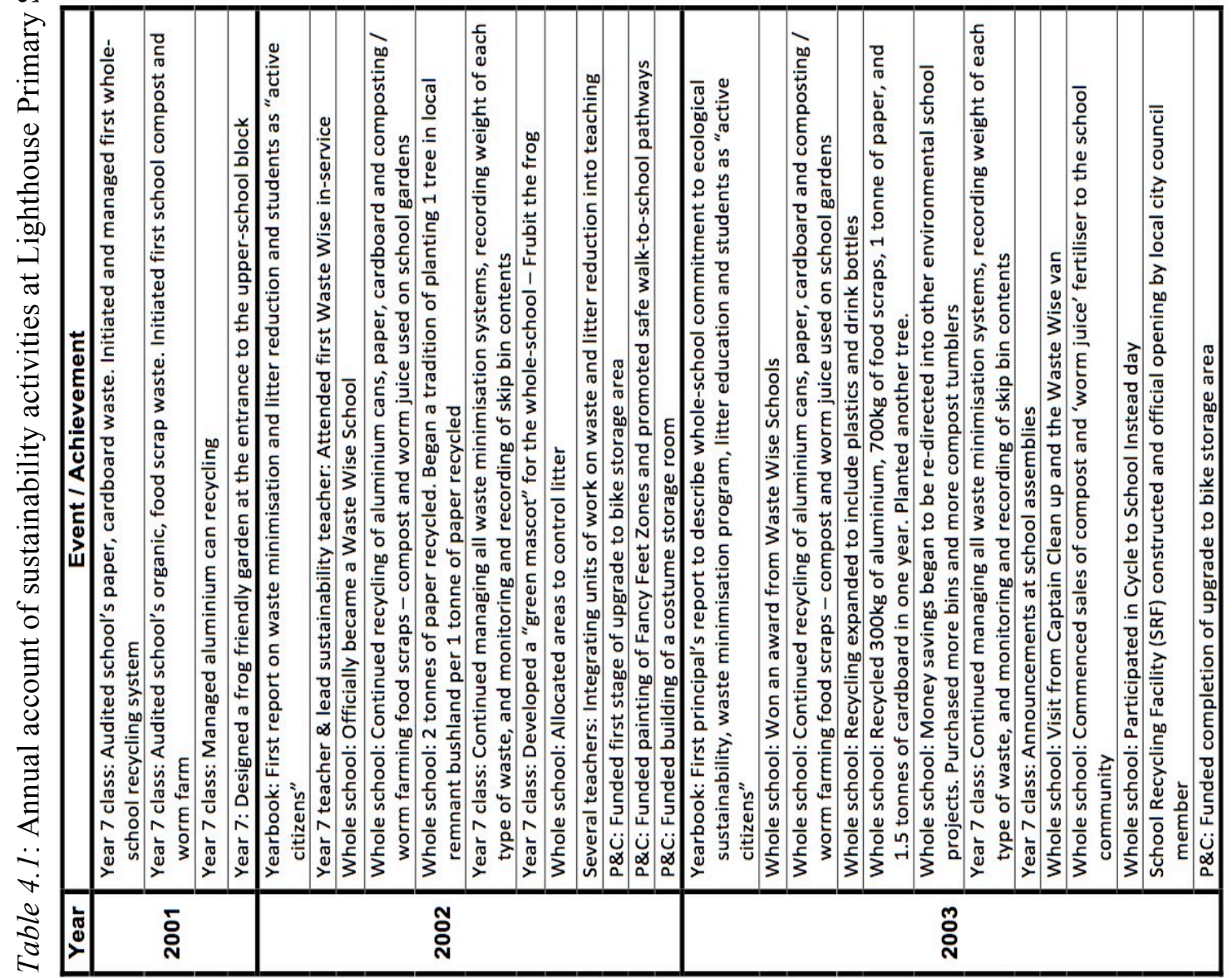




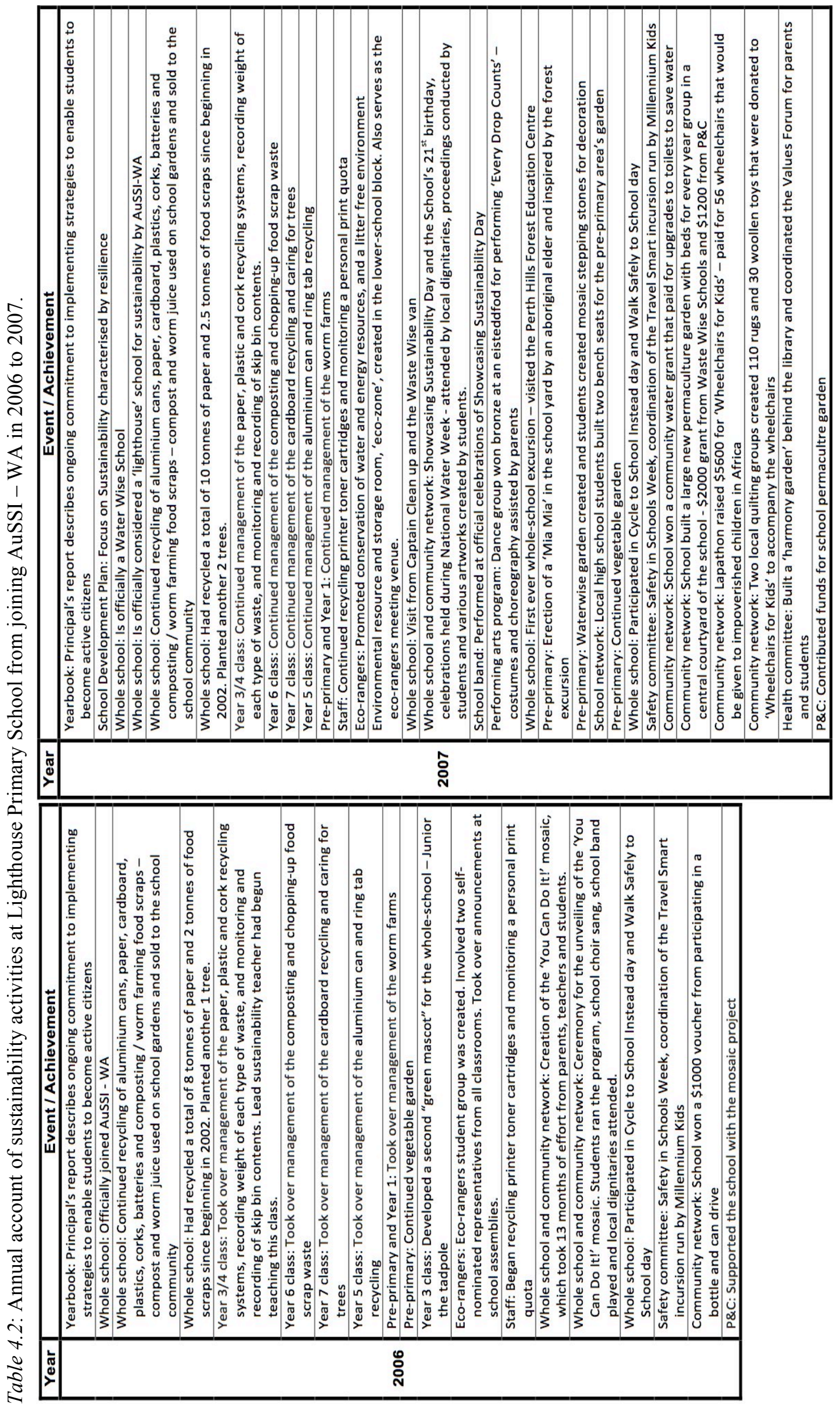




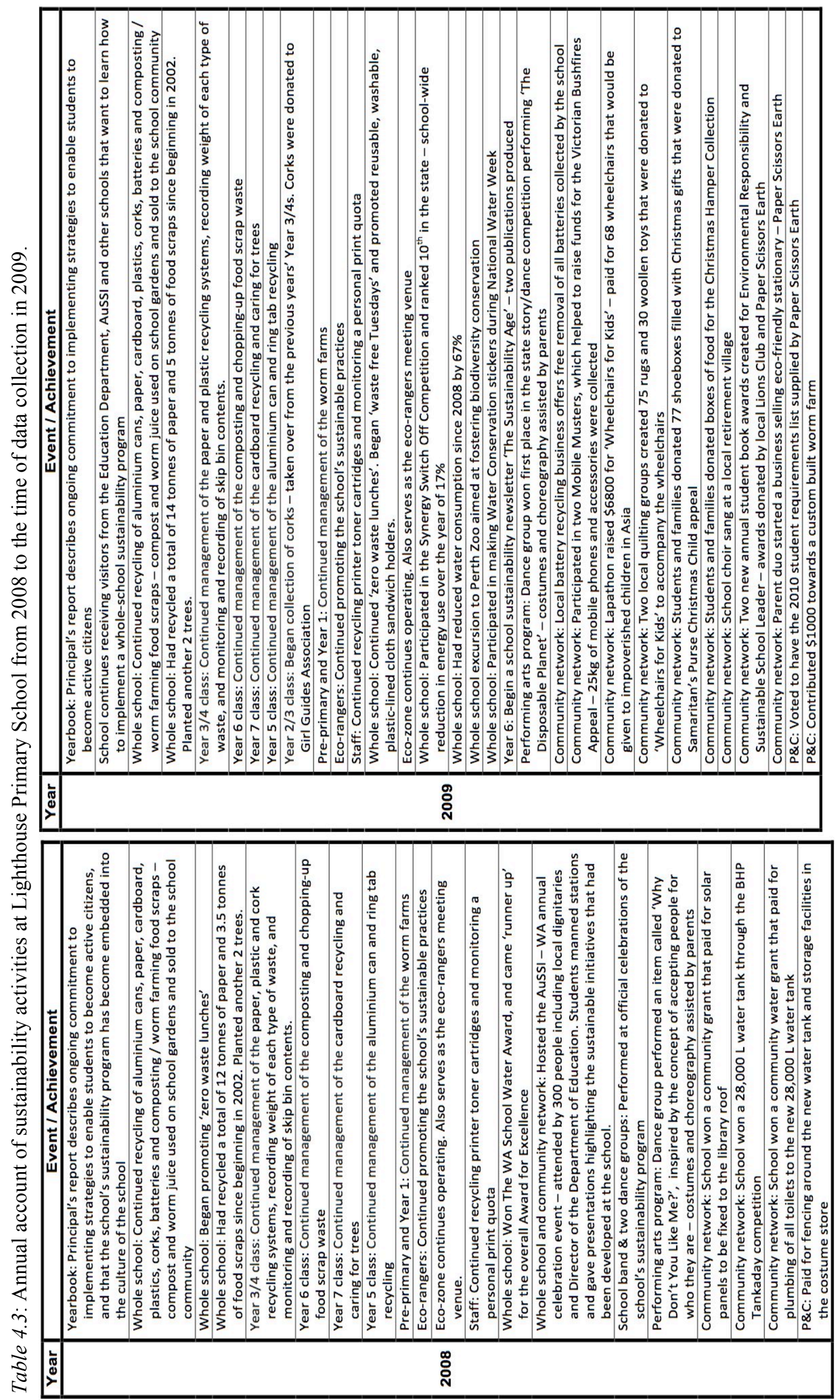




\section{School Governance}

The principal at Lighthouse Primary School was supportive of the sustainability initiatives and systems operating within the school. He described how his support began when Mrs Brolga started the first minimisation initiatives in 2001 and had grown throughout every development and expansion of the initiatives over the following eight years. The principal described his personal involvement in various projects, most notably the design and production of the twenty-metre long mosaic that wrapped around three walls of the school canteen that portrayed principles of environmental and social sustainability (Figure 4.1 - described in a later section). He expressed great pride in his school's achievements and noted a long list of important visitors they had received to see the school's sustainability priorities in action, stating,

One thing that keeps us going is the fact that people recognise what you're doing. So when people come it's like a pat on the back. I mean, we did that big sustainability thing last year ... that was one time when I said we are going to do it, there's a very good opportunity for us because we can do this, and I know at the end of it you'll have trouble walking through the doors because your head will be so big! That's the exact words I said to them. And that's exactly what happened. They were, you know, people were just amazed.

The principal, Mr Honeyeater, had a vision for the longevity of the school's sustainability focus, despite pressure from the Department of Education to meet and excel literacy and numeracy targets. Mr Honeyeater described the approach he encouraged among the staff,

What we 're trying to do with sustainability is, to say okay, the department doesn't want us to be so good at sustainability and have poor literacy and numeracy results. Alright, they want results here, they don't care about that. ... So what we've tried to do is say, "that's still important and will always remain very important, now, how can we do both?" Well, when you've got outcome statements, you need a vehicle for your lessons. So we say the vehicle will be sustainability. I mean, what kid doesn't like animals? What kid doesn't like the grounds? And all those sort of things.

Mr Honeyeater described his vision of how sustainability initiatives within schools can be self-supportive providing there is a whole-school commitment to make sure the systems function every day, saying, "what you want is they're just part and parcel of school business". He affirmed that, by the time of data collection in 2009 , the school's sustainability focus was "nothing out of the box anymore. It is something that this school does. You just do it”.

With such a visionary principal and enthusiastic lead sustainability coordinator it is not surprising that so many sustainability systems and achievements had been 
implemented at this school over nine years. Fostering a collaborative approach to governance, however, presented itself as an ongoing challenge. All stakeholders were invited to support the many new and ongoing initiatives, but at times there had been little opportunity to contribute to decisions. It seemed that when resistance was shown towards certain priorities or initiatives, it was paid little attention by the primary decision makers. Mrs Mallard expressed that sometimes, "you feel as if you're hitting your head against a brick wall because you're saying all of the same things time and time again" and, "There just needs to be some better communication. Better give and take, on both sides". The deputy principal, Mr Magpie stated,

[Mrs Brolga] is so focused and so passionate about it that sometimes she fails to realise that other people may not be. Even though they still have a passion it's not the passion that drives them, whereas it drives her. ... There's been times when it's been a little difficult in staff meetings or when there's projects that she wants to get off the ground. While people are happy to support them, they'll do their bit, but they draw the line at a point below where she draws her line.

It appeared that a small group of teachers within the upper primary school maintained mild resistance to the wave of change that had swept over the school since 2001. Some evidence of this was seen in their lack of interest in being interviewed for this study. None of the other Year 4 teachers or the Year 5 teachers consented to be interviewed and only one Year 6 teacher was willing. Mrs Mallard carefully gave her view about the apparent low desire of some teachers to collaborate in the whole-school sustainability initiatives, describing it as a difference of priorities,

I think that sometimes it can be overdone. You have to find this middle line, middle ground. [Where people can express themselves?] Yeah, be free to, without being thought worse for it or that they don't care. It's not a matter of don't caring it's a matter of having different priorities perhaps. So in this school it has caused a few minor, bubbling under the ground issues. ... There's equity value there, with regards to money. Where budgets go to. And that is a source of mild discontent.

Mr Magpie, the deputy principal, explained that although some teachers were put off by Mrs Brolga's passion and energy for sustainability and were themselves not as driven, they were all still proud of their school's achievements and all participated in some way and all cared for the environment. He stated,

I'm sure everybody that you interview and even those that haven't chosen to be interviewed would candidly say, "yes the environment is precious to us and we need to do something about it". But to what degree they're prepared to get out there and do it is variable. ... We all feel very grateful for being here. We've all got colleagues in less favourable areas and in schools where these sorts of initiatives may be happening but not to the same degree. ... You'll often hear 
said, "we really should take time to stop and think and look around us and see the sort of clientele that we've got and the kids that we're working with and the sorts of things that we can do here and should be doing and must maintain."

\section{School Planning}

Mr Honeyeater and Mrs Brolga both explained that sustainability priorities had become increasingly integrated into the school's operational plans. By 2009, specific targets were defined to improve the focus on sustainability within the key elements of curriculum integration, student voice and engagement, community networks and partnerships, and school networks (DoE, 2012b). Strategies were outlined to meet every target; resources were considered, the responsible person or people assigned to ensure its implementation and a means of evaluating the success of that strategy identified. Within the key element curriculum integration targets and strategies were defined for every topic from the ecological footprint - energy, air, water, biodiversity and waste (DoE, 2012d). Some strategies were applicable for certain staff or classes only but many were applicable to all staff or all classes. For example, a strategy to meet the topic of waste in the key element curriculum integration was to "continue promotion of zero waste lunches", which was facilitated through "parent and P\&C newsletters", overseen by "all staff" and the success of this strategy evaluated by seeing a "reduction in plastic waste and other package waste" (Lighthouse Primary School Sustainability Action Plan, 2009).

After joining AuSSI - WA in 2006, all staff members at school development meetings regularly evaluated the whole of school focus on sustainability using the AuSSI - WA Key Elements Rubric at these meetings. All staff were invited to contribute their feedback on the school's progress across four stages of growth: starting, establishing, achieving, and excelling. Mr Honeyeater explained, "We use that assessment thing. That grid. We've used that for quite a few years. ... The teachers are normally pretty hard on themselves", but "in the end it doesn't matter, because we're not in competition with anyone". Mr Honeyeater elaborated that the areas of staff consensus help to define what kind of sustainability priorities are written into the school operational plans for each year. But he differentiated these plans from the school's development plans that are reported to Department of Education, saying, "it doesn't go in the school development plan because we're only accountable to ourselves".

The success of the school's focus on sustainability priorities from the previous year also were reflected upon at these meetings, and informed plans for the current year. Mr Honeyeater explained, 
When we had that thing [the whole-staff evaluation] we went through what we said we'd do and what we did, and what we said we'd do and what we didn't do, and we have a look. Then we plan again. And some of the things that we had down for this year if we didn't do them then we would carry them over.

Following these whole of staff meetings, Mrs Brolga refined the school's sustainability priorities and wrote them into the school's action plan. She sought input from the principal, deputy principal and two or three other teaching staff who were also passionate about the school's sustainability priorities. All of these people were keen to set up structures that would strengthen sustainability systems in place and enforce the whole-school approach to sustainability education.

In the early stages of the school's programs, however, when the focus was primarily on waste minimisation, not all of the teaching staff were supportive of all these new policies and expectations. Mrs Brolga described the development of these processes and the varied support of other teachers as follows,

From 2002 I started to branch out and different people were given the opportunity, it was offered to them, you know, who would like to look after the cans or who would like to look after the cardboard. And then gradually, gradually each year different people started to come on board. And at the beginning of each year I would give out a responsibility sheet to the staff and go over with new staff all the things that were there. [I did this] in the hope that $A B C D E$ all have responsibilities but HI\&J don't have anything. Hopefully they might think 'okay maybe I will come on board'. [I was] trying to push it -that it's giving their kids the opportunity.

It was clear that, especially in the early years of the program, some teachers were uncomfortable with the expectations associated with the whole-school sustainability program and had different teaching priorities. From 2006 onwards, however, there appeared to be a shift in the overall staff support for the program. This shift can be attributed to the school's partnership with AuSSI - WA, which encouraged whole of staff input towards the development of the school's sustainability goals and provided a broader definition of sustainability as encompassing interlocking perspectives of social, environmental and economic justice. Mr Magpie described the change in the school's sustainability focus saying, "I think that's been very influential in guiding us towards some of the areas that we may not have thought about" and that in the early years of the program, "we may have focused more on environmental issues rather than the social or emotional". Mr Magpie described that this shift caused a greater willingness to collaborate from some of the previously less willing teachers because, "some of them have come on board through those other facets" which have "appealed to them and they've realised a need for those sorts of things to be [focused on]". Overall, 
the school staff were committed to the program and did their best to foster principles of sustainability into their teaching. Mrs Mallard explained,

It amazes me sometimes what they do, do here. And in particular, [all staff] take it on board to do the sustainability. To do all those, as that big picture of what sustainability is. It's not just say veggie gardens and water, and things like that it comes down to. You've got to look at the effect on the people and how they're going to be affected by it. What we can do. Community spirit is very good. Love it. And the things that the school earns money for and donates money to. I think that's wonderful.

Mr Magpie expressed his confidence in the longevity of their school's sustainability priorities if the principal or Mrs Brolga were to leave the school, "I don't think that would worry the program because it's written in concrete in our school development plan, our strategic plan" and "sustainability will always be a part of the strategic plan in the school". He continued by stating, "The children now operate it more or less independently of the teachers particularly in [Mrs Brolga's] class". However, Mr Magpie stressed the importance of having a dedicated, passionate staff member to drive the school's program, its plans and initiatives,

If it wasn't for [Mrs Brolga] we wouldn't be here today in such a strong 'in your face' sort of way. Because she has energy that I can't fathom. I can't imagine where she gets it. So to have [Mrs Brolga] at the helm is really the strongest point about the whole thing we do here. ... It's always going to need someone to oversee the program, when that time comes, because there's a lot of paperwork, the context to be maintained, the profile to be maintained.

\section{Community Networks and Partnerships}

The Parents and Citizens Committee (P\&C) at Lighthouse Primary School had been actively involved in supporting sustainability initiatives since 2002; early in the life of the school's program (Table 4.1). Parents had supported the sustainability initiatives at this school in many ways, including the design and construction of a large mosaic (Figure 4.1, Table 4.2) in the school undercover area, planting a native 'harmony garden' with students, care and maintenance of the vegetable gardens, and sewing costumes for school performances that become a resource hireable to other schools (Tables 4.1, 4.2 and 4.3). Mr Honeyeater described the input of parents in this way,

It doesn't matter what a school does. Teachers can do so much. Let's bake the cake, but after that if you're going to put icing on it you've got to have help from somewhere else and it normally comes in the form of parents.

In 2006, staff, parents and students created a sustainability themed mosaic that wrapped around three walls of the school's undercover area, took over one year to make 
and ended up being much larger than the original design (Figure 4.1, Table 4.2). The mosaic's theme was based upon the school's involvement with the You Can Do It program (ASG, 2012), which focuses on five keys to successfully fostering student wellbeing that can support students' social, emotional and academic outcomes. The principal described one of his proudest and most favourite memories in over 20 years of being principal at Lighthouse Primary School as unveiling the mosaic at a special school assembly with several local dignitaries present and the school band performing. Mr Honeyeater described the moment, saying,

When the time came, what we did was just let the curtain drop to the ground, and honestly there would have been tears in everyone's eyes. It was just silent. It was really silent. All these people were glued, you know, because it was bright and absolutely fantastic.

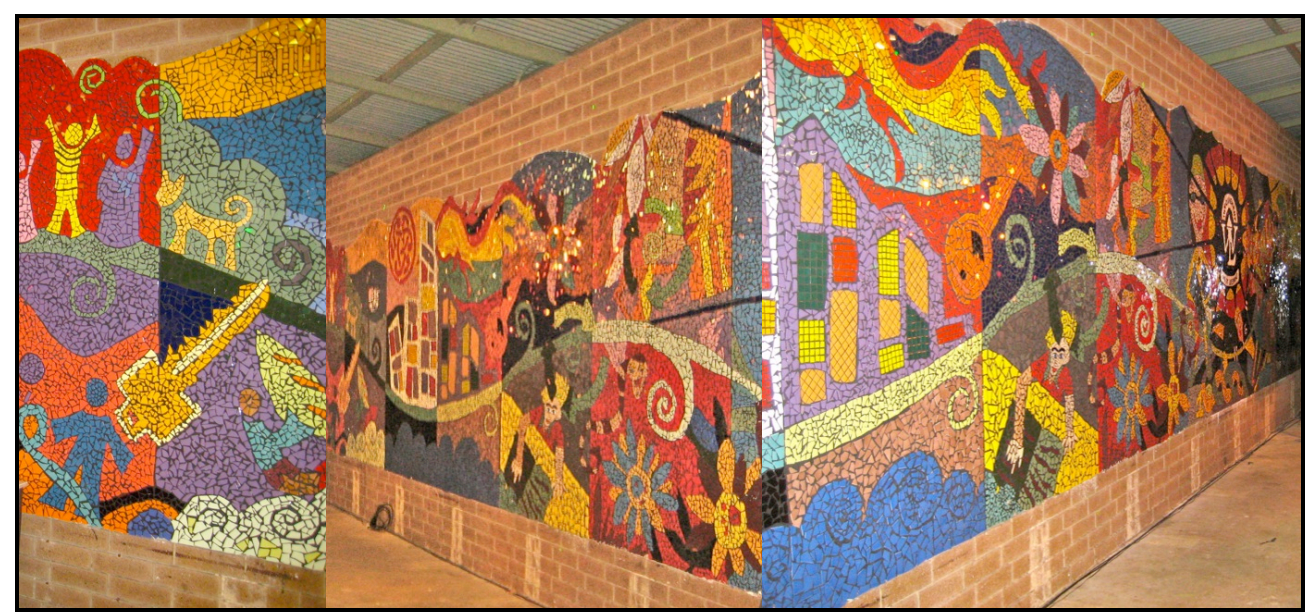

Figure 4.1. Large sustainability themed mosaic, contributed to by many dedicated staff, students, administrators and parents. Completed in 2006.

In 2009, two parents, inspired by the sustainability focus of the school, took it upon themselves to source environmentally, socially and economically sustainable stationary. These two mothers, each with children attending the school, saw discrepancies in the school's sustainability focus and its reliance on unsustainably manufactured stationary, such as bleached paper from pine plantations. They researched many alternatives and became so enthusiastic that they started their own retail stationary distribution company called 'Paper Scissors Earth'. In 2009, these mothers put forward a formal submission to the principal, the teaching staff and the P\&C to source all new stationary including bulk paper purchases, via their company, from ethical sources of their choice. Their submission was approved by the P\&C, such that the 2010 student stationary requirements list, advertised to all parents across the school, would only feature items from this company (Table 4.3). These mothers also marketed their business to other sustainable schools across Perth. 
Lighthouse Primary School had developed partnerships with the state government environmental education programs: Waste Wise, Waterwise and Travel Smart. Collaboration with these program providers gave the school access to extra resources and ideas, which, combined with the significant efforts of a few teachers and a supportive administration, enabled the school to create manageable systems and garner support from more teachers. The systems created included extensive waste, energy and water management processes and awareness raising activities as described in Tables 4.1, 4.2 and 4.3. Lighthouse Primary School had also developed partnerships with organisations such as: Wheel Chairs for Kids for whom they collected aluminium that could be turned into wheelchairs for kids in impoverished countries; two community quilt making groups who made quilts to go with each one of the wheelchairs; the local Lions Club who funded two student sustainability awards per year; the local city council who provided yellow-topped bins for free; and a local battery recycling company who collected batteries from the school for free.

Lighthouse Primary School's efforts had been well publicised through AuSSI WA and Waste Wise, such that many other primary schools sent representatives to visit and get ideas for their own whole-school sustainability education programs. Lighthouse Primary School had also attempted to develop networks with a local high school that many of their Year 7 graduates would transition into. Networks with high schools were limited, however, because of the mutual effort required for coordination and because the Year 6 and Year 7 teachers at Lighthouse Primary School were possibly not as keen to foster the connection as Mrs Brolga who had attempted to establish the networks. Mrs Brolga described the limitations to developing strong networks with the local high school, saying,

My idea was that the high school kids would come down and teach the older kids here how to use the equipment with the solar panels - the computer program, etc - and the science behind the whole thing, what it means, what's happening. But that didn't happen this year because I am not the person that would be doing that. It's really for the upper school teachers, maybe for the sixes and sevens to do that. ... I had suggested to the Year 7 teacher that they could do some powerpoint presentations on waste management, energy reduction and their class could communicate to some younger kids in the school so it could be kids teaching kids. But that didn't happen. ... You can suggest it a few times but you can't ram it down somebody's throat.

\section{Student Voice and Engagement}

Mr Honeyeater and Mrs Brolga explained that the primary motivation for implementing a sustainability focus in Lighthouse Primary School had always been to 
"give students the opportunity to show active citizenship and develop the values needed to respect the environment" (Lighthouse Primary School Yearbook, 2003, p. 37). Mrs Brolga described the method she encourages to develop active citizenship saying, "it's actually in the involvement, in the doing that you're going to get kids to be environmentally responsible", and "not just talking about it or writing an essay about it but actually doing something to make a difference". This perspective displayed prioritisation towards the for in education for sustainability and understanding of the importance of developing a willingness to act among students.

In 2006, with many new school-wide systems in place, Mrs Brolga began teaching a Year 3/4 class which allowed her more time to dedicate to her sustainability priorities. Mrs Brolga gave her new Year 3/4 class responsibility for maintaining the school's paper, plastic and cork recycling systems (Table 4.2). She had green sashes and large badges made for each of the children in her class and they became known as the 'Envirokids' (Figure 4.2). Every Thursday, before lunchtime, Envirokids would go in pairs to each classroom to collect a paper-recycling box, which they brought to Mrs Brolga's classroom to be weighed and recorded before tipping the paper into several larger yellow-topped recycling bins and returning the empty box to the appropriate classroom. Other Envirokids collected each of the schoolyard recycling bins, removed any contamination before also emptying those bins into the larger yellow-topped recycling bins (Figure 4.2). 


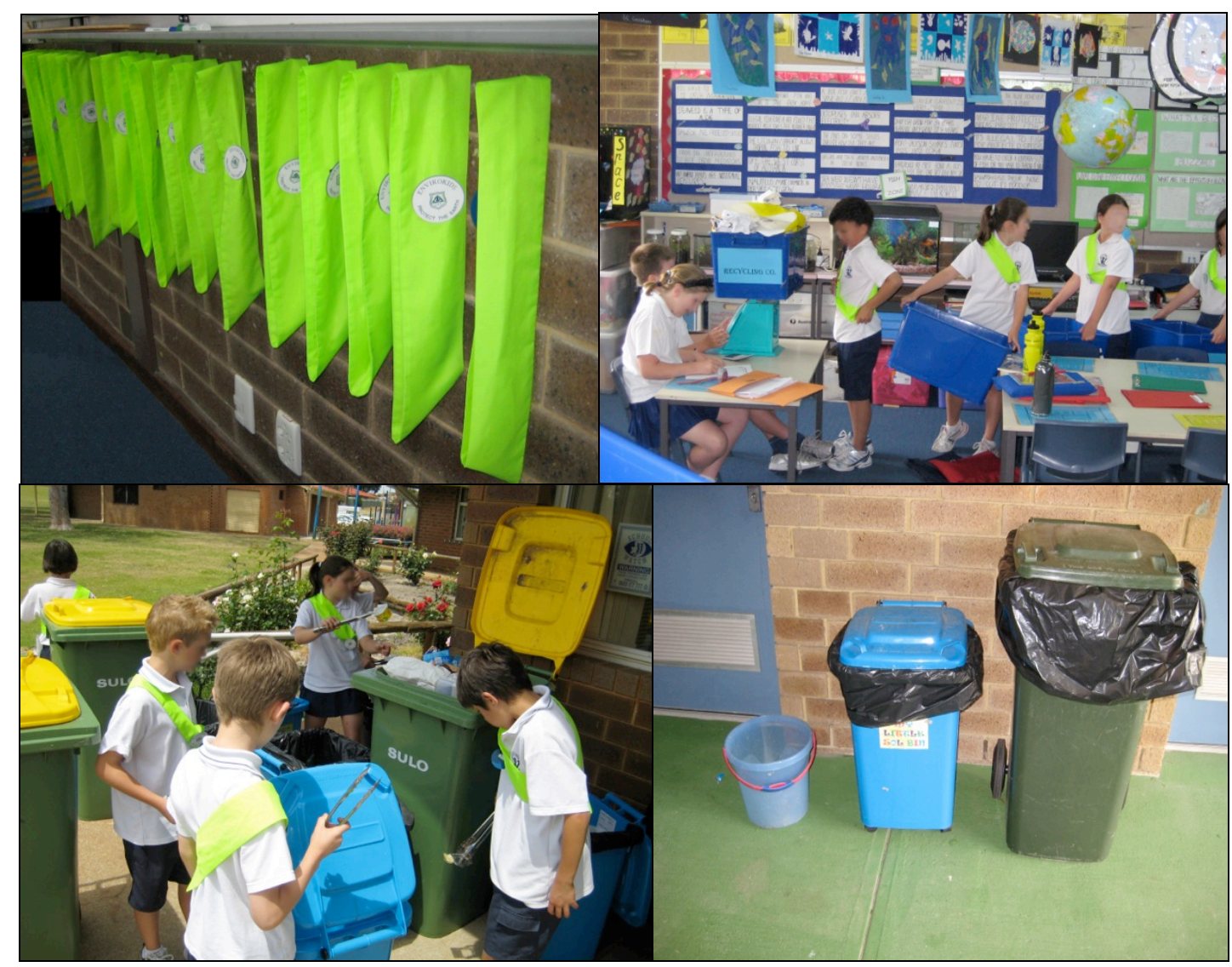

Figure 4.2. Top left: Green Envirokids sashes on display in Mrs Brolga's classroom.

Top right: Envirokids lining up for the weekly weighing of paper recycling boxes collected from every classroom and office in the school.

Bottom left: Envirokids removing contamination from schoolyard recycling bins before tipping the contents into the yellow-topped recycling bins.

Bottom right: The three bin waste sorting system at Lighthouse Primary School compost bucket, blue recycling bin, green general waste bin.

Students in Mrs Brolga's class were always more involved than students in other classes or year groups (Tables 4.1, 4.2 and 4.3), but as more teachers became involved in the sustainability efforts, most notably after 2006, there was an increase and diversification of opportunities for students to get involved (Tables 4.2 and 4.3). These opportunities ranged from being on the Year 6 composting team, being an Eco-Ranger or simply putting food scraps into the correct bin, to performing items in dance Eisteddfods that illustrated themes of sustainability or participating in school-wide charity drives such as the Christmas Shoe Box Appeal.

Examples of this diversification were the initiatives of Mrs Osprey and her Year 6 class. The children in this class started a school newspaper called the 'Sustainability Age', which was designed to be read by all students and parents (Table 4.3). Articles in the newspaper included stories, interviews or news pieces about the school's various sustainability initiatives: the waste minimisation and water conservation efforts, dance 
and musical performances, and sporting achievements. Sustainability themed crosswords and colouring in pages were included towards the end of the newspaper. Some students in her class also took on the role of chopping up the daily fruit and vegetable waste then feeding it to the compost tumbler or worm farm (Figure 4.3, Table 4.2). Mrs Opsrey described the influence of these students' involvement on the rest of her class, saying,

They're always exposed to it, and they know that the kids are at compost every day. Coz I'll say "alright, when the composters get back". So they know. They're not actually doing it but they know what's happening. ... [The compost bins] are all around the school so they see them every day. If they've got fruit or whatever they have to obviously put it in the bin.

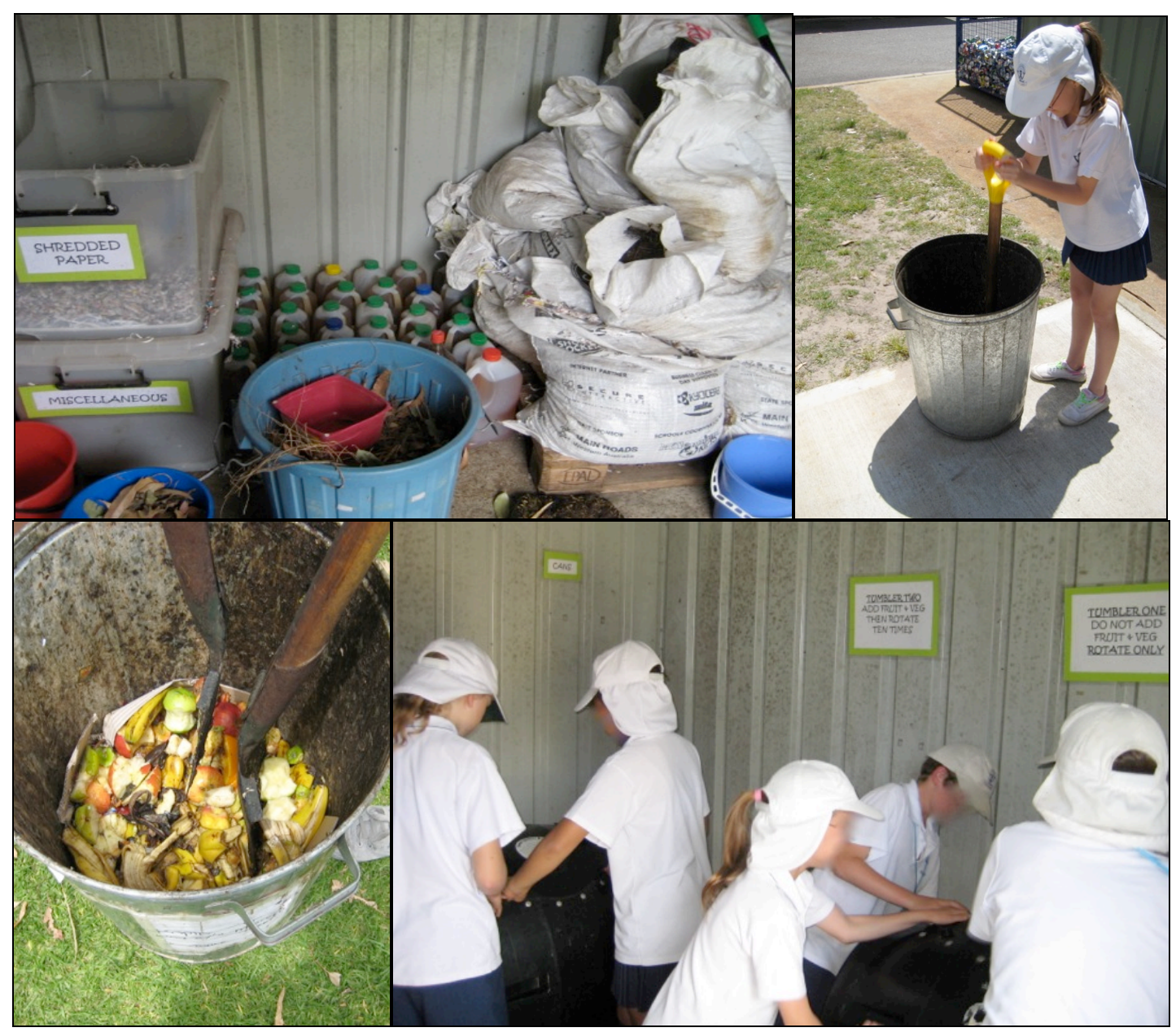

Figure 4.3. Top left: Carbon material (paper, dried leaves, etcetera) for adding into compost. Bottles of worm juice fertiliser and bags of compost stored for later sale.

Top right: Girl from Year 6 composting team chopping-up the daily fruit and vegetable scraps.

Bottom left: Closer look at how the fruit and vegetable scraps are chopped.

Bottom right: Year 6 composting team turning the compost tumblers. 
There was evidence that the behaviours of students across the whole school were being influenced by the focus on sustainability. Mrs Mallard commented,

What I have noticed is that the school is clean. The kids do not leave their rubbish around. They're very conscious about doing that. ... They're always keen and enthusiastic to volunteer, to do anything - as a lot of children are, I know - but I never hear anybody saying, "Oh. I've got to go and collect the rubbish! Or the boxes or the paper". It's not like that at all. I think it's a really positive environment for them.

A school-wide students' environmental committee called 'Eco-rangers', established in 2007 (Table 4.2), invited two representatives from each classroom in Years 1 - 7. Mrs Brolga established the Eco-rangers with the intention of "empowering the kids to be able to take on the initiatives that we've got at the school" and with the hope that students would "take it back to their class to get in so that those classes who didn't have that involvement still felt involved and felt important".

The Eco-rangers would meet during lunchbreaks, three occasions per term. To be a class representative it required self-nomination from the students and for their class teacher to decide which two of the nominees would be an Eco-ranger for that term. Interviewed students who had been an Eco-ranger described their interest in this role as coming from simple curiosity or personal concern for environmental topics. Regarding the sacrifice of his lunchtime, one enthusiastic student remarked, "It takes up your lunchtime, but when you think about it, your lunchtime isn't as important as saving the planet. No planet no lunchtime anyway".

One of the responsibilities of the Eco-rangers, together with the Envirokids, was to make sustainability related announcements at school assemblies. They finished every announcement with the school motto, "if you're not part of the solution, you're part of the problem", which began being used in 2004 by students from Mrs Brolga's Year 7 class (Table 4.1).

Researcher observations from two Eco-ranger meetings revealed that students did not display particular connection to the group or ownership of the sustainability initiatives. They appeared to see their role as an opportunity to report what they had seen other students or teachers doing wrong, as though they were the environment police. For example, some Eco-rangers reported that a classroom had left their heater on past the 10am winter curfew, or that students were playing in the toilet block and wasting water on a hot day.

These reports from the students were useful for Mrs Brolga and other administrators to review policies or discipline students who were wasting water, but 
seemed far from the goal of student empowerment and cultivating a willingness to act. These observations were reinforced by comments Mrs Brolga made in her interview regarding waning interest from students in the upper-school,

I felt last year that we had kids in the upper school where there were people who didn't want to be Eco-rangers. There can be a number of reasons for that, number one, the teacher's not motivated - 'do you want to be an Eco-ranger, okay get your maths book out' sort of thing. Whether it's the badge? And I've often wondered like the size of the badge -it's a big round badge rather than a councillors or captain's badge, whether that's something that the older kids don't want to wear.

Teacher motivation or badge size may well have been a factor in waning student interest from the upper-school, but it is also possible that older students would resonate better with being allowed greater opportunities to contribute to the direction and shape of the school's sustainability initiatives.

\section{Curriculum Integration}

Whole-systems thinking and integrated learning in education for sustainability requires seeing sustainability not as an extra activity but as a "vehicle through which you can teach", as Mrs Brolga attested. Mrs Brolga explained that such efforts provide context and make learning more interesting to students because students are "very motivated when you're talking about animals and the Earth and they relate to it". In this way, teachers at Lighthouse Primary School were making efforts to build concepts across learning areas such as, mathematics, English, science and technology, art, and history. Mrs Mallard gave an example of how the environment can even be explored through music,

This year we've done the water cycle, so I'd go through the water cycle with them, "so what sort of sounds are you going to make up in the sky, what sort of sounds are coming down?" We would record that. That was their water cycle music. Some of the songs are definitely connected to the environment. And some of the lyrics when we listen to the lyrics you say, "Well, what is this meaning?". And I think they realise that perhaps through song you can get a message across. ... I do try to bring it in. Sometimes it is hard, if you're having a look at composers or classical music in different periods.

Mrs Osprey asserted that there should be a balance in the approach to integrating sustainability concepts, saying,

With any topic you can incorporate it, but sometimes it is nice to step back a little bit. When you start it again they're sort of fresher.

Mrs Brolga discussed the need for compulsory professional learning and preservice university education to help teachers develop whole-systems thinking and to 
learn how to integrate sustainability concepts "into the whole curriculum, not see it as just an add-on extra, and not just as a subject that you're going to teach". Her suggestion to AuSSI - WA was that there "should be compulsory professional learning that [all teachers] need to do that needs to be updated, it's not just a one off thing", and "it should be something in each term of the year, four times a year, that they focus on so that it is a major thing".

As a new teacher to the school and new to teaching, Mrs Osprey described how joining the school had influenced her ability and interest in integrating sustainability principles into her classroom teaching. She also said that before working at this school she "probably" would have liked to have more pre-service education about sustainability, but since "coming into this school" she would "most definitely" have appreciated prior knowledge. Mrs Osprey was proud of what she had learned from being at Lighthouse Primary School, however, and stated that, "even going into other schools now I've been here, I have a lot to offer them in my knowledge and how to implement certain things".

The school's focus had not only influenced Mrs Osprey's teaching, it had impacted her personal motivation towards behaviours such as recycling and sorting waste at home. In particular, Mrs Osprey noted the impact of the school motto on her attitudes, saying, “'If you're not part of the solution, you're part of the problem', that always sticks in my head. And they say it every assembly".

The principal, Mr Honeyeater, displayed a deep understanding of whole-systems thinking. He described how the performing arts could be linked with principles of social and environmental sustainability and that daily readings of the solar power meter can be used to support mathematics outcomes. He also explained that he sees environmental sustainability inextricably linked with values and social sustainability, that "caring for others is the same principle as caring for place". Mr Honeyeater continued by stating that he encourages "out-of-self thinking" by making sure the school does something for charity every year, such as fundraising for Wheel Chairs for Kids or Christmas gift boxes for the needy donated through the local Lions Club charitable organisation (Tables 4.2 and 4.3). He explained that instead of giving funds to large charities, like many schools (e.g. Telathon), their school's fundraising goes to a local charity so that the "kids' and communities' efforts are visible".

Mr Honeyeater was enthusiastic about the need, the benefits and the ease of integrating sustainability principles across all curriculum learning areas. He gave examples of children whose academic performance across all subject areas, school 
attendance and attitude to learning had increased as a result of being more hands-on at school, stating,

One of the things you want to do for kids is make them wake up in the morning and want to go to school. It is something where hopefully they get a job, a responsibility in sustainability to do with their class - to tend the garden, to water the garden, so that they wake up and say, "I need to go to school because I'm important. I've got stuff to do and they rely on me doing it". That's what you want. Then you start teaching them and say, 'okay we will do all that but we've got to do reading and writing first'.

\section{Summary}

The sustainability efforts at this school were deep and widely spread across the school. A large proportion of teachers, students, parents and administrators supported the program and were actively involved in maintaining the various systems established into weekly school routines. A number of teachers and parents also showed interest in contributing ideas or spearheading small projects that complemented the overall school sustainability focus. It was apparent that the program would not have been as deeply embedded without the monumental drive and motivation of Mrs Brolga or the support and vision of Mr Honeyeater.

It was also apparent that becoming an AuSSI - WA school helped many teachers who had previously been reticent to participate or disinterested by environmental themes, to find ways of engaging with the program. The broad definition of education for sustainability encouraged by AuSSI - WA seemed to help these teachers to cross a philosophical bridge and see that their passions in music, sports, dance or values education can not only complement a whole-school sustainability education focus, but can add enormous value and life to the program.

There was evidence to suggest that the school could do more towards engaging student voice and cultivating a willingness to act. This research will provide feedback to Lighthouse Primary School and Mrs Brolga, that they could do more to create authentic opportunities for the students to raise and discuss their concerns about sustainability issues in and around the school, and to garner the students' ideas about how they could tackle issues as a group. More could also be done to develop group identity with team building exercises. 


\section{Research Question 2: What was the Environmental and Sustainability Knowledge of Upper-Primary Students at Lighthouse Primary School?}

Mind maps were used to estimate students' knowledge of pro-environmental behaviours, their understanding of sustainability and the extent of their whole-systems thinking. The depth, volume and breadth of students' responses to two central constructs: sustainability and things I can do to help the environment, were used as indicators to estimate knowledge. Mind maps were conducted with students from Years 4, 5 and $6(\mathrm{n}=161)$. The results are presented and discussed in this section, and are discussed again in the conclusion of this chapter to triangulate with behaviour data.

\section{Results}

Mind maps were coded into a quantitative format using the coding scheme described in Chapter 3. Non-parametric tests were performed on the data to determine if statistical differences existed between year groups (Years 4, 5 and 6), or constructs (sustainability and things I can do to help the environment), for depth, volume and breadth of student knowledge. The total number of hierarchies that a student drew from each construct represented depth of knowledge. The total number of ideas that a student gave for each construct represented volume of ideas. The total number, or scope, of themes across which a student generated ideas for each construct represented breadth of student knowledge. To illustrate patterns and significant differences, the median number of hierarchies, ideas and scope of themes were graphed for each of the year groups and central constructs.

Further, non-parametric analyses were performed to determine if there were significant differences in the proportion of students that responded for each of the nine emergent themes. To achieve this, students' responses were simplified to a binary format (presence $=1$, absence $=0$ ). These data provided a measure of percent response per year group and per construct. Results are presented graphically and discussed.

Depth. Kruskal-Wallis tests found no statistical difference in depth of student knowledge (number of hierarchies) across year groups or between the two constructs sustainability and things I can do to help the environment. Figure 4.4 illustrates the findings. 


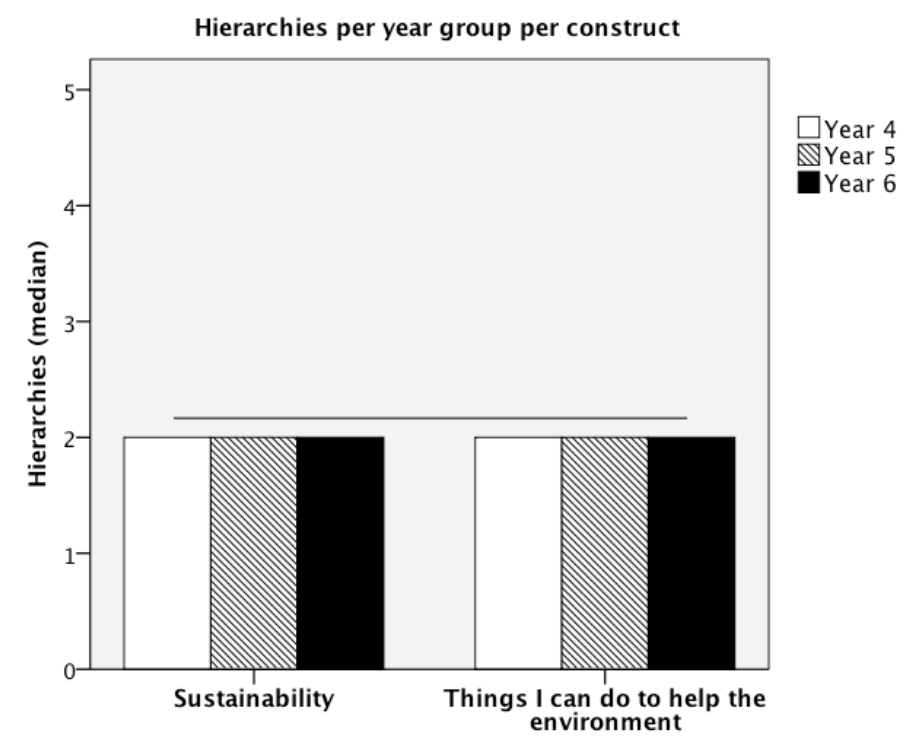

Figure 4.4. Depth of knowledge for each construct, $n_{S}=161, n_{H E}=161$.

Volume. Analyses of volume of knowledge (total number of ideas) did not include responses from the theme simple. Table 4.4 presents the statistical results from Kruskal-Wallis tests. No significant difference was found in volume of knowledge year groups, but a statistical difference was found in volume of knowledge between the two constructs sustainability and things I can do to help the environment. The construct things I can do to help the environment displayed greater number of ideas than did sustainability. Figure 4.5 illustrates the findings.

Table 4.4. Statistical results from Kruskal-Wallis tests of Ideas compared across year groups and constructs.

\begin{tabular}{lcccc}
\hline & $d f$ & $n$ & $\chi^{2}$ & $p$ \\
\hline Ideas: year groups & 2 & 322 & 3.11 & .211 \\
Ideas: constructs & 1 & 322 & 29.40 & $* *$ \\
\hline
\end{tabular}

$* p<.05, * * p<.01$ 


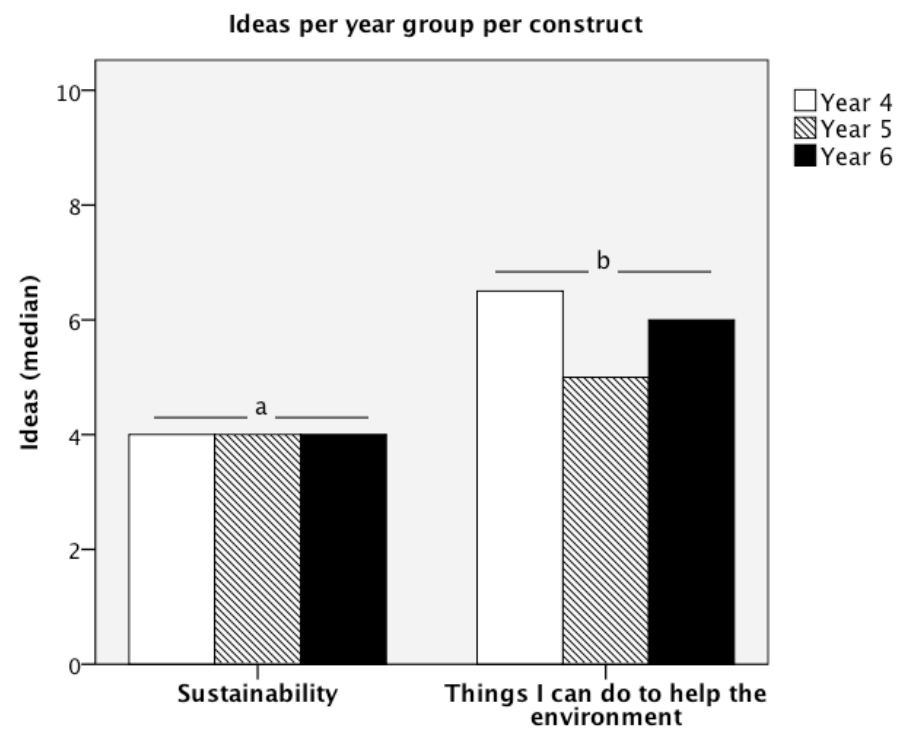

Figure 4.5. Volume of knowledge for each construct, $n_{S}=161, n_{H E}=161$.

Breadth. Analyses of breadth of knowledge (scope of themes) did not include responses from the theme simple. Table 4.5 presents the statistical results from KruskalWallis tests. A Kruskal-Wallis test found no significant difference in breadth of knowledge across year groups. Another Kruskal-Wallis test revealed statistical difference in breadth of knowledge between the two constructs sustainability and things I can do to help the environment. The construct things I can do to help the environment displayed greater scope of themes than did sustainability. Figure 4.6 illustrates the findings.

Table 4.5. Statistical results from Kruskal-Wallis tests of Scope of Themes compared across year groups and constructs.

\begin{tabular}{lcccc}
\hline & $d f$ & $n$ & $\chi^{2}$ & $p$ \\
\hline Themes: year groups & 2 & 322 & .39 & .824 \\
Themes: constructs & 1 & 322 & 24.77 & $* *$ \\
\hline
\end{tabular}

$* p<.05, * * p<.01$ 


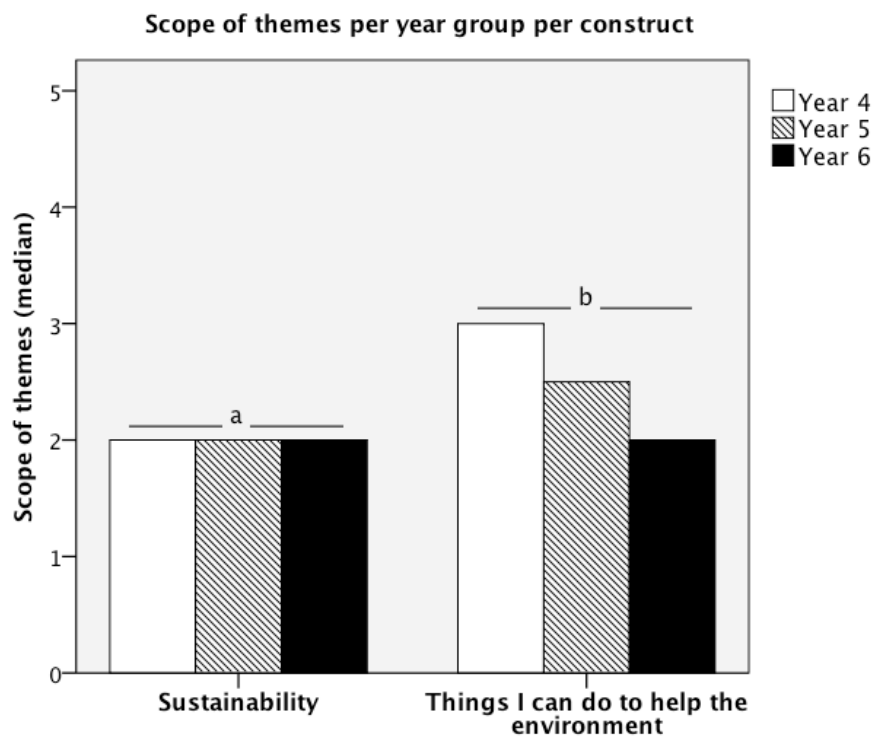

Figure 4.6. Breadth of knowledge for each construct, $n_{S}=161, n_{H E}=161$.

Percent response. Percent response per theme was investigated to determine if there were differences in the proportion of students in each year group that responded to each theme per construct. All students' responses were minimised to a binary format (presence $=1$, absence $=0$ ) to look for patterns of percent response per theme.

Kruskal-Wallis tests were performed, comparing the proportion of students' responses across themes per construct, and found significant differences between constructs for nearly all of the themes, with things I can do to help the environment scoring higher than sustainability on all environmental themes, and sustainability scoring higher on the themes values, advocacy and philanthropy and simple. Table 4.6 summarises the statistics for these significant differences and Figure 4.7 illustrates the patterns of each theme per construct.

Table 4.6. Significant results from Kruskal-Wallis tests of percent response compared across constructs.

\begin{tabular}{lcccc}
\hline & $d f$ & $n$ & $\chi^{2}$ & $p$ \\
\hline Waste & 1 & 322 & 6.38 & $*$ \\
Water & 1 & 322 & 14.52 & $* *$ \\
Biodiversity & 1 & 322 & 19.51 & $* *$ \\
Energy & 1 & 322 & 9.53 & $* *$ \\
Air \& Transport & 1 & 322 & 8.40 & $* *$ \\
Values & 1 & 322 & 9.41 & $* *$ \\
Simple & 1 & 322 & 18.47 & $* *$ \\
\hline$* p<.05, * * p<.01$ & & & &
\end{tabular}




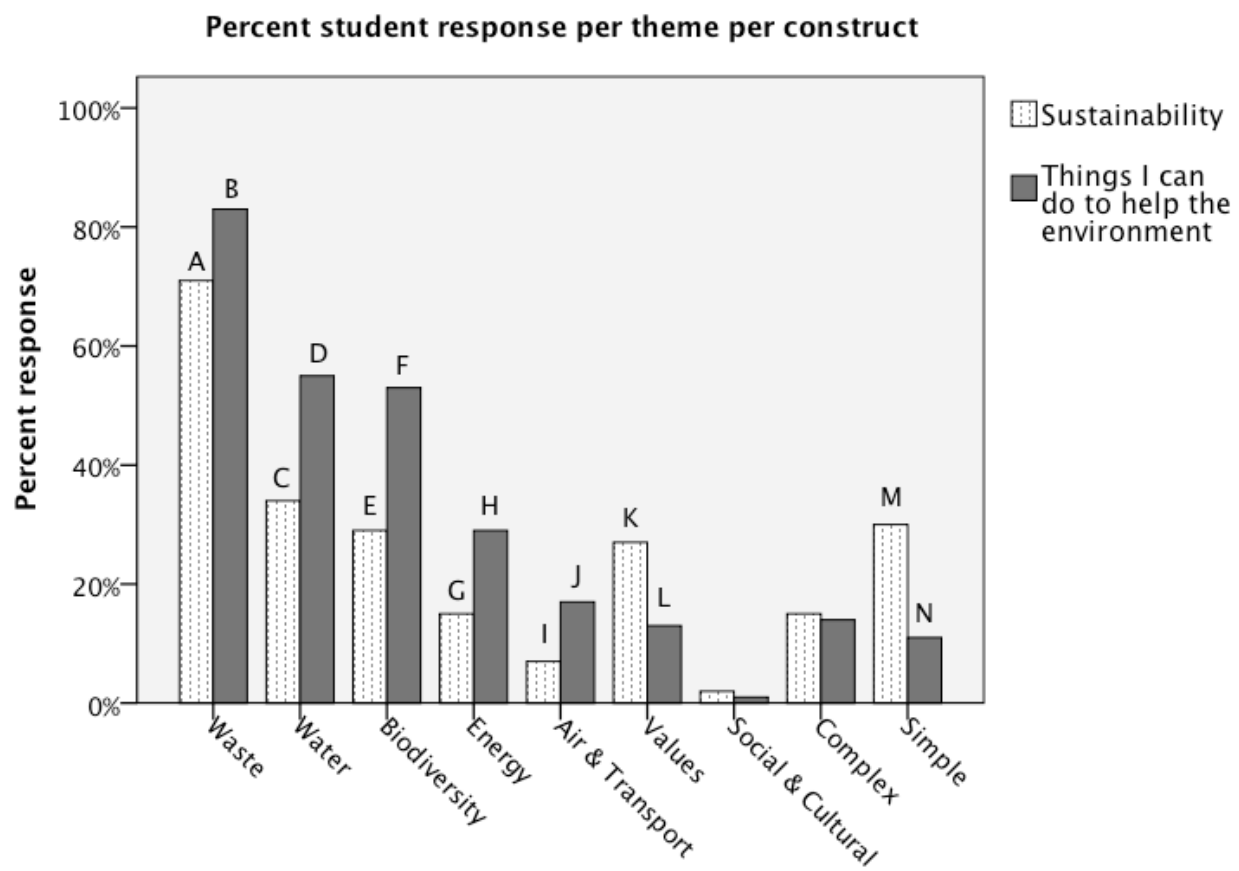

Figure 4.7. Percent response per theme per construct, $n_{S}=161, n_{H E}=161$.

Further Kruskal-Wallis tests were performed, separately for each construct, on the proportion of students' responses for each theme per year group, and significant differences were found, as presented in Table 4.7. Post hoc Mann-Whitney U tests were performed to determine which year groups were most different, as presented in Table 4.8. Figure 4.8 illustrates the patterns for each construct, year group and theme.

Table 4.7. Significant results from Kruskal-Wallis tests of percent response compared across year groups per construct.

\begin{tabular}{lcccc}
\hline & $d f$ & $n$ & $\chi^{2}$ & $p$ \\
\hline Biodiversity environment & 2 & 161 & 9.18 & $* *$ \\
Energy environment $_{\text {Complex }}$ sustainability & 2 & 161 & 7.80 & $*$ \\
Simple $_{\text {sustainability }}$ & 2 & 161 & 6.73 & $*$ \\
\hline
\end{tabular}


Table 4.8. Results from post hoc Mann-Whitney U tests of percent response compared across year groups.

\begin{tabular}{|c|c|c|c|c|c|}
\hline & & $U$ & $z$ & $p$ & $r$ \\
\hline \multirow{3}{*}{ Biodiversity environment } & Post hoc: $Y r 4$ and Yr 5 & 1345 & -.44 & .658 & -.04 \\
\hline & Post hoc: $\operatorname{Yr} 4$ and $\operatorname{Yr} 6$ & 1145 & -2.38 & $*$ & -.23 \\
\hline & Post hoc: $\operatorname{Yr} 5$ and $\operatorname{Yr} 6$ & 1042 & -2.79 & $* *$ & -.27 \\
\hline \multirow{3}{*}{ Energy environment } & Post hoc: Yr 4 and Yr 5 & 1257 & -1.28 & .200 & -.12 \\
\hline & Post hoc: $\operatorname{Yr} 4$ and $\operatorname{Yr} 6$ & 1276 & -1.53 & .126 & -.15 \\
\hline & Post hoc: $\operatorname{Yr} 5$ and $\operatorname{Yr} 6$ & 1079 & -2.76 & $* *$ & -.27 \\
\hline \multirow{3}{*}{ Complex sustainability } & Post hoc: Yr 4 and Yr 5 & 1157 & -2.46 & $*$ & -.24 \\
\hline & Post hoc: $\operatorname{Yr} 4$ and $\operatorname{Yr} 6$ & 1406 & -.92 & .359 & -.09 \\
\hline & Post hoc: $\operatorname{Yr} 5$ and $\operatorname{Yr} 6$ & 1254 & -1.62 & .105 & -.16 \\
\hline \multirow{3}{*}{ Simple $_{\text {sustainability }}$} & Post hoc: Yr 4 and Yr 5 & 1121 & -2.18 & .029 & -.21 \\
\hline & Post hoc: Yr 4 and Yr 6 & 1452 & -.28 & .780 & -.03 \\
\hline & Post hoc: Yr 5 and Yr 6 & 1109 & -2.46 & $*$ & -.24 \\
\hline
\end{tabular}

$* p<.017, * * p<.01$ (Bonferroni adjusted alpha level of .17)

$r$ is Cohen's $r-$ a measure of effect size. Cohen's $r$ effect size range: $.1=$ small, $.3=$ medium, $.5=$ large.

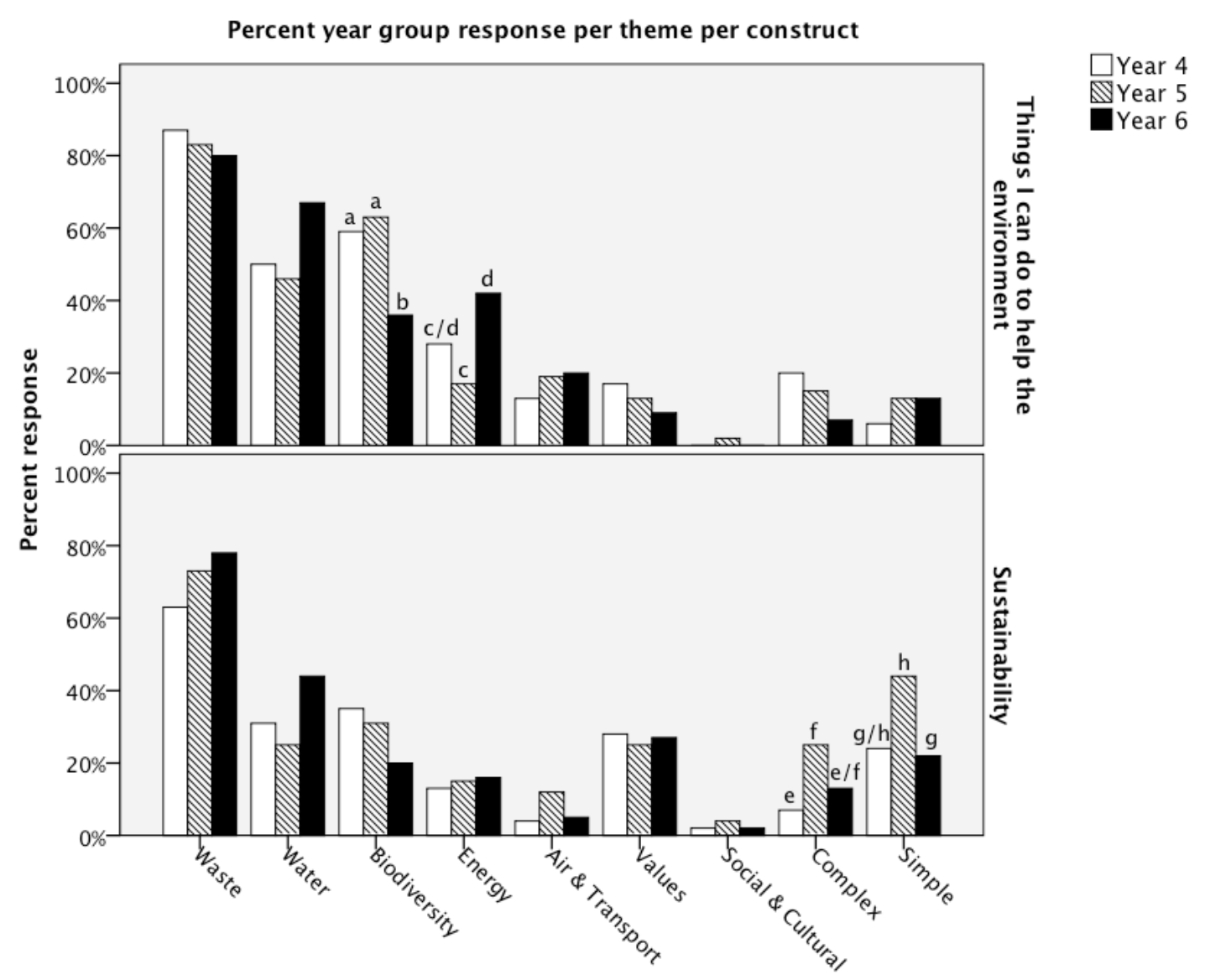

Figure 4.8. Percent of year group response per theme per construct, $n_{4}=54, n_{5}=52, n_{6}=55$. 


\section{Discussion}

Year group differences. There were no differences across year groups for each of depth, volume and breadth of knowledge (Figures 4.4, 4.5 and 4.6). This may reflect that the whole-school approach to sustainability education had equally reached children in all year groups. A look at the proportion of year group responses across themes (Figure 4.8) illustrated year group differences in biodiversity conservation and energy reduction for the construct things I can do to help the environment and year group differences in complex and simple for the construct sustainability, which may reflect differences in the focus of the year groups.

The patterns found for things I can do to help the environment suggest that students in Year 4 and 5 may have done a recent unit of work on plants and animals, compared to Year 6 students, and that this difference only emerged for the construct that specifically prompted their responses to environmental actions (Figure 4.8). Similarly, students in Year 6 especially, had possibly been learning about reducing energy use, compared with students in Year 5. Interestingly, however, interviewed teachers indicated that the Year 4, 5 and 6 students had been learning about water, because of the recent timing of National Water Week. Furthermore, Mrs Osprey, a Year 6 teacher, stated that students across the whole school had incidental exposure to messages about reducing energy use "every day, with our lights and with the notices over the PA", and did not describe a recent focus on energy reduction in her teaching plans.

For most themes in things I can do to help the environment, it is interesting that the proportions of responses from students were consistent across year groups. It is possible that this result was affected by the whole-school approach to sustainability education and perhaps also bolstered by Year 4 students who were in Mrs Brolga's class at the time of data collection or had in the past been in Mrs Brolga's class, and were consequently more likely to have a broad knowledge of environmental actions because of their frequent exposure to these topics.

Patterns were different for sustainability, however, with a significantly greater proportion of students in Year 5 showing more complex ideas (ideas associated with more than one theme) as well as more simple ideas (usually simple nouns) (Figure 4.8). These results initially seem to contradict each other, but it was likely that the students who responded with complex ideas were different from those who responded with simple ideas. Such results suggest that students who gave complex ideas were more familiar with issues of sustainability and possibly that these students were being exposed to a broader perspective of sustainability in Year 5, as well as having 
previously been in Mrs Brolga's class, an Eco-ranger or otherwise closely involved in the school's sustainability initiatives. By contrast, the students who responded with simple ideas, were probably less familiar with issues of sustainability and either had little interest in being involved in the school's sustainability initiatives or had missed opportunities to become involved.

Construct differences. There were no differences between the two constructs for depth of knowledge (Figure 4.4), but there were differences between constructs for volume and breadth of knowledge (Figures 4.5 and 4.6), with things I can do to help the environment scoring higher than sustainability. Significant differences were also found between the two constructs in the proportion of student responses toward nearly all of the themes, as illustrated in Figure 4.7. Not surprisingly, there was a greater proportion of students who gave environmentally related ideas for things I can do to help the environment, but environmental themes also were predominantly mentioned for sustainability. The very low proportion of responses for social and cultural wellbeing, compared with the large proportion of responses for the various environmentally related themes, indicate that for most students, sustainability was more broadly associated with environmental themes than socio-cultural or economic perspectives.

Interestingly, there was a significantly higher proportion of students who had ideas about values, advocacy and philanthropy for the construct sustainability compared with things I can do to help the environment, indicating that some students may have had a broader understanding of sustainability. However, these kinds of responses may have been implied by the way the researcher had defined sustainability. Sustainability was defined for all students as "helping the world stay healthy for a long time". Examples of responses coded into the theme values, advocacy and philanthropy were: "raise money", "tell everyone", "helping future generations", "keep it healthy" and "look after the environment".

There was also, however, 19 percent more students who gave simple ideas for the construct sustainability compared with things I can do to help the environment (Figure 4.7). This result may highlight confusion in students' understanding of sustainability as a concept, and could suggest that sustainability was an ambiguous term for many students. Overall, these results suggest that students had definitely differentiated between the two constructs in their minds and that most students found it easier to think of many and more various ideas of how they could help the environment compared with ideas about sustainability. 
Trends in percent response per theme. An overall trend in rates of response towards certain themes was found in the data, as illustrated in Figure 4.7, where waste management, water conservation and biodiversity conservation had higher rates of response than other themes that were either more difficult for students to generate ideas or themes the students were less exposed to in their lives. These trends were consistent across constructs although they were stronger for things I can do to help the environment. Data from document searches (Tables 4.1, 4.2 and 4.3) illustrate that waste management, water conservation and biodiversity conservation were the most heavily emphasised themes in Lighthouse Primary School's sustainability initiatives. Whereas, other themes such as air pollution and transport choices and energy reduction had been somewhat less of a focus at Lighthouse Primary School.

For example, walking and cycling to school had been an annual focus from 2004 to 2007, but had not been strongly emphasised in recent years (Tables 4.1, 4.2 and 4.3) because it was not strongly supported by parents. To this effect, Mrs Osprey commented, "Not this year but the first two years I was here, we had Millennium Kids [who ran the Travel Smart incursion] and that was always part of our school". Mr Honeyeater explained,

We've tried getting the walking bus and all that but just can't get it going. It's much harder to get it now because of all the problems around the place. It's just people have that perception. [How many percent of students would live close to the school?] About 80, and very few would walk. [And why would that be?] Worry, not letting the kids out. I don't think they're spoiled but I call it overindulged ... And because we go over [a large main road] a lot of them would be picked up. And if you look at how many ride their bikes, there'd be 6 bikes, 7 bikes, not many, not many. ... All the footpaths have got those footprints, the blue ones, which are the safest way to come to school. But we haven't been able to get that [going].

Reducing energy use, however, had become a strong focus in recent years (Tables 4.1, 4.2 and 4.3), so it is unexpected that less than 30 percent of students mentioned this theme. This finding could indicate that that energy reduction was less tangibly associated with the environment or sustainability, that it was less reinforced in their homes, or that the school's emphases on waste management, water conservation and biodiversity conservation caused students to weight their responses towards these themes.

\section{Summary}

Mind mapping of Year 4, 5 and 6 students at Lighthouse Primary School highlighted four key implications: 
1) There was no difference in the depth, volume or breadth of environmental or sustainability knowledge between Year 4, 5 or 6 students, which indicates that the whole-school sustainability focus had permeated all year groups.

2) Students had a greater volume and breadth of ideas for the construct things I can do to help the environment than for the construct sustainability, which could indicate latent confusion or ambiguity towards sustainability as a concept.

3) The majority of students related sustainability with environmental themes and a significantly larger proportion of students gave simple ideas for sustainability, which indicates sustainability was a concept that most students thought of as environmental and was a difficult term for many of them to grasp.

4) A large proportion of all students gave ideas in the themes of waste management, water conservation and biodiversity conservation, but other environmental themes such as air pollution and transport choices and energy reduction were less popular. Triangulated with data from interviews and document searches this result confirms that students' responses were influenced by those themes that were being emphasised most frequently in the school's sustainability initiatives and, in the case of air pollution and transport choices, were being reinforced by parents.

\section{Research Question 3: What were the Environmental Behaviours of Upper- Primary Students at Lighthouse Primary School?}

This research question examined the impact of education for sustainability on the adoption of environmental behaviours in upper-primary students at Lighthouse Primary School. The question was investigated using surveys conducted with students from Years 4, 5 and $6(n=161)$. Follow-up surveys were conducted in 2010 with students from Years 5, 6 and $7(n=157)$. In 2010, there were 29 students that had either left the school or were not present on the day of the survey (Yr $5=10, \operatorname{Yr} 6=10, \operatorname{Yr} 7$ =9). There were, however, 25 new students in 2010 (Yr 5 =9, Yr 6=9, Yr $7=7$ ) who participated in the survey at Lighthouse Primary School.

This section explores seven common pro-environmental behaviours that students could practice in their homes with little family support (as described in Chapter 3). These were:

1) Turning off lights

2) Recycling paper or plastic

3) Having short showers 
4) Saving water in other ways

5) Walking, biking, or bussing to school

6) Eating home grown fruits or vegetables

7) Putting food scraps into a worm farm or compost bin

The 2009 and 2010 student surveys included sets of questions to measure: 1) students' self-reported frequency of undertaking each of the seven pro-environmental behaviours at home, 2) students' perceived frequency of learning about related environmental topics at school - Learning, 3) students' perceived importance of school environmental experiences - Importance, and 4) students' degree of participation in each behaviour at home - Participation. Student responses to these questions built a picture about which pro-environmental behaviours were being practiced by students with greater frequency and enabled inferences to be made about why certain patterns may have emerged.

\section{Results}

The analyses highlighted interesting patterns in students' pro-environmental behaviour. Behavioural mechanisms were deduced by triangulating results from the descriptive statistics and chi-square analyses for each behaviour and comparison variable measured. Certain behaviours displayed similar patterns and were grouped together. The groups were categorised according to the percentage of students that indicated they performed a behaviour on a more than weekly basis: high, moderate and low (Figure 4.9). The groups are presented and discussed in the following sections. 


\section{Frequency of pro-environmental behaviours at home}

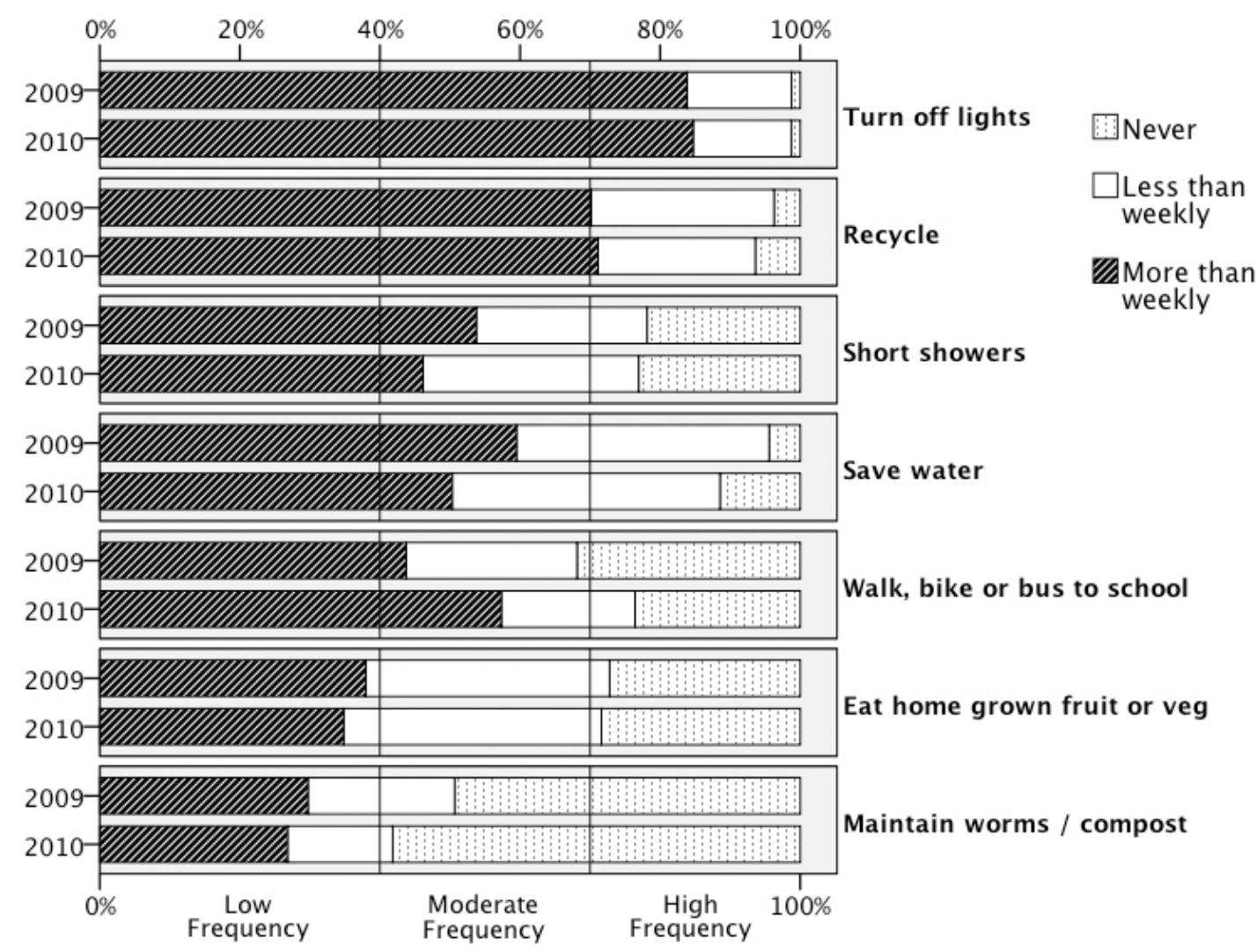

Figure 4.9. Percentage of students that reported they undertook each of the seven proenvironmental behaviours in 2009 and 2010 'never', 'less than weekly' or 'more than weekly'. $\mathrm{n}_{2009}=161, \mathrm{n}_{2010}=157$. Resulting patterns suggested certain behaviours grouped together to form three categories: high $(>70 \%)$, moderate $(40 \%-70 \%)$ and low $(<40 \%)$ frequency.

Chi-square tests were conducted to investigate whether certain behaviours were performed in greater frequency than others because of a relationship with Learning, Importance or Participation. This was done separately for the data from 2009 and 2010. If significant associations were found, variable width box plots were performed to observe and infer the patterns.

Results from 2009 and 2010 surveys at Lighthouse Primary School, are summarised in Table 4.9, and suggest that varying combinations of Learning, Importance and Participation drive Year 4, 5 and 6 students to participate in certain proenvironmental behaviours at home. The stories that emerged from the relationships between each of the seven measured behaviours and the three comparison variables: Learning, Importance and Participation, are discussed in the following paragraphs.

\section{Summary and Discussion}

At Lighthouse Primary School, the weekly practice of pro-environmental behaviours by upper-primary school students in their homes was largely related to the students' degree of participation within their families. Table 4.9 displays a summary of 
the dominant relationships between the seven estimated behaviours and the three comparison variables: Learning, Importance and Participation. Detailed results from relationship testing using chi-square tests and box plots are presented and described in Appendix 4. The following discussion draws on data presented primarily in Table 4.9 but also from the more detailed data analysis presented in Appendix 4.

Table 4.9. Summary of the dominant relationships between seven pro-environmental behaviours that students could practice in their homes and the three variables: Learning, Importance and Participation. The prevalence of each behaviour is shown as a proportion of the total sample. Dominant patterns between Learning, Importance and Participation and weekly behaviour are presented to infer the features that had greatest influence on each behaviour.

\begin{tabular}{|c|c|c|c|c|c|}
\hline \multirow[t]{2}{*}{ Behaviour } & \multirow[t]{2}{*}{ Prevalence* } & \multicolumn{4}{|c|}{ Practiced weekly, when: } \\
\hline & & Learning & Importance & Participation $†$ & Other \\
\hline Turning off lights & Widespread & - & - & Family norm & - \\
\hline $\begin{array}{l}\text { Recycling paper or } \\
\text { plastic }\end{array}$ & Widespread & - & - & Family norm & - \\
\hline Short showers & Common & Weekly & Important & $\begin{array}{l}\text { Student } \\
\text { co-enthusiast }\end{array}$ & - \\
\hline Saving water & Common & Weekly & Important & $\begin{array}{l}\text { Family norm } \\
(2009) \\
\text { Student } \\
\text { co-enthusiast } \\
(2010)\end{array}$ & - \\
\hline $\begin{array}{l}\text { Walking, biking or } \\
\text { bussing to school }\end{array}$ & Common & $\begin{array}{l}\text { Weekly or } \\
\text { less }\end{array}$ & - & $\begin{array}{l}\text { Student } \\
\text { co-enthusiast }\end{array}$ & $\begin{array}{l}\text { Proximity } \\
<2 \mathrm{~km}\end{array}$ \\
\hline $\begin{array}{l}\text { Eating home grown } \\
\text { fruits or vegetables }\end{array}$ & Uncommon & $\begin{array}{l}\text { Weekly or } \\
\text { less }\end{array}$ & - & $\begin{array}{l}\text { Student } \\
\text { co-enthusiast }\end{array}$ & - \\
\hline $\begin{array}{l}\text { Putting food scraps } \\
\text { into a worm farm or } \\
\text { compost bin }\end{array}$ & Uncommon & - & - & Family norm & - \\
\hline
\end{tabular}

* Prevalence: Widespread, $>70$ percent of all students did this weekly; Common, 40 - 70 percent of all students did this weekly; Uncommon, $<40$ percent of all students did this weekly.

$\dagger$ Participation: Family norm $=$ Students participated weekly even if they were not one of the most active family members. Student co-enthusiast $=$ Students participated weekly when they were one of the most active family members.

Many students at Lighthouse Primary School turned off lights, recycled and put food scraps into a worm farm or compost bin on a weekly basis when it was a family norm (Table 4.9), and indicate that the practice of these pro-environmental behaviours by students in their homes was directly related to whether the behaviour was a family priority. The term family norm was inferred when it was observed that most students who practiced a behaviour on a weekly basis did so even if they were not one of the most active family members. For example, students who put food scraps into a worm farm or compost bin on a weekly basis did so even if they identified that their parents did this more often. For other behaviours, however, it depended on the student being a 
co-enthusiast (Table 4.9). The term co-enthusiast was inferred when it was observed that most students who practiced a behaviour on a weekly basis did so when they were one of the most proactive family members in this activity. In families where parents or siblings were most proactive in these behaviours students were less likely to do the behaviour weekly. Water saving, however, was related with family norms in 2009, but in 2010 depended on the student being a co-enthusiast (Table 4.9).

The behaviours whose frequencies were related to the behaviour being a family norm were: turning off lights, recycling and putting food scraps into a worm farm or compost bin (Table 4.9). Turning off lights is a very simple behaviour that can be done multiple times per day, and when the data were explored for daily trends it was found that most students did indeed turn off lights daily (Appendix 4). Is suspected that students turned off lights regularly, regardless of which family members were most proactive and without influence of Learning or Importance, because of the inherent simplicity of this behaviour. Moreover, it is postulated that turning off lights was a daily habit for most students. Turning off lights is also likely encouraged by parents, so it is probable that in families where parents were most active, the children were being encouraged to turn off lights regularly, thus masking any difference.

Recycling was done weekly by most students and was considered a family norm (Table 4.9). It is suspected that recycling was a priority for most families, and was an easy behaviour for students to participate in to the extent they chose. Similar to turning off lights, the weekly practice of recycling was not influenced by Learning or Importance, most likely because these are both easy behaviours to perform and are often featured in large scale awareness campaigns at school and through public media (DCCEE, 2012; Gardner, Szatow, Horn, \& Quezada, 2009; Ha \& Santucci, 2005). Furthermore, recycling has become a norm in Australia, and for most Australian households, is made easier because of recycling bins and removal services provided by local and regional councils (Ha \& Santucci, 2005; RRT, 2012). Many local and regional councils also provide recycling education to their constituent households by way of pamphlets and other free materials.

Putting food scraps into a worm farm or compost bin on a weekly basis was an uncommon behaviour, and in families that had either of these systems students would participate weekly even if their parents or siblings were most proactive (Table 4.9). It is uncertain if these students considered putting food scraps into a worm farm or compost bin the same as putting food scraps into a kitchen bucket that would be taken outside to a worm farm or compost bin, so it is possible that true frequency of behaviour could be 
less. Figure 4.9 illustrates that at least 40 percent of families had a worm farm or compost bin, but the majority of families did not, which was likely because of the resources, time, skills and effort required to maintain either of these systems (McKenzie-Mohr, 2011; McKenzie-Mohr, Schultz, Kotler, \& Lee, 2012). It is asserted that schools wishing to influence the prevalence of students' composting or worm farming at home, should involve parent education and involvement into their overarching agenda. For example, by forming a partnership with a local community organisation that already offers educational courses, like Living Smart or Earth Carers that both operate in Perth, Western Australia.

The behaviours whose frequencies depended on students being a co-enthusiast were: eating home grown produce, alternative transport to school and short showers, (Table 4.9). The finding that more students would eat home grown produce weekly if they were a co-enthusiast (Table 4.9), was possibly related to them being one of the family members most involved in growing produce at home. If so, these students would probably have had more interest in eating their own produce compared with students whose parents were most active. This behaviour might, in turn, be influenced by an increased level of skills developed through learning at school about growing produce, as indicated by the significant relationship between Learning and eating home grown produce (Appendix 4). This relationship showed that students' weekly behaviours were impacted by any frequency of learning about growing fruits or vegetables, and suggests that the permaculture gardens maintained by each year group at Lighthouse Primary School may have been successful in influencing the behaviours of students.

Figure 4.9 illustrates that at least 70 percent of families grew produce at home. The low prevalence of eating home grown produce on a weekly basis, however, was unlikely because students were not interested or unskilled, but perhaps because produce is not always available every week. It also was possible that more family support was required to grow even simple herbs and fruits throughout the year. Interview data from parents, discussed in Chapter 8, indicated that some families did start growing their own fruits or vegetables at home because of the school's influence. One parent described that participating in busy bees to maintain the school's permaculture gardens was a positive influence on their family's adoption of growing produce at home, saying "We've both been up and worked on the garden when they were setting it up and the little orchard", and "thinking, well if they're doing that at school, we should be doing more of that at home". Together, these data suggest that if a school wishes to influence the prevalence of students' eating (and growing) produce at home, the focus should involve parent 
participation and possibly also a partnership with a community group, such as Living Smart, that could offer weekend permaculture courses for interested parents.

Weekly walking, riding or bussing to school also was directly related to the student being a co-enthusiast (Table 4.9). When demographics were analysed it was found that students who lived less than 2 kilometres from the school were much more likely to walk, ride or bus to school on a greater than weekly basis compared with students who lived further than 2 kilometres from the school (Appendix 4). Consequently, it is suspected that proximity had greater influence on whether a student took alternative transport to school; thus, the relationship with Participation should not be over stated. For example, active students should not be compared to families where parents or siblings were more frequent in taking alternative transport to work or school because the household's proximity to Lighthouse Primary School was likely a mediating factor.

Nonetheless, it is interesting that, in 2009, walking, biking or bussing to school was a weekly behaviour for 44 percent of students, when 73 percent of students lived less than 2 kilometres from the school (Figure 4.9 and Appendix 4). It is particularly interesting, however, that in 2010, the proportion of students walking, biking or bussing to school on a weekly basis had increased by 13 percent (Figure 4.9). Figure 4.9 also illustrates that the proportion of students taking alternative transport to school at any time in the school year had also increased from 68 percent in 2009 to 76 percent of students in 2010. The 2009 result is concordant with the statement from Mr Honeyeater presented earlier in this chapter regarding the waning interest in walking or biking to school, but the 2010 result indicates that the school may have reinvigorated its walk-toschool promotions. Chi-square results from 2010 support this assertion and indicate that the majority of students were walking, biking or bussing weekly when they learned about this topic at any frequency: less or more than weekly (Appendix 4.13). In addition, Mr Honeyeater had indicated, in his interview near the end of 2009, that the school was planning to do more promotions, saying, "There's a new plan out now. A much simpler one", and described, "You just do a couple of things ... the first one is even if you start talking about the bus". So, the results of this survey are encouraging and indicate that this new approach may have been effective.

Taking short showers at least weekly was directly related to the student being a co-enthusiast (Table 4.9) and was most likely associated with motivation. Having short showers is an individual decision and a student that does not want to take short showers will not do so even if it is a family priority. This assertion is supported by the significant 
relationship between Importance and short showers, indicating that students who attributed more importance to school environmental experiences were more motivated to moderate their shower length.

Interestingly, however, there was a significant relationship between learning weekly about saving water and taking short showers at least weekly (Appendices 4.6 and 4.7). The relationship with Learning could generally be attributed to the impact of a persistent focus on water conservation at Lighthouse Primary School. Figure 4.9 also illustrates that more students were active in having short showers in 2009 than in 2010. This difference could have arisen because the week that surveys were conducted in 2009 was National Water Week and several teachers at the school had been focussing their teaching around the theme of water conservation. Although the survey questions asked students to think back on a scale of how frequently they learned about water saving and took short showers at home, the recent focus of teaching could have skewed results in 2009. Surveys were conducted at a later time in 2010, and might represent truer frequencies of learning about household water saving and student showering durations. Essentially, these results suggest an assertion that when students learned more frequently about water conservation they were more diligent in taking shorter showers and Importance became less related to their showering behaviours.

Water saving behaviour was different to the other six behaviours assessed because it was related with family norms in 2009, but in 2010 depended on the student being a co-enthusiast (Table 4.9). Similar to results for short showers, general water saving was related with Importance and Learning (Table 4.9), and it is suspected that a focus on water conservation in 2009, because of National Water Week, influenced students to practice water saving behaviours weekly who may not usually have done so. In 2010, however, it is asserted that students' water saving behaviours were more consistent with their 'usual' frequencies. Overall, these results are similar to those for short showers, and give a positive indication that, when students learned more frequently about saving water, they were more diligent in doing so.

With regard to Importance and its relationship with the two water saving behaviours, this can be interpreted in two ways: 1) if environmental experiences are important to a student, they will perform pro-environmental behaviours frequently, 2) if students perform pro-environmental behaviours frequently, environmental experiences will become more important to them. For the water saving behaviours, weekly behaviour also was related to weekly learning, so it is suspected that these relationships should be interpreted in the first way: students who place importance on environmental 
experiences will take short showers and save water at home more often, especially if they are being regularly encouraged or reminded to do so. By comparison, and despite low numbers, students that worm farmed or composted weekly also tended to place more importance on environmental experiences. However, because this behaviour was uncommon and dependent on family support, this relationship was interpreted in the second way: maintaining a worm farm or compost bin at home positively influences a student's expressed importance towards environmental experiences.

Overall, it is evident that the easy, quick behaviours, turning off lights and recycling, were widespread and probably impacted less by school learning experiences and more by social norms and available infrastructure. The time consuming behaviours, home grown produce and organic waste systems, were uncommon and impacted less by school learning and more by constraining factors of family support, time, effort, skills and resources. Travel to school was unique and impacted primarily by the students' proximity to school. Finally, water saving behaviours were common and impacted by school learning as well as students' expressed importance of environmental experiences.

\section{Chapter Conclusion}

Lighthouse Primary School had established an integrated, systematised wholeschool sustainability education program that was supported and endorsed by a large proportion of staff, parents and students. The sustainability program was initially spearheaded by one pioneering teacher, but after much time, energy, support and resources being injected into the program by multiple collaborators, together with some vision and tools provided by AuSSI - WA, the school's achievements could be acknowledged as belonging to all staff, students and parents. There was, however, an impression that student involvement in the program was simply that, involvement, as opposed to authentic engagement where students' voices help to shape and direct initiatives.

It appears reasonable to conclude that whole-school sustainability education at Lighthouse Primary School had impacted students' knowledge of environmental actions, but that many students were confused about what sustainability is and whether it is distinct from environmental perspectives. Nonetheless, the absence of year group differences for depth, volume and breadth of knowledge suggests that the sustainability initiatives had indeed permeated the whole school (or at least the upper-school). It can be inferred that whole-school sustainability education at Lighthouse Primary School had some impact on the regularity that students practiced several of the seven pro- 
environmental behaviours - either directly through weekly learning experiences or indirectly by influencing the degree of student participation at home. Turning off lights and recycling, however, were primarily influenced by family priorities. Overall, it was apparent that students at Lighthouse Primary School were surrounded by opportunities to develop pro-environmental knowledge, skills and motivation to act, and many students had indeed developed elements of action competence.

The following chapter presents results from River's Edge Primary School, which was in the early stages of setting up a whole-school sustainability program at the time of data collection in 2009. The cross-case comparison of results from Lighthouse, River's Edge and Fertile Ground Primary Schools will be explored in Chapter 9, the synthesis. 


\section{Chapter 5: SMALL StePS AND Giant LeAPS - RIVER's EDGE PRIMARY SCHOOL}

\section{Education for sustainability is ultimately about education and capacity building and only secondly about environmental problem-solving.}

(John Fien, 2001, p. 19)

This chapter presents a case study framed within whole-school, whole-system approaches to environmental education for sustainability. River's Edge Primary School's sustainability program was supported by the Australian Sustainable Schools Initiative in Western Australia (AuSSI - WA) and facilitated by Millennium Kids Inc. In 2008, the school set out to implement sustainability education using principles of action competence, shared responsibility and student leadership. At the time of data collection in 2009: 1) several teachers across year groups had begun to develop units of work that integrated sustainability concepts and actions, 2) a student representative committee was leading various whole-school initiatives, and 3) sustainability goals had been written into school plans, but 4) parent awareness and support of the program were minimal. This case study was characterised by the school's newly adopted emphasis on sustainability education that was contrasted with a 'lucky country' reliance on natural resources by many families whose children attend the school, and resolutions proffered by Millennium Kids.

River's Edge Primary School is a prestigious private school located in a high socioeconomic suburb of Perth, roughly 15 kilometres west of the city. On the Index of Community Socio-Educational Advantage (ACARA, 2012b), River's Edge Primary School was rated 1172 in 2009 . This suburb and those surrounding it, are among the greatest polluters, biggest water users and have the highest eco-footprints, per person per year, in the state of Western Australia (ACF, 2010).

Surveys and mind maps with students, interviews with teachers, the school principal, parents and students, observations of the school grounds, and document searches, were carried out at River's Edge Primary School in 2009 and surveys were conducted with students once more in 2010. Twenty nine percent of the 155 students surveyed in 2009 and twenty six percent of the 128 students surveyed in 2010 lived within 2.5 kilometres of the school. 


\section{Research Question 1: What Organizational Factors Fostered or Impeded the Establishment of Sustainability Initiatives at River's Edge Primary School?}

This section explores the organisational outcomes and challenges that River's Edge Primary School encountered since the sustainability focus began and, whether being aligned with AuSSI - WA and facilitated by Millennium Kids influenced their focus. Results are presented across six themes, first, the history of sustainability education at the case study school and obstacles to its establishment, followed by five organisational elements important to the establishment of sustainability education: 1) school governance, 2) school planning, 3) community networks and partnerships, 4) student voice and engagement, and 5) curriculum integration.

This section presents a discussion of the school's sustainability focus, as reported by school staff. The main protagonists presented here are: Mrs Eagle Ray, the principal; Mrs Moray, the deputy principal; Mrs Redfin, the lead sustainability coordinator and teacher of Year 5; Mrs Salmon the coordinator of the student sustainability committee and teacher of Year 5; Mrs Marlin, a Year 6 teacher, and Mr Mackerel, a Year 4 teacher. Where relevant to support patterns in the data, quotations are also presented from personal communication with the CEO of Millennium Kids and from student interviews.

It is relevant to note that at the time of data collection in 2009, River's Edge Primary School $(\mathrm{K}-12)$ had been operating for 78 years, since 1931 . However, the separate junior school campus $(\mathrm{K}-6)$ where this research was undertaken had only been open for three years, since 2006. Mrs Eagle Ray had been principal of the junior school for seven years. Mrs Moray had been teaching at the school for six years, Mrs Redfin for two years, Mrs Salmon for one year, Mrs Marlin for 20 years and $\mathrm{Mr}$ Mackerel for five years.

\section{History of Sustainability Education at River's Edge Primary School}

Table 5.1 provides a summary of the sustainability initiatives that occurred each month at River's Edge Primary School, from when the school commenced its focus in 2008 to the time of data collection in 2009 . This table will be referred to throughout this qualitative analysis of organisational outcomes and challenges encountered by River's Edge Primary School.

In early 2008, the case study school signed up to AuSSI - WA and in June 2008 Mrs Eagle Ray, in consultation with the teaching staff, contracted Millennium Kids to facilitate their sustainability initiatives. The CEO of Millennium Kids described their 
collaboration as a 'partnership' and stated, "A partnership is more than Millennium Kids giving to the schools. It's about sharing knowledge and ideas". The case study school's partnership with Millennium Kids was founded upon a pre-existing interest among the school's staff towards adopting a whole-school sustainability focus (Figure 5.1). From June 2008 onwards, the number and diversity of sustainability initiatives undertaken by the school grew rapidly (Table 5.1).

\begin{tabular}{|c|c|c|c|c|c|c|c|}
\hline $\begin{array}{l}\text { Teachers with } \\
\text { pre-existing } \\
\text { interest in } \\
\text { environmental } \\
\text { education }\end{array}$ & & $\begin{array}{l}\text { Construction } \\
\text { began on a new } \\
\text { Junior School } \\
\text { campus which } \\
\text { incorporated } \\
\text { sustainable } \\
\text { design features }\end{array}$ & & $\begin{array}{l}\text { Junior } \\
\text { School } \\
\text { moved } \\
\text { to new } \\
\text { campus }\end{array}$ & & $\begin{array}{c}\text { Explored hiring a } \\
\text { sustinability consultant } \\
\text { Joined AuSSI - WA } \\
\text { Two teachers attended } \\
\text { AuSSI - WA professional } \\
\text { development }\end{array}$ & \\
\hline Pre- 2003 & 2003 & 2004 & 2005 & 2006 & $2006-2008$ & Early 2008 & June 2008 \\
\hline & $\begin{array}{c}\text { New } \\
\text { Principal }\end{array}$ & & $\begin{array}{l}\text { First seeds of } \\
\text { thought: } \\
\text { Teaching } \\
\text { Australia project } \\
\text { with Richard } \\
\text { Neville }\end{array}$ & & $\begin{array}{c}\text { Sustainability } \\
\text { workshops with } \\
\text { staff \& community } \\
\text { Newly hired staff } \\
\text { keen and passionate } \\
\text { about sustainability }\end{array}$ & & $\begin{array}{l}\text { Millennium } \\
\text { Kids contracted } \\
\text { as the school's } \\
\text { sustainability } \\
\text { facilitator }\end{array}$ \\
\hline
\end{tabular}

Figure 5.1. Timeline of sustainability activities at River's Edge Primary School before their partnership with AuSSI - WA and Millennium Kids.

Although River's Edge Primary School's affiliation with AuSSI - WA and Millennium Kids began in close succession, teachers and the school principal were very satisfied with the close facilitation and support provided by Millennium Kids. In describing the differences between the school's connection with AuSSI - WA and Millennium Kids, Mrs Redfin explained,

Millennium Kids will be our first port of call. ... Having that connection allows those kids to access a global perspective, which perhaps they wouldn't have been able to do if we didn't have Millennium Kids. ... It just pulls it all together having agencies, specifically Millennium Kids, who are more one on one with us. ... Whereas AuSSI provides us with a state perspective and another resource for teachers but not on a specific school level. ... We get a lot of AuSSI stuff through Millennium Kids. ... AuSSI's been what I wanted it to be. I haven't had any problems with accessing what I need from them. And if I do it's through Millennium Kids that I'll go first.

Millennium Kids worked closely with the principal and the lead sustainability coordinator to provide step-by-step support to the school. They delivered professional development tailored to the staff's sustainability interests, used the Millennium Kids Ten Step Methodology with students, and helped the school foster relationships with parents, other sustainable schools, organisations and educational providers. When asked whether and in what ways the partnership helped the school develop its sustainability 

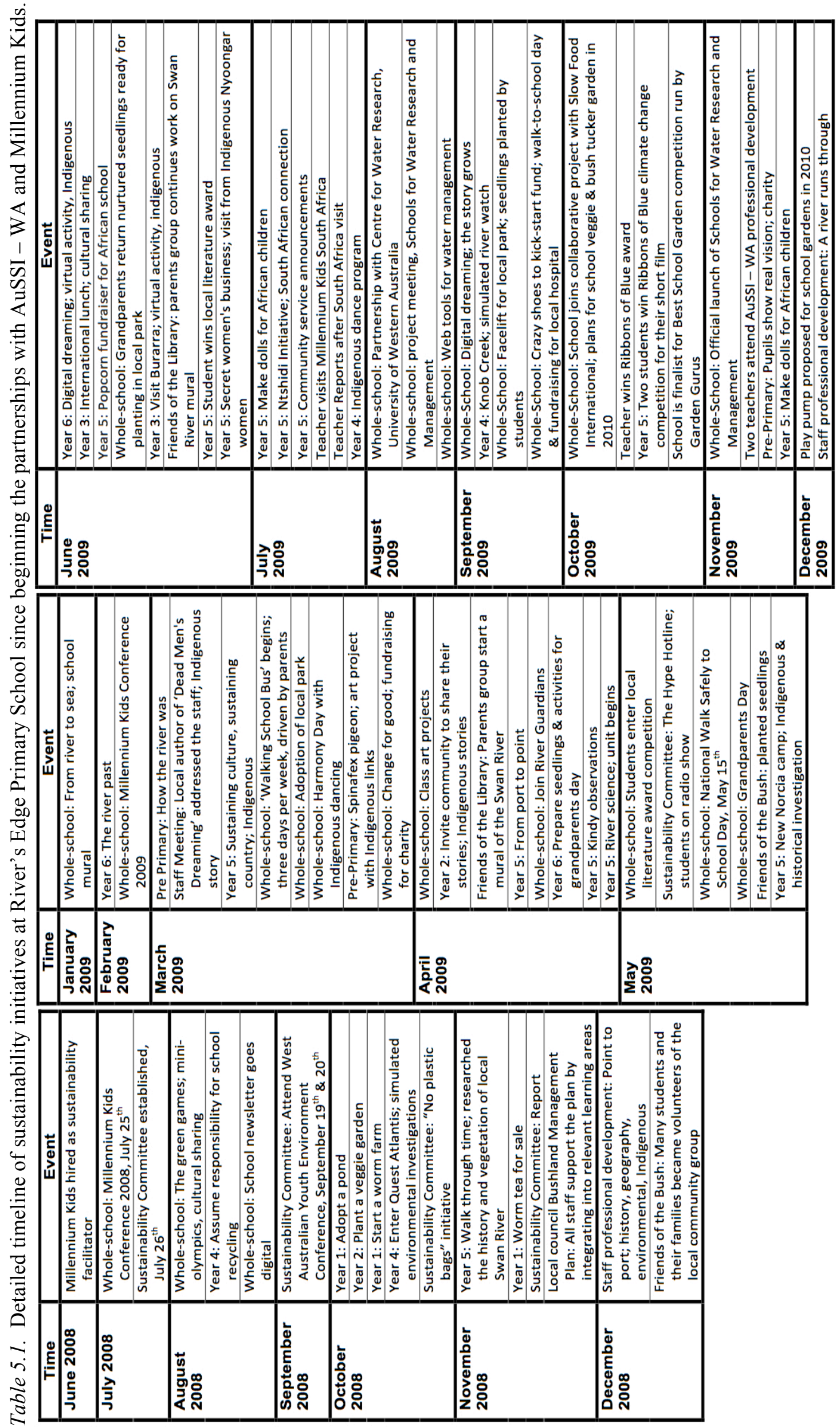
focus and policies, Mrs Moray said, "definitely [by providing] guidelines, expertise, passion, they've got the passion".

When Millennium Kids began their partnership with the case study school in June 2008, they presented a professional development workshop to all staff "about the AuSSI framework and how it married with Millennium Kids" (CEO Millennium Kids, personal communication, 4 August 2010). A few months later Millennium Kids together with the deputy principal organised another professional development called 'point to port' (Table 5.1), during which school staff spent a day journeying along the Swan River learning about the "history, culture, geography, botany and animal life" ("Timeline", 2010, para. 1) of the local area. Dr Noel Nannup, a respected Indigenous Nyoongar elder, was one of their guides on the day. Mrs Moray described the day,

It became apparent to the staff as a whole that our direction must see us develop partnerships in a sustainable community and design learning activities to support a curriculum based on understanding the local effects of climate change, the diversity of both past and present, respect for all cultures and understanding of our landscape.

\section{School Governance}

The principal, Mrs Eagle Ray, is a highly motivated woman whose leadership style could be described as 'managerial', where influence is exercised through positions of authority (O'Donoghue \& Clarke, 2010). The principal stated that "leadership is essential", and "there's a certain culture here where principal and head of junior school are key decision makers". Mrs Eagle Ray was determined to influence the adoption of a whole-school sustainability program at River's Edge Primary School, citing memories from her childhood, and a personal interest in environmental protection and reducing social disadvantage as key drivers for her passion in sustainable living. Her enthusiasm and direction were evident when she stated,

I'm in the position to try and influence things [by introducing initiatives such as] fair trade coffee [in the staff room], reduce the amount of [plastic] wrap that's used to wrap up dishes, ... Encouraging walk to school with the community. And institutionally talking about how often you should be using your heating and air conditioning. It sounds a bit dictatorial, but there are whole-school things that you can actually do, like the whole-school recycling.

Mrs Eagle Ray explained the steps leading up to their partnership with Millennium Kids, stating, "We got more staff on board who were really keen and passionate, then I drove the priorities". She was aware that teachers integrated sustainability to "different extents" and shared her vision that "as the students go from teacher to teacher they'll pick up inspiration for different things". 
All of the teachers interviewed acknowledged that leadership of their principal was integral to the school's sustainability focus, and that losing her could be a threat to the process. They also voiced the importance of being flexible with time, resources and expectations, and not over-directing the process but providing support and collaboration. Mr Mackerel expressed his frustration with the expectations coming from the principal and other passionate staff members, stating,

As a teacher it can get boring because you just keep doing it again and again and again, and you want to be able to have a bit of fun with it. It's got to loosen up a bit. The problem we've got is there's so much that we need to teach, and that we're expected to teach.

Engaging all collaborators in the decision making process was a difficult task, especially in these early stages of River's Edge Primary School's initiatives, and Mrs Redfin explained it as a delicate balance. She explained that the challenge for the school's administration was being able to "keep staff motivated but at the same time not giving them additional work" because "when you start loading up the curriculum with initiatives that the school takes on you have to be very aware that you can lose staff". She elaborated, saying,

Taking on a big initiative at a school like this, you need to allow staff to take it on when they're ready and not to say right in 2010 we're doing this amazing project, the project's going to be fantastic and I want you to do this. You just turn staff off, you know? Staff have got to be given a timeline of perhaps two years if you want something done well. And each staff member, all people take it on at a level they are ready to take it on. And support, collaboration, it's just so incredibly important that staff can work with other staff and share the load, and share the love I guess of what you're doing. ... Being on the teacher level I'm aware, you know? You can see ripplings. You don't need a seeing eye glass to know that "okay, people are tired, it's not the time to bring this up".

Mrs Redfin also clarified her role as lead sustainability coordinator and teacher stating that she has “to be very careful because I'm a colleague and you don't want to saturate them yourself with your face". She described her approach to encouraging participation from other staff members saying, "you have to let them find their own way of taking it on", which she did by "encourag[ing] them and providing them with the resources".

\section{School Planning}

River's Edge Primary School had begun to integrate sustainability principles into their school policy documents, but these policies were limited in their relevance and impact within the school because they had not been collaboratively contributed to or evaluated by all staff. Instead, the policy had been created jointly by Mrs Eagle Ray, 
Mrs Redfin and Mrs Moray with guidance from the CEO of Millennium Kids. Some policies included: 1) setting up of resources and infrastructure for class projects, such as garden beds or stoves, 2) initiating collaborations with community organisations, such as Slow Food International (partnership began in 2010), and 3) instituting waste minimisation policies in the staff rooms or energy reduction policies in classrooms.

It was apparent from various examples described by the principal, teachers and in school documents, that the dominant perception of sustainability being encouraged among teachers and administrators at River's Edge Primary School was of interlocking and equally weighted pursuits of socio-cultural equity, environmental preservation and economic justice. This conception of sustainability had been fostered by the school's close collaboration with Millennium Kids, whose sustainability agendas - the "eight pillars of sustainability" had been adopted in school documents, sustainability conferences and in whole-school community outreach initiatives.

The eight pillars of sustainability encouraged by Millennium Kids were: 1) waste, 2) water, 3) air, 4) native plants, 5) native animals, 6) energy, 7) leadership, and 8) peace and lifestyle - which encompasses a range of socio-cultural, indigenous and community concerns. The CEO of Millennium Kids described these pillars as complementary to the ten fingers and toes of the environmental footprint and social handprint resources offered by AuSSI - WA, and encouraged River's Edge Primary School to use both frameworks in setting their goals and policies.

\section{Community Networks and Partnerships}

In less than two years, the school built relationships with various agencies to tailor activities relevant to the school's focus and the students' interests. Millennium Kids facilitated connections with groups such as Ribbons of Blue, Travel Smart, Slow Food International, Millennium Kids Global Projects - South Africa and Indonesia, Aboriginal groups, other schools, the local town council, local bushland friends group and a local supermarket. Of this the principal said, "There are lots more ventures that are happening, like us connected with The Centre for Water Research [at The University of Western Australia]".

The CEO of Millennium Kids explained their approach to sustainability facilitation as "about capacity building... It's not about taking a package in. It's actually about sitting around collaborating and creating" (CEO Millennium Kids, personal communication, 4 August 2010). Mrs Eagle Ray described their collaboration as dynamic, saying "they keep stimulating us, keep us moving along, stop us from becoming complacent". Mrs Salmon explained, "Millennium Kids are constantly in the 
school. ... They come to staff meetings, they come to assemblies" and "We see them quite a lot and they're always explaining new things that are going on. They're easy to get in touch with". Of the support provided by Millennium Kids, Mrs Marlin stated,

I think it focuses us, I think it helps us to find useful activities that you can do in school. Other schools have done them so you can have a look and follow through. That's a real strength.

Millennium Kids had also encouraged the school to weave sustainability messages into some of the existing whole-school traditions and priorities, such as Harmony Day and Friends of the Library (Table 5.1). These included attempts, described by Mrs Salmon as ways to "involve parents in initiatives that we are doing". Mrs Eagle Ray explained, "We're trying to build in some of our current traditions and then just double up on it", for example,

We have Grandparents Day every year. But what we did this time was we actually got the grandparents and children to compare the carbon footprint when they went to school versus the children. (Figure 5.2)

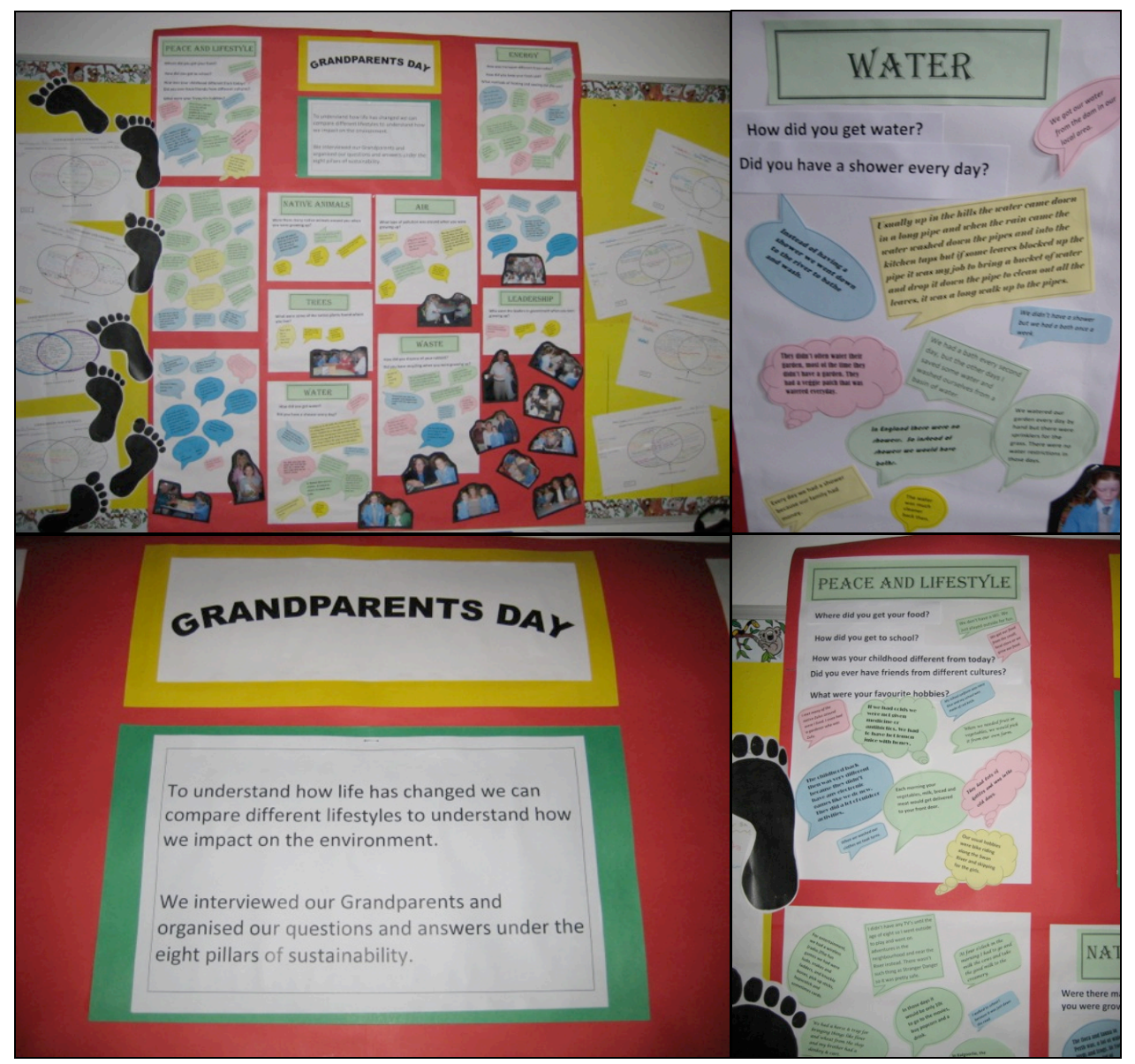

Figure 5.2. Examples of student work created after Grandparents' Day and references made to the "eight pillars of sustainability".

Despite best efforts the school encountered some challenges related to the recent rush of various sustainability activities and messages being provided to the students. 
Mrs Marlin remarked that her approach with parents was to "tread carefully because there's potential for it to backfire and for them to think it's all too difficult we won't bother with any of it". She continued stating,

I think you have to be careful because you can get to the stage where if [the students] are coming home every week, [saying] "I think we should be doing this, I think we should be doing that", then I think you can overload the parents and they'll just shut down. A lot of the parents will be doing it anyway, but those that are not would feel perhaps overwhelmed by all of this directive perceived from school.

There were also challenges related to River's Edge Primary School's status as a prestigious private, primary school and a lucky country mentality observed among many parents. Mrs Eagle Ray and staff were conscious that many of the children's parents work in the mining and resources industry and may be more financially driven than environmentally driven. Mr Mackerel said, "You don't want to annoy anyone too much because a lot of the parents at this school work in the oil and gas industry". Mrs Eagle Ray acknowledged,

We're fighting an upward battle of very wealthy and endowed families who perhaps are financially driven more than necessarily environmentally driven. ... There's an unwritten, unspoken sort of expectation that everything is just perfect. I think there is a slight expectation that we should be providing the service before looking after the environment. You know, I paid good money so why can't I have my newsletter in paper?

The principal and staff also were aware, however, that many of the students were from families of influence and that some of them may be in a position to lead systemic change when they grow up. Mrs Eagle Ray described her commitment towards driving the sustainability priorities, saying, "the students at this school are more than likely going to be decision makers for big companies or part of a private enterprise" and "these people can influence because some of these kids may go into politics and could make systemic change”.

\section{Student Voice and Engagement}

Millennium Kids fostered student engagement through use of their Ten Steps Methodology. This tool was used in student conferences (Figure 5.3 and Table 5.1), where students were given opportunities to voice their concerns and opinions about their environment and society. "The concerns realised were centred around the issues of air, water, trees, waste, native animals, energy, peace/lifestyle and leadership" ("Timeline", 2010, para. 1), and became the platform from which the school set its focus (Figure 5.2). The deputy principal, Mrs Moray, spoke about the process, “They 
[Millennium Kids] treat them [the students] like adults. They give them adult type activities, for instance creating an audit of what they see as important".

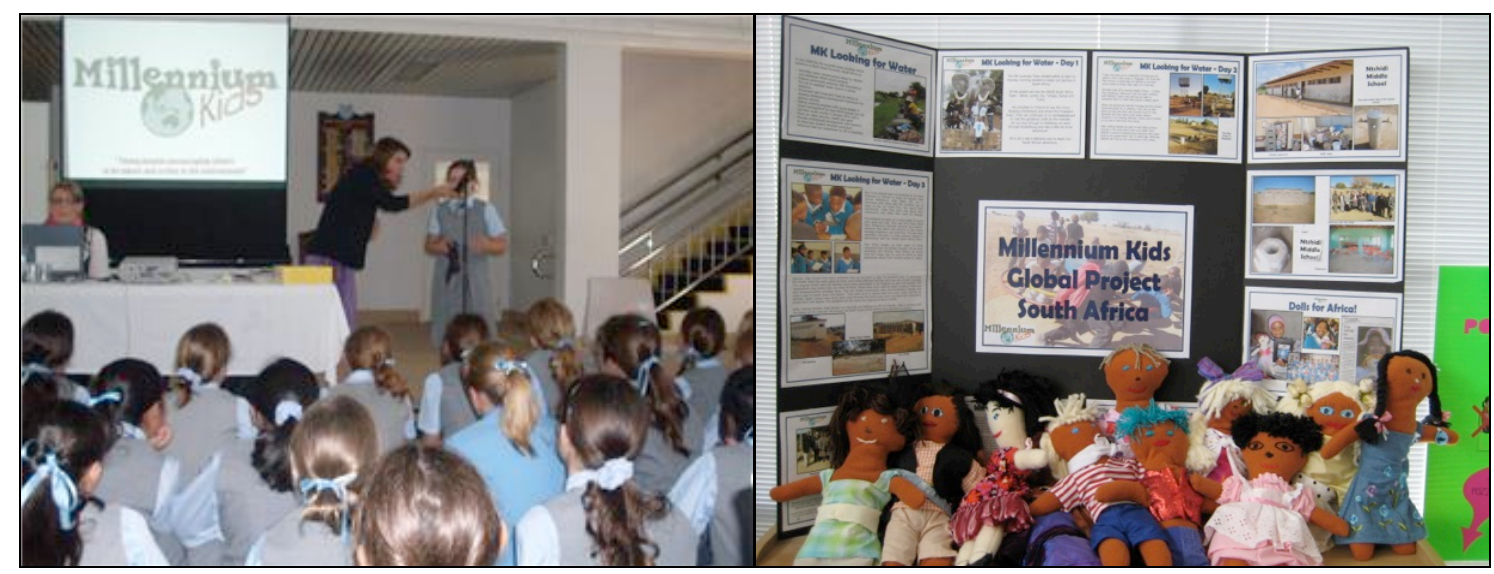

Figure 5.3. Left: Examples of Millennium Kids' student conferences.

Right: Dolls made for student art activities that were donated to a Millennium Kids development project in South Africa.

An immediate result of the first student conference in July 2008 was to establish a committee (Table 5.1) comprising teachers and students who worked together "to action the student body concerns arising from the Millennium Kids School Conference and the audited results" ("Timeline", 2010, para. 1). Students on the sustainability committee met monthly during lunchtimes and were encouraged to work through the Ten Step Methodology to refine ideas for whole-school projects. These students were then given leadership roles in the student led sustainability projects around the school and took turns to make announcements at school assemblies. Mrs Salmon, the coordinator of the sustainability committee, explained,

We meet weekly, usually the kids come along, they take the minutes, we'll discuss what's been going on, or if there's an assembly coming up the kids will create a speech to give and they might give out awards to people that they see being sustainable around the school. It's quite nice to see them involved. ... The students come up with ideas to promote sustainability within the school. At the moment they're collating all the information of what every year group is doing in sustainability and then they're going to create a movie to promote what we're doing.

To be a member of the sustainability committee, students had to nominate themselves and write short answers to a series of questions that were reviewed by Mrs Redfin and Mrs Salmon. The committee was initially comprised of one student from each classroom in Years 4, 5 and 6, but from 2010 onwards would be extended to include students from across all year groups. The committee was overseen by Mrs Redfin together with Mrs Salmon who described her personal commitment to the student committee and facilitating their understanding of sustainability, saying, "I'd like 
to continue it ... It's important" and "They're like sponges they love it, they love talking about it".

There was evidence that students valued the collaborative process of being on the sustainability committee and the activities they were able to participate in. One student remarked, "Last year we went to a Millennium Kids conference and that was pretty inspirational because there were lots of people who were talking and we went to lots of places". Another student described some of the initiatives of the committee, "We discuss what's coming up, like water week and environmental week" and "We bring in games from different cultures and play them at house meeting times". However, this student also commented that these leadership roles sometimes caused undue pressure, "I'm happy to be on it. It can just be a bit hard sometimes because I miss out on class time " and "then I have to do it all at home and I don't understand it".

Staff were asked to participate in the student conferences to observe the Millennium Kids Methodology and were encouraged to develop their yearly planning around one or more of the students' main concerns. Mrs Eagle Ray said, “There's things you can do personally, things you could do curriculum-wise and things we can do as an institution". She explained that each teacher has an area of sustainability they are personally interested in, such as indigenous culture, waste minimisation, or water conservation, so she tells teachers they should "follow their passion" when incorporating sustainability into lesson planning "because then you'll do it properly". Mrs Eagle Ray also described how action competence could be developed among students, "instead of thinking just classroom and the wider world, by looking locally they could actually act, the kids could be empowered”. Mrs Eagle Ray said that as a result of her broad but firm encouragement, "each year level has run with something they can manage and are aware of themselves". Mrs Salmon commented, “There's a lot of teachers who are willing to get their teeth sunk into it" and Mrs Redfin explained,

The Year Fours come around and empty the recycling bins every week. ... The Year Fives are focusing on the river so that's their thing, the Year Ones have got the worm farm and other year levels have got other things. There's a lot of things happening. (Table 5.1)

One initiative that was picked up by the Year 5 students in their arts activities was to sew woollen dolls that could be donated to orphan children in rural South Africa who had no toys (Figure 5.3). The handmade dolls were donated together with a photo and short statement from the girl who created each doll, as well as with money that the Year 5 students raised from a school wide 'popcorn sale', to an orphanage that the 
members of Millennium Kids Global Projects in South Africa had developed a connection with, and hand delivered by Mrs Redfin when she visited South Africa in mid-2009. The stories shared by Mrs Redfin and the experience of personalising their handmade gift, fostered in the Year 5 students at River's Edge Primary School a meaningful connection with the plight and disadvantage of children in rural South Africa. One student demonstrated her insight stating,

Most kids here don't have to worry about money. Well, when we looked at kids in Africa and what they had and what they wanted we found that compared to them we've got so much more resources. Some people here just don't really care about what they're spending and they just want what they want and they don't really think that if you gave your old toy car to some kid in Africa it would mean a whole lifetime of happiness for them.

\section{Curriculum Integration}

A whole systems approach requires teachers to weave sustainability messages across curriculum learning areas, which can be a challenge for some teachers. In this case study, several teachers said it was possible to weave sustainability messages across learning areas. Mrs Redfin explained, "As long as the kids are excited and engaged and the teachers are keen and interested the course sort of evolves". Mrs Redfin gave descriptions of units of work that she and other Year 5 teachers created around the theme of water and the Swan River (Figure 5.4), and described that, aside from the obvious choice of exploring water conservation in the society and environment curriculum learning area, it could be used as a context for English, science, mathematics, and various subject areas, stating,

Once you start going down that track things open up for you, ... so long as you're addressing outcomes that we have to cover. And sustainability, in terms of the social sciences it's in all the areas, and in terms of English being a tool for the social sciences, maths, everything. I mean, all the maths program last week for national water week was based on analysing data about water usage in the last ten years so there was huge mathematical opportunities and it was a relevant context. Sustainability just falls into place naturally. 


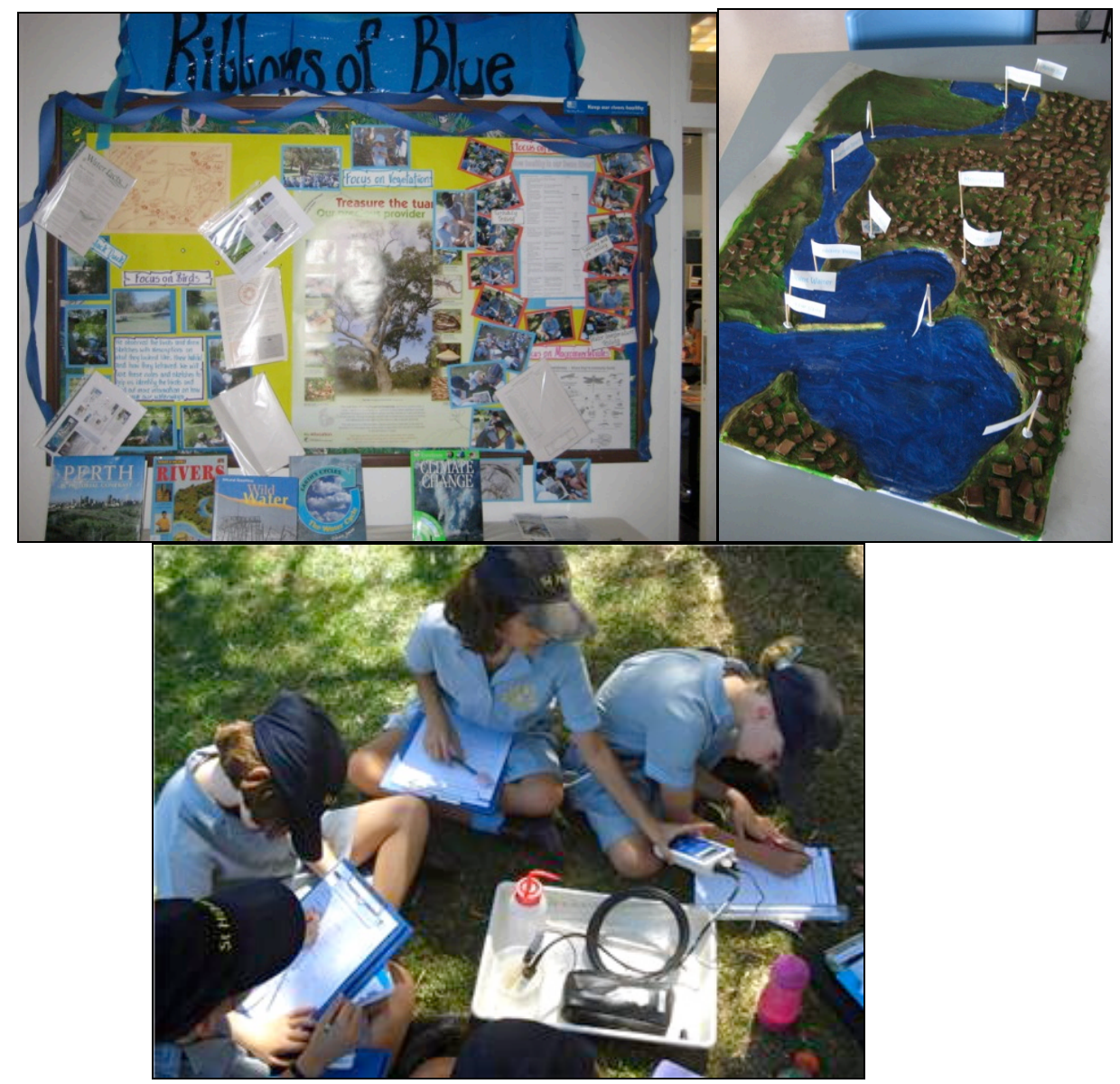

Figure 5.4. Examples of the Year 5 focus on water conservation.

It appeared that the main groups engaging with the sustainability program in 2009 were teachers of Year 5 and the school's administrators. The CEO of Millennium Kids described her perception of the challenges faced by River's Edge Primary School, stating,

There's a number of teachers finding it very difficult to [maintain] the enthusiasm, even though it very clearly marries into a whole variety of areas in the curriculum. ... It's very difficult for them to see that sustainability is a range of content within a whole lot of subject headings. And what they want is a subject heading otherwise they can't often see the interconnection.

Various teachers were indeed less inclined or facing challenges in their attempts to weave sustainability across various curriculum areas or to plan activities that connected issues and students' interests to their regular teaching requirements. $\mathrm{Mr}$ Mackerel described his approach in this way, "I tend not to incorporate the learning into the other areas, but I do incorporate the action ... as an incidental learning kind of thing". Mrs Moray, the deputy principal discussed the challenges that teachers face in trying to incorporate sustainability concepts and actions into some of their regular teaching requirements, 
The biggest weakness is the enormity of the issue really. And then conflicting with the perceived essential learning areas, you know, reading and writing. Timetable is a big problem. Having time to fit everything in. You have to teach smart and incorporate it in a lot of different learning areas but without overkill, which we could be in danger of doing with one or two components. So we've got to really balance it up a bit.

Nonetheless, Mrs Moray conveyed that before affiliating with AuSSI - WA and Millennium Kids teachers were integrating concepts of sustainability into their learning objectives but not with the depth and focus that these partnerships provoked. She explained that sustainability "tended to be underpinning a lot of what we were doing" and had "been ongoing for a long time". Mrs Moray continued, saying that Millennium Kids had played an important role in "tightening it up and filling in the gaps" and, "We've actually channelled it in now since we've joined with Millennium Kids. ... Before that, [sustainability] was done, but there was no definition".

\section{Summary}

The sustainability facilitation provided by Millennium Kids had significantly assisted River's Edge Primary School to establish patterns of whole-school, wholesystem sustainability education in less than two years by fostering certain organisational elements. Nonetheless, these elements were characterised by several unresolved tensions: 1) tension between the school's sustainability focus and a lucky country mentality observed among the parent body, 2) tension between the principal's determination to drive initiatives and the staff's involvement in decision-making, and 3) tension between the expectation on teachers to integrate sustainability messages across curriculum learning areas and the time, effort and training required to do so. These tensions did not prevent the establishment of sustainability education at this school, but they may encumber the longevity, integration and support for these initiatives in future years if not addressed. 


\section{Research Question 2: What was the Environmental and Sustainability Knowledge of Upper-Primary Students at River's Edge Primary School?}

As described in Chapter 4, mind maps were used to estimate students' knowledge of pro-environmental behaviours, their understanding of sustainability and the extent of their whole-systems thinking. Mind maps were created by students from Years 4, 5 and $6(\mathrm{n}=154)$. The results are presented and discussed in this section, and are discussed again in the conclusions of this chapter to triangulate with behaviour data. The analyses and organisation of results presented in this section are similar to the section on Knowledge described in more detail in Chapter 4.

\section{Results}

Mind maps were coded into a quantitative format using the coding scheme described in Chapter 3. Non-parametric tests were performed on the quantitative mind map data to determine year group and construct differences in the depth, volume and breadth of students' environmental and sustainability knowledge. Following these analyses, responses were simplified to a binary format (presence $=1$, absence $=0$ ) to determine the proportion of students per year group, per construct that responded for each of the nine emergent themes.

Depth. Table 5.2 presents the statistical results from Kruskal-Wallis tests and Table 5.3 presents results from post hoc Mann-Whitney U tests. A Kruskal-Wallis test found that depth of knowledge (number of hierarchies) differed significantly across year groups. Post hoc testing revealed no significant difference between Year 5 and 6. However, Year 5 and Year 6 were both significantly greater than Year 4.

A Kruskal-Wallis test revealed no statistical difference in depth of knowledge between the two constructs sustainability and things I can do to help the environment. Figure 5.5 illustrates the findings.

Table 5.2. Statistical results from Kruskal-Wallis tests of Hierarchies compared across year groups and constructs.

\begin{tabular}{lcccc}
\hline & $d f$ & $n$ & $\chi^{2}$ & $p$ \\
\hline Hierarchies: year groups & 2 & 308 & 24.30 & $* *$ \\
Hierarchies: constructs & 1 & 308 & .56 & .460 \\
\hline$* p<.05, * * p<.01$ & & &
\end{tabular}


Table 5.3. Statistical results from post hoc Mann-Whitney U tests of Hierarchies compared across year groups.

\begin{tabular}{lcccc}
\hline & $U$ & $z$ & $p$ & $r$ \\
\hline Post hoc: $Y r 4 \wedge$ and $Y r 5^{\wedge}$ & 3136 & -4.06 & $* *$ & -.29 \\
Post hoc: $Y r 4$ and Yr 6^ & 3045 & -4.60 & $* *$ & -.33 \\
Post hoc: $Y$ Yr 5 and Yr 6 & 5924 & -.75 & .453 & -.05 \\
\hline
\end{tabular}

$\wedge$ Year $4(M d=1, n=84)$, Year $5(M d=2, n=110)$, Year $6(M d=2, n=114)$.

$* p<.017, * * p<.01$ (Bonferroni adjusted alpha level of .17)

$r$ is Cohen's $r-$ a measure of effect size. Cohen's $r$ effect size range: $.1=$ small, $.3=$ medium, $.5=$ large.

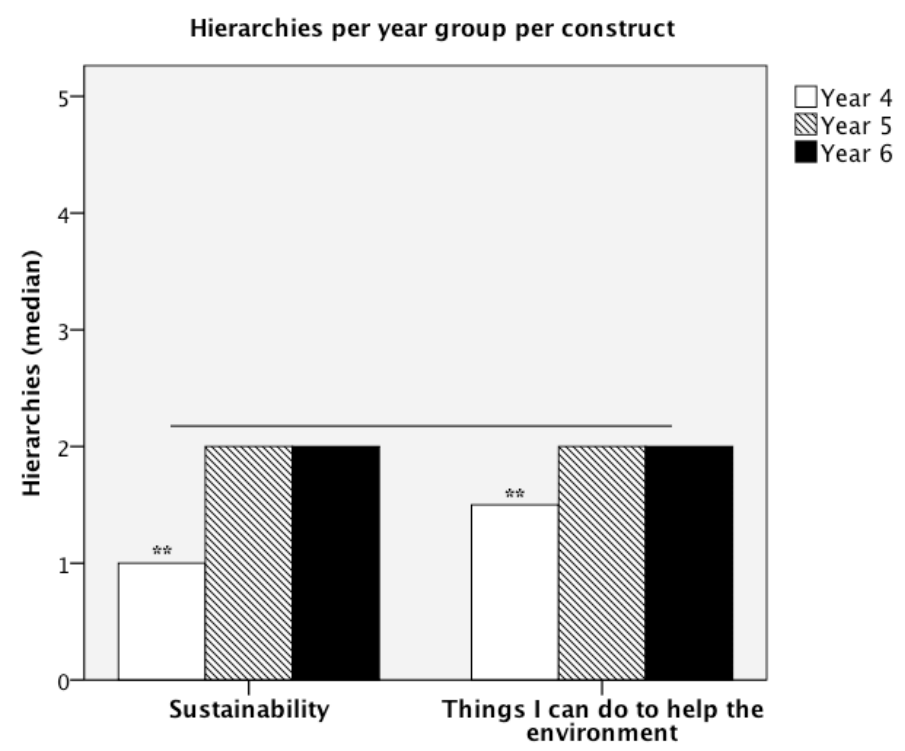

Figure 5.5. Depth of knowledge for each construct, $n_{S}=154, n_{H E}=154 .(* * p<.01)$

Volume. Normality testing revealed two extreme outliers the analysis of volume of knowledge (total number of ideas): cases 96 (38 total ideas) and 145 (34 total ideas). The 5 percent trimmed mean (8.02) was considered different enough from the mean (7.57) to reduce the influence of these extreme outliers by re-coding them to be the same score as the third highest case (26 total ideas), as suggested in Pallant (2007).

As mentioned in Chapter 4, analysis of volume of knowledge did not include responses from the theme simple. Table 5.4 presents the statistical results from KruskalWallis tests and Table 5.5 presents results from post hoc Mann-Whitney U tests. A Kruskal-Wallis test found that volume of knowledge differed significantly across year groups. Post hoc testing revealed no significant difference between Year 5 and Year 6. There was a significant difference between Year 5 and Year 4, with Year 5 greater than Year 4. Year 6 was also significantly greater than Year 4.

A Kruskal-Wallis test revealed statistical difference in volume of knowledge between the two constructs Sustainability and Things I can do to help the environment. 
The construct Things I can do to help the environment displayed greater number of ideas than did Sustainability. Figure 5.6 illustrates the findings.

Table 5.4. Statistical results from Kruskal-Wallis tests of Ideas compared across year groups and constructs.

\begin{tabular}{lcccc}
\hline & $d f$ & $n$ & $\chi^{2}$ & $p$ \\
\hline Ideas: year groups & 2 & 308 & 25.09 & $* *$ \\
Ideas: constructs & 1 & 308 & 18.62 & $* *$
\end{tabular}

$* p<.05, * * p<.01$

Table 5.5. Statistical results from post hoc Mann-Whitney U tests of Ideas compared across year groups.

\begin{tabular}{lcccc}
\hline & $U$ & $z$ & $p$ & $r$ \\
\hline Post hoc: Yr 4^ and Yr 5^ & 3256 & -3.53 & $* *$ & -.25 \\
Post hoc: Yr 4 and Yr 6^ & 2865 & -4.84 & $* *$ & -.34 \\
Post hoc: Yr 5 and Yr 6 & 5433 & -1.73 & .083 & -.12 \\
\hline
\end{tabular}

${ }^{\wedge}$ Year $4(M d=5, n=84)$, Year $5(M d=7, n=110)$, Year $6(M d=9, n=114)$.

$* p<.017,{ }^{* *} p<.01$ (Bonferroni adjusted alpha level of .17)

$r$ is Cohen's $r-$ a measure of effect size. Cohen's $r$ effect size range: $.1=$ small, $.3=$ medium, $.5=$ large.

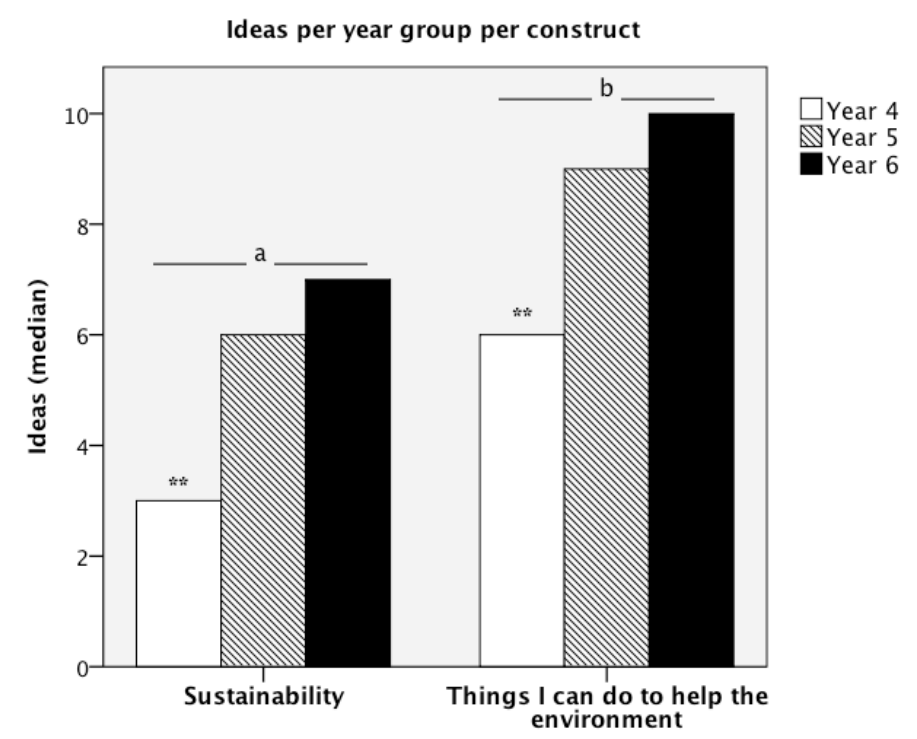

Figure 5.6. Volume of knowledge for each construct, $n_{S}=154, n_{H E}=154$. $(* * p<.01)$

Breadth. As mentioned in Chapter 4, analyses of breadth of knowledge (scope of themes) did not include responses from the theme simple. Table 5.6 presents the statistical results from Kruskal-Wallis tests and Table 5.7 presents results from post hoc Mann-Whitney U tests. A Kruskal-Wallis test found that breadth of knowledge differed significantly across year groups. Post hoc testing revealed no significant difference between Year 5 and Year 6 . There was a significant difference between Year 5 and 
Year 4, with Year 5 greater than Year 4. Year 6 was also significantly greater than Year 4 .

A Kruskal-Wallis test revealed statistical difference in breadth of knowledge between the two constructs Sustainability and Things I can do to help the environment. The construct Things I can do to help the environment displayed greater scope of themes than did Sustainability. Figure 5.7 illustrates the findings.

Table 5.6. Statistical results from Kruskal-Wallis tests of Scope of Themes compared across year groups and constructs.

\begin{tabular}{lcccc}
\hline & $d f$ & $n$ & $\chi^{2}$ & $p$ \\
\hline Themes: year groups & 2 & 308 & 24.71 & $* *$ \\
Themes: constructs & 1 & 308 & 25.93 & $* *$ \\
\hline
\end{tabular}

$* p<.05, * * p<.01$

Table 5.7. Statistical results from post hoc Mann-Whitney U tests of Scope of Themes compared across year groups.

\begin{tabular}{lcccc}
\hline & $U$ & $z$ & $p$ & $r$ \\
\hline Post hoc: $Y r 4^{\wedge}$ and $Y r 5^{\wedge}$ & 3257 & -3.59 & $* *$ & -.26 \\
Post hoc: $Y r 4$ and $Y r 6^{\wedge}$ & 2879 & -4.87 & $* *$ & -.35 \\
Post hoc: $Y r$ 5 and Yr 6 & 5617 & -1.37 & .171 & -.09
\end{tabular}

$\wedge$ Year $4(M d=2, n=84)$, Year $5(M d=3, n=110)$, Year $6(M d=4, n=114)$.

$* p<.017, * * p<.01$ (Bonferroni adjusted alpha level of .17)

$r$ is Cohen's $r-$ a measure of effect size. Cohen's $r$ effect size range: $.1=$ small, $.3=$ medium, $.5=$ large.

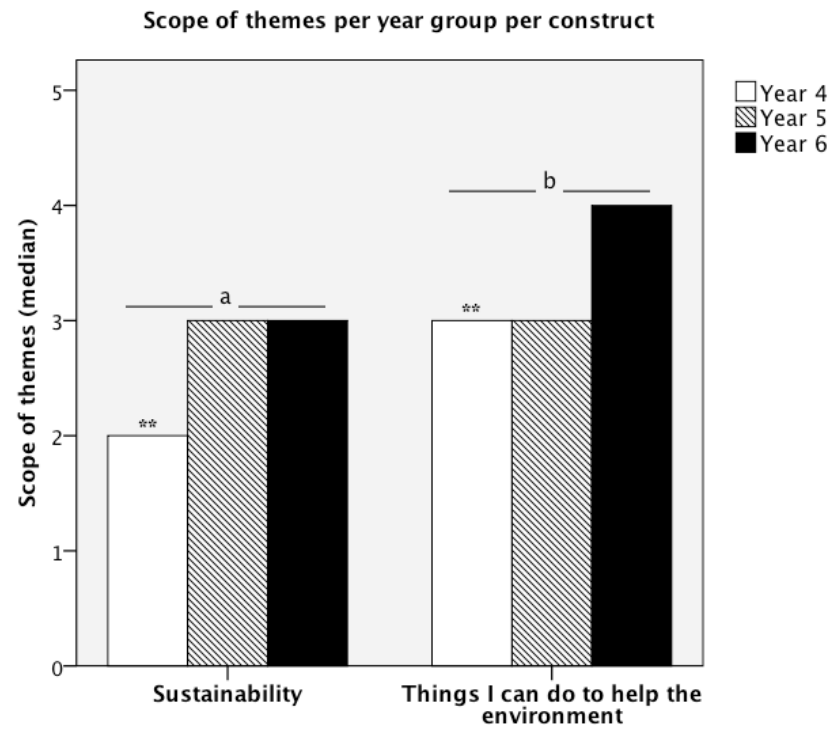

Figure 5.7. Breadth of knowledge for each construct, $n_{S}=154, n_{H E}=154 .(* * p<.01)$ 
Percent response. Percent response per theme was investigated to determine if there were differences in the proportion of students in each year group that responded to each theme per construct. All students' responses were minimised to a binary format (presence $=1$, absence $=0$ ) to look for patterns of percent response per theme.

Kruskal-Wallis tests were performed, comparing the proportion of students' responses across themes per construct, and found significant differences between constructs for nearly all themes, with things I can do to help the environment scoring higher than sustainability on all environmental themes, and sustainability scoring higher on the themes social and cultural wellbeing and simple. Table 5.8 summarises the statistics for these significant differences and Figure 5.8 illustrates the patterns of each theme per construct.

Table 5.8. Significant results from Kruskal-Wallis tests of percent response compared across constructs.

\begin{tabular}{lcccc}
\hline & $d f$ & $n$ & $\chi^{2}$ & $p$ \\
\hline Waste & 1 & 308 & 23.88 & $* *$ \\
Water & 1 & 308 & 12.63 & $* *$ \\
Biodiversity & 1 & 308 & 12.05 & $* *$ \\
Energy & 1 & 308 & 8.19 & $* *$ \\
Air \& Transport & 1 & 308 & 14.96 & $* *$ \\
Social \& Cultural & 1 & 308 & 7.14 & $* *$ \\
Simple & 1 & 308 & 24.61 & $* *$
\end{tabular}

$* p<.05, * * p<.01$

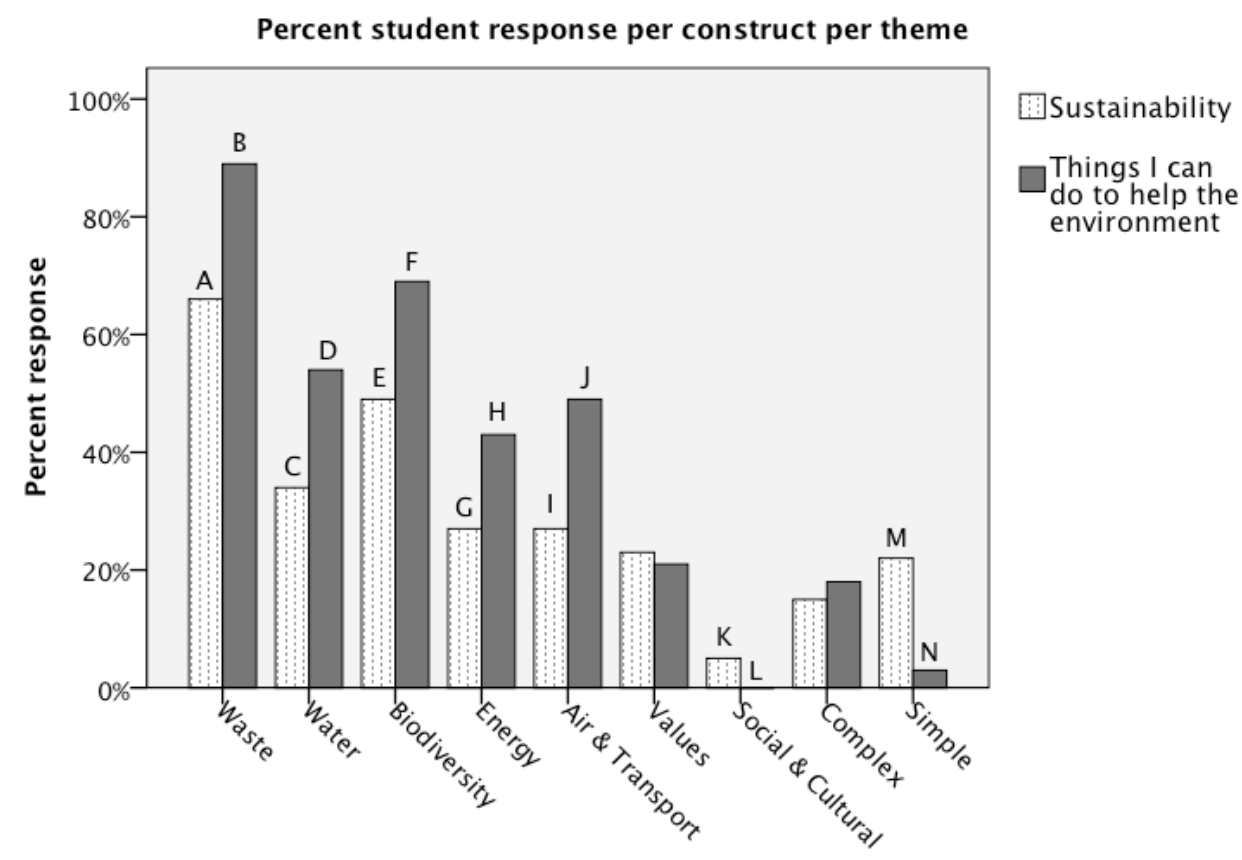

Figure 5.8. Percent response per theme per construct, $n_{S}=154, n_{H E}=154$. 
Further Kruskal-Wallis tests were performed, separately for each construct, on the proportion of students' responses for each theme per year group, and significant differences were found, as presented in Table 5.9. Post hoc Mann-Whitney U tests were performed to determine which year groups were most different, as presented in Table 5.10. Figure 5.9 illustrates the patterns for each construct, year group and theme.

Table 5.9. Significant results from Kruskal-Wallis tests of percent response compared across year groups per construct.

\begin{tabular}{lcccc}
\hline & $d f$ & $n$ & $\chi^{2}$ & $p$ \\
\hline Water $_{\text {environment }}$ & 2 & 154 & 36.05 & $* *$ \\
Water $_{\text {sustainability }}$ & 2 & 154 & 29.31 & $* *$ \\
Complex $_{\text {sustainability }}$ & 2 & 154 & 9.97 & $* *$ \\
\hline$* p<.05, * * p<.01$ & & & &
\end{tabular}

Table 5.10. Results from post hoc Mann-Whitney U tests of percent response compared across year groups.

\begin{tabular}{llcccc}
\hline & & $U$ & $z$ & $p$ & $r$ \\
\hline \multirow{3}{*}{ Water $_{\text {environment }}$} & Post hoc: Yr 4 and Yr 5 & 676 & -4.11 & $* *$ & -.42 \\
& Post hoc: Yr 4 and Yr 6 & 473 & -5.93 & $* *$ & -.60 \\
& Post hoc: Yr 5 and Yr 6 & 1270 & -2.14 & .032 & -.20 \\
\hline \multirow{2}{*}{ Water $_{\text {sustainability }}$} & Post hoc: Yr 4 and Yr 5 & 763 & -4.01 & $* *$ & -.41 \\
& Post hoc: Yr 4 and Yr 6 & 575 & -5.44 & $* *$ & -.55 \\
& Post hoc: Yr 5 and Yr 6 & 1285 & -1.91 & .057 & -.18 \\
\hline \multirow{2}{*}{ Complex $_{\text {sustainability }}$} & Post hoc: Yr 4 and Yr 5 & 889 & -3.10 & $* *$ & -.31 \\
& Post hoc: Yr 4 and Yr 6 & 1058 & -1.98 & .047 & -.20 \\
& Post hoc: Yr 5 and Yr 6 & 1389 & -1.51 & .130 & -.14 \\
\hline
\end{tabular}

$* p<.017, * * p<.01$ (Bonferroni adjusted alpha level of .17)

$r$ is Cohen's $r$ - a measure of effect size. Cohen's r effect size range: $.1=$ small, $.3=$ medium, $.5=$ large. 


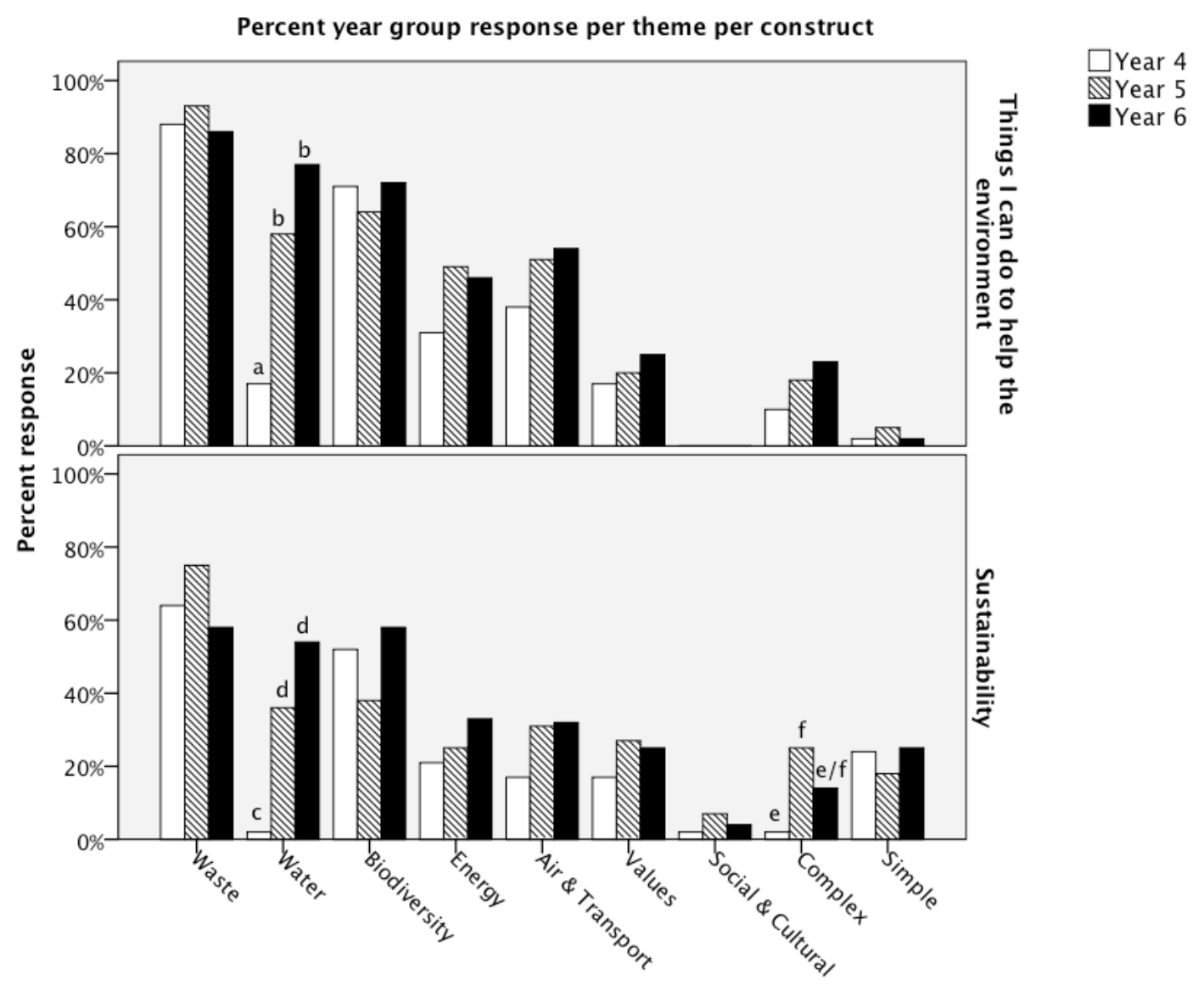

Figure 5.9. Percent of year group response per theme per construct, $n_{4}=42, n_{5}=55, n_{6}=57$.

\section{Discussion}

Year group differences. Years 5 and 6 were not statistically different to each other but were both significantly different to Year 4 for each of depth, volume and breadth of knowledge (Figures 5.5, 5.6 and 5.7). This may reflect differences in the focus of the year groups and suggests that teachers of Years 5 and 6 had been weaving topics relevant to the environment and sustainability into their lessons more than the Year 4 teachers. Investigation of the proportion of year group responses across themes illustrated year group differences for water conservation for both constructs and year group differences in complex for the construct sustainability (Figure 5.9).

There was a pronounced difference in the proportion of responses across year groups in water conservation for both constructs (Figure 5.9). Results demonstrate that similar proportions of students in Year 5 and 6 generated responses about water conservation, and were significantly greater than students in Year 4. These differences in knowledge about water conservation could reflect a lack of focus on water issues by Year 4 teachers and a focus on water conservation by Year 5 and 6 teachers. Furthermore, Year 6 students may have had accumulated knowledge about water conservation because of a focus on the topic in the previous year and a stronger focus 
on water issues in Year 6. Interviews with teachers confirmed this hypothesis, indicating that Year 4 students had been focussing on recycling and waste, Year 5 on the Swan River and indigenous perspectives, and Year 6 on water catchments. Mrs Marlin stated,

Every year level has their focus. The Year Fours, with the recycling, they're getting a specific program and a lot of information about the three Rs [reduce, reuse, recycle] and that's their focus. Then they'll come into [Year Five and Six] and they'll be doing all this stuff on the Swan River.

Although teacher interviews indicated that Year 4 teachers had not adopted the topic of water conservation as a focus area, the low proportion of responses from Year 4 students is inconsistent with media coverage in Perth, a city that is among the driest cities in Australia whose residents are regularly exposed to media campaigns that encourage reduction in household water use. This finding may suggest that Year 4 students were comparatively less impacted by media reports about water conservation in Perth and perhaps less involved in family discussion on the topic than Year 5 and 6 students. It could also indicate that students at River's Edge Primary School were strongly influenced by a focus on water conservation in Year 5 and 6, possibly because their families may not have prioritised water conservation at home.

Year group differences were also apparent for the theme complex in sustainability with a significantly greater proportion of students in Year 5 and 6 producing more complex ideas (ideas associated with more than one theme), than students in Year 4 (Figure 5.9). This result could reflect an understanding among 30 percent of Year 5s and 20 percent of Year 6s at River's Edge Primary School, of the complex interaction of themes common to issues of sustainability, and that sustainability may have been particularly challenging for the Year 4 students.

Construct differences. The two constructs, sustainability and things I can do to help the environment, were not significantly different for depth of knowledge (Figure 5.5), but were significantly different for volume and breadth of knowledge with things $I$ can do to help the environment scoring higher than sustainability (Figures 5.6 and 5.7). Significant differences were also found between the two constructs in the percent of student responses toward nearly all of the themes, as illustrated in Figure 5.8. Similar to results from Lighthouse Primary School, there was a greater proportion of students in all year groups who gave simple ideas for the construct sustainability compared with things I can do to help the environment. These results support the hypothesis asserted in 
Chapter 4 that students saw a difference between the two constructs, and that sustainability may have been an ambiguous or confusing term for many students.

Another similarity to Lighthouse Primary School was that predominantly environmentally related themes were observed for both constructs (Figure 5.8), indicating that sustainability was more broadly associated with environmental themes than socio-cultural or economic perspectives. Different to Lighthouse Primary School, the proportion of students that mentioned ideas related to values, advocacy and philanthropy was similar across both constructs and all year groups. Furthermore, the theme social and cultural wellbeing was only observed for the construct sustainability, however, the proportion of student response was less than 5 percent. Examples of responses coded into this theme were: "world vision", "races", "traditions", "help poor people", "individuality". This suggests that there was a very small proportion of students at River's Edge Primary School that had a broad understanding of sustainability.

Trends in percent response per theme. Also similar to Lighthouse Primary School, a trend was found in the data for the rates of student response towards certain themes (Figure 5.8), where waste management, water conservation and biodiversity conservation had higher rates of response than the less popularly thought of themes air pollution and transport choices and energy reduction. These trends were consistent across constructs although they were stronger for things I can do to help the environment. Data from document searches illustrates that, similar to Lighthouse Primary School, waste management, water conservation and biodiversity conservation were the most heavily emphasised themes in River's Edge Primary School's wholeschool sustainability initiatives (Table 5.1). Further unpacking this trend by referencing teacher interviews and student postcodes (collected via the surveys), found that River's Edge Primary School had attempted an emphasis on walking and cycling to school, but this initiative had not been popular for several reasons: 1) over 70 percent of students lived further than 2.5 kilometres from the school, 2) the school was far from public transport, 3) students had multiple before and after school commitments, and 4) many parents displayed resistance to allowing their children to walk unaccompanied. Mrs Eagle Ray explained,

We still have so many pick ups and drop offs and we don't have enough bike riding. And it's really quite safe to bike ride and walk. I would really love to have more people walking. Kids have so many rehearsals and practices that with all their gear they have to be dropped off-because of different times, the parents feel more comfortable with dropping them off at 7 am rather than having 
them walk so early for safety reasons, or their perceived safety reasons. I don't think this area is unsafe. So I think that is an uphill battle. ... We're not that close to public transport. [Transperth] had to put on a bus especially so they can do the connection, but because of all the [students'] commitments the use of the bus is not that good. ... We only had about 9 kids so they abandoned it, which I can understand.

\section{Summary}

Mind mapping of Year 4, 5 and 6 students at River's Edge Primary School highlighted several key implications:

1) Year 5 and 6 students had a greater volume and breadth of ideas compared with Year 4 students, which indicates there were differences in the focus and depth of teaching about the environment and sustainability at River's Edge Primary School, which suggests that the sustainability program was yet to permeate the whole school.

2) A significantly lower proportion of Year 4 students gave ideas for the theme water conservation than students in Years 5 and 6, which was most likely related to an increased focus on water conservation by teachers in the older year groups and may have been compounded by a low level of student awareness or family reinforcement about the importance of conserving water.

3) Students had a greater volume and breadth of ideas for the construct things I can do to help the environment than for the construct sustainability, which supports the assertion made in Chapter 4 that students found the concept sustainability confusing or ambiguous.

4) The majority of students related sustainability with environmental themes and a significantly larger proportion of students gave simple ideas for sustainability, which further supports the assertion made in Chapter 4 that sustainability was a concept that most students thought of as environmental and was an ambiguous or confusing term for many of them.

5) A large proportion of all students gave ideas in the themes of waste management, water conservation and biodiversity conservation, but other environmental themes such as air pollution and transport choices and energy reduction were less popular. Taken together with data from interviews, document searches and demographics, this result indicates that students' responses were influenced by the dominant emphases in the school's sustainability initiatives and, in the case of air pollution and transport choices, the tangibility of the activity and support from parents. 


\section{Research Question 3: What were the Environmental Behaviours of Upper- Primary Students at River's Edge Primary School?}

Environmental behaviours were investigated using surveys conducted with students from Years 4, 5 and $6(n=155)$ and interviews with nine students in 2009. Follow-up surveys were conducted in 2010 with students from Years 5 and $6(n=128)$. In 2010 there were 15 students that had either left the school or were not present on the day of the survey ( $\operatorname{Yr} 5=9$, Yr $6=6$ ). There were, however, 46 new students in 2010 (Yr $5=31$, Yr $6=15$ ) who participated in the survey at River's Edge Primary School. It was not possible to survey Year 7 students in 2010 as they had moved to the senior school campus.

This section explores relationships between students' frequency of undertaking seven common pro-environmental behaviours and three comparison variables: Learning, Importance and Participation. The data in this section came from the student surveys conducted in 2009 and 2010. The analyses and organisation of results presented in this section are similar to the section on Behaviours described in more detail in Chapter 4, so the rationale for these is not repeated here.

\section{Results and discussion}

Descriptive statistics and chi-square analyses were conducted and triangulated for each behaviour and comparison variable. For consistency across findings chapters, behaviours were categorised as high, moderate or low, according to the percentage of students that indicated they performed a behaviour on a more than weekly basis (Figure 5.10). The groups are presented and discussed in the following paragraphs. 


\section{Frequency of pro-environmental behaviours at home}

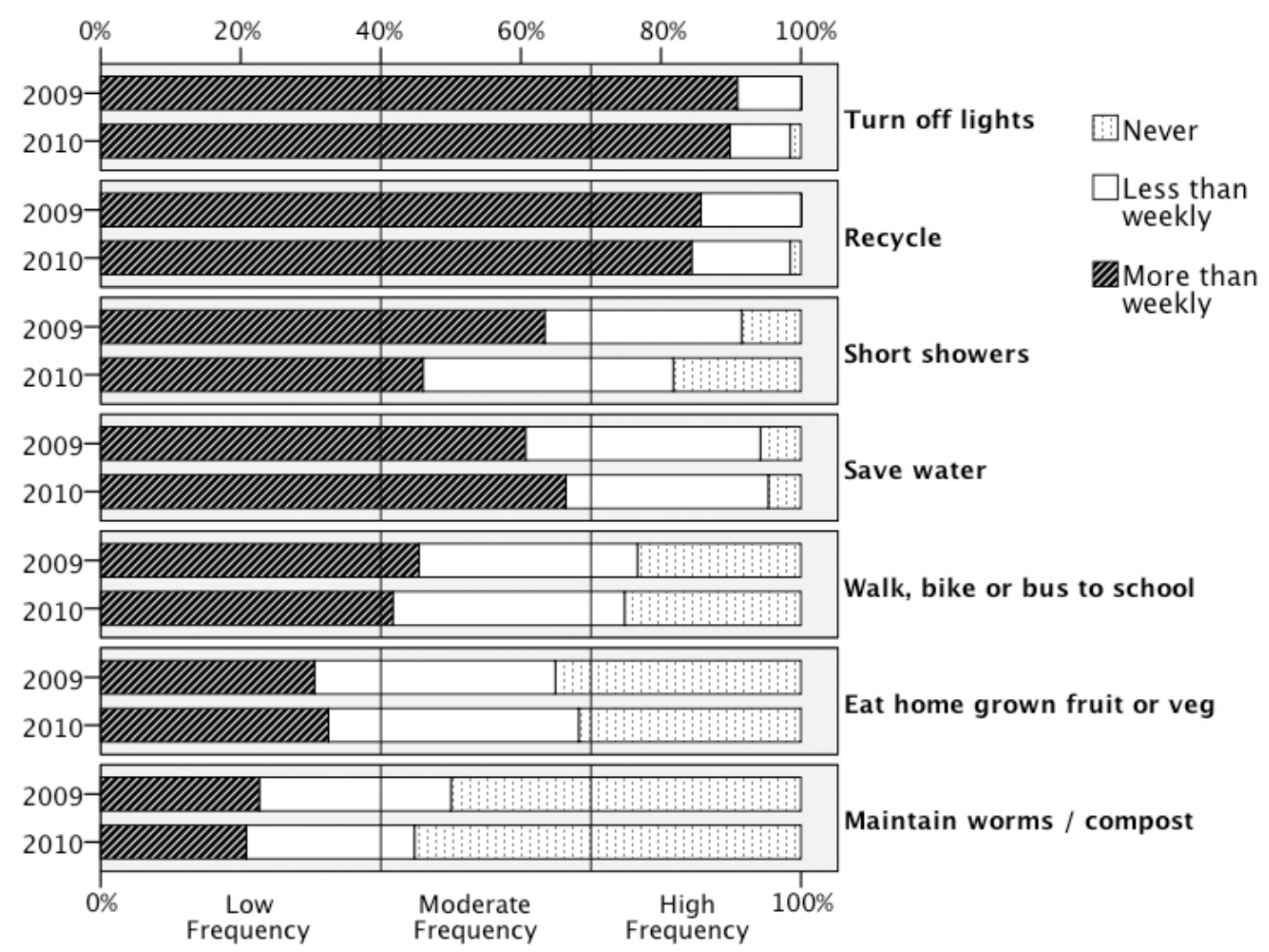

Figure 5.10. Percentage of students that reported they undertook each of the seven proenvironmental behaviours in 2009 and 2010 'never', 'less than weekly' or 'more than weekly'. $\mathrm{n}_{2009}=155, \mathrm{n}_{2010}=128$. Resulting patterns suggested certain behaviours grouped together to form three categories: high (> 70\%), moderate $(40 \%-70 \%)$ and low $(<40 \%)$ frequency.

\section{Summary and discussion}

At River's Edge Primary School, the weekly practice of pro-environmental behaviours by upper-primary school students in their homes was predominantly related to the students' degree of participation within their families. Table 5.11 displays a summary of the dominant relationships between the seven estimated behaviours and three comparison variables: Learning, Importance and Participation. Detailed results from relationship testing using chi-square tests and box plots are presented and described in Appendix 5. The following discussion draws on data presented primarily in Table 5.11 but also from the more detailed data analysis presented in Appendix 5. 
Table 5.11. Summary of the dominant relationships between seven pro-environmental behaviours that students could practice in their homes and the three variables: Learning, Importance and Participation. The prevalence of each behaviour is shown as a proportion of the total sample. Dominant patterns between Learning, Importance and Participation and weekly behaviour are presented to infer the features that had greatest influence on each behaviour.

\begin{tabular}{|c|c|c|c|c|c|}
\hline \multirow[t]{2}{*}{ Behaviour } & \multirow[t]{2}{*}{ Prevalence* } & \multicolumn{4}{|c|}{ Practiced weekly, when: } \\
\hline & & Learning & Importance & Participation $†$ & Other \\
\hline Turning off lights & Widespread & - & - & Family norm & - \\
\hline $\begin{array}{l}\text { Recycling paper or } \\
\text { plastic }\end{array}$ & Widespread & - & - & Family norm & - \\
\hline \multirow[t]{2}{*}{ Short showers } & Common & $\begin{array}{l}\text { Weekly or } \\
\text { less }\end{array}$ & $\begin{array}{l}\text { Important } \\
(2010)\end{array}$ & $\begin{array}{l}\text { Family norm } \\
(2009)\end{array}$ & - \\
\hline & & & & $\begin{array}{l}\text { Student } \\
\text { co-enthusiast } \\
(2010)\end{array}$ & \\
\hline \multirow[t]{2}{*}{ Saving water } & Common & $\begin{array}{l}\text { Weekly } \\
(2009)\end{array}$ & Important & Family norm & - \\
\hline & & $\begin{array}{l}\text { Weekly or } \\
\text { less (2010) }\end{array}$ & & & \\
\hline $\begin{array}{l}\text { Walking, biking or } \\
\text { bussing to school }\end{array}$ & Common & $\begin{array}{l}\text { Weekly } \\
(2009)\end{array}$ & Important & $\begin{array}{l}\text { Student } \\
\text { co-enthusiast }\end{array}$ & $\begin{array}{l}\text { Age }>11 \\
\text { years old } \\
(2009)\end{array}$ \\
\hline $\begin{array}{l}\text { Eating home grown } \\
\text { fruits or vegetables }\end{array}$ & Uncommon & - & - & $\begin{array}{l}\text { Student } \\
\text { co-enthusiast }\end{array}$ & - \\
\hline $\begin{array}{l}\text { Putting food scraps } \\
\text { into a worm farm or } \\
\text { compost bin }\end{array}$ & Uncommon & - & - & Family norm & - \\
\hline
\end{tabular}

* Prevalence: Widespread, $>70$ percent of all students did this weekly; Common, $40-70$ percent of all students did this weekly; Uncommon, $<40$ percent of all students did this weekly.

$\dagger$ Participation: Family norm $=$ Students participated weekly even if they were not one of the most active family members. Student co-enthusiast $=$ Students participated weekly when they were one of the most active family members.

A majority of students at River's Edge Primary School turned off lights, recycled and put food scraps into a worm farm or compost bin on a weekly basis when it was a family norm (Table 5.11). The term family norm was inferred when it was observed that most students who practiced a behaviour on a weekly basis did so even if they were not one of the most proactive family members. By comparison, students who ate home grown produce weekly did so when they were a co-enthusiast (Table 5.11). The term co-enthusiast was inferred when it was observed that most students who practiced a behaviour on a weekly basis did so when they were one of the most proactive family members in this activity. In families where parents or siblings were most proactive in these behaviours students were less likely to do the behaviour weekly. Taking alternative transport to school and the two water saving behaviours were more complex. These behaviours were related in different ways to each of the comparison 
variables: Learning, Importance and Participation (Table 5.11).

Similar to the results from Lighthouse Primary School, it is suspected that the widespread weekly, and indeed daily (Appendix 5), frequency of turning off lights and recycling were influenced by the simplicity of the task, available infrastructure and family expectations. This finding is discussed in further depth in Chapter 9, synthesis and conclusions.

Students who maintained organic waste weekly did so when it was a family norm, whereas students who ate home grown produce weekly did so when they were a co-enthusiast (Table 5.11). This could suggest that students who regularly ate home grown produce were also engaged in caring for their fruit trees or vegetables and had a vested interest in eating fruits and vegetables that they had produced, or possibly that eating home grown produce was an activity that all family members did together, thus doing it equally as often. By comparison, students who put food scraps into a worm farm or compost bin weekly, may simply have understood the question as putting food scraps into a kitchen bucket, with many of their parents doing this more often.

Eating home grown produce and maintaining organic waste at home on a weekly basis was uncommon among students at River's Edge Primary School, which is a result similar to those from Lighthouse Primary School. However, Figure 5.10 illustrates that at least 60 percent of families at River's Edge Primary School grew produce at home, and over 45 percent of families had a worm farm or compost bin. Nevertheless, a large percentage of students indicated that no one in their family did either of these behaviours, and supports an assertion that eating home grown produce and maintaining organic waste are mediated primarily by whether there is family support, such as infrastructure and time.

Taking alternative transport to school on a weekly basis was most strongly related with age of the students, weekly learning and being a co-enthusiast in their household (Table 5.11). For the 2009 data, it was found that more 11 and 12 year old students took alternative transport weekly compared with 9 and 10 year old students (Appendix 5). Learning also had a positive relationship with taking alternative transport in 2009, so it was possible that Learning had more impact or was more directed to older students (Appendix 5.15). However, mind map results from 2009 indicated no significant year group differences for students' responses toward transport choices (Figure 5.9), reflecting no difference in knowledge across year groups, so it was perhaps more possible that older students in 2009 were simply more willing or supported by their families to take alternative transport. 
Figure 5.10 illustrates that over 70 percent of students at River's Edge Primary School took alternative transport to school at any time in the school year, and is a 30 percent increase on the students who did this activity on a weekly basis. This could indicate that the school's walk-to-school initiatives were impacting roughly 30 percent of students in the upper-primary years. Moreover, this is useful feedback for the school principal who stated (earlier in this chapter) that many obstacles, including lack of parental support, had faulted the school's walk-to-school and bus-to-school initiatives that there had been reduced participation among students and Transperth (bus company) had cancelled the bus service.

Unlike Lighthouse Primary School, taking alternative transport to school on a weekly basis was not related to students' proximity to the school. This result is not surprising for two reasons. First, River's Edge Primary School is an elite private school that drew students from various suburbs across Perth, making it difficult for students to travel long distances to school (Appendix 5). Second, it is likely that parents were cautious about allowing their children to walk, bike or bus to school, regardless of how close they lived to the school, because of fears for their children's safety and the volume of equipment required for their child's various extra curricular activities, as indicated by a quotation from Mrs Eagle Ray cited earlier in this chapter.

It is suspected that, similar to Lighthouse Primary School, a focus on water conservation during National Water Week in 2009 affected results for the two water saving behaviours. In 2009 weekly short showers was related to the behaviour being a family norm and was practiced by the majority of students irrespective of how often they learned about the topic (Table 5.11). Nevertheless, because of National Water Week it is probable that students had been learning in more depth about the topic and the recent focus may have influenced their frequency of behaviour at the time of the survey and their self-reporting. Whereas, in 2010 short showers were performed weekly by students who were a co-enthusiast, who learned about water conservation weekly and who said that school environmental experiences were important to them (Appendix 5). This change in relationships in 2010, likely indicated a return to 'normal' levels such that only students who felt strongly about environmental experiences were motivated to participate in this behaviour in their homes. Figure 5.10 demonstrates the 18 percent drop in students taking short showers in 2010. Essentially, these results support an assertion made in Chapter 4, that when students learn more about water conservation, Importance becomes less related to their showering behaviour and Participation increases. 
Saving water at home on a more than weekly basis was practiced by the majority of students when it was a family norm (Table 5.11). This relationship was not different across 2009 and 2010 even though it appears that students in 2009 were influenced by a learning focus on water conservation because of National Water Week (Appendix 5). It is possible that saving water was encouraged among family members more frequently than short showers or easier for students to participate in than regular short showers, which require more self-determination.

The weekly frequency of short showers and saving water were also related to the importance that students placed on school-based environmental experiences, particularly in 2010 when the impetus from National Water Week had passed. Interviews with children selected for their high expressed importance of environmental experiences support this relationship. A Year 5 student who ranked environmental experiences as very important said of her behaviour at home,

We try to use as little water as possible, turn off lights when we don't need them, only use air con and heater if completely necessary, use a clothes line instead of a dryer, try to have as short a shower as possible.

In summary, to turn off lights and recycle are both behaviours that have become normalised in this school's community, require minimal skill, and the infrastructure is available in every home to make it easier for students and adults to undertake these behaviours. Eating home grown produce and maintaining organic waste were uncommon and require household investment in infrastructure and parental support. Taking alternative transport to school appears to be relative to the context and demographic of families whose children attend the school, with older students at River's Edge Primary School taking alternative transport more often than younger students. Water saving behaviours, particularly short showers, appear to be more difficult for upper-primary aged students to do frequently without continued reminders from school or prioritisation within the family, even though Perth often has water restrictions and advertising campaigns to encourage this behaviour. 


\section{Chapter Conclusion}

River's Edge Primary School was in the early stages of implementation of a whole-school sustainability program at the time of data collection, and was facing several challenges related to broad staff support, curriculum integration and collaborative decision-making processes. Despite these, their collaboration with Millennium Kids as the school's sustainability facilitator had helped certain key staff members at River's Edge Primary School to understand the interlocking perspectives of sustainability, and to undertake various integrated activities that involved elements of community engagement and student leadership. The school still had a long way to go before it could claim to have an established whole-school sustainability program, but certain important foundational elements were in place.

Similar to conclusions from Lighthouse Primary School, sustainability education at River's Edge Primary School had impacted students' knowledge of environmental actions, but that many students were confused about what sustainability is and whether it is distinct from environmental perspectives. Furthermore, differences in year group responses to depth, volume, breadth of knowledge, together with very low water awareness levels among Year $4 \mathrm{~s}$, suggests that the sustainability program, was yet to permeate the whole school. Similar again to Lighthouse Primary School, it also appeared that the regularity of students' practicing several of the seven proenvironmental behaviours had been impacted either directly through weekly learning experiences or indirectly by influencing the degree of student participation at home. Turning off lights and recycling, however, were primarily influenced by family norms. Overall, it seemed clear that some students at River's Edge Primary School, in particular Year 5s, had access to opportunities to develop pro-environmental knowledge, skills and motivation to act, but that only a few students, particularly those on the sustainability committee, had developed elements of action competence.

The following chapter presents results from the comparison case study, Fertile Ground School. The cross-case comparison of results from Lighthouse, River's Edge and Fertile Ground Primary Schools will be explored in Chapter 9, the synthesis. 
THIS PAGE HAS PURPOSELY BEEN LEFT BLANK 


\section{Chapter 6: Potential For GROWTH \\ - Fertile Ground PRimary SCHOOL}
Education - in all its forms and all levels - is not only an end in itself but is also one of the most powerful instruments we have for bringing about the changes required to achieve sustainable development.

(Kõichirõ Matsuura, former Director General of UNESCO)

This chapter presents a case study school with no recognised sustainability or environmental education programs in operation. Fertile Ground Primary School is a government public school and was chosen as a comparison school because at the time of data collection in 2009 , the school was:

1) From an upper-middle socioeconomic suburb of Perth, roughly 11 kilometres north of the city: similar demographically to the two other case study schools, where most children were unlikely to be faced with serious social or economic issues at home

2) On the Index of Community Socio-Educational Advantage (ACARA, 2012b), Fertile Ground Primary School was rated 1038 in 2009

3) Not a member of AuSSI schools

4) Not a member of Water Wise schools

5) Not a member of Waste Wise schools

6) Not associated with Millennium Kids

Surveys and mind maps with students, interviews with teachers and the school principal, and observations of the school grounds, were carried out at Fertile Ground Primary School in 2009. Sixty nine percent of the 26 students surveyed in 2009 lived within two kilometres of the school. It was decided not to collect data in 2010, as was done at the two other case study schools, because the number of student participants, after dropouts, was too low for meaningful comparisons to be made $(\mathrm{n}<20)$. 


\section{Research Question 1: What Organisational Factors Fostered or Impeded the Establishment of Sustainability Initiatives at Fertile Ground Primary School?}

This section highlights and discusses the organisational potentialities available at Fertile Ground Primary School that could support the establishment of sustainability education, and the obstacles that school staff identified as inhibitive to the uptake of sustainability education. Results are presented across six themes, first, the history of sustainability education at the case study school and obstacles to its establishment, followed by five organisational elements important to the establishment of sustainability education: 1) school governance, 2) school planning, 3) community networks and partnerships, 4) student voice and engagement and 5) curriculum integration.

This section presents a discussion of the school's lack of sustainability focus, as reported by school staff. The main protagonists presented here are: Mr Sugar Glider, the principal; Mrs Platypus, the deputy principal and teacher of Year 5; Mrs Antechinus, a Year 6 teacher, and Mrs Rock-wallaby, a Year 4 teacher.

It is relevant to note that at the time of data collection in 2009 , the school $(\mathrm{K}-7)$ had been operating for 45 years, since 1964, and Mr Sugar Glider had been principal at the school for two years. Mrs Platypus had been teaching at the school for three years, Mrs Antechinus for 16 years and Mrs Rock-wallaby for 19 years.

\section{History of Sustainability Education at Fertile Ground Primary School and Obstacles to its Establishment}

Fertile Ground Primary School had never practiced whole-school sustainability education, nor had it participated in any government supported whole-school waste, or water reduction initiatives. However, interviews with the principal and several teachers revealed that a few simple and easy-to-coordinate initiatives were operating at the school on a class-by-class basis and depended heavily on the motivation of the class teacher. These included paper recycling, growing vegetables, power saving and attempts at encouraging students to walk to school.

Whole-school paper recycling had recently been adopted at the school. Mr Sugar Glider remarked, "We don't do a lot in this school in terms of the environment. We've just started recycling our paper. We started that this year". Mrs Antechinus clarified that the Year 6 and 7 students were responsible for ensuring the recycling program operated, stating, "Admin asked if after school we'll do it, so we're sharing it between the two classes" and "twice a week the kids go around and empty all the stuff into the bin outside". 
Growing vegetables was done on a class-by-class basis. Mrs Rock-wallaby explained, "Every year most classes would plant or grow something as part of their program", and "the year ones are doing plants at the moment and they're growing little tomatoes". However, because of concern for vandalism, the year one teacher had resorted to having a few pots of tomatoes in a wheelbarrow that could be wheeled out onto the playground every day (Figure 6.1). Mrs Antechinus remarked, "You've got to be careful, people can come in on the weekend and ruin it".

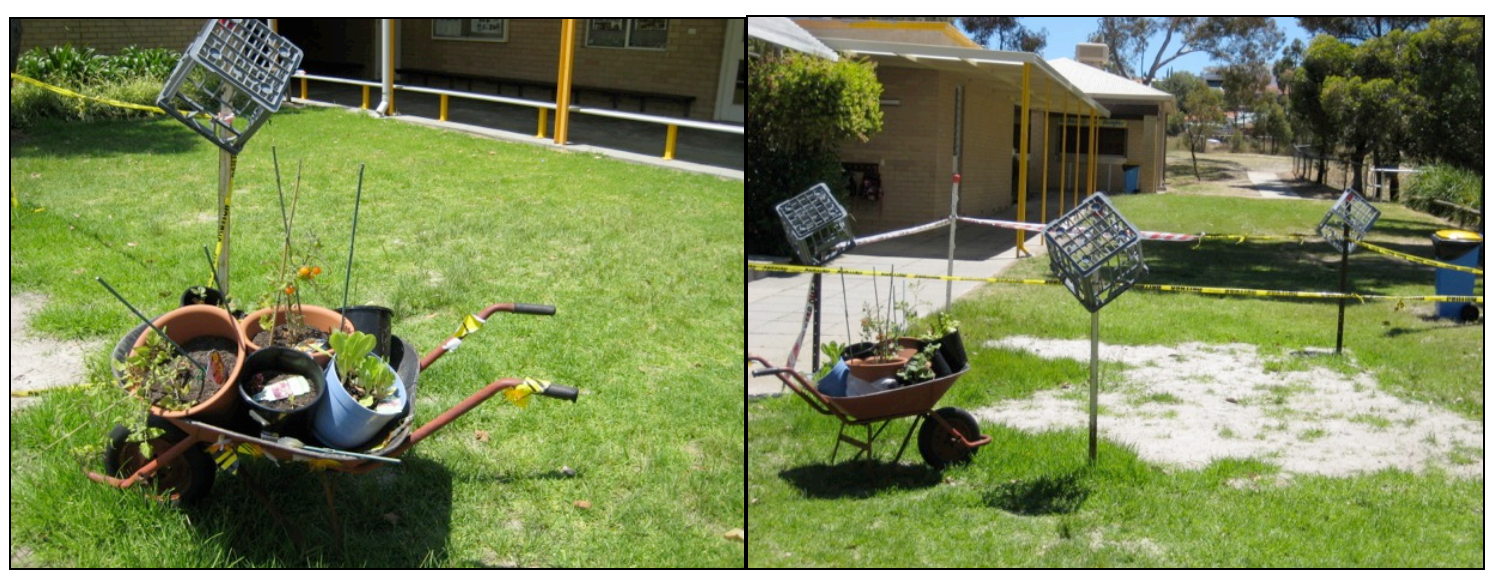

Figure 6.1. The tomatoes in a wheelbarrow being grown by a Year 1 class.

Saving power around the school also depended on the motivation of each class teacher, and was pursued primarily for financial reasons. Mrs Rock-wallaby explained, "We save a lot of money if we turn off lights and fans after we leave the room. ...five or six thousand dollars a year", which "can be spent on resources". Mrs Rock-wallaby continued to describe power saving as her personal project, stating, "I've always pushed every year for the staff to turn off their lights and fans when they're not in the room", and "teach your kids to do it - whoever's last out of the room, turn off your power".

Attempts at encouraging students to walk to school, which Mr Sugar Glider described was "like all schools, where kids walk to school and we put a breakfast on for them", were not successful at encouraging students to regularly walk to school. $\mathrm{Mr}$ Sugar Glider commented, "Most of our kids would live within four to five minutes walk of the school and probably 95 percent get dropped off in a car", a behaviour he described as being driven by fear, saying, "I think the media has put fear in people that we live in an awful place and kids aren't safe and it's just not true".

Receptivity was present, among the staff, for an integrated whole-school sustainability program to be introduced at the school providing that specific obstacles were addressed. The main obstacles identified were: 1) finding a passionate, dedicated staff member to drive the sustainability program, 2) managing the program so that it did not decrease instruction time, 3) vandalism on the school grounds, and 4) that the 
principal was committed to prioritising sustainability goals and would remain at the school long enough for the program to become established.

The main obstacle, identified by all those interviewed, was the lack of a dedicated, enthusiastic staff member to drive the sustainability program. Mrs Platypus stated, "You need a very very good coordinator because the coordinator then keeps everyone enthused". The principal, Mr Sugar Glider, who took responsibility for establishing the school recycling program and described his own personal pursuits towards living a sustainable home life, discussed his desire to see several more environmental initiatives rolled out at the school, but concluded that he was not the person to make these happen. He stated, “...it takes someone on the staff to be really dedicated and keen, and whilst I am, I don't have the time to commit to it". Mrs Antechinus reflected,

You'd love to do more, I mean, you get all this literature on how you can be a sustainable school and all these things you could do. Set this up in your school, set that up, but it's just too much to organise. Unless it was really a huge passion of someone who wanted to do it in their own time, it's too difficult.

Staff also identified time management and task allocation as an obstacle to the establishment of a sustainability program in their school. Mrs Platypus stated that establishing a sustainability program would be achievable because "it's one of those things that comes down to time and management", and Mr Sugar Glider described it as a process that can become embedded into school life, saying, "It's a process isn't it? Once you've got a process in place and people get used to it, it becomes habitual". However, Mrs Antechinus remarked, "You only have to be careful that it's just not another job for teachers to do because we are pretty snowed under", and warned that the administration should "be careful that it's organised in such a way that it's not just another thing that takes up time out of the kids' instruction time”. Mrs Rock-wallaby expressed concern that certain projects may not be a worthwhile use of time, such as a school vegetable garden, and stated, "We've got so much to teach in the primary school, so much of the basics, that for this school I don't think it is necessary". Despite some concerns there was support for the potential of fostering a sustainability focus at the school. Mrs Antechinus suggested, “There's lots of ways of doing things, I mean, admin can help, the P\&C maybe could do something".

Another obstacle identified by all interviewed staff, was a concern that any efforts to 'green' the school grounds would be destroyed by vandals. Mr Sugar Glider, the principal justified why he and his staff had decided not to apply for a grant for solar 
panels because "on the weekends we get vandalism on our roof, they ruin our air conditioners, we've had chairs thrown on our roofs", and said the staff were concerned they would "have smashed panels all the time on the roof, and we thought it's just another headache we've got to get fixed". Mr Sugar Glider continued,

Same with water tanks, we didn't get water tanks because of the graffiti. Maybe it's a negative view but it's just another management thing for me because I've got to report faults. The school should be fenced. And that's the issue with my veggie garden, there's a very good chance that if I put a veggie garden in it's going to get trashed.

When asked if the school could be fenced as a means of reducing the incidences of vandalism, Mr Sugar Glider identified money as the limiting factor. However, he discussed his ambitions for a future school vegetable garden that could be set up alongside some new buildings that were in the progress of being built because, "there may be a chance to have only three sides of fencing instead of four, so it can be done cheaply".

Some staff also identified that integral to the success of a whole-school sustainability focus, was the direction and prioritisation applied by Mr Sugar Glider and the longevity of his leadership. Mrs Rock-wallaby stated, "On the whole, I think your leadership is where things will change". It was clear that Mr Sugar Glider had a strong personal passion for sustainability education and environmental sustainability when he stated,

Our push for numeracy and literacy tends to forget the whole person ... There's so much more to creating a little person than just numeracy and literacy, although it's very important. So, as a system, putting energy and time into something else is not easy to justify, but in terms of developing whole, rounded, well-adjusted people it's very easy to justify.

I'm a really strong believer that too many of our kids and adults don't know anything about the Earth anymore. They wouldn't smell it they wouldn't know what it's like to have it through their hands. And that's going back to that concept of you going to the shop, you buying it off the shelf, you know. It's a very manufactured world.

Despite potential for Mr Sugar Glider to support and prioritise a sustainability program at Fertile Ground Primary School, there were indications that he may not remain at the school long enough to see them establish. Mr Sugar Glider himself acknowledged that "with the things I've brought in here, I hope if I leave, that in two years time they're still going" and commented that "it's about building the capacity of the people around you so that change is sustainable". 
Despite significant obstacles, the school displayed a firm foundation upon which whole-school sustainability education could be built. A foundation that included supportive leadership and operational structures, community engagement and staff unity. Examples of these are detailed in the following paragraphs.

\section{School Governance}

Observations and interviews with teachers from Fertile Ground Primary School indicated that staff were satisfied that their views were considered in staff meetings, and were content with the management and leadership of the principal, Mr Sugar Glider. There was also evidence that the staff body were united, supportive of each other, and that class time was used efficiently because managing difficult student behaviour was not a big issue at the school. Mrs Platypus expressed her views on the school atmosphere saying,

We're very lucky here, we have a fantastic staff and we have a fantastic school. The kids are great. They all want to learn and they all are focussed. You can walk into any classroom in the school and you will see children who are very focussed on whatever is going on. And I'm very grateful to be here.

There was also evidence that many teachers were already teaching elements of environmental sustainability in their classrooms. Mrs Rock-wallaby remarked, "From my observations of other teachers, they're pretty aware and do things as well". When asked if the teaching staff would support any teacher that wanted to initiate sustainability projects around the school, Mrs Antechinus responded, "Yeah. It's a good staff like that. Depending what it was I suppose, but staff are actually very good here and I think they would". And Mrs Rock-wallaby said, "The staff would probably follow, yes. Especially this staff, it's a fairly positive staff. ... I think most people would fall in line".

Mr Sugar Glider described willingness among staff towards supporting the school's recycling initiative that he had recently spearheaded, saying,

It's been great. The staff have been great. It's always a concern because to do recycling kids have to leave the classroom. Some teachers are quite happy to accommodate for those things and some teachers aren't. And that was my only concern. But interestingly, because it's recycling, they all went for it. I think the will is there. And I think with most people the will is there.

However, teachers expressed concerns regarding the longevity of such programs, which may fall away without continued leadership and encouragement. For example, teachers, who had been at the school longer than Mr Sugar Glider, remarked that paper recycling used to happen, but on a smaller scale. Mrs Antechinus reflected, 
"We did do paper recycling but what we did was just recycle it within the school". When asked why it stopped, Mrs Rock-wallaby stated, "I can't remember exactly why, it just dropped off. I think with a lot of things there's always a push to start with..." and Mrs Antechinus said, "You always need an organiser, you need someone in charge ".

Mrs Rock-wallaby identified that visionary, committed leadership would be integral to getting a sustainability program up and running at Fertile Ground Primary School, "Your leader, your boss, is very important for things. If he wants something to happen, if he pushes it, it will happen”.

Combined with strong leadership, all teachers identified that a sustainability program would only be established at Fertile Ground Primary School if at least one staff member drove the program. Mrs Rock-wallaby stated, "You just need someone who is very motivated and get-up-and-go and who believes in something and it will happen". The principal at the Fertile Ground indicated that he would enthusiastically support sustainability priorities in the school as long as there was "someone or a couple of people who were committed to driving it".

\section{School Planning}

Fertile Ground Primary School had no specific policies or plans in place to foster or support sustainability education. However, Mr Sugar Glider had a suggestion to help foster sustainability education in a significant way across all schools. He stated,

The government throws money hand over fist at all sorts of things, but you think about this, if every school had a teacher on point five - so it wouldn't have to be full time - or even one day a week in every school, that was committed to recycling and sustainability, what sort of programs would be running in every school and what sort of education would be going on in every school? Rather than sending out a file. A file's useless really. But if the kids are living it, and breathing it, and doing it, it's a real thing to get learning going on and they're part of the process. So that's really, I think, the answer.

Mr Sugar Glider continued to speak emphatically about the money that is spent on generating files and paper based resources for teachers, saying,

It's not new. The resources have always been there. People believe that if you throw money at creating resources everything will be fine but it's not true, that doesn't bring about change.

\section{Community Networks and Partnerships}

All interviewed staff identified parents as keen supporters of school projects, many of whom would be likely to actively support sustainability projects if one of the teaching staff were able to drive the initiatives. When asked about the role that parents 
might play, Mr Sugar Glider responded that involving parents was "the only way to go" and that "if the school is to be the beginning, the nucleus, just having parents bringing their recyclables to the school is a good place to start". And Mrs Rock-wallaby stated, "Anything that you did you'd need parent support, if not involvement", and "the more they're involved the more likelihood you'd get more parents interested because you have a few, they talk to a few and so on". Mrs Rock-wallaby also stated that the involvement of parents would enhance the impact of the sustainability program on the students, saying, "It rubs off on the kids. If both the parents and the teachers are the same then the kids will be the same".

It appeared that if Fertile Ground Primary School were to adopt a sustainability education program they would likely garner the support and involvement of their parent body. Mrs Platypus commented on the likelihood that parents would be supportive of a whole-school sustainability program saying, "This is a nice closely knit community. It's got that nice friendly atmosphere and I think people would be supportive". She described the involvement of parents in plans for a new vegetable garden project, saying,

I think that people would be receptive. We had a chat with one of the parents earlier this year about a garden for the canteen, so that the children are producing food stuffs that the canteen can actually use, and we have some parents that are interested in helping with that. That's just one very small aspect but it would work and the kids would be enthusiastic.

\section{Student Voice and Engagement}

At Fertile Ground Primary School, teachers talked about students as learners in an educational process, which sometimes involved doing environmentally sustainable tasks. Mrs Rock-wallaby stated, 'I've got a power ranger. That's the person at the end of the day who turns off the computers, makes sure everything's off'. And Mrs Antechinus described how often the older year groups were assigned to do tasks that might require greater levels of competence or responsibility, saying, "Our kids end up doing lots of extra jobs", and "it can't always be the Year 7s and the student councillors".

Mrs Platypus described her efforts to encourage student voice in her classroom saying, "Sometimes someone will make a comment and you're able to go off on a tangent, and you're able to investigate or discuss that". She explained her opinion towards creating opportunities outside of the classroom for students to learn, saying, "It's not just about content. ... Incidental ways of learning are often just as forceful as a full on lesson in the classroom". 
If Fertile Ground Primary School were to adopt a sustainability education program, they might consider looking at examples from other schools where student voice and involvement has been engaged in other, more significant and meaningful ways.

\section{Curriculum Integration}

At Fertile Ground Primary School, some teachers expressed an understanding of cross-curricula, whole-systems thinking. For example, Mrs Antechinus had developed units of work around environmental footprints, energy reduction, and renewable energies that were integrated across the learning areas of English, society and environment, science, and technology and enterprise (Figure 6.2). In another example, Mrs Rock-wallaby described how she had programmed integrated units of work around the topic of water,

We'll do poems or stories about it. We're doing a graph. We're actually doing water capacity at the moment so that links in with it. We'll be doing graphs about the amount of liquid each container holds and we bar graph it. So within reason I try and integrate it. (Figure 6.3)

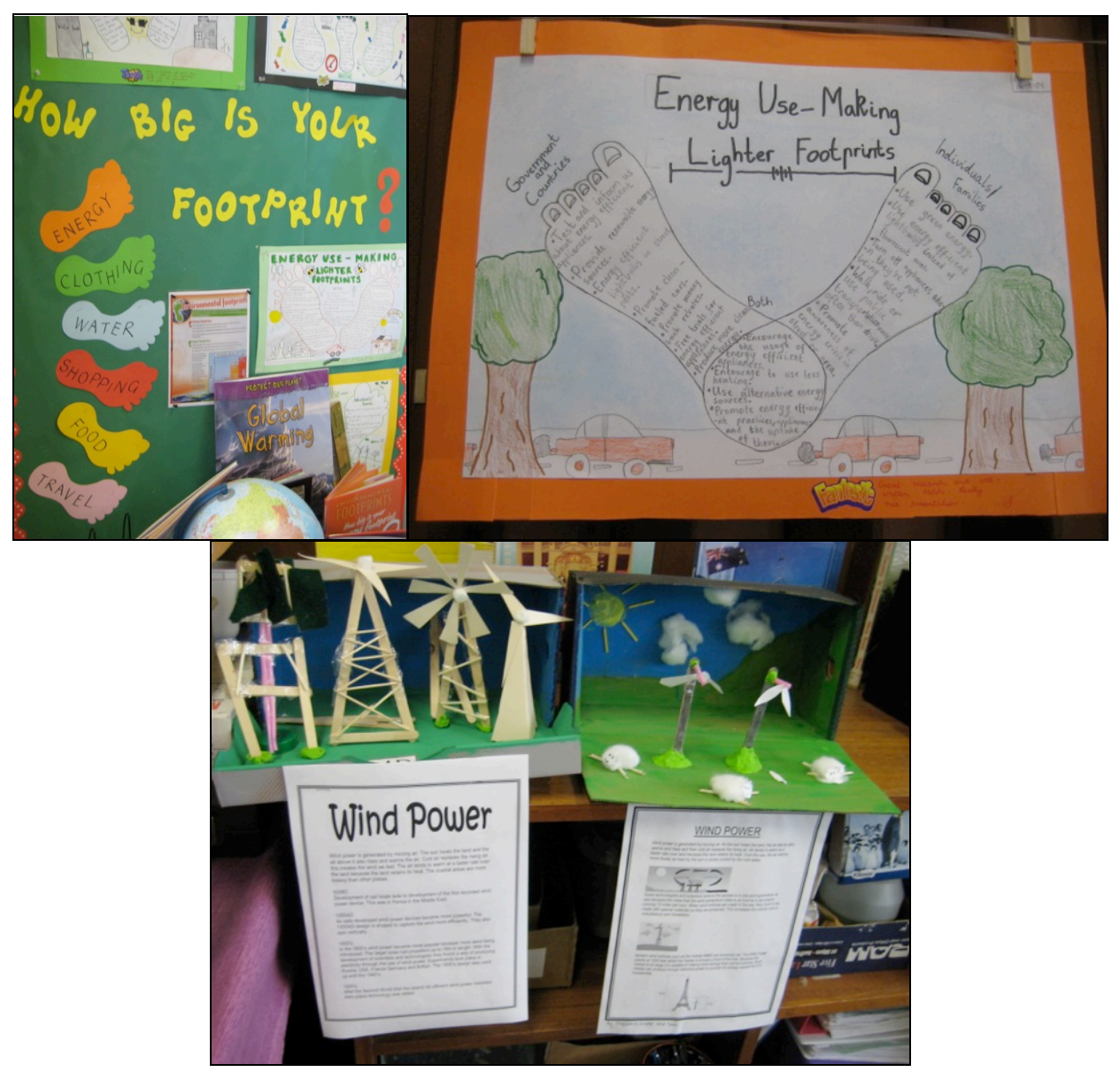

Figure 6.2. Examples of Year 5 students' work on environmental footprints, energy reduction and renewable energies. 


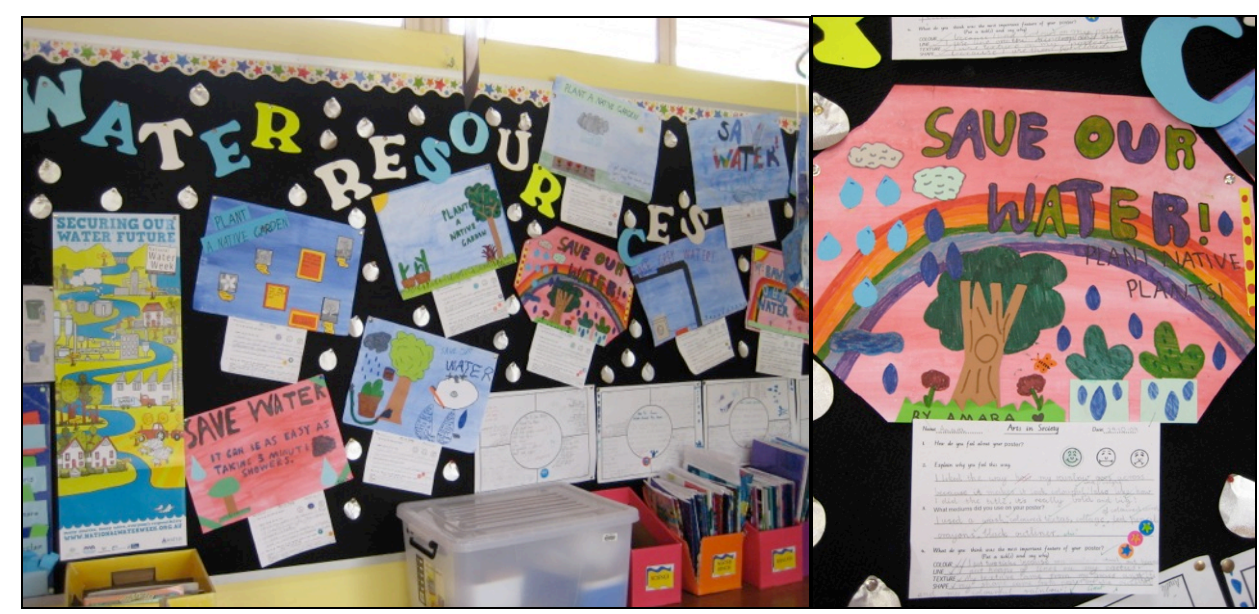

Figure 6.3. Examples of Year 4 students' work on the theme of water conservation.

Despite using integrated approaches to foster student learning, the concept of sustainability was primarily associated with the environment alone. Mr Sugar Glider described his vision, "Every class will cover some level of the environment, which would probably lead to sustainability, probably from about Year 4 onwards, in science". Some teachers also appeared to think of sustainability as 'another thing to teach', and expressed frustration with the curriculum being loaded up with so many priorities that teachers often feel overwhelmed and overworked. Mrs Platypus remarked,

That's the problem with our curriculum, extra things being laid down on you and nothing's ever taken away. You know? There's a problem within the community over something, the school's will fix it - the AIDS program, the preventive education program, stranger danger - you keep going and it won't change. We can do so much but where does our role stop? Where's the division between what is the school's responsibility and what is the community or parents' responsibility?

\section{Summary}

This research indicates that Fertile Ground Primary School was well placed to adopt a whole-school sustainability education focus and to expand their existing classbased environmental initiatives. The main feature required to commence a whole-school sustainability program at Fertile Ground Primary School would have been a passionate, dedicated staff member who could manage the program in such a way as to inspire and engage other staff, parents and students in the process. Of the approach required, $\mathrm{Mr}$ Sugar Glider stated, 'I don't think it's that complicated, I actually think it's quite simple" and of the nature of the person needed to drive the program he stated that they should be "infectious, passionate, and not pushy".

With no one on the staff to coordinate and drive sustainability efforts at Fertile Ground Primary School, the enthusiastic support of Mr Sugar Glider, the collegial solidarity of the staff, and the potential keen interest among parents could be likened to 
the fertile ground upon which the seeds of sustainability education simply needed to be sown and nurtured.

\section{Research Question 2: What was the Environmental and Sustainability Knowledge of Upper-Primary Students at Fertile Ground Primary School?}

As described in Chapters 4 and 5, mind maps were used to estimate students' knowledge of pro-environmental behaviours, their understanding of sustainability and the extent of their whole-systems thinking. Mind maps were created by students from Years 4, 5 and $6(\mathrm{n}=26)$. The results are presented and discussed in this section, and are discussed again in the conclusions of this chapter to triangulate with behaviour data. The analyses and organisation of results presented in this section are similar to the section on Knowledge described in more detail in Chapter 4.

\section{Results and discussion}

Mind maps were coded into a quantitative format using the coding scheme described in Chapter 3. Non-parametric tests were performed on the quantitative mind map data to determine year group and construct differences in the depth, volume and breadth of students' environmental and sustainability knowledge. Following these analyses, responses were simplified to a binary format (presence $=1$, absence $=0$ ) to determine the proportion of students per year group, per construct that responded for each of the nine emergent themes.

The responses from students in Year 4 were excluded from analyses that involved comparison across year groups because the sample size of Year 4 students was very low $(\mathrm{n}=2)$. For comparisons across constructs year groups were pooled, and all student responses were included in these analyses.

Depth. Kruskal-Wallis tests found no statistical difference in depth of knowledge (number of hierarchies) across year groups, and no statistical difference in depth of knowledge between the two constructs sustainability and things I can do to help the environment. Figure 6.4 illustrates the findings. 


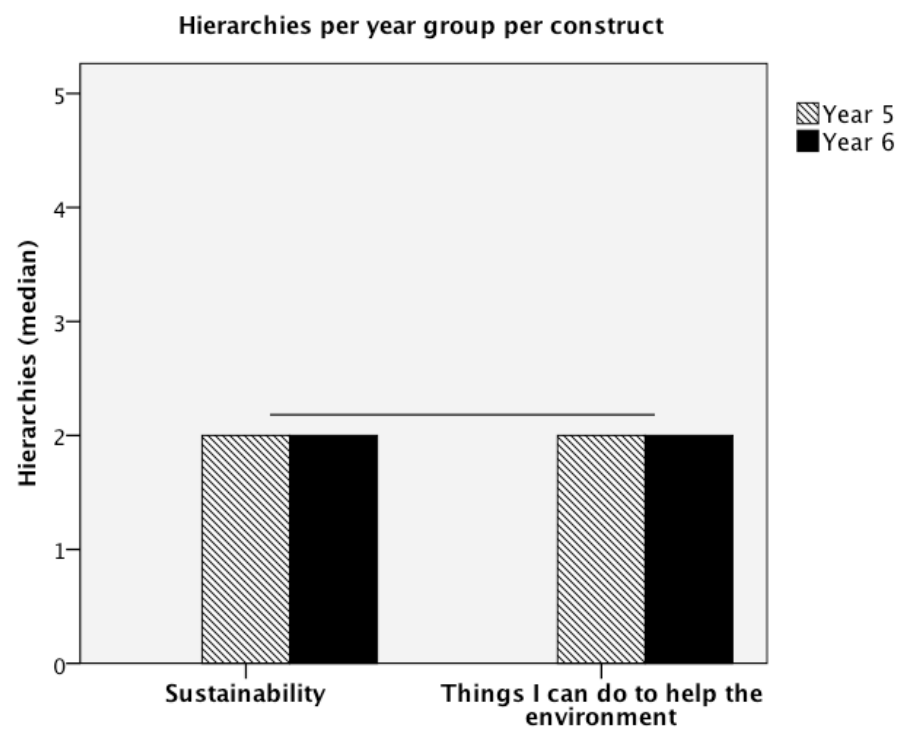

Figure 6.4. Depth of knowledge for each construct, $n_{S}=26, n_{H E}=26$.

Volume. As mentioned in Chapter 4, analysis of volume of knowledge (total number of ideas) did not include responses from the theme simple. Table 6.1 presents the statistical results from Kruskal-Wallis tests. No significant difference was found in volume of knowledge across year groups, but a statistical difference was found in volume of knowledge between the two constructs sustainability and things I can do to help the environment. The construct things I can do to help the environment displayed greater number of ideas than did sustainability. Figure 6.5 illustrates the findings.

Table 6.1. Statistical results from Kruskal-Wallis tests of Ideas compared across year groups and constructs.

\begin{tabular}{lcccc}
\hline & $d f$ & $n$ & $\chi^{2}$ & $p$ \\
\hline Ideas: year groups & 1 & 41 & .11 & .740 \\
Ideas: constructs & 1 & 44 & 16.57 & $* *$ \\
\hline
\end{tabular}

$* p<.05, * * p<.01$ 


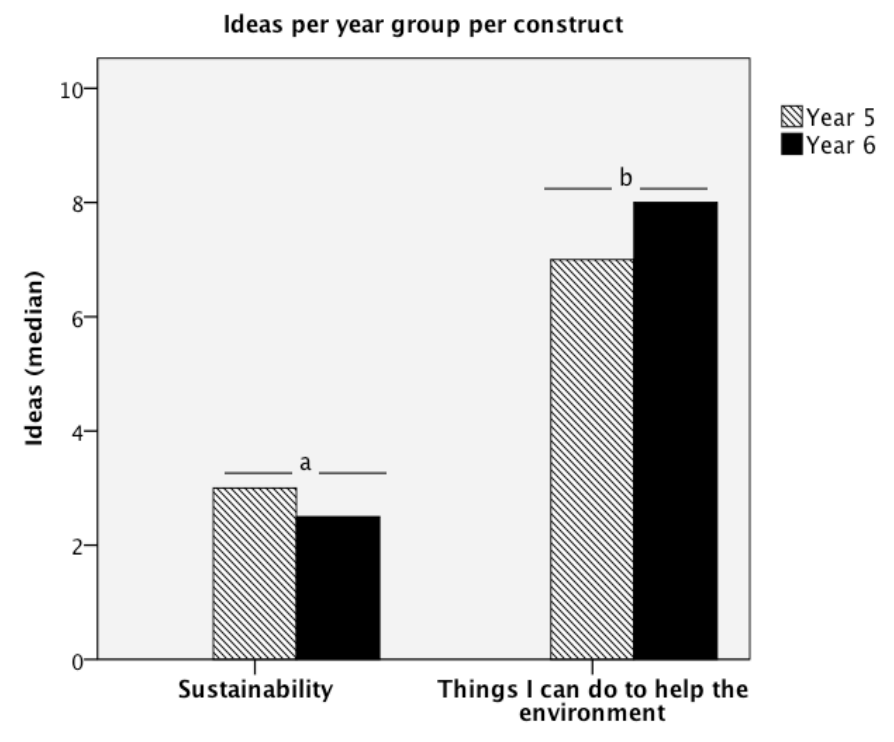

Figure 6.5. Volume of knowledge for each construct, $n_{S}=26, n_{H E}=26$.

Breadth. As mentioned in Chapter 4, analyses of breadth of knowledge (scope of themes) did not include responses from the theme simple. Table 6.2 presents the statistical results from Kruskal-Wallis tests. A Kruskal-Wallis test found no significant difference in breadth of knowledge across year groups. Another Kruskal-Wallis test revealed statistical difference in breadth of knowledge between the two constructs sustainability and things I can do to help the environment. The construct things I can do to help the environment displayed greater scope of themes than did sustainability. Figure 6.6 illustrates the findings.

Table 6.2. Statistical results from Kruskal-Wallis tests of Scope of Themes compared across year groups and constructs.

\begin{tabular}{lcccc}
\hline & $d f$ & $n$ & $\chi^{2}$ & $p$ \\
\hline Themes: year groups & 1 & 41 & .26 & .611 \\
Themes: constructs & 1 & 44 & 8.17 & $* *$ \\
\hline
\end{tabular}

$* p<.05, * * p<.01$ 


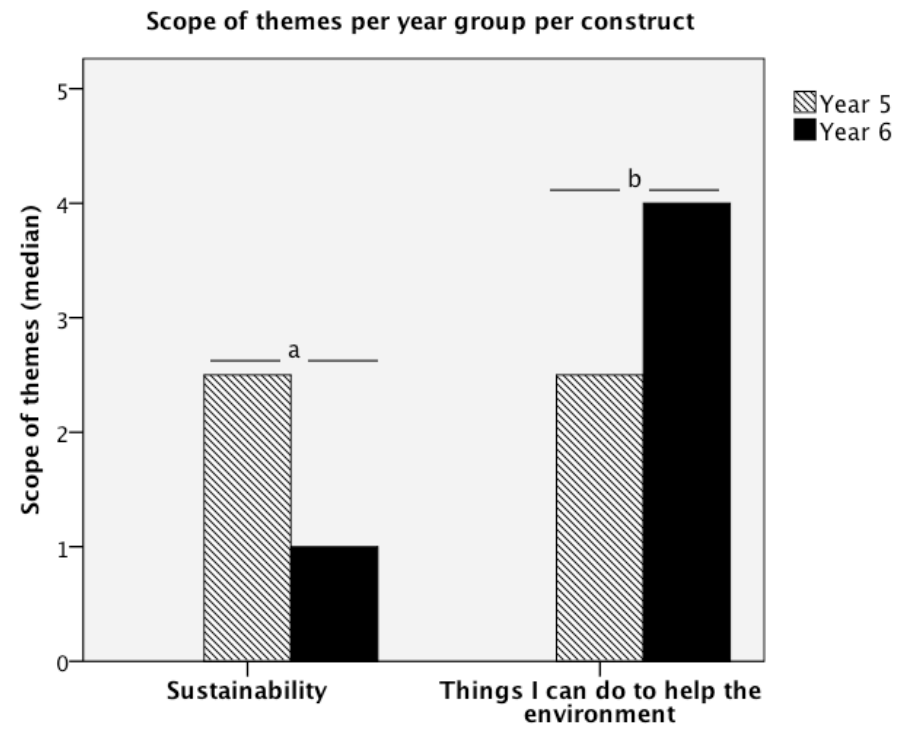

Figure 6.6. Breadth of knowledge for each construct, $n_{S}=26, n_{H E}=26$.

Percent response. Percent response per theme was investigated to determine if there were differences in the proportion of students that responded to each theme per construct. All students' responses were minimised to a binary format (presence $=1$, absence $=0$ ) to look for patterns of percent response per theme.

Kruskal-Wallis tests were performed, comparing the proportion of students' responses across themes per construct, and found significant differences between constructs for the themes waste management, energy reduction, air pollution and transport choices and simple. Table 6.3 summarises the statistics for these significant differences and Figure 6.7 illustrates the patterns of each theme per construct.

Table 6.3. Significant results from Kruskal-Wallis tests of percent response compared across constructs.

\begin{tabular}{lcccc}
\hline & $d f$ & $n$ & $\chi^{2}$ & $p$ \\
\hline Waste & 1 & 52 & 5.33 & $*$ \\
Energy & 1 & 52 & 9.25 & $* *$ \\
Air \& Transport & 1 & 52 & 17.00 & $* *$ \\
Simple & 1 & 52 & 12.75 & $* *$ \\
\hline
\end{tabular}




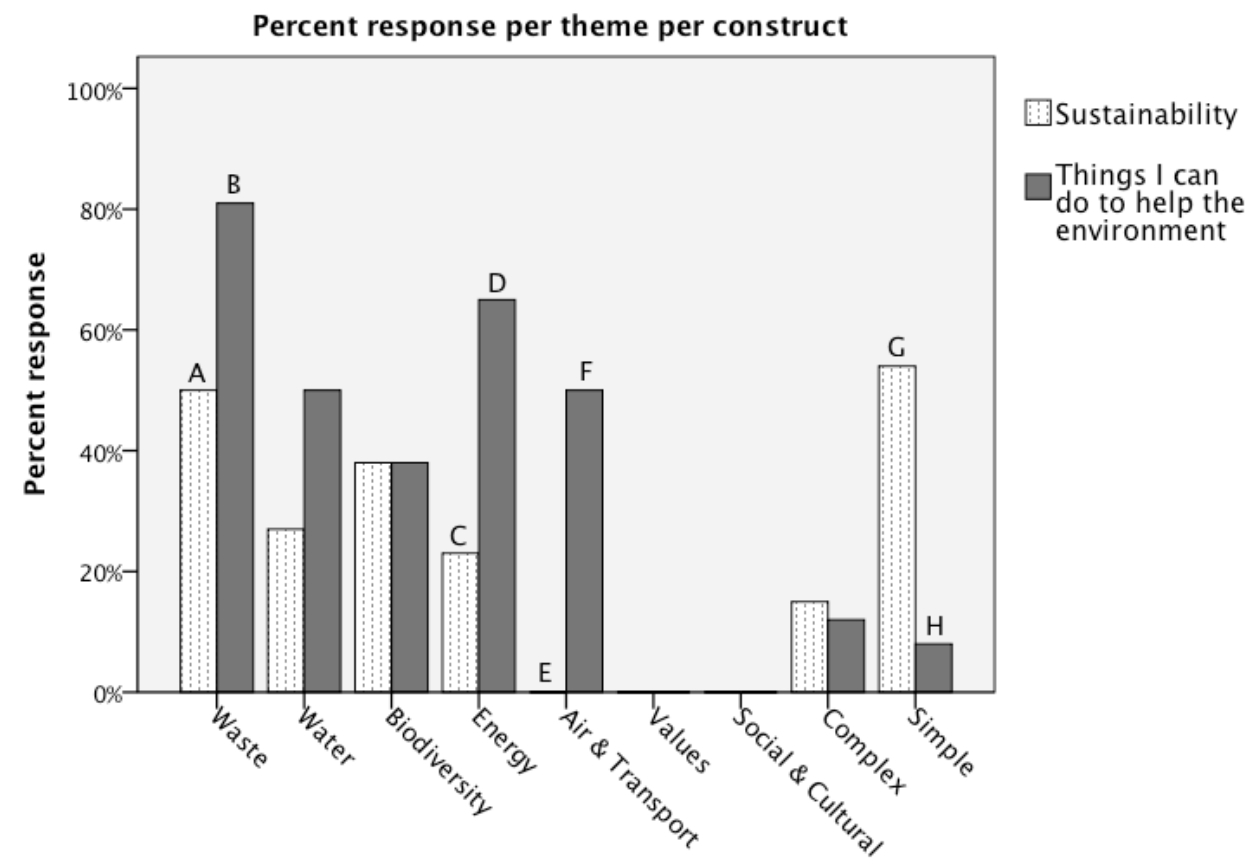

Figure 6.7. Percent response per theme per construct, $n_{S}=26, n_{H E}=26$.

Further Kruskal-Wallis tests were performed, separately for each construct, on the proportion of students' responses for each theme per year group, and no significant differences were found. Figure 6.8 illustrates the patterns for each construct, year group and theme. The figure suggests that significant differences might exist between year groups for certain themes, such as waste management or simple, however, sample sizes per theme were too small for the variance to be adequately explored. 


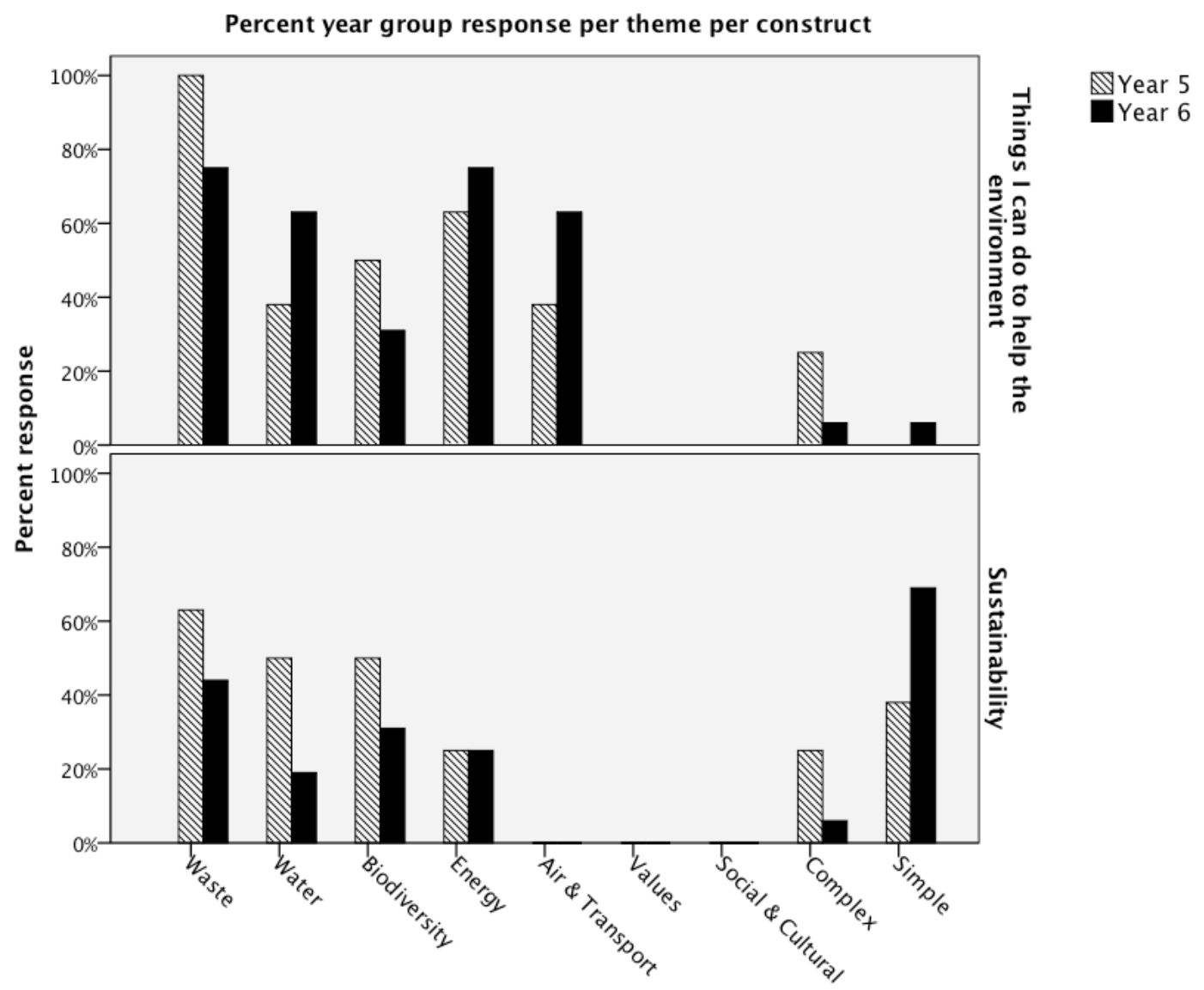

Figure 6.8. Percent of year group response per theme per construct, $n_{5}=8, n_{6}=16$.

\section{Discussion}

Year group differences. For each of depth, volume and breadth of knowledge there were no differences across year groups. There were also no year group differences found for the percent of student response per theme. It could be considered that students in Years 5 and 6 responded similarly to mind maps, however, given the small sample size of students from this school, it is most likely that the sample size was too small to adequately capture the variance associated with each year group. Consequently, year group will not be considered as a mediating factor of student responses to mind maps at Fertile Ground Primary School nor will it be discussed further in this section.

Construct differences. There was no difference between constructs depth of knowledge, but there were differences between constructs for volume and breadth of knowledge, and in both cases things I can do to help the environment scored higher than sustainability. Examination of the proportion of student responses to each theme showed that for most themes things I can do to help the environment had a higher proportion of responses than sustainability and that environmental themes were predominant for both constructs. Furthermore, simple ideas were significantly more apparent for the construct sustainability. These results are consistent with results from 
Lighthouse and Riverside Primary Schools and supports the hypothesis asserted in Chapters 4 and 5 that students perceived a difference between the two constructs. It is suspected that the generality of students, regardless of whether they attend a school with a sustainability focus, find it easier to think of many and more various ideas of how they can help the environment compared with ideas about sustainability because sustainability is a confusing and ambiguous term.

At Fertile Ground Primary School, simple ideas consisted primarily of the simple nouns 'seeds', 'wood', 'technology' and 'resources'. Not only did these responses reflect a lack of understanding about sustainability, they also reflected the most recent unit of work that the Year 5 and 6 teachers had been working on Resources, as reflected in a statement from Mrs Platypus, "This semester we were concentrating on resources for S\&E [Society and Environment curriculum learning area]".

Trends in percent response per theme. The trend in the proportion of student responses to the different themes (Figure 6.7) was different to results from Lighthouse and Riverside Primary Schools, because water conservation and biodiversity conservation received lower rates of response than energy reduction. Nonetheless, waste management remained the most popular theme across all schools, probably because nearly all children could at least think of "picking up litter" as a way of 'helping the environment' or of 'helping the world stay healthy for a long time'. In addition, there were no students who expressed ideas related to values, advocacy and philanthropy or social and cultural wellbeing for either construct, indicating that students at Fertile Ground Primary School were not familiar with these themes being associated with the environment or sustainability.

It is interesting to note the high proportion of responses (over 50 percent) in energy reduction as these are higher than the proportion of responses for this theme from Lighthouse and Riverside Primary Schools (under 50 percent), and most likely indicate that students at Fertile Ground Primary School were either picking up these messages from their parents, television and public media, or from some cursory information that their teachers were providing at school. Or, that students at Lighthouse and Riverside Primary Schools were being inundated with so many messages about waste management, water conservation and biodiversity conservation that ideas about reducing energy usage were less familiar to them. 


\section{Summary}

These results indicate that students at Fertile Ground Primary School had a good understanding of behaviours they could adopt to help the environment but an ambiguous understanding of sustainability, which was associated by all students with environmental themes. These findings are congruent with what might be expected of a school without a sustainability focus, however, the low sample size makes it difficult to generalise from these results.

\section{Research Question 3: What were the Environmental Behaviours of Upper- Primary Students at Fertile Ground Primary School?}

This section explores relationships between students' frequency of undertaking seven common pro-environmental behaviours and three comparison variables: Learning, Importance and Participation. The data in this section come from the student surveys conducted in 2009. Surveys were conducted with students from Years 4, 5 and $6(n=26)$. The analysis and organisation of results presented in this section are similar to the section on Behaviours from Chapters 4 and 5, so the rationale for these is not repeated here.

\section{Results and discussion}

Descriptive statistics and chi-square tests were conducted and triangulated for each behaviour and comparison variable. For consistency across data chapters, behaviours were categorised as high, moderate or low, according to the percentage of students that indicated they performed a behaviour on a more than weekly basis (Figure 6.9). The groups are presented and discussed in the following paragraphs. 


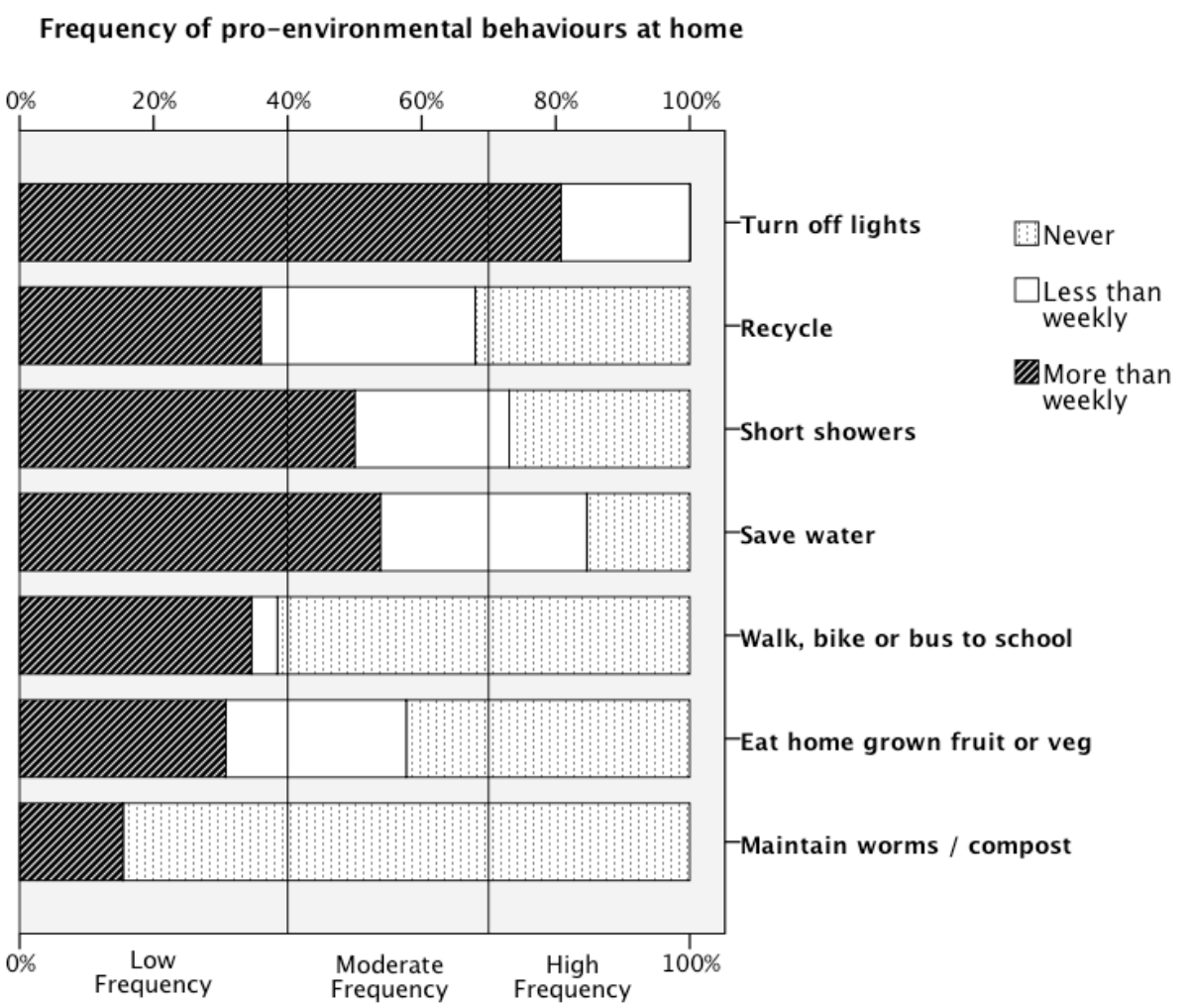

Figure 6.9. Percentage of students that reported they undertook each of the seven proenvironmental behaviours in 2009 either 'never', 'less than weekly' or 'more than weekly', $\mathrm{n}_{2009}$ $=26$. Resulting patterns suggested certain behaviours grouped together to form three categories: high $(>70 \%)$, moderate $(40 \%-70 \%)$ and low $(<40 \%)$ frequency.

\section{Summary and discussion}

At Fertile Ground Primary School, the weekly practice of pro-environmental behaviours by upper-primary school students in their homes was largely unrelated to whether students learned about environmental topics at school, whether they found school environmental experiences important or whether they participated in behaviours at home with other family members. Table 6.4 displays a summary of the dominant relationships between the seven estimated behaviours and three comparison variables: Learning, Importance and Participation. Detailed results from relationship testing using chi-square tests and box plots are presented and described in Appendix 6. The following discussion draws on data presented primarily in Table 6.4 but also from the more detailed data analysis presented in Appendix 6. 
Table 6.4. Summary of the dominant relationships between seven pro-environmental behaviours that students could practice in their homes and the three variables: Learning, Importance and Participation. The prevalence of each behaviour is shown as a proportion of the total sample. Dominant patterns between Learning, Importance and Participation and weekly behaviour are presented to infer the features that had greatest influence on each behaviour.

\begin{tabular}{|c|c|c|c|c|c|}
\hline \multirow[t]{2}{*}{ Behaviour } & \multirow[t]{2}{*}{ Prevalence* } & \multicolumn{4}{|c|}{ Practiced weekly, when: } \\
\hline & & Learning & Importance & Participation $†$ & Other \\
\hline Turning off lights & Widespread & - & - & Family norm & - \\
\hline $\begin{array}{l}\text { Recycling paper or } \\
\text { plastic }\end{array}$ & Widespread & - & - & Family norm & - \\
\hline Short showers & Common & - & - & Family norm & - \\
\hline Saving water & Common & - & Important & $\begin{array}{l}\text { Student } \\
\text { co-enthusiast }\end{array}$ & - \\
\hline $\begin{array}{l}\text { Walking, biking or } \\
\text { bussing to school }\end{array}$ & Common & - & - & Family norm & - \\
\hline $\begin{array}{l}\text { Eating home grown } \\
\text { fruits or vegetables }\end{array}$ & Uncommon & $\begin{array}{c}\text { Negative } \\
\text { relationship } \\
\text { (i.e. no } \\
\text { learning = } \\
\text { more } \\
\text { active) }\end{array}$ & Important & $\begin{array}{l}\text { Student } \\
\text { co-enthusiast }\end{array}$ & - \\
\hline $\begin{array}{l}\text { Putting food scraps } \\
\text { into a worm farm or } \\
\text { compost bin }\end{array}$ & Uncommon & - & - & Family norm & - \\
\hline
\end{tabular}

* Prevalence: Widespread, $>70$ percent of all students did this weekly; Common, $40-70$ percent of all students did this weekly; Uncommon, $<40$ percent of all students did this weekly.

$\dagger$ Participation: Family norm $=$ Students participated weekly even if they were not one of the most active family members. Student co-enthusiast $=$ Students participated weekly when they were one of the most active family members.

Most of the seven pro-environmental behaviours were unrelated to the comparison variables (Table 6.4). The only two behaviours that revealed relationships between any of the three comparison variables and the frequency that students practiced the behaviours in their homes were saving water and eating home grown produce. The small sample size indicates that these relationships must have been strong for separation between groups to be found.

For both of these behaviours, students who indicated that school environmental experiences were important to them saved water or ate home grown produce weekly, whereas students who rated environmental experiences of average or low importance practiced these behaviours less than weekly or never (Appendix 6). Most students who saved water and ate home grown produce, on a greater than weekly basis, also indicated that they were a co-enthusiast (Table 6.4). These results could suggest that these students were from families that regularly saved water or produced fruits or vegetables from their home garden. If so, their family's behaviours may have influenced their own 
frequency of practicing these behaviours and might also, have increased their interest in school environmental experiences.

Eating home grown produce was the only behaviour that produced a relationship with Learning, but unexpectedly, the relationship was negative (Appendix 6.5). It is unlikely that not learning at school about growing fruits and vegetables influenced students to do this behaviour at home on a weekly basis, and more likely that many families were already practicing this behaviour at home despite the minimal focus on learning about this behaviour at Fertile Ground Primary School. These findings suggest that the school may have had support from many families and receptivity among their students if they were to set up a school vegetable garden, and consequently weave such topics into class learning activities. Given that, at the time of data collection in 2009, the administrative staff had planned to start a school vegetable garden, future research at Fertile Ground Primary School might instead yield a positive relationship between Learning and eating home grown produce.

It is interesting to note that recycling was an uncommonly practiced behaviour among students at Fertile Ground Primary School, especially considering it was widespread among students at Lighthouse and Riverside Primary Schools and is a relatively simple behaviour for households to adopt. During data collection, it was discovered that the local council area surrounding Fertile Ground Primary School does not support manual household waste separation. Instead, the local council upholds a one-bin system and boasts a cutting-edge waste separation facility that separates waste with greater accuracy and saleable quality than household manual waste separation ever could. Nonetheless, many teachers (and apparently many students and parents) were unaware or sceptical about the one-bin system. Mrs Rock-wallaby said, "I'd like to go and see how they do it because I just like shires who have recycling bins", and suggested, "I think people could do it. Why should you have a whiz-bang recycling plant? I think people are quite keen to do something”.

\section{Chapter Conclusion}

Altogether, these results suggest that students, staff and administrators at Fertile Ground Primary School would be receptive to a sustainability program being established at their school and there would likely be support from the surrounding parent community for the program. Moreover, if such a program were commenced it may be prudent to begin with expanding the themes of household water saving and home grown produce, which some environmentally motivated students were already 
doing regularly at home with their families. It would also be beneficial to provide focussed professional development around the concept of sustainability and examples of ways to engage students with the issues and actions of various interconnected sustainability initiatives. Furthermore, for such a program to be sustained the school would need one or two committed, enthusiastic staff members to begin driving the initiatives who, together with the administrators, had a vision for prioritising collaborative staff planning and evaluation, and understood basic stages of growth in the lifecycle of a whole-school sustainability program. Fertile Ground Primary School truly had potential for the growth of a whole-school sustainability program, which could be sown on fertile ground.

The next two chapters present findings from Lighthouse and Riverside Primary Schools about student attitude-behaviour relationships and dominant family dynamics in intergenerational transfer. The findings from this case study will be discussed again in the cross-case analysis, Chapter 9. 


\section{Chapter 7: Student Environmental AtTitudes AND BeHAviours \\ - Lighthouse AND River's Edge PRIMARY SCHOOLS}

In addition, an individual must possess a desire to act. One's desire to act appears to be affected by a host of personality factors. These include locus of control, attitudes, and personal responsibility. Thus, an individual with an internal locus of control, positive attitudes toward the environment and toward taking action, and with a sense of obligation toward the environment will likely develop a desire to take action.

(Hines, Hungerford \& Tomera, 1987, p. 7)

This chapter addresses Research Question 4 (p. 7), the relationship between student environmental attitudes and pro-environmental behaviours. Data comes from the 2010 survey administered with students at Lighthouse and River's Edge Primary Schools $(n=285)$. The analysis required that data from both schools be pooled; hence, they are presented here in a separate chapter. Results from internal consistency and factor extraction of the three scales, and model testing between latent variables are presented in the following sections.

Student attitudes were not examined at the Fertile Ground School because the sample size was too low $(\mathrm{n}=20)$ for surveys to be worthwhile. Also, it would not have been appropriate to analyse the attitude data from this school with attitude data from Lighthouse and River's Edge Primary Schools because the differences in the schools' sustainability priorities meant the populations were too different to pool.

\section{Research Question 4: What was the Relationship Between the Environmental Attitudes and Behaviours of Upper-Primary Students?}

Students' attitudes to the environment were explored across to two levels: 1) their attitudes towards their educational context, herein described as school environmental activities; and 2) their attitudes towards global environmental issues, herein referred to as environmental worldviews. Consequently, two scales were used to estimate student attitudes: one designed specifically to estimate student attitudes to school environmental activities, and another that had been designed to estimate children's environmental worldviews and had been borrowed with permission from researchers in the United States (Manoli, personal communication, 14 December 2010). 
Student pro-environmental behaviour was estimated using the seven categorical behaviour questions described in Chapter 3.

To determine if a relationship existed between student attitudes and behaviours relationships were tested using structural equation modelling. Before relationship models could be tested, the internal consistency of the three scales had to be validated and latent constructs had to be identified through factor extraction.

\section{Internal Consistency and Factor Extraction}

Exploratory factor analyses using maximum likelihood and oblique rotation were performed separately on the two continuous attitude scales in SPSS. The categorical behaviour scale was analysed with an exploratory factor analysis using robust weighted least squares (WLSMV) and oblique rotation in Mplus. Refer to Chapter 3 for more detail about the selected extraction and rotation methods.

Scale 1: Attitudes to school environmental activities. It was anticipated that the nine-item scale of attitudes to school environmental activities would reveal a onefactor solution. But the possibility was considered that it might present a two-factor solution because of the different wording of items $1-3$ and items $4-9$, with items 1 3 estimating student attitudes to school-wide environmental activities and items $4-9$ estimating student attitudes to their individual role in environmental activities.

Results. Seven of the 285 students surveyed had missed items in the attitudes to school environmental activities scale and were excluded from analysis. Internal consistency of the scale was checked prior to factor analysis, and revealed a satisfactory Chronbach's alpha of .71, however the inter-item correlation matrix (Appendix 7.1) showed that item 4, I would like more opportunities at school to do things that help care for the environment, correlated negatively and very low $(r<|.28|)$ with all of the other items. Consequently, it was decided to remove this item from the scale before further analysis, which also raised the Chronbach's alpha to .79, a result much closer to the preferred alpha level of .80 (Pallant, 2007).

After satisfying internal consistency, the suitability of the data for factor analysis was assessed. Inspection of the correlation matrix revealed the presence of many coefficients above .30, except for items 3 and 8, which had more than 90 percent of their coefficients below .30, and item 9, which had more than 50 percent below .30. The Kaiser-Meyer-Oklin value was .85 , exceeding the recommended value of .60 , and Bartlett's Test of Sphericity was statistically significant, thus supporting the choice to continue with factor analysis (Pallant, 2007). 
After satisfying internal consistency and factorability, exploratory factor analysis was conducted using maximum likelihood and oblique rotation. Exploratory factor analysis of the eight remaining items revealed a one-factor solution that explained 42 percent of the variance (Table 7.1). Eigenvalues above 1, factor loadings above .32 (Table 7.1) and scree plot showing a sharp decrease in values after the first factor (Appendix 7.2) supported the decision to retain a one-factor solution (Hair et al., 2010; Pallant, 2007; Worthington \& Whittaker, 2006), but the rotated item communalities suggested that some items should be removed. The rotated item communalities of items 3, 8 and 9 were below .30 (Table 7.1), thus indicating they were not highly correlated with one or more of the other items (Pallant, 2007; Worthington \& Whittaker, 2006). The item with lowest communality (item 8) was removed and the analysis was re-run.

The second factor analysis revealed a one-factor solution that explained 46 percent of the variance (Table 7.1), however, communalities of items 3 and 9 were still below .30 (Table 7.1). The item with next lowest communality (item 3 ) was removed and the analysis was run again.

The third factor analysis revealed a one-factor solution that explained 51 percent of the variance (Table 7.1), but communalities for item 9 remained below 30 (Table 7.1). Finally, item 9 was removed and the analysis was run again.

The fourth and final factor analysis revealed a one-factor solution that explained 56 percent of the variance (Table 7.1). Communalities were all above 30 (Table 7.1) and factor loadings were all above .60 (Table 7.1). These results indicate that the remaining five items best represented the latent construct of attitudes to school environmental activities. 


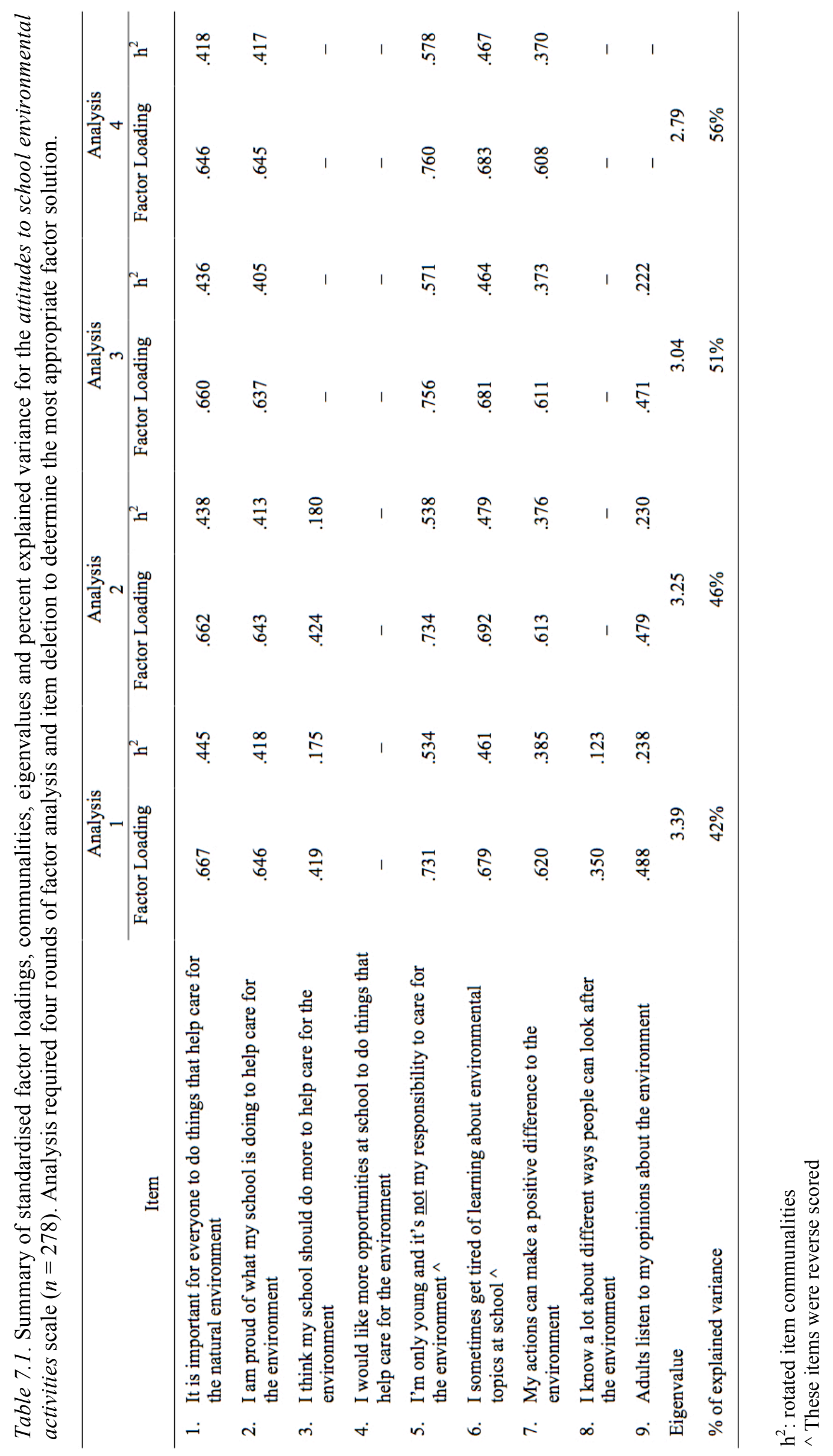


Scale 2: Environmental worldviews. Manoli et al. (2007) found that the tenitem scale of environmental worldviews revealed a three-factor solution, with items 1, 4 and 7 loading on the construct 'rights of nature', items 2, 5, 8 and 10 loading on the construct 'eco-crisis', and items 3, 6 and 9 loading on the construct 'human exemptionalism'. They also discussed the possibility that their scale items would load together as one factor. In this research it was expected to find similar item loading on these three latent constructs or that items would load together as one factor.

Results. Seven of the 285 students surveyed had missed items in the environmental worldviews scale and were excluded from analysis. Internal consistency of the scale was checked prior to factor analysis, and revealed an unsatisfactory Chronbach's alpha of .58. The inter-item correlation matrix (Appendix 7.3) showed that items 2, 3 and 9 correlated negatively and very low $(r<|.18|)$ with all of the items. The corrected item-total correlation showed that item 3 was the most problematic, giving a negative coefficient of -.07. Consequently, it was decided to remove item 3 from the scale before further analysis. Removing this item raised the Chronbach's alpha to a value that was still unsatisfactory, .65. The consequent corrected item-total correlations indicated that item 9, with a coefficient of .01, should be deleted. Deleting item 9 raised the Chronbach's alpha to .69. The following corrected item-total correlations showed that to get an adequate Chronbach's alpha, item 2, with a coefficient of .15, had to be deleted. After deleting items 2, 3 and 9 the Chronbach's alpha was .72 and sufficiently high enough to proceed.

After satisfying internal consistency, the suitability of the data for factor analysis was assessed. Inspection of the correlation matrix revealed the presence of many coefficients below .30, suggesting that the items were not sufficiently related to each other for the scale to give an adequate indication of children's environmental worldviews. However, the Kaiser-Meyer-Oklin value was .74, exceeding the recommended value of .60, and Bartlett's Test of Sphericity was statistically significant, thus supporting the choice to continue with factor analysis (Pallant, 2007).

After satisfying internal consistency and factorability, exploratory factor analysis was conducted using maximum likelihood and oblique rotation. Exploratory factor analysis of the seven remaining items revealed a two-factor solution that explained a cumulative total of 53 percent of the variance, explaining 38 and 15 percent of the variance respectively (Table 7.2). Inspection of the eigenvalues (Table 7.2) and scree plot (Appendix 7.4) indicated that a one-factor solution was most appropriate. Factor loadings suggested the presence of a second factor but several cross-loadings 
(Table 7.2) and a large correlation between the two factors $(r=.545)$ indicated that the second factor was not stable and supported the decision to retain a one-factor solution. The analysis was run again with a one-factor solution forced on the data set.

The resulting one-factor solution (Table 7.3) explained 38 percent of the variance but the rotated item communalities of items 4, 5, 6, 7 and 10 were below .30 (Table 7.3), indicating they were not highly correlated with one or more of the other items and should be removed (Pallant, 2007; Worthington \& Whittaker, 2006). Item 6 was the first to be removed as it had the lowest communality.

The third factor analysis revealed a one-factor solution that explained 40 percent of the variance (Table 7.3), however, the communalities of items 7,8 and 10 were below .30 (Table 7.3). The item with lowest communality (item 7) was removed and the analysis was run again.

The fourth factor analysis revealed a one-factor solution that explained 44 percent of the variance (Table 7.3), however, the communalities of items 1 and 10 were below .30 (Table 7.3). Both items had the same communality, .28, but item 10 was removed in preference because it had the lower factor loading. The analysis was run again.

The fifth factor analysis revealed a one-factor solution that explained 48 percent of the variance (Table 7.3) but the communalities of items 1 and 8 were below .30 (Table 7.3). The item with lowest communality (item 8) was removed and the analysis was run again.

The sixth factor analysis revealed a one-factor solution that explained 56 percent of the variance (Table 7.3), however, the communalities of items 1 and 5 were below .30 (Table 7.3). Removing either of these items would leave the scale with only two items to explain the variance, which is not recommended, especially when there is less than .70 correlation between the remaining items (Worthington \& Whittaker, 2006), as indicated by the low communalities. Consequently, it was decided to discard the entire environmental worldviews scale. 
Table 7.2. Summary of standardised factor loadings on each of two factors, communalities, eigenvalues and percent of explained variance for the environmental worldviews scale $(n=$ 278). Further rounds of factor analysis on this scale are displayed in Table 7.3.

\begin{tabular}{|c|c|c|c|}
\hline \multirow{3}{*}{ Item } & \multicolumn{3}{|c|}{$\begin{array}{c}\text { Analysis } \\
1\end{array}$} \\
\hline & \multicolumn{2}{|c|}{ Factor Loading } & \multirow[t]{2}{*}{$\mathrm{h}^{2}$} \\
\hline & 1 & 2 & \\
\hline 1. Plants and animals have as much right as people do to live & .552 & -.035 & .306 \\
\hline 2. There are too many (or almost too many) people on earth & - & - & - \\
\hline 3. People are clever enough to keep from ruining the earth ${ }^{\wedge}$ & _ & _ & _ \\
\hline 4. People must still obey the laws of nature & 651 & -.394 & .579 \\
\hline 5. When people mess with nature it has bad results & .523 & -.179 & .306 \\
\hline $\begin{array}{l}\text { 6. Nature is strong enough to handle the bad effects of our } \\
\text { modern lifestyle }\end{array}$ & .420 & .345 & .296 \\
\hline 7. People are supposed to rule over the rest of nature ${ }^{\wedge}$ & .466 & .016 & .218 \\
\hline 8. People are treating nature badly & .569 & .330 & .433 \\
\hline $\begin{array}{l}\text { 9. People will someday know enough about how nature works } \\
\text { to be able to control it }{ }^{\wedge}\end{array}$ & - & - & - \\
\hline $\begin{array}{l}\text { 10. If things don't change, we will have a big disaster in the } \\
\text { environment soon }\end{array}$ & .509 & .290 & .343 \\
\hline Eigenvalue & 2.62 & 1.07 & \\
\hline$\%$ of explained variance & $38 \%$ & $15 \%$ & \\
\hline Factor correlation & & & \\
\hline
\end{tabular}

$h^{2}$ : rotated item communalities

$\wedge^{\wedge}$ These items were reverse scored 


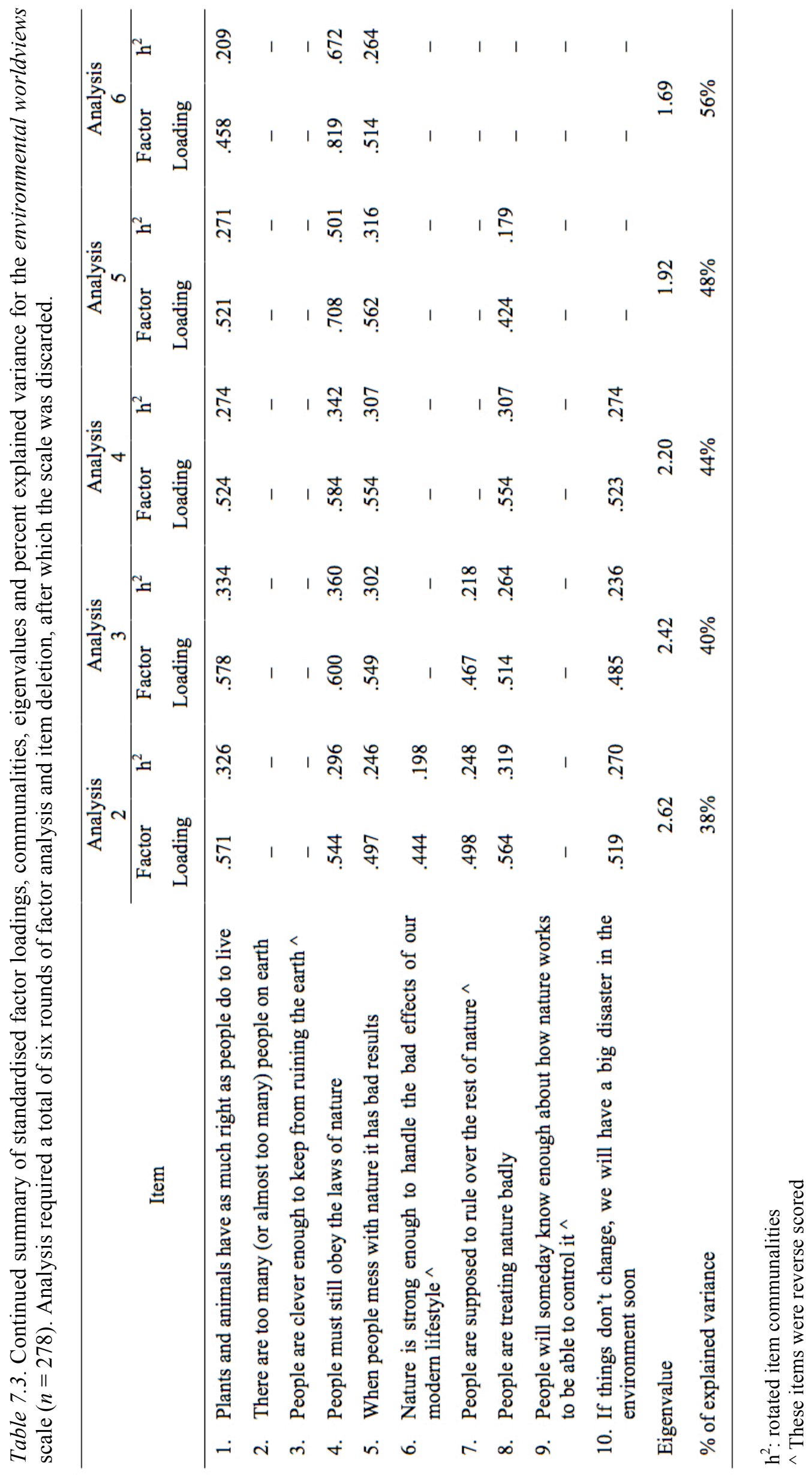


Scale 3: Pro-environmental behaviour. The seven-item behaviour scale was developed to serve two purposes: 1) to provide an estimate of pro-environmental behaviour that could be compared to student attitudes using structural equation modelling, and 2) to provide a descriptive account of the proportion of students that participated in each of the behaviours at a given frequency, as reported in Chapters 4, 5 and 6. The results presented and discussed here refer to the refinement of the proenvironmental behaviour scale.

Exploratory factor analysis of the pro-environmental behaviour scale was conducted in Mplus because it has the capacity to conduct factor analysis on scales with categorical items. It was expected that the seven-item scale of pro-environmental behaviour would either reveal a one-factor solution where all items clustered together as one construct. Or, based on results from descriptive analysis of this data presented in Chapters 4 and 5, would reveal a two-factor solution, where sets of items estimated behaviours of varying complexity, easy and difficult. Specifically, items 1, 2, 3 and 4 would estimate 'easy to achieve' pro-environmental behaviours, and items 5, 6 and 7 would estimate 'difficult to achieve' pro-environmental behaviours.

Results. Four of the 285 students surveyed had missed items in the proenvironmental behaviour scale and were excluded from analysis. Due to the categorical nature of the data, internal consistency and factorability were assessed by checking the correlation matrix for items with multiple correlations below .30 (Appendix 7.5). Item 5 was found to have very small correlations $(r<.12)$ with all other items and it was considered appropriate to remove this item prior to the factor analysis. Items 6 and 7 correlated with each other at $r=.51$ and had small correlations with all other items $(r<$ .30 ), but it was decided to retain items 6 and 7 for the factor analysis in case they loaded onto a second factor.

Factor analysis was conducted on the remaining six items and a two-factor solution was revealed that explained a cumulative total of 61 percent of the variance, explaining 40 and 21 percent of the variance respectively (Table 7.4). Inspection of the eigenvalues (Table 7.4) and scree plot (Appendix 7.6) indicated that a two-factor solution was most appropriate and the chi-square and goodness-of-fit indices were a better fit for the two-factor solution (Table 7.4). The factor loadings on the two-factor solution showed that items 6 and 7 loaded as one factor and items 1, 2, 3 and 4 loaded as a second factor (Table 7.4). No cross-loadings above the critical value of .32 were present (Table 7.4). Correlation between the two factors was small $(r=.12)$, indicating stability of the second factor and supporting a decision to retain two factors. 
In deciding whether to retain items 6 and 7 as a second factor, however, reference was made to the literature. Factors with fewer than three items can be problematic, as there is less confidence that it will be a reliable factor in future studies (Tabachnick \& Fidell, 2007). Nonetheless, it is allowable to retain a factor with two items if the items correlate above .70 and are relatively uncorrelated with other items (Worthington \& Whittaker, 2006). Worthington and Whittaker (2006) suggest in these cases that researchers consider interpretability of the factor in deciding whether to retain it and, for future studies, consider generating new items that are likely to load on that factor. Items 6 and 7 could well have been interpreted as providing an estimate for difficult to achieve pro-environmental behaviours, however, items 6 and 7 did not correlate strongly enough with each other $(r=.51)$ to fit the requirements of a two-item factor.

Finally, items 6 and 7 were removed from the scale and it was decided to retain a one-factor solution with items 1, 2, 3 and 4, which could be interpreted as the easy to achieve pro-environmental behaviours scale. The factor analysis was run again with these four items and revealed a factor solution explained 52 percent of the variance (Table 7.4). Eigenvalue above 1, SRMR below .05, factor loadings above .32 (Table 7.4) and scree plot showing a sharp decrease in values after the first factor (Appendix 7.6) supported the decision to retain the one-factor solution (Cunningham, 2010; Hair et al., 2010; Pallant, 2007; Worthington \& Whittaker, 2006), however, chi-square, TFI and CLI were slightly below the ideal thresholds of $.05, .995$ and .995 respectively (Table 7.4). As mentioned in Chapter 3, debate in the literature highlights that when determining the most suitable factor solution, the researcher must take into account the goodness-of-fit indices together with information from eigenvalues, factor loadings and the overall interpretability of the factor (Cunningham, 2010; Worthington \& Whittaker, 2006). Because these results were close to the recommended thresholds on some fit indices, within the acceptable range for other indices, and the factor was interpretable and made theoretical sense, it was decided to retain the four-item factor solution. 


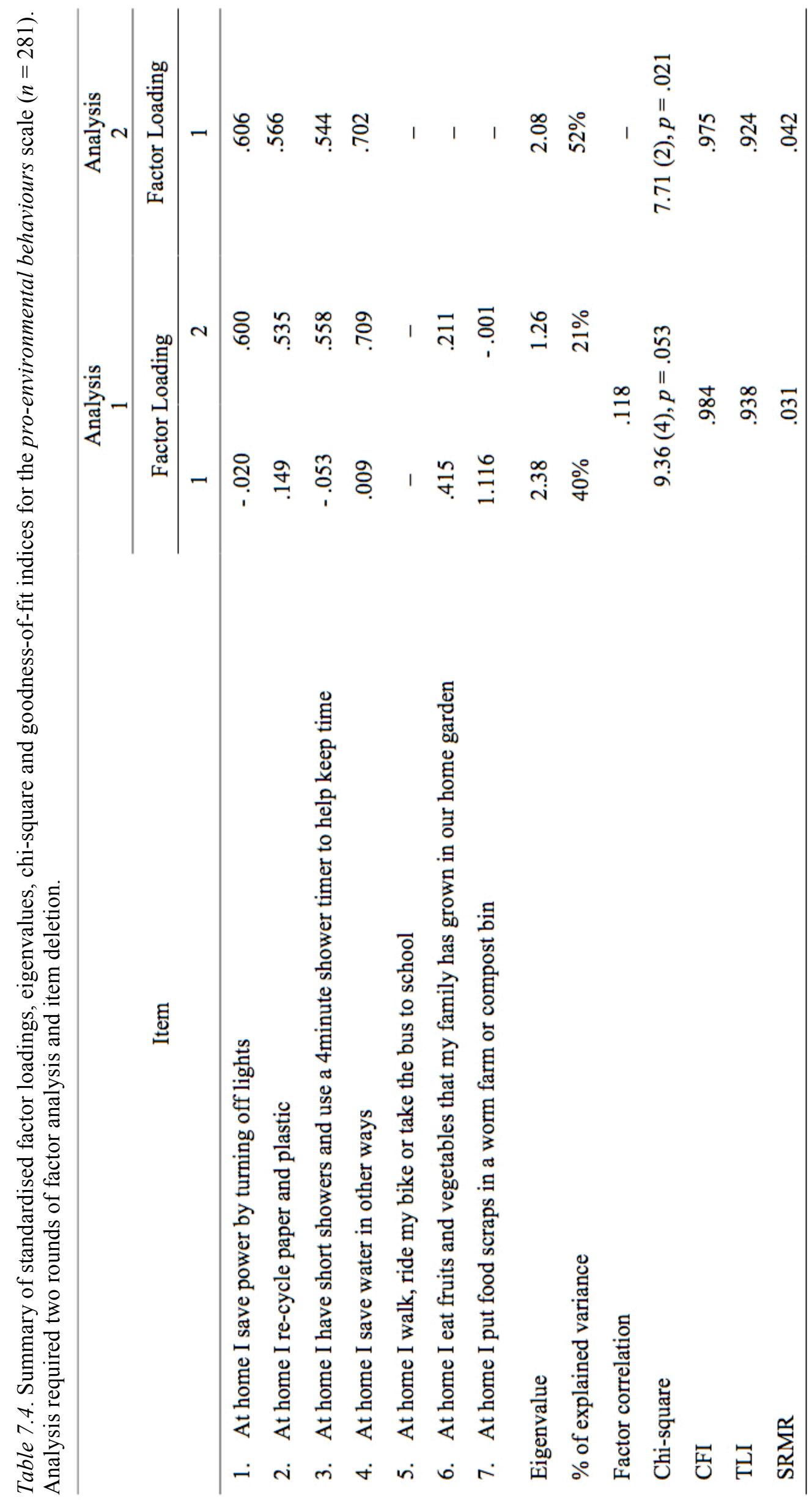


Discussion: The three scales. The attitudes to school environmental activities scale revealed a one-factor solution that was supported by five items. Together these five items explained 56 percent of the variance (Table 7.1), which was well above the recommended minimum of 30 percent for a scale that measures educational data (Kline, 2011). With such an encouraging result, this univariate five-item scale could be used in structural equation modelling to estimate the relationship between students' attitudes to school environmental activities and their pro-environmental behaviours.

For example, four items were deleted from the attitudes to school environmental activities scale due to their inadequate correlation with other items. Of particular note was item 4, I would like more opportunities at school to do things that help care for the environment, which correlated negatively with all of the other items (Appendix 7.1). This finding indicates that students who gave overall positive responses to school environmental activities, did not want more opportunities in their schools for environmental leadership or responsibility. Such a finding might suggest that students were tired of learning about the environment or did not think it was their responsibility to care for the environment, however, student responses to items 5 and 6 , which estimated these exact parameters, were positive (after reversing the scores) and consequently were not consistent with this suggestion. Instead, this interesting result could indicate students' unwillingness to take on leadership roles in the school, however, more research would be required to determine what actions students specifically associated with the word 'opportunities'.

It had been considered that the attitudes to school environmental activities scale might estimate two latent constructs: 1) student attitudes towards school-wide activities and 2) student attitudes towards their role in school activities, because of the different wording of items 1 - 3 and items 4 - 9. This did not occur, however, and it is probable that there were not enough questions of either type to adequately differentiate between students' attitudes to school-wide activities or their personal-roles in activities. Future iterations of this scale could include more questions to determine if there is a difference between students' attitudes across these two pursuits. If such differentiation was found, it would be interesting to model their relationships with each other to determine if students who rated a whole-school focus on environmental education as positive would have also felt positively about their personal-role in environmental activities.

The environmental worldviews scale did not reveal an adequate factor solution. This finding suggests that the New Environmental Paradigm Scale for Children is not suitable for an Australian context, which could be due to the wording of some items. An 
example of this was identified with item 3: people are clever enough to keep from ruining the earth. This item was reverse scored during development of the scale (Manoli et al., 2007) because in America, the word 'clever' is understood as a negative term (Manoli, personal communication, 4 September 2011). In this research, students primarily perceived item 3 in a positive way (after reversing the scores), as indicated by the negative correlations with seven of the ten items (Appendix 7.3). For item 3 to be perceived by Australian students in a negative way, as was intended, future studies might consider substituting the word 'clever' with the word 'cunning'.

Another example from this research of the contextually inappropriate or ambiguous wording of some items in the New Environmental Paradigm Scale for Children were items 2 and 9, which were both found to have very low and negative correlations with seven of the ten items (Appendix 7.3). Using descriptive statistics it was found that these items had proportionately high levels of the middle score, 'not sure', indicating that Australian students did not understand these items well. In a qualitative study involving Dutch children, Kopnina (2011) found that several of the items from the New Environmental Paradigm Scale for Children were ambiguous and difficult to comprehend. For example item 2, there are too many (or almost too many) people on earth, revealed a complex pattern of different statements from children about population, that were derived from social, institutional, political and other sources (Kopnina, 2011).

One reason why the New Environmental Paradigm Scale for Children may have worked better in the original American context is that the children in Manoli et al.'s 2007 research had all been participants of specific environmental awareness programs; Earthkeepers and Sunship Earth, and re-wording and validation of the scale depended on the children's comprehension of topics taught in those programs. The Earthkeepers and Sunship Earth programs both specifically focused on helping students to "develop an understanding of ecological concepts, build positive feelings for the natural world, and change their environmental behaviors" (Manoli et al., 2007, p. 6). It can be argued, that this focus contributed to students' comprehension of the wording of each item, and overall consistent responses to items that utilised both sides of the response range.

For these reasons, together with results from her own research, Kopnina (2011) suggests that the New Environmental Paradigm Scale for Children is not crossculturally appropriate or relevant and that ethnographic analyses of the socio-cultural context in which the research is being conducted should be conducted to assist with modifying the scale prior to its use. The findings of this research support this 
recommendation and, moreover, suggest that the current New Environmental Paradigm Scale for Children is better applied in a limited context where students have pre-existent knowledge of environmental conservation and where students have been exposed to the specific language that is used in the survey.

The two scales, attitudes to school environmental activities and environmental worldviews both included reverse scored items. It is common for scale developers to include reverse scored items as a way of forcing participants to think carefully about their responses (Cunningham, 2010; Kline, 2011; Rodebaugh et al., 2007). However, in exploratory factor analysis, reverse scored items can cause the occurrence of an unwanted and artificial second factor (known as a method factor) for a latent construct that one had hoped would be unidimensional (Rodebaugh et al., 2007). This is because participants have been known to respond less strongly to negatively worded items, which can cause these reverse scored items to load more strongly with each other and less strongly with other items in the scale. For this reason, it is recommended to retain reverse scored items only if no such method factor arises (Cunningham, personal communication, 20 February 2012).

In this research, the presence of negatively worded items did not cause a method factor to result. The two negatively worded items in the attitudes to school environmental activities scale, items 5 and 6, both loaded strongly onto the single factor solution (Table 7.1). In the environmental worldviews scale, two of the four negatively worded items, items 3 and 9, were removed before factor analysis could be conducted not because they correlated with each other, but because they did not correlate with any of the items (Appendix 7.2). The other two negatively worded items in the environmental worldviews scale, items 6 and 7, were also later removed because their rotated item communalities indicated they were not highly correlated with other items within the factor (Table 7.3), and should be deleted (Pallant, 2007; Worthington \& Whittaker, 2006). Albeit, future iterations of either of these scales should consider carefully the use of negatively worded items. In particular, when more than one factor is anticipated, the scales would benefit from designing all reverse scored items to estimate one of the factors or not including negatively worded items at all (Rodebaugh et al., 2007).

The pro-environmental behaviour scale revealed a one-factor solution that was supported by four items. Together these four items explained 52 percent of the variance (Table 7.3), which was a satisfactory result for a scale that measures educational data (Kline, 2011). The clustering of items in the scale could be interpreted as representing 
easy to achieve pro-environmental behaviours. Consequently, this scale could be used in structural equation modelling to estimate the relationship between students' attitudes to school environmental activities and their easy to achieve pro-environmental behaviours.

It was anticipated that two latent constructs might be identified through exploratory factor analysis of the seven behaviours in the scale that would: 1) identify pro-environmental behaviours that are relatively easy to enact, such as turning off lights and recycling, and 2) identify pro-environmental behaviours that are comparatively more difficult to carry out, such as composting and growing fruits or vegetables at home. Despite this, only one latent construct was extracted, which was interpreted as estimating easy to achieve pro-environmental behaviours. It was found, however, that some of the goodness-of-fit indices for the easy to achieve pro-environmental behaviours scale were slightly below the recommended minimum values, but the eigenvealues, SRMR and factor loadings all indicated that the four-item factor solution was a good fit for the data (Table 7.4). Nevertheless, future iterations of this instrument should include more items in an effort to overcome these discrepancies and to better estimate easy to achieve pro-environmental behaviours.

Items 6 and 7 were found to load together on a second factor, however, and could have been interpreted as estimating the difficult to achieve pro-environmental behaviours. But it was decided to remove them from the analysis because they did not correlate strongly enough with each other to be confident in the stability of a scale that only included these two items (Worthington \& Whittaker, 2006). In future research, more items should be developed to estimate the latent construct of difficult to achieve pro-environmental behaviours.

Finally, it must be acknowledged that the attitudes to school environmental activities scale and the easy to achieve pro-environmental behaviours scale are limited to the context of this research and, consequently, are not replicatable or generalisable. If the scales were to be used beyond this research, further validation of the wording of items via qualitative interviews and peer-examination should be performed. Moreover, new items should be generated that incorporate appropriate wording changes and that are informed by new information about these constructs.

\section{Modelling}

Structural equation modelling was used in this research, to determine the strength of relationships the newly formed latent variables: attitudes to school environmental activities and easy to achieve pro-environmental behaviours. Modelling 
was conducted with the aggregated approach that accounted for the multi-level data (Figure 7.1) and was performed using robust maximum likelihood (MLR) in Mplus. As described in Chapter 3, the aggregated approach uses the Huber-White (Sandwich) estimator, is robust to non-normality, and is appropriate when the goal of the research is to make inferences at the lowest level of a hierarchical design. In this research, the lowest level of the design was the level of students, and the goal was to make inferences about the overall relationship between students' attitudes to school environmental activities and their easy to achieve pro-environmental behaviours.
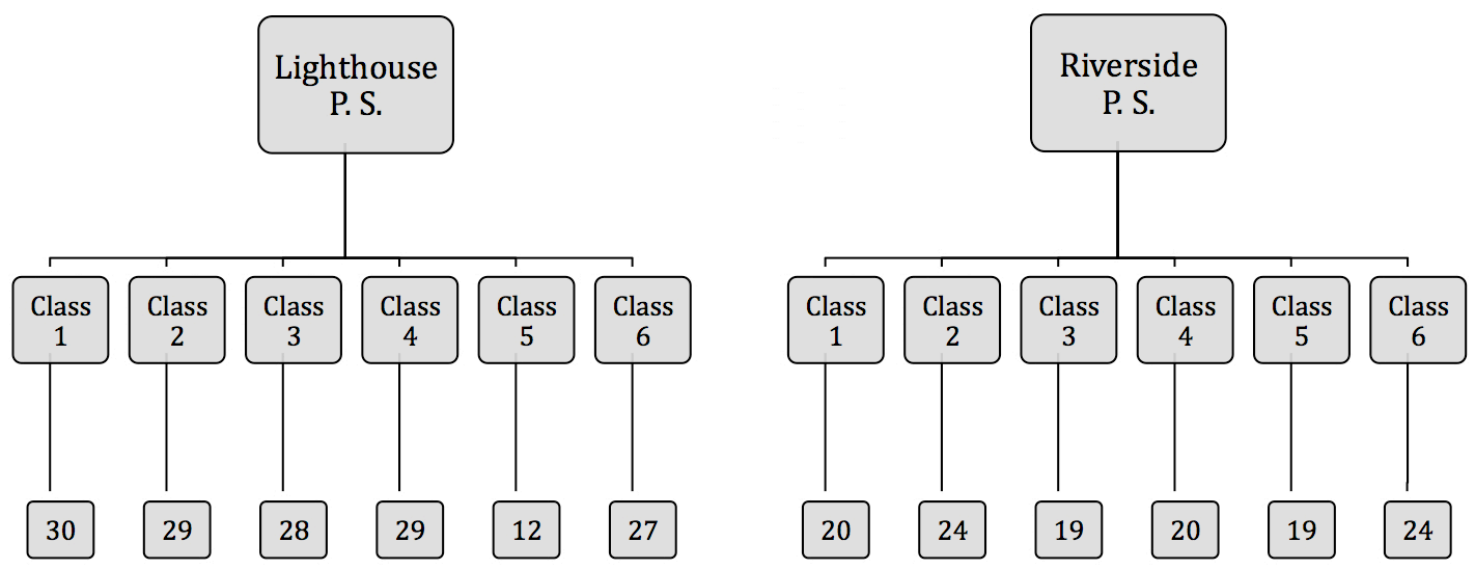

Figure 7.1. The nested hierarchical design of this research, showing number of students surveyed within classrooms and within schools. Originally shown in Chapter 3, but replicated here for the benefit of the reader.

Results. Four of the 285 students surveyed had missed items in both the fiveitem attitudes to school environmental activities scale the four-item easy to achieve proenvironmental behaviour scale, and were excluded from analysis. As described in Chapter 3, prior to estimating the relationship between latent constructs, it had to first be determined whether the hierarchical structure of the data (Figure 7.1) had enough measurement invariance for the data to be considered as collected from one population (Cunningham, 2010). The tests used were: 1) invariant invariance (omnibus test), 2) configural invariance, and 3) metric invariance.

The omnibus test revealed a significant difference between responses from the two schools to the attitude scale $\left(\chi^{2}(15)=41.39, p<.001\right)$, but not the behaviour scale $\left(\chi^{2}(10)=7.65, p=.663\right)$. From hereon, the attitude scale had to be tested, adjusted and re-tested to determine if adequate measurement invariance could be obtained for the scale to be used in structural equation modelling.

A test for configural invariance on the attitude scale yielded a poor fit $\left(\chi^{2}(10)=\right.$ 28.14, $p=.002 ; \mathrm{CFI}=.946 ; \mathrm{TLI}=.893)$, and indicated that items in the scale were loading differently for each school group (Appendix 7.7). This meant that removing one 
item from the scale might improve the results of measurement invariance. Consequently, the item that loaded the weakest onto both groups was removed, Item 6: I sometimes get tired of learning about environmental topics at school (reversed) (Appendix 7.7). Removing Item 6 from the attitudes to school environmental activities scale improved the validity of the scale and increased the proportion of explained variance to 59 percent (Appendix 7.7).

Removing Item 6 from the attitude scale and re-running the ombnibus test still found significance between the two groups $\left(\chi^{2}(10)=32.09, p<.001\right)$, but tests for configural invariance $\left(\chi^{2}(4)=1.91, p=.752 ; \mathrm{CFI}=1.000 ; \mathrm{TLI}=1.026\right)$ and metric invariance $\left(\Delta \chi^{2}(3)=5.42, p=.144\right)$ revealed adequate fits. These results indicated that although the two schools responded differently to the attitude scale, the relationship of indicator items to the latent variable were consistent across both schools and sufficient to proceed to structural equation modelling (Cunningham, 2010). However, because the two schools were found to respond differently to the attitude scale, it was possible that variance also existed at the level of classroom (Figure 7.1), and a modelling technique had to be selected that accounted for any variance due to the nested hierarchical design.

To determine if there was variance at the level of classroom, the proportion of group level variance (within) had to be compared with the total variance (between), using a test for intraclass correlation (ICC) and design effect (Deff) (Cunningham, 2010). These tests revealed significant variance between classrooms, and consequently, a modelling technique was selected that accounted for this variance. As mentioned, the aggregated approach to modelling was selected for this purpose because it could account for variance at the clustering level of classroom (Figure 7.1). Furthermore, the aggregated approach could give information about the overall relationship of latent variables while also providing correct chi-square and goodness-of-fit statistics, and an appropriate (albeit often larger) standard error (Cunningham, 2010).

A structural equation model using the aggregated approach was performed on the four-item attitudes to school environmental activities scale the four-item easy to achieve pro-environmental behaviour scale (Figure 7.2). Results yielded an acceptable non-significant chi-square of $25.13(p<.05)$, an acceptable SRMR value of .036, and a CFI and TLI that were slightly below the ideal minimum values of 995 (Figure 7.2). Together these results indicated that the model was an acceptable fit for the data and could be reported.

After establishing model fit, the regression co-efficient of attitudes on behaviour, and its standard error, could be interrogated. A regression co-efficient of .65 
with standard error of .10 was revealed (Figure 7.2), indicating a strong positive association between students' attitudes to school environmental activities and easy to achieve pro-environmental behaviours within a 10 percent degree of confidence.

Discussion. The results of structural equation modelling in this research revealed a significantly stronger relationship between attitudes and behaviours than the mean results derived from two meta-analyses of attitude-behaviour studies. Hines, Hungerford and Tomera (1987) compared nine studies and found a mean attitudebehaviour correlation of $.35(\sigma=.08)$, and a meta-analysis by Bamberg and Möser (2007) of seventeen studies, found a mean attitude-behaviour correlation of .42 $(\sigma=$ $.07)$. By contrast, the result of $.65(\sigma=.10)$ revealed in this research was more than one standard error greater, and thus significantly stronger than the mean results of many other studies. Furthermore, .60 can be interpreted as a moderately strong positive relationship between variables (Malgady \& Krebs, 1986).

Consequently, it can be declared that there was a strong positive relationship between students' attitudes and behaviours at Lighthouse and River's Edge Primary Schools. Moreover, students with positive attitudes towards school environmental activities were more likely to frequently practice 'easy' pro-environmental behaviours, or likewise, students who frequently practiced 'easy' pro-environmental behaviours were more likely to have positive attitudes towards school environmental activities. It is possible that the strength of the attitude-behaviour relationship was due to the focus on sustainability education at both of these schools. Nonetheless, it could be argued that student attitudes were more likely to be strongly related to behaviours that could be practiced with little effort than behaviours that would be more complex or time consuming to carry out. It is also possible that student attitudes toward global environmental issues might have been less strongly related to their behaviours than their attitudes toward environmental activities that were contextual and immediately relevant to their daily school experience. It is unfortunate then, that the worldviews and difficult to achieve pro-environmental behaviour scales, were not suitable for structural equation modelling. Future exploration of students' attitude-behaviour relationships would benefit from including these other latent constructs in the structural equation model, 

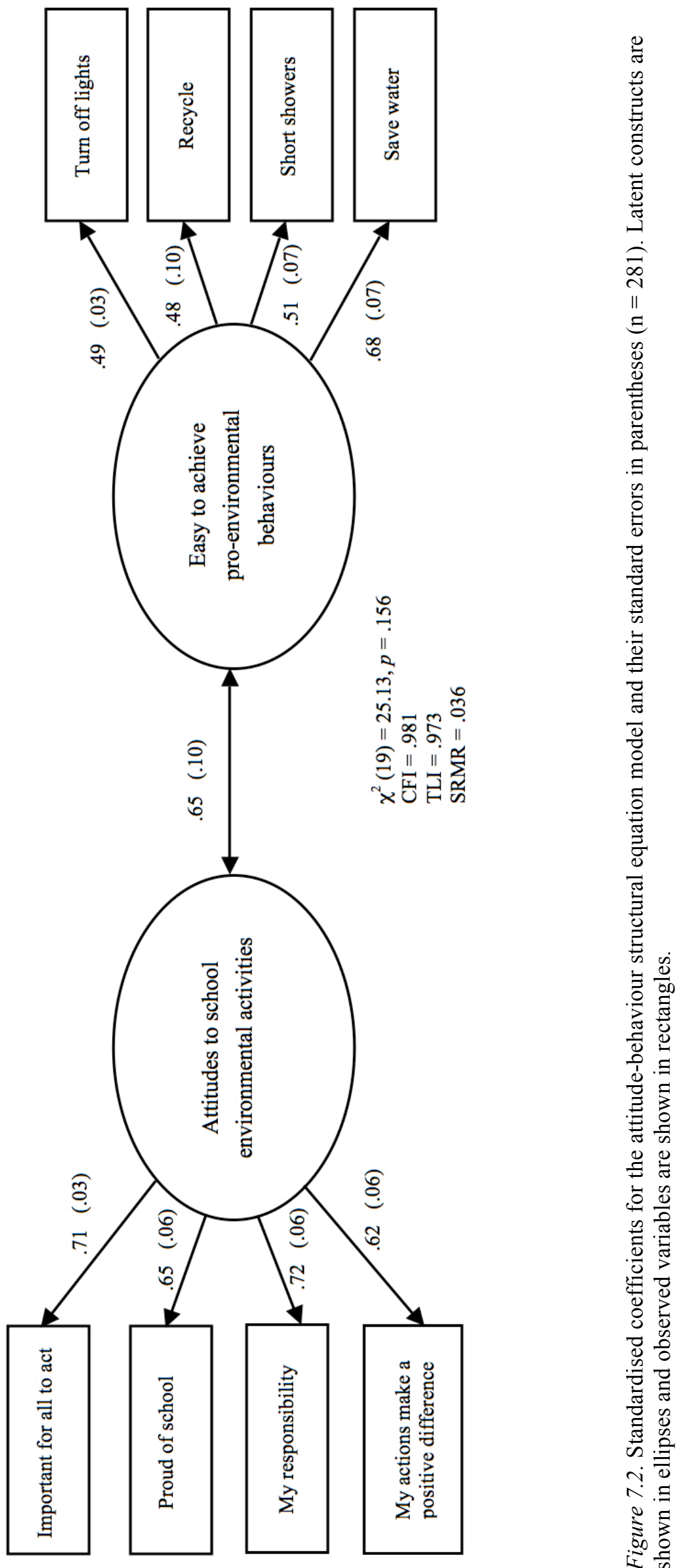
so that it is possible to extract nuances in the attitude-behaviour relationship of students that attended schools with operational whole-school sustainability programs.

In addition to finding a strong positive attitude-behaviour correlation at the level of individuals, it is interesting to note that differences were found in the way students responded at each school to the attitudes to school environmental activities scale. In this research it was not possible to model the group by group responses of students to the attitudes to school environmental activities scale with the grouped responses of students to the easy to achieve pro-environmental behaviour scale because the sample size of each group was too low (i.e. River's Edge $<150$ ) for separate analyses, and there were too few groups (i.e. $<30)$ to conduct multi-level structural equation modelling that could account for variation at the level of groups (Cunningham, 2010).

Nevertheless, it is interesting to simply observe the factor loadings of certain items in the attitudes to school environmental activities scale when they were partitioned by responses from each school group (Appendix 7.7). Appendix 7.7 shows that Item 2: I am proud of what my school is doing to help care for the environment, was a significantly stronger $(>1 \sigma)$ predictor of student attitudes at Lighthouse Primary School than student attitudes from River's Edge Primary School. Whereas, Item 5: I'm only young and it's not my responsibility to care for the environment (reversed), was a significantly stronger $(>1 \sigma)$ predictor of student attitudes at River's Edge Primary School than student attitudes from Lighthouse Primary School. This observation alone, suggests intriguing differences between the dominant student attitudes at each school, however, to be able to infer meaning from these findings would require triangulation with other data sources. Consequently, this result will be triangulated with interview, mind map and descriptive statistical data from each school and discussed in the crosscase synthesis, Chapter 9.

\section{Chapter Conclusion}

This chapter presented and discussed results from factor analyses of three scales, and structural equation modelling between students' attitudes and behaviours. The latent construct of students' attitudes to school environmental activities was strongly related with the latent construct of students' easy to achieve pro-environmental behaviours. This indicates that at Lighthouse and River's Edge Primary Schools, students with positive attitudes towards school environmental activities were $55-75$ percent more likely to practice 'easy' pro-environmental behaviours than students with negative 
attitudes; or alternatively, students who practiced 'easy' pro-environmental behaviours frequently were $55-75$ percent more likely to have positive attitudes than students who rarely or never practiced 'easy' pro-environmental behaviours. By extrapolation this implies that whole-school sustainability education had a positive effect on students' willingness to act or their actual behaviours at home. Results will be triangulated and discussed further in the cross-case synthesis, Chapter 9, with results from interviews, mind maps and descriptive statistics.

The following chapter presents results regarding the family dynamics that affected uptake of new pro-environmental behaviours in the homes of students who attended Lighthouse and River's Edge Primary Schools. 
THIS PAGE HAS PURPOSELY BEEN LEFT BLANK 


\section{CHAPTER 8: FAMILY DYNAMICS AND INTERGENERATIONAL INFLUENCE - Lighthouse AND River's Edge Primary SchoOls}

...the process of intergenerational influence whereby school students act as catalysts of environmental change among their parents and other community members could be a powerful but, as yet, untapped means of addressing current environmental problems.

To achieve this, school environmental education programs could arguably be designed to help students become competent and motivated to act responsibly on behalf of the environment and, consequently, encourage them to share their informed views and skills with others in the home and community.

(Ballantyne, Connell \& Fien, 1998, p. 286)

This chapter explores Research Question 5 (p. 7): the impact of family dynamics on intergenerational influence and the uptake (or non-uptake) of new environmental behaviours in the homes of students in schools adopting different whole-school sustainability agendas. Data came from individual semi-structured interviews with nine students from Lighthouse and from River's Edge Primary Schools $\left(n_{\text {students }}=18\right)$ and their parent/s $\left(n_{\text {parents }}=21\right)$. Family dynamics and intergenerational influence were not examined at the Fertile Ground School, because it did not have any whole-school programs in place that might affect transfer of pro-environmental behaviours into students' homes.

Data from Lighthouse and River's Edge Primary Schools were pooled for the purpose of extracting greater overall meaning. Analysis followed a process of meaning condensation (Kvale \& Brinkmann, 2009), where meaning units and themes emerged from the data through a process of reading, note taking, interrogation and reflection (described in Chapter 3).

\section{Research Question 5: What Were the Family Dynamics that Contributed to} Intergenerational Influence and the Uptake of New Environmental Behaviours in the Homes of Students at Lighthouse and River's Edge Primary Schools?

This section sets out to explore and summarise family dynamics or "complex intergenerational learning processes" (Larsson et al., 2010, p. 140) that operated between children and their parents and contributed to the uptake or non-uptake of new environmental behaviours in the families' homes - behaviours that were discernibly related to the school's sustainability education program. 
In the analysis set out below, parents and their children have been assigned a letter to distinguish them from one another. Parents and children from Lighthouse Primary School are lettered A to I; parents and children from River's Edge Primary School are lettered J to R.

\section{Meaning Condensation}

Family dynamics were categorised using meaning condensation analysis of the parent and child interview data (as described in Chapter 3). Meaning units consisted of sections of each interview that demonstrated themes relevant to family dynamics, intergenerational influence and uptake or non-uptake of environmental behaviours. Each theme included a range of positive and negative responses, which were noted and helped to define the typologies of family dynamics (described in later paragraphs). The central themes of each meaning unit identified included:

- Parent/child's issues-based knowledge of climate change;

- Parent/child's attitudes towards the complex issues surrounding climate change;

- Parent/child's environmental behaviours practiced at home;

- Parent's pre-existing interest in environmental topics and practices;

- Child's interest in environmental topics and practices;

- Child's willingness to act and action competence for environmental behaviours;

- Parent's encouragement of their child's interest in environmental topics and practices;

- Parent's support for and involvement in the school's sustainability education program.

Through a process of refinement and data reduction, one cluster of themes was identified as having potential to influence the transfer of environmental behaviours from school to home via the child. This cluster was:

1) Child's interest in environmental topics and practices as cultivated by the school together with parent's encouragement of their child's interest.

Negative variations of this cluster also existed, where either children were not interested, parents were not encouraging or both. In these negative variations, no new behaviours were described. Moreover, when this cluster of themes was present in the positive for both child's interest and parents' encouragement, no new behaviours were identified in families' homes unless other themes were also present. This observation is described in later paragraphs.

Child's interest in environmental topics was identified when a child described their enjoyment of learning about environmental topics at school, said that they wanted 
to learn more, expressed concern for the world's future, or they attributed importance to actions that benefited the environment. For example, Child M said, "It will help if everyone does it, it will help the environment and it's just fun doing it". Low child interest was identified when a child appeared ambivalent or disinterested by environmental topics, or expressed a lack of time or low concern for environmental pursuits. For example, Child Q stated, "I'm more worrying about school work so that I can get into uni and get a good job because my Mum's pushing me".

Parent encouragement was identified when a parent described opportunities they had created at home for their child to express his or her interest in environmental practices, or described a connection between their child's emotional wellbeing and his or her interest in environmental topics, or described their own openness to being reprimanded by their child for misuse of resources. For example, Parent D remarked, "It is good when they say to you, 'Oh Mum, you're having a long shower'.... It's good. You know they're learning all about it". Low parent encouragement was identified when a parent described importance of other household priorities, or ascribed environmental actions as pointless. For example, Parent $\mathbf{J}$ stated, "The danger is if people think by doing little things they are actually making a difference, then they are completely mistaken, mislead".

In addition to identifying positive child interest and parent encouragement as contributing to the potential for uptake of new behaviours in family homes, two clusters of themes were identified as having influenced the uptake of new environmental behaviours in the family home because of the school's influence via the child. These clusters of themes were:

2) Child's willingness to act and action competence for environmental behaviours, which was only observed when child's interest and parents' encouragement were also present.

3) Parent's support for and involvement in the school's sustainability education program, which was observed as an extension of their child's willingness to act and action competence.

Child's willingness to act was identified when a child expressed a sense of responsibility toward adopting environmental actions in their life, and placed high importance on environmental actions. Their action competence was inferred from the child's description of the various environmental actions that they were responsible for driving in their family home or at school. For example, Child C stated, 
[Composting] is good because we're helping the plants grow and we don't have to use as much water, and then we can have more water for other things. [Is that something you'd like to do when you're in Year 6?] Yeah, I'd really really like to [be on the composting team] because it sounds really fun and I'd like to have a responsibility like that.

Parent support and involvement were identified when a parent described their satisfaction with the school's focus on sustainability and environmentalism, or their personal contribution to the school's initiatives, such as through involvement with the Parent and Citizen $(\mathrm{P} \& \mathrm{C})$ committee or regular working bees. For example, Parent D described a mutually beneficial relationship that her husband's business had with the school, saying, "My husband is a lawn mowing contractor and he actually dumps all the grass at the school" because "They're using it for compost and fertilizing around the garden".

Using these clusters of themes and considering the positive and negative response variations observed within the first cluster, four main types of family dynamics were identified as influential to the uptake or non-uptake of environmental behaviours in the family home because of the school's influence. The four types were characterised by high and low child interest in environmental topics and practices, and high and low parent encouragement of their child's interest (as summarised in Figure 8.1). Figure 8.1 shows that when parents were not encouraging of their child's interest and/or their children were not interested, then no new behaviours were adopted in the family home. Whereas when parents were encouraging and their children were interested, the potential existed for adoption of new behaviours in the family home. Consequently, families categorised into Types 2, 3 and 4 exhibited no uptake of environmental behaviours in the family home because of the school's influence. Families categorised into Type 1 exhibited the uptake, or potential for uptake, of environmental behaviours in the family home because of the school's influence. 


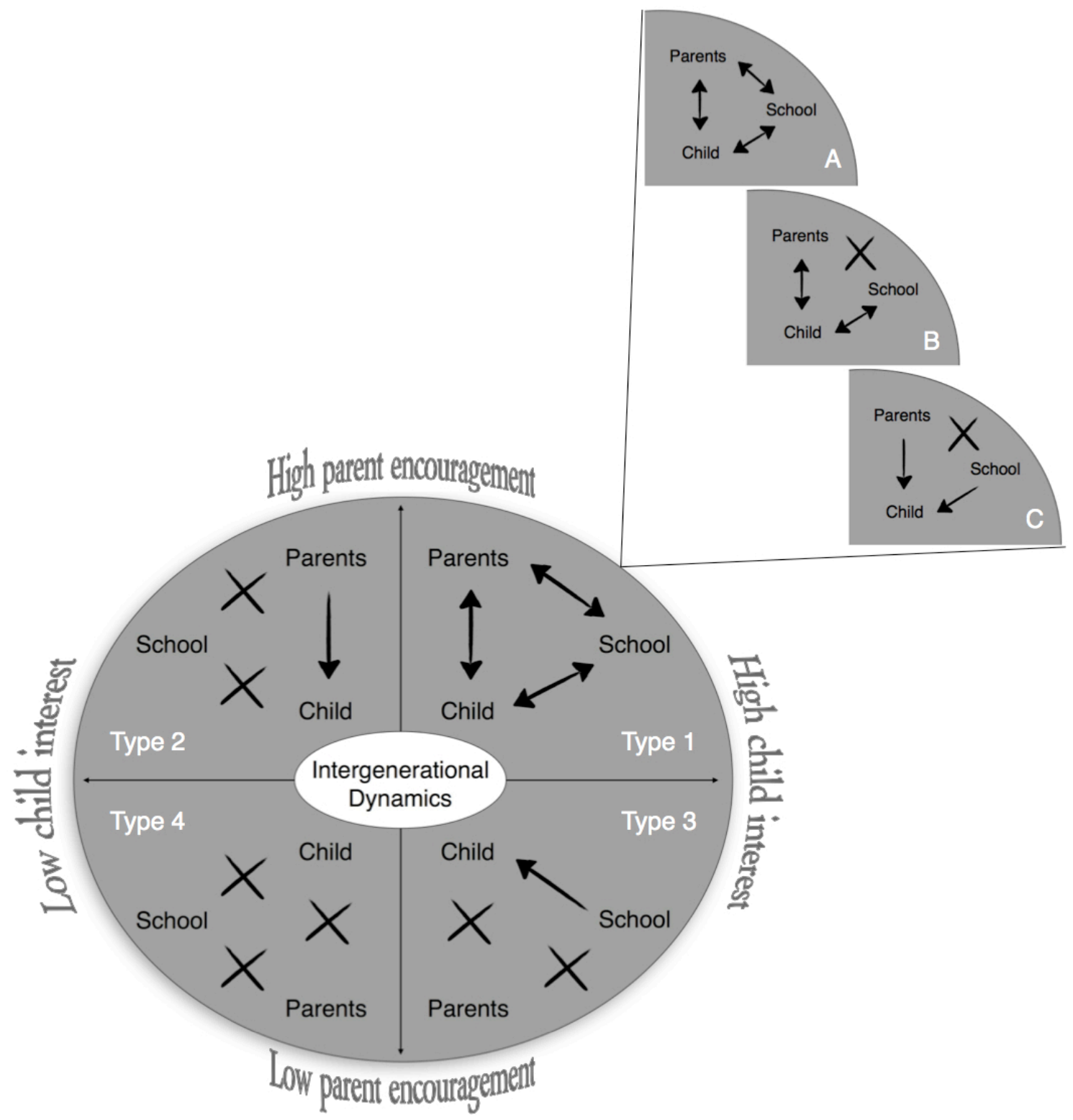

Figure 8.1. Simplification of the spectrum of intergenerational dynamics.

Type 1 is shown to feature three subtypes: $A, B$ and $C$ (Figure 8.1). These three subtypes are based on the three clusters of themes mentioned above, which were identified as having influenced or had the potential to influence uptake of environmental behaviours in the family home. Families categorised into Type 1 -Subtypes $A$ and B, were the only families to describe new environmental behaviours adopted in their homes as influenced by the school's sustainability program. Subtype $A$ was distinguished by parents' support for and involvement in the school's sustainability program and, their child's willingness to act and action competence. This relationship is shown in Figure 8.1 as three double headed arrows between child and parents, child and school, and, parents and school. Subtype B was distinguished by the child's willingness to act and action competence but no school-parent interaction. This relationship is 
shown in Figure 8.1 as two double headed arrows between child and parents, and child and school; and a cross between parents and school.

Families categorised into Type 1 - Subtype $C$, were identified as having potential for the uptake of environmental behaviours because of the school's influence. Subtype $C$ was distinguished by the child's interest and parents' encouragement, but no child willingness to act and action competence, or school-parent interaction. This pattern is shown in Figure 8.1 as two single headed arrows from school to child, and parents to child; and a cross between parents and school. This subtype was grouped into Type 1 together with Subtypes $A$ and $B$, for the reason that if willingness to act and action competence had been cultivated in these children, the family may well have adopted new behaviours because of the school's influence.

Excerpts from parent and child interviews are exhibited in Table 8.1 for Lighthouse Primary School and Table 8.2 for River's Edge Primary School. These excerpts give examples of positive and negative combinations of parent encouragement and child interest, as relevant to the four types of family dynamics identified. Further, examples of child willingness to act and action competence, and parent support for and involvement with the school, as relevant to Type 1 -Subtypes $A$ and $B$ are provided. Descriptive examples of each of these types and subtypes are presented in the following paragraphs, and the differences found between Lighthouse and River's Edge Primary Schools are discussed.

\section{Results Expanded}

Five out of nine interviewed parents at Lighthouse Primary School described adopting new water saving, power saving, waste reducing, or biodiversity conserving behaviours in their homes as a consequence of their children bringing ideas home from school. These parents also described their support for and varied involvement in the school's sustainability initiatives. Their children also described becoming more active in certain behaviours at home as a consequence of learning about them or being exposed to them at school. These families were all categorised into Type 1 -Subtype A (Table 8.3). The four other families from Lighthouse Primary School exhibited variations of parent encouragement and child interest, and were categorised into Types 2, 3 or 4 (Table 8.3).

By comparison, one out of nine interviewed parents at River's Edge Primary School described how the school's focus had impacted their family's uptake of new environmental behaviours, mostly because of their daughters' newfound passion for the topic, but that their family was not otherwise connected with the school's sustainability program. The child from this family expressed responsibility for environmental pursuits 


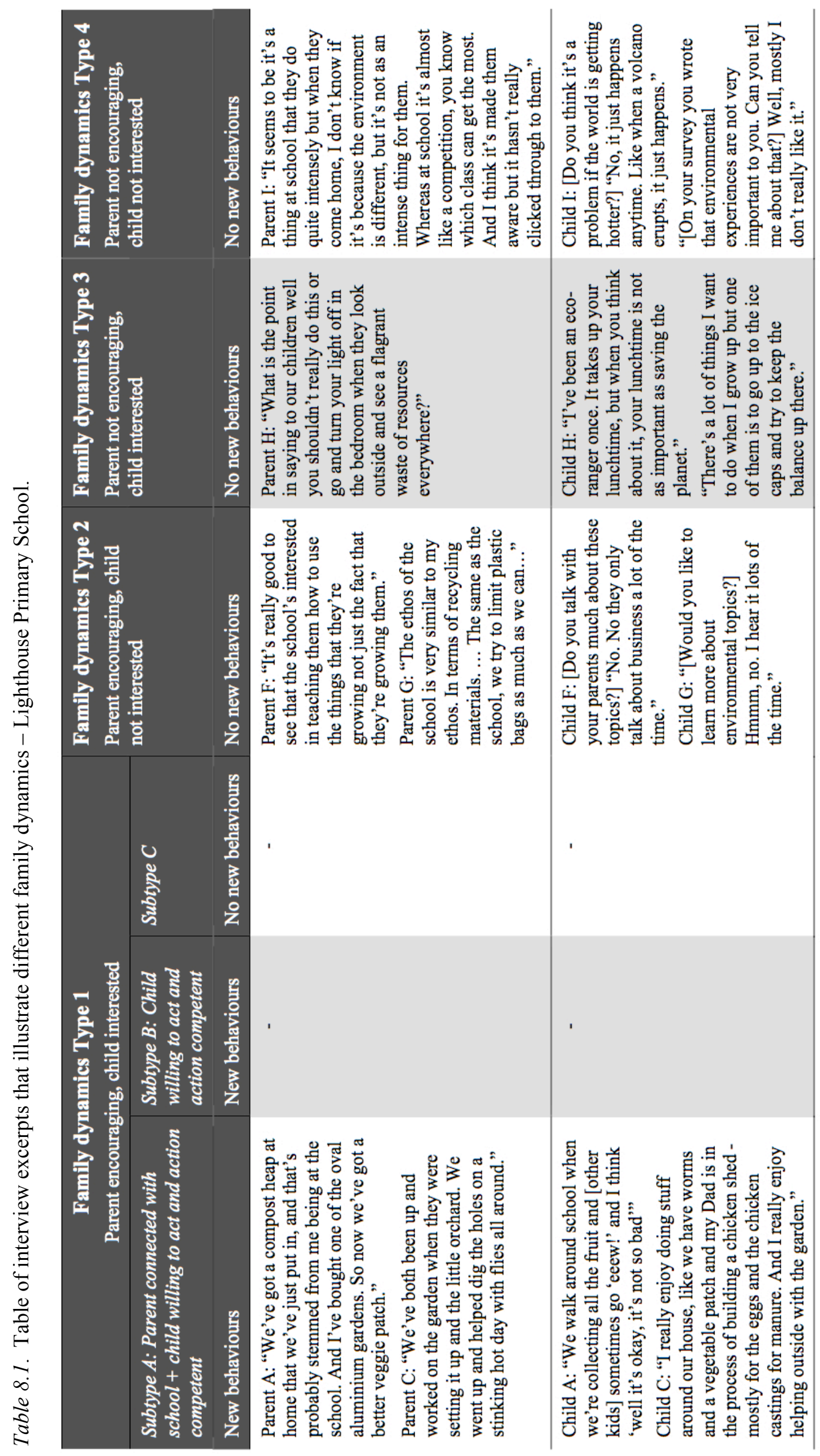




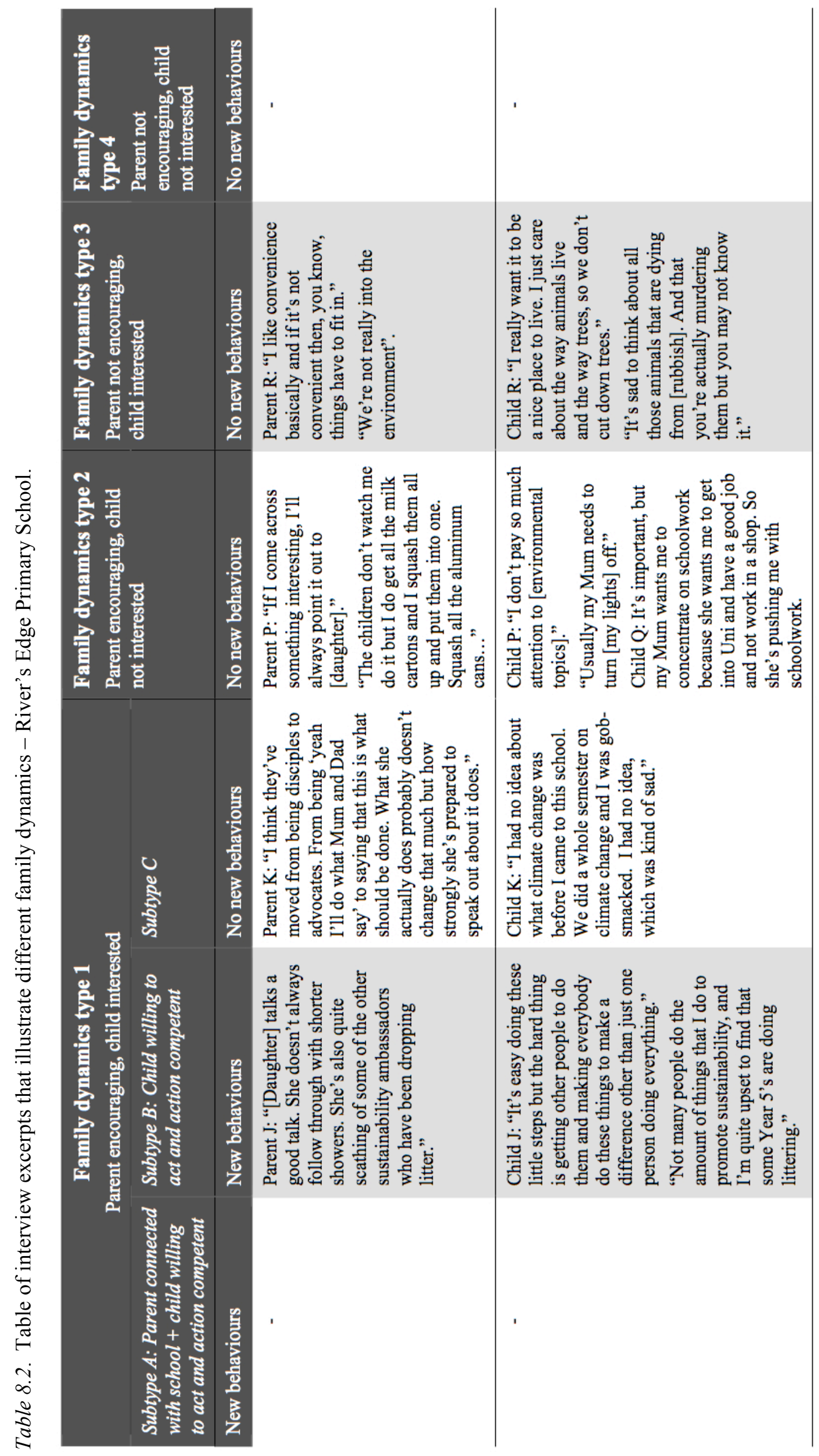


and described how she had become active in driving many new behaviours at home as a result of learning about them at school. This family was categorised into Type 1 Subtype B (Table 8.3).

Furthermore, five out of nine interviewed parents at River's Edge Primary School expressed a lack of awareness of the school's focus on sustainability or environmental themes, but said that they already practiced many environmental behaviours in their homes and encouraged their children's interest in environmental topics. Their children explained that the school's sustainability focus had sparked their interest in environmental topics and, as a consequence, they were participating more in the environmental priorities already fostered by their parents. These families were categorised into Type 1 - Subtype C (Table 8.3). Three other families from River's Edge Primary School exhibited variations of parent encouragement and child interest, and were categorised into Types 2 or 3 (Table 8.3).

Table 8.3. Number of each family type identified at each school $\left(n_{\text {Lighthouse }}=9, n_{\text {River's Edge }}=9\right)$.

\begin{tabular}{|c|c|c|c|c|c|c|}
\hline \multirow{2}{*}{ SCHOOL } & \multicolumn{3}{|c|}{ Туре 1} & \multirow{2}{*}{ Type 2} & \multirow{2}{*}{ Type 3} & \multirow{2}{*}{ Туре 4} \\
\hline & $\mathbf{A}$ & B & C & & & \\
\hline Lighthouse & 5 & - & - & 2 & 1 & 1 \\
\hline River's Edge & - & 1 & 5 & 2 & 1 & - \\
\hline
\end{tabular}

Each of the family types identified are explained in more detail below, with reference to excerpts of parent/child interviews from both schools. Some of the eighteen families were, at times, difficult to categorise because elements of their interviews raised further intricacies. These intricacies are discussed because they helped to elucidate the overall implications of the data.

Family dynamic Type 1 - Subtype $A$. This subtype was characterised by high parent encouragement and high child interest, parents supportive and involved in the school's activities, and the child displaying a willingness to act and action competence. As a result of this combination of family dynamics, new behaviours had been adopted in the family home because of the school's influence. Examples of these families, all of which were from Lighthouse Primary School, are set out in the following paragraphs, but because of other intricacies identified, another layer of meaning was added to the analysis of families in this subtype: complexity of the new behaviours and parent preexisting interest. Consequently, the five families of Type 1 -Subtype A are presented here, differentiated by the complexity of the new behaviours adopted in their homes. 
Examples from these families also illustrate willingness to act and action competence in the children, and involvement with and support of the school's environmental initiatives by parents.

Interview data showed that certain families, who had implemented various environmental behaviours in their homes prior to their association with the school, had adopted more complex behaviours since their child joined the school. The newly adopted behaviours could be considered complex because they involved a large outlay of money, time, energy and resources. For example, Parent A and Child A elaborated,

I think we're doing pretty well compared to other families. We do quite a bit at home. ... We put in a fishpond out the front because [daughter] started up the frog garden last year with Mrs $R$, and she was interested in putting a frog garden in so we've put a pond in by our front door and we've actually started hearing frogs now. And that's just to help our local environment. (Parent A)

I'm in the compost team and worm farm [at school]. I learn a little bit more each day and that's helped me understand so much more, and how the worms are important in the eco-system. ... We've recently got a compost [at home] and we put all our food scraps in there. We don't have a worm farm but in third term we got to take some worms and keep them so I put them in our veggie patch. It's making it grow really well. (Child A)

It is suspected that the reason these family's behaviours were more complex than other families' was that the parents had high pre-existing personal interest and motivation, to the extent that the parent was often driving the uptake of new behaviours in the home. Parents A and B described,

It's more probably us coming up with ideas than her specifically but then she jumps right on board. ... She has never actually said 'I want a veggie garden'. ... Though she's always willing to help and everything. And she can see the benefits of it. (Parent A)

What's my motivation for doing all the recycling, etcetera? I guess I'm essentially a greenie. I love outdoor things. I've always loved the bush. I've always loved that really nature back-to-basic kind of stuff. Not that I'm going to go and live in it, but I can appreciate the value of it and I don't want to lose that. (Parent B)

Interview data indicated that parents could be receptive to adopting new environmental behaviours at home and encouraging of their child's interest in such topics even when they personally had low to moderate pre-existing interest in the subject matter. It was these parents who described several new moderately easy-toimplement environmental behaviours in their home and admitted that they had previously not been very environmentally active. Parents $\mathrm{C}$ and $\mathrm{D}$ described, 
It was only when we came back and went to school here that all this stuff came up.... It's only having been here and the boys bringing stuff home that's really made us [change]. I've always been interested in it but that's been the drive to do it. ... They're not just learning maths and English they're learning all about values and their keys to success, which are commitment and perseverance. ... We need to back up the school and enforce what they do at school for the message to get through to [the children]. If they were doing something that I really didn't believe in then I wouldn't do it at home. But stuff like that, I think if they're getting it there and getting it here, they're more likely to act on those principles. (Parent $C$ )

I think we're more aware of it. Definitely the water consumption, especially showers, you know having shorter showers or bathing the kids all together in one lot of water. ... Like having the taps running when they're cleaning their teeth. And hand watering in the garden. ... The recycling as well, they've really become aware of that just because they do it at school. (Parent D)

In these families, motivation to adopt new behaviours seemed to be influenced not only by the school's activities, and a desire to encourage their child's interest in the subject matter, but also to maintain social norms. For example, when asked why his parents were so interested in environmental practices, Child C stated, "Well a lot of people on our street are really into that stuff, probably about half the street" and, "We're really into the environment and I think [Mum] just wants to do her bit".

Family dynamic Type 1 - Subtype B: This subtype was characterised by high parent encouragement and high child interest, and the child displaying a willingness to act as well as action competence. From this interaction of family dynamics, new behaviours had been adopted in the family home because of the school's influence.

Only one family, Family J from River's Edge Primary School, showed this combination of family dynamics. In this family, both parents consented to be interviewed and each had differing opinions about climate change and different approaches towards encouraging their daughter's enthusiasm, which contributed to interesting intricacies in the data. The father of Family $\mathbf{J}$ was highly informed about the issues of climate change and actively pursued new information from scientific journals and high-profile books on the subject. His attitudes were pessimistic and represented a doomsdayist perspective, saying, "It's warming faster than ever in history. ... The consequences are dire". He did not actively support the introduction of proenvironmental behaviours in their home, saying, "In the big scale of things what we do is trivial, it's cosmetic", and further stated, "In terms of what's actually achieved in terms of pollution and the environment it's absolutely totally meaningless, it makes absolutely no difference". 
By contrast, however, the mother from Family $\mathrm{J}$ displayed only general knowledge of the issues and talked about incidentally reading articles on the subject. Her attitudes were similar to her husband in believing that climate change is happening, is human induced and is going to get a lot worse. However, she also reasoned that humans should collectively adopt pro-environmental behaviours saying that what is needed is "small steps" and "until the politicians make a big step it's just got to be about a local message". This mother also described her encouragement of her daughter's enthusiasm saying, "We go along to help out at the bush reserve so we're thinking about native plants and that sort of thing". Furthermore, this mother commented on the school's impact on her daughter's willingness to act and action competence, saying,

I think the Millennium Kids thing and the sustainability ambassadors have made her go, 'well this is something that's important'. She does believe in it, but it's having that position [as a sustainability ambassador] that has given her selfesteem.

Child J's willingness to act and action competence for environmental behaviours were clear when she stated, "Without making changes we're not really going to have a future" and "Hopefully I can become a leader in the environment and teach other people to be better". She also described the effect she had had on the family's environmental behaviours,

I feel if I'm not making a change then nobody else around me is making a change, so I thought, 'I've got to be doing something', and every month or so we'd be bringing in something else to make our house more sustainable.

We're relying on the bread that my Mum makes at home. I prefer it, because I prefer the stuff that hasn't been made in big factories, which uses up so much energy. Just using the stuff, which you make at home, feels as if it's a lot better for the environment. It doesn't have the packaging as well which also is better for plastic use. We don't really need plastic and yet we use it so much.

The interesting contrast of parent encouragement juxtaposed with Child J's obvious willingness to act and action competence indicated that the mother in this family was the enabler of her daughter's enthusiasm. This observation suggests that if a child is interested in environmental topics, and has opportunities available at school to cultivate their willingness to act and action competence, and if at least one parent is encouraging of their child's pro-environmental behaviour, then new behaviours are more likely to be adopted in the family home.

Based on findings from Lighthouse Primary School, new behaviours could have been further bolstered if a parent-school relationship had also been developed. A low depth of parent-school involvement was perceived from several parents at River's Edge 
Primary School compared with the descriptions of parent-school involvement at Lighthouse Primary School. For example, Parent Q stated, “I don't have much to do with the school. I just drive in drop her off, pick her up". And Parent K suggested,

In terms of schools encouraging families, you could do a busy bee day with the veggie garden or have plots for different classes that parents could donate different seeds to.

It was apparent that some parents were satisfied with low parent involvement on school sustainability initiatives and thought their school was doing a good job. Parent $\mathrm{M}$ stated, "I think the school is doing a lot. I don't think it can do more initiatives". And Parent Q stated,

What could they do really? They're really very good. They're leading by example, the plants they plant, what they do, it's all leading by example. I think that's great.

When asked about how the school could develop parent-school relationships for sustainability initiatives, Parent P commented,

Most people who come to a private school do well because they're plundering the environment. You're more likely to find environmental people not coming to this school. So when you say dialogue with families, I don't think the families to a school like this will...talk about it. ... You'll get a mixture I suppose.

Family dynamic Type 1 - Subtype $C$. This subtype was characterised by high parent encouragement and high child interest, but no new behaviours adopted in the family home because of the school's influence. This subtype was grouped into Type 1 together with Subtypes $A$ and $B$, because it was considered that potential existed for new behaviours to have been adopted because of the school's influence, if, willingness to act and action competence had been cultivated in these children. Interestingly, families in this subtype were only from River's Edge Primary School.

Examples of high parent encouragement were apparent in statements such as this from Parent N regarding encouraging her children to take short showers, "We're sort of trying to do it in a funny way. Like competition power showers". However, Parent N highlighted some difficulties that had arisen with encouraging her daughter, describing,

When we shop, she [daughter], will get really frustrated because she'll want to get the plastic bags for me to put the apples in ... whereas I'll put them all in the trolley and she thinks that's kind of the wrong thing.

Despite this description, Child N's interest in environmental topics and practices were exhibited with the statements, "I don't want [the world] to get all polluted everywhere and littered everywhere. I want it to just stay nice how it is", and "There's 
still a lot of littering around my area and I try to pick up as much as I can, just as I'm walking around". This example, together with her mother's description, illustrate that Child N's understanding of the cycle of plastic bag pollution was flawed, but that a nascent willingness to act was present that could have been further channelled at home or at school. When asked about whether the school had influenced the environmental behaviours her family undertook, Child $\mathrm{N}$ stated, I think we just know how to do it already. I don't really learn about, like, I don't think anything at school has helped it or anything".

Another example of high parent encouragement was the response from Parent $\mathrm{K}$ to a question regarding whether children should be taught more environmental skills at school, "For our children, they get it from home, but for other children yes definitely because you need to educate that next generation". Child $\mathrm{K}$ demonstrated her interest in environmental topics and practices with the statement,

It is quite important because I want to go on living knowing that my children and my children's children, etcetera, will be able to have a Swan River, and a river next to them and to have a home by the beach and to experience those things but if [climate change] keeps happening there probably might not even be a beach. It's a bit distressing.

Child K's environmental interest had, however, not influenced the environmental behaviours of her family, which initially was suspected as being because of her parents' strong pre-existing interest in environmental behaviours. Parent $\mathrm{K}$ described her and her husband's pre-existing interest in environmental behaviours, saying, "We do it because it's the right thing to do" and, "It's not something we think 'ooh I'm going to save the planet today', it's just our mindset. It's the right thing". When asked about whether their children had brought any new ideas home from school, Parent K responded, "We're a tough nut to crack. We've got it sussed already. We're already a step ahead of them", and "The kids will take a reinforcement from school more so than it being something completely out of the blue". Even so, it was found that some families in Type 1 - Subtype $A$ also had strong pre-existing interest in environmental topics, and yet the child's willingness to act and action competence, and the parent's involvement with the school's programs, had contributed to new, often more complex, behaviours being adopted in the family home. For this reason, it is asserted that there were differences in the approaches of fostering willingness to act and action competence in children between Lighthouse and River's Edge Primary Schools that should be considered. 
One consideration for River's Edge Primary School to leverage their impact on environmental behaviours of families is that they could increase emphasis across all year groups on fostering willingness to act and action competence in students that are interested to learn about these topics. Moreover, it appeared that this school could create meaningful opportunities for families that were already practicing pro-environmental behaviours to engage with the school's environmental programs, which may involve simply relaxing their doors to more parent input.

Family dynamic Type 2. Family dynamic Type 2 was characterised by high parent encouragement of environmental practices in their homes but their child's low interest in environmental topics and practices. Moreover, environmental behaviours had not been adopted in the family home that were a result of the school's programs. Parents of this type described their personal interest in adopting environmental practices in their homes and encouragement of their child's interest. Parent F explained, "We're quite serious about trying to do something that's going to make an impact in the long term" and "I think it's vital to their longevity that [children] learn how to be more responsible to the planet".

Whereas, the interviewed children of these families did not show interest in environmental topics or practices. Child F stated, "I'm not worried yet but I might be in the future when I learn more about environmentally friendly stuff". Child F also described his parents' interest in environmental practices saying, "They know a lot about that sort of stuff. They've got water tanks and they've got a bit of solar panels everywhere", and when asked when these features were implemented in their home he replied, "I have no idea. I don't think I was born when they put it in".

In another example of low child interest compared with high parent encouragement, Parent P stated, "I don't think she has much idea. ... I have to re-teach her when she gets home". Parent P then gave the example that his daughter "doesn't really understand why you need native plants... It's concepts; you've got to teach the concepts". And Child P remarked,

Usually I'm just getting on with my everyday life, doing my school homework, a bit busy. ... I would like to know about [environmental topics] but I also want to get on with my actual everyday life as well.

Family dynamic Type 3. Family dynamic Type 3 was characterised by low parent encouragement of environmental messages and practices, their child's high interest in environmental topics and practices, and no new environmental behaviours adopted in the home because of the school's programs. Parents of this category 
described time and convenience as limitations to their environmental behaviours. Parent $\mathrm{R}$ stated, "For me it's very much a time constraint that would probably prevent me. I like convenience basically". She also explained that cost saving would be a motivation for their family, "If there's things we could do that would save money, [my husband] would probably be interested".

Interestingly, Child R described her interest in environmental topics saying, "It's quite important because we don't want the world to become a bad place and not very clean" and "I really like to try and help with the world. I really don't want the world to go downwards in being a disgusting place". But her mother, Parent R, was cynical of her daughter's environmental interest describing it as "moralistic" and provided an example, saying,

[Daughter] has mentioned it that it's better for us to have [a lunchbox] ... But she actually prefers the little bags because she can throw them away and she doesn't have to go back to her bag, whereas if you have a little tub she has to put it back in her bag. So it depends how moralistic she's feeling that day.

Other parents also described lack of collective action or politics as barriers to personal action. Parent $\mathrm{H}$ asserted,

What I do as an individual is irrelevant in the grand scheme of things. ... I don't think there's any purpose at this stage unless the whole community receives informed and proactive leadership. There's no point to me switching off that one light globe when the whole street is lit up until 2o'clock in the morning. There's no point in you making a sacrifice and riding a bike to work when we've got a transport system that's out of control in terms of costs.

In contrast to his father's cynicism, however, Child $\mathrm{H}$ showed interest in environmental topics and practices, stating,

I try to do it in my own ways. I just pick up some rubbish [from the playground] and put it in a bin later. Sometimes I forget and it's still in my pockets when I get home and my Dad gets mad.

One reason for Child H's interest in environmental topics could have been the apparently juxtaposing views of his mother, who was not interviewed. Both Parent $\mathrm{H}$ and Child $\mathrm{H}$ described the wife/mother's interest in environmental topics, but neither of them described new behaviours that had been adopted in the family home because of her influence. Child H described his mother's environmental interests saying,

I know a fair bit because my Mum met Al Gore. Not on the Internet, she actually met him. She then became very knowledgeable about the facts of global warming so she cares about the environment much more now. She taught me that the ice caps were melting and that polar bears were being forced to swim because they 
couldn't find enough ice to keep themselves on and some of them couldn't find enough ice and they ended up dying. And I like polar bears.

Family dynamic Type 4. Family dynamic Type 4 was characterised by low parent encouragement of environmental messages and practices, their child's low interest in environmental topics and practices, and no new environmental behaviours being adopted in the home because of the school's programs. Parents of this category also referred to time, lack of collective action or politics as barriers to personal action. Moreover, Parent I described his philosophical consideration of the lack of a broad social perspective in children as a hindrance to children being able to properly engage with environmental messages or to sustain them over their lives, stating,

Kids don't generally have a global picture, they can't think abstractly so they tend to think of issues in isolation because they're still too young so it's difficult to bring the global picture in. ... So at the moment it's 'well we should recycle this and we should recycle that' but do you know why? ... They go through the motions and they do this and that but they don't fully understand why. And later down the track it's going to be 'oh, what's the point, what's the problem'.

Child I showed no interest in environmental practices, stating,

I really don't like the environment that much. Well with the bushes out there, if there's junk in there I don't pick it up because if it's empty then some worms might get in there and mostly if people kick it around I don't pick it up because there's more spiders living in there. ... I mostly go on the computer or the PS2 or play with my Lego and build.

\section{Summary and Discussion}

Results indicate that where there was high parent encouragement and high child interest, there existed either:

Subtype A) new environmental behaviours in the family home, the child becoming a co-driver of these behaviours, and their parent/s becoming more involved in the life of the school and supportive of the school's sustainability initiatives,

Subtype B) new environmental behaviours in the family home and the child becoming a co-driver of these behaviours, or

Subtype C) no new environmental behaviours but the potential for the characteristics of subtypes A and B to be developed.

The question then arises, how can the outcomes observed in Subtypes $A$ and $B$ be cultivated? With reference to results from other sections of this thesis, it appears that student willingness to act and action competence can be cultivated through creating more opportunities for students to learn actions-based environmental knowledge (skills) 
at school, through the establishment of systems such as recycling, composting, gardening, and through the establishment of authentic leadership opportunities where students' opinions help to shape the direction of some initiatives.

Cultivating family involvement and support seems more complex, but on the most abstract level appears to fall down to creating an open, inviting school culture, where parents are welcome on school grounds and where their input and involvement are encouraged and invited. Whilst seemingly simple, this was an obstacle at River's Edge Primary School, which could go further towards building relationships with families. This will be discussed further and triangulated with teacher interviews in the following chapter.

In summary, environmental educators might consider fostering willingness to act and action competence in children by developing more opportunities for students to learn environmental skills that can be incorporated at home, and by providing programs with authentic leadership opportunities. In addition, educators should consider creating paths for parents to engage with the school and be invited to learn more about the various initiatives being undertaken, which could involve adult education opportunities.

\section{Chapter Conclusion}

School sustainability education can influence a child's interest in environmental topics and their motivation to care for the environment. The extent that these messages and behaviours carry into the child's home life is mediated by: 1) parents' encouragement of their child's interest, 2) their child's willingness to act and action competence, and 3) school-parent relationships. Moreover, this study has demonstrated that parents with a high level of pre-existing interest can be encouraged to adopt complex new environmental behaviours. This research suggests that the school can be a catalyst for those parents who are somewhat interested in environmental topics and practices but are not actively practicing them at home, or those parents who are interested and already active but are keen to implement more complex behaviours at home.

The following chapter presents a synthesis of findings and final conclusions for each research question, and discussion of these findings and conclusions based on the literature. 


\title{
Chapter 9: UnPaCKIng Sustainability - SYNTHESIS AND CONCLUSIONS
}

\begin{abstract}
At the educational level, curricula must seek to develop a sense of responsibility towards the natural environment as well as foster a spirit of inquiry and innovation so that the diversity of human experience can be brought to bear on the challenge of creating an environmentally sustainable development pathway. ... It must coherently link environmental issues to social and economic priorities, for none of these can advance in isolation.
\end{abstract}

(Bahá'í International Community, 2008, II.13)

This chapter addresses the five research questions by presenting the triangulated results from interviews and observations, document searches, mind maps, and surveys, conducted at the case study schools. The synthesis and discussion of these findings are presented in the following order:

1) Organisational factors that foster or impede whole-school sustainability education

2) Environmental knowledge, attitudes and behaviours of students

3) The role of family dynamics on the potential for intergenerational influence between students and their families

Each synthesis ends with a series of assertions about ways that whole-school sustainability education could be improved in the case study schools. Limitations of this research are then outlined. Recommendations are made for maximising the impact of whole-school education for sustainability followed by a discussion about whether and how the results from this research lend weight towards advocacy efforts for the Australian Sustainable Schools Initiative (AuSSI) in Western Australia. This chapter and thesis conclude with consideration of future research possibilities.

\section{Organisational Factors that Foster or Impede Whole-School Sustainability Education}

This section discusses results from the investigation of Research Question 1 (p. 7) presented in Chapters 4, 5 and 6. The organisational outcomes and challenges that the two AuSSI schools encountered after embarking on their sustainability journey are explored and compared with similar organisational elements examined at the comparison school. The discussion is presented across the five key elements of 
sustainability education investigated in this research: 1) school governance, 2) school planning, 3) community networks and partnerships, 4) student voice and engagement, and 5) curriculum integration. These five key elements were explored because they are among twelve elements asserted by AuSSI - WA as integral for successful wholeschool sustainability education (DoE, 2012b). Literature about each of these elements was explored in depth in Chapter 2, and will again be referred to here where relevant to the findings from this research.

Table 9.1 summarises the results from investigation of the five key elements at the case study schools, and categorises them across specific themes that emerged from the data. For the purpose of comparison, each theme was given a score on a rating scale of 1 to 4 , where 1 is starting (i.e. foundational characteristics were present) and 4 is excelling. Following Table 9.1 is a discussion of these themes, which compares themes across cases and makes references to the literature. The discussion closes with a summary comparison of the case study schools, and this section on organisational elements will conclude with a series of assertions about features required to foster a successful whole-school sustainability program. These assertions will be of interest to the case study schools, other AuSSI schools, AuSSI - WA and their partner agencies, and to sustainability facilitators and educators more broadly.

\section{School Governance}

Research has shown that if a whole-school initiative falls on one teacher alone, its potential for long-term and deep integration into school life is compromised (Pepper, 2007). Often, if the key staff member leaves the school or takes on new responsibilities, the initiatives they drove will wane and fizzle out (Lewis, 2012; Pepper, 2007). However, the example of Fertile Ground Primary School has illustrated that if no teacher volunteers to spearhead a whole-school sustainability focus, despite other elements being in place that indicate potential support for such a program, activities with a sustainability spin may happen, but on an ad hoc basis without integration within an overarching vision for sustainability in the school.

When a teacher does volunteer to spearhead a whole-school sustainability program, the approach they adopt is integral to the long-term support for the program by other staff and the depth that the program will be integrated into school life (Lewis, 2012; Pepper, 2007). To be effective, their approach should invite the views and collaboration of all other stakeholders, and celebrate varied contributions as part of 
Table 9.1. Cross-case analysis of the case study schools compared across the five key elements investigated and themes that emerged from the data. Themes were assessed using a $1-4$ rating scale, where 1 = starting, 2 = establishing, 3 = achieving and $4=$ excelling. '-' indicates that a feature was non-existent.

\begin{tabular}{|c|c|c|c|c|}
\hline $\begin{array}{l}\text { KEY ELEMENTS } \\
\text { EXPLORED }\end{array}$ & EMERGENT THEMES & $\begin{array}{c}\text { Fertile } \\
\text { Ground } \\
\text { P.S. }\end{array}$ & $\begin{array}{l}\text { River's } \\
\text { Edge } \\
\text { P. S. }\end{array}$ & $\begin{array}{l}\text { Lighthouse } \\
\text { P.S. }\end{array}$ \\
\hline \multirow[t]{4}{*}{$\begin{array}{l}\text { School } \\
\text { governance }\end{array}$} & $\begin{array}{l}\text { Passionate staff member/s } \\
\text { enlisting support of other staff }\end{array}$ & - & 3 & 4 \\
\hline & $\begin{array}{l}\text { Supportive principal who } \\
\text { understands sustainability vision }\end{array}$ & 1 & 4 & 4 \\
\hline & $\begin{array}{l}\text { Collaborative - all participants' } \\
\text { views represented and heard }\end{array}$ & 1 & 2 & 3 \\
\hline & $\begin{array}{l}\text { Cost savings redirected back into } \\
\text { sustainability projects }\end{array}$ & - & - & 3 \\
\hline \multirow[t]{3}{*}{ School planning } & $\begin{array}{l}\text { Sustainability embedded into } \\
\text { school plans and policies }\end{array}$ & - & 2 & 4 \\
\hline & Regular evaluation by all staff & - & - & 4 \\
\hline & $\begin{array}{l}\text { Sustainability viewed by all staff } \\
\text { as more than environmental }\end{array}$ & 1 & 3 & 4 \\
\hline \multirow{4}{*}{$\begin{array}{l}\text { Community } \\
\text { networks } \\
\text { \& partnerships }\end{array}$} & Networks with community groups & 1 & 2 & 4 \\
\hline & $\begin{array}{l}\text { Partnerships with relevant } \\
\text { agencies and organisations }\end{array}$ & - & 3 & 3 \\
\hline & Networks with other schools & - & 1 & 3 \\
\hline & $\begin{array}{l}\text { Parent involvement in } \\
\text { sustainability projects }\end{array}$ & 1 & 1 & 4 \\
\hline \multirow{4}{*}{$\begin{array}{l}\text { Student voice } \\
\text { \& engagement }\end{array}$} & Student committee established & - & 3 & 3 \\
\hline & $\begin{array}{l}\text { Diverse opportunities for all } \\
\text { students to become engaged }\end{array}$ & - & 1 & 4 \\
\hline & $\begin{array}{l}\text { Students contribute to the } \\
\text { direction and shape of projects }\end{array}$ & - & 2 & 2 \\
\hline & $\begin{array}{l}\text { Students display action } \\
\text { competence }\end{array}$ & - & 2 & 4 \\
\hline \multirow[t]{5}{*}{$\begin{array}{l}\text { Curriculum } \\
\text { integration }\end{array}$} & $\begin{array}{l}\text { Whole-system integration across } \\
\text { learning areas }\end{array}$ & 1 & 2 & 4 \\
\hline & $\begin{array}{l}\text { Whole-school contribution to } \\
\text { sustainability and a continuity of } \\
\text { learning across year levels }\end{array}$ & - & 2 & 4 \\
\hline & $\begin{array}{l}\text { Multiple, diverse 'systems' } \\
\text { operating around the school }\end{array}$ & 1 & 2 & 4 \\
\hline & $\begin{array}{l}\text { Relevant professional learning } \\
\text { accessed by all staff }\end{array}$ & - & 3 & 3 \\
\hline & $\begin{array}{l}\text { Collegial support and } \\
\text { encouragement among staff }\end{array}$ & 1 & 3 & 3 \\
\hline
\end{tabular}


a collective achievement (Gough \& Sharpley, 2005; Pepper \& Wildy, 2008; Tilbury, 2004; Wooltorton, 2004). Together with the lead sustainability coordinator, the principal plays an important role in fostering collaborative governance (O'Donoghue \& Clarke, 2010; Pepper \& Wildy, 2008; Wooltorton, 2004), which if not fostered can lead to divisions and resistance among other staff (N. S. Evans et al., 2012; Wooltorton, 2004). Different approaches to governance were observed at Lighthouse and River's Edge Primary Schools. At both schools, the principal was supportive, visionary and encouraging of the whole-school sustainability focus, and at both schools, at least one member of the teaching staff was responsible for spearheading the initiatives.

At Lighthouse primary school, Mr Honeyeater's leadership style could be considered transformational - providing vision and appealing to the morals of all staff (O'Donoghue \& Clarke, 2010) - as well as attempting to be distributed - inviting the input and collaboration of all staff within an agreed framework for collaborative action (O'Donoghue \& Clarke, 2010). Mrs Brolga's approach as lead sustainability coordinator could be described as passionate and persistent, yet sometimes dismissive to the concerns of other staff. Together, Mr Honeyeater and Mrs Brolga forged a new vision for the school, which seemed to evolve as organically as the sweet corn in their permaculture garden; seeds were planted by the first initiatives of Mrs Brolga's Year 7 class, and slowly, over the next seven years, new initiatives were incorporated into the system, and other teachers took on roles and responsibilities for various aspects of the whole-school program. Like any new garden, however, there were obstacles encountered along the way, the evidence of which were still apparent at the time of data collection.

Most notable of these obstacles was a strong sense that some staff members did not feel heard and may, at times, have been pressured to contribute to the sustainability program in ways they had not personally wanted to. It also appeared, however, that from the time that Lighthouse Primary School joined AuSSI - WA a greater focus was placed on inviting the views of other stakeholders and celebrating their varied input.

This finding highlights the important role that AuSSI - WA can play in raising an understanding of the breadth of sustainability education among staff members with diverse interests (Lewis et al., 2009; Pepper \& Wildy, 2008). Fostering such a broad understanding can help to mediate relationships between staff and allows individuals with interests not directly connected to the environment to feel they are contributing to the whole-school focus. 
At River's Edge Primary School, Mrs Eagle Ray's leadership style could be considered as managerial - focussing on functions and tasks, and exercising influence through a position of authority (O'Donoghue \& Clarke, 2010). Mrs Redfin's approach as lead sustainability coordinator could be described as enthusiastic yet pragmatic and sensitive to the concerns of other staff. Together, Mrs Eagle Ray and Mrs Redfin were navigating a new sustainability pathway for the school, which at times appeared to be firmly directed by Mrs Eagle Ray's particular vision. Whilst Mrs Eagle Ray said she encouraged all teachers to contribute in ways that were relevant to their personal interest, there were new whole-school initiatives being introduced in which all teachers were expected to participate, such as the partnership with Slow Food International that was set to begin in 2010. Mrs Redfin, however, was sensitive to the 'ripplings' that she observed among staff and gave a detailed description about the collaborative approach to governance that the school should be practicing.

It is these similar examples observed at Lighthouse and River's Edge Primary Schools that highlight the importance of building collaborative governance into the vision of a whole-school sustainability program from the outset. No matter which member of staff is most passionate about the program and wants to see it move ahead in leaps and bounds, it is important for this to occur harmoniously so that all staff can travel forward together at a compatible pace and contribute collaboratively to setting the priorities and regularly evaluating the program. It is perhaps a lesson for those most impassioned about sustainability in the school context to incorporate detachment and flexibility into their suite of skills together with their determination, passion and persistence. These examples have important implications for other schools commencing their whole-school sustainability programs, and in particular, for those leading the charge.

Another important implication from these findings, which is consistent with other research, is that the fostering of a broad definition of sustainability is more inclusive of staff with diverse interests and can encourage greater staff engagement with whole-school sustainability initiatives, than a definition that primarily advocates the straightforward environmental themes of water, waste, biodiversity, etcetera (Lewis, 2012; Lewis et al., 2009; Pepper \& Wildy, 2008).

\section{School Planning}

The principal and the school's administration must fully appreciate the goals and challenges of implementing a whole-school sustainability program, and be completely supportive of the vision, if funding, preparation time and other resources are to be 
allocated and utilised effectively across the school (Pepper \& Wildy, 2008; Wooltorton, 2004). School principals, in particular, have significant impact on whether sustainability is prioritised in the school's agenda and policy documents.

At Lighthouse and River's Edge Primary Schools, the principals had prioritised the roll out of sustainability initiatives across the whole school. They both described having embedded sustainability goals into the school's policy documents and plans.

The plans were more complex from Lighthouse Primary School compared with River's Edge Primary School, which could be for two main reasons. First, Lighthouse Primary School had the advantage of time: their program had been tried and tested for 6 years longer than that of River's Edge Primary School. Second, Lighthouse Primary School had, since 2006 and partnering with AuSSI - WA, begun to incorporate annual collaborative evaluation of their school's program using the AuSSI - WA Key Elements Rubric, where the views and opinions of all staff were invited and encouraged. These whole of staff evaluations helped to form the plans for the following year, and consequently, the school's sustainability policies were diverse and representative of many areas of school life - from the performing arts program, to the canteen, to society and environment learning outcomes.

By contrast, the sustainability policies at River's Edge Primary School were representative of an overarching managerial perspective that prioritised logistic or institutional goals, such as the principal's decisions to provide only fair trade coffee in the staff room and to encourage whole of school reductions in power used for heating or cooling. It was apparent that River's Edge Primary School would benefit from inviting whole of staff evaluation and contribution towards developing the school's sustainability goals.

Not surprisingly, Fertile Ground Primary School did not have a sustainability policy, because they did not have a sustainability program. However, when asked about resources that might help their school foster a sustainability program the principal, $\mathrm{Mr}$ Sugar Glider, asserted that government money is wasted on preparing, printing and posting files and glossy resources for schools. He argued that government money should otherwise be pooled and provided to schools to employ a specialist staff member or pay one of their staff for extra hours of work towards coordinating their whole-school sustainability program. Suggestions such as these should be given careful consideration by government funding agencies that seek to promote sustainability education in schools. 
Consistent with other research, these results indicate that AuSSI schools would benefit from collaborative governance that incorporates regular collaborative evaluation (Henderson \& Tilbury, 2004; Lewis et al., 2009). Moreover, whole of staff evaluations benefit from utilising the AuSSI - WA Key Elements Rubric (Lewis et al., 2009).

AuSSI schools would also benefit from having a fully paid or subsidised staff member whose role is to coordinate the school's sustainability initiatives and to coach other staff members in their efforts towards integrating these concepts into their classroom practise. Accessing funding to employ a specialist sustainability teacher is however, a difficult task that depends either on the motivation of that person to seek and access their own sources of funding or on the school principal to prioritise and allocate such funding (Hayles \& Holdsworth, 2008; Lewis, 2012).

\section{Community Networks and Partnerships}

By forming partnerships with government agencies and networks with community groups, including the school parent body, the growth, integration and longevity of a whole-school sustainability program is greatly enhanced (Davis \& Ferreira, 2009; Henderson \& Tilbury, 2004; Ilich, 2008; Salter, Venville, et al., 2011; Tilbury, 2004). This assertion was supported in this research with evidence from Lighthouse and River's Edge Primary Schools. Both schools had developed partnerships with government initiatives, such as Waterwise Schools and Travel Smart, and had formed networks with community groups - locally and interstate. Unsurprisingly, Lighthouse Primary School had built a greater variety of networks and partnerships that were also more integrated into their whole of school approach than those developed in the short span of time that River's Edge Primary School's sustainability program had been operational. Nevertheless, for a school less than two years into a whole of school approach to sustainability education, River's Edge Primary School had built multiple collaborations across diverse types of initiatives, of which most had been facilitated by Millennium Kids.

The facilitatory role that Millennium Kids played in River's Edge Primary School, was similar to the webbed network approach described by Davis and Ferreira (2009, p. 67), which involves "dynamic, shifting relationships" where "outcomes and interactions are not 'controlled' by any participant in the network". However, the role of Millennium Kids was also similar to a network of facilitators approach (Davis \& Ferreira, 2009; Larri, 2006), because there was a central organisation that helped to drive the process. In this way, Millennium Kids introduced opportunities to the principal, teachers and students at River's Edge Primary School, but left it to these 
protagonists to decide which connections to foster, which to postpone and which not to take up. It was also left to these protagonists to shape the direction and outcomes of projects, and to continue their relationships with the partner organisations or not.

It is asserted here that an evolved version of the webbed network approach (Davis \& Ferreira, 2009) would incorporate the role of a facilitator that is allied with AuSSI and the diverse range of potential partnerships available (Larri, 2006), acting as a bridge, but not mediating or controlling these partnerships. This assertion is based on the rationale that it can be overwhelming and time consuming for a school's protagonists to know where to look, who to contact or how a partnership can complement their individual teaching goals or the whole-school program, if it is left entirely to them to coordinate all of these logistics (Eames \& Bolstad, 2004; Ilich, 2008; Larri, 2006). Furthermore, a facilitator can help to diversify the relationships between school staff members and the different partner agencies (Ilich, 2008; Larri, 2006).

Taking the example of Lighthouse Primary School, it was apparent that the main intermediary between the school and the partner organisations was the school's sustainability coordinator, Mrs Brolga. This led to a power play between her and other teaching staff, where certain other staff appeared either intimidated or reticent to express their different opinions because they seemed to think their voices would not be heard. It appeared that if AuSSI - WA had not provided a broader definition of sustainability to the school in 2006, interactions between staff could have deteriorated. While the school's program was successful in many respects, some fractures existed, and it is asserted here that if the school had been able to access regular facilitation and mentoring from the outset of their program, or at least from the time of their partnership with AuSSI - WA, the objective, dynamic input from an external agent might have helped the voices of these other staff to be heard more clearly, their individual capacities and interests to be developed, and power to be shared between Mrs Brolga and other members of staff.

In a review of AuSSI - NSW and AuSSI - ACT, Larri (2006) described the significant positive impacts that a school sustainability facilitator could provide to participating schools. In a review of AuSSI - WA, Illich (2008) suggested that a group of facilitators should work closely with participating AuSSI schools. He acknowledged the financial constraints that would restrict AuSSI - WA from hiring a dedicated team of facilitators, constraints which still remain (AESA, 2012; Sandell, 2012, June 22), and suggested that each of the main partner organisations to AuSSI - WA could donate one staff member towards such a facilitatory role (Ilich, 2008). Illich (2008) clarified that 
when working as AuSSI - WA facilitators this team of individuals should put aside their funding organisation's agendas, and instead of facilitating a particular product (Davis \& Ferreira, 2009), should act in a way that would be similar to the webbed network approach (Davis \& Ferreira, 2009) by fostering connections and collaborations between schools and partner agencies but not 'managing' the change process (Ilich, 2008).

Consideration of such a variation on the facilitator approach tried in other states, requires recognition of problems associated with heavy facilitator workload, limited resources and the slow speed of change in schools (Larri, 2006). Nevertheless, it is argued here that the benefits of establishing a team of AuSSI - WA allied school sustainability facilitators would outweigh these problems. It is further argued that such a team of AuSSI - WA allied facilitators would benefit from observing the Millennium Kids approach to facilitation.

Another element of community interaction reported by schools involved in sustainability initiatives, is greater involvement in the life of the school by parents and the community as a whole (Flowers \& Chodkiewicz, 2009; Gough, 2005; Henderson \& Tilbury, 2004; Lewis, 2012). For many schools such involvement has been garnered through collective efforts towards greening the school and meaningful participation on school governing bodies, such as the Parents and Citizens Committee (P\&C) (Henderson \& Tilbury, 2004). Lighthouse Primary School had demonstrated success in engaging parent support for their sustainability program by involving parents in school busy-bees and collaborating with the $\mathrm{P} \& \mathrm{C}$ to gain broad parent support and to source funding for projects. At Lighthouse Primary School it was also found that the receptivity among parents for adopting pro-environmental behaviours in their homes was enhanced when parents were involved in sustainability projects at the school and could see their children being positively affected by the school's sustainability focus (discussed in more detail later in this chapter). The principal and teachers at Fertile Ground Primary School described how parents would likely support a whole-school sustainability education program by becoming involved in activities such as a school garden project, and further illustrated the latent potential of this school to adopt such a program.

By contrast, parent involvement at River's Edge Primary School was hedged by their demographic and the school's reputation. Teachers appeared unwilling to engage parents in the sustainability program 'too much' because of a perception that parents might 'feel overwhelmed by the directive from the school'. The prestigious reputation 
of the school and lucky country mentality among many families could be acknowledged as a barrier to fostering parent engagement at the River's Edge Primary School. Similar barriers might be encountered at other prestigious private schools. Nevertheless, initiatives such as the sustainability spin on 'grandparents day' appeared to be a good attempt at starting to garner support from parents and other family members.

\section{Student Voice and Engagement}

Research indicates that for sustainability programs to meet a transformative goal of creating young people who are empowered to continue improving their world, those programs should make room for authentic engagement of students in the development of school priorities and class projects, leadership and management of initiatives, and celebration of milestones (Eames et al., 2006; Henderson \& Tilbury, 2004; Higgs \& McMillan, 2006). Fostering authentic engagement of students has been described in literature about developing students' action competence (Eames et al., 2010; Eames et al., 2006; Fontes, 2004; Jensen, 2004; Jensen \& Schnack, 2006). A key feature of the action competence approach in environmental education is about cultivating within students the desire to take actions that are based on thoughtful informed choices as opposed to indoctrinating students to undertake behaviours of which they may not understand the relevance (Jensen, 1993, 2004; Jensen \& Schnack, 2006).

At Lighthouse Primary School, it seemed apparent that students were predominantly 'involved' in the school's sustainability program, that some students were engaged more than others, and that student voice did not greatly affect the direction or shape of the sustainability focus. Nonetheless, it is possible that many students had developed a degree of action competence because of an awareness of issues gleaned from their teachers or school assemblies, their involvement in activities that developed their skills and a generally positive willingness to act reflected by positive attitudes to school environmental activities, in particular, by their strong pride of their school's achievements (Chapter 7).

By comparison, it appeared that some students at River's Edge Primary School had developed a degree of action competence even though they were exposed to far fewer activities that developed their skills compared with students at Lighthouse Primary School. Students at River's Edge Primary School also appeared to have had a generally positive willingness to act reflected by positive attitudes to school environmental activities, in particular, by their strong sense of responsibility to care for the environment (Chapter 7). 
All upper-primary students at River's Edge Primary School had participated in developing the sustainability goals for the school, which they did at an annual student conference convened by Millennium Kids. After these conferences the student sustainability committee and teachers would apparently develop the goals further, thus indicating these students may have been given opportunities to become more action competent than other students. This approach was a variation on the use of the Ten Step inquiry methodology promoted by Millennium Kids, where all students would ideally be more involved in developing the group's goals further (La Mar, 2006; Taylor, 2010).

It was not possible for the researcher to observe a committee meeting at River's Edge Primary School, but it was gleaned from interview data that students on the sustainability committee were essentially responsible for speaking at assemblies and thinking of ways to raise awareness among other students. It seems unlikely that student voice affected the direction or shape of the sustainability focus outside of the annual student conferences. These annual conferences, however, afforded students more opportunity to influence the direction or shape of the sustainability focus than was apparently available to students at Lighthouse Primary School.

Reflection on the emergence of the sustainability focus at Lighthouse Primary School, however, indicated that students in Mrs Brolga's Year 7 class of 2002 had been involved in an inquiry process that required them to determine if there was an issue with waste, how it could be mitigated and to develop implementable strategies that would help them realise their waste minimisation goals. That initiative, it could be argued, was an example of authentic engagement of student voice. It begs the question, then, why did the sustainability program at Lighthouse Primary School appear to have lost touch with that authentic engagement of student voice? Moreover, when students are authentically engaged in developing new systems how does a school continue those systems after those original students have left the school whilst creating room for other students to develop new initiatives?

These questions hark to the challenges of engaging student voice and creating opportunities for students to become partners in the decision-making process. Challenges that can emerge span issues that include attachment to conservative pedagogies, teacher competence in utilising a cross-curricula inquiry approach to learning, limitations on teacher time, and questions of credibility and pressure to perform (Eames et al., 2006; Higgs \& McMillan, 2006; Lewis, 2012; Rennie et al., 2012). Consideration of these issues and questions would benefit schools early in their 
sustainability programs or schools that might one day adopt a program, such as Fertile Ground Primary School.

Based on the findings of this research, it is asserted that whole-school sustainability education will develop in students a degree of action competence by providing: 1) an awareness of issues - gleaned from their teachers or school assemblies, 2) opportunities to become involved in activities that develop their awareness of actions and skills, and 3) a generally positive willingness to act - reflected by positive attitudes to school environmental activities. But including regular opportunities for student voice to influence the direction or shape of the sustainability focus could further increase action competence. An initial step could be to hold annual or biannual student conferences with the whole school, with the upper and lower students separately or within each year group.

\section{Curriculum Integration}

Integrating sustainability principles, concepts and actions in a whole-school, whole-system way requires adequate conceptual understanding of sustainability and flexibility in pedagogy (Carter \& Smith, 2010; Henderson \& Tilbury, 2004; Lewis, 2012; Summers et al., 2003). Furthermore, it is necessary to raise the sustainability awareness and conceptual understanding of all school staff, not solely the classroom teachers (Hopkins \& McKeown, 2005; Lewis, 2012). Once familiar with the broad concept of sustainability, and provided tips and guidance on how it can be integrated into their existing teaching priorities, teachers can learn to save time and not feel overwhelmed with the variety of extra skills that they might consider themselves expected to teach (N. S. Evans et al., 2012; Lewis, 2012; Pepper \& Wildy, 2008; Summers et al., 2003; Tilbury et al., 2005). School leaders can also help to shape the vision of the program across various interconnected pursuits (Henderson \& Tilbury, 2004; Pepper \& Wildy, 2008).

Examples from each of the case study schools have illustrated that if the teachers are not provided a vision for how sustainability can be integrated across learning areas, despite some exceptions, sustainability will simply be seen as 'another thing to teach'. This was observed, not only at Fertile Ground Primary School where it was expected, but also at the two AuSSI - WA schools.

While yet early in the implementation of their whole-school sustainability focus, teachers at River's Edge Primary School exhibited different conceptualisations of how to weave sustainability issues and actions into their lessons. It appeared that the Year 4 teacher, Mr Mackerel, either did not understand, or was not willing, to attempt to 
integrate sustainability concepts across learning areas. By contrast, the two Year 5 teachers, Mrs Redfin and Mrs Salmon, described how simple it could be to use sustainability concepts as a foundation upon which other learning requirements could be built. Furthermore, the principal and deputy principal appeared to share this understanding of whole-systems thinking. The whole-systems understanding among some teachers at River's Edge Primary School appeared to have been fostered by the facilitation and mentoring provided by Millennium Kids. Nonetheless, it was evident that not all teachers accessed or wished to access this mentoring.

A similar discrepancy between teachers who did and did not adopt sustainability as a 'vehicle through which they could teach' appeared to have been encountered at Lighthouse Primary School. Whilst some teachers exhibited subtle resistance to the whole-school sustainability focus, Mrs Mallard and Mrs Magpie also conveyed that even these quietly resistant teachers did, in their own ways, integrate sustainability concepts into their teaching and were proud of their school's achievements. The resistance to integrating sustainability across learning areas appeared to have been more prominent in the past, before Lighthouse Primary School's association with AuSSI WA and before sustainability was understood as more than a focus on environmental topics. Mr Magpie explained that the conceptualisation of sustainability elucidated by AuSSI - WA increased the willingness among several teachers at Lighthouse Primary School to become involved and to find ways of making it relevant to their pedagogy, teaching focus and personal interest.

Each of these examples illustrates the importance of creating relevant professional learning modules for teachers to engage with, as has been attested by many other authors (Carter \& Smith, 2010; Dow \& Prabawa, 2012; Ferreira et al., 2007; Henderson \& Tilbury, 2004; Hopkins \& McKeown, 2005; Lewis, 2012; Summers et al., 2003). The example of River's Edge Primary School also illustrates the great potential for continuity and contextualisation of professional learning that AuSSI - WA allied sustainability facilitators can provide to a school, especially one that is just starting out, as was asserted by Illich (2008). The findings of this research support an existing assertion that without relevant professional learning, including pre-service education and access to ongoing mentorship of sustainability coordinators and school administrators, a school is likely to encounter significant obstacles in their journey towards excelling in their whole-school sustainability program (N. S. Evans et al., 2012; Lewis, 2012; Pepper \& Wildy, 2008; Salter, Venville, et al., 2011) - obstacles that in 
some schools may cause significant fractures among staff and efforts that are stymied by persistent resistance.

\section{Summary Cross-Case Comparisons}

Lighthouse Primary School was excelling in many of the key elements investigated and, indeed, was a lighthouse and an inspiration to other schools early in their sustainability journey. Lighthouse Primary School was also ahead in their implementation of whole-school sustainability initiatives compared with River's Edge Primary School. The facilitation provided to River's Edge Primary School, however, had assisted them in fostering sustainability priorities and in laying a foundation of certain key elements that if built upon could contribute to manifold advances in their whole-school program. Even so, both schools had encountered specific obstacles in their implementation of sustainability initiatives. Some of these obstacles were comparable and others were specific to the demographic and reputation of the school.

Comparing these two sustainability schools with Fertile Ground Primary School, highlighted important differences in the organisational outcomes and challenges present in schools with any degree of sustainability focus and a school without such focus. In particular, it was evident that Fertile Ground Primary School had promising characteristics that if nurtured could see the school channel their priorities towards a whole-school sustainability agenda. The specific feature required to assist Fertile Ground Primary School in moving towards a whole-school sustainability focus, identified by the principal and all staff members interviewed, was a dedicated, passionate staff member to spearhead the program. It is further asserted that, together with a dedicated staff member, an AuSSI - WA allied sustainability facilitator would provide important skills and vision required to foster this school's potential and to help them navigate the typical obstacles faced by other schools.

\section{School Organisational Assertions}

This section on organisational outcomes and challenges concludes with a series of assertions about features required to foster a successful whole-school sustainability education program. 'Successful', being an objective term, here refers to the condition of a school where sustainability is integrated across curriculum learning areas, into school policies and throughout school daily life, when the school is valued at the centre of a community, and when all stakeholders are given fair opportunities to contribute towards visioning, planning, enacting and evaluating initiatives (Henderson \& Tilbury, 2004). 
These assertions are consistent with findings from other research about wholeschool sustainability education (as discussed in the preceding sections) and will be of interest to the case study schools, other AuSSI schools, AuSSI - WA and their partner agencies, and to sustainability facilitators and educators more broadly. These assertions include valuable insights that will likely be applicable to schools from similar contexts, whist keeping in mind, however, that the findings from this case study research should not be widely generalised or be assumed to apply to every whole-school sustainability education context.

Successful whole-school sustainability education requires:

Assertion 1: A vision of sustainability that is broader than environmental themes. As with any organisation, schoolteachers have diverse interests and backgrounds. Fostering an understanding of sustainability that encompasses social, economic and environmental themes can encourage greater staff engagement with the whole-school sustainability focus.

Assertion 2: Visionary leadership and collaborative governance involving regular whole of staff evaluations. It is import to build collaborative governance into the vision of a whole-school sustainability program from the outset. Whist it is certainly important to have visionary, committed leadership from the school administrators and sustainability coordinators, all staff should travel forward together at a compatible pace and contribute collaboratively to setting the priorities and regularly evaluating the program.

Assertion 3: A few core staff to spearhead projects. It is necessary for at least one member of staff to spearhead and coordinate projects. Lead sustainability coordinators can help to: 1) build capacity in other staff to spearhead projects of their choice, and 2) foster collaborative governance and a shared vision for the program among stakeholders.

Assertion 4: Facilitation and mentoring. AuSSI - WA allied school sustainability facilitators can work closely with a school's administration and lead sustainability coordinators, to mentor and build their capacity in line with principles of collaborative governance, shared responsibility and organic growth of a school's program.

Assertion 5: Authentic engagement of student voice. Students can develop a degree of action competence because of an awareness of issues they glean from their teachers or school assemblies, their involvement in activities that develop their skills and a generally positive willingness to act reflected by positive attitudes to school 
environmental activities. To maximise authentic engagement of student voice, students can be invited to shape the direction of school sustainability priorities.

Assertion 6: Contextualised and relevant professional learning. Appropriate professional learning for all teachers and mentorship of school leaders, can help to overcome obstacles that may arise such as significant fractures among staff and efforts that are stymied by persistent resistance.

\section{Environmental Knowledge, Attitudes and Behaviours of Students}

This section discusses the main findings from investigation of Research Questions 2, 3 and 4 (p. 7), which explored the knowledge, behaviours and attitudebehaviour relationships of students at the case study schools. Each of the main findings is related to the literature. To conclude this section, the findings are discussed in context of the Model of Responsible Environmental Behaviour (Hines et al., 1987), and plausible connections between students' knowledge, attitudes and behaviours are discussed and implications inferred. This section concludes with a series of assertions about factors that influence student's pro-environmental behaviour.

\section{Knowledge}

Cross-case synthesis. In this research, mind maps were used to measure students' whole-systems thinking, and action-based and issues-based knowledge of the environment and sustainability. Moreover, mind maps were used to determine if there was a difference in the depth, volume and breadth of their responses across two constructs, sustainability and things I can do to help the environment.

Quantitative assessment of student knowledge using mind maps, showed that students at all case study schools displayed greater volume and breadth of ideas for the construct things I can do to help the environment than for the construct sustainability (Chapters 4, 5 and 6). At River's Edge Primary School a further difference was found between year groups, with Years 5 and 6 students generating statistically greater volume and breadth of ideas compared with Year 4 students (Chapter 5). This result may reflect a deficiency in their whole-school focus or a greater overall focus by Year 5 and 6 teachers on environmental and sustainability concepts. Both scenarios are supported by interview data that showed at least one Year 4 teacher was less committed to the program than several Year 5 and 6 teachers.

Results showed that students in Years 5 and 6 at River's Edge Primary School had greater volume of ideas than students in Year 4 at the same School (Chapter 5). 
Comparison of results across schools showed that students in Year 4 at River's Edge Primary School had a similar volume of ideas to students in all year levels at Lighthouse and Fertile Ground Primary Schools (Chapters 4, 5 and 6). This comparison supports an assertion that Year 5 and 6 teachers at River's Edge Primary School were strongly focussed on building environmental and sustainability knowledge in these students.

Comparison of results across schools further indicated that students at Fertile Ground Primary School produced similar volume of ideas about things I can do to help the environment when compared with students from Lighthouse and River's Edge Primary School (Chapters 4, 5 and 6). However, the volume of ideas about sustainability were proportionately less among students from Fertile Ground Primary School compared with students from Lighthouse and River's Edge Primary School (Chapters 4, 5 and 6).

Furthermore, students from all schools appeared to find the term sustainability unclear and associated it predominantly with environmental themes or simple nouns (Chapters 4, 5 and 6). Interestingly, a higher proportion of students at Fertile Ground Primary School (54 percent) generated more simple responses for sustainability compared with students at Lighthouse and River's Edge Primary Schools (30 percent and 22 percent respectively). This result indicates that students at Lighthouse and River's Edge Primary Schools were somewhat more familiar with the term sustainability than students at a school without a sustainability focus.

Discussion. Because sustainability has been defined as encompassing a range of environmental, socio-cultural and economic perspectives (UNESCO, 2002, 2005a, 2005b), and this is the definition affirmed by AuSSI - WA and Millennium Kids, it was expected that students who understood the term sustainability would have written words associated with each of these perspectives.

It is not surprising, however, that students predominantly associated sustainability with environmental themes or were confused by the term. Sustainability is an ambiguous term that is being used by many agencies and corporations to describe a variety of products, programs and projects (Jickling \& Wals, 2012). Despite the differing conceptualisations of sustainability, as discussed in Chapter 2, the word is primarily conceptualised among the general public as related to environmental concerns (Jickling \& Wals, 2012; Kagawa, 2007).

There are several reasons why students, in particular, may associate sustainability with environmental themes. It could be a reflection of the current public debate on sustainability in Australia as portrayed by the media, which is focused on 
environmental concerns and 'green behaviours' - a simple google search will reveal countless news articles that reference sustainability as environmental. It could also be a reflection of the topics taught in schools, even in Lighthouse and River's Edge Primary Schools where some activities were linked to socio-cultural concerns but were often underpinned by an environmental theme (Chapters 4 and 5). Furthermore, in schools with a sustainability focus it could be a reflection of the tangibility of environmental behaviours compared with the abstract intangibility of economic or socio-cultural perspectives. This effect may be pronounced in primary aged students; especially students at Lighthouse and River's Edge Primary Schools who were from high socioeconomic demographic suburbs and may never have experienced social or economic hardship. Finally, it is possible that students were baffled by sustainability and by juxtaposing the two constructs on the same page, it was easy for students to associate sustainability with a topic they were more able to generate ideas for - the environment.

Whole-system thinking in students was estimated by their knowledge of a breadth of issues or actions that were all connected to one central concept. Breadth of knowledge showed that students, on average, thought of two themes for sustainability and three themes for things I can do to help the environment (Chapters 4, 5 and 6). Interestingly, results from Lighthouse and River's Edge Primary Schools were not different from Fertile Ground Primary School, which may indicate that: 1) more emphasis could be placed on using an integrated curriculum in AuSSI - WA schools, or 2) in the 15 minutes allocated for mind mapping, students of this age range can only think of a small number of topics.

Whole-systems thinking is a well-regarded approach to teaching sustainability because it focuses on an holistic understanding of the interconnections and interdependence between all things and helps foster action competence, rather than teaching separate subjects which the students may not connect with a bigger picture (Lewis \& Baudains, 2007; Lewis et al., 2008; Sterling, 2003). Although the credibility of using an integrated curriculum with the purpose of fostering integrated knowledge continues to be debated (Rennie et al., 2012), there is evidence that this type of knowledge is more powerful than silo, discipline restricted, fact-based knowledge (Lewis \& Baudains, 2007; Rennie et al., 2012; Sterling, 2003; Venville, Sheffield, \& Rennie, 2008). Venville, et al. (2008, p. 17) found that students who participated in an integrated, community-based science project "not only learned important science concepts, but they could relate these ideas to the environmental issues associated with the local wetlands, and critique and debate these ideas". It would provide a fuller 
estimate of students' whole-system thinking if future iterations of this mind mapping exercise included student interviews, with their mind maps as the point of discussion, to determine the degree of interconnection they perceived between themes.

A parallel purpose of this research was to validate an approach to collecting and analysing data using mind maps and thematic content analysis, and to determine the usefulness of this approach as an assessment tool. This research demonstrated that mind maps were useful to determine the overall pattern of students' knowledge and to identify specific themes that were most or least present in a population of students. From this information inferences could be made and triangulated with other data for increased reliability. Mind maps are tools that teachers can administer with little training (Brinkmann, 2003; Buzan \& Buzan, 1996), and it is possible that they could do simple content analysis of mind maps without a lot of extra effort. Content analysis of mind maps could even be turned into a class project, thus leading the meaning making and inferences to become more powerful for the students' reflection and learning. Alternatively, computer packages already exist that simplify mind map collection (Buzan \& Buzan, 1996). Modifications could be made to automate the assessment of whole clusters of mind maps, providing teachers with a summarised report. With such creative approaches, mind maps could be used more efficiently as an assessment tool.

\section{Attitudes}

Validation of students' surveys, conducted at Lighthouse and River's Edge Primary Schools, revealed one latent construct of students' attitudes that could be used to model a relationship with students' behaviours: attitudes to school environmental activities (Chapter 7). At the outset of this research it was anticipated that modelling would also be conducted with a univariate scale that estimated the latent construct students' environmental worldviews, however, this was not possible because the scale used to assess environmental worldviews (the NEP scale for children) did not hold together through the factor analysis process (Chapter 7). Validation was also conducted on the seven pro-environmental behaviours and revealed four behaviours that clustered together as a latent construct: turning off lights, recycling, taking short showers and saving water around the home (Chapter 7). These behaviours were inferred as easy to achieve and the latent construct was termed: easy to achieve pro-environmental behaviours.

Modelling of the association between the latent variables, attitudes to school environmental activities and easy to achieve pro-environmental behaviours, revealed a strong positive relationship $(r=.65, \sigma=.10)$. This result suggests that students with 
positive attitudes towards school environmental activities were 55 - 75 percent more likely to practice 'easy' pro-environmental behaviours frequently than students with negative attitudes towards school environmental activities. Causation is not being inferred in this research because no other data were collected to determine the direction of this relationship (Eilam \& Trop, 2012a; Kline, 2011). However, it is asserted that the strength of the attitude-behaviour relationship was due to the focus on sustainability education at both of the two AuSSI - WA schools. Specifically, whole-school sustainability education may have had a positive impact on students' willingness to act or had a positive impact on their actual behaviours at home. Exploration of the individual behaviours provided further insight into the impact of the school's program on these student's behaviours.

It was observed in the attitudes to school environmental activities scale that item 2: I am proud of what my school is doing to help care for the environment, was a significantly stronger $(>1 \sigma)$ predictor of student attitudes at Lighthouse Primary School than student attitudes from River's Edge Primary School. In contrast, Item 5: I'm only young and it's not my responsibility to care for the environment (reversed), was a significantly stronger $(>1 \sigma)$ predictor of student attitudes at River's Edge Primary School than student attitudes from Lighthouse Primary School. This observation suggests intriguing differences between the dominant student attitudes at each school, which when correlated with findings from teacher interviews regarding engagement of student voice, could indicate that students at River's Edge Primary School were being afforded more opportunities to demonstrate their responsibility towards issues of environmental concern. Furthermore, students at Lighthouse Primary School may have been aware of their school's status as a lighthouse school, probably reminded of this status by their teachers and principal, and were proud to be involved in such a movement.

\section{Behaviours}

Cross-case synthesis. Surveys of students' self-reported frequency of practicing a range of pro-environmental behaviours in their homes, found that the proportion of students who practiced these behaviours at home on a greater than weekly basis, less than weekly basis or never, were similar across the three schools for most behaviours, except for recycling, alternative transport to school and maintaining organic waste (Chapters 4, 5 and 6). Table 9.2 displays the summarised results from each school for: 1) prevalence of students' reportedly enacting each of the seven behaviours in their 
homes, and 2) the degree of students' participation with their families. Simple tasks such as turning off lights were practiced at home by $70-100$ percent of all students on a greater than weekly basis, and were thus considered to be widespread (Table 9.2). More complex behaviours such as maintaining a worm farm or compost were practiced on a greater than weekly basis by $0-40$ percent of all students, and were thus considered to be uncommon (Table 9.2). Participation within families is included in Table 9.2 in preference to the two other comparison variables: Learning and Importance, because Participation was most consistently related with each of the seven behaviours and was inferred as the most influential variable on students' frequency of behaviour.

Research has found that often people will undertake certain groups of proenvironmental behaviours and not others, depending on their motivations (Cleveland et al., 2005; Heimlich \& Ardoin, 2008; Kollmuss \& Agyeman, 2002). Heimlich and Ardoin (2008, p. 223) refer to these as, "constellations of behaviours that may be expected to occur together" and explain that they potentially represent levels of complexity or degrees of difficulty. In this research, constellations of behaviours were found and it is asserted that they differed in degrees of complexity and the willingness to act required to make them part of a weekly set of pro-environmental behaviours. It is further asserted that family norms impact a student's willingness to act and whether a behaviour will be deemed too complex to introduce into the home or to practice with weekly regularity. The following paragraphs briefly describe the constellations of behaviours found in this research and discuss their implications. 
Table 9.2. Cross-case analysis of survey responses of Year 4, 5 and 6 students from the case study schools showing students' prevalence* of environmental behaviours and the degree of students' participation $\dagger$ within their families that was associated with their weekly practice of each behaviour.

\begin{tabular}{|c|c|c|c|c|}
\hline \multicolumn{2}{|l|}{ BEHAVIOUR } & \multirow{3}{*}{$\begin{array}{c}\begin{array}{c}\text { Fertile Ground } \\
\text { P. S. }\end{array} \\
\text { Widespread } \\
\text { Family Norm }\end{array}$} & \multirow{3}{*}{$\begin{array}{c}\text { River's Edge } \\
\text { P. S. } \\
\text { Widespread } \\
\text { Family Norm }\end{array}$} & \multirow{3}{*}{$\begin{array}{c}\begin{array}{c}\text { Lighthouse } \\
\text { P.S. }\end{array} \\
\text { Widespread } \\
\text { Family Norm }\end{array}$} \\
\hline Turning off lights & Prevalence * & & & \\
\hline \multirow{3}{*}{$\begin{array}{l}\text { Recycling paper or } \\
\text { plastic }\end{array}$} & Participation $†$ & & & \\
\hline & Prevalence & Uncommon & Widespread & Widespread \\
\hline & Participation & Family Norm & Family Norm & Family Norm \\
\hline \multirow[t]{2}{*}{ Short showers } & Prevalence & Common & Common & Common \\
\hline & Participation & Family Norm & $\begin{array}{l}\text { Family Norm } \\
\qquad(2009) \\
\text { Student } \\
\text { co-enthusiast } \\
(2010)\end{array}$ & $\begin{array}{c}\text { Student } \\
\text { co-enthusiast }\end{array}$ \\
\hline \multirow[t]{2}{*}{ Saving water } & Prevalence & Common & Common & Common \\
\hline & Participation & $\begin{array}{c}\text { Student } \\
\text { co-enthusiast }\end{array}$ & Family Norm & $\begin{array}{c}\text { Family Norm } \\
\text { (2009) } \\
\text { Student } \\
\text { co-enthusiast } \\
\text { (2010) }\end{array}$ \\
\hline \multirow{2}{*}{$\begin{array}{l}\text { Walking, biking or } \\
\text { bussing to school }\end{array}$} & Prevalence & Uncommon & Common & Common \\
\hline & Participation & Family Norm & $\begin{array}{c}\text { Student } \\
\text { co-enthusiast }\end{array}$ & $\begin{array}{c}\text { Student } \\
\text { co-enthusiast }\end{array}$ \\
\hline \multirow{2}{*}{$\begin{array}{l}\text { Eating home grown } \\
\text { fruits or vegetables }\end{array}$} & Prevalence & Uncommon & Uncommon & Uncommon \\
\hline & Participation & $\begin{array}{c}\text { Student } \\
\text { co-enthusiast }\end{array}$ & $\begin{array}{c}\text { Student } \\
\text { co-enthusiast }\end{array}$ & $\begin{array}{c}\text { Student } \\
\text { co-enthusiast }\end{array}$ \\
\hline \multirow{2}{*}{$\begin{array}{l}\text { Putting food scraps } \\
\text { into a worm farm or } \\
\text { compost bin }\end{array}$} & Prevalence & Uncommon & Uncommon & Uncommon \\
\hline & Participation & Family Norm & Family Norm & Family Norm \\
\hline
\end{tabular}

* Prevalence: Widespread, $>70$ percent of all students did this weekly; Common, $40-70$ percent of all students did this weekly; Uncommon, $<40$ percent of all students did this weekly.

$\dagger$ Participation: Family norm = Students participated weekly even if they were not one of the most active family members. Student co-enthusiast $=$ Students participated weekly when they were one of the most active family members.

Turning off lights and recycling. At all case study schools, turning off lights and recycling grouped together in a constellation because they were widespread among students (Table 9.2) and it was inferred that these were simple or easy to enact behaviours. Closer inspection of the data showed that for most students, particularly at Lighthouse and River's Edge Primary Schools, turning off lights and recycling were done on a daily basis, thus indicating these were habitual for many students. The one exception to this was that recycling among students at Fertile Ground Primary School was uncommon (Table 9.2), but this was confounded because the city council in which 
Fertile Ground Primary School was located had a centralised recycling facility and a one-bin system, so students could not recycle even if they had wanted to. Based on results from Lighthouse and River's Edge Primary School, it is inferred that if students at Fertile Ground Primary School could recycle more easily, it would have been a widespread behaviour.

It is asserted that the widespread weekly (and daily) frequency of turning off lights and recycling were more influenced by the simplicity of the task, available infrastructure, social norms and family expectations, than the schools' specific waste minimisation programs. Recycling and simple energy saving behaviours are widely promoted in Australia (DCCEE, 2012; Gardner et al., 2009; Ha \& Santucci, 2005) and around the world (e.g. Figure 9.1), and recycling infrastructure, provided as a service by local councils, has become a common feature of Australian households (Ha \& Santucci, 2005; RRT, 2012), as described in Chapter 4. These large-scale awareness raising campaigns, together with readily available household infrastructure and advances in reporting local area energy usage on household bills, have been found to impact the perceived subjective norms of adults, which in turn impact their practice of these behaviours (Gardner et al., 2009; McKenzie-Mohr et al., 2012; Nye \& Hargreaves, 2009). It is suspected that parents project these social norms onto their children as expectations of family participation.

Parental expectations and requirements of family participation have been found to create subjective norms that influence students' pro-environmental behaviours (Matthies, Selge, \& Klöckner, 2012). Moreover, Matthies, Selge and Klöckner (2012) found that parents become role models for specific household recycling behaviours by involving children in every day household waste separation practices. In contrast, however, they found that the children's re-use behaviours were not related to parent role modelling or expectations, thus, suggesting that complexities exist in the mechanisms that trigger the regular practice of different household waste minimisation behaviours. To this effect, whole school programs that focus on a variety of easy, moderate and difficult waste minimisation strategies have been found to increase students' practice of some of these more complex behaviours at home (Armstrong, Sharpley, \& Malcolm, 2004; Cutter-Mackenzie, 2010; Grodzinska-Jurczak, 2003).

It is interesting at this juncture, to triangulate the survey results with results from students' mind maps for the construct things I can do to help the environment. Mind maps showed that waste minimisation was the most popularly thought of theme at Lighthouse and River's Edge Primary Schools, with 85 - 90 percent of students in 2009 
mentioning at least one idea about waste minimisation (Chapters 4 and 5) This theme included all kinds of recycling, and suggests that the vast majority of students relate this action with pro-environmental behaviour. It is not surprising then that this was also a behaviour practiced weekly at home by 85 precent of students at River's Edge Primary School in 2009 (Chapter 5), but unexpected that it was only practiced weekly at home by 70 percent of students at Lighthouse Primary School (Chapter 4)

In contrast, however, energy conservation was mentioned by 30 percent of students at Lighthouse Primary School and 45 precent of students at River's Edge Primary School in 2009 (Chapters 4 and 5), but it was the behaviour practiced most frequently, often daily, by 85 - 90 percent of students at both schools (Chapters 4 and 5). This finding could indicate that at least 45 percent of students did not think about turning off lights because it had become a habit, or they did not think about it as a proenvironmental behaviour at all, or perhaps, turning off lights was just a task that their parents frequently remind them to do. Results for energy conservation at Fertile Ground Primary School, however, revealed that over 65 percent of students mentioned this topic (Chapter 6). Comparing this result with those from Lighthouse and River's Edge Primary Schools, and considering the different nature of each of these schools, may indicate that students at Lighthouse and River's Edge Primary Schools had been exposed to a great variety of pro-environmental behaviours and that a large proportion of them did not think of energy conservation during the limited time allocated for mind mapping.

Water saving. The next constellation of behaviours found was water saving behaviours, which at all case study schools were commonly practiced on a weekly basis (Table 9.2). It was inferred that these behaviours required little motivation for some students but required more motivation for other students to enact. A closer look at the relationships between these behaviours and the comparison variables, showed that students' weekly water saving efforts were related with Importance at all three schools, and frequent short showers was related with Importance at Lighthouse and River's Edge Primary Schools, indicating that students who attributed more importance to school environmental experiences were more motivated to moderate their shower length or generally save water.

There were greater proportions of students saving water, in particular taking shorter showers, in 2009 compared with 2010, which, it is inferred, was because data were collected during National Water Week in 2009 and at a later time of year in 2010. So, although the survey questions asked students to think back on a scale of how 
frequently they learned about water saving and took short showers at home, the recent focus of teaching during National Water Week at Lighthouse and River's Edge Primary Schools could have skewed results in 2009. Surveys were conducted at a later time in 2010 and might represent truer frequencies of learning about household water saving and student showering durations. Essentially, these results support an assertion that when students learned more frequently about water conservation they were more diligent in taking shorter showers and saving water weekly and Importance became less related to their water saving behaviours. Furthermore, these results support literature that suggests that taking short showers can be difficult to maintain and often requires frequent reminders (e.g. Figure 9.1) or the pressures of social norms (McKenzie-Mohr et al., 2012).

Recent learning experiences serve as prompts or reminders and can impact a person's behaviour (Gardner et al., 2009; McKenzie-Mohr et al., 2012). Prompts have been found to work best when the behaviour is simple, the reminder is recent and if the person is already inclined to undertake the behaviour (McKenzie-Mohr et al., 2012). Consequently, it is asserted that the occurrence of National Water Week during the first round of survey collection in 2009 influenced students' frequency of undertaking water saving behaviours compared with the second round of survey collection in 2010, which was roughly six weeks later in the year.

Comparing these results from student surveys with results from student mind maps, found that water conservation was mentioned by $50-60$ percent of students at all case study schools for the construct things I can do to help the environment (Chapters 4, 5 and 6). This mirrors the proportion of students who undertook water saving behaviours in their homes in 2009 , which ranged between $50-65$ percent at all schools (Chapters 4, 5 and 6).

Organic waste and home grown produce. Another constellation of behaviours found was eating home grown produce and maintaining organic waste. Exploring relationships between these behaviours and the comparison variables, showed that students who ate home grown produce on a weekly basis did so when they were a coenthusiast (Table 9.2), indicating they were more likely to do this when they were one of the most pro-active family members and suggests they may also have participated in growing the produce at home. The low prevalence of eating home grown produce on a weekly basis may have, in part, been because produce is not often available every week. It was also possible that family support was required to grow vegetables and fruits throughout the year. 
Students who maintained organic waste on a weekly basis did so when it was a family norm (Table 9.2), probably because it was a family priority and their parents required the children to help put food scraps into the worm farm or compost bin. The low prevalence of putting food scraps into a worm farm or compost bin was likely because of the resources, time, skills and effort required to maintain either of these systems (McKenzie-Mohr, 2011; McKenzie-Mohr et al., 2012).

Few studies have explored the impact of whole-school sustainability education on the adoption of composting or worm farming behaviours in students (Armstrong et al., 2004; Cutter-Mackenzie, 2010; Grodzinska-Jurczak, 2003), and results indicate that school programs do shift the behaviours of some students and their families. Results from this research support these findings and further indicate that if schools want to influence the prevalence of students growing and eating produce or composting and worm farming at home, they should integrate parent education and involvement as part of their overarching agenda. For example, schools could form partnerships with local community organisations that already offer educational courses, like Living Smart or Earth Carers that both operate in Perth, Western Australia.

It is interesting to note that at Lighthouse and River's Edge Primary Schools another 15 - 20 percent of students indicated they maintained organic waste on a less than weekly basis (Chapters 4 and 5). Whereas at Fertile Ground Primary School there were no students who put food scraps into a worm farm or compost on a less than weekly basis (Chapter 6), and students who practiced this behaviour weekly also indicated that school environmental experiences were important to them (Chapter 6). These comparisons suggest that whole-school sustainability programs may impact the composting or worm farming behaviours of students such that more students practice them infrequently than might otherwise not do so at all. Consequently, in schools with a sustainability focus it is likely that some students will begin to help maintain an organic waste system that their family already had functioning or some families will start a worm farm or compost after joining the school.

Results of students' surveys for eating home grown produce and maintaining organic waste were not triangulated with mind map results because connections with themes from the mind map data were considered too distant. The most relevant themes would have been waste minimisation and biodiversity, but these themes were mostly associated by the students with littering / recycling and animals / trees respectively.

Alternative transport. Taking alternative transport to school was not included in a constellation with any of the other behaviours because this activity was not 
consistent in weekly frequency across the three schools. Instead, it was grouped in its own constellation because of interesting patterns that emerged from the analysis.

Taking alternative transport to school was a common behaviour among students at Lighthouse and River's Edge Primary Schools, but an uncommon behaviour among students at Fertile Ground Primary School (Table 9.2). Students at Lighthouse and River's Edge Primary Schools who walked, biked or bussed to school on a weekly basis appeared to do so if they were one of the most proactive in their households to take alternative transport to school (or work), whereas students at Fertile Ground Primary School who walked, biked or bussed to school weekly did so when it was a family norm (Table 9.2). These weekly behaviours among students at Lighthouse and River's Edge Primary Schools also were related to living close to the school (Lighthouse Primary School) or being over 11 years of age and school environmental experiences being important to them (River's Edge Primary School).

It is interesting to note that proximity to school was not related to this behaviour among students at River's Edge Primary School, which was unexpected, because over 70 percent of students lived further than 2.5 kilometres from the school. It is asserted that at River's Edge Primary School, weekly walking, biking or bussing to school was predominantly mediated by parents who were probably more inclined to allow their children to take alternative transport to school once they were above a certain age and who did not want their children walking to school with heavy backpacks and when they had after school commitments. There were possibly also some underlying fears among parents about child safety.

Furthermore, it was observed that over 70 percent of students at Lighthouse and River's Edge Primary Schools walked, biked or bussed to school at any time in the school year (Chapters 4 and 5) compared with less than 40 percent of students at Fertile Ground Primary School (Chapter 6). It was inferred that the walk-to-school initiatives encouraged at Lighthouse and River's Edge Primary Schools had impacted the behaviour of a majority of students, many of whom would otherwise not have walked, biked or bussed to school, and at River's Edge Primary School in particular, many of whom lived up to 8 kilometres from the school.

Finally, the results of this research support an assertion that more students walk, bike or bus to school on a weekly basis when their school has an emphasis on alternative transport than when their school has no such focus. Moreover, at schools with an emphasis on taking alternative transport to school, including occasional 'walk- 
to-school' days, parents and students do try to participate, even if it would usually be difficult for them to do so.

This assertion is supported by research showing that school programs with an emphasis on alternative transport and supported by the government funded TravelSmart program, do positively impact the behaviours of students and families with the effect of reducing car travel to school and encouraging students to walk, bike or bus to school instead (Denise, 2008; Hansen, Peart, \& John, 2012; RED3, 2005). The TravelSmart to School program has become established in several states across Australia and is advertised to parents and students for the benefits of minimising carbon emissions and encouraging healthy lifestyles. Practitioners report that these programs contribute to influence the perceived social norms of students and their families, which are further impacted by frequent reminders and other media (e.g. Figure 9.1).

Comparing the results from student surveys with the results from student mind maps, showed that air pollution and transport choices was mentioned by only 18 percent of students at Lighthouse Primary School (Chapter 4) and by 50 percent of students at River's Edge and Fertile Ground Primary Schools for the construct things I can do to help the environment (Chapters 5 and 6). It was surprising that 32 percent fewer students at Lighthouse Primary School did not mention air pollution and transport choices when so many of these students were walking, biking or bussing to school on a weekly or less than weekly basis. This unexpected finding may suggest that many of these students did not associate alternative transport as a pro-environmental behaviour. It is possible that students at Lighthouse Primary School walked, biked or bussed to school because they simply lived close to the school, it was convenient, they enjoyed doing it, or they were simply compliant with what their parents or teachers encouraged them to do.

Social norms. Changing values or perceived importance of pro-environmental action is a complex task and difficult to achieve (Gardner et al., 2009; Kollmuss \& Agyeman, 2002; Norgaard, 2009), but research into subjective norm theory has shown that this may not be necessary (Goldstein \& Cialdini, 2007; McKenzie-Mohr, 2011; McKenzie-Mohr et al., 2012). Family life, public media and peer pressure can create subjective norms, which influence habit formation. Moreover, many educational materials and programs have been created to influence behaviours and ultimately social norms (Gardner et al., 2009; Jakobowicz \& Dabas, 2007; McKenzie-Mohr et al., 2012).

Figure 9.1 shows illustrations reproduced from a children's colouring book produced for the United Nations Economic Commission for Europe. These illustrations 
are shown as examples of resources being created to mould and shift the perceived subjective norms of children across the world, that may, in turn, impact the behaviours of their families (Gardner et al., 2009; Jakobowicz \& Dabas, 2007; McKenzie-Mohr et al., 2012). Each illustration was designed to empower children to shift the perceived subjective norms by including dialogue where the child is encouraging the parent to undertake various pro-environmental behaviours. The child is also shown as more knowledgeable about the actions and benefits of pro-environmental behaviours than the parent, which is often the goal of environmental education programs (Ballantyne et al., 1998b; Ballantyne et al., 2001b; Duvall \& Zint, 2007; Uzzell et al., 1994). The first two illustrations show a child encouraging her father to save wood, water and energy by recycling paper, and to save water by turning off the tap whilst shaving. The next two illustrations show the child as being more knowledgeable about the actions and benefits of composting than her father, and the child racing ahead of the parent on their bicycles, suggesting that the child, rather than the parent, is the environmentally proactive person, and as a consequence, more fit and healthy. 

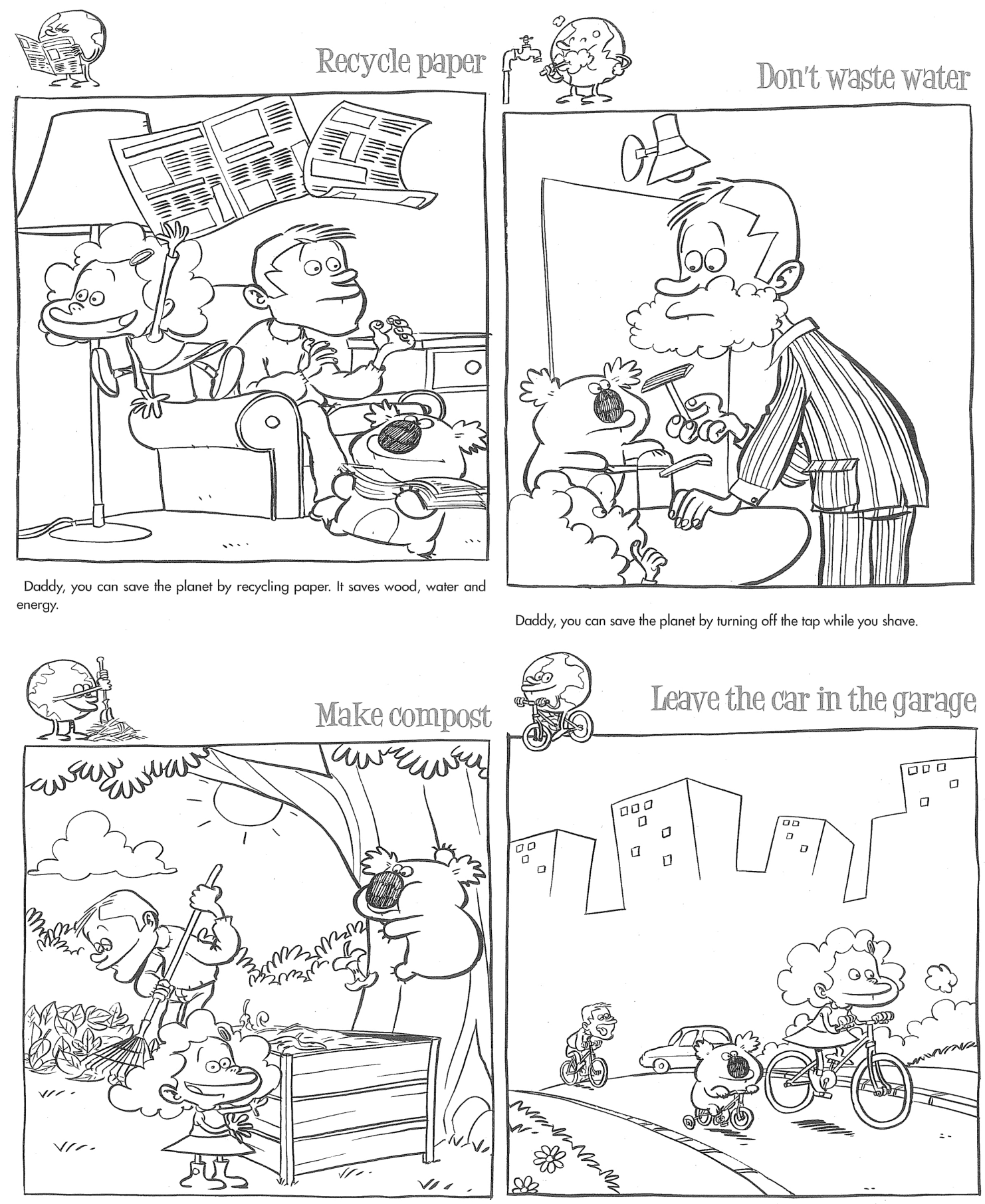

Daddy, you can save the planet by furning off the tap while you shave.

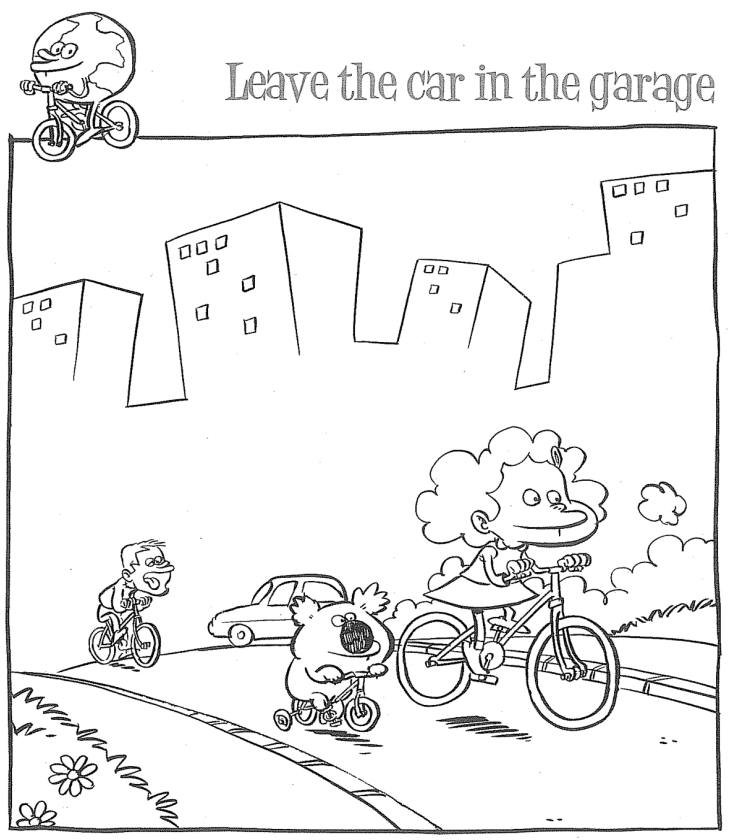

Daddy, you can save the planet by making compost
garden which will be used as fertilizer or for heating.

Daddy, you can save the planet by using your bicycle and leaving your car in the garage: it's good for your health and for the air we breathe.

Figure 9.1. Illustrations in a children's colouring book titled 'Daddy you can save the planet', produced for the UNECE (Jakobowicz \& Dabas, 2007). Reproduced with permission from UNECE (2007).

Summary. These findings support literature about behaviours that occur in 'constellations' that are each influenced by a different set of variables (Cleveland et al., 2005; Heimlich \& Ardoin, 2008; Kollmuss \& Agyeman, 2002). These seven proenvironmental behaviours, in particular, differed in degrees of complexity, family priority and the willingness to act required for students to make them part of a weekly set of pro-environmental behaviours. 


\section{The Model of Responsible Environmental Behaviour}

The Model of Responsible Environmental Behaviour (Hines et al., 1987) was proposed to describe the theoretical interaction of knowledge, attitudes and behaviours. This model was selected for use in this research, as described in Chapter 2, and the results from tests of students' knowledge, attitudes and behaviours described above will now be discussed in the context of this model. The Model of Responsible Environmental Behaviour (Hines et al., 1987) is illustrated below along with the elements of Jensen's (1993) action competence approach, also referred to in this research (Figure 9.2). These elements: issues-based knowledge, action-based knowledge and willingness to act are overlayed on The Model of Responsible Environmental Behaviour (Hines et al., 1987) to highlight the similarities between these two models.

The two models of change presented in Figure 9.2 illustrate how knowledge and attitudes together contribute to a person's intention or competence to act. However, results from this research indicate that this is not so straightforward. It is proposed that knowledge of issues and actions, and positive attitudes contributed to students practicing water saving behaviours with greater frequency than students with negative attitudes and little knowledge. However, the results also indicated that recycling and turning off lights were more likely to be impacted by situational factors, such as: simplicity of the task, household recycling infrastructure, family expectations and social norms.

The overall results of this research corroborate the two models of change presented in Figure 9.2, but findings about constellations of behaviours suggest these models can be extended and that pathways can be specified for the different constellations. The extension of theory being proposed in this research is illustrated in Figure 9.2 by pathways A and B. Pathway A represents the constellation of simple household water saving behaviours that are more likely to be affected by knowledge and willingness to act. Pathway B represents the constellation of simple household recycling and energy saving behaviours that are more likely to be affected by situational factors. 


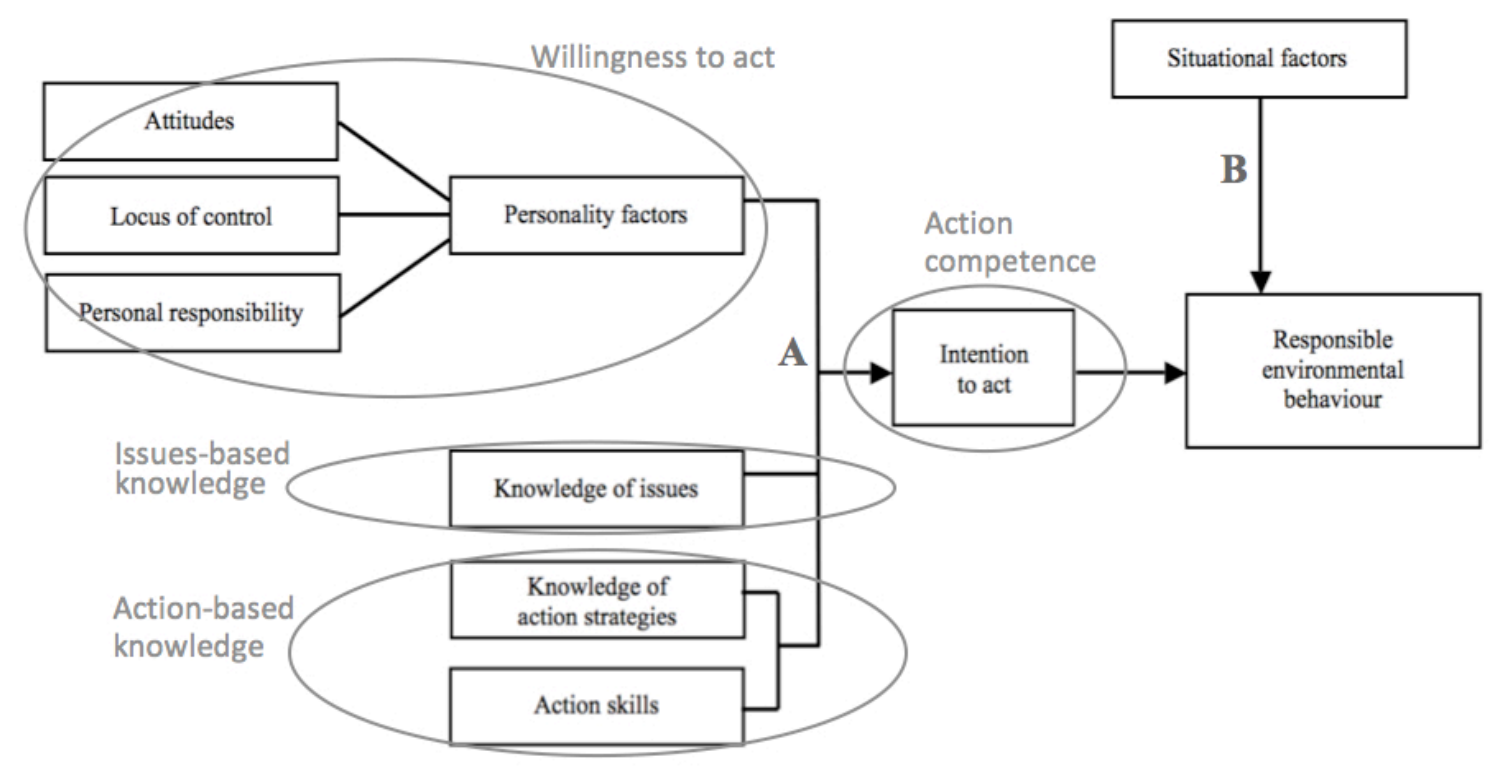

Figure 9.2. The Model of Responsible Environmental Behaviour (Hines et al., 1987) and Jensen's (1993) action competence approach overlayed. Two constellations of behaviours that are impacted by different factors are also illustrated. Pathway A represents a constellation of simple household water saving behaviours, and pathway B represents a constellation of simple household recycling and energy saving behaviours.

Extrapolating these results to lessons that schools, AuSSI - WA or other change agents can utilise in their work, it is suggested that water saving behaviours are impacted by increased attitudes to environmental experiences and increased knowledge, and should be given priority and emphasis in a school program. Whereas, household recycling and simple energy saving behaviours that are already features of most households should be reinforced and encouraged in a whole-school program, and programs should be extended to include opportunities for students to learn about and develop skills in dealing with complex variations of these behaviours.

This research did not assess complex waste minimisation or energy reduction behaviours, such as reducing single use plastics in the family home, or using electrical devices or air conditioning less frequently for the purpose of saving power. However, other research suggests that such complex variations of waste minimisation and energy reduction are positively impacted by a whole-school education program that targets students' and parents' awareness and skills (Armstrong et al., 2004; Cutter-Mackenzie, 2010; Grodzinska-Jurczak, 2003). Further research into the impact of whole-school education for sustainability programs would benefit from exploring the frequency that students practice an array of easy, moderate and difficult to achieve waste minimisation and energy reduction behaviours.

An extension of this research would also benefit from exploring a wider array of other complex household behaviours, such as managing organic waste, growing and eating home grown produce, or taking alternative transport to school, to better 
determine if these are impacted by increased issues-based and action-based knowledge, and attitudes to environmental activities. Initial inferences from descriptive statistics, in this research, suggest there is some impact of the whole-school program on these behaviours. A behavioural pathway could not be proposed for the model in Figure 9.2 because a behaviour scale including these behaviours was not suitable for modelling with attitudes. However, it is suspected that managing organic waste, growing and eating home grown produce, and taking alternative transport to school are impacted by a combination of situational factors and action competence. Such that, if situational factors are favourable (e.g. proximity to school, household infrastructure, family support), then a whole-school education focus on any of these behaviours will lead to increased issues-based and action-based knowledge, and attitudes to environmental activities in students, and ultimately to action competence and the desired behaviour.

\section{Pro-Environmental Behaviour Assertions}

This section on students' pro-environmental knowledge, attitudes and behaviours concludes with a series of assertions about features that can influence proenvironmental behaviour. These assertions are based on the findings from this case study research, which should not be generalised or be assumed to apply to every wholeschool sustainability education context, however, these assertions include valuable insights that will likely be applicable to schools from similar contexts.

Assertion 1: Student knowledge about sustainability. Many students have a spurious understanding of the concept of sustainability and associate sustainability primarily with environmental themes or are confused by the term.

Assertion 2: Student attitudes towards school environmental activities. Wholeschool sustainability education can have a positive impact on students' attitudes to school environmental activities and their actual behaviours at home. Furthermore, students with positive attitudes to school environmental activities are more likely to have a positive willingness to act.

Assertion 3: Constellations of student behaviours. Pro-environmental behaviours that students can practice in their homes differ in degrees of complexity and the willingness to act required to make them part of a weekly set of pro-environmental behaviours.

Assertion 4: Family norms mediate the behaviours practiced in students' homes. Family norms impact a student's willingness to act and whether a behaviour will be deemed too complex to introduce into the home or to practice with regularity. 
Assertion 5: Turning off lights and recycling. Turning off lights and recycling on a weekly basis are behaviours that are widespread among students in many schools regardless of whether the school has a whole-school sustainability program. These behaviours are impacted by situational factors, such as: simplicity of the task, household recycling infrastructure, family expectations and social norms.

Assertion 6: Water saving. Taking short showers and saving water around the home on a weekly basis is common among students in many schools regardless of whether the school has a whole-school sustainability program. However, students who consider school environmental experiences as important to them are most motivated to moderate their shower length or generally save water. Furthermore, when any student learns more frequently about water conservation they can become more diligent in taking shorter showers and saving water weekly.

Assertion 7: Organic waste and home grown produce. Eating home grown produce and maintaining organic waste on a weekly basis is uncommon among students and is mediated primarily by whether there is family support. However, whole-school sustainability programs may impact the composting or worm farming behaviours of students such that more students practice them infrequently than might otherwise not do so at all. Family support for these behaviours is impacted by infrastructure, motivation, time, skills and complexity of the task.

Assertion 8: Alternative transport. More students walk, bike or bus to school on a weekly basis when their school has an emphasis on alternative transport than when their school has no such focus.

\section{Family Dynamics and Intergenerational Influence}

This section discusses results from investigation of Research Question 5 (p. 7). As described in Chapter 2, great hope has been pinned on the potential for children to transfer environmental learning to their parents and thus effect change in their households (Ballantyne et al., 1998b; Ballantyne et al., 2001a, 2001b; Duvall \& Zint, 2007; Larsson et al., 2010). Moreover, family dynamics has been considered an important mediator of this potential but very few studies have attempted to investigate the role of family dynamics in intergenerational influence (Duvall \& Zint, 2007; Larsson et al., 2010; Payne, 2005), let alone the interaction of family dynamics and school factors that might affect intergenerational influence positively or negatively.

This research set out to investigate family dynamics and school factors that affected the intergenerational transfer potential of children that attended two schools 
with a whole-school sustainability program in operation, and revealed interesting patterns. It was important for the purpose of building on other research that the schools selected in this research had a whole-school program in place, because this was thought to positively influence the depth and integration of environmental experiences that children were exposed to in their schools (Ballantyne et al., 2001c; Duvall \& Zint, 2007; Sutherland \& Ham, 1992). Previous studies have only explored the intergenerational influence of environmental programs that lasted from a few days to a few months (Duvall \& Zint, 2007).

\section{Synthesis and Discussion}

Family dynamics were found to influence the intergenerational transfer of environmental behaviours between students and their parents. Results were summarised in a model, displayed in Chapter 8, that illustrated four main interactions of high and low parent encouragement, and, high and low child interest. Furthermore, results indicated that where there was high parent encouragement and high child interest, there existed three subtypes:

Subtype A) new environmental behaviours in the family home, the child becoming a co-driver of these behaviours, and their parent/s becoming more involved in the life of the school and supportive of the school's sustainability initiatives,

Subtype B) new environmental behaviours in the family home and the child becoming a co-driver of these behaviours, or

Subtype C) no new environmental behaviours but the potential for the characteristics of subtypes A and B to be developed.

This finding raised questions about how the outcomes observed in Subtypes A and $\mathrm{B}$ could be cultivated. Literature on action competence shows that creating opportunities for students to develop action-based knowledge, issues-based knowledge and willingness to act is the key to unlocking a student's action competence (Eames et al., 2010; Eames et al., 2006; Fontes, 2004; Jensen, 2004; Jensen \& Schnack, 2006). To achieve action competence, educators are encouraged to foster students' capacities for democratic decision making, critical investigation and problem solving, and to provide socially relevant contexts in which to centre the learning experience (Eames et al., 2006; Fontes, 2004; Jensen \& Schnack, 2006). Moreover, results from teacher interviews, student mind maps and student surveys in this research, support these recommendations and demonstrate that student willingness to act and action competence can be cultivated through the establishment of authentic leadership opportunities where students' 
opinions help to shape the direction of some initiatives, and through creating opportunities for students to learn actions-based environmental knowledge at school, for example with integrated, regular activities such as recycling, composting, gardening.

Nevertheless, results from this research indicate that new behaviours are unlikely to be adopted in the family home unless one or both parents are encouraging of their child's interest. This finding implies that educators should not be discouraged when their efforts will not affect all families, but take heart that they will influence those families where parents are encouraging of their child's interest, even if these parents themselves have little interest in the environment or little time to engage with the school.

Parental support and encouragement has previously been asserted as necessary to enhance the effectiveness of their children's pro-environmental efforts at home (Ballantyne et al., 2001a; Uzzell, 1999), and this research provides evidence of this important family dynamic. Further research would be necessary to probe what factors might be required to motivate the parents who were not encouraging of their child's interest, or receptive to the school's influence. It may be that these types of families are essentially among the 'late adopters' described in Diffusions of Innovations Theory (Rogers, 1995). If so, Diffusions of Innovations Theory indicates that this group of people do not necessarily need to be targeted by educational or awareness campaigns and that they will be more effectively influenced by an increased pressure of social norms (McKenzie-Mohr, 2011; Rogers, 1995).

Cultivating family involvement and parent support appears to be complex and dependent on the school context. To this effect, Ballantyne, Fien and Packer (2001a, p. 5) suggest that parent support could be fostered by including into a program "... environmental testing/ monitoring activities or student projects and presentations that involve parents as partners in student learning at home". This research further indicates that on an abstract level, cultivating parent support appears to be about creating an open, inviting school culture, where parents are welcome on school grounds and where their input and involvement are encouraged and invited. Whilst seemingly simple, this was an obstacle at River's Edge Primary School, which could go further towards building relationships with families. As has been illustrated in teacher interviews, however, this school had complex barriers towards encouraging parents' involvement in the program. Many teachers and the principal considered most parents to be uncomfortably sensitive to environmental topics, and results from parent interviews indicated that there were parents who thought the school was already doing enough, but there were other parents 
who indicated they would like to see more parent engagement with the school's sustainability program.

Fostering parent support and involvement with the school, as observed at Lighthouse Primary School, has a potential outcome of helping to cultivate social norms. Parents are primarily responsible for instituting changes to household practices, which can contribute to social norms at the community-level and thereby influence a collective approach to environmental action (Henderson \& Tilbury, 2004; Uzzell, 1999). Cultivating social norms within the school community may impact the longevity and depth of integration of behaviours in each household (McKenzie-Mohr, 2011).

Figure 9.3 is another example provided in this chapter of the kinds of resources created to shape and shift social norms and the intergenerational influence of children across the world. The front and inside cover of this children's colouring book explicitly advocates that the child should "educate their parents", and emphasises the hope of environmental educators that children will be 'catalysts of environmental change' (Ballantyne et al., 1998b; Ballantyne et al., 2001b; Duvall \& Zint, 2007; Uzzell et al., 1994).

Summary. Educators and school sustainability coordinators may not be able to influence a parent's environmental interest, but they can create meaningful leadership opportunities that can turn a child's interest into empowerment. They can also foster collaborative parent and school relationships that create social norms by creating communities. 

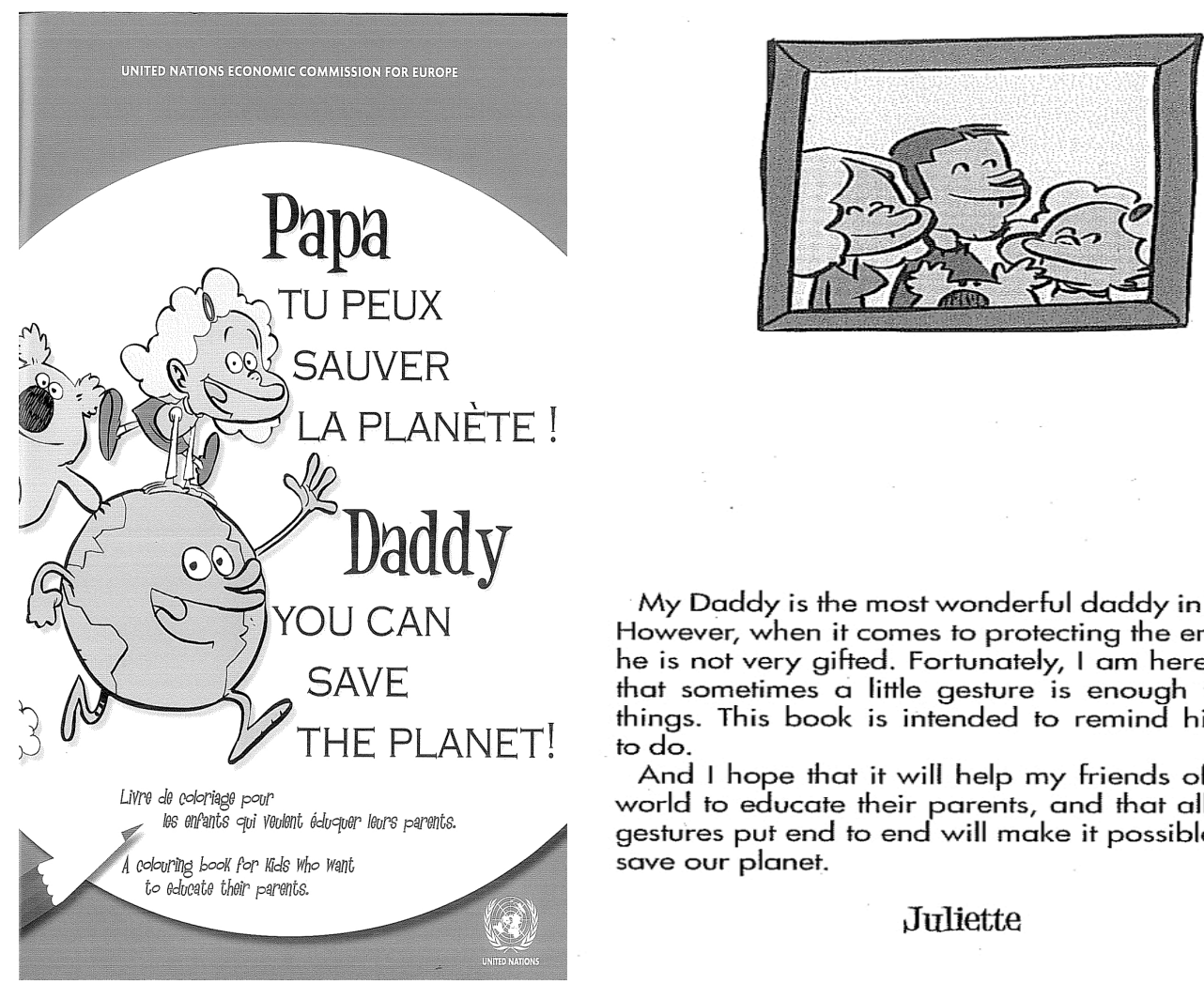

My Daddy is the most wonderful daddy in the world! However, when it comes to protecting the environment he is not very giffed. Fortunately, I am here to tell him that sometimes a little gesture is enough to improve things. This book is intended to remind him of what to do.

And I hope that it will help my friends of the whole world to educate their parents, and that all these little gestures put end to end will make it possible to help to save our planet.

Juliette

Figure 9.3. Front and inside covers of a children's colouring book titled 'Daddy you can save the planet', produced for the UNECE (Jakobowicz \& Dabas, 2007). Reproduced with permission from UNECE (2007).

\section{Intergenerational Assertions}

This section on family dynamics and intergenerational influence concludes with a series of assertions about factors that can influence uptake of pro-environmental behaviours in students' homes. These assertions are based on the findings from this case study research, which should not be generalised or be assumed to apply to every wholeschool sustainability education context, however, these assertions include valuable insights that will likely be applicable to schools from similar contexts.

Assertion 1: School sustainability education can positively influence a child's interest in caring for the environment. The extent that this interest carries into a child's home life is mediated by encouragement from one or both of their parents.

Assertion 2: High child interest and parent encouragement can lead to intergenerational transfer of pro-environmental behaviours. Children who are interested in caring for the environment, whose interest is encouraged by their parents, and who are given opportunities to learn practical skills at home and/or at school, will develop willingness to act and action competence to care for the environment, thereby promoting adoption of new behaviours in the family home. 
Assertion 3: When parents are invited to participate in or contribute to school environmental activities the potential for intergenerational transfer is stronger. In families where children are interested, parents are encouraging and parents are invited to participate in or contribute to school environmental activities, children are more likely to develop willingness to act and action competence to care for the environment, and new behaviours will be adopted in the family home.

Assertion 4: Adoption of complex behaviours that involve a large outlay of money, time, energy and resources require more supporting factors. In families where parents have a high pre-existing interest in caring for the environment, their children are interested, they are encouraging of their child's interest and they are invited to participate or contribute in school environmental activities, children are more likely to develop willingness to act and action competence to care for the environment, and the family is more likely to adopt complex new behaviours in the family home.

\section{Limitations}

Factors were identified that, in isolation, might have limited the inferences that could be made from this research. These limitations, however, were not considered to diminish the validity of the findings because of the variety of data collected and the increased rigour afforded from triangulation. Nonetheless, it is important to acknowledge and describe the limitations and they are summarised as follows:

1) Self reporting inflation: People tend to over-estimate their behaviours when selfreporting (Corral-Verdugo, 1997). However, they do this consistently across behaviours, so an internal comparison of different behaviours was valid.

2) Small sample size of students at Fertile Ground School $(n=26)$ : It is possible, that with a larger sample size, relationships between frequency of behaviour and the comparison variables may have been detected for more of the pro-environmental behaviours.

3) Potentially biased questions: Some of the pro-environmental behaviour questions were potentially biased due to unintentional problems with the question wording. Despite these potential limitations, the survey results provide useful information and insight into the different frequencies with which students practice certain proenvironmental behaviours at home, and the dominant influencing factors. In future iterations of the survey it would be important for researchers to use these findings 
and give careful thought to all possible interpretations of the questions. Examples of the problems with question wording are:

a) The question regarding short showers was written, "At home I have short showers and use a four minute shower timer". During the first stage of data collection it became apparent that this was two questions in one because some students asked for clarification. Clarification was provided to all students from then onwards, stating that it did not matter if they had a shower timer, only that they took short showers. In future the question could instead state, "At home I have short showers to save water".

b) The large percent response of students for the variable turning off lights at home could have been caused by ambiguity in the question wording that allowed students to consider all the various times they turned off lights regardless of whether it was specifically to save power or not. The question stated, "At home I save power by turning off lights" and might instead have stated, "At home I turn off lights to help save power".

4) Potentially confounded question: It is also apparent that future iterations of the survey should separate the question - frequency of learning about recycling and composting - into two questions, one for recycling and the other for worm farming or composting. This would more accurately capture responses for Learning that correspond with the home behaviours being estimated. During survey development this was not done for two reasons: a) to minimise the number of questions that students had to answer and thus minimise time, and b) it was anticipated that teachers would cover recycling and composting together during any classroom exercises.

5) Potential bias: It is possible that the mind mapping instrument biased responses towards environmental themes by juxtaposing both constructs on the same page. Further refinement and testing of the mind mapping instrument would be required to determine if juxtaposition of constructs causes bias in responses, or, if the potential benefits of direct comparison and time saved in collecting mind maps outweigh any issues with bias.

6) Potential bias: It is possible that the definition of sustainability provided to all students influenced some students to consider sustainability through an environmental lens. Sustainability was defined as "helping the world stay healthy 
for a long time". A broader definition that more obviously incorporated social and economic aspects might increase the breadth of student responses.

\section{Recommendations}

Recommendations for maximising whole-school education for sustainability emerged from the assertions posed throughout this chapter, and include: 1) strategies that AuSSI - WA can adopt to better support schools, 2) strategies for schools to inform and engage parents, teachers and students towards adopting pro-environmental practices in the short and long term, and 3) strategies towards improving effectiveness of intergenerational transfer and increasing the adoption of new pro-environmental behaviours in households. These recommendations are detailed as follows:

\section{Strategies to Better Support Schools}

Recommendation 1: AuSSI - WA should maintain the broad definition of sustainability (as encompassing social, environmental and economic themes). Furthermore, AuSSI - WA should continue to encourage and advocate this understanding with all schools and among all staff members.

Recommendation 2: Principals should be coached to adopt a distributed, collaborative approach to leadership. Lead sustainability coordinators should incorporate detachment and flexibility into their suite of skills together with determination, passion and persistence.

Recommendation 3: All staff should travel forward together at a compatible pace and contribute collaboratively to setting the priorities and regularly evaluating a school's program.

Recommendation 4: It is necessary for at least one member of staff to spearhead and coordinate projects. Governments should consider providing money to schools to employ a specialist staff member or pay staff for time towards coordinating the wholeschool sustainability program.

Recommendation 5: AuSSI - WA should establish a team of allied school sustainability facilitators who act as a bridge between schools and partner organisations, but do not mediate or control these partnerships. Such a team of AuSSI - WA allied facilitators would benefit from observing the Millennium Kids approach to facilitation.

Recommendation 6: Regular opportunities for student voice to influence the direction or shape of the sustainability focus should be incorporated into a whole-school program to increase the degree of action competence developed in students. These 
should be done in addition to raising students' awareness of issues and providing opportunities for students to learn action skills. An initial step could be to hold annual or biannual student conferences for the whole of school or per year group.

Recommendation 7: Relevant, contextualised professional learning, including pre-service education and access to ongoing mentorship of sustainability coordinators and school administrators, must be included in the support available for whole-school education for sustainability programs. This is integral to bolstering a school's capacity to overcome and avoid potentially disabling obstacles.

\section{Strategies for Promoting Pro-Environmental Practices}

Recommendation 8: Schools with a whole-school sustainability program should foster an understanding of the broad scope of sustainability in students and to help them build connections across a breadth of ideas, as is the goal of whole-systems thinking.

Recommendation 9: Whole-school sustainability education, with action-based learning opportunities, should be given priority in schools because, in this research, students' attitudes and willingness to act were impacted by school environmental activities.

Recommendation 10: Family support was a mediator of students' practice of pro-environmental behaviours in their homes, in this research, and could be increased by the school partnering with a local community organisation that already offers adult educational courses, like Living Smart or Earth Carers that both operate in Perth, Western Australia.

Recommendation 11: Environmental and sustainability program providers, like AuSSI - WA, should give priority and emphasis in a school program to encouraging students' water saving behaviours, because these were among the behaviours, in this research, most directly impacted by increased attitudes to school environmental activities and increased knowledge.

Recommendation 12: Household recycling and simple energy saving behaviours were already features of most households in this research. These behaviours should be reinforced and encouraged in a whole-school program, and programs should be extended to include opportunities for students to learn about and develop skills in dealing with complex variations of these behaviours. 


\section{Strategies Towards Increasing the Adoption of New Household Pro- Environmental Behaviours}

Recommendation 13: Educators wanting to influence household proenvironmental behaviours should consider fostering willingness to act and action competence in children by developing opportunities for students to learn environmental skills that can be incorporated at home and by providing programs with authentic leadership opportunities.

Recommendation 14: Educators wanting to influence household proenvironmental behaviours as well as cultivate social norms, should create activities that encouraged family engagement, are open and inviting to the contribution of parents, and may involve adult education.

Recommendation 15: Schools could consider partnering with a community organisation that offers educational courses to increase action-based knowledge and skills, for example, Living Smart or Earth Carers in Western Australia.

\section{Advocacy for AuSSI - WA}

This research has illustrated that schools engaged with AuSSI - WA are successful in positively impacting the knowledge, attitudes and behaviours of students. These programs also have potential to impact the pro-environmental behaviours undertaken in family homes. There is always room for improvement, however, and as an important contact point and resource hub for schools that have implemented a sustainability education program or wish to begin a sustainability education program, AuSSI - WA and AuSSI federally may find the recommendations outlined above useful.

One important recommendation that will be restated here is that for AuSSI WA to achieve these goals it should employ a group of facilitators that can work closely with participating schools, providing one-to-one support which may include fostering networks between schools and partnerships between schools and various agencies. Providing such support to participating schools is currently beyond the capacity of AuSSI or AuSSI - WA as they are limited by budgetary constraints and limited political will (AESA, 2012; Sandell, 2012, June 22). Funding and governmental will must be increased for AuSSI - WA to provide adequate service to the 400 plus participating schools. 


\section{Future Research}

Future research is necessary to further investigate some of the findings from this research. The suggested areas of future research are:

1) Broad view of sustainability: Sustainability is broader than environmental issues, so future research into whole-school sustainability education should investigate students' knowledge, attitudes and behaviours towards other sustainability related issues. For example, this future research could examine estimates of other parameters of sustainability such as student wellbeing, and knowledge of sociocultural issues and actions.

2) Parents' understanding: If students' conceptions are environmentally skewed it is likely that their parents and teachers' conceptions of sustainability are also skewed towards environmental themes. Future research could assess the sustainability conceptions of parents and teachers using mind mapping.

3) Student attitude: Further research is required to determine if complex household behaviours are likely to be impacted by more positive attitudes to environmental experiences.

4) Student behaviour: Further research should explore the frequency that students practice a diverse array of easy, moderate and difficult to achieve household behaviours.

5) Family norms: Further research is necessary to explore the role of family norms and situational factors in mediating students' willingness to act and the behaviours that transfer into the family home.

6) Intergenerational dynamics: Further research is necessary to probe what factors might be required to motivate parents who are not encouraging of their child's interest, or whether this would be a fruitful pursuit.

7) Continuity: Future research into whole-school sustainability education should include investigation of the change in students' knowledge, attitudes and behaviours towards the environment, or more broadly towards sustainability, between primary and secondary school and retention of attitudes and behaviours later in life.

\section{Conclusion}

This thesis provided a detailed exploration of the impact of whole-school education for sustainability on upper-primary students and their families. Using a case 
study, mixed method approach it specifically examined: 1) the organisational factors that fostered or impeded the establishment of whole-school education for sustainability programs at three schools, 2) the environmental knowledge, attitudes and behaviours of upper-primary students that attended the three case study schools, and 3) family dynamics that contributed to intergenerational influence and the uptake of new environmental behaviours in students' homes. This research was unique in integrating the exploration of these key facets of whole-school sustainability education into one research project. This research was also conducted at a significant time in the Decade of Education for Sustainable Development when the findings of such research could be used to advocate for further political, financial and in-kind support of whole-school education for sustainability initiatives. Support, the like of which, could make or break the future of government situated programs that assist schools to set up, manage and maintain their sustainability initiatives; programs such as AuSSI and AuSSI - WA.

This research has contributed to the body of evidence in support of wholeschool education for sustainability programs and provides a series of recommendations to assist practitioners, program providers and AuSSI - WA in improving training opportunities, facilitation and student and family outcomes. At a time when sustainability has been incorporated as an overarching priority in The Australian Curriculum, it is poignant to consider the implications from this research. 
THIS PAGE HAS PURPOSELY BEEN LEFT BLANK 


\section{REFERENCES}

"Timeline". (2010). Swan-Canning online schools project, Millennium Kids Ning: Timeline. Accessed on 12 August 2010, from http://millenniumkids.ning.com/page/timeline-2

ABS. (2010). Environmental awareness and action Australian social trends: Canberra, ACT: Australian Bureau of Statistics.

ACARA. (2012a). My School, Australian Government: Australian Curriculum, Assessment and Reporting Authority. Accessed on 4 September 2012, http://www.myschool.edu.au

ACARA. (2012b). My School - Glossery, Australian Government: Australian Curriculum, Assessment and Reporting Authority. Accessed on 4 September 2012, from, http://www.acara.edu.au/myschool/myschool_glossary.html

ACARA. (2012c). National Assessment Program - Literacy and Numeracy (NAPLAN), Australian Government: Australian Curriculum, Assessment and Reporting Authority. Accessed on 4 September 2012, from http://www.naplan.edu.au

ACARA. (2012d). The shape of the Australian curriculum: Version 3. Sydney, NSW: Australian Curriculum, Assessment and Reporting Authority.

ACF. (2010). Resource consumption atlas, eco-footprint in Western Australia, Australian Conservation Foundation. Accessed on 6 August 2010, from http://202.60.88.196/consumptionatlas/

from http://www.acfonline.org.au/consumptionatlas/

AESA. (2012). Australian Sustainable Schools Initiative (AuSSI) - Phase 2 proposal. Sydney, NSW: Australian Education for Sustainability Alliance.

AG. (2012). Australian stories: Identity - The lucky country, Australian Government: Culture Portal. Accessed on 1 July 2012, from http://www.cultureandrecreation.gov.au/articles/luckycountry/

Ajzen, I. (1991). The theory of planned behavior. Organizational Behavior and Human Decision Processes, 50(2), 179-211.

Ajzen, I., \& Fishbein, M. (1980). Understanding attitudes and predicting social behavior. Englewood Cliffs, NJ: Prentice Hall.

Alimahomed, S., \& Keeler, B. (1995). The youth role in creating a healthy future for the earth: An examination of the link between collective action for the environment and the emotional health of children. Environmental Health Perspectives, 103(Suppl. 6), 63-66.

Allen, G. (2011). Public affairs and mining in Australia: A rescued license to operate. Journal of Public Affairs, 11(4), 382-386.

APA. (2010). Publication manual of the American Psychological Association (6th edition). Washington D.C.: American Psychological Association.

ARIES. (2009). Education for Sustainability: The role of education in engaging and equipping people for change: Sydney, NSW: A report prepared by the Australian Research Institute in Education for Sustainability (ARIES), Macquarie University, for the Australian Government, Department of the Environment, Water, Heritage and the Arts.

Armstrong, P., \& Bottomley, E. (2003). Sustainable schools program: A one-stop shop for sustainability education. Paper presented at the North American Association for Environmental Education (NAAEE) 32nd Annual Conference. Thinking globally while acting culturally. Anchorage, Alaska.

Armstrong, P., Sharpley, B., \& Malcolm, S. (2003). Waste wise schools: Cultural change through successful partnerships. Paper presented at the North American Association for Environmental Education (NAAEE) 32nd Annual Conference: Thinking globally while acting culturally. Anchorage, Alaska. 
Armstrong, P., Sharpley, B., \& Malcolm, S. (2004). The waste wise schools program: Evidence of educational, environmental, social and economic outcomes at the school and community level. Australian Journal of Environmental Education, 20(2), 1-13.

ARTD. (2010). Evaluation of operational effectiveness of the Australian Sustainable Schools Initiative (AuSSI): Sydney, NSW: Produced by ARTD Consultants for the Department of the Environment, Water, Heritage and the Arts.

ASG. (2012). About: You Can Do It! Education, Australian Scholarships Group. $\begin{array}{lllll}\text { Accessed on } & \text { September } & \text { 2012, } & \text { from }\end{array}$ http://www.youcandoit.com.au/AboutYouCanDoIt/

$\mathrm{Au}, \mathrm{W}$. (2007). High-stakes testing and curricular control: A qualitative metasynthesis. Educational Researcher, 36(5), 258-267.

Ballantyne, R., Connell, S., \& Fien, J. (1998a). Factors contributing to intergenerational communication regarding environmental programs: Preliminary research findings. Australian Journal of Environmental Education, 14, 1-10.

Ballantyne, R., Connell, S., \& Fien, J. (1998b). Students as catalysts of environmental change: A framework for researching intergenerational influence through environmental education. Environmental Education Research, 4(3), 285-298.

Ballantyne, R., Fien, J., \& Packer, J. (2001a). Intergenerational influence in environmental education: A quantitative analysis. Australian Journal of Environmental Education, 17, 1-7.

Ballantyne, R., Fien, J., \& Packer, J. (2001b). Program effectiveness in facilitating intergenerational influence in environmental education: Lessons from the field. The Journal of Environmental Education, 32(4), 8-15.

Ballantyne, R., Fien, J., \& Packer, J. (2001c). School environmental education programme impacts upon student and family learning: A case study analysis. Environmental Education Research, 7(1), 23-37.

Bamberg, S., \& Möser, G. (2007). Twenty years after Hines, Hungerford, and Tomera: A new meta-analysis of psycho-social determinants of pro-environmental behaviour. Journal of Environmental Psychology, 27(1), 14-25.

Barbour, R. (2008). Introducing qualitative research: A student guide to the craft of doing qualitative research. London: SAGE Publications Inc.

Barmby, P., Kind, P., \& Jones, K. (2008). Examining changing attitudes in secondary school science. International Journal of Science Education, 30(8), 1075-1093.

Barratt-Hacking, E., Barratt, R., \& Scott, W. (2007). Engaging children: Research issues around participation and environmental learning. Environmental Education Research, 13(4), 529-544.

Bennett, J., \& Hogarth, S. (2009). Would you want to talk to a scientist at a party? High school students' attitudes to school science and to science. International Journal of Science Education, 3(14), 1975-1998.

BIC. (1998). Valuing spirituality in development, concepts from the Bahá'í International Community. Paper presented at the World Faiths and Development Dialogue. Lambeth Palace, London. Paper retrieved from http://info.bahai.org/article-1-81-5.html\#V.

BIC. (2008). Eradicating poverty: Moving forward as one The Bahá'i international community's statement on poverty. New York, USA: United Nations Office.

Boeve-de Pauw, J., Donche, V., \& Van Petegem, P. (2011). Adolescents' environmental worldview and personality: An explorative study. Journal of Environmental Psychology, 31(2), 109-117.

Bogner, F. X. (1996). Environmental perspectives of pupils: The development of an attitude and behaviour scale. Environmentalist, 16(2), 95-110. 
Bolstad, R., Baker, R., Barker, M., \& Keown, P. (2004). A review of national and international research literature on environmental education practices, in Environmental education in New Zealand schools: Research into current practices and future possibilities (Volume 2). Wellington, New Zealand: A report produced by New Zealand Council for Educational Research and University of Waikato for the Ministry of Education Retrieved from http://www.minedu.govt.nz.

Brennan, M. (2009). Steering teachers: Working to control the feminized profession of education. Journal of Sociology, 54(4), 339-359.

Briant, E., \& Doherty, C. (2012). Teacher educators mediating curricular reform: Anticipating the Australian curriculum. Teaching Education, 23(1), 51-69.

Brinkmann, A. (2003). Graphical knowledge display: Mind mapping and concept mapping as efficient tools in mathematics education. Mathematics Education Review, 16, 35-48.

Brundtland, G. H. (1987). Our common future: New York, USA: United Nations, Report of the World Commission on Environment and Development.

Budd, J. W. (2004). Mind maps as classroom exercises. The Journal of Economic Education, 35(1), 35-46.

Bunting, T. E., \& Semple, T. M. (1979). The development of an environmental response inventory for children. In D. Seidel \& S. Danford (Eds.), Environmental design: Research, theory and application EDRA 10 (pp. 273-283). Washington DC, USA: Environmental Design Research Association.

Burrell, A. (2012, May 19). Mine companies wary as Barnett's west rakes in the royalties, The Australian. Retrieved from http://www.theaustralian.com.au/

Buys, L., Miller, E., \& Megen, K. v. (2012). Conceptualising climate change in rural Australia: Community perceptions, attitudes and (in)actions. Regional Environmental Change, 12(1), 237-248.

Buzan, T., \& Buzan, B. (1996). The mind map book: How to use radiant thinking to maximize your brain's untapped potential (2nd edition). New York, USA: PLUME, Penguin Books Inc.

Carter, L., \& Smith, C. (2010). The time is right: Embedding education for sustainable development into pre-service science and technology teacher education. In S. Dolinšek \& T. Lyons (Eds.), Socio-cultural and human values in science and technology education (pp. 238-248): Institute for Innovation and Development of University of Ljubljana.

Chung, M. (2012, June 26). The boom is predicted to continue long past 2020, ABC News. Retrieved from http://www.abc.net.au/

Cialdini, R., \& Goldstein, N. J. (2004). Social influence: Compliance and conformity. Annual Review Pschology, 55, 591-621.

Cleveland, M., Kalamas, M., \& Laroche, M. (2005). Shades of green: Linking environmental locus of control and pro-environmental behaviour. The Journal of Consumer Marketing, 22(12), 198-212.

Cohen, L., Manion, L., \& Morrison, K. (2011). Research methods in education (7th edition). New York, USA: Routledge, Taylor and Francis Group.

Corbetta, P. (2003). Social research: Theory, methods and techniques. London, UK: SAGE Publications Inc.

Corcoran, P. B., Walker, K. E., \& Wals, A. E. J. (2004). Case studies, make-your-case studies, and case stories: A critique of case-study methodology in sustainability in higher education. Environmental Education Research, 10(1), 7-21.

Corral-Verdugo, V. (1997). Dual 'realities' of conservation behaviour: Self-reports vs. observations of re-use and recycling behaviour. Journal of Environmental Psychology, 17(2), 135-145. 
Corraliza, J. A., \& Berenguer, J. (2000). Environmental values, beliefs, and actions: A situational approach. Environment and Behavior, 32(6), 832-848.

Crano, W., \& Prislin, R. (2006). Attitudes and persuasion. Annual Review of Psychology, 57, 345-374.

Creswell, J. W. (2009). Research design: Qualitative, quantitative, and mixed methods approaches (3rd edition). Los Angeles, USA: SAGE Publications Inc.

Creswell, J. W., \& Plano Clark, V. L. (2011). Designing and conducting mixed methods research (2nd Edition). Thousand Oaks, CA: SAGE Publications Inc.

Cunningham, E. (2010). A practical gudie to structural equation modelling using Mplus. Malvern East, Victoria: Statsline - Education and Statistics Consultancy.

Cutter-Mackenzie, A. (2010). Australian waste wise schools program: Its past, present, and future. The Journal of Environmental Education, 41(3), 165-178.

D'Antoni, A. V., Zipp, G. P., \& Olson, V. G. (2009). Interrater reliability of the mind map assessment rubric in a cohort of medical students. BMC Medical Education, 9(1), 19-27.

Davis, J. M., \& Ferreira, J. (2009). Creating cultural change in education: A proposal for a continuum for evaluating the effectiveness of sustainable schools implementation strategies in Australia. Australian Journal of Environmental Education, 25, 59-70.

DCCEE. (2012). Living greener, Australian Government: Department of Climate Change and Energy Efficiency. Accessed on 4 September 2012, from, http://www.livinggreener.gov.au

De Young, R. (2000). New ways to promote proenvironmental behavior: Expanding and evaluating motives for environmentally responsible behavior. Journal of Social Issues, 56(3), 509-526.

Denise, F. (2008). NSW TravelSmart schools program 2006 - 2007: Summary report: Sydney, NSW: Report prepared for the New South Wales Government Premier's Council for Active Living.

DEWHA. (2008). Australian Sustainable Schools Initiative: A partnership of the Australian Government, the states and territories. Canberra, ACT: Australian Government Department of the Environment, Water, Heritage and the Arts.

Dillon, J., \& Huang, J. (2010). Education for sustainable development: Opportunity or threat? School Science Review, 92(338), 39-44.

DoE. (2012a). AuSSI - WA: About the intitiative, Government of Western Australia, Department of Education. Accessed on 17 July 2012, from http://www.det.wa.edu.au/curriculumsupport/sustainableschools/detcms/navigati on/about-the-initiative/

DoE. (2012b). AuSSI - WA: Key elements rubric, Government of Western Australia, Department of Education. Accessed on 17 July 2012, from http://www.det.wa.edu.au/curriculumsupport/sustainableschools/detcms/schoolsupport-programs/sustainable-schools/aussi-wa-toolkit/documents/review-planand-evaluate-docs/key-elements-rubric-

pdf.en?oid=com.arsdigita.cms.contenttypes.FileStorageItem-id-1850829

DoE. (2012c). AuSSI - WA: Participating schools, Government of Western Australia, Department of Education. Accessed on 17 July 2012, from http://www.det.wa.edu.au/curriculumsupport/sustainableschools/detcms/navigati on/about-the-initiative/participating-schools/

DoE. (2012d). AuSSI - WA: Toolkit. review, plan and celebrate, Government of Western Australia, Department of Education. Accessed on 17 July 2012, from http://www.det.wa.edu.au/curriculumsupport/sustainableschools/detcms/navigati on/aussi-wa-toolkit/ 
DoE. (2012e). School improvement and accountability framework, Government of Western Australia, Department of Education. Accessed on 26 August 2012, from http://www.det.wa.edu.au

DoE. (2012f). School reports, Government of Western Australia, Department of Education. Accessed on 26 August 2012, from http://www.det.wa.edu.au

Dow, V., \& Prabawa, K. (2012). Research into education for sustainability in WA high schools: Perth, WA: A report prepared by EcoChange Consulting for the Community Education Branch of the Western Australian Department of Environment and Conservation.

DPC. (2003). Hope for the future: The Western Australian state sustainability strategy: Perth, WA: Government of Western Australia, Department of the Premier and Cabinet.

DSEWPC. (2012a). Australian Sustainable Schools Initiative (AuSSI), Australian Government: Department of Sustainability, Environment, Water, Population and Communities. Accessed on 12 August 2012, from http://www.environment.gov.au/education/aussi/index.html

DSEWPC. (2012b). What is AuSSI? , Australian Government: Department of Sustainability, Environment, Water, Population and Communities. Accessed on 12 August 2012, from http://www.environment.gov.au/education/aussi/what-isaussi/index.html

Dunlap, R. E., \& Van Liere, K. D. (1978). The new environmental paradigm. Journal of Environmental Education, 9, 10-19.

Dunlap, R. E., Van Liere, K. D., Mertig, A. G., \& Jones, R. E. (2000). Measuring endorsement of the new environmental paradigm: A revised NEP scale. Journal of Social Issues, 56(3), 425-442.

Duvall, J., \& Zint, M. (2007). A review of research on the effectiveness of environmental education in promoting intergenerational learning. The Journal of Environmental Education, 38(4), 14-24.

Eagles, P. F. J., \& Demare, R. (1999). Factors influencing children's environmental attitudes. The Journal of Environmental Education, 30(4), 33-37.

Eames, C., Barker, M., Wilson-Hil, F., \& Law, B. (2010). Investigating the relationship between whole-school approaches to education for sustainability and student learning (Summary): Wellington, NZ: Teaching and Learning Research Institute.

Eames, C., \& Bolstad, R. (2004). The role of partnerships in environmental education in New Zealand schools: Some findings from a recent research project. Paper presented at the New Zealand Association for Environmental Education. Christchurch, New Zealand. Paper retrieved from http://www.nzcer.org.nz/pdfs/12819.pdf

Eames, C., Law, B., Barker, M., Iles, H., McKenzie, J., Patterson, R., . . . Wilson-Hill, F. (2006). Investigating teachers' pedagogical approaches in environmental education that promote students' action competence (Summary): Wellington, NZ: Teaching and Learning Research Initiative.

Eilam, E., \& Trop, T. (2012a). Environmental attitudes and environmental behavior: Which is the horse and which is the cart? Sustainability, 4(9), 2210-2246.

Eilam, E., \& Trop, T. (2012b). Factors influencing adults' environmental attitudes and behaviors and the role of environmental schools in influencing their communities. Education and Urban Society. Advance online publication. doi: $10.1177 / 0013124512447100$.

Eisenhardt, K. M. (1989). Building theories from case study research. The Academy of Management Review, 14(4), 532-550. 
Environment. (2004). Environmental education strategy and action plan: Perth, WA: Government of Western Australia, Department of Environment.

Eppler, M. J. (2006). A comparison between concept maps, mind maps, conceptual diagrams, and visual metaphors as complementary tools for knowledge construction and sharing. Information Visualization, 5(3), 202-210.

Epstein, R. (1991). Skinner, creativity, and the problem of spontaneous behavior. Psychological Science 2(6), 362-370.

Evans, G. W., Brauchle, G., Haq, A., Stecker, R., Wong, K., \& Shapiro, E. (2007). Young children's environmental attitudes and behaviors. Environment and Behavior, 39(5), 635-659.

Evans, N. S., Whitehouse, H., \& Gooch, M. (2012). Barriers, successes and enabling practices of education for sustainability in far North Queensland schools: A case study. The Journal of Environmental Education, 43(2), 121-138.

Evans, S. M., Gill, M. E., \& Marchant, J. (1996). Schoolchildren as educators: The indirect influence of environmental education in schools on parents' attitudes towards the environment. Journal of Biological Education, 30(4), 243-248.

Evrekli, E., İnel, D., \& Balım, A. G. (2010). Development of a scoring system to assess mind maps. Procedia - Social and Behavioral Sciences, 2(2), 2330-2334.

Fabrigar, L. R., Wegener, D. T., MacCallum, R. C., \& Strahan, E. J. (1999). Evaluating the use of exploratory factor analysis in psychological research. Psychological Methods, 4(3), 272-299.

Ferreira, J., Ryan, L., \& Tilbury, D. (2007). Planning for success: Factors influencing change in teacher education. Australian Journal of Environmental Education, 23, 45-55.

Fien, J. (2001). Education for sustainability: Reorientating Australian schools for a sustainable future. In N. Blake, M. Krockenberger, H. Saddler, L. Sandercock, R. Slatyer \& D. Yencken (Eds.), Tela (Vol. 8): Melbourne, Victoria: A report prepared for The Australian Conservation Foundation, The Australian Association for Environmental Education, and The Trust for Young Australians.

Fien, J., \& Tilbury, D. (2002). The global challenge of sustainability. In D. Tilbury, R. B. Stevenson, J. Fien \& D. Schreuder (Eds.), Education and sustainability responding to the global challenge (pp. 1-12). Gland, Switzerland and Cambridge, UK: Commission on Education and Communication, IUCN.

Fishbein, M., \& Ajzen, I. (1975). Belief, attitude, intention and behavior: An introduction to theory and research. Boston, USA: Addison-Wesley Publication Company.

Flowers, R., \& Chodkiewicz, A. (2009). Local communities and schools tackling sustainability and climate change. Australian Journal of Environmental Education, 25, 71-81.

Fontes, P. J. (2004). Action competence as an integrating objective for environmental education. Canadian Journal of Environmental Education, 9(1), 148-162.

Fowler, F. F. (2009). Survey research methods (4th edition). Thousand Oaks, CA: SAGE Publications Inc.

Fritze, J. G., Blashki, G. A., Burke, S., \& Wiseman, J. (2008). Hope, despair and transformation: Climate change and the promotion of mental health and wellbeing. International Journal of Mental Health Systems, 2(13), 1-10.

Funnell, S. C., \& Rogers, P. J. (2011). Purposeful prgram theory: Effective use of theories of change and logic models. San Francisco, CA: Jossey-Bass.

Gardner, J., Szatow, T., Horn, M., \& Quezada, G. (2009). Sustainable living: A review of behavioural influences and policy options for Australia. (Report number P2009/1726): Sydney, NSW: A report prepared for the Commonwealth Scientific and Industrial Research Organisation (CSIRO). 
Garrison, J. (1995). Deweyan pragmatism and the epistemology of contemporary social constructivism. American Educational Research Journal, 32(4), 716-740.

Gerstner, S., \& Bogner, F. X. Y. (2009). Concept map structure, gender and teaching methods: An investigation of students' science learning. Educational Research, 51(4), 425-438.

Glasman, L. R., \& Albarracín, D. (2006). Forming attitudes that predict future behavior: A meta-analysis of the attitude-behavior relation. Psychological Bulletin, 132(5), 778-822.

Goldstein, N. J., \& Cialdini, R. (2007). Using social norms as a lever of social influence. In A. Pratkanis (Ed.), The science of social influence: Advances and future progress (pp. 167-192). New York, USA: Psychology Press.

Gonski, D., Boston, K., Greiner, K., Lawrence, C., Scales, B., \& Tannock, P. (2011). Review of funding for schooling: Final report: Canberra, ACT: A report prepared for the Department of Education, Employment and Workplace Relations.

González-Gaudiano, E. J. (2006). Environmental education: A field in tension or in transition? Environmental Education Research, 12(3-4), 291-300.

Gough, A. (2005). Sustainable schools: Renovating educational processes. Applied Environmental Education and Communication, 4(4), 339-351.

Gough, A. (2006a). A long, winding (and rocky) road to environmental education for sustainability in 2006. Australian Journal of Environmental Education, 22(1), 71-76.

Gough, A. (2006b). Sustainable schools in the UN Decade of Education for Sustainable Development: Meeting the challenge? Southern African Journal of Environmental Education, 23, 48-63.

Gough, A., \& Sharpley, B. (2005). Education for a sustainable future: A national environmental education statement for Australian schools. In A. Cloud (Ed.): Carlton, Victoria: A report prepared for the Australian Government Department of the Environment and Heritage.

Gralton, A., Sinclair, M., \& Purnell, K. (2004). Changes in attitudes, beliefs and behaviour: A critical review of research into the impacts of environmental education initiatives. Australian Journal of Environmental Education, 20(2), 4152.

Grodzinska-Jurczak, M. (2003). Evaluating the impact of a school waste education programme upon students', parents' and teachers' environmental knowledge, attitudes and behaviour. International Research in Geographical and Environmental Education, 12(2), 106-122.

Grøhøj, A., \& Thøgersen, J. (2009). Like father, like son? Intergenerational transmission of values, attitudes, and behaviours in the environmental domain. Journal of Environmental Psychology, 29(4), 414-421.

Grøhøj, A., \& Thøgersen, J. (2012). Action speaks louder than words: The effect of personal attitudes and family norms on adolescents' pro-environmental behaviour. Journal of Econmic Psychology, 33, 292-302.

Guagnano, G. A., Stern, P. C., \& Dietz, T. (1995). Influences on attitude behaviour relationships: A natural experiement with curbside recycling. Environment and Behavior, 27(5), 699-718.

Guba, E. G., \& Lincoln, Y. S. (1989). Fourth generation evaluation. Newburg Park, CA: SAGE Publications Inc.

Guba, E. G., \& Lincoln, Y. S. (2005). Paradigmatic controversies and emerging confluences. In N. K. Denzin \& Y. S. Lincoln (Eds.), The Sage handbook of qualitative research (3rd edition) (pp. 191-215). Thousand Oaks, CA: SAGE Publications Inc. 
Ha, T., \& Santucci, D. (2005). 10 years of recycling: The good, the bad and the ugly. In J. Dee \& G. Van Rijswijk (Eds.): Sydney, NSW: A report prepared for the Planet Ark Environmental Foundation.

Hair, J. F., Black, W. C., Babin, B. J., \& Anderson, R. E. (2010). Multivariate data analysis (7th edition). New York, USA: Macmillion Publishing Company.

Halcomb, E. J., \& Davidson, P. M. (2006). Is verbatim transcription of interview data always necessary? Applied Nursing Research, 19, 38-42.

Hammersley, M. (2008). Troubles with triangulation. In M. M. Bergman (Ed.), Advances in mixed methods research: Theories and applications (pp. 22-36). London, UK: SAGE Publications Inc.

Hansen, D., Peart, J., \& John, G. (2012). Engaging young minds. Addressing school travel challenges through innovation. Paper presented at the Australasian Transport Research Forum. Perth, Australia. Paper retrieved from http://www.atrf.info/papers/2012/2012_Hansen_Peart_John.pdf

Hawcroft, L. J., \& Milfont, T. L. (2010). The use (and abuse) of the new environmental paradigm scale over the last 30 years: A meta-analysis. Journal of Environmental Psychology, 30(2), 143-158.

Hayles, C. S., \& Holdsworth, S. E. (2008). Curriculum change for sustainability

. Journal for Education in the Built Environment, 3(1), 25-48.

Heimlich, J. E., \& Ardoin, N. M. (2008). Understanding behavior to understand behavior change: A literature review. Environmental Education Research, 14(3), 215-237.

Henderson, K., \& Tilbury, D. (2004). Whole-school approaches to sustainability: An international review of whole-school sustainability programs. Canberra, ACT: Report prepared by the Australian Research Institute in Education for Sustainability (ARIES) for the Australian Government Department of the Environment and Heritage.

Hesselink, F., van Kempen, P. P., \& Wals, A. E. J. (2000). ESDebate: International online debate on education for sustainable development: Gland, Switzerland: International Union for the Conservation of Nature (IUCN).

Higgs, A. L., \& McMillan, V. M. (2006). Teaching through modeling: Four schools' experiences in sustainability education. The Journal of Environmental Education, 38(1), 39-53.

Hineline, P. N. (1992). A self-interpretive behavior analysis. American Psychologist 47(11), 1274-1286.

Hines, J. M., Hungerford, H. R., \& Tomera, A. N. (1987). Analysis and synthesis of research on responsible environmental behavior: A meta-analysis. The Journal of Environmental Education, 18(2), 1-8.

Hopkins, C., \& McKeown, R. (2005). Guidelines and recommendations for reorienting teacher education to address sustainability. In UNESCO (Ed.), UN Decade of Education for Sustainable Development (DESD, 2005-2014): Paris, France: United Nations Educational Scientific and Cultural Organisation, Education for Sustainable Development in Action, Technical Paper No. 2.

Horne, D. (1964). The lucky country. Ringwood, Victoria: Penguin Books Australia.

Hsieh, H.-F., \& Shannon, S. E. (2005). Three approaches to qualitative content analysis. Qualitative Health Research, 15(9), 1277-1288.

Hungerford, H., \& Volk, T. (1990). Changing learner behaviour through environmental education. The Journal of Environmental Education, 21(3), 8-21.

Ilich, J. (2008). 2008 review of the Australian Sustainable Schools Initiative - WA (pp. 1-52): Perth, WA: A report prepared for the Australian Sustainable Schools Initiative - WA (AuSSI-WA). 
Îngeç, S. K. (2009). Analysing concept maps as an assessment tool in teaching physics and comparison with the achievement tests. International Journal of Science Education, 31(14), 1897-1915.

IPCC. (2007). Intergovernmental Panel on Climate Change: Summary for policy makers. In S. Solomon, D. Qin, M. Manning, Z. Chen, M. Marquis, K. Averyt, M. Tignor \& H. Miller (Eds.), Climate change 2007: The physical science basis. Contribution of working group 1 to the fourth assessment report of the IPCC: New York: Cambridge University Press.

Jakobowicz, J. M., \& Dabas, N. (2007). Daddy you can save the planet! A colouring book for kids who want to educate their parents. Geneva, Switzerland: United Nations Economic Comission for Europe (UNECE).

Jensen, B. B. (1993). The concepts of action and action competence. Paper presented at the The First International Workshop on the Project Children as Catalysts of Global Environmental Change. Department of Psychology, University of Surrey, Guildford.

Jensen, B. B. (2002). Knowledge, action and pro-environmental behaviour. Environmental Education Research, 8(3), 325-334.

Jensen, B. B. (2004). Environmental and health education viewed from an actionoriented perspective: A case from Denmark. Journal of Curriculum Studies, 36(4), 405-425.

Jensen, B. B., \& Schnack, K. (2006). The action competence approach in environmental education. Environmental Education Research, 3(2), 163-178.

Jickling, B. (2006). The Decade of Education for Sustainable Development: A useful platform? Or an annoying distraction? A canadian perspective. Australian Journal of Environmental Education, 22(1), 99-104.

Jickling, B., \& Spork, H. (1998). Education for the environment: A critique. Environmental Education Research, 4(3), 309-327.

Jickling, B., \& Wals, A. E. J. (2008). Globalization and environmental education: Looking beyond sustainable development. Journal of Curriculum Studies, 40(1), $1-21$.

Jickling, B., \& Wals, A. E. J. (2012). Debating education for sustainable development 20 years after Rio: A conversation between Bob Jickling and Arjen Wals. Journal of Education for Sustainable Development, 6(1), 49-57.

Johnson, S. (2001). The children's voice: Their concerns and search for a role in influencing the environment of the future (Unpublished masters thesis). Curtin University of Technology, Perth, Western Australia.

Kagawa, F. (2007). Dissonance in students' perceptions of sustainable development and sustainability: Implications for curriculum change. International Journal of Sustainability in Higher Education, 8(3), 317-338.

Kennelly, J., Taylor, N., \& Serow, P. (2011). Environmental education and the whole school approach in one Australian primary school. Economic and Environmental Studies, 11(2), 125-143.

Kinchin, I. M., Hay, D. B., \& Adams, A. Y. (2000). How a qualitative approach to concept map analysis can be used to aid learning by illustrating patterns of conceptual development. Educational Research, 42(1), 43-57.

Kind, P., Jones, K., \& Barmby, P. (2007). Developing attitudes towards science measures. International Journal of Science Education, 29(7), 871-893.

Kline, R. B. (2011). Principles and practice of structural equation modelling (3rd edition). New York, USA: The Guilford Press.

Kollmuss, A., \& Agyeman, J. (2002). Mind the gap: Why do people act environmentally and what are the barriers to pro-environmental behavior? Environmental Education Research, 8(3), 239-260. 
Kopnina, H. (2011). Qualitative revision of the new ecological paradigm (NEP) scale for children. International Journal of Environmental Research, 5(4), 1025 1034.

Korporaal, G. (2012, June 1). Booming west wary of eastern states job snobs, The Australian. Retrieved from http://www.theaustralian.com.au

Kraus, S. J. (1995). Attitudes and the prediction of behavior: A meta-analysis of the empirical literature. Personality and Social Psychology Bulletin, 21(1), 58-75.

Krippendorff, K. (2004). Content analysis: An introduction to its methodology. California, USA: SAGE Publications Inc.

Kvale, S., \& Brinkmann, S. (2009). Interviews: Learning the craft of qualitative research interviewing (2nd edition). Thousand Oaks, CA: SAGE Publications Inc.

La Mar, B. (2006). Marine-based ecological education: Marine discovery centres, Millennium Kids, environmental citizenship, and a vision for an eco-camp. (Unpublished masters thesis). (Masters Thesis), Murdoch University, Perth, Western Australia.

Lansdown, G. (2001). Promoting children's participation in democratic descisionmaking: Florence, Italy: UNICEF, United Nations Children's Fund, Innocenti Research Centre.

Lapinski, M. K., \& Rimal, R. N. (2005). An explication of social norms. Communication Theory, 15(2), 127-147.

Larri, L. J. (2006). Comparative assessment: Australian Sustainable Schools Initiative pilot programme in NSW and Victoria. Bendalong, NSW: Prepared by Renshaw-Hitchen \& Associates for the Australian Government Department of the Environment and Heritage.

Larsson, B., Andersson, M., \& Osbeck, C. (2010). Bringing Environmentalism Home: Children's influence on family consumption in the Nordic countries and beyond. Childhood, 17(1), 129-147.

Lawrence, C. (2012, August 24). Gonski, inequality and schools funding: What the debate needs right now, The Conversation. Retrieved from http://theconversation.edu.au

Leeming, F. C., Bracken, B. A., \& Dwyer, W. O. (1995). Chidren's environmental attitude and knowledge scale: Construction and validation. The Journal of Environmental Education, 26(3), 22-33.

Legault, L., \& Pelletier, L. G. (2000). Impact of an environmental education program on students' and parents' attitudes, motivation, and behaviours. Canadian Journal of Behavioural Science, 32(4), 243-250.

Leppänen, J., Haahla, A. E., Lensu, A. M., \& Kuitunen, M. T. (2012). Parent-child similarity in environmental attitudes: A pairwise comparison. The Journal of Environmental Education, 43(3), 162-176.

Levett, C. (2005). Environmental education is more than just planting trees: Developing positive environmental awareness in primary school children. (Unpublished masters thesis). Royal Melbourne Institute of Technology, Melbourne, Victoria.

Leviston, Z., Leitch, A., Greenhill, M., Leonard, R., \& Walker, I. (2011). Australians' views of climate change National research flagships: Canberra, ACT: A report prepared for the Commonwealth Scientific and Industrial Research Organisation's (CSIRO) Social and Economic Sciences Program and the Ecosystem Sciences Division.

Lewandowski, G. W., Ciarocco, N. J., \& Gately, E. L. (2012). The effect of embodied temperature on perceptions of global warming. Current Psychology, 31(3), 318324. 
Lewis, E. (2012). Impact of education for sustainability at a Montessori primary school: From silos to systems thinking. (Unpublished doctoral thesis). Murdoch University, Perth, Western Australia.

Lewis, E., \& Baudains, C. (2007). Whole systems thinking: Education for sustainability at a Montessori school. Eingana, 30(1), 9-11.

Lewis, E., Baudains, C., \& Mansfield, C. (2009). The impact of AuSSI-WA at a primary school. Australian Journal of Environmental Education, 25, 45-57.

Lewis, E., Mansfield, C., \& Baudains, C. (2008). Getting down and dirty: Values in education for sustainability. Issues in Educational Research, 18(2), 138-155.

Li, Y., Johnson, E. J., \& Zaval, L. (2011). Local warming: Daily temperature change influences belief in global warming. Psychological Science, 22(4), 454-459.

Lucas, A. M. (1979). Environment and environmental education: Conceptual issues and curriculum implications. Kew, Victoria: Australia International Press and Publications.

Malgady, R. G., \& Krebs, D. E. (1986). Understanding correlation coefficients and regression. Physical Therapy, 66, 110-120.

Manoli, C. C., Johnson, B., \& Dunlap, R. E. (2007). Assessing children's environmental worldviews: Modifying and validating the new ecological paradigm scale for use with children. The Journal of Environmental Education, 38(4), 3-13.

Matsumoto, D. (2009). The cambridge dictionary of psychology. Cambridge, UK: Cambridge University Press.

Matthies, E., Selge, S., \& Klöckner, C. A. (2012). The role of parental behaviour for the development of behaviour specific environmental norms - The example of recycling and re-use behaviour. Journal of Environmental Psychology, 32, 277284.

McGill, R., Tukey, J. W., \& Larsen, W. A. (1978). Variations of box plots. The American Statistician, 32(1), 12-16.

McGuire, W. J. (1964). Inducing resistance to persuasion: Some contemporary approaches. In L. Berkowitz (Ed.), Advances in experimental social psychology, Volume 1 (pp. 191-229). New York, USA: Academic Press.

McKenzie-Mohr, D. (2000). Promoting sustainable behavior: An introduction to community-based social marketing. Journal of Social Issues, 56(3), 543-554.

McKenzie-Mohr, D. (2011). Fostering sustainable behavior. British Columbia, Canada: New Society Publishers.

McKenzie-Mohr, D., Schultz, P. W., Kotler, P., \& Lee, N. R. (2012). Social marketing to protect the environment: What works. Thousand Oaks, California: SAGE Publications Inc.

McKeown, R., \& Hopkins, C. (2003). EE =/= ESD: Defusing the worry. Environmental Education Research, 9(1), 117-128.

Mertens, D. M. (2009). Research and evaluation in education and psychology: Integrating diversity with quantitative, qualitative, and mixed methods (3rd edition). Thousand Oaks, California: SAGE Publications Inc.

Miles, M. B., \& Huberman, A. M. (1994). Qualitative data analysis: An expanded sourcebook. Thousand Oaks, California: SAGE Publications Inc.

Milfont, T. L. (2009). The effects of social desirability on self-reported environmental attitudes and ecological behaviour. Environmentalist, 29(3), 263-269.

Milfont, T. L., \& Duckitt, J. (2004). The structure of environmental attitudes: A firstand second-order confirmatory factor analysis. Journal of Environmental Psychology, 24(3), 289-303.

Milfont, T. L., \& Duckitt, J. (2010). The environmental attitudes inventory: A valid and reliable measure to assess the structure of environmental attitudes. Journal of Environmental Psychology, 30(1), 80-94. 
MK. (2012). Millennium Kids: About, Millennium Kids. Accessed on 12 August 2012, from http://www.millenniumkids.com.au/?page_id=23

Monroe, M. C. (2003). Two avenues for encouraging conservation behaviors. Human Ecology Review, 10(2), 113-125.

Morse, J. M., Barrett, M., Mayan, M., Olson, K., \& Spiers, J. (2008). Verification strategies for establishing reliability and validity in qualitative research. International Journal of Qualitative Methods, 1(2), 13-22.

Musser, L., \& Malkus, A. (1994). The children's attitudes toward the environment scale. The Journal of Environmental Education, 25(3), 22-26.

Neal, D., Norton, M., \& Ariely, D. (April 2011). Australian attitudes towards wealth inequality and the minimum wage: A national survey of knowledge, attitudes and perceptions of wealth inequality and the minimum wage: Fitzroy, Victoria: A report prepared by Emperica Research for the Australian Council of Trade Unions.

Neuendorf, K. A. (2002). The content analysis guidebook. Thousand Oaks, California: SAGE Publications Inc.

NHMRC. (2007). National statement on ethical conduct in human research: Canberra, ACT: National Health and Medical Research Council in conjuction with The Australian Research Council and The Australian Vice-Chancellors' Committee.

Norgaard, K. M. (2009). Cognitive and behavioral challenges in responding to climate change Development economics -The World Bank: Washington, USA: The World Bank, World Development Report Team.

Nye, M., \& Hargreaves, T. (2009). Exploring the social dynamics of proenvironmental behavior change. Journal of Industrial Ecology, 14(1), 137-149.

O'Donoghue, T., \& Clarke, S. (2010). Leading learning: Process, themes and issues in international contexts. London, UK: Routledge.

Ojala, M. (2011). Hope and climate change: The importance of hope for environmental engagement among young people. Environmental Education Research. Advance online publication. doi:10.1080/13504622.2011.637157, 1-18.

Oreskes, N., \& Conway, E. (2010). Merchants of doubt: How a handful of scientists obscured the truth on issues from tobacco smoke to global warming. New York, USA: Bloomsbury Press.

Pallant, J. (2007). SPSS survival manual: A step-by-step guide to data analysis using SPSS for Windows (3rd edition). Sydney, Australia: Allen \& Unwin.

Palmer, J., \& Neal, P. (1994). The handbook of environmental education. London, UK: Routledge.

Payne, P. (2005). Families, homes and environmental education. Australian Journal of Environmental Education, 21, 81-95.

Pepper, C. M. (2007). Leading for sustainability. (Unpublished doctoral thesis). Murdoch University, Perth, Western Australia.

Pepper, C. M., \& Wildy, H. (2008). Leading for sustainability: Is surface understanding enough. Journal of Educational Administration, 46(5), 613-629.

Polesel, J., Dulfer, N., \& Turnbull, M. (2012). The experience of education: The impacts of high stakes testing on school students and their families - literature review: Sydney, NSW: The Whitlam Institute within the University of Western Sydney.

Potter, S. (2007). Rock hopping, yoga and student empowerment: A case study of a sustainable school. Australian Journal of Environmental Education, 23 13-21.

Preacher, K. J., \& MacCallum, R. C. (2003). Repairing Tom Swift's electric factor analysis machine. Understanding Statistics, 2(1), 13-43. 
Priestley, M. (2010). Australia, China and the global financial crisis. Canberra, ACT: Parliament of Australia, Economics Section. Retrieved from http://www.aph.gov.au

Punch, K. (2010). Introduction to social research: Quantitative and qualitative approaches (2nd edition). London, UK: SAGE Publications Inc.

Ramsey, C. E., \& Rickson, R. E. (1976). Environmental knowledge and attitudes. The Journal of Environmental Education, 8(1), 10-18.

Rea, L. M., \& Parker, R. A. (1997). Designing and conducting survey research: A comprehensive guide. San Francisco, USA: Jossey-Bass Publishers.

RED3. (2005). Evaluation of Australian TravelSmart Projects in the ACT, South Australia, Queensland, Victoria and Western Australia: 2001-2005. Canberra, Australia: Report prepared for the Australian Greenhouse Office in the Australian Government Department of the Environment and Heritage.

Reid, N. (2006). Thoughts on attitude measurement. Research in Science and Technological Education, 24(1), 3-27.

Rennie, L. J. (2007). Learning science outside of school. In S. K. Abell \& N. G. Lederman (Eds.), Handbook of research on science education (pp. 125-167). Mahwah, NJ: Lawrence Erlbaum Associates, Publishers.

Rennie, L. J., Venville, G., \& Wallace, J. (2012). Integrating science, technology, engineering, and mathematics: Issues, reflections, and ways forward. New York, USA: Routledge.

Risen, J. L., \& Critcher, C. R. (2011). Visceral fit: While in a visceral state, associated states of the world seem more likely. Journal of Personality and Social Psychology, 100(5), 777-793.

Robottom, I. (2007). Re-badged environmental education: Is ESD more than just a slogan? Southern African Journal of Environmental Education, 24, 90-96.

Rodebaugh, T. L., Woods, C. M., \& Heimberg, R. G. (2007). The reverse of social anxiety is not always the opposite: The reverse-scored items of the social interaction anxiety scale do not belong. Behaviour Therapy, 38(2), 192-206.

Rogers, E. (1995). Diffusion of innovations (4th edition). New York, USA: The Free Press.

RRT. (2012). Recycle right program: Final report - part 1: Bankstown, NSW: A report produced by the Resource Recovery Team (RRT) for the City Planning and Environment department of the Bankstown City Council.

Rye, J. A., \& Rubba, P. A. (2002). Scoring concept maps: An expert map-based scheme weighted for relationships. School Science and Mathematics, 102(1), 33-44.

Salter, Z., Longnecker, N., \& Venville, G. (2011). Sustainability education at a Perth primary school: What difference does it make anyway? . Paper presented at the 6th biennial World Environmental Education Congress. Brisbane, QLD.

Salter, Z., Venville, G., \& Longnecker, N. (2011). An Australian story: School sustainability education in the lucky country. Australian Journal of Environmental Education, 27(1), 149-159.

Sandell, E. (2012, June 22). Sustainable Australia can start in schools, WA Today. Retrieved from http://www.watoday.com.au

ScepticalScience. (2012). Is there a scientific consensus on global warming? , Sceptical Science. Accessed on 12 August 2012, from http://www.skepticalscience.com/global-warming-scientific-consensusbasic.htm

SCEW. (1974). Project environment: London, UK: Schools Council of England and Wales, Harlow Longman Publishers. 
Schultz, P. W., Nolan, J. M., Cialdini, R. B., Goldstein, N. J., \& Griskevicius, V. (2007). The constructive, destructive, and reconstructive power of social norms. Psychological Science, 18(5), 429-434.

Schultz, P. W., Shriver, C., Tabanico, J. J., \& Khazian, A. M. (2004). Implicit connections with nature. Journal of Environmental Psychology, 24(1), 31-42.

SCSA. (1998). Technology and enterprise: Learning area statement The curriculum framework (pp. 289-320): Western Australian Government, School Curriculum and Standards Authority.

SCSA. (2012). The Australian Curriculum - Implementation, phase 1: F (Pre-primary) 10 English, mathematics, science and history, School Curriculum and Standards Authority. Accessed on 4 September 2012, from http://www.curriculum.wa.edu.au/internet/Australian_Curriculum/Implementati on

Shallcross, T., \& Robinson, J. (2008). Sustainability education, whole school approaches, and communities of action Participation and learning (pp. 299-320): Springer Netherlands.

Shavelson, R. J., Ruiz-Primo, M. A., \& Wiley, E. W. (2005). Windows into the mind. Higher Education, 49(4), 413-430.

Sheehan, P. (2012, August 22). Investments are nearing their peak, but the mining boom isn't over yet, The Conversation. Retrieved from http://theconversation.edu.au/

Smeed, J., Spiller, K., \& Kimber, M. (2009). Issues for principals in high-stakes testing. Principal Matters, 81, 32-34.

Smith, S. T. (2006). Sustainable schools. In D. Tilbury \& K. Ross (Eds.), Living change: Documenting good practice in education for sustainability in NSW: Sydney, NSW: Macquarie University and the Nature Conservation Council.

Speering, W., \& Rennie, L. J. (1996). Students' perceptions about science: The impact of transition from primary to secondary school. Research in Science Education, 26, 283-298.

Stake, R. E. (2005). Qualitative case studies. In N. K. Denzin \& Y. S. Lincoln (Eds.), The Sage handbook of qualitative research (3rd edition) (pp. 443-466). Thousand Oaks, CA: SAGE publications Inc.

Sterling, S. (2003). Whole systems thinking as a basis for paradigm change in education: Explorations in the context of sustainability. (Unpublished doctoral thesis). University of Bath, UK.

Stern, P. C. (2000). New environmental theories: Toward a coherent theory of environmentally significant behavior. The Journal of Social Issues, 56(3), 407424.

Summers, M., Corney, G., \& Childs, A. (2003). Teaching sustainable development in primary schools: An empirical study of issues for teachers. Environmental Education Research, 9(3), 327-346.

Sutherland, D., \& Ham, S. (1992). Child-to-parent transfer of environmental ideology in Costa Rican families: An ethnographic case study. The Journal of Environmental Education, 23(3), 9-16.

Tabachnick, B. G., \& Fidell, L. S. (2007). Using multivariate statistics (5th edition). Boston, USA: Pearson Education.

Taylor, F. (2010). Young people active in communities: Stories from around Australia: Melbourne, Victoria: Australian Youth Research Centre and the Foundation for Young Australians.

Thomson, S., \& De Bortoli, L. (2008). Exploring scientific literacy: How Australia measures up. The PISA 2006 survey of students' scientific, reading and mathematical literacy skills. Camberwell, Victoria: ACER Press, an imprint of Australian Council for Educational Research Ltd. 
Tilbury, D. (1995). Environmental Education for Sustainability: Defining the new focus of environmental education in the 1990s. Environmental Education Research, $1(2), 195-212$.

Tilbury, D. (2004). Rising to the challenge: Education for sustainability in Australia. Australian Journal of Environmental Education, 20(2), 103-114.

Tilbury, D., Coleman, V., \& Garlick, D. (2005). A national review of environmental education and its contribution to sustainability in Australia: School education: Canberra, ACT: Australian Government Department of the Environment and Heritage and Australian Research Institute in Education for Sustainability (ARIES).

Trench, B. (2008). Towards an analytical framework of science communication models: New models, new practices. In D. Cheng, M. Claessens, T. Gascoigne, J. Metcalfe, B. Schiele \& S. Shi (Eds.), Communicating science in social contexts (pp. 119-135). Netherlands: Springer.

Trenwith, C. (2012, April 18). 'If you can't handle the hard work, give up': PM tells Porter, WA Today. Retrieved from http://www.watoday.com.au

Tucci, J., Mitchell, J., \& Goddard, C. (2007). Children's fears, hopes and heroes: Modern childhood in Australia: Melbourne, Victoria: Australian Childhood Foundation.

UNDESA. (1992). Agenda 21, United Nations Department of Economic and Social Affairs: Division for Sustainable Development. Accessed on 23 August 2012, from http://www.un.org/esa/dsd/agenda21/index.shtml

UNESCO. (2002). Teaching and learning for a sustainable future: Module 4: Activity 1, Retrieved from http://www.unesco.org/education/tlsf/

UNESCO. (2005a). The DESD at a glance. UN Decade of Education for Sustainable Development 2005 - 2014: Paris, France: United Nations Educational Scientific and Cultural Organisation, Division for the Promotion of Quality Education.

UNESCO. (2005b). International implementation scheme. UN Decade of Education for Sustainable Development 2005 - 2014: Paris, France: United Nations Educational Scientific and Cultural Organisation, Division for the Promotion of Quality Education.

UNESCO. (2007). The first two years. UN Decade of Education for Sustainable Development (DESD 2005-2014): Paris, France: United Nations Educational Scientific and Cultural Organisation, Division for the Coordination of UN Priorities in Education.

UNICEF. (20 November 1989). The United Nations convention on the rights of the child, resolution 25, session 44: London, UK: United Nations Children's Fund. Ratified by the United Nations General Assembly.

Uzzell, D. (1999). Education for environmental action in the community: New roles and relationships. Cambridge Journal of Education, 29(3), 397-413.

Uzzell, D., Davallon, J., Jensen, B. B., Gottesdiener, H., Fontes, J., Kofoed, J., . . . Vognsen, C. (1994). Children as catalysts of environmental change (Final report, number DGXII/D-5) Research on Economic and Social Aspects of the Environment (SEER): Brussels, Belgium: Report to European Commission.

Uzzell, D., \& Rutland, A. (1993). Intergenerational social influence: Changing environmental competence and performance in children and adults. Paper presented at the The Second International Workshop on Children as Catalysts of Global Environmental Change. Portugal, CEFOPE University of Braga.

Vaughan, C., Gack, J., Solorazano, H., \& Ray, R. (2003). The effect of environmental education on schoolchildren, their parents, and community members: A study of intergenerational and intercommunity learning. The Journal of Environmental Education, 34(3), 12-21. 
Venville, G., Sheffield, R., \& Rennie, L. J. (2008). Implementation of an integrated, community-based science project: Balancing civic responsibility and subject specialization. Paper presented at the American Education Research Association Annual Conference. New York.

Venville, G., Sheffield, R., Rennie, L. J., \& Wallace, J. (2008). The writing on the wall: Classroom context, curriculum implementation, and student learning in integrated, community-based science projects. Journal of Research in Science Teaching, 45(8), 857-880.

WACOSS. (2011). The rising cost of living in WA. West Perth, WA: Western Australian Council of Social Service Inc.

Wals, A. E. J. (2009). Review of contexts and structures for education for sustainable development: 2009. In UNESCO (Ed.), UN Decade of Education for Sustainable Development (DESD, 2005-2014): Paris, France: United Nations Educational Scientific and Cultural Organisation, Division for the Coordination of United Nations Priorities in Education.

Wigglesworth, G., Simpson, J., \& Loakes, D. (2011). NAPLAN language assessments for Indigenous children in remote communities: Issues and problems. Australian Review of Applied Linguistics, 34(3), 320-343.

Willis, C. L., \& Miertschin, S. L. (2006). Mind maps as active learning tools. Journal of computing sciences in colleges, 21(4), 266-272.

Wooltorton, S. (2004). Local sustainability at school: A political reorientation. Local Environment, 9(6), 595-609.

Worthington, R. L., \& Whittaker, T. A. (2006). Scale development research: A content analysis and recommendations for best practices. The Counseling Psychologist, 34(6), 806-838.

Yin, R. K. (1989). Case study research: Design and methods. California, USA: SAGE Publications Inc.

Yin, R. K. (2008). Case study research: Design and methods (4th edition). Thousand Oaks, California: SAGE Publications Inc.

Young, R. (2012). Don't Know Responses in Survey Research. (Doctor of Philosophy), The Pennsylvania State University.

Zeller, R. A. (1997). Validity. In J. P. Keeves (Ed.), Educational research, methodology and measurement: An international handbook (2nd edition) (pp. 822-829). Oxford, UK: Elsevier.

Zimmermann, L. (1996). The development of an environmental values short form. The Journal of Environmental Education, 28(1), 32-37.

Zipp, G. P., Maher, C., \& D'Antoni, A. V. (2009). Mind maps: Useful schematic tool for organising and integrating concepts of complex patient care in the clinic and classroom. Journal of College Teaching and Learning, 6(2), 59-68. 
APPENDIX $1.1 \quad$ Interview Questions for Principals

\begin{tabular}{|c|c|c|}
\hline \multicolumn{2}{|c|}{ Today's date } & \multirow{3}{*}{$\begin{array}{l}\text { Years of being a principal total } \\
\text { Number of previous principal jobs \& names of } \\
\text { those schools }\end{array}$} \\
\hline \multicolumn{2}{|l|}{ Name } & \\
\hline \multicolumn{2}{|l|}{ Age } & \\
\hline $25-35 \square$ & 35-45 $\square \quad 45-55 \square \quad 55-65 \square$ & \\
\hline \multicolumn{2}{|c|}{ Postcode where you live } & \\
\hline \multicolumn{2}{|l|}{ School } & \\
\hline \multicolumn{2}{|c|}{ Years of being principal at this school } & Years of teaching prior \\
\hline
\end{tabular}

\section{Climate Change:}

1. Do you have an opinion about climate change and the science behind it? If yes, please explain...

2. Are you concerned about the implications of climate change and global warming? Do you think it will affect us here in Perth?

3. How have you learnt about these environmental issues?

a. For example: media (TV, internet, radio, newspapers), school, parents, friends

b. Do you feel you can trust these sources?

\section{Teaching focus:}

4. Do any of your staff teach anything about the environment or sustainability?
a. If not: why? Are there barriers like limited time, money, etc? Or lack of interest by staff?
b. If yes: continue with questions below...

AuSSI + School + school community:

5. Please describe the schools journey towards being a sustainable school
a. How did it all start? When, why, who, what?
b. How have you worked with your staff year to year to improve the focus?
c. When did you become an AuSSI school?
d. Have you collaborated with any non-government groups? If so, how, who, what, when, why?
e. What are your favourite memories \& milestones?
f. What are your school's plans for future? 
6. What are some of the key features in the set up and maintenance sustainability initiatives in the school? (leadership, staff motivation \& willingness, gardener, supportive parents, etc)

7. Have you noticed differences in the children's attitudes or behaviour towards the environment and/or the community since your school adopted a sustainability focus?

8. Overall, do you think involvement with AuSSI (and Millennium Kids) has made changes to the school and school community? Positive or negative?

9. Part of the purpose of my research is to investigate ways that the environmental initiatives the school is involved in can influence what families do at home. I would very much like your opinion about how schools could better work with families to become environmentally friendly.

a. Do many of the children's parents support these environmental activities? If so, in what ways do they support them?

b. Are there factors that might make some parents more supportive than others?

Other:

10. Is there anything else you would like to tell me that we haven't discussed yet? 
APPENDIX 1.2

Interview Questions for

\section{Lead Sustainability Teachers}

$\begin{array}{lll}\text { Today's date } & \text { Year level that you teach } \\ \text { Name } & \text { School } \\ \text { Age } & \text { Years of teaching total } \\ 25-35 \square \quad 35-45 \square \quad 45-55 \square \quad 55-65 \square & \text { Years of teaching at this school } \\ \text { Postcode where you live } & \end{array}$

\section{Climate Change:}

1. Do you have an opinion about climate change and the science behind it? If yes, please explain...

2. Are you concerned about the implications of climate change and global warming? Do you think it will affect us here in Perth?

3. How have you learnt about these environmental issues?
a. For example: media (TV, internet, radio, newspapers), school, parents, friends
b. Do you feel you can trust these sources?

\section{Your teaching:}

4. Do you teach anything about the environment or sustainability?
a. If not: why? Are there barriers like limited time, money, etc? Or lack of interest by staff?

5. Please describe a program that gives a good example of what you teach on sustainability.
a. Did you organise this?
b. Who decides what projects your class will be involved in?
c. Do you feel supported by your school to undertake these activities?

6. How do you program your units of work within other learning areas across one week? Are they integrated? If so how?

7. Do you think your children learn most about these topics in your classroom or through other incidental experiences around the school?
a. Have you noticed differences in the children's attitudes or behaviour towards the environment since they started in your class?

8. What was your focus area at the time of the survey? E.g. water, waste, air... 


\section{AuSSI + School + school community:}

9. Please describe the schools journey towards being a sustainable school

a. How did it all start? When, why, who, what?

b. How have you worked with your staff year to year to improve the focus?

c. When did you become an AuSSI school?

d. Have you collaborated with any non-government groups? If so, how, who, what, when, why?

e. What are your favourite memories \& milestones?

f. What are your school's plans for future?

10. What are some of the key features in the set up and maintenance sustainability initiatives in the school? (leadership, staff motivation \& willingness, gardener, supportive parents, etc)

11. Have you noticed differences in the children's attitudes or behaviour towards the environment and/or the community since your school adopted a sustainability focus?

12. Overall, do you think involvement with AuSSI (and Millennium Kids) has made changes to the school? Positive or negative?

13. Part of the purpose of my research is to investigate ways that the environmental initiatives the school is involved in can influence what families do at home. I would very much like your opinion about how schools could better work with families to become environmentally friendly.

a. Do many of the children's parents support these environmental activities? If so, in what ways do they support them?

b. Are there factors that might make some parents more supportive than others?

\section{Other:}

14.Is there anything else you would like to tell me that we haven't discussed yet? 


\section{APPENDIX 1.3 Interview Questions for Teachers}

\begin{tabular}{|ll|}
\hline Today's date & Year level that you teach \\
Name & School \\
Age & Years of teaching total \\
$25-35 \square$ 35-45 $\square$ 45-55 $\square$ 55-65 $\square$ & Years of teaching at this school \\
Postcode where you live & \\
\hline
\end{tabular}

\section{Climate Change:}

1. Do you have an opinion about climate change and the science behind it? If yes, please explain...

2. Are you concerned about the implications of climate change and global warming? Do you think it will affect us here in Perth?

3. How have you learnt about these environmental issues?

a. For example: media (TV, internet, radio, newspapers), school, parents, friends

b. Do you feel you can trust these sources?

\section{Your teaching:}

4. Do you teach anything about the environment or sustainability?

a. If not: why? Are there barriers like limited time, money, etc? Or lack of interest by staff?

5. Please describe a program that gives a good example of what you teach on sustainability.

a. Did you organise this?

b. Who decides what projects your class will be involved in?

c. Do you feel supported by your school to undertake these activities?

6. How do you program your units of work within other learning areas across one week? Are they integrated? If so how?

7. Do you think your children learn most about these topics in your classroom or through other incidental experiences around the school?

a. Have you noticed differences in the children's attitudes or behaviour towards the environment since they started in your class?

8. What was your focus area at the time of the survey? E.g. water, waste, air... 


\section{AuSSI + School + school community:}

9. Please comment on the school's involvement with AuSSI (and Millennium Kids) using the SWOT method:
a. Strengths:
b. Weaknesses:
c. Opportunities:
d. Threats:

10. Overall, do you think involvement with AuSSI (and Millennium Kids) has made changes to the school? Positive or negative?

11. Part of the purpose of my research is to investigate ways that the environmental initiatives the school is involved in can influence what families do at home. I would very much like your opinion about how schools could better work with families to become environmentally friendly.

a. Do many of the children's parents support these environmental activities? If so, in what ways do they support them?

b. Are there factors that might make some parents more supportive than others?

Other:

12. Is there anything else you would like to tell me that we haven't discussed yet? 
APPENDIX 1.4

Interview Questions for Parents

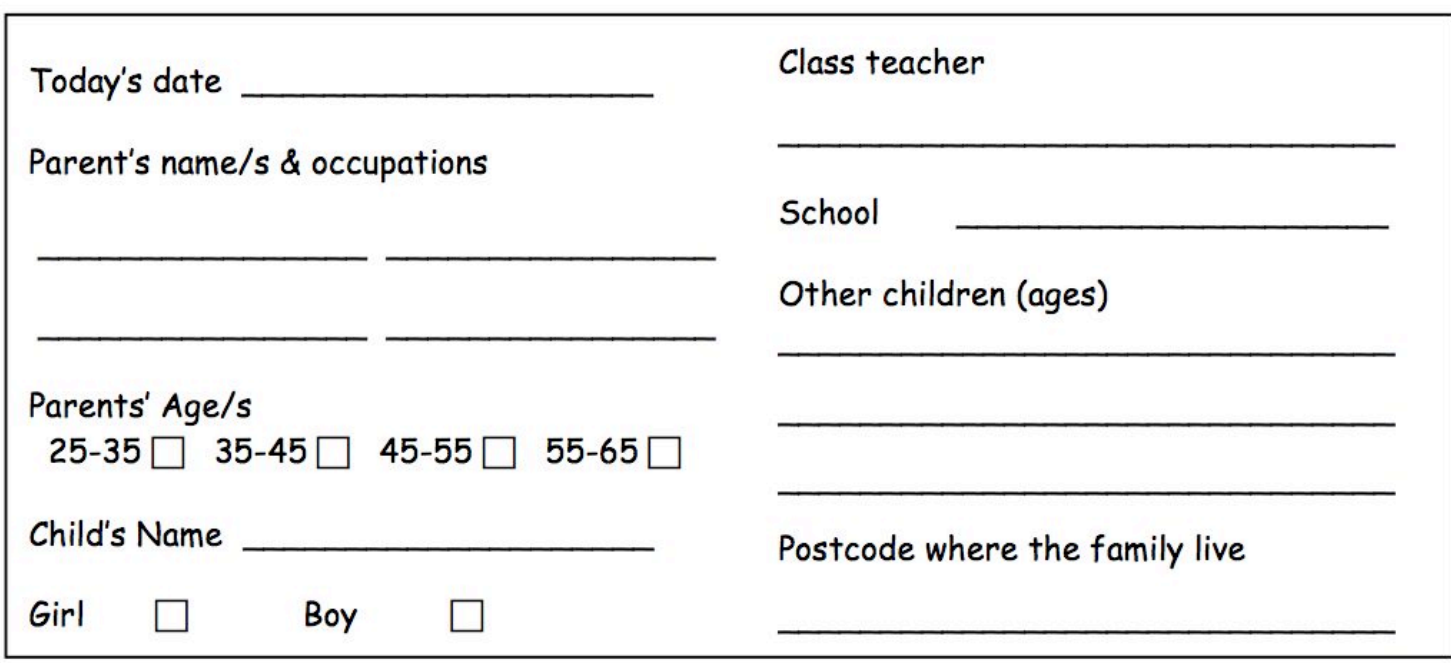

\section{Climate Change:}

1. Do you have an opinion about climate change and the science behind it? If yes, please explain...

2. Are you concerned about the implications of climate change and global warming? Do you think it will affect us here in Perth?

3. How have you learnt about these environmental issues?

a. For example: media (TV, internet, radio, newspapers), school, parents, friends

b. Do you feel you can trust these sources?

4. Do you talk with your children about this topic? Is this a topic that you want them to learn about at school?

\section{From School:}

5. Do your children talk with you about the environmental experiences they have at school? What do they say?

a. Do you value your child's participation in these kinds of activities at school? If so, why?

6. Have any of your children ever brought home environmental ideas from school? If so, what kinds of things?

a. Have you changed the way you do things at home as a result?

7. Have you noticed differences in your child/children's attitudes or behaviour towards the environment since they started at this school?

8. Do you think your children will keep these behaviours into high school? 


\section{At home:}

9. What kind of things do you do at home to care for the environment? (Save power, conserve water, decrease air pollution, and minimise waste)
a. How important are these to you?
b. Are they easy or difficult to maintain at home?
c. How do you encourage your family to be involved?

10.Please tell me more about how you deal with your waste at home. (3R's)

11. How have you learnt about environmental initiatives that you can do at home?

12. Would you like help setting up environmental initiatives at home? What kind of help? (Information, courses, groups, websites, etc)

\section{Parents \& School:}

13. Do you know about the school's involvement with AuSSI -the Australian Sustainable School's Initiative and Millennium Kids?

a. If yes, what changes has this made to the school? Positive or negative?

14. Part of the purpose of my research is to investigate ways that the environmental initiatives the school is involved in can influence what families do at home. I would very much like your opinion about how schools could better work with families to become environmentally friendly.

15. Have you \& your spouse been involved with the school initiatives? If yes, what has made you want to get involved?

\section{Local Community:}

16. Do you or your family support local community initiatives to help the natural environment? If so, what kinds of things?

a. For example: weeding at a local nature reserve, planting a veggie patch in a community garden, clean up Australia Day, etc.

\section{Other:}

Is there anything else you would like to tell me that we haven't discussed yet? 


\section{APPENDIX 1.5 Interview Questions for Students}

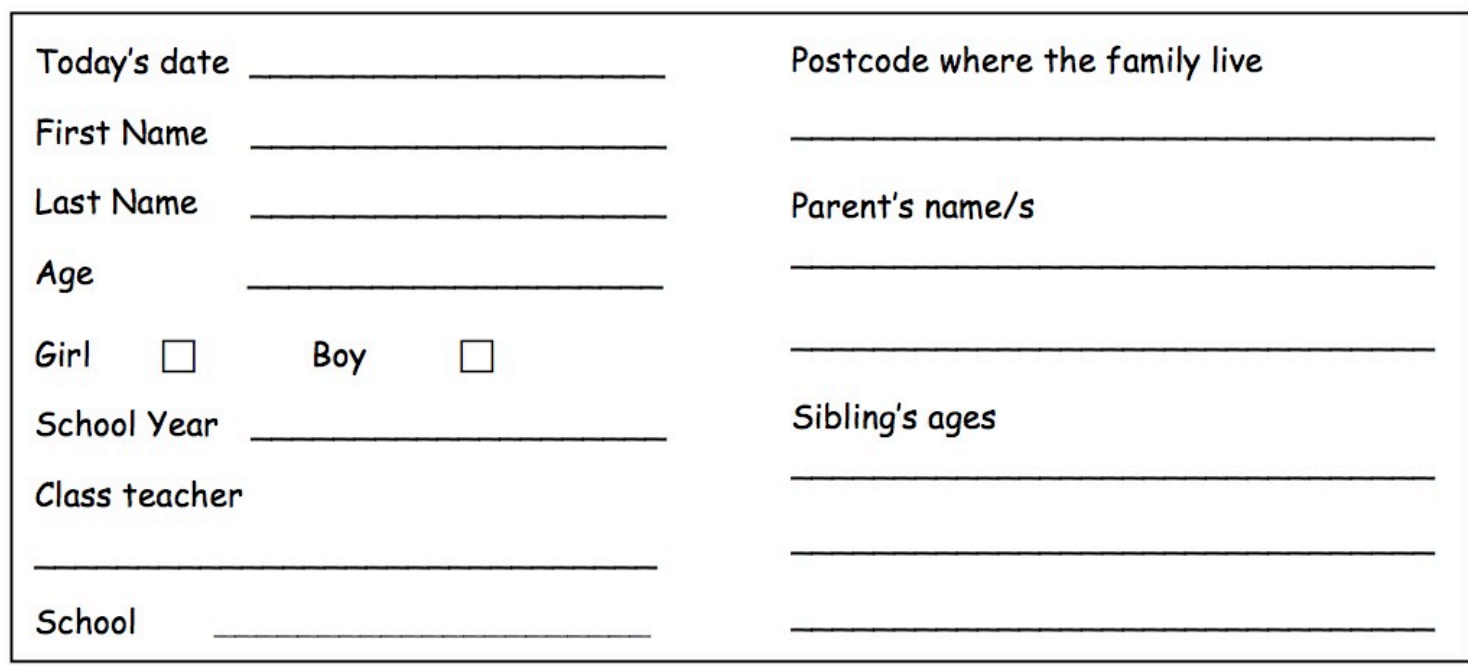

\section{Climate Change:}

1. What do you know about climate change?

2. How do you find out about climate change?

a. For example: media (TV, internet, radio, newspapers), school, parents, friends

3. How important is this topic to you? How do you feel when you think about it? What do you think people can do to stop it?

\section{From the survey:}

4. In your survey you said that at school you learn often about Recycling and Composting. I'm really interested to know more:

a. Give me an example, When did you do this, Who with -guest speaker or normal class, What did you do, Did it make you do anything differently or think differently, How did it make you feel?

b. Who, What, Where, When, Why, How

c. Have you learned about this more in the past with another teacher? Tell me more... Would you like to learn about it more with your current teacher? Tell me more...

5. You said that these environmental experiences are important to you. Can you tell me more about this? Why is that? 


\section{What you and your family do at home:}

6. In your survey you said you and your family do some things at home like to care for the environment.
a. Which of these is your favourite? Tell me more about when you do this?
b. Do you remember when your family started doing this at home? Do you know why?
c. How did you learn about these environmental actions you can do at home?
d. Who, What, Where, When, Why, How

7. Have you learned anything at school that helped your family start or keep doing these things at home? Tell me more...

8. Have your parents, grandparents or other family members taught you about things you can do at home to care for the environment? Tell me more...

e. For example: doesn't your Mum make you get out of the shower quickly? Or turn off lights when you're not in the room?

9. Is it important or not important to you to keep up these environmental actions at home? Why? Who should do these things?

10.Is it easy or difficult for you to keep up these environmental actions at home? What makes it easy or difficult? Why?

11.What would make it easier?

a. For example: help from parents, time, more information

\section{Local Community:}

12. Have you or your family ever worked with other people to care for the environment, outside of school time? If, yes, tell me more about what you did, how often, where, and who with.

a. For example: weeding at a local nature reserve, planting a veggie patch in a community garden, etc.

\section{Other:}

13.Is there any other thing you want to tell me about what you do to help the environment? Or something else you know? 
ApPendix 2 - Mind MAP Templates ANd Coding Materials

APPENDIX 2.1

Name:

Age:

Year:

Class Teacher:

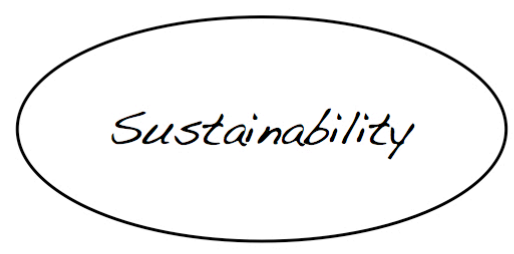

Things I can do to

help the environment

APPENDIX 2.2

Example Mind-Map

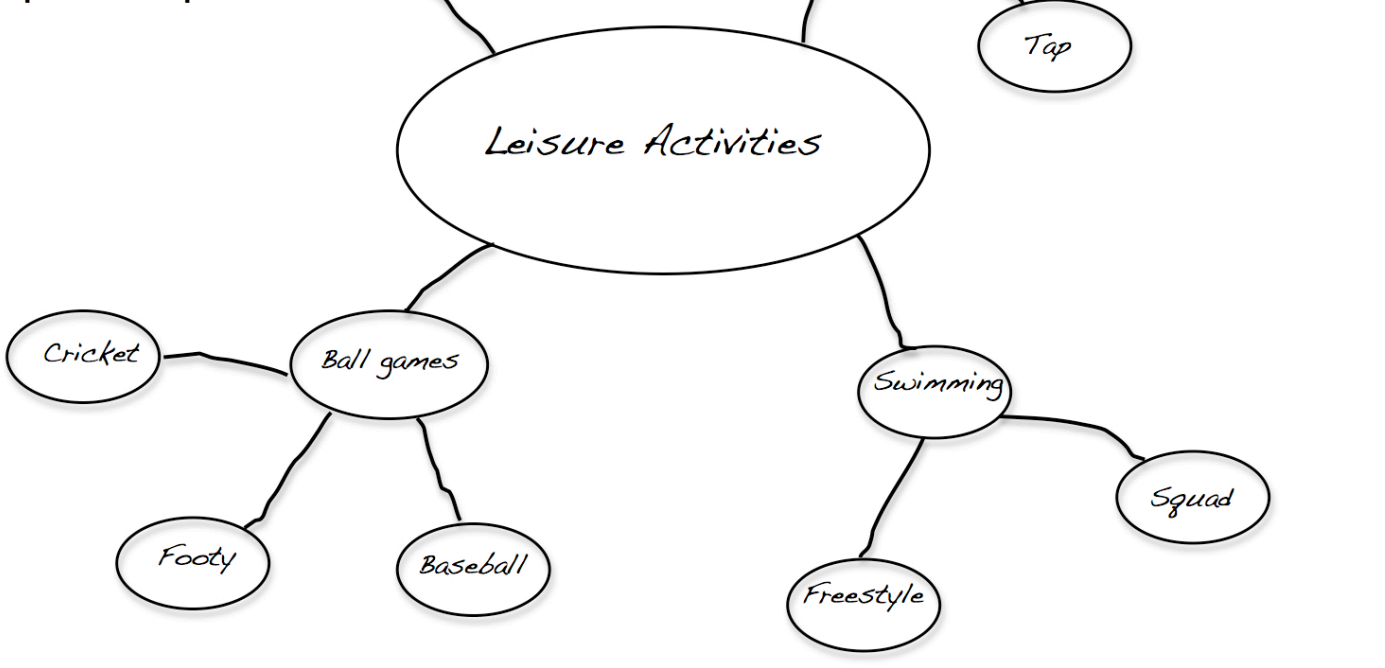




\begin{tabular}{|c|c|c|c|c|c|}
\hline \multicolumn{6}{|c|}{ Mind-Map Coding Guide } \\
\hline \multicolumn{6}{|c|}{ Waste management } \\
\hline Litter pro-active & Litter responsible & Reduce & $\begin{array}{l}\text { Reuse (bags, } \\
\text { clothes, etc) }\end{array}$ & Recycle & Organic waste \\
\hline $\begin{array}{l}\text { pick up litter even } \\
\text { not yours }\end{array}$ & $\begin{array}{l}\text { rubbish in right } \\
\text { bin }\end{array}$ & reduce paper use & \begin{tabular}{|l|} 
reusable \\
shopping \\
bags
\end{tabular} & recycle & worm farms \\
\hline pick up litter & don't litter & zero waste lunch & reuse clothes & yellow bins & compost \\
\hline $\begin{array}{l}\text { pick up your dog's } \\
\text { dropping }\end{array}$ & $\begin{array}{l}\text { don't throw stuff } \\
\text { out of your boat }\end{array}$ & $\begin{array}{l}\text { don't use plastic } \\
\text { bags }\end{array}$ & $\begin{array}{l}\text { reuse } \\
\text { contatainers }\end{array}$ & recycle plastic & \\
\hline & & use less paper & reuse boxes & recycle clothes & \\
\hline \multicolumn{6}{|c|}{ Water conservation } \\
\hline wash full load & $\begin{array}{l}\text { reduce water } \\
\text { wastage }\end{array}$ & reuse water & water health & & \\
\hline $\begin{array}{l}\text { dishwashing=full } \\
\text { load }\end{array}$ & short showers & bucket in shower & $\begin{array}{l}\text { Keeping rivers } \\
\text { clean }\end{array}$ & & \\
\hline $\begin{array}{l}\text { clothes washer = } \\
\text { full load }\end{array}$ & have $1 / 2$ bath & reuse bath water & $\begin{array}{l}\text { looking after } \\
\text { the river }\end{array}$ & & \\
\hline & shower timer & $\begin{array}{l}\text { spare water on } \\
\text { plants }\end{array}$ & $\begin{array}{l}\text { saving the } \\
\text { Swan River }\end{array}$ & & \\
\hline & water saving taps & $\begin{array}{l}\text { wash car on } \\
\text { grass }\end{array}$ & & & \\
\hline & turn off taps & water tank & & & \\
\hline & $\begin{array}{l}\text { don't play with } \\
\text { taps }\end{array}$ & grey water & & & \\
\hline & $\begin{array}{l}\text { sprinkler } \\
\text { restrictions }\end{array}$ & & & & \\
\hline & use pool cover & & & & \\
\hline & $\begin{array}{l}\text { don't water when } \\
\text { raining }\end{array}$ & & & & \\
\hline \multicolumn{6}{|c|}{ Conserving Biodiversity } \\
\hline Plant trees & Plant generally & $\begin{array}{l}\text { Care for animals } \\
\text { and plants }\end{array}$ & $\begin{array}{l}\text { Stop } \\
\text { deforestation }\end{array}$ & $\begin{array}{l}\text { Responsible } \\
\text { land } \\
\text { management }\end{array}$ & Excursions \\
\hline planting trees & planting natives & $\begin{array}{l}\text { don't hit or } \\
\text { break trees }\end{array}$ & $\begin{array}{l}\text { stop cutting } \\
\text { down trees }\end{array}$ & No pesticides & $\begin{array}{l}\text { Naturaliste } \\
\text { Marine Discovery } \\
\text { Centre (NMDC) }\end{array}$ \\
\hline $\begin{array}{l}\text { for every tree } \\
\text { chopped down } \\
\text { plant another tree }\end{array}$ & grow things & $\begin{array}{l}\text { keep the } \\
\text { gardens healthy }\end{array}$ & $\begin{array}{l}\text { don't cut } \\
\text { down too } \\
\text { many trees }\end{array}$ & $\begin{array}{l}\text { build where } \\
\text { trees already } \\
\text { cut down }\end{array}$ & Museum \\
\hline & plant flowers & $\begin{array}{l}\text { look where you } \\
\text { step }\end{array}$ & $\begin{array}{l}\text { save animals } \\
\text { homes }\end{array}$ & $\begin{array}{l}\text { Weed your } \\
\text { garden }\end{array}$ & Zoo \\
\hline & & $\begin{array}{l}\text { don't kill / poach } \\
\text { animals }\end{array}$ & & grow own food & Aquarium \\
\hline & & Give them sun & & No fertilisers & Perth Hills NPC \\
\hline & & Give them space & & $\begin{array}{l}\text { organic } \\
\text { fertiliser }\end{array}$ & \\
\hline & & Water the plants & & $\begin{array}{l}\text { choose } \\
\text { waterwise } \\
\text { plants }\end{array}$ & \\
\hline & & care for animals & & $\begin{array}{l}\text { sustaining } \\
\text { crops }\end{array}$ & \\
\hline & & & & & \\
\hline & & & & & \\
\hline
\end{tabular}




\begin{tabular}{|c|c|c|c|c|c|}
\hline \multicolumn{4}{|c|}{ Energy } & & \\
\hline Switch off & $\begin{array}{l}\text { Reduce personal } \\
\text { energy use }\end{array}$ & $\begin{array}{l}\text { Renewable } \\
\text { energies }\end{array}$ & $\begin{array}{l}\text { Reduce } \\
\text { national } \\
\text { energy use }\end{array}$ & & \\
\hline switch off lights & $\begin{array}{l}\text { open the } \\
\text { windows, don't } \\
\text { use fans }\end{array}$ & wind & $\begin{array}{l}\text { use fossil } \\
\text { fuels less }\end{array}$ & & \\
\hline $\begin{array}{l}\text { Switch off } \\
\text { appliances }\end{array}$ & $\begin{array}{l}\text { don't use the } \\
\text { phone too long }\end{array}$ & hydro & & & \\
\hline & $\begin{array}{l}\text { install energy } \\
\text { saving lights }\end{array}$ & solar & & & $\begin{array}{l}\text { Cultural \& } \\
\text { social }\end{array}$ \\
\hline & gas saving stoves & geothermal & & & wellbeing \\
\hline & $\begin{array}{l}\text { less school } \\
\text { computer time }\end{array}$ & & & & races \\
\hline & $\begin{array}{l}\text { use gas ovens / } \\
\text { BBQs }\end{array}$ & & & & traditions \\
\hline & $\begin{array}{l}\text { don't use the } \\
\text { dryer }\end{array}$ & & & & individuality \\
\hline \multicolumn{3}{|c|}{ Air \& Transport } & & & world vision \\
\hline Reduce pollution & $\begin{array}{l}\text { Transport other } \\
\text { than cars }\end{array}$ & Technology & & & $\begin{array}{l}\text { money for poor } \\
\text { people }\end{array}$ \\
\hline no can deodorant & carpool & Hybrid cars & & & help poor people \\
\hline $\begin{array}{l}\text { reduce carbon } \\
\text { emissions }\end{array}$ & walk & & & & \\
\hline $\begin{array}{l}\text { don't use many } \\
\text { chimneys }\end{array}$ & bus & & & & \\
\hline $\begin{array}{l}\text { don't drive } \\
\text { everywhere }\end{array}$ & train & & & & \\
\hline less aerosole cans & bike & & & & \\
\hline \multicolumn{6}{|c|}{ Philanthropy, Advocacy, Values (for the environment) } \\
\hline Philanthropy & Advocacy & & Values & & \\
\hline $\begin{array}{l}\text { clean up Australia } \\
\text { Day }\end{array}$ & tell everyone & $\begin{array}{l}\text { duty, job, } \\
\text { responsibility }\end{array}$ & $\begin{array}{l}\text { look after the } \\
\text { environment }\end{array}$ & helping & \\
\hline $\begin{array}{l}\text { raise money for } \\
\text { the environment }\end{array}$ & eco-rangers & $\begin{array}{l}\text { helping future } \\
\text { generations }\end{array}$ & $\begin{array}{l}\text { keep it } \\
\text { healthy }\end{array}$ & saving & \\
\hline donate to zoos & $\begin{array}{l}\text { Sustainability } \\
\text { committee }\end{array}$ & help clean up & supporting & keep it clean & \\
\hline \multicolumn{3}{|c|}{ Simple / Confused } & & \multicolumn{2}{|c|}{$\begin{array}{r}\text { Complex } \\
\end{array}$} \\
\hline Confused & \multicolumn{2}{|l|}{ Simple } & & Human Health & Complex idea* \\
\hline $\begin{array}{l}\text { recycle, reduce, } \\
\text { reproduce }\end{array}$ & water & trees & & safety & $\begin{array}{l}\text { have very little } \\
\text { mines }\end{array}$ \\
\hline $\begin{array}{l}\text { fewer electric } \\
\text { sockets }\end{array}$ & soil & alive & & not smoking & less building \\
\hline throw away & plant & pretty & & staying hygenic & no pollution \\
\hline $\begin{array}{l}\text { water plants every } \\
\text { day }\end{array}$ & grow & healthy & & & $\begin{array}{l}\text { Use non-toxic } \\
\text { chemicals }\end{array}$ \\
\hline $\begin{array}{l}\text { ** keep it going } \\
\text { for a long time }\end{array}$ & flowers & & & & \\
\hline $\begin{array}{l}\text { ** sustain for a } \\
\text { long time }\end{array}$ & $\begin{array}{l}\text { trees provide } \\
\text { oxygen }\end{array}$ & & & & $\begin{array}{l}\text { Use friendly } \\
\text { cleaning products }\end{array}$ \\
\hline & factories & & & & \\
\hline \multicolumn{3}{|c|}{$\begin{array}{l}\text { ** These are definitions, and are similar to the } \\
\text { definition of sustainability that I gave to the students. }\end{array}$} & \multicolumn{3}{|c|}{$\begin{array}{l}\text { *A complex idea is one that crosses several } \\
\text { themes } \& \text { is difficult to place. For this reason } \\
\text { 'don't' or 'turn off' can be classed as complex. }\end{array}$} \\
\hline
\end{tabular}




\begin{tabular}{|c|c|c|c|c|c|c|c|c|c|c|c|c|c|}
\hline \multicolumn{5}{|c|}{ APPENDIX 2.4} & \multicolumn{9}{|c|}{ Mind-Map Coding Sheet } \\
\hline \multirow[b]{2}{*}{ ID } & \multirow[b]{2}{*}{ S/HE } & \multirow[b]{2}{*}{ Links } & \multirow[b]{2}{*}{ Hierarchies } & \multirow[b]{2}{*}{ Ideas } & \multirow[b]{2}{*}{ Waste } & \multirow[b]{2}{*}{ Water } & \multirow[b]{2}{*}{$\begin{array}{l}\text { Biodiv } \\
\text { ersity }\end{array}$} & \multicolumn{3}{|c|}{ Themes } & \multirow{3}{*}{$\begin{array}{l}\text { Social/ } \\
\text { Cultural }\end{array}$} & \multirow[b]{2}{*}{$\begin{array}{l}\text { Compl } \\
\text { ex }\end{array}$} & \multirow[b]{2}{*}{\begin{tabular}{|l} 
Simple/ \\
Confus \\
ed
\end{tabular}} \\
\hline & & & & & & & & Energy & \begin{tabular}{|l} 
Air \& \\
Trans \\
port
\end{tabular} & $\begin{array}{l}\text { Values, } \\
\text { Advocacy, } \\
\text { Philanthropy }\end{array}$ & & & \\
\hline & s & & & & & & & & & & & & \\
\hline & HE & & & & & & & & & & & & \\
\hline & s & & & & & & & & & & & & \\
\hline & HE & & & & & & & & & & & & \\
\hline & $\mathrm{s}$ & & & & & & & & & & & & \\
\hline & $\mathrm{HE}$ & & & & & & & & & & & & \\
\hline & $\mathrm{s}$ & & & & & & & & & & & & \\
\hline & $\mathrm{HE}$ & & & & & & & & & & & & \\
\hline & $\mathrm{s}$ & & & & & & & & & & & & \\
\hline & $\mathrm{HE}$ & & & & & & & & & & & & \\
\hline & s & & & & & & & & & & & & \\
\hline & HE & & & & & & & & & & & & \\
\hline & s & & & & & & & & & & & & \\
\hline & $\mathrm{HE}$ & & & & & & & & & & & & \\
\hline & $\mathrm{s}$ & & & & & & & & & & & & \\
\hline & HE & & & & & & & & & & & & \\
\hline & s & & & & & & & & & & & & \\
\hline & $\mathrm{HE}$ & & & & & & & & & & & & \\
\hline & $\mathrm{s}$ & & & & & & & & & & & & \\
\hline & HE & & & & & & & & & & & & \\
\hline & $\mathrm{s}$ & & & & & & & & & & & & \\
\hline & HE & & & & & & & & & & & & \\
\hline & $\mathrm{s}$ & & & & & & & & & & & & \\
\hline & HE & & & & & & & & & & & & \\
\hline & s & & & & & & & & & & & & \\
\hline & HE & & & & & & & & & & & & \\
\hline & s & & & & & & & & & & & & \\
\hline & $\mathrm{HE}$ & & & & & & & & & & & & \\
\hline & s & & & & & & & & & & & & \\
\hline & HE & & & & & & & & & & & & \\
\hline & s & & & & & & & & & & & & \\
\hline & $\mathrm{HE}$ & & & & & & & & & & & & \\
\hline & s & & & & & & & & & & & & \\
\hline & HE & & & & & & & & & & & & \\
\hline & s & & & & & & & & & & & & \\
\hline & HE & & & & & & & & & & & & \\
\hline & $\mathrm{s}$ & & & & & & & & & & & & \\
\hline & $\mathrm{HE}$ & & & & & & & & & & & & \\
\hline
\end{tabular}




\section{Mind-Map Coding Manual}

\section{Directions}

1. Write ID number in column for ID

2. S \& HE: represent separate 'bubbles' and are treated separately

- $\mathrm{S}=$ sustainability

- $\mathrm{HE}=$ things I can do to help the environment

3. Links:

- If the child has drawn any direct links between the bubbles for S \& HE then write the total number of links

- Note: If a child makes links then any ideas \& hierarchies involved on that link belong to both bubbles and are counted for each.

4. Hierarchies: levels of thinking/branches.

- Number of hierarchies is counted by scoring the single highest number of extensions, even if it only occurs once from the bubble.

- If the child has only extended their ideas one level out from the bubble $=$ write 1 in the hierarchies column.

- If the child has extended any idea two levels out $=$ write 2 in the hierarchies column.

- If the child has extended any idea three levels out $=$ write 3 in the hierarchies column.

- If the child has extended any idea four levels out $=$ write 4 in the hierarchies column.

5. Ideas:

- Count the total number of separate ideas the child has written for that bubble.

6. Themes:

- Using the Coding Guide, assign numbers of ideas to each of the themes available for each bubble.

- The number of ideas across all themes should add up to the total number of ideas for that bubble. 


\section{Double Check}

7. Double check that the number of ideas across all themes adds up to the total number of ideas for that bubble. If not, re-count or re-analyse.

\section{Rules}

8. If the student has written an idea that stands alone (no extensions) and the idea is unclear (it has no associated descriptions or actions that help to determine what the child was thinking) $=$ code as 'simple/confused'

- E.g. "water" as opposed to: "recycle water"

- E.g. "grow" as opposed to: "grow native plants"

9. If the student has branched an idea (beyond one level of hierarchy) these are the rules:

- If the original idea can be clearly categorised AND the extended idea is unclear by itself $=$ code the branched idea in the same theme as the original idea.

- E.g. Plant trees --- natives

- If the original idea can be clearly categorised AND the extended idea is clearly different to the original idea $=$ code the extended idea in the appropriate different theme.

- E.g. Conserve water ---- Conserve Paper

- If the original idea is unclear by itself AND the extended idea can be clearly categorised $=$ code the original idea in the same theme as the extended idea.

- E.g. Turn off ---- taps

- If the original idea is unclear by itself AND the extended idea can be clearly categorised BUT there are more extensions than one, which fall across different themes = code the original idea as 'complex'.

- E.g. Turn off ---- taps ---- showers ---- tumble dryer ---- lights

- If the original idea is unclear by itself AND the extended idea is also unclear $=$ code both ideas as 'simple/confused'

- E.g. Natural things ---- water cycle

10. If a student writes 'etc' = ignore \& do not count as an idea. This is not a valid idea.

11. A definition of sustainability is not a valid response = code as 'confused'

- E.g. "Keep it going for a long time" OR "Keep it healthy for a long time"

- These are similar to the definition of sustainability that I gave to the students. 


\section{APPENDIX 3 - SURVEY QUESTIONNAIRES}

APPENDIX 3.1.

\section{Student Survey}

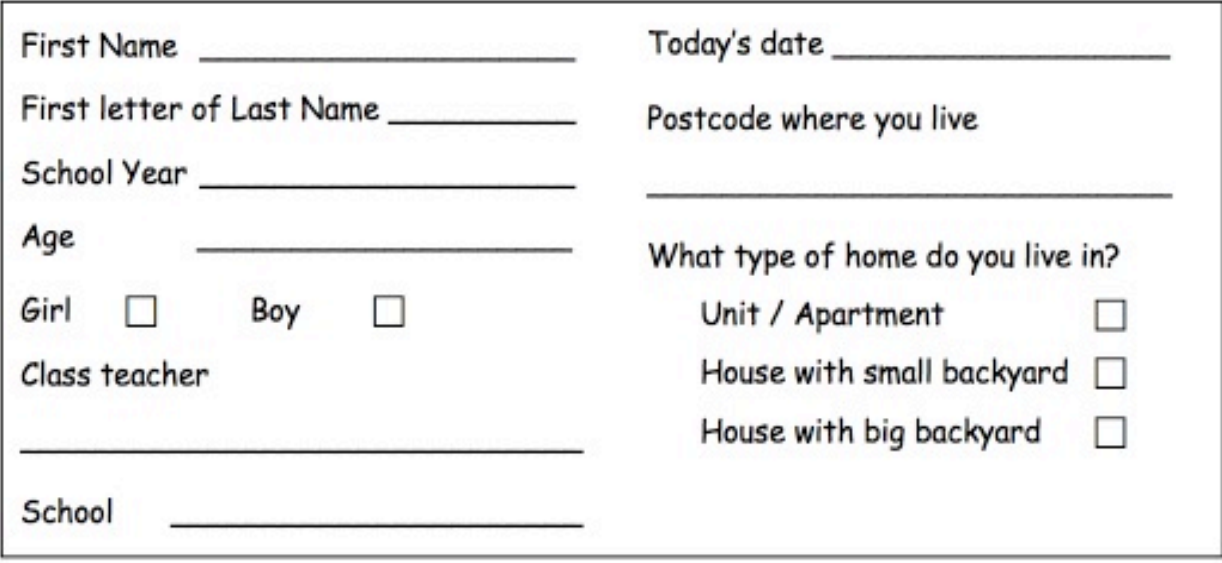

\section{At school}

(For the questions below, circle the options that best suit you)

1) At school I learn about:

a. Reducing household power use

\begin{tabular}{|c|c|c|c|c|c|}
\hline $\begin{array}{l}\text { Don't know } \\
\text { what this is }\end{array}$ & $\begin{array}{l}\text { Never leam } \\
\text { about it }\end{array}$ & $\begin{array}{l}\text { Rarely } \\
\text { (once a year } \\
\text { or more) }\end{array}$ & $\begin{array}{l}\text { Sometimes } \\
\text { (once a term } \\
\text { or more) }\end{array}$ & $\begin{array}{l}\text { Often } \\
\text { (once a week } \\
\text { or more) }\end{array}$ & Every Day \\
\hline \multicolumn{6}{|c|}{ b. Using transport other than cars } \\
\hline $\begin{array}{l}\text { Don't know } \\
\text { what this is }\end{array}$ & $\begin{array}{l}\text { Never leam } \\
\text { about it }\end{array}$ & $\begin{array}{l}\text { Rarely } \\
\text { (once a year } \\
\text { or more) }\end{array}$ & $\begin{array}{l}\text { Sometimes } \\
\text { (once a term } \\
\text { or more) }\end{array}$ & $\begin{array}{l}\text { Often } \\
\text { (once a week } \\
\text { or more) }\end{array}$ & Every Day \\
\hline \multicolumn{6}{|c|}{ c. Re-cycling and composting } \\
\hline $\begin{array}{l}\text { Don't know } \\
\text { what this is }\end{array}$ & $\begin{array}{l}\text { Never leam } \\
\text { about it }\end{array}$ & $\begin{array}{l}\text { Rarely } \\
\text { (once a year } \\
\text { or more) }\end{array}$ & $\begin{array}{l}\text { Sometimes } \\
\text { (once a term } \\
\text { or more) }\end{array}$ & $\begin{array}{l}\text { Often } \\
\text { (once a week } \\
\text { or more) }\end{array}$ & Every Day \\
\hline \multicolumn{6}{|c|}{ d. Growing and eating fruits and vegetables from a home or school garden } \\
\hline $\begin{array}{l}\text { Don't know } \\
\text { what this is }\end{array}$ & $\begin{array}{l}\text { Never leam } \\
\text { about it }\end{array}$ & $\begin{array}{l}\text { Rarely } \\
\text { (once a year } \\
\text { or more) }\end{array}$ & $\begin{array}{l}\text { Sometimes } \\
\text { (once a term } \\
\text { or more) }\end{array}$ & $\begin{array}{l}\text { Often } \\
\text { (once a week } \\
\text { or more) }\end{array}$ & Every Day \\
\hline \multicolumn{6}{|c|}{ e. Reducing household water use } \\
\hline $\begin{array}{l}\text { Don't know } \\
\text { what this is }\end{array}$ & $\begin{array}{l}\text { Never leam } \\
\text { about it }\end{array}$ & $\begin{array}{l}\text { Rarely } \\
\text { (once a year } \\
\text { or more) }\end{array}$ & $\begin{array}{l}\text { Sometimes } \\
\text { (once a term } \\
\text { or more) }\end{array}$ & $\begin{array}{l}\text { Often } \\
\text { (once a week } \\
\text { or more) }\end{array}$ & Every Day \\
\hline
\end{tabular}

2) These environmental experiences are important to me:

$\begin{array}{llll}\text { Not at all Alittle Average } & \text { A lot } & \text { Very } \\ & & & \text { important }\end{array}$




\section{At home}

(For the questions below, circle the options that best suit you AND in the boxes below, write who in your family does each of these things most often. Is it your Mum or Dad, brother or sister, you, or the whole family equally? Write your answer in the box.)

Example: I feed the dog

Don't know Never do what this is this

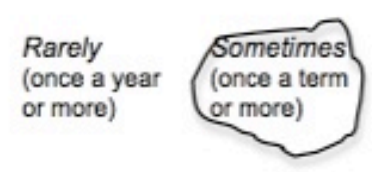

Often

(once a week or more)

Every
Day

My

brother

Who in your family does this most often?

\section{1) At home:}

A. I save power by turning off lights

$\begin{array}{lll}\text { Don't know } & \text { Never do } & \begin{array}{l}\text { Rarely } \\ \text { (once a year } \\ \text { or more) }\end{array}\end{array}$

Sometimes

(once a term or more)

B. I walk, ride my bike or take the bus to school

Don't know Never do

$\begin{array}{ll}\text { Rarely } & \text { Sometimes } \\ \text { (once a year } & \text { (once a term } \\ \text { or more) } & \text { or more) }\end{array}$

C. I re-cycle paper and plastic

\section{Don't know} what this is

$\begin{array}{ll}\text { Never do } & \text { Rarely } \\ \text { this } & \text { (once a year } \\ & \text { or more) }\end{array}$

Sometimes
(once a term

or more)
Often

(once a week or more)

Often

(once a week or more)

Every

Day

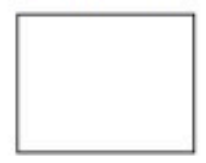

Every

Day

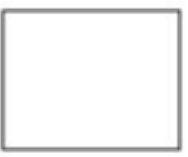

Every

Day

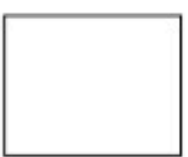

(once a week or more)

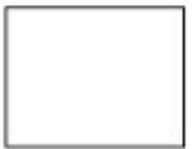

\begin{tabular}{|c|c|c|c|c|}
\hline $\begin{array}{l}\text { on't know } \\
\text { hat this is }\end{array}$ & $\begin{array}{l}\text { Never do } \\
\text { this }\end{array}$ & $\begin{array}{l}\text { Rarely } \\
\text { (once a year } \\
\text { or more) }\end{array}$ & $\begin{array}{l}\text { Sometimes } \\
\text { (once a term } \\
\text { or more) }\end{array}$ & $\begin{array}{l}\text { Often } \\
\text { (once a week } \\
\text { or more) }\end{array}$ \\
\hline
\end{tabular}

E. I eat fruits and vegetables that my family has grown in our home garden

\begin{tabular}{|c|c|c|c|c|}
\hline $\begin{array}{l}\text { on't know } \\
\text { hat this is }\end{array}$ & $\begin{array}{l}\text { Never do } \\
\text { this }\end{array}$ & $\begin{array}{l}\text { Rarely } \\
\text { (once a year } \\
\text { or more) }\end{array}$ & $\begin{array}{l}\text { Sometimes } \\
\text { (once a term } \\
\text { or more) }\end{array}$ & $\begin{array}{l}\text { Often } \\
\text { (once a week } \\
\text { or more) }\end{array}$ \\
\hline
\end{tabular}

F. I have short showers and use a 4 minute shower timer to help keep time

$\begin{array}{cccccc}\begin{array}{l}\text { Don't know } \\ \text { what this is }\end{array} & \begin{array}{l}\text { Never do } \\ \text { this }\end{array} & \begin{array}{l}\text { Rarely } \\ \text { (once a year } \\ \text { or more) }\end{array} & \begin{array}{l}\text { Sometimes } \\ \text { (once a term } \\ \text { or more) }\end{array} & \begin{array}{l}\text { Often } \\ \text { (once a week } \\ \text { or more) }\end{array} & \begin{array}{l}\text { Every } \\ \text { Day }\end{array} \\ \text { G. I save water in other ways } & \begin{array}{llll}\text { Rarely } \\ \text { (once a year } \\ \text { or more) }\end{array} & \begin{array}{l}\text { Sometimes } \\ \text { (once a term } \\ \text { what this is }\end{array} & \begin{array}{l}\text { Often } \\ \text { (once a week } \\ \text { this }\end{array} & \text { or more) } & \text { Day }\end{array}$
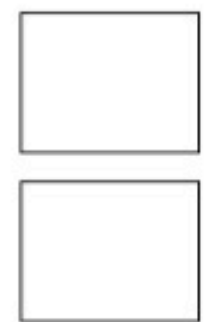

Don't know Never do Rarely or more)

or more)

or more)

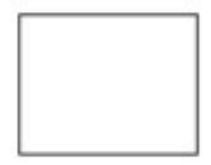


APPENDIX 3.2.

\section{Student Survey}

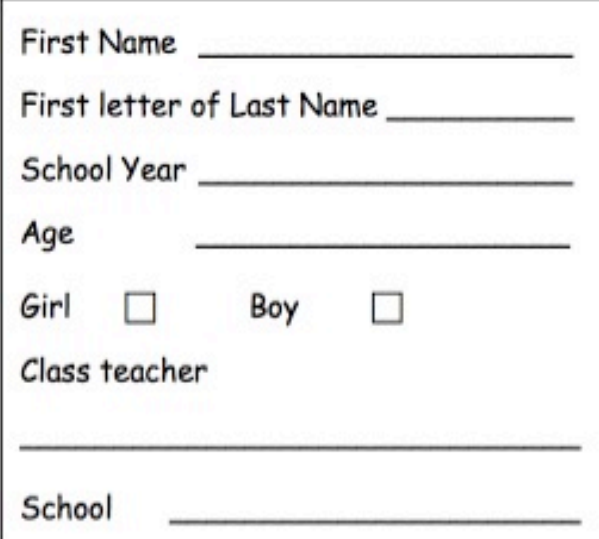

Today's date

Postcode where you live

What type of home do you live in?

Unit / Apartment

House with small backyard

House with big backyard

\section{At school}

(For the questions below, circle the options that best suit you)

1) At school I learn about:

a. Reducing household power use

$\begin{array}{lll}\text { Don't know } & \text { Never leam } & \text { Rarely } \\ \text { what this is } & \text { about it } & \text { (once a year } \\ & & \text { or more) }\end{array}$

b. Using transport other than cars

$\begin{array}{ccc}\begin{array}{c}\text { Don't know } \\ \text { what this is }\end{array} & \begin{array}{l}\text { Never leam } \\ \text { about it }\end{array} & \begin{array}{l}\text { Rarely } \\ \text { (once a year } \\ \text { or more) }\end{array} \\ \text { c. Re-cycling and composting }\end{array}$

Sometimes
(once a term
or more)
Often (once a week or more)

Every Day

$\begin{array}{lll}\text { Don't know } & \text { Neverleam } & \text { Rarely } \\ \text { what this is } & \text { about it } & \text { (once a year } \\ & & \text { or more) }\end{array}$

Sometimes
(once a term
or more)

\section{Often}

(once a week or more)

d. Growing and eating fruits and vegetables from a home or school garden

\begin{tabular}{|c|c|c|c|c|}
\hline $\begin{array}{l}\text { Don't know } \\
\text { what this is }\end{array}$ & $\begin{array}{l}\text { Never leam } \\
\text { about it }\end{array}$ & $\begin{array}{l}\text { Rarely } \\
\text { (once a year } \\
\text { or more) }\end{array}$ & $\begin{array}{l}\text { Sometimes } \\
\text { (once a term } \\
\text { or more) }\end{array}$ & $\begin{array}{l}\text { Often } \\
\text { (once a week } \\
\text { or more) }\end{array}$ \\
\hline
\end{tabular}

e. Reducing household water use

$\begin{array}{lllll}\begin{array}{l}\text { Don't know } \\ \text { what this is }\end{array} & \begin{array}{l}\text { Never leam } \\ \text { about it }\end{array} & \begin{array}{l}\text { Rarely } \\ \text { (once a year } \\ \text { or more) }\end{array} & \begin{array}{l}\text { Sometimes } \\ \text { (once a term } \\ \text { or more) }\end{array} & \begin{array}{l}\text { Often } \\ \text { (once a week } \\ \text { or more) }\end{array}\end{array}$

2) These environmental experiences are important to me:

Not at all

$$
\text { A little }
$$

Average

A lot 


\section{At school}

(For the questions below, circle the options that best suit you)

1) It is important for everyone to do things that help care for the natural environment:

Strongly Disagree Not Sure Agree Strongly

Disagree Agree

2) I am proud of what my school is doing to help care for the environment:

\begin{tabular}{|c|c|c|c|}
\hline $\begin{array}{l}\text { Strongly } \\
\text { Disagree }\end{array}$ & Disagree & Not Sure & Agree \\
\hline
\end{tabular}

3) I think my school should do more to help care for the environment:

\begin{tabular}{|c|c|c|c|}
\hline $\begin{array}{l}\text { Strongly } \\
\text { Disagree }\end{array}$ & Disagree & Not Sure & Agree \\
\hline
\end{tabular}

4) I would like more opportunities at school to do things that help care for the environment:

\begin{tabular}{|c|c|c|c|}
\hline $\begin{array}{l}\text { Strongly } \\
\text { Disagree }\end{array}$ & Disagree & Not Sure & Agree \\
\hline
\end{tabular}

5) I'm only young and it's not my responsibility to care for the environment:

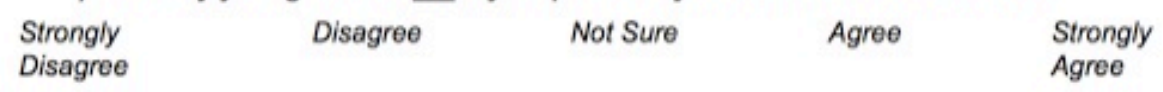

6) I sometimes get tired of learning about environmental topics at school:

\begin{tabular}{|c|c|c|c|c|}
\hline $\begin{array}{l}\text { Strongly } \\
\text { Disagree }\end{array}$ & Disagree & Not Sur & Agre & $\begin{array}{l}\text { Strongly } \\
\text { Agree }\end{array}$ \\
\hline
\end{tabular}

7) My actions can make a positive difference to the environment:

\begin{tabular}{|c|c|c|c|}
\hline $\begin{array}{l}\text { Strongly } \\
\text { Disagree }\end{array}$ & Disagree & Not Sure & Agree \\
\hline
\end{tabular}

8) I know a lot about different ways people can look after the environment:

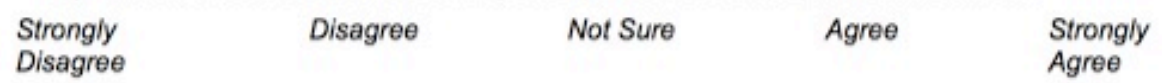

9) Adults listen to my opinions about the environment:

\begin{tabular}{|c|c|c|}
\hline $\begin{array}{l}\text { Strongly } \\
\text { Disagree }\end{array}$ & Disagree & Not Sure \\
\hline
\end{tabular}




\section{At home}

(For the questions below, circle the options that best suit you AND in the boxes below, write who in your family does each of these things most often. Is it your Mum or Dad, brother or sister, you, or the whole family equally? Write your answer in the box.)

Example: I feed the dog

Don't know Never do what this is this

\section{(once a year} or more)

or more)

Often

or more)

Day

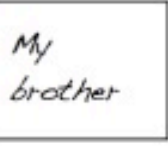

Who in your family does this most often?

\section{1) At home:}

A. I save power by turning off lights

\begin{tabular}{|c|c|c|}
\hline $\begin{array}{l}\text { Don't know } \\
\text { what this is }\end{array}$ & $\begin{array}{l}\text { Never do } \\
\text { this }\end{array}$ & $\begin{array}{l}\text { Rarely } \\
\text { (once a year } \\
\text { or more) }\end{array}$ \\
\hline
\end{tabular}

Sometimes

(once a term or more)

B. I walk, ride my bike or take the bus to school

$\begin{array}{lll}\text { Don't know } & \text { Never do } & \begin{array}{l}\text { Rarely } \\ \text { what this is }\end{array} \\ & \text { this } & \begin{array}{l}\text { once a year } \\ \text { or more) }\end{array}\end{array}$

C. I re-cycle paper and plastic

Don't know what this is

$\begin{array}{ll}\text { Never do } & \text { Rarely } \\ \text { this } & \text { (once a year } \\ & \text { or more) }\end{array}$

Sometimes
(once a term
or more)

\section{Often}

(once a week or more)

\section{Often}

(once a week or more)

Every

Day

Often

(once a week

or more)

Every

(once a term

or more)

D. I put food scraps in a worm farm or compost bin

Don't know

$\begin{array}{lll}\begin{array}{l}\text { Never do } \\ \text { this }\end{array} & \begin{array}{l}\text { Rarely } \\ \text { (once a year }\end{array} & \begin{array}{l}\text { Sometimes } \\ \text { (once a term } \\ \text { or more) }\end{array} \\ & \text { or more) }\end{array}$

Often

(once a week

or more)

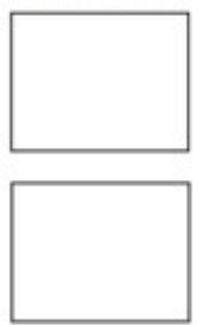

E. I eat fruits and vegetables that my family has grown in our home garden

\begin{tabular}{|c|c|c|c|c|}
\hline $\begin{array}{l}\text { Don't know } \\
\text { what this is }\end{array}$ & $\begin{array}{l}\text { Never do } \\
\text { this }\end{array}$ & $\begin{array}{l}\text { Rarely } \\
\text { (once a year } \\
\text { or more) }\end{array}$ & $\begin{array}{l}\text { Sometimes } \\
\text { (once a term } \\
\text { or more) }\end{array}$ & $\begin{array}{l}\text { Often } \\
\text { (once a week } \\
\text { or more) }\end{array}$ \\
\hline
\end{tabular}

F. I have short showers and use a 4 minute shower timer to help keep time

Don't know

what this is
Never do

this
Rarely

or more)

G. I save water in other ways

Don't know what this is

\section{Never do} this

\section{Rarely}

(once a yea or more)
Sometimes

(once a term or more)

Sometimes
(once a term
or more)

Often

(once a week or more)

Every

Day

$\begin{array}{ll}\text { Often } & \text { Every } \\ \text { (once a week } & \text { Day } \\ \text { or more) } & \end{array}$
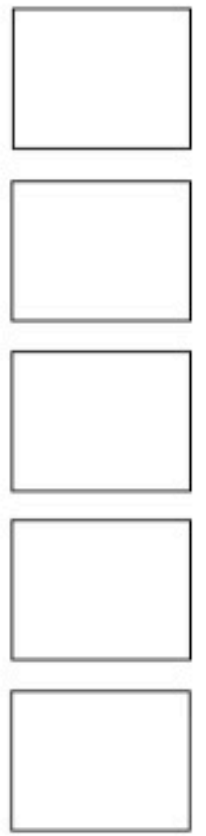


\section{In the World}

(For the questions below, circle the options that best suit you)

1) Plants and animals have as much right as people do to live:

\begin{tabular}{|c|c|c|c|}
\hline $\begin{array}{l}\text { Strongly } \\
\text { Disagree }\end{array}$ & Disagree & Not Sure & Agree \\
\hline
\end{tabular}

2) There are too many (or almost too many) people on earth:

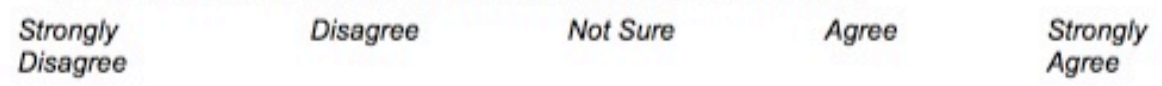

3) People are clever enough to keep from ruining the earth:

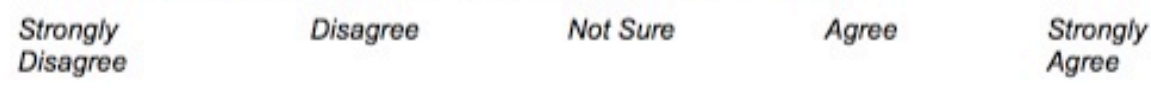

4) People must still obey the laws of nature:

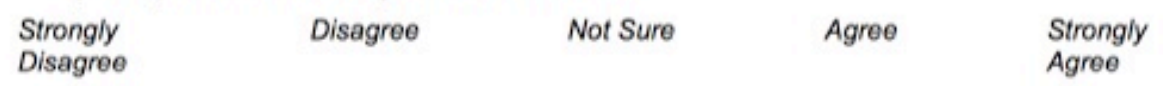

5) When people mess with nature it has bad results:

\begin{tabular}{|c|c|c|}
\hline $\begin{array}{l}\text { Strongly } \\
\text { Disagree }\end{array}$ & Disagree & Not Sure \\
\hline
\end{tabular}

6) Nature is strong enough to handle the bad effects of our modern lifestyle:

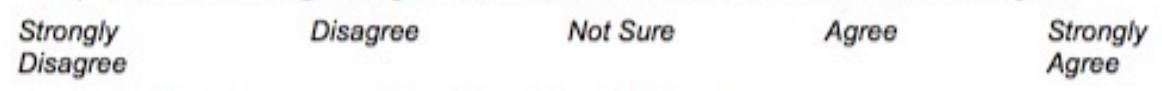

7) People are supposed to rule over the rest of nature:

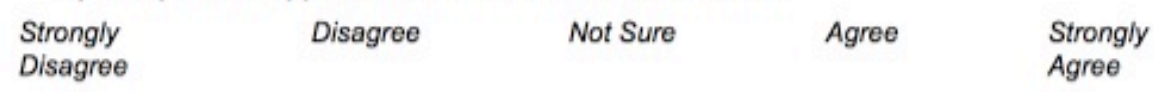

8) People are treating nature badly:

\begin{tabular}{|c|}
\hline $\begin{array}{l}\text { Strongly } \\
\text { Disagree }\end{array}$ \\
\hline
\end{tabular}

9) People will someday know enough about how nature works to be able to control it:

\begin{tabular}{|c|c|c|c|}
\hline $\begin{array}{l}\text { Strongly } \\
\text { Disagree }\end{array}$ & Disagree & Not Sure & Agree \\
\hline
\end{tabular}

10) If things don't change, we will have a big disaster in the environment soon:

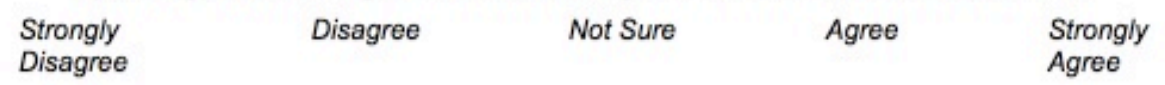




\section{ApPendix 4 - Detailed Student Behaviour Results From LIGHTHOUSE PRIMARY SCHOOL}

Significant results from the chi-square tests indicate the presence and strength of relationships between students' frequency of undertaking seven common proenvironmental behaviours and the three comparison variables: Learning, Importance and Participation. The chi-square results for each behaviour and comparison variables are presented and discussed in the following paragraphs.

Results from 2009 and 2010 were analysed and graphed separately because in 2010 some students had left the school and new students had joined. It was decided to retain all the collected student information and explore group trends rather than analyse specific changes between each students' scores in 2009 and the same students' scores in 2010. Classes and teachers had also changed in 2010, which provided another reason for graphing and analysing 2009 and 2010 data separately and comparing them descriptively. Excluding 2010 from the analysis was considered, but it was decided to retain it and descriptively compare the results from 2009 and 2010 because doing so contributed to the reliability of the data and robustness of the discussion - similarities could be emphasised and differences could be explored. 


\section{High frequency behaviours: Turning off lights and Recycling}

The two behavioural variables, Turning off lights and Recycling were considered high frequency because in 2009 and 2010 greater than 70 percent of students performed them on a weekly basis (Figure 4.9). Appendix 4.1 provides a summary of results from the chi-square tests performed for Turning off lights and Recycling.

Appendix 4.1. Survey results of Year 4, 5, 6 students (end of term 3, 2009) and Year 5, 6, 7 students (beginning of term 4, 2010). Chi-square analyses for power saving and recycling behaviours, $\mathrm{n}_{2009}=161, \mathrm{n}_{2010}=157$, showing relationships between Learning, Importance and Participation.

\begin{tabular}{|c|c|c|c|c|}
\hline & & Learning & Importance & Participation \\
\hline Year & & $\begin{array}{l}\text { Chi-square of } \\
\text { 'learn at school' } \\
\text { and 'do at home' }\end{array}$ & $\begin{array}{l}\text { Chi-square of } \\
\text { 'importance' and } \\
\text { 'do at home' }\end{array}$ & $\begin{array}{l}\text { Chi-square of } \\
\text { 'who at home' and } \\
\text { 'do at home' }\end{array}$ \\
\hline 2009 & $\begin{array}{l}\text { Saving power by } \\
\text { turning off lights }\end{array}$ & Non-significant & $\begin{array}{l}\text { Significant } \\
\text { FET }^{*}(4,161)= \\
15.97, p^{*}=.005 \\
V^{*}=.22\end{array}$ & Non-significant \\
\hline 2010 & $\begin{array}{l}\text { Saving power by } \\
\text { turning off lights }\end{array}$ & Non-significant & $\begin{array}{l}\text { Significant } \\
\text { FET }(4,154)= \\
10.22, p=.020 \\
V=.18\end{array}$ & $\begin{array}{l}\text { Significant } \\
\text { FET }(6,156)= \\
26.28, p<.000 ; \\
V=.29\end{array}$ \\
\hline 2009 & $\begin{array}{l}\text { Recycle paper or } \\
\text { plastic }\end{array}$ & Non-significant & $\begin{array}{l}\text { Significant } \\
\text { FET }(4,161)= \\
37.72, p<.000 \\
V=.34\end{array}$ & $\begin{array}{l}\text { Significant } \\
\text { FET }(6,158)= \\
33.41, p<.000 \\
V=.33\end{array}$ \\
\hline 2010 & $\begin{array}{l}\text { Recycle paper or } \\
\text { plastic }\end{array}$ & Non-significant & $\begin{array}{l}\text { Significant } \\
\text { FET }(4,153)= \\
11.37, p=.020 \\
V=.19\end{array}$ & $\begin{array}{l}\text { Significant } \\
\text { FET }(6,154)= \\
23.00, p<.000 ; \\
V=.27\end{array}$ \\
\hline
\end{tabular}

* FET indicates that Fisher's exact test of significance was used in place of $\chi^{2}$ because more than 20 percent of cells had expected frequencies of less than 5. $p$ is the probability value at .05 significance level. $V$ is Cramer's V - a measure of effect size. Cramer's V effect size range: $.07=$ small, $.21=$ medium, .35 $=$ large.

Turning off lights. Turning off lights at home was practiced on a greater than weekly basis by 84 and 85 percent of upper-primary students at Lighthouse Primary School in 2009 and 2010 respectively and 1 percent of students indicated that they never turned off lights at home (Figure 4.9). Chi-square results indicate that turning off lights at home was not related to Learning but was related to Importance and Participation.

Chi-square results showed significant associations in 2009 and 2010, with medium to small effect sizes, between the importance students place on school environmental experiences and their frequency of turning off lights at home. Appendix 4.2 illustrates these associations and indicates that the majority of students turned off lights on a greater than weekly basis regardless of the importance they placed on school 
environmental experiences, and those that rated school environmental experiences as of little to no importance were only somewhat less likely to have turned off lights on a greater than weekly basis.

In 2010 only, chi-square results show a significant relationship, with medium effect size, between the family member/s who turned off lights most often and the frequency that students turned off lights. Appendix 4.3 depicts that the majority of students turned off lights weekly, in 2009 and 2010, irrespective of which family members were most active. The significant chi-square result from 2010 was likely caused by a very small number of students who reported that no one in their family turned off lights most often and that they turned off lights less than weekly. It was also interesting that in 2010 most students turned off lights weekly if their parents or siblings were the most active family members to do this in their home. Further exploration of the data showed that 94 percent of that category was parents, indicating that parents were far more active in turning off lights regularly than any other family member.

Turning off lights at home on a greater than weekly basis was widespread among students at Lighthouse Primary School, and only somewhat related to Importance and Participation. Further exploration of the data highlighted that 50 and 60 percent of all students in 2009 and 2010 turned off lights daily; indicating that turning off lights at home was a very frequent pro-environmental behaviour for most students probably a daily habit.

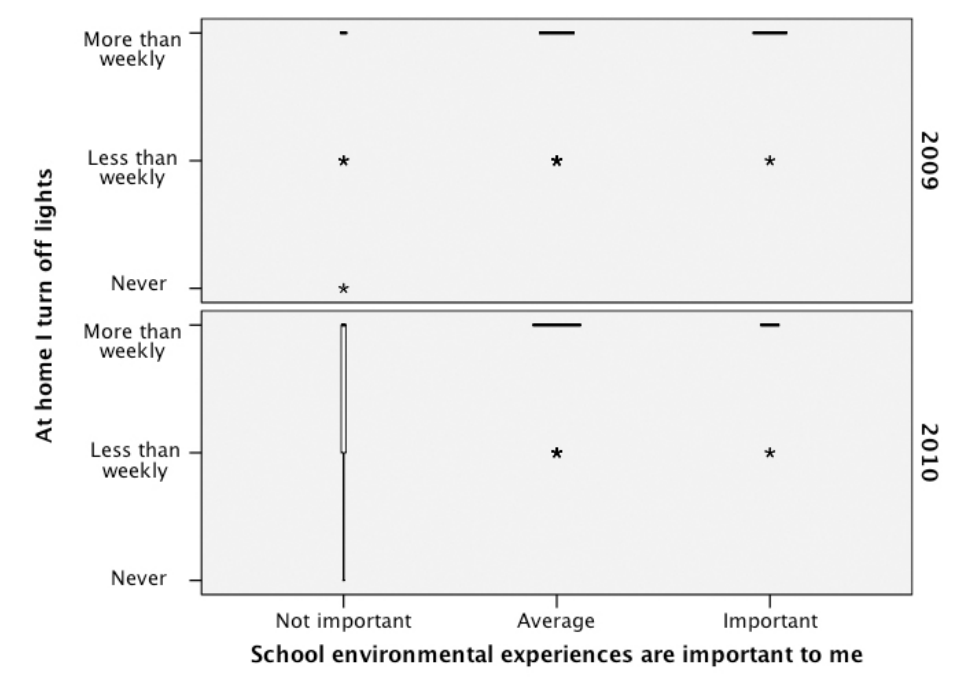

Appendix 4.2. Variable width box plots of students' self-reported frequency of turning off lights at home (y axis) and students' importance of school environmental experiences (x axis). 2009 ( $n$ ${ }_{n o t}$ important $\left.=29, n_{\text {average }}=67, n_{\text {important }}=65\right)$ and $2010\left(n_{\text {not important }}=26, n_{\text {average }}=83, n_{\text {important }}=\right.$ 45). 


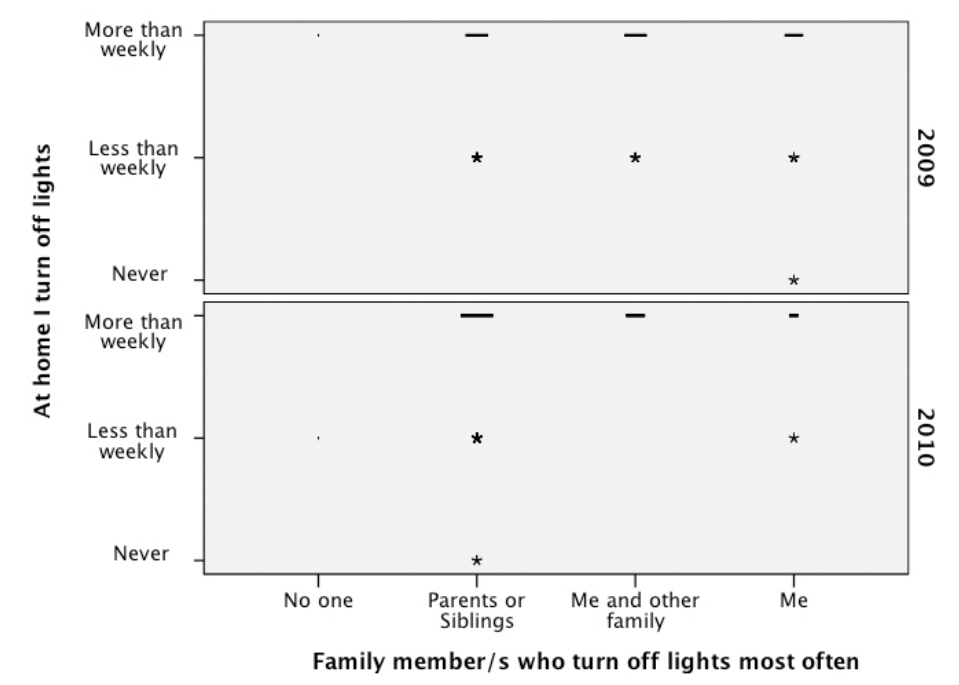

Appendix 4.3. Variable width box plots of students' self-reported frequency of turning off lights at home (y axis) and students' degree of participation in turning off lights at home (x axis). 2009 ( $\left.n_{\text {no one }}=2, n_{\text {parents or siblings }}=56, n_{\text {me and other family }}=56, n_{\text {me }}=46\right)$ and 2010 ( $n_{\text {no one }}=2, n_{\text {parents or }}$ siblings $\left.=82, n_{\text {me and other family }}=48, n_{m e}=24\right)$.

Recycling. Recycling at home was practiced on a greater than weekly basis by 70 and 71 percent of upper-primary students at Lighthouse Primary School in 2009 and 2010 respectively, and four and six percent of students indicated that they never recycled at home (Figure 4.9). Chi-square results indicate that recycling at home was not related to Learning and was related to Importance and Participation.

Chi-square results showed significant relationships, with medium effect sizes, between the importance students placed on school environmental experiences and their frequency of recycling at home in 2009 and 2010. Appendix 4.4 illustrates that students who rated school environmental experiences as important recycled at home on a greater than weekly basis. Most students who rated school environmental experiences as average also recycled weekly but there was greater variation in responses from this group.

In both 2009 and 2010 there were significant relationships, with medium effect sizes, between the family member/s at home who recycled most often and students' frequency of recycling at home. Appendix 4.5 illustrates that weekly recycling at home was a common feature of most families. Students recycled on a more than weekly basis when they were one of the family members that recycled most often at home. In homes where parents or siblings were the family members most active in recycling, the majority of students would also recycle more than weekly but there were a large proportion of students who recycled less than weekly or not at all.

Recycling at home on a greater than weekly basis was widespread among students at Lighthouse Primary School. Results show that frequency of recycling at 
home was somewhat influenced by Importance and largely influenced by the degree of student participation in the home. Students were more likely to recycle on a greater than weekly basis if they were one of the family members responsible for recycling, but by and large recycling was done weekly by the majority of students regardless of whether they were one of the main drivers of the behaviour.

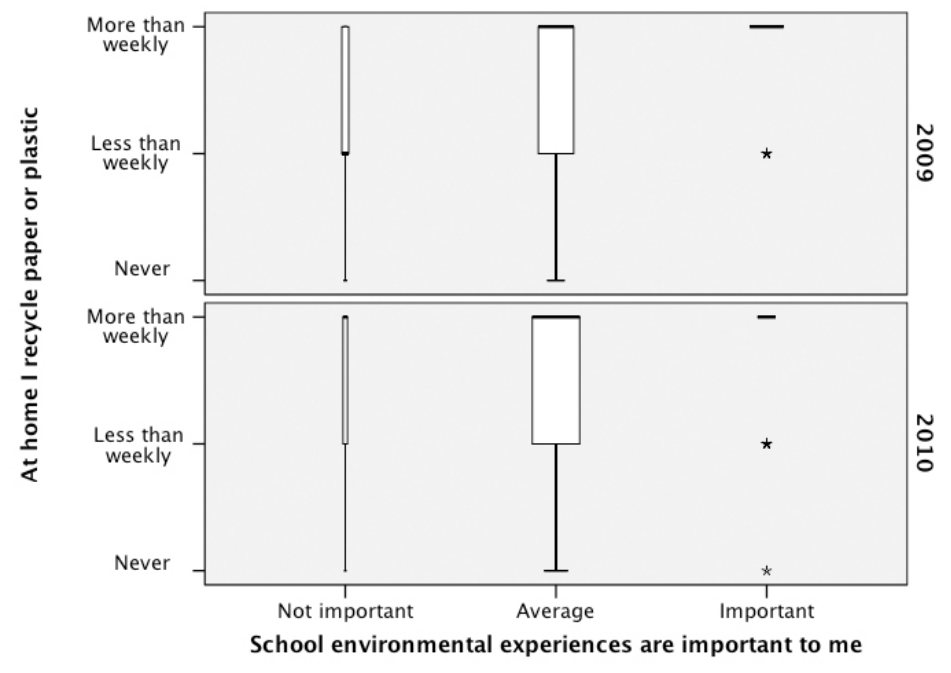

Appendix 4.4. Variable width box plots of students' self-reported frequency of recycling at home (y axis) and students' importance of school environmental experiences (x axis). 2009 ( $n$ $\left.n_{\text {not important }}=29, n_{\text {average }}=67, n_{\text {important }}=65\right)$ and $2010\left(n_{\text {not important }}=26, n_{\text {average }}=83, n_{\text {important }}=\right.$ $45)$.

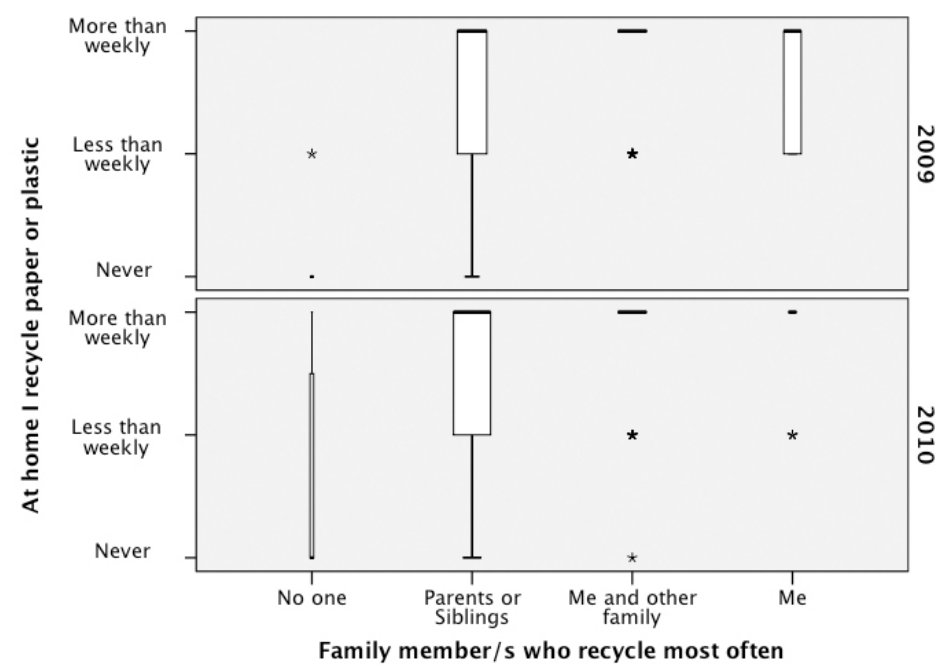

Appendix 4.5. Variable width box plots of students' self-reported frequency of recycling at home (y axis) and students' degree of participation in recycling at home (x axis). 2009 ( $n_{\text {no one }}=$ $\left.6, n_{\text {parents or siblings }}=59, n_{\text {me and other family }}=58, n_{m e}=35\right)$ and $2010\left(n_{\text {no one }}=7, n_{\text {parents or siblings }}=74\right.$, $n_{\text {me and other family }}=58, n_{m e}=16$ ). 


\section{Moderate frequency behaviours: Water saving and transport to school}

Appendix 4.6 provides a summary of results from the chi-square tests performed for the three behavioural variables: Short showers, saving water and transport to school. These behaviours were considered moderate frequency because in 2009 and 2010 between 40 and 70 percent of students performed these behaviours on a weekly basis (Figure 4.9).

Appendix 4.6. Survey results of Year 4, 5, 6 students (end of term 3, 2009) and Year 5, 6, 7 students (beginning of term 4, 2010). Summary of statistical analyses for water saving behaviours and transport to school, $\mathrm{n}_{2009}=161, \mathrm{n}_{2010}=157$, showing relationships between Learning, Importance and Participation.

\begin{tabular}{|c|c|c|c|c|}
\hline & & Learning & Importance & Participation \\
\hline Year & & $\begin{array}{l}\text { Chi-square of } \\
\text { 'learn at school' } \\
\text { and 'do at home' }\end{array}$ & $\begin{array}{l}\text { Chi-square of } \\
\text { 'importance' and } \\
\text { 'do at home' }\end{array}$ & $\begin{array}{l}\text { Chi-square of } \\
\text { 'who at home' and } \\
\text { 'do at home' }\end{array}$ \\
\hline 2009 & $\begin{array}{l}\text { Short showers } \\
\text { (And use a four } \\
\text { minute shower } \\
\text { timer) }\end{array}$ & $\begin{array}{l}\text { Significant } \\
\text { FET }^{*}(4,159)= \\
9.67, p^{*}=.048 \\
V^{*}=.17\end{array}$ & $\begin{array}{l}\text { Significant } \\
\chi^{2 *}(4,160)=25.53 \\
p<.000 \\
V=.28\end{array}$ & $\begin{array}{l}\text { Significant } \\
\chi^{2}(6,155)=77.39 \\
p<.000 \\
V=.50\end{array}$ \\
\hline 2010 & $\begin{array}{l}\text { Short showers } \\
\text { (And use a four } \\
\text { minute shower } \\
\text { timer) }\end{array}$ & Non-significant & $\begin{array}{l}\text { Significant } \\
\chi^{2}(4,153)=12.71 \\
p=.013 \\
V=.20\end{array}$ & $\begin{array}{l}\text { Significant } \\
\chi^{2}(6,151)=89.70 \\
p<.000 \\
V=.54\end{array}$ \\
\hline 2009 & $\begin{array}{l}\text { Save water in other } \\
\text { ways }\end{array}$ & $\begin{array}{l}\text { Significant } \\
\text { FET }(4,157)= \\
23.28, p<.000 ; \\
V=.27\end{array}$ & $\begin{array}{l}\text { Significant } \\
\text { FET }(4,158)= \\
39.45, p<.000 \\
V=.35\end{array}$ & $\begin{array}{l}\text { Significant } \\
\text { FET }(6,151)= \\
48.28, p<.000 \\
V=.40\end{array}$ \\
\hline 2010 & $\begin{array}{l}\text { Save water in other } \\
\text { ways }\end{array}$ & Non-significant & $\begin{array}{l}\text { Significant } \\
\text { FET }(4,154)= \\
27.05, p<.000 \\
V=.30\end{array}$ & $\begin{array}{l}\text { Significant } \\
\chi^{2}(6,151)= \\
120.97, p<.000 \\
V=.63\end{array}$ \\
\hline 2009 & $\begin{array}{l}\text { Walk, bike or bus } \\
\text { to school }\end{array}$ & $\begin{array}{l}\text { Significant } \\
\text { FET }(4,157)= \\
11.66, p=.020 \\
V=.19\end{array}$ & Non-significant & $\begin{array}{l}\text { Significant } \\
\chi^{2}(6,155)=82.07 \\
p<.000 \\
V=.52\end{array}$ \\
\hline 2010 & $\begin{array}{l}\text { Walk, bike or bus } \\
\text { to school }\end{array}$ & Non-significant & Non-significant & $\begin{array}{l}\text { Significant } \\
\chi^{2}(6,156)=97.47 \\
p<.000 \\
V=.56\end{array}$ \\
\hline
\end{tabular}

$* \chi^{2}$ is the Pearson chi-square statistic (test for independence) at the specified degrees of freedom and sample size. FET indicates that Fisher's exact test of significance was used because more than 20 percent of cells had expected frequencies of less than 5. $p$ is the probability value at .05 significance level. $V$ is Cramer's V - a measure of effect size. Cramer's V effect size range: $.07=$ small, $.21=$ medium, $.35=$ large.

Short showers. Short showers at home were practiced on a greater than weekly basis by 54 and 46 percent of upper-primary students at Lighthouse Primary School in 2009 and 2010 respectively, and 22 and 23 percent of students indicated that they never took short showers at home (Figure 4.9). Chi-square results indicate that having short showers at home was related to Learning, Importance and Participation. 
Appendix 4.7 depicts a positive relationship between students' perceived frequency of learning at school about reducing household water and their frequency of having short showers at home in 2009 and 2010, indicating that students who learned more often about water saving also had short showers more often. However, only 2009 chi-square results show a marginally significant relationship between these variables, indicating there was just enough separateness between the observed and expected counts for significance to be found. Chi-square results for 2010 were only marginally not significant $(\mathrm{FET}=9.34, p=.051, V=.17)$, suggesting there was a weak positive relationship between short showers and learning at school in both 2009 and 2010.

Chi-square results show significant relationships, with medium effect sizes, between the importance students placed on school environmental experiences and their frequency of having short showers at home in 2009 and 2010. Appendix 4.8 illustrates a positive relationship between the importance students placed on school environmental experiences and their frequency of having short showers at home in 2009 and 2010. This indicates that students who place more importance on environmental experiences tend to have short showers more often.

In both 2009 and 2010 there were significant relationships between the family member/s at home who took short showers most often and students' frequency of taking short showers at home. Both of these relationships had very large effect sizes, indicating the strength of the relationships. Appendix 4.9 illustrates that students had short showers on a more than weekly basis when they participated equally as often as other family members, possibly indicating that short showers was a family priority. In homes where the student was the most active family member, most students took short showers weekly but a large proportion did so less than weekly. In homes where parents or siblings were the family members most active in taking short showers, the majority of students took short showers less than weekly. In homes where no one was most active the majority of these students never had short showers.

Having short showers at home on a greater than weekly basis was common among students at Lighthouse Primary School. Results indicate that students were slightly more likely to take short showers on a greater than weekly basis if they learned at school every week about reducing household water use, and most likely to do so if environmental experiences were important to them and if short showers were a family priority that they participated in equally with other family members. 


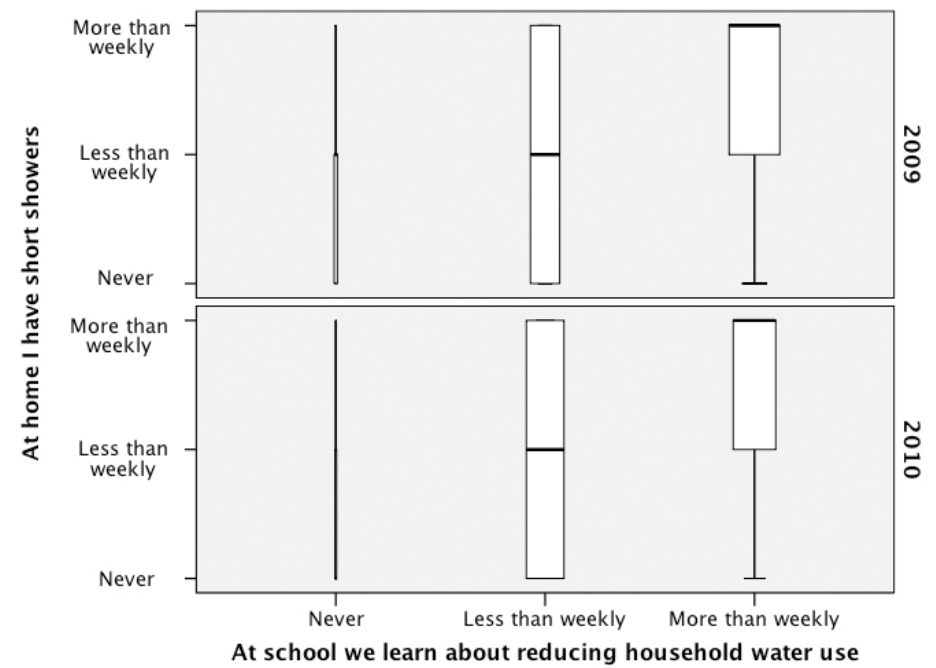

Appendix 4.7. Variable width box plots of students' self-reported frequency of having short showers at home (y axis) and students' self-reported frequency of learning at school about reducing household water use (x axis). $2009\left(n_{\text {Learn never }}=6, n_{\text {Learn less than weekly }}=56, n_{\text {Learn more than }}\right.$ weekly $=98)$ and $2010\left(n_{\text {Learn never }}=3, n_{\text {Learn less than weekly }}=72, n_{\text {Learn more than weekly }}=82\right)$.

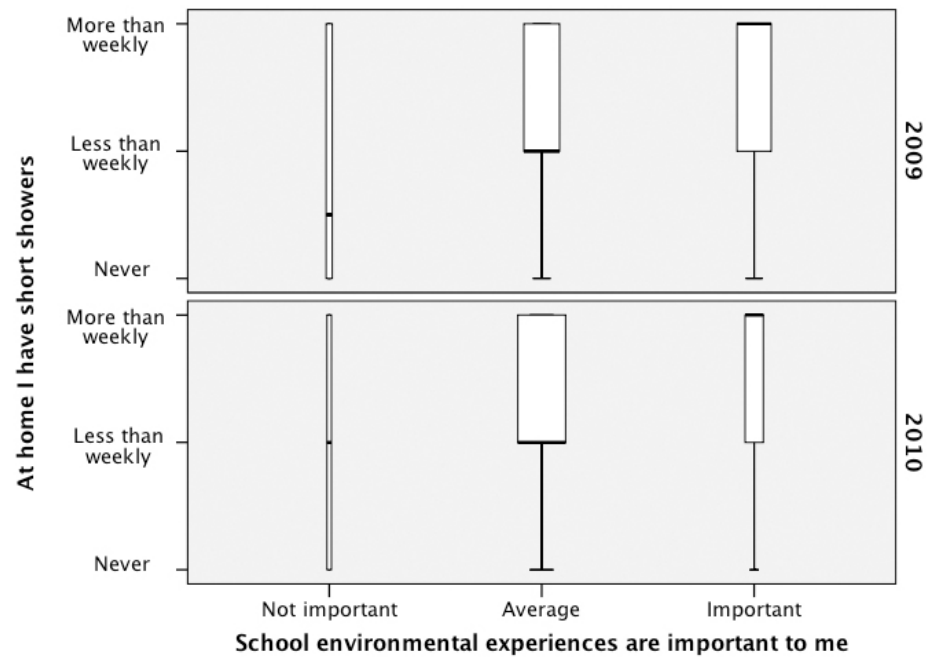

Appendix 4.8. Variable width box plots of students' self-reported frequency of having short showers at home (y axis) and students' importance of school environmental experiences (x axis). $2009\left(n_{\text {not important }}=29, n_{\text {average }}=67, n_{\text {important }}=65\right)$ and $2010\left(n_{\text {not important }}=26, n_{\text {average }}=\right.$ $\left.83, n_{\text {important }}=45\right)$. 


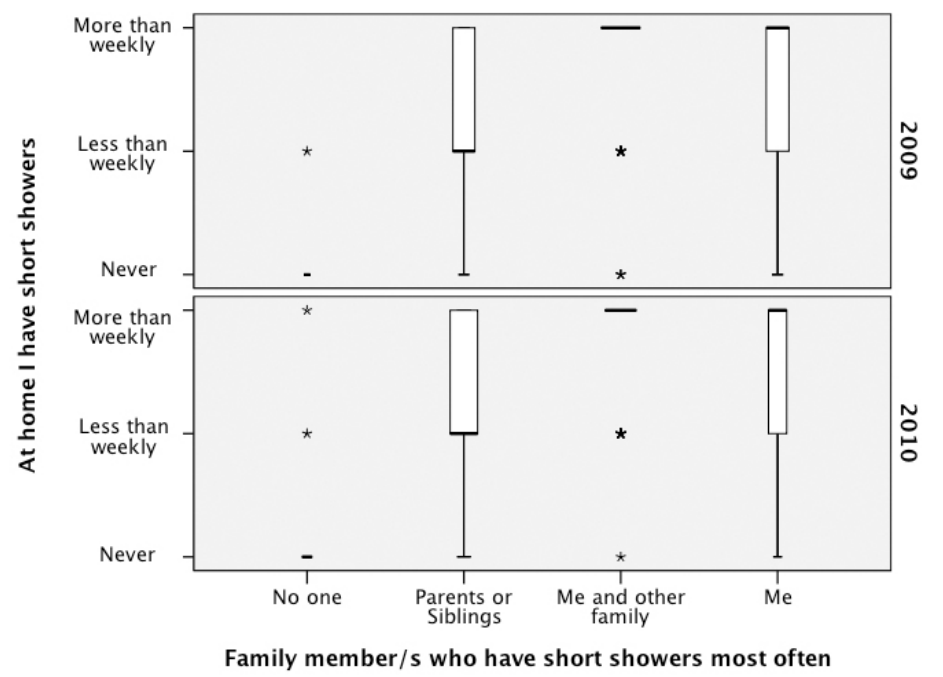

Appendix 4.9. Variable width box plots of students' self-reported frequency of having short showers at home (y axis) and students' degree of participation in having short showers at home (x axis). 2009 ( $n_{\text {no one }}=19, n_{\text {parents or siblings }}=38, n_{\text {me and other family }}=60, n_{\text {me }}=39$ ) and 2010 ( $n_{\text {no one }}$ $=24, n_{\text {parents or siblings }}=45, n_{\text {me and other family }}=50, n_{m e}=33$ ).

Save water in other ways. Saving water at home was practiced on a greater than weekly basis by 59 and 50 percent of upper-primary students at Lighthouse Primary School in 2009 and 2010 respectively, and 4 and 11 percent of students indicated that they never saved water at home (Figure 4.9). Chi-square results indicate that saving water at home was related to Learning, Importance and Participation.

Chi-square results between students' perceived frequency of learning at school about reducing household water and their frequency of saving water at home in 2009 show a strong significant relationship between these variables, with medium effect size. Chi-square results from 2010 were not significant $(p=.441)$. Appendix 4.10 depicts a positive relationship between the variables in 2009 and 2010. But in 2009 more students indicated they learned about saving water on a weekly basis, which caused enough separateness between the observed and expected counts for significance to be found.

Similar to the results for short showers, students were also more likely to save water at home if school environmental experiences were important to them. Chi-square results show strong significant relationships, with large and medium effect sizes, in 2009 and 2010. Appendix 4.11 shows that almost all students who placed importance on environmental experiences saved water at home more than weekly.

In 2009 and 2010 there were strong significant relationships, with large effect sizes, between the family member/s who saved water most often and students' frequency of saving water at home. Appendix 4.12 illustrates that the majority of students saved water on a more than weekly basis when any combination of family members were most active in this behaviour. In 2010 students were less inclined to be 
one of the family members most responsible for saving water. The greater participation of students in 2009, particularly when they were not one of the main family members responsible for household water saving, could also be linked to the school focus on National Water Week.

Saving water at home on a greater than weekly basis was common among students at Lighthouse Primary School. Water saving at home was related to Learning, Importance and Participation. Results indicate that students were more likely to save water on a greater than weekly basis if they learned weekly at school about reducing household water use, if environmental experiences were important to them and if water saving was a family priority.

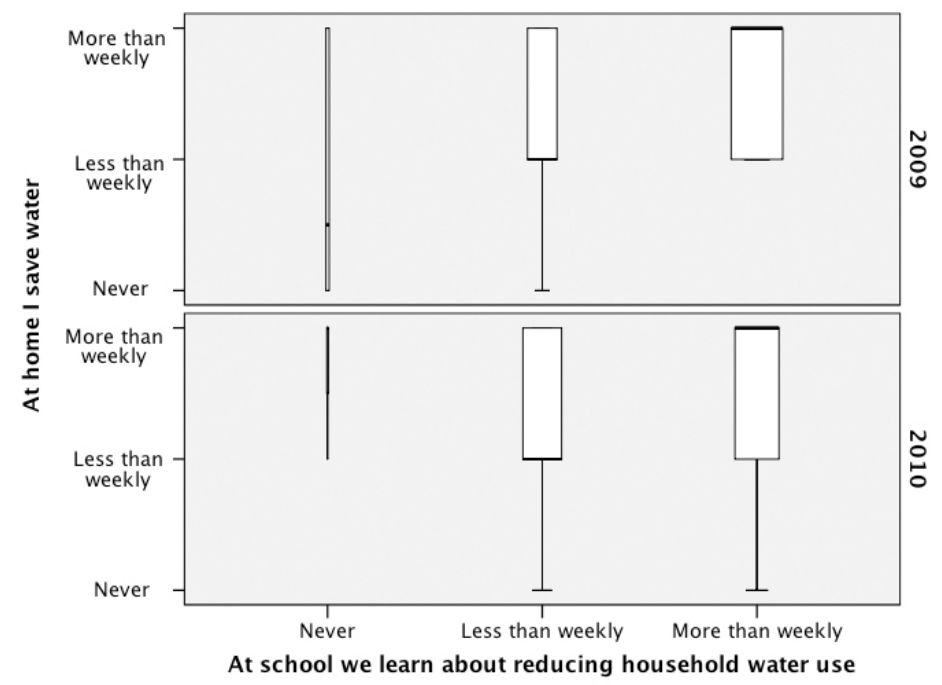

Appendix 4.10. Variable width box plots of students' self-reported frequency of saving water at home (y axis) and students' self-reported frequency of learning at school about reducing household water use (x axis). 2009 ( $n_{\text {Learn never }}=6, n_{\text {Learn less than weekly }}=56, n_{\text {Learn more than weekly }}=$ $98)$ and $2010\left(n_{\text {Learn never }}=3, n_{\text {Learn less than weekly }}=72, n_{\text {Learn more than weekly }}=82\right)$.

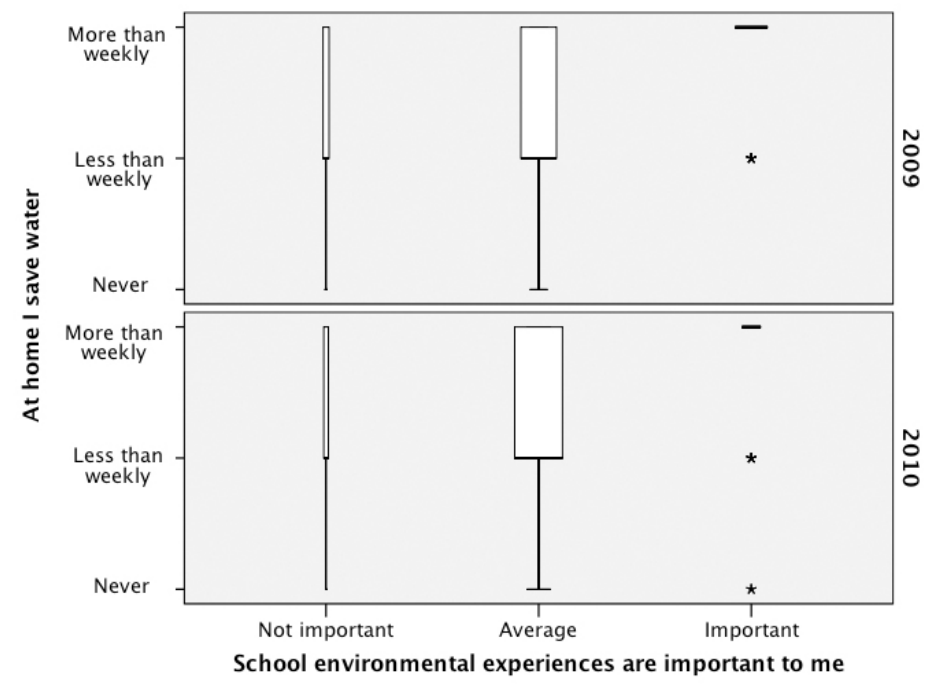

Appendix 4.11. Variable width box plots of students' self-reported frequency of saving water at home (y axis) and students' importance of school environmental experiences (x axis). 2009 ( $n$ $\left.n_{\text {not important }}=29, n_{\text {average }}=67, n_{\text {important }}=65\right)$ and $2010\left(n_{\text {not important }}=26, n_{\text {average }}=83, n_{\text {important }}=\right.$ $45)$. 


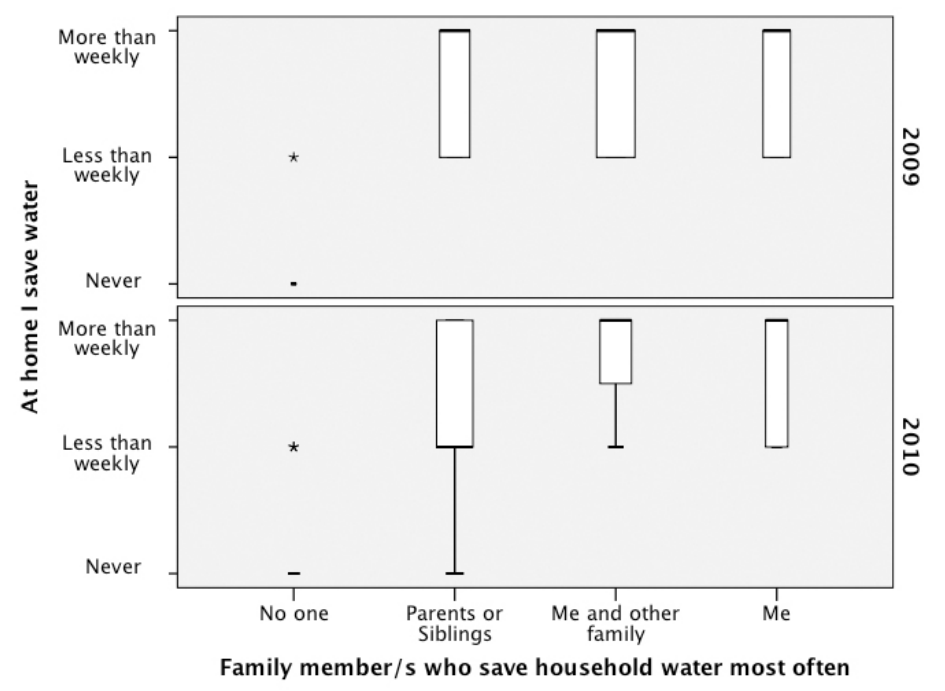

Appendix 4.12. Variable width box plots of students' self-reported frequency of saving water at home (y axis) and students' degree of participation in saving water at home (x axis). 2009 ( $n_{n o}$ $\left.{ }_{\text {one }}=10, n_{\text {parents or siblings }}=45, n_{\text {me and other family }}=57, n_{\text {me }}=41\right)$ and $2010\left(n_{\text {no one }}=17, n_{\text {parents or }}\right.$ siblings $=54, n_{\text {me and other family }}=47, n_{m e}=33$ ).

Alternative transport. Walking, biking or bussing to school was practiced on a greater than weekly basis by 44 and 57 percent of upper-primary students at Lighthouse Primary School in 2009 and 2010 respectively, and 32 and 24 percent of students indicated that they never walked, biked or bussed to school (Figure 4.9). Chi-square results indicate that taking alternative transport to school was not related to Importance and was related to Learning and Participation.

In 2009 only, a significant relationship, with small effect size, was found between learning at school about using transport other than cars and walking, biking or bussing to school. Appendix 4.13 shows that in 2009, most students who learned weekly about alternative transport also walked, biked or bussed to school and those that learned less than weekly tended to do this less than weekly. In 2010 there was not a significant relationship between Learning and taking alternative transport to school, but there was an increase in the number of students who walked, biked or bussed to school weekly. This increase was not significantly related to weekly Learning about the topic, because students were walking, bussing or biking to school weekly even when they learned about it less often (Appendix 4.13).

It was suspected that the increase in students taking alternative transport to school in 2010, and reduction of students who never took alternative transport to school, might be related to a corresponding increase in the age range of the students from $9-11$ years old to $10-12$ years old. Chi-square tests comparing age with frequency of walking, biking or bussing to school in 2009 and 2010, found no significant relationships. 
It was also suspected that the increase in number of students taking alternative transport to school in 2010 might be related to the proximity of students' homes to the school. Chi-square tests comparing proximity to school (less than or greater than $2 \mathrm{~km}$ ) with frequency of walking, biking or bussing to school found strong significant relationships, with large effect sizes, in $2009\left(\chi^{2}=32.10, p=.000, V=.45\right)$ and 2010 $\left(\chi^{2}=32.10, p=.000, V=.45\right)$. These results strongly indicate that students who lived less than 2 kilometres from the school were much more likely to walk, ride or bus to school on a greater than weekly basis compared with students who lived further than 2 kilometres from the school. But it does not explain why 13 percent more students walked, biked or bussed to school weekly in 2010.

In 2009 and 2010 there were strong significant relationships, with large effect sizes, between the family member/s who took alternative transport most often and students' frequency of walking, biking or bussing to school. Appendix 4.14 illustrates that the majority of students walked, biked or bussed to school on a more than weekly basis when they were one of the most active family members. In homes where parents or siblings were most active, there was greater variation in students' frequency of taking alternative transport, but the proportion of these homes was quite small compared with the majority of families. And, in homes where no one was active, students did not take alternative transport to school. In 2010 a greater number of students were themselves the main family member responsible for taking alternative transport.

Taking alternative transport to school on a greater than weekly basis was common among students at Lighthouse Primary School. Results indicate that students were likely to walk, bike or bus to school on a greater than weekly basis if they lived less than 2 kilometres from the school and if they were one of the family members most active in this behaviour. 


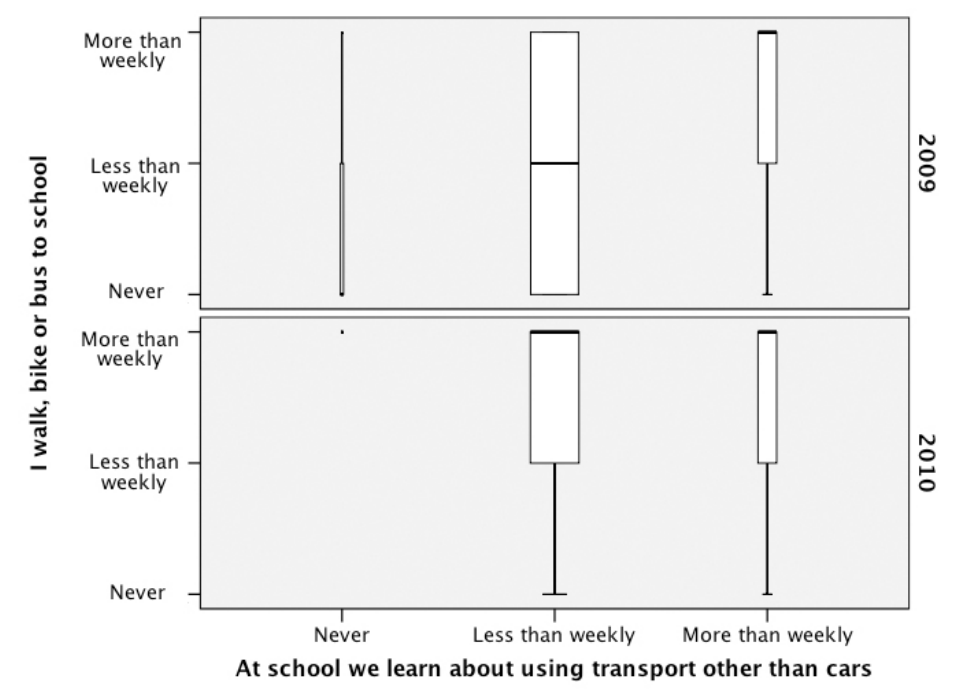

Appendix 4.13. Variable width box plots of students' self-reported frequency of walking, biking or bussing to school (y axis) and students' self-reported frequency of learning at school about using transport other than cars (x axis). $2009\left(n_{\text {Learn never }}=7, n_{\text {Learn less than weekly }}=109, n_{\text {Learn more }}\right.$ than weekly $=42)$ and $2010\left(n_{\text {Learn never }}=3, n_{\text {Learn less than weekly }}=72, n_{\text {Learn more than weekly }}=82\right)$.

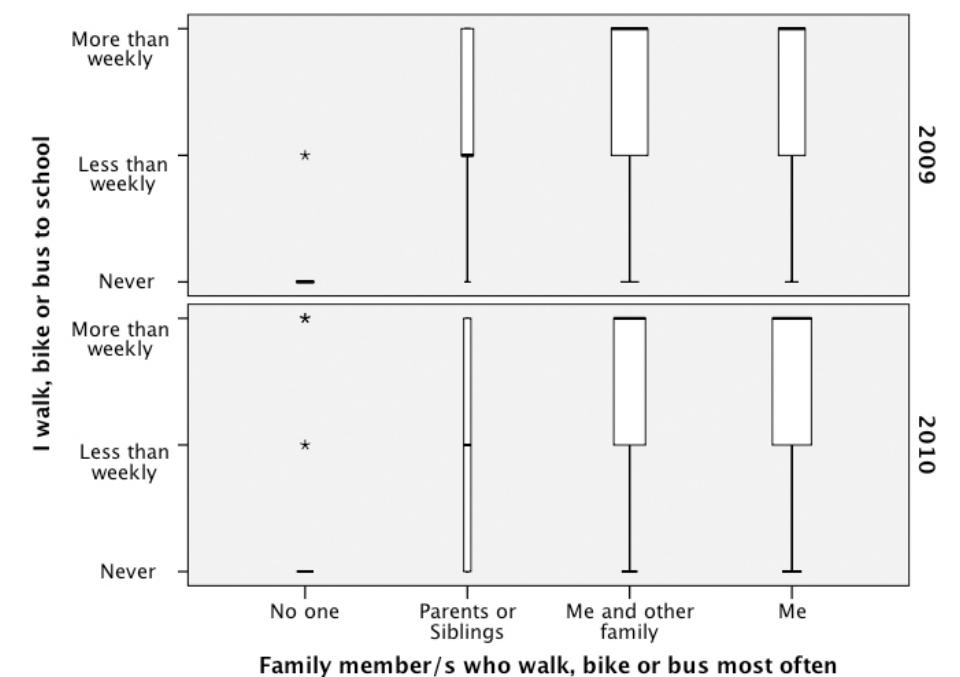

Appendix 4.14. Variable width box plots of students' self-reported frequency of walking, biking or bussing to school (y axis) and students' degree of participation in walking, biking or bussing from home (x axis). 2009 ( $n_{n o}$ one $\left.=33, n_{\text {parents or siblings }}=25, n_{\text {me and other family }}=55, n_{\text {me }}=43\right)$ and 2010 ( $\left.n_{\text {no one }}=30, n_{\text {parents or siblings }}=19, n_{\text {me and other family }}=49, n_{m e}=58\right)$. 


\section{Low frequency behaviours: Eating home grown produce and maintaining organic} waste

Appendix 4.15 provides a summary of results from the descriptive and statistical tests for the behavioural variables: Eating home grown produce and Maintaining organic waste. These behaviours were considered low frequency because less than 40 percent of students, in 2009 and 2010, indicated they practiced either of these behaviours on a greater than weekly basis (Figure 4.9).

Appendix 4.15. Survey results of Year 4, 5, 6 students (end of term 3, 2009) and Year 5, 6, 7 students (beginning of term 4,2010). Summary of statistical analyses for eating home grown produce and composting behaviours, $\mathrm{n}_{2009}=161, \mathrm{n}_{2010}=157$, showing relationships between Learning, Importance and Participation.

\begin{tabular}{|c|c|c|c|c|}
\hline & & Learning & Importance & Participation \\
\hline Year & & $\begin{array}{l}\text { Chi-square of } \\
\text { 'learn at school' } \\
\text { and 'do at home' }\end{array}$ & $\begin{array}{l}\text { Chi-square of } \\
\text { 'importance' and } \\
\text { 'do at home' }\end{array}$ & $\begin{array}{l}\text { Chi-square of 'who } \\
\text { at home' and 'do } \\
\text { at home' }\end{array}$ \\
\hline 2009 & $\begin{array}{l}\text { Eat home grown } \\
\text { fruits or vegetables }\end{array}$ & $\begin{array}{l}\text { Significant } \\
\text { FET }^{*}(4,156)= \\
19.05, p^{*}<.000 \\
V^{*}=.25\end{array}$ & Non-significant & $\begin{array}{l}\text { Significant } \\
\chi^{2 \star}(6,151)=97.74, \\
p<.000 \\
V=.57\end{array}$ \\
\hline 2010 & $\begin{array}{l}\text { Eat home grown } \\
\text { fruits or vegetables }\end{array}$ & Non-significant & Non-significant & $\begin{array}{l}\text { Significant } \\
\text { FET }(6,152)= \\
102.10, p<.000 \\
V=.58\end{array}$ \\
\hline 2009 & $\begin{array}{l}\text { Put food scraps } \\
\text { into a worm farm or } \\
\text { compost bin }\end{array}$ & Non-significant & $\begin{array}{l}\text { Significant } \\
\chi^{2}(4,148)=17.18 \\
p=.002 \\
V=.24\end{array}$ & $\begin{array}{l}\text { Significant } \\
\chi^{2}(6,146)=83.28 \\
p<.000 \\
V=.53\end{array}$ \\
\hline 2010 & $\begin{array}{l}\text { Put food scraps } \\
\text { into a worm farm or } \\
\text { compost bin }\end{array}$ & Non-significant & Non-significant & $\begin{array}{l}\text { Significant } \\
\text { FET }(6,151)= \\
123.81, p<.000 \\
V=.64\end{array}$ \\
\hline
\end{tabular}

* $\chi^{2}$ is the Pearson chi-square statistic (test for independence) at the specified degrees of freedom and sample size. FET indicates that Fisher's exact test of significance was used because more than 20 percent of cells had expected frequencies of less than 5. $p$ is the probability value at .05 significance level. $V$ is Cramer's V - a measure of effect size. Cramer's V effect size range: $.07=$ small, $.21=$ medium, $.35=$ large.

Eating home grown produce. Eating home grown fruits or vegetables was practiced on a greater than weekly basis by 38 and 35 percent of upper-primary students at Lighthouse Primary School in 2009 and 2010 respectively, and 27 and 28 percent of students indicated that they never ate home grown produce (Figure 4.9). Chi-square results indicate that eating home grown produce was not related to Importance and was related to Learning and Participation.

Chi-square results from 2009 only, indicate there was a strong significant relationship, with medium effect size, between the frequency that students learned at school about growing and eating home grown produce and the frequency that students 
ate home grown produce. Appendix 4.16 displays this positive relationship, and shows that in 2010 a greater number of students learned less than weekly about growing and eating home grown produce, but even so, a fair proportion of them indicated they ate home grown fruits or vegetables more than weekly. These results suggest that frequency of eating home produce was somewhat related to Learning but that other variables were also involved.

In 2009 and 2010, chi-square results indicated strong relationships, with large effect sizes, between frequency of eating home grown produce and the family member/s most active in this at home. Appendix 4.17 illustrates that the majority of students were most likely to eat home grown produce weekly when they did so equally with other family members. It also indicates that in homes where eating home grown produce was not done, most students never did this.

Eating home grown fruits or vegetables on a greater than weekly basis was uncommon among students at Lighthouse Primary School. Results indicated that students were most likely to eat home grown produce on a greater than weekly basis if they were one of the family members most active in this behaviour. Which suggests that eating home grown produce was largely impacted by whether it was a family priority and the degree that students were engaged at home, which might in turn be influenced by an increased level of skills developed through learning at school about growing produce.

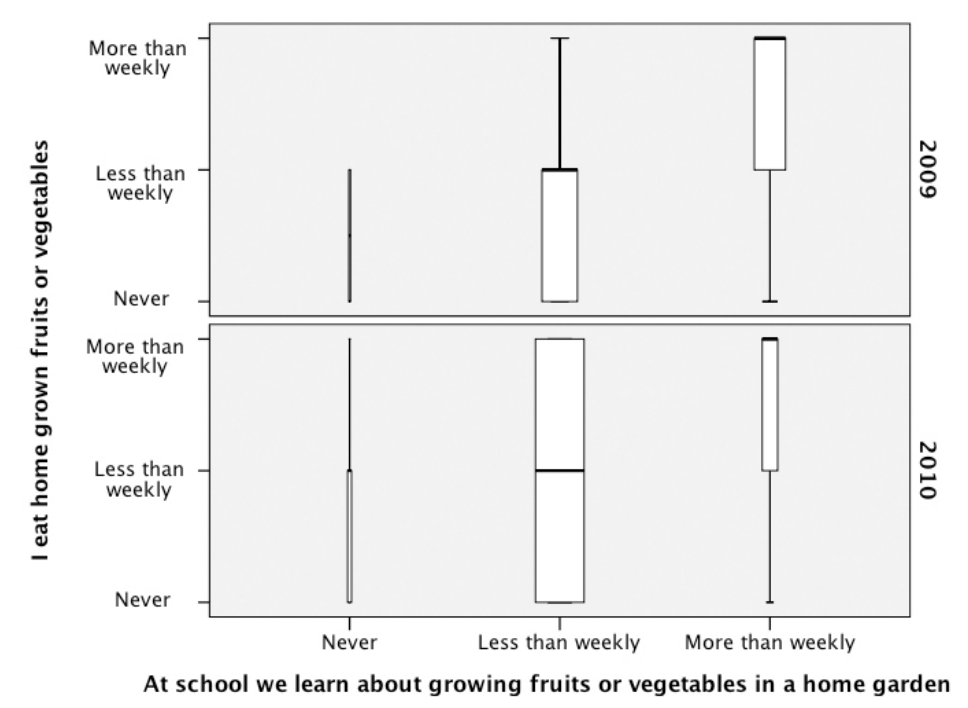

Appendix 4.16. Variable width box plots of students' self-reported frequency of eating home grown fruits or vegetables (y axis) and students' self-reported frequency of learning at school about growing fruits or vegetables in a home garden (x axis). 2009 ( $n_{\text {Learn never }}=4, n_{\text {Learn less than }}$ weekly $\left.=83, n_{\text {Learn more than weekly }}=71\right)$ and $2010\left(n_{\text {Learn never }}=9, n_{\text {Learn less than weekly }}=113, n_{\text {Learn more }}\right.$ than weekly $=35)$. 


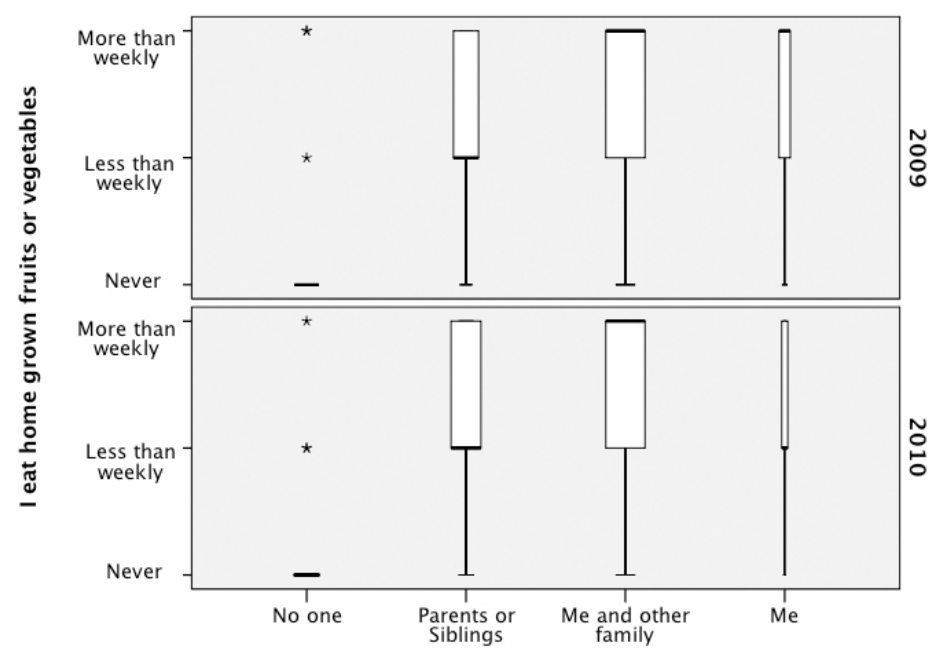

Family member/s who eat home grown fruits or vegetables most often

Appendix 4.17. Variable width box plots of students' self-reported frequency of eating home grown fruits or vegetables (y axis) and students' degree of participation in eating home grown fruits or vegetables (x axis). 2009 ( $n_{\text {no one }}=39, n_{\text {parents or siblings }}=38, n$ me and other family $=59, n_{\text {me }}=$ 17 ) and 2010 ( $\left.n_{\text {no one }}=39, n_{\text {parents or siblings }}=45, n_{\text {me and other family }}=59, n_{\text {me }}=9\right)$.

Maintaining organic waste. Putting food scraps into a worm farm or compost bin was practiced on a greater than weekly basis by 30 and 27 percent of upper-primary students at Lighthouse Primary School in 2009 and 2010 respectively, and 49 and 58 percent of students indicated that they never worm farmed or composted at home (Figure 4.9). Chi-square results indicate that maintaining organic waste processes at home was not related to Learning and was related to Importance and Participation.

Chi-square results in 2009 show a significant relationship, with medium effect size, between the frequency that students put food scraps into a worm farm or compost bin at home and the importance they placed on school environmental experiences. Appendix 4.18 shows that in 2009 and 2010, students who placed greater importance on school environmental experiences maintained a worm farm or compost bin at home less than weekly, compared to the bulk of students who never maintained a worm farm or compost bin at home and also did not care much for school environmental experiences. In 2009 the relationship was more distinct, causing significance because of greater separateness between the observed and expected counts.

In 2009 and 2010, significant chi-square relationships, with large effect sizes, were found between the frequencies that students worm farmed or composted at home and the family member/s most responsible for this behaviour at home. Appendix 4.19 illustrates that a large number of students lived in homes where no one worm farmed or composted and consequently they never practiced this behaviour. The students who lived in homes where worm farming or composting took place practiced this behaviour weekly or less. 
Putting food scraps into a worm farm or compost bin on a greater than weekly basis was uncommon among students at Lighthouse Primary School. Overall, these results indicate that worm farming or composting at home was largely impacted by whether it was a family priority, which might in turn influence a student's expressed importance towards environmental experiences. It was likely that a lot of families did not have a worm farm or compost bin at home because of the resources, time, skills and effort required to maintain either of these practices.

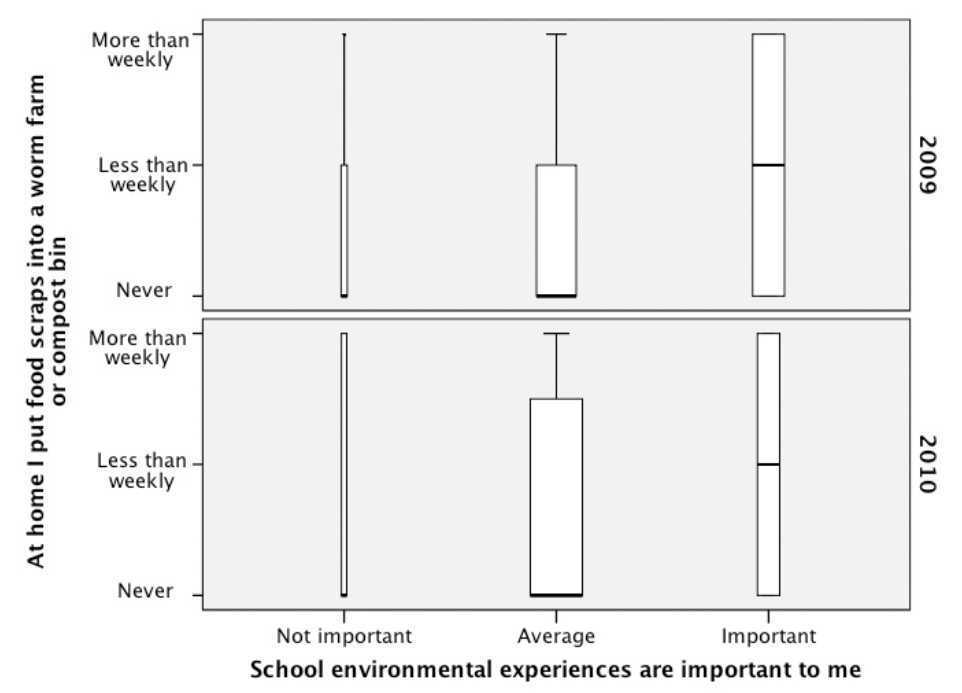

Appendix 4.18. Variable width box plots of students' self-reported frequency of putting food scraps into a worm farm or compost bin at home (y axis) and students' importance of school environmental experiences (x axis). $2009\left(n_{\text {not important }}=29, n_{\text {average }}=67, n_{\text {important }}=65\right)$ and $2010\left(n_{\text {not important }}=26, n_{\text {average }}=83, n_{\text {important }}=45\right)$.

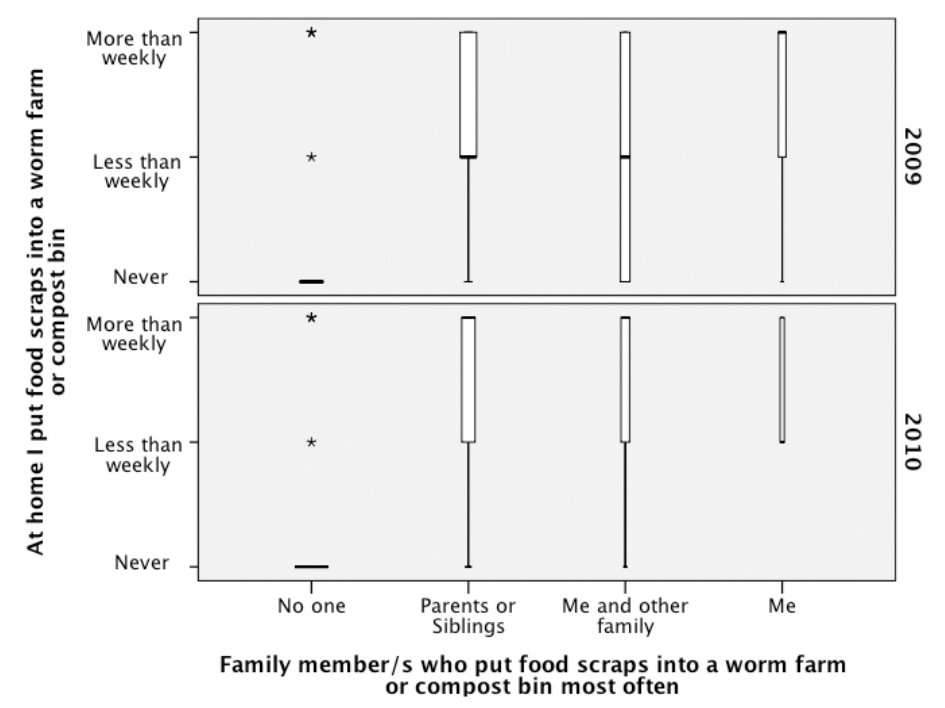

Appendix 4.19. Variable width box plots of students' self-reported frequency of putting food scraps into a worm farm or compost bin at home (y axis) and students' degree of participation in putting food scraps into a worm farm or compost bin at home (x axis). 2009 ( $n_{\text {no one }}=72, n_{\text {parents }}$ or siblings $\left.=42, n_{\text {me and other family }}=24, n_{\text {me }}=19\right)$ and $2010\left(n_{\text {no one }}=86, n_{\text {parents or siblings }}=34, n_{\text {me and }}\right.$ other family $\left.=22, n_{m e}=11\right)$. 
THIS PAGE HAS PURPOSELY BEEN LEFT BLANK 


\section{ApPENDiX 5 - Detailed Student Behaviour Results FROM RIVER's EDGE PRIMARY SCHOOL}

Significant results from the chi-square tests indicate the presence and strength of relationships between students' frequency of undertaking seven common proenvironmental behaviours and the three comparison variables: Learning, Importance and Participation. The chi-square results for each behaviour and comparison variables are presented and discussed in the following paragraphs.

\section{High frequency behaviours: Turning off lights and recycling}

Appendix 5.1 provides a summary of results from the chi-square tests for the two behavioural variables, Turning off lights and Recycling. These behaviours were considered high frequency because in 2009 and 2010 greater than 80 percent of students performed them on a weekly basis (Figure 5.10). Further exploration of the data showed that of that greater than 50 percent of students performed these behaviours daily. This result alone suggests that these two behaviours were highly habitual. 
Appendix 5.1. Survey results of Year 4, 5, 6 students (end of term 3, 2009) and Year 5, 6 students (beginning of term 4, 2010). Chi-square analyses for power saving and recycling behaviours, $\mathrm{n}_{2009}=155, \mathrm{n}_{2010}=128$, showing relationships between Learning, Importance and Participation.

\begin{tabular}{|c|c|c|c|c|}
\hline \multirow[b]{2}{*}{ Year } & & Learning & Importance & \multirow{2}{*}{$\begin{array}{l}\text { Participation } \\
\text { Chi-square of } \\
\text { 'who at home' and } \\
\text { 'do at home' }\end{array}$} \\
\hline & & $\begin{array}{l}\text { Chi-square of } \\
\text { 'learn at school' } \\
\text { and 'do at home' }\end{array}$ & $\begin{array}{l}\text { Chi-square of } \\
\text { 'importance' and } \\
\text { 'do at home' }\end{array}$ & \\
\hline 2009 & $\begin{array}{l}\text { Saving power by } \\
\text { turning off lights }\end{array}$ & 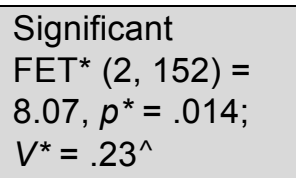 & $\begin{array}{l}\text { Significant } \\
\text { FET }(2,150)= \\
5.83, p=.049 \\
V=.20^{\wedge}\end{array}$ & $\begin{array}{l}\text { Significant } \\
\text { FET }(2,154)= \\
6.47, p=.042 \\
V=.20^{\wedge}\end{array}$ \\
\hline 2010 & $\begin{array}{l}\text { Saving power by } \\
\text { turning off lights }\end{array}$ & Non-significant & $\begin{array}{l}\text { Significant } \\
\text { FET }(4,127)= \\
12.87, p=.013 \\
V=.23\end{array}$ & $\begin{array}{l}\text { Significant } \\
\text { FET }(6,128)= \\
9.91, p=.047 \\
V=.20\end{array}$ \\
\hline 2009 & $\begin{array}{l}\text { Recycle paper or } \\
\text { plastic }\end{array}$ & $\begin{array}{l}\text { Significant } \\
\chi^{2 \star}(2,154)= \\
12.62, p=.002 ; \\
V=.29^{\wedge}\end{array}$ & $\begin{array}{l}\text { Significant } \\
\chi^{2}(2,151)=9.79 \\
p=.007 \\
V=.26^{\wedge}\end{array}$ & Non-significant \\
\hline 2010 & $\begin{array}{l}\text { Recycle paper or } \\
\text { plastic }\end{array}$ & Non-significant & $\begin{array}{l}\text { Significant } \\
\text { FET }(4,127)= \\
16.13, p=.004 ; \\
V=.25\end{array}$ & $\begin{array}{l}\text { Significant } \\
\text { FET }(6,127)= \\
14.86, p=.030 \\
V=.24\end{array}$ \\
\hline
\end{tabular}

$* \chi^{2}$ is the Pearson chi-square statistic (test for independence) at the specified degrees of freedom and sample size. FET indicates that Fisher's exact test of significance was used in place of $\chi^{2}$ because more than 20 percent of cells had expected frequencies of less than 5. $p$ is the probability value at .05 significance level. $V$ is Cramer's V - a measure of effect size. Cramer's V effect size range: $.07=$ small, $.21=$ medium, $.35=$ large.

$\wedge$ In these chi-square tests, fewer rows warranted a different Cramer's V effect size range: $.01=$ small, .30 $=$ medium, $.50=$ large. These tests had fewer rows because there were no responses in the category 'never'.

Turning off lights. Turning off lights at home was practiced on a greater than weekly basis by 91 and 90 percent of upper-primary students at River's Edge Primary School in 2009 and 2010 respectively and in 2010 only, 2 percent of students indicated that they never turned off lights at home (Figure 5.10). Chi-square results indicate that turning off lights at home was related to Learning, Importance and Participation.

In 2009 only, chi-square results show a significant association, with small effect size, between the frequency that students learned at school about reducing household power use and the frequency that they turned off lights at home. Appendix 5.2 indicates this is because of a small number of students in 2009 that reported they never learned about reducing household power use at school and who also tended to turn off lights less than weekly. There was, however, a strong indication that the majority of students turned off lights on a greater than weekly basis regardless of how often they learned about it at school. 
In 2009 and 2010 there were significant relationships, with small and medium effect sizes, between the importance students placed on school environmental experiences and the frequency that students turned off lights at home. Appendix 5.3 shows that a greater number of students considered school environmental experiences as important in 2009 and 2010, but the majority of all students turned off lights on a greater than weekly basis regardless of the importance they placed on environmental experiences. A small number of students in 2010 that considered environmental experiences as not important reported they never turned off lights or did so less than weekly, which explains the stronger significance and effect size in the 2010 chi-square results.

Chi-square results from 2009 and 2010, between the family member/s that turned off lights most often and the frequency that students turned off lights at home, were marginally significant with small effect sizes. Appendix 5.4 illustrates that most students turned off lights more than weekly, irrespective of which family member was most active. It is likely that a few outliers caused just enough separateness between the observed and expected counts for marginal significance to be found. It is important to note that there were no households where no one was active in turning off lights and, in the majority of households, parents or siblings were most responsible for turning off lights. Further investigation of the data showed that 98 and 97 percent of that category were parents, indicating that parents were far more active in turning off lights than any other family member.

Turning off lights on a greater than weekly basis was a widespread behaviour among students at River's Edge Primary School, and only minimally related to Learning, Importance and Participation. Further exploration of the data showed that 58 and 57 percent of students in 2009 and 2010 turned off lights on a daily basis, which supports the assertion made about students at Lighthouse Primary School; turning off lights at home was a daily habit for most students. 


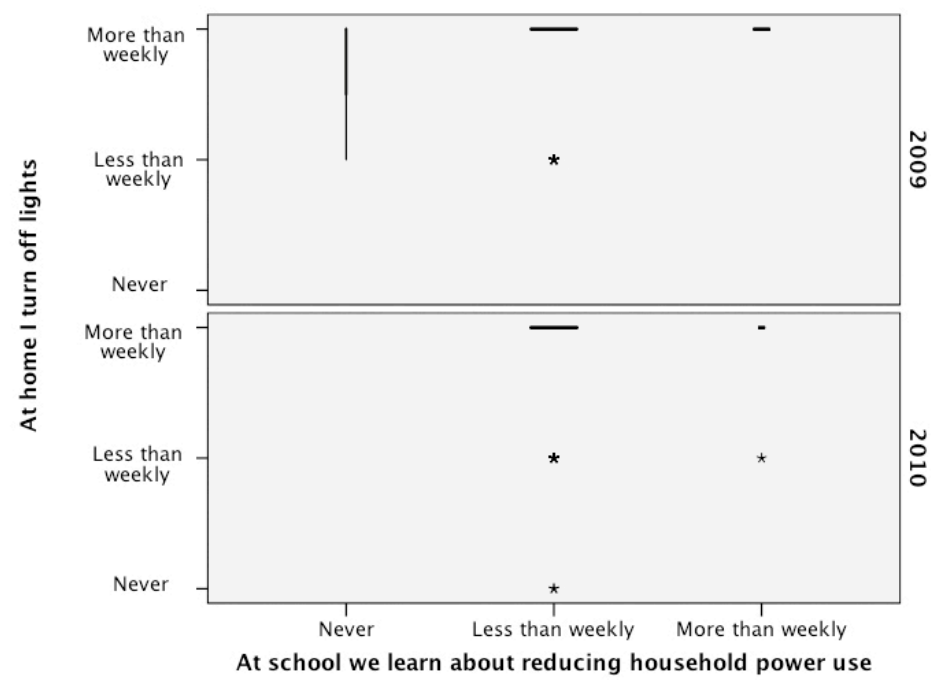

Appendix 5.2. Variable width box plots of students' self-reported frequency of turning off lights at home (y axis) and students' self-reported frequency of learning at school about reducing household power use (x axis). $2009\left(n_{\text {Learn never }}=3, n_{\text {Learn less than weekly }}=110, n_{\text {Learn more than weekly }}=\right.$ $40)$ and $2010\left(n_{\text {Learn never }}=0, n_{\text {Learn less than weekly }}=111, n_{\text {Learn more than weekly }}=16\right)$.

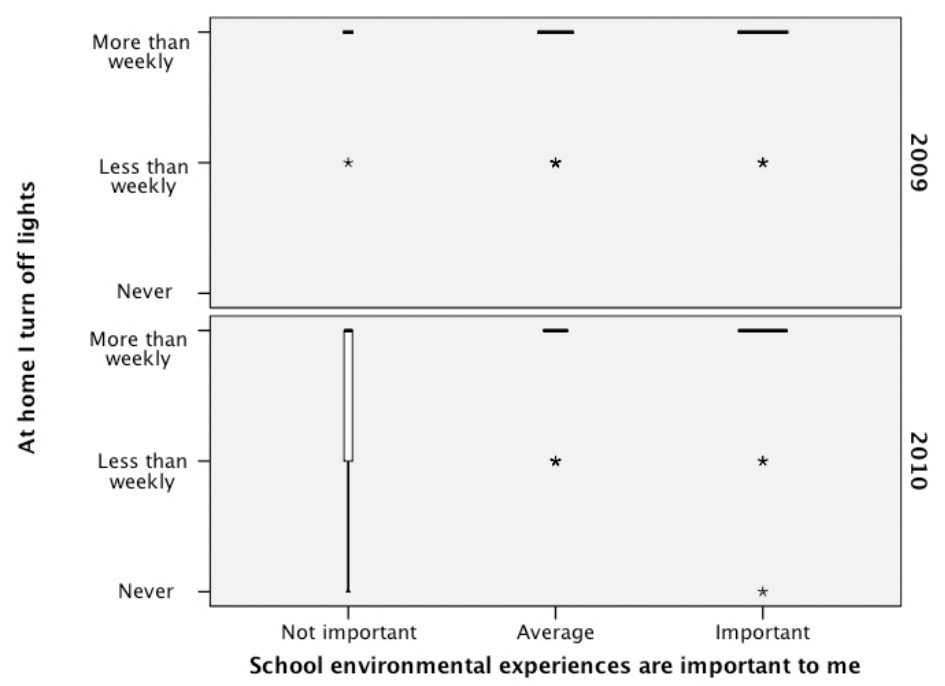

Appendix 5.3. Variable width box plots of students' self-reported frequency of turning off lights at home (y axis) and students' importance of school environmental experiences (x axis). 2009 ( $n$ ${ }_{n o t}$ important $\left.=16, n_{\text {average }}=56, n_{\text {important }}=79\right)$ and $2010\left(n_{\text {not important }}=13, n_{\text {average }}=38, n_{\text {important }}=\right.$ 76). 


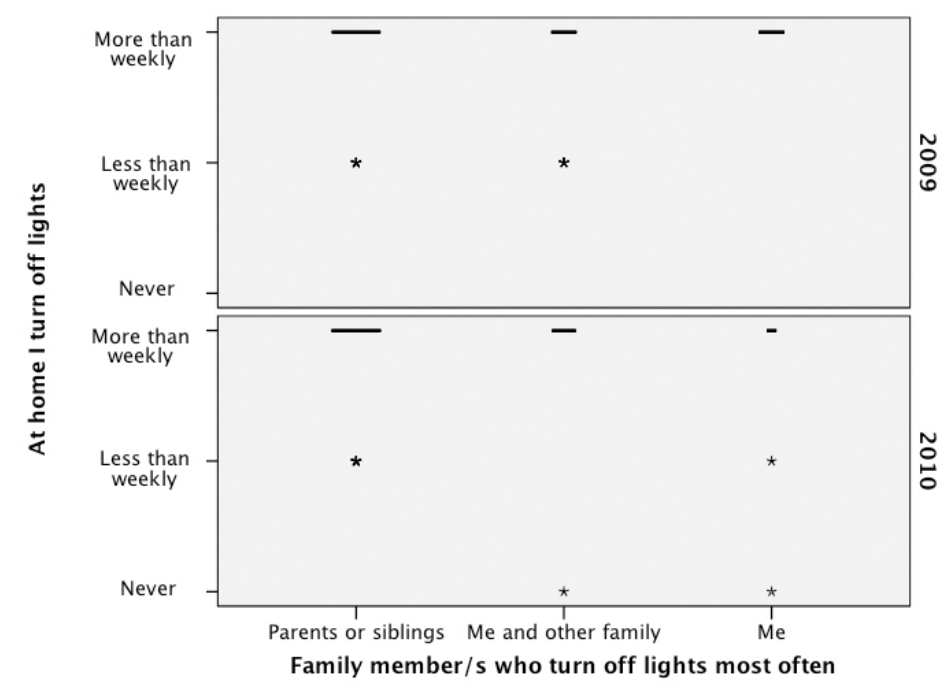

Appendix 5.4. Variable width box plots of students' self-reported frequency of turning off lights at home (y axis) and students' degree of participation in turning off lights at home (x axis). 2009 $\left(n_{\text {no one }}=0, n_{\text {parents or siblings }}=76, n_{\text {me and other family }}=39, n_{\text {me }}=40\right)$ and 2010 ( $n_{\text {no one }}=0, n_{\text {parents or }}$ siblings $=76, n_{\text {me and other family }}=37, n_{m e}=15$ ).

Recycling. Recycling at home was practiced on a greater than weekly basis by 86 and 84 percent of upper-primary students at River's Edge Primary School in 2009 and 2010 respectively, and in 2010 only, two percent of students indicated that they never recycled at home (Figure 5.10). Chi-square results indicate that recycling at home was related to Learning, Importance and Participation.

In 2009 only, a significant association, with small effect size, was found between the frequency that students learned at school about recycling and composting, and the frequency that students recycled at home. Appendix 5.5 shows that for most students recycling at home was not related to Learning and was something they did on a greater than weekly basis. But in 2009, a small number of students who indicated they never learned about recycling and composting at school were less frequent in their recycling at home.

Chi-square results from 2009 and 2010 produced significant relationships, with small and medium effect sizes, between the importance students placed on school environmental experiences and the frequency that they recycled at home. Appendix 5.6 indicates this significance is caused by a few students that placed little to no importance on environmental experiences, where as the majority of students recycled weekly irrespective of the importance they placed on environmental experiences.

In 2010 only, there was a significant relationship, with medium effect size, between the family member/s at home who recycled most often and students' frequency of recycling at home. Appendix 5.7 illustrates that weekly recycling at home was a common feature of almost all families and that students recycled on a more than weekly 
regardless if they were one of the family members that recycled most often at home or not. The significant chi-square result from 2010 was likely caused by a very small number of students who reported that no one in their family recycled most often and that they never recycled.

Recycling at home on a greater than weekly basis was widespread among students at River's Edge Primary School, and only somewhat related with Learning, Importance and Participation. Similar to results for turning off lights, data mining revealed that 50 and 55 percent of students in 2009 and 2010 recycled at home on a daily basis, which suggests that for most students at River's Edge Primary School recycling may also have been a daily habit.

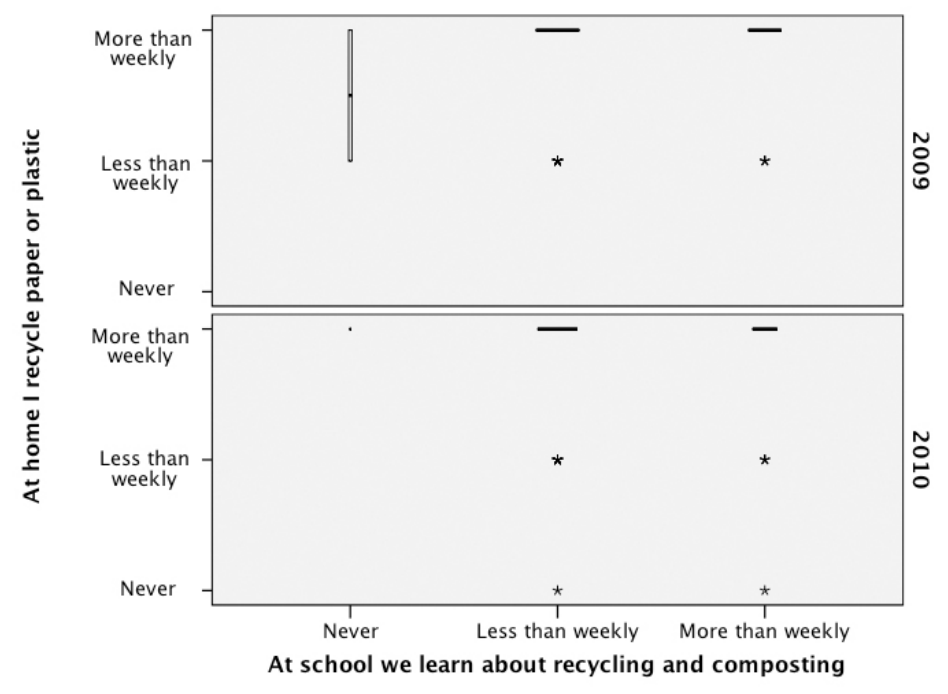

Appendix 5.5. Variable width box plots of students' self-reported frequency of recycling at home (y axis) and students' self-reported frequency of learning at school about recycling and composting (x axis). $2009\left(n_{\text {Learn never }}=6, n_{\text {Learn less than weekly }}=85, n_{\text {Learn more than weekly }}=64\right)$ and $2010\left(n_{\text {Learn never }}=3, n_{\text {Learn less than weekly }}=77, n_{\text {Learn more than weekly }}=48\right)$.

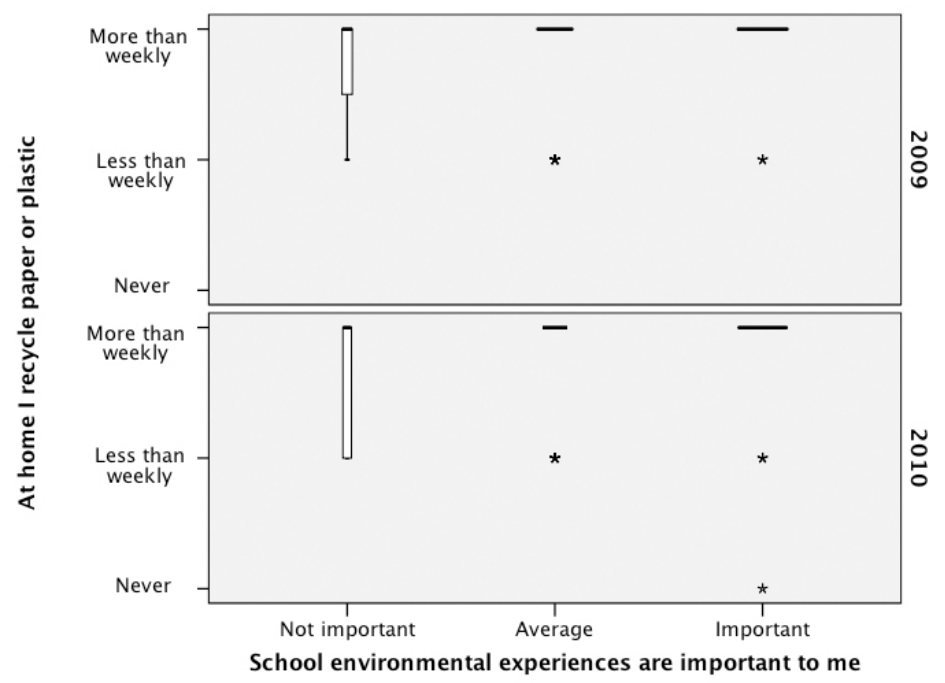

Appendix 5.6. Variable width box plots of students' self-reported frequency of recycling at home (y axis) and students' importance of school environmental experiences (x axis).-2009 ( $n$ ${ }_{n o t}$ important $\left.=16, n_{\text {average }}=56, n_{\text {important }}=79\right)$ and $2010\left(n_{\text {not important }}=13, n_{\text {average }}=38, n_{\text {important }}=\right.$ 76). 


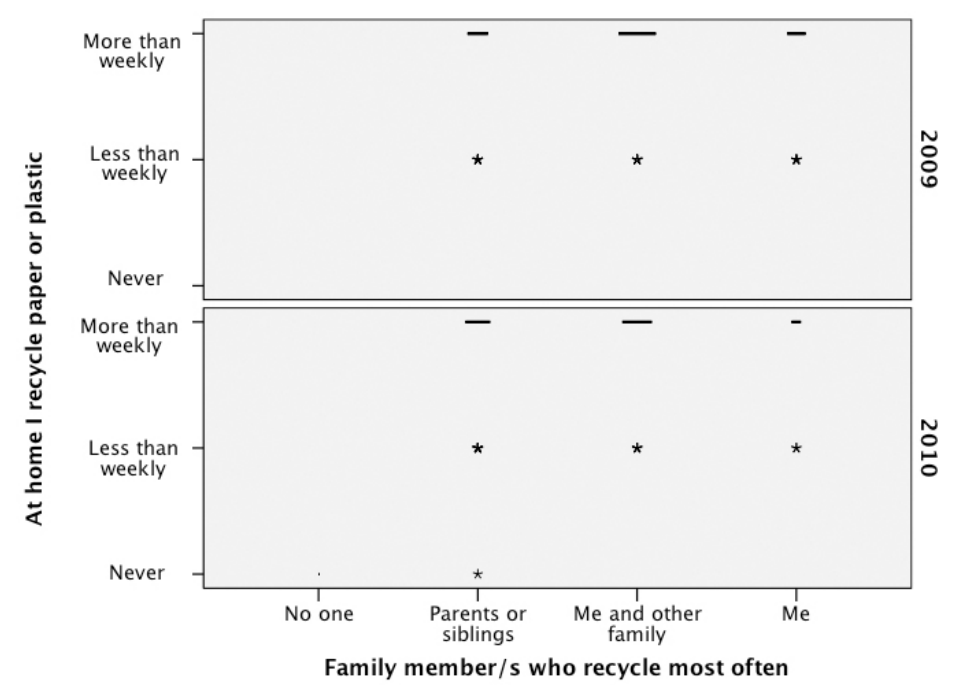

Appendix 5.7. Variable width box plots of students' self-reported frequency of recycling at home (y axis) and students' degree of participation in recycling at home (x axis). 2009 ( $n_{\text {no one }}=$ $\left.0, n_{\text {parents or siblings }}=42, n_{\text {me and other family }}=75, n_{\text {me }}=37\right)$ and $2010\left(n_{\text {no one }}=1, n_{\text {parents or siblings }}=49\right.$, $n_{\text {me and other family }}=59, n_{m e}=18$ ).

\section{Moderate frequency behaviours: Water saving and transport to school}

Appendix 5.8 provides a summary of results from the descriptive and statistical tests for the three behavioural variables: Short showers, saving water and transport to school. These behaviours were considered moderate frequency because in 2009 and 2010 between 40 and 70 percent of students performed these behaviours on a weekly basis (Figure 5.10). 
Appendix 5.8. Survey results of Year 4, 5, 6 students (end of term 3, 2009) and Year 5, 6 students (beginning of term 4, 2010). Summary of statistical analyses for water saving behaviours and transport to school, $\mathrm{n}_{2009}=155, \mathrm{n}_{2010}=128$, showing relationships between Learning, Importance and Participation.

\begin{tabular}{|c|c|c|c|c|}
\hline \multirow[b]{2}{*}{ Year } & & Learning & Importance & \multirow{2}{*}{$\begin{array}{l}\text { Participation } \\
\text { Chi-square of } \\
\text { 'who at home' ano } \\
\text { 'do at home' }\end{array}$} \\
\hline & & $\begin{array}{l}\text { Chi-square of } \\
\text { 'learn at school' } \\
\text { and 'do at home' }\end{array}$ & $\begin{array}{l}\text { Chi-square of } \\
\text { 'importance' and } \\
\text { 'do at home' }\end{array}$ & \\
\hline 2009 & $\begin{array}{l}\text { Short showers } \\
\text { (And use a four } \\
\text { minute shower } \\
\text { timer) }\end{array}$ & Non-significant & Non-significant & Non-significant \\
\hline 2010 & $\begin{array}{l}\text { Short showers } \\
\text { (And use a four } \\
\text { minute shower } \\
\text { timer) }\end{array}$ & $\begin{array}{l}\text { Significant } \\
\text { FET }(4,126)= \\
9.94, p=.047 \\
V=.20\end{array}$ & $\begin{array}{l}\text { Significant } \\
\text { FET }(4,125)= \\
25.64, p<.000 \\
V=.32\end{array}$ & $\begin{array}{l}\text { Significant } \\
\chi^{2}(6,126)=77.20 \\
p<.000 \\
V=.55\end{array}$ \\
\hline 2009 & $\begin{array}{l}\text { Save water in other } \\
\text { ways }\end{array}$ & $\begin{array}{l}\text { Significant } \\
\text { FET }(4,154)= \\
29.25, p<.000 \\
V=.31\end{array}$ & $\begin{array}{l}\text { Significant } \\
\text { FET }(4,151)= \\
21.71, p<.000 \\
V=.27\end{array}$ & $\begin{array}{l}\text { Significant } \\
\text { FET }(6,149)= \\
49.65, p<.000 \\
V=.41\end{array}$ \\
\hline 2010 & $\begin{array}{l}\text { Save water in other } \\
\text { ways }\end{array}$ & Non-significant & $\begin{array}{l}\text { Significant } \\
\text { FET }(4,127)= \\
11.63, p=.018 \\
V=.21\end{array}$ & $\begin{array}{l}\text { Significant } \\
\text { FET }(6,128)= \\
23.38, p<.000 \\
V=.30\end{array}$ \\
\hline 2009 & $\begin{array}{l}\text { Walk, bike or bus } \\
\text { to school }\end{array}$ & $\begin{array}{l}\text { Significant } \\
\text { FET }(4,152)= \\
14.26, p=.006 \\
V=.22\end{array}$ & Non-significant & $\begin{array}{l}\text { Significant } \\
\chi^{2}(6,150)= \\
103.69, p<.000 \\
V=.59\end{array}$ \\
\hline 2010 & $\begin{array}{l}\text { Walk, bike or bus } \\
\text { to school }\end{array}$ & Non-significant & Non-significant & $\begin{array}{l}\text { Significant } \\
\chi^{2}(6,127)=79.48 \\
p<.000 \\
V=.56\end{array}$ \\
\hline
\end{tabular}

$* \chi^{2}$ is the Pearson chi-square statistic (test for independence) at the specified degrees of freedom and sample size. FET indicates that Fisher's exact test of significance was used in place of $\chi^{2}$ because more than 20 percent of cells had expected frequencies of less than 5. $p$ is the probability value at .05 significance level. $V$ is Cramer's V - a measure of effect size. Cramer's V effect size range: $.07=$ small, $.21=$ medium, $.35=$ large.

Short showers. Short showers at home were practiced on a greater than weekly basis by 63 and 46 percent of upper-primary students at River's Edge Primary School in 2009 and 2010 respectively, and 8 and 18 percent of students indicated that they never took short showers at home (Figure 5.10). Chi-square results indicate that having short showers at home was related to Learning, Importance and Participation, but only in 2010.

Chi-square results from 2010 revealed a mild significance, with small effect size, between the frequency that students learn at school about saving household water, and the frequency that they have short showers at home. Chi-square results from 2009 were not significant $(p=.183)$. Appendix 5.9 illustrates that in 2009 the majority of students had short showers at home, irrespective of Learning, where as in 2010 students 
that learned less than weekly also had short showers on a less than weekly basis. It is also evident that compared to 2009, a greater number of students in 2010 indicated they learned less than weekly about saving household water.

This result is curious because in 2009, teachers had described that students in Years 5 and 6 learned more often and in greater depth about water related topics than students in Year 4, and in 2010 Year 5 and 6 students were the only year groups surveyed. It is possible that the reason for this result is consistent with the assertion made for water saving results at Lighthouse Primary School; that at the time of conducting surveys in 2009, all students had been learning about water conservation because of National Water Week.

Chi-square results from 2010 showed a significant association, with medium effect size, between the importance students placed on school environmental experiences and the frequency that students took short showers at home. Appendix 5.10 depicts this positive relationship in 2010, where students that placed less importance on environmental experiences took short showers on a less than weekly basis or never took short showers. In 2009 there is no such relationship, which could also be an artefact of National Water Week.

Chi-square results from 2010 presented a strongly significant relationship, with large effect size, between the family member/s that have short showers at home most often and the frequency that students have short showers. Appendix 5.11 shows that in 2009 most students reported they took short showers more than weekly regardless of which family member had short showers most often at home. But in 2010, in households where parents or siblings, or no one, took short showers most often, students took short showers less than weekly, where as when they were one of the active family members they tended to take showers more than weekly.

Having short showers at home was a common behaviour among students at River's Edge Primary School, and was only related with Learning, Importance and Participation in 2010. Results from 2009 were likely affected by a recent focus on water with perhaps more emphasis on short showers, during and leading up to National Water Week. It is also possible that the Year 5 and 6 teachers' focus on water in 2010 had reduced or changed emphasis compared with 2009.

Overall, results indicate that students are somewhat more likely to take short showers weekly when they learn weekly about water saving, if environmental experiences are important to them and if short showers are a family priority that they participate in equally with other family members. Results also suggest that when 
students learn more frequently about water saving, Importance becomes less related to their showering behaviour and Participation increases.

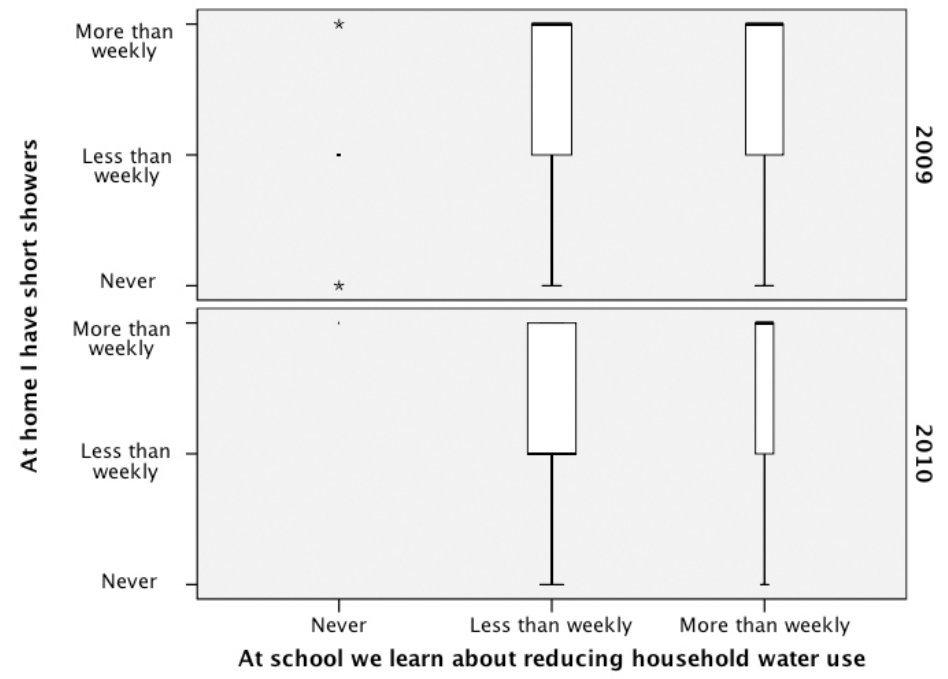

Appendix 5.9. Variable width box plots of students' self-reported frequency of having short showers at home (y axis) and students' self-reported frequency of learning at school about reducing household water use (x axis). $2009\left(n_{\text {Learn never }}=6, n_{\text {Learn less than weekly }}=75, n_{\text {Learn more than }}\right.$ weekly $=73)$ and $2010\left(n_{\text {Learn never }}=1, n_{\text {Learn less than weekly }}=93, n_{\text {Learn more than weekly }}=34\right)$.

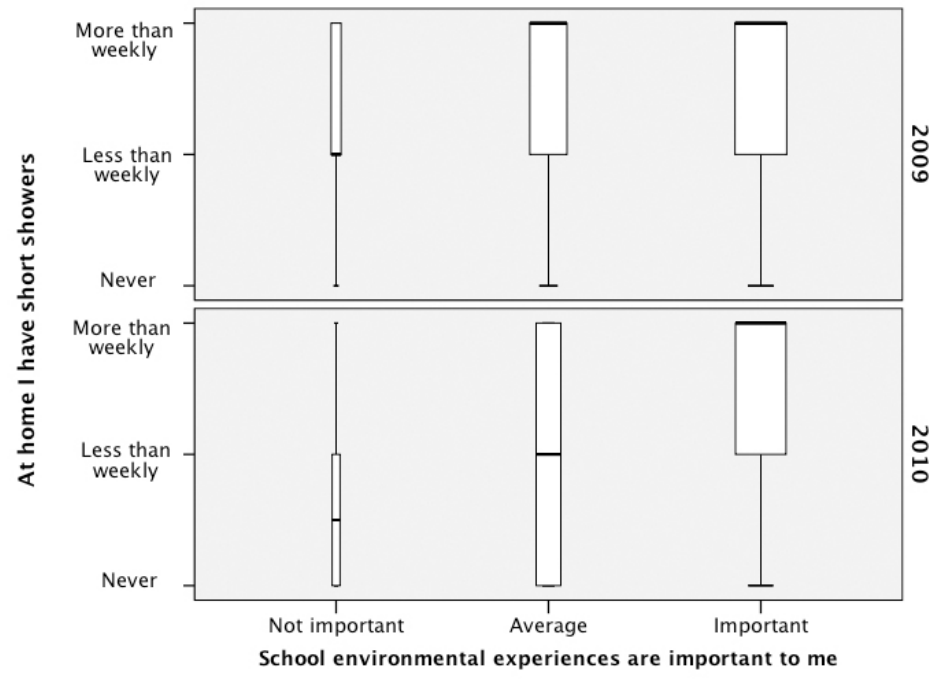

Appendix 5.10. Variable width box plots of students' self-reported frequency of having short showers at home (y axis) and students' importance of school environmental experiences (x axis). $2009\left(n_{\text {not important }}=16, n_{\text {average }}=56, n_{\text {important }}=79\right)$ and $2010\left(n_{\text {not important }}=13, n_{\text {average }}=\right.$ $\left.38, n_{\text {important }}=76\right)$. 


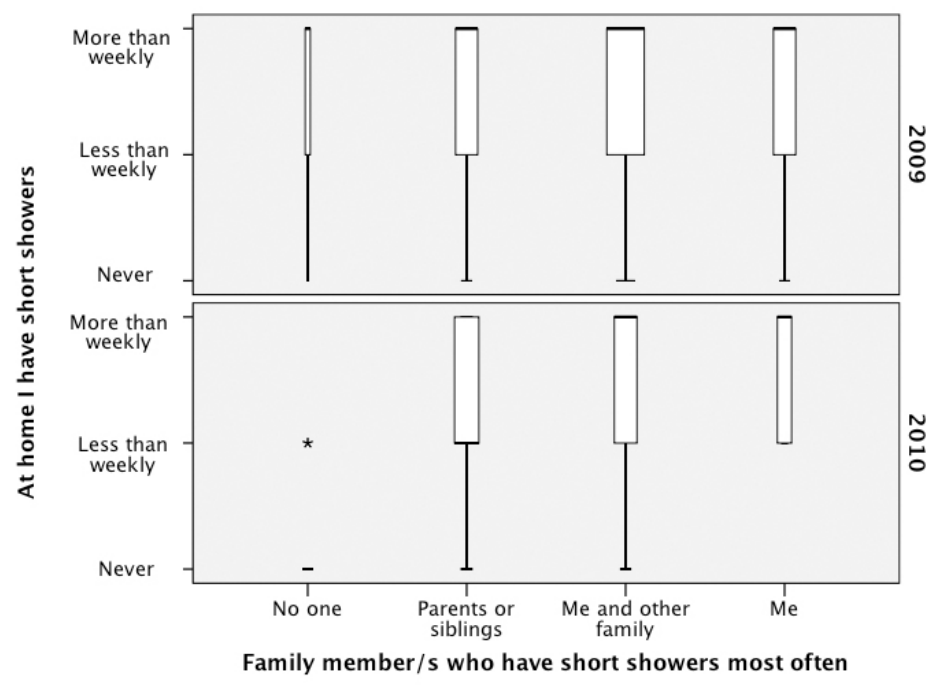

Appendix 5.11. Variable width box plots of students' self-reported frequency of having short showers at home (y axis) and students' degree of participation in having short showers at home (x axis). 2009 ( $\left.n_{\text {no one }}=9, n_{\text {parents or siblings }}=39, n_{\text {me and other family }}=68, n_{\text {me }}=39\right)$ and 2010 ( $n_{\text {no one }}$ $\left.=19, n_{\text {parents or siblings }}=44, n_{\text {me and other family }}=40, n_{m e}=25\right)$.

Save water in other ways. Saving water at home was practiced on a greater than weekly basis by 61 and 66 percent of upper-primary students at River's Edge Primary School in 2009 and 2010 respectively, and 6 and 5 percent of students indicated that they never saved water at home (Figure 5.10). Chi-square results indicate that saving water at home was related to Learning, Importance and Participation.

In 2009 only, chi-square results indicated a significant relationship, with medium effect size, between the frequency that students learned about saving household water and the frequency that students saved water at home. Appendix 5.12 shows a positive relationship between Learning and saving water at home in 2009 with students that learned weekly, saving water weekly. Similar to short showers it is also evident that in 2009 a greater proportion of students learned weekly about household water saving than students in 2010, which is likely related to the surveys being conducted during National Water Week in 2009. However, an interesting difference to results from short showers is that the majority of students in 2010 saved water weekly regardless of how often they learned about reducing household water use.

Chi-square results from 2009 and 2010 showed significant relationships, with medium effect sizes, between water saving at home and the importance students' placed on school environmental experiences. Appendix 5.13 depicts that students in 2009 and 2010 who considered environmental experiences as important, saved water at home on a greater than weekly basis, and students who placed less importance on environmental experiences had greater variation in their frequency of saving water at home. In 2010, 
however, the majority of students saved water weekly despite the importance they placed on environmental experiences.

Significant chi-square relationships, with large and medium effect sizes, were also found in 2009 and 2010 between students' degree of participation in water saving at home and their frequency of water saving. Appendix 5.14 illustrates that those students who saw themselves at the most active family member, saved water weekly in both 2009 and 2010. But, the majority of students saved water weekly in 2009 and 2010 irrespective of whether they were one of the main family members to save water, except students in households where no one saved water.

Saving water at home on a greater than weekly basis was a common behaviour among students at River's Edge Primary School, and was related to Learning, Importance and Participation. Results indicate that students are more likely to save water weekly if they learn weekly at school about reducing household water use, if environmental experiences are important to them and if water saving is a family priority.

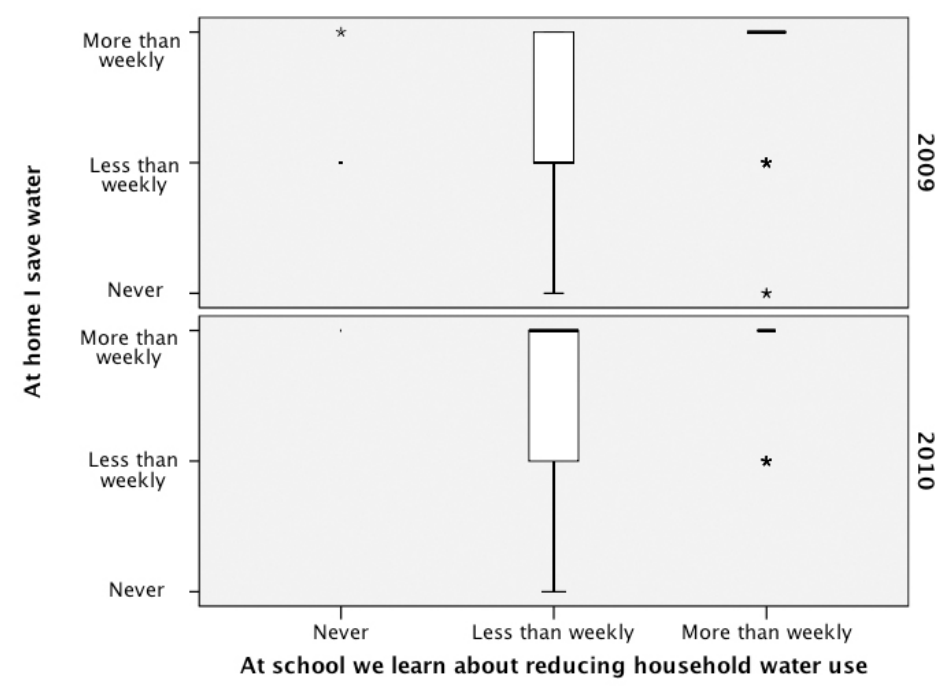

Appendix 5.12. Variable width box plots of students' self-reported frequency of saving water at home (y axis) and students' self-reported frequency of learning at school about reducing household water use (x axis). 2009 ( $n_{\text {Learn never }}=6, n_{\text {Learn less than weekly }}=75, n_{\text {Learn more than weekly }}=$ $73)$ and $2010\left(n_{\text {Learn never }}=1, n_{\text {Learn less than weekly }}=93, n_{\text {Learn more than weekly }}=34\right)$. 


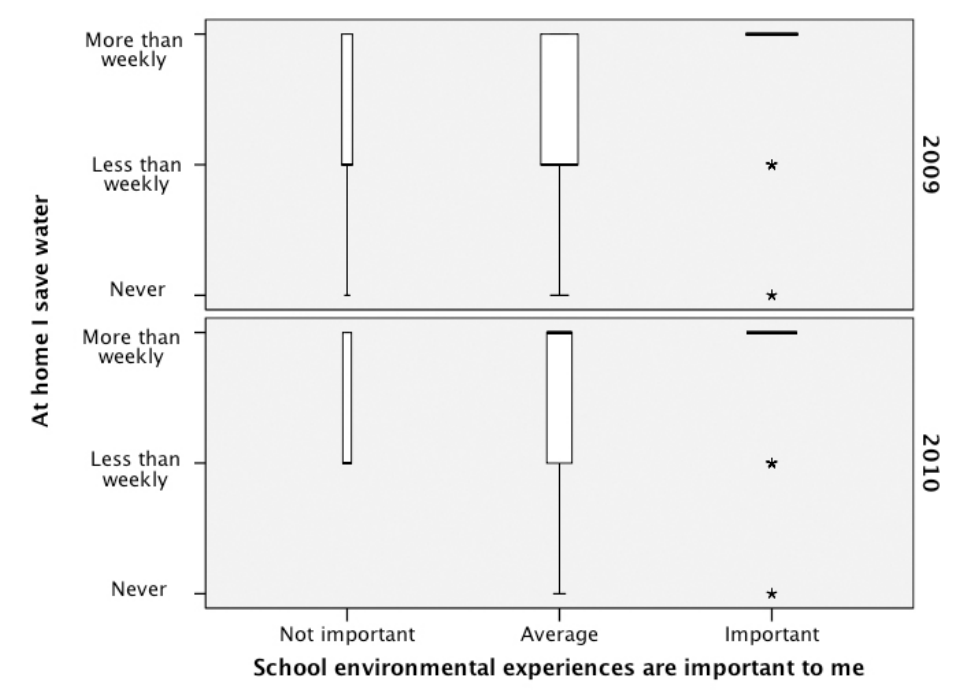

Appendix 5.13. Variable width box plots of students' self-reported frequency of saving water at home (y axis) and students' importance of school environmental experiences (x axis). 2009 ( $n$ $\left.n_{\text {not important }}=16, n_{\text {average }}=56, n_{\text {important }}=79\right)$ and $2010\left(n_{\text {not important }}=13, n_{\text {average }}=38, n_{\text {important }}=\right.$ 76).

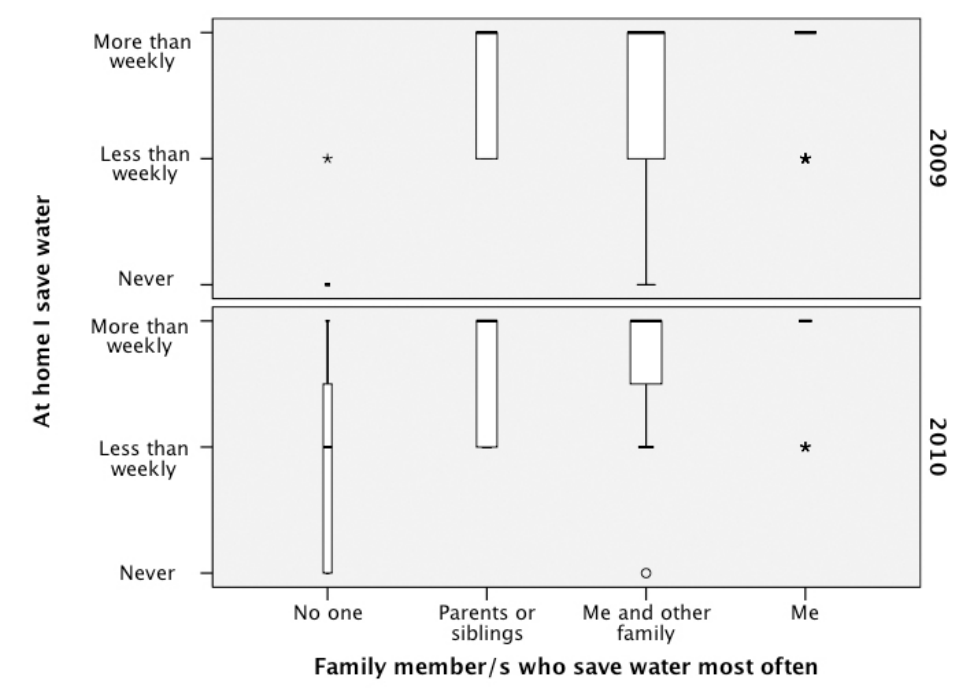

Appendix 5.14. Variable width box plots of students' self-reported frequency of saving water at home (y axis) and students' degree of participation in saving water at home (x axis). 2009 ( $n_{n o}$ one $\left.=9, n_{\text {parents or siblings }}=37, n_{\text {me and other family }}=65, n_{\text {me }}=38\right)$ and $2010\left(n_{n o ~ o n e}=15, n_{\text {parents or siblings }}\right.$ $=36, n_{\text {me and other family }}=55, n_{m e}=22$ ).

Alternative transport. Walking, biking or bussing to school was practiced on a greater than weekly basis by 45 and 42 percent of upper-primary students at River's Edge Primary School in 2009 and 2010 respectively, and 23 and 25 percent of students indicated that they never walked, biked or bussed to school (Figure 5.10). Chi-square results indicate that taking alternative transport to school was not related to Importance and was related to Learning and Participation.

In 2009 only, chi-square results presented a significant association, with medium effect size, between the frequency that students learned at school about taking alternative transport to school and the frequency that students walked, biked or bussed 
to school. Appendix 5.15 illustrates that in both 2009 and 2010, most students that reported they learned weekly about alternative transport, took alternative transport to school on a greater than weekly basis. In 2009 the positive relationship between Learning and taking alternative transport was more apparent, however, a similar relationship appears to have existed in 2010 - although there was not enough separateness between observed and expected scores for the chi-square results to be significant. Chi-square results from 2010 were not significant $(p=.098)$.

It was suspected that age or proximity to school might also be related with students' frequency of walking, biking or bussing to school. Chi-square tests comparing age with frequency of taking alternative transport found a mildly significant relationship, with large effect size, in $2009\left(\chi^{2}=13.17, p=.042, V=.30\right)$, but no significant relationship in 2010. The chi-square output showed that, in 2009, older students (11 and 12 years of age) took alternative transport more frequently than younger students (9 and 10 years of age). Since Learning also had a positive relationship with taking alternative transport in 2009 , it was possible that Learning had more impact or was more directed to older students.

The non-significant results in 2010, for age and Learning related with taking alternative transport, suggest that there was reduced emphasis in 2010 about taking alternative transport to school. This hypothesis is congruent with a statement from the school principal (cited in Chapter 5) that their walk-to-school and bus-to-school initiatives had been faulted by many obstacles, including lack of parental support, that there had been reduced participation among students and Transperth had cancelled the bus service.

Chi-square tests comparing proximity to school with the frequency that students took alternative transport to school found no significant relationships in 2009 or 2010. Students that lived within 2.5 kilometres from the school were not more likely to walk, bike or bus to school than students who lived up to or over 8 kilometres from the school. This result is not surprising for two reasons. First, the school is an elite private school that drew students from various suburbs across Perth, making it difficult for students to travel long distances to school. Descriptive statistics showed that only 29 and 26 percent of students lived within 2.5 kilometres of the school in 2009 and 2010 respectively, and 25 and 23 percent of students lived over 8 kilometres away from the school. Second, it is likely that parents were cautious of allowing their children to walk, bike or bus to school, regardless of how close they lived to the school, because of inflated fears for their children's safety and the volume of equipment required for their 
child's various extra curricular activities, as validated by a quotation from Mrs Eagle Ray cited in Chapter 5.

Chi-square results, from 2009 and 2010, showed significant associations between the degree of student participation among their family members and their frequency of taking alternative transport to school. Appendix 5.16 displays this positive relationship and shows that students who were among the most active family members to take alternative transport, were more likely to walk, bike or bus to school on a greater than weekly basis. In homes where no one was active, students did not take alternative transport to school. The proportion of homes where no one took alternative transport was also not a small amount.

Walking, biking or bussing to school was a common behaviour among students at River's Edge Primary School, and was most related with age and Learning. Older students were more likely to take alternative transport to school in 2009. It seems likely that the significant associations between learning and taking alternative transport to school in 2009 were because of a greater emphasis on this topic and that learning was most directed towards these older students.

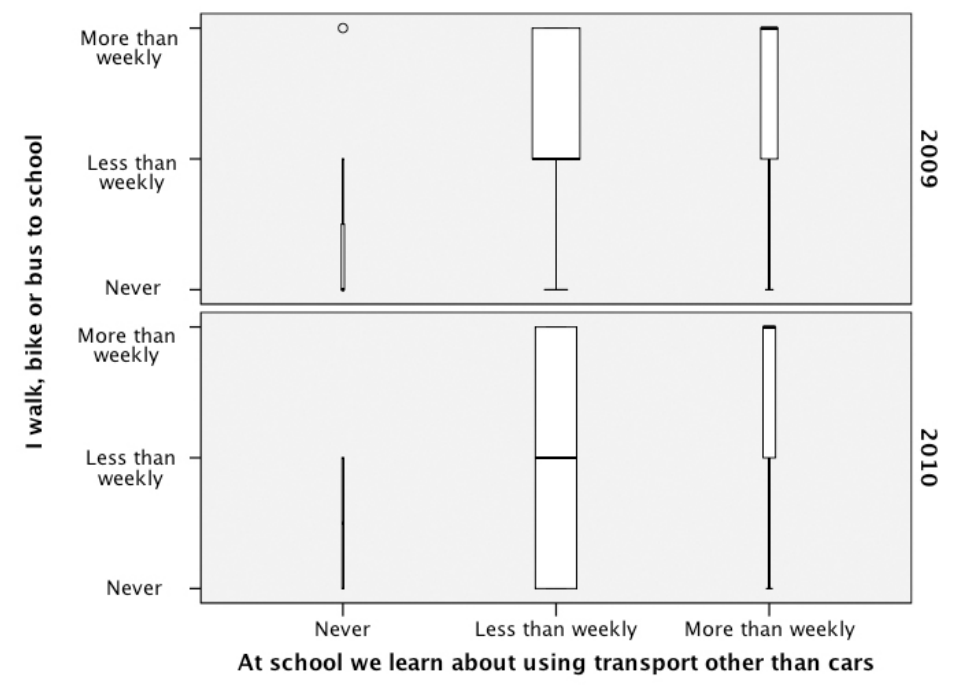

Appendix 5.15 Variable width box plots of students' self-reported frequency of walking, biking or bussing to school (y axis) and students' self-reported frequency of learning at school about using transport other than cars (x axis). $2009\left(n_{\text {Learn never }}=7, n_{\text {Learn less than weekly }}=107, n_{\text {Learn more }}\right.$ than weekly $=39)$ and $2010\left(n_{\text {Learn never }}=4, n_{\text {Learn less than weekly }}=94, n_{\text {Learn more than weekly }}=28\right)$. 


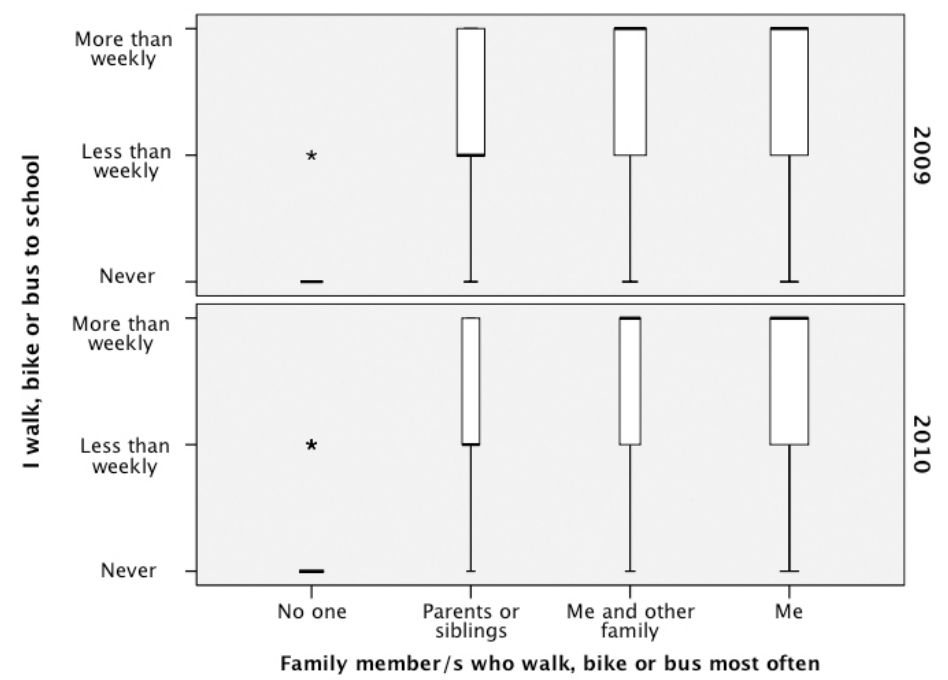

Appendix 5.16. Variable width box plots of students' self-reported frequency of walking, biking or bussing to school (y axis) and students' degree of participation in walking, biking or bussing from home (x axis). 2009 ( $n_{n o}$ one $\left.=28, n_{\text {parents or siblings }}=35, n_{\text {me and other family }}=40, n_{\text {me }}=48\right)$ and $2010\left(n_{\text {no one }}=32, n_{\text {parents or siblings }}=22, n_{\text {me and other family }}=26, n_{\text {me }}=48\right)$.

\section{Low frequency behaviours: Eating home grown produce and maintaining organic waste}

Appendix 5.17 provides a summary of results from the descriptive and statistical tests for the behavioural variables: Eating home grown produce and Maintaining organic waste. These behaviours were considered low frequency because less than 40 percent of students, in 2009 and 2010, indicated they practiced either of these behaviours on a greater than weekly basis (Figure 5.10). 
Appendix 5.17. Survey results of Year 4, 5, 6 students (end of term 3, 2009) and Year 5, 6 students (beginning of term 4, 2010). Summary of statistical analyses for eating home grown produce and composting behaviours, $\mathrm{n}_{2009}=155, \mathrm{n}_{2010}=128$, showing relationships between Learning, Importance and Participation.

\begin{tabular}{|c|c|c|c|c|}
\hline & & Learning & Importance & Participation \\
\hline Year & & $\begin{array}{l}\text { Chi-square of } \\
\text { 'learn at school' } \\
\text { and 'do at home' }\end{array}$ & $\begin{array}{l}\text { Chi-square of } \\
\text { 'importance' and } \\
\text { 'do at home' }\end{array}$ & $\begin{array}{l}\text { Chi-square of } \\
\text { 'who at home' } \\
\text { and 'do at home' }\end{array}$ \\
\hline 2009 & $\begin{array}{l}\text { Eat home grown } \\
\text { fruit or vegetables }\end{array}$ & Non-significant & Non-significant & $\begin{array}{l}\text { Significant } \\
\chi^{2}(6,148)= \\
106.17, p<.000 \\
V=.59\end{array}$ \\
\hline 2010 & $\begin{array}{l}\text { Eat home grown } \\
\text { fruit or vegetables }\end{array}$ & Non-significant & Non-significant & $\begin{array}{l}\text { Significant } \\
\chi^{2}(6,126)= \\
120.75, p<.000 ; \\
\text { FET, } \\
V=.66\end{array}$ \\
\hline 2009 & $\begin{array}{l}\text { Put food scraps } \\
\text { into a worm farm } \\
\text { or compost bin }\end{array}$ & $\begin{array}{l}\text { Significant } \\
\text { FET }(4,146)= \\
10.29, p=.034 \\
V=.19\end{array}$ & $\begin{array}{l}\text { Significant } \\
\text { FET }(4,148)= \\
123.16, p<.000 \\
V=.65\end{array}$ & Non-significant \\
\hline 2010 & $\begin{array}{l}\text { Put food scraps } \\
\text { into a worm farm } \\
\text { or compost bin }\end{array}$ & Non-significant & Non-significant & $\begin{array}{l}\text { Significant } \\
\text { FET }(6,125)= \\
95.61, p<.000 ; \\
V=.62\end{array}$ \\
\hline
\end{tabular}

$* \chi^{2}$ is the Pearson chi-square statistic (test for independence) at the specified degrees of freedom and sample size. FET indicates that Fisher's exact test of significance was used in place of $\chi^{2}$ because more than 20 percent of cells had expected frequencies of less than 5. $p$ is the probability value at .05 significance level. $V$ is Cramer's V - a measure of effect size. Cramer's V effect size range: $.07=$ small, $.21=$ medium, .35 = large.

Eating home grown produce. Eating home grown fruits or vegetables was practiced on a greater than weekly basis by 31 and 33 percent of upper-primary students at River's Edge Primary School in 2009 and 2010 respectively, and 35 and 32 percent of students indicated that they never ate home grown produce (Figure 5.10). Chi-square results indicate that eating home grown produce was not related to Learning or Importance and was related to Participation.

In 2009 and 2010, strong significant chi-square relationships, with very large effect sizes, were found between the family member/s who ate home grown produce most often and the frequency that students ate home grown produce. Appendix 5.18 shows that the majority of students ate home grown produce on a greater than weekly basis when they lived in households where they did so equally with other family members. There were also a large number of students that never ate home grown produce and lived in households where no one did this.

Eating home grown fruits or vegetables was uncommon among students at River's Edge Primary School. Results indicate that weekly eating of home grown produce was primarily related to whether the student participated in this behaviour with 
other family members. This suggests that regular eating of home grown produce is largely impacted by whether it is a family priority and the degree that students are engaged at home.

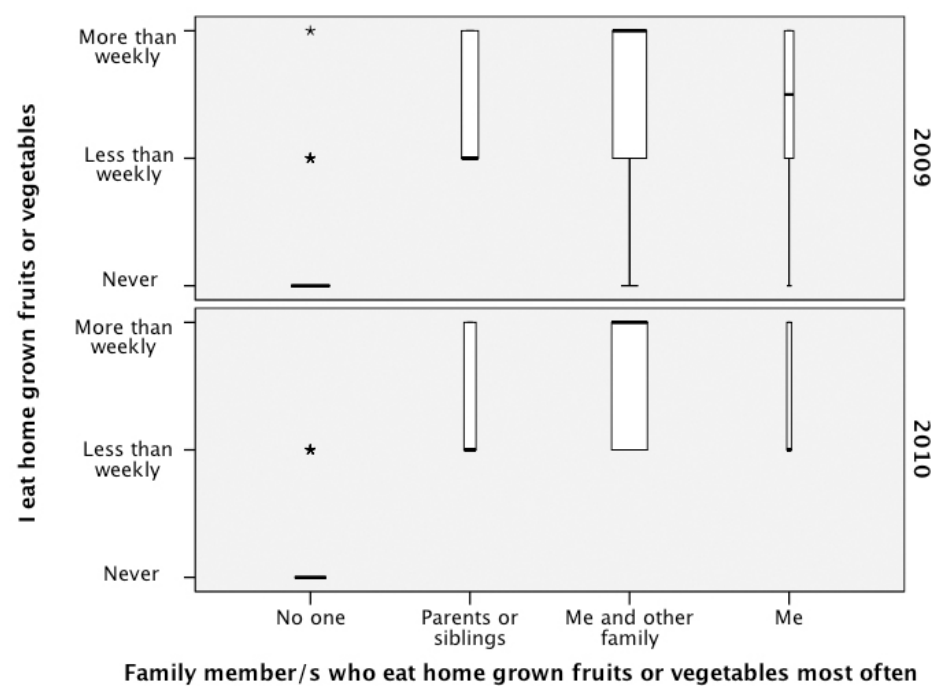

Appendix 5.18. Variable width box plots of students' self-reported frequency of eating home grown fruits or vegetables (y axis) and students' degree of participation in eating home grown fruits or vegetables (x axis). 2009 ( $n_{\text {no one }}=58, n_{\text {parents or siblings }}=25, n_{\text {me and other family }}=51, n_{\text {me }}=$ $14)$ and 2010 ( $\left.n_{\text {no one }}=48, n_{\text {parents or siblings }}=18, n_{\text {me and other family }}=55, n_{m e}=7\right)$.

Maintaining organic waste. Putting food scraps into a worm farm or compost bin was practiced on a greater than weekly basis by 23 and 21 percent of upper-primary students at River's Edge Primary School in 2009 and 2010 respectively, and 50 and 55 percent of students indicated that they never worm farmed or composted at home (Figure 5.10). Chi-square results indicate that maintaining organic waste processes at home was related to Learning, Importance and Participation.

Chi-square results from 2009 only, produced a significant relationship, with small effect size, between the frequency that students learned about recycling and composting and the frequency that students put food scraps into a worm farm or compost bin at home. Appendix 5.19 depicts that in 2009, most students who learned weekly about recycling and composting, maintained organic waste at home on a less than weekly basis. However, it also illustrates that the majority of students in 2009 and 2010 never put food scraps into a worm farm or compost bin at home, despite how frequently they learned about this topic. These findings are congruent with teacher interviews that described very minimal learning about worm farming or composting by Years 4, 5 and 6, because the Year 3 students were responsible for maintaining the school worm farm and there was not a compost or food scrap collection system at the school (Chapter 5). 
In 2009, chi-square results indicated a strong significant association, with very large effect size, between students' perceived importance of school environmental experiences and their frequency of putting food scraps into a worm farm or compost bin. Appendix 5.20 illustrates a positive relationship between these two variables in 2009, which shows that students who placed more importance on environmental experiences were more likely to maintain organic waste at home on a less than weekly basis, whereas students with little to no importance were likely never to do this at home. In 2010 this pattern was very mild, but still present.

Chi-square results from 2010 showed a strong significant relationship, with very large effect size, between the family member/s most active in maintaining organic waste at home and the frequency that students did this at home. Appendix 5.21 shows that the majority of students, in 2009 and 2010, lived in households where no one maintained organic waste and they never did so either. It also indicates that when students lived in homes where one or more of their family members maintained organic waste they participated occasionally. Furthermore in 2010 only, most students put food scraps into a worm farm or compost bin on a greater than weekly basis when they were one of the most active family members in the household for this behaviour, however, this is based on a small number of students (Appendix 5.21). Overall, it appeared that students who put food scraps into a worm farm or compost bin on a weekly basis did so when any combination of family members were most active.

Putting food scraps into a worm farm or compost bin on a greater than weekly basis was an uncommon behaviour among students at River's Edge Primary School, which was predominantly impacted by whether it was a family priority. Students that maintained organic waste at home at any frequency may have been influenced by what they learned at school on the topic and whether environmental experiences were important to them. 


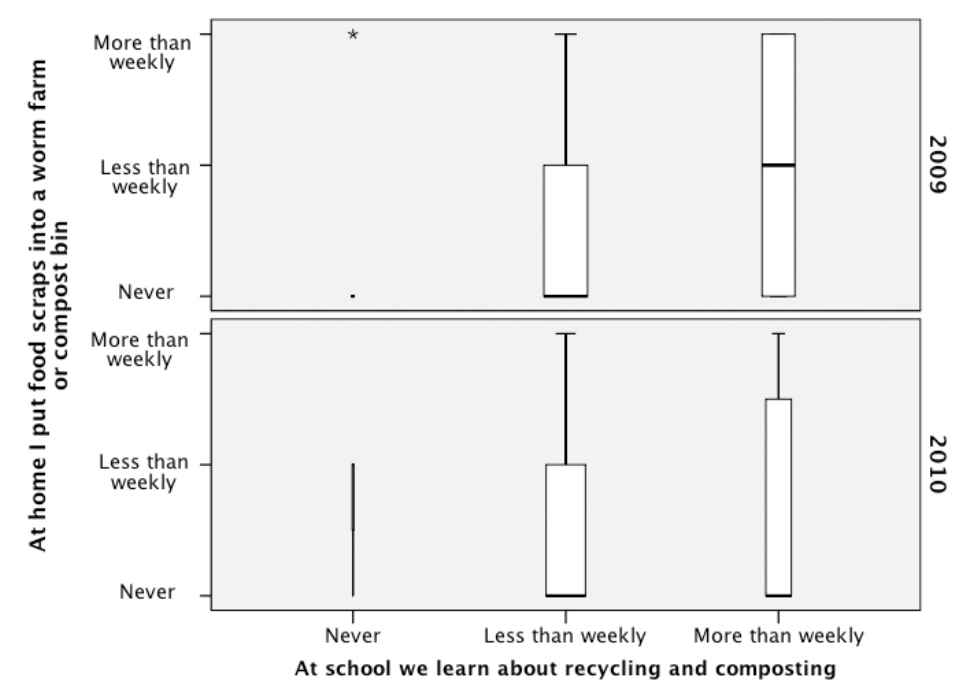

Appendix 5.19. Variable width box plots of students' self-reported frequency of putting food scraps into a worm farm or compost bin at home (y axis) and students' self-reported frequency of learning at school about recycling and composting at home (x axis). 2009 ( $n_{\text {Learn never }}=6, n$ Learn less than weekly $\left.=85, n_{\text {Learn more than weekly }}=64\right)$ and $2010\left(n_{\text {Learn never }}=3, n_{\text {Learn less than weekly }}=77, n\right.$ Learn more than weekly $=48$ ).

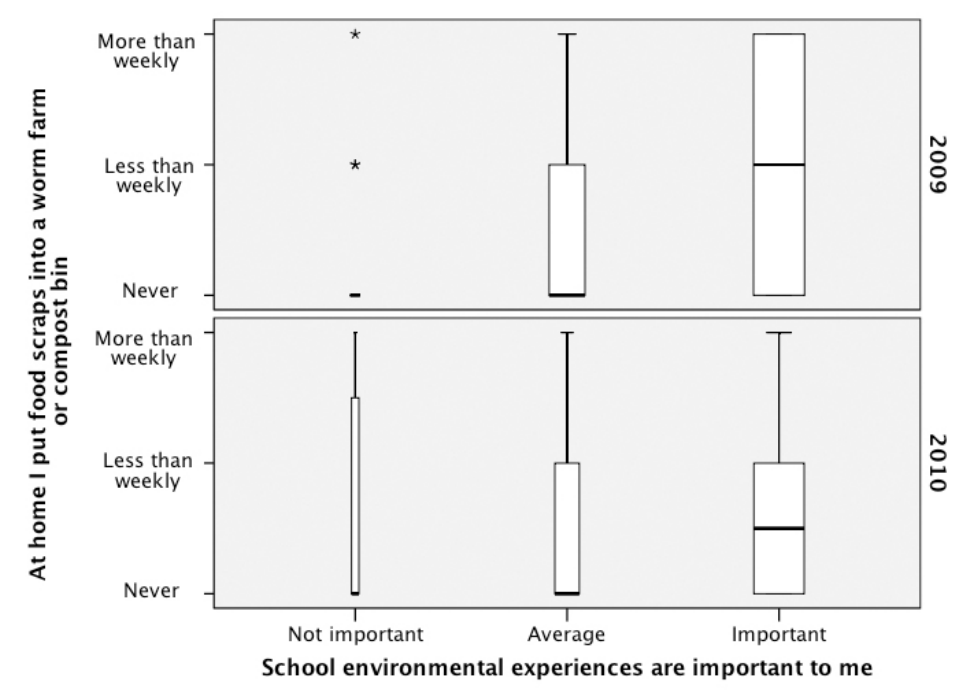

Appendix 5.20. Variable width box plots of students' self-reported frequency of putting food scraps into a worm farm or compost bin at home (y axis) and students' importance of school environmental experiences (x axis). $2009\left(n_{\text {not important }}=16, n_{\text {average }}=56, n_{\text {important }}=79\right)$ and $2010\left(n_{\text {not important }}=13, n_{\text {average }}=38, n_{\text {important }}=76\right)$. 
ApPendix 5 - Detailed Student Behaviour Results From River's Edge Primary School

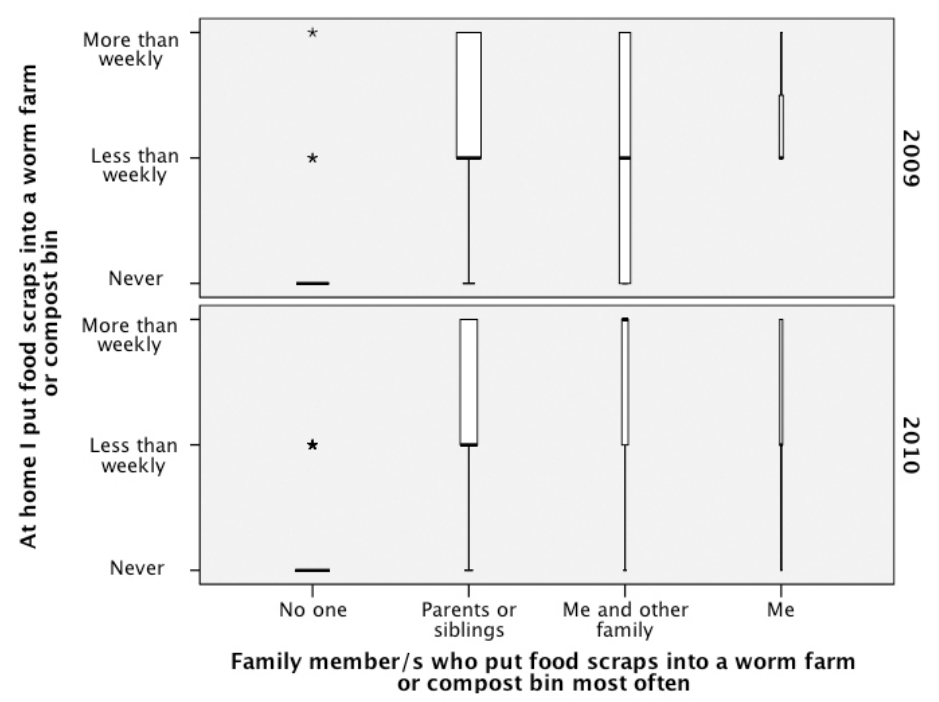

Appendix 5.21. Variable width box plots of students' self-reported frequency of putting food scraps into a worm farm or compost bin at home (y axis) and students' degree of participation in putting food scraps into a worm farm or compost bin at home (x axis). 2009 ( $n_{\text {no one }}=69, n_{\text {parents }}$ or siblings $\left.=50, n_{\text {me and other family }}=23, n_{\text {me }}=8\right)$ and $2010\left(n_{\text {no one }}=72, n_{\text {parents or siblings }}=35, n_{\text {me and }}\right.$ other family $=13, n_{m e}=6$ ). 
THIS PAGE HAS PURPOSELY BEEN LEFT BLANK 


\section{Appendix 6 - Detailed Student Behaviour Results From}

\section{Fertile Ground PRIMARY SCHOOL}

Significant results from the chi-square tests indicate the presence and strength of relationships between students' frequency of undertaking seven common proenvironmental behaviours and the three comparison variables: Learning, Importance and Participation. The chi-square results for each behaviour and comparison variables are presented and discussed in the following paragraphs.

\section{High frequency behaviours: Turning off lights}

The behavioural variable, Turning off lights was considered high frequency because in 2009 greater than 70 percent of students turned off lights on a weekly basis (Figure 6.9). Chi-square tests performed for Turning off lights were all non-significant.

Turning off lights. Turning off lights at home was practiced on a greater than weekly basis by 81 percent of upper-primary students at Fertile Ground Primary School in 2009 and none of the surveyed students indicated that they never turned off lights at home (Figure 6.9). Closer inspection of the data revealed that 62 percent of students turned off lights daily, which supports the assertions made for students at Lighthouse and Riverside Primary Schools; turning off lights at home was a daily habit for most students.

Chi-square results found that turning off lights at home was not related to any of the three comparison variables, Learning, Importance or Participation. Box plots are not shown because there were no relationships. The degree of inference from these results is limited because of the small sample size, but inspection of the chi-square output showed that most students were turning off lights more than weekly regardless of Learning, Importance or Participation. Consequently, if students were doing this behaviour weekly they did it regardless of how often they learned about energy reduction, how important school environmental experiences were to them and which family members were most proactive.

\section{Moderate frequency behaviours: Water saving and transport to school}

Appendix 6.1 provides a summary of results from the chi-square tests performed for the two behavioural variables: Short showers and saving water. These behaviours were considered moderate frequency because in 2009 between 40 and 70 percent of students performed these behaviours on a weekly basis (Figure 6.9). 
Appendix 6.1. Survey results of Year 4, 5, 6 students (end of term 3, 2009). Summary of statistical analyses for water saving behaviours, $\mathrm{n}_{2009}=26$, showing relationships between Learning, Importance and Participation.

\begin{tabular}{|c|c|c|c|c|}
\hline & & Learning & Importance & Participation \\
\hline Year & Behaviour & $\begin{array}{l}\text { Chi-square of } \\
\text { 'learn at school', } \\
\text { and 'do at home' }\end{array}$ & $\begin{array}{l}\text { Chi-square of } \\
\text { 'importance' and } \\
\text { 'do at home' }\end{array}$ & $\begin{array}{l}\text { Chi-square of } \\
\text { 'who at home' and } \\
\text { 'do at home' }\end{array}$ \\
\hline 2009 & $\begin{array}{l}\text { Short showers } \\
\text { (And use a four } \\
\text { minute shower timer) }\end{array}$ & Non-significant & Non-significant & Non-significant \\
\hline 2009 & $\begin{array}{l}\text { Save water in other } \\
\text { ways }\end{array}$ & Non-significant & 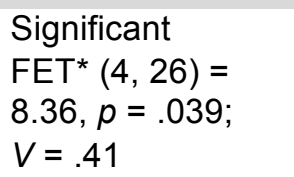 & $\begin{array}{l}\text { Significant } \\
\text { FET }(6,26)= \\
10.84, p=.039 \\
V=.51\end{array}$ \\
\hline
\end{tabular}

* FET indicates that Fisher's exact test of significance was used in place of $\chi^{2}$ because more than 20 percent of cells had expected frequencies of less than 5. $p$ is the probability value at .05 significance level. $V$ is Cramer's V - a measure of effect size. Cramer's V effect size range: $.07=$ small, $.21=$ medium, .35 $=$ large.

Short showers. Short showers at home were practiced on a greater than weekly basis by 50 percent of upper-primary students at Fertile Ground Primary School in 2009 and 27 percent of students indicated that they never took short showers at home (Figure 6.9). Chi-square results indicate that having short showers at home was not related to any of the three comparison variables, Learning, Importance or Participation. Box plots are not shown because there were no relationships. Consequently, if students were doing this behaviour weekly they did it regardless of how often they learned about water conservation, how important school environmental experiences were to them and which family members were most proactive.

Save water in other ways. Saving water at home was practiced on a greater than weekly basis by 54 percent of upper-primary students at Fertile Ground Primary School in 2009 and 15 percent of students indicated that they never saved water at home (Figure 6.9). Chi-square results indicate that saving water at home was not related to Learning and was related to Importance and Participation.

Chi-square results show a significant relationship, with large effect size, between the frequency that students saved water at home and the importance students placed on school environmental experiences. Appendix 6.2 depicts a positive trend between these two variables that indicates students who placed greater value on school environmental experiences were more likely to save water at home on a greater than weekly basis.

Chi-square results that compared students' frequency of water saving at home and the family members most active in this behaviour, found a significant relationship 
with very large effect size. Appendix 6.3 illustrates that students who saved water on a greater than weekly basis were also one of the most active family members, indicating that participation at home may influence the frequency that students save water.

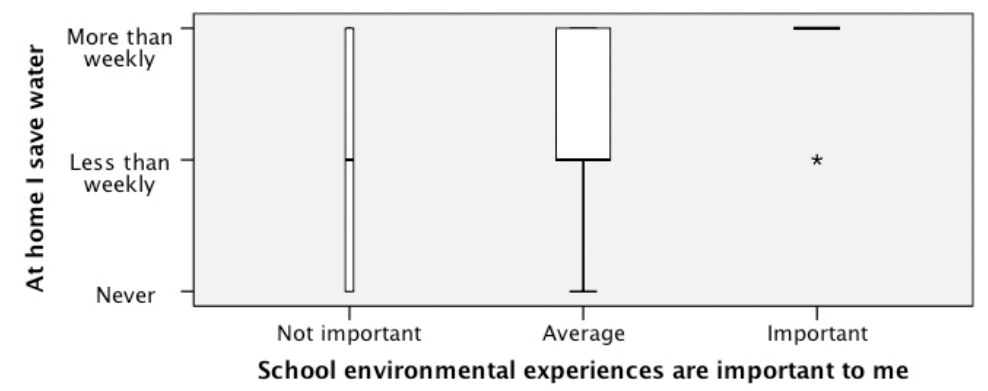

Appendix 6.2. Variable width box plots of students' self-reported frequency of saving water at home (y axis) and students' importance of school environmental experiences (x axis). 2009 ( $n$ not important $\left.=2, n_{\text {average }}=13, n_{\text {important }}=11\right)$.

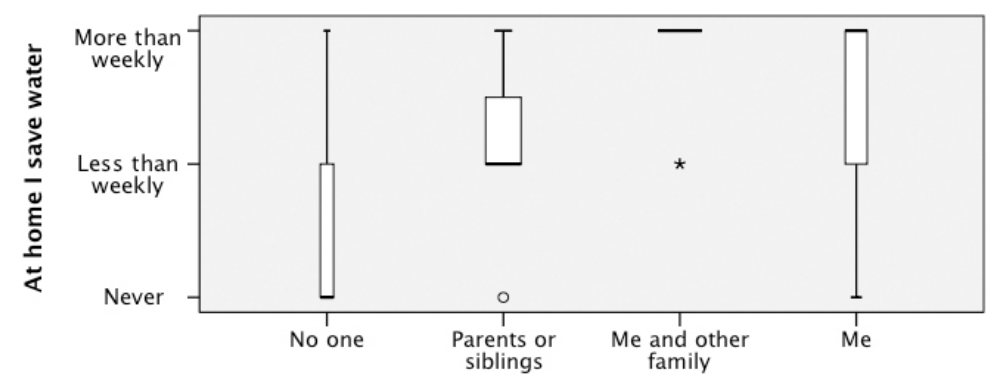

Family member/s who save household water most often

Appendix 6.3. Variable width box plots of students' self-reported frequency of saving water at home (y axis) and students' degree of participation in saving water at home (x axis). 2009 ( $n_{n o}$ one $=5, n_{\text {parents or siblings }}=10, n_{\text {me and other family }}=8, n_{\text {me }}=3$ ).

\section{Low frequency behaviours: Recycling, transport to school, eating home grown produce and maintaining organic waste}

Appendix 6.4 provides a summary of results from the descriptive and statistical tests for the behavioural variables: Recycling, transport to school, eating home grown produce and maintaining organic waste. These behaviours were considered low frequency because less than 40 percent of students in 2009 indicated they practiced either of these behaviours on a greater than weekly basis (Figure 6.9). 
Appendix 6.4. Survey results of Year 4, 5, 6 students (end of term 3, 2009). Summary of statistical analyses for recycling, transport to school, eating home grown produce and composting behaviours, $\mathrm{n}_{2009}=26$, showing relationships between Learning, Importance and Participation.

\begin{tabular}{|c|c|c|c|c|}
\hline & & Learning & Importance & Participation \\
\hline Year & Behaviour & $\begin{array}{l}\text { Chi-square of } \\
\text { 'learn at school' } \\
\text { and 'do at home' }\end{array}$ & $\begin{array}{l}\text { Chi-square of } \\
\text { 'importance' and } \\
\text { 'do at home' }\end{array}$ & $\begin{array}{l}\text { Chi-square of 'who } \\
\text { at home' and 'do } \\
\text { at home' }\end{array}$ \\
\hline 2009 & $\begin{array}{l}\text { Recycle paper or } \\
\text { plastic }\end{array}$ & Non-significant & Non-significant & Non-significant \\
\hline 2009 & $\begin{array}{l}\text { Walk, bike or bus to } \\
\text { school }\end{array}$ & Non-significant & Non-significant & Non-significant \\
\hline 2009 & $\begin{array}{l}\text { Eat home grown } \\
\text { fruits or vegetables }\end{array}$ & $\begin{array}{l}\text { Significant } \\
\text { FET }^{*}(4,25)= \\
7.95, p=.041 \\
V=.41\end{array}$ & $\begin{array}{l}\text { Significant } \\
\text { FET }^{*}(4,26)= \\
9.39, p=.025 \\
V=.44\end{array}$ & $\begin{array}{l}\text { Significant } \\
\text { FET }(6,26)=12.82 \\
p=.020 \\
V=.51\end{array}$ \\
\hline 2009 & $\begin{array}{l}\text { Put food scraps into } \\
\text { a worm farm or } \\
\text { compost bin }\end{array}$ & Non-significant & Non-significant & Non-significant \\
\hline
\end{tabular}

* FET indicates that Fisher's exact test of significance was used in place of $\chi^{2}$ because more than 20 percent of cells had expected frequencies of less than 5. $p$ is the probability value at .05 significance level. $V$ is Cramer's V - a measure of effect size. Cramer's V effect size range: $.07=$ small, $.21=$ medium, .35 $=$ large.

Recycling. Recycling at home was practiced on a greater than weekly basis by 36 percent of upper-primary students at Fertile Ground Primary School in 2009 and 32 percent of students indicated that they never recycled at home (Figure 6.9). Chi-square results indicate that recycling at home was not related to any of the three comparison variables, Learning, Importance or Participation. Box plots are not shown because there were no relationships. Consequently, if students were doing this behaviour weekly they did it regardless of how often they learned about waste minimisation, how important school environmental experiences were to them and which family members were most proactive.

Alternative transport. Walking, biking or bussing to school was practiced on a greater than weekly basis by 35 percent of upper-primary students at Fertile Ground Primary School in 2009 and 65 percent of students indicated that they never walked, biked or bussed to school (Figure 6.9). Chi-square results indicate that taking alternative transport to school was not related to any of the three comparison variables, Learning, Importance or Participation. Box plots are not shown because there were no relationships. Consequently, if students were doing this behaviour weekly they did it regardless of how often they learned about alternative transport choices, how important 
school environmental experiences were to them and which family members were most proactive.

Chi-square tests were also performed to determine if a relationship existed between taking alternative transport to school and students' age or proximity to the school (less than or greater than $2 \mathrm{~km}$ ). Results were non-significant, indicating that age and proximity had no impact on whether students took alternative transport to school.

Eating home grown produce. Eating home grown fruits or vegetables was practiced on a greater than weekly basis by 31 percent of upper-primary students at Fertile Ground Primary School in 2009 and 42 percent of students indicated that they never ate home grown produce (Figure 6.9). Chi-square results indicate that eating home grown produce was related to all three of the comparison variables, Learning, Importance and Participation.

Chi-square results revealed a significant relationship, with large effect size, between the frequency that students learned at school about growing and eating home grown fruits and vegetables and the frequency that students ate home grown produce. Appendix 6.5 illustrates that this was a negative relationship, where students who indicated they never learned at school about growing produce at home were more likely to eat fruits and vegetables grown at their home with some regularity, while the majority of those who said they learned at school with some regularity indicated they never ate home grown produce. This is an unexpected finding and could be an artefact of the small sample size, however, it could also indicate that a decent proportion of students from Fertile Ground Primary School were familiar with growing and eating produce from their home and might be receptive to the topic being given more priority in their class time or on their school grounds.

Chi-square results of the relationship between the importance students placed on school environmental experiences and the frequency that students ate home grown produce, revealed a significant relationship with large effect size. Appendix 6.6 shows a positive relationship between these two variables and suggests that students who placed greater importance on environmental experiences were more likely to eat home grown fruits and vegetables on a greater than weekly basis.

Chi-square results showed a significant relationship, with very large effect size, between the frequency that students ate home grown produce and the family members who ate home grown produce most often. Appendix 6.7 indicates that the majority of students were most likely eat home grown produce weekly when they did so equally 
with other family members, which could suggest that growing and eating fruits and vegetables from home was a normal feature of life for these families.

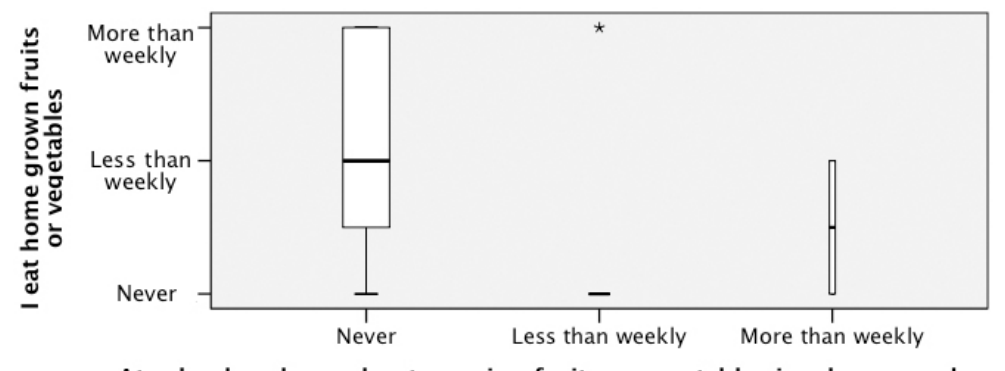

At school we learn about growing fruits or vegetables in a home garden

Appendix 6.5. Variable width box plots of students' self-reported frequency of eating home grown fruits or vegetables (y axis) and students' self-reported frequency of learning at school about growing fruits or vegetables in a home garden (x axis). 2009 ( $n_{\text {Learn never }}=16, n_{\text {Learn less than }}$ weekly $=7, n_{\text {Learn more than weekly }}=2$ ).

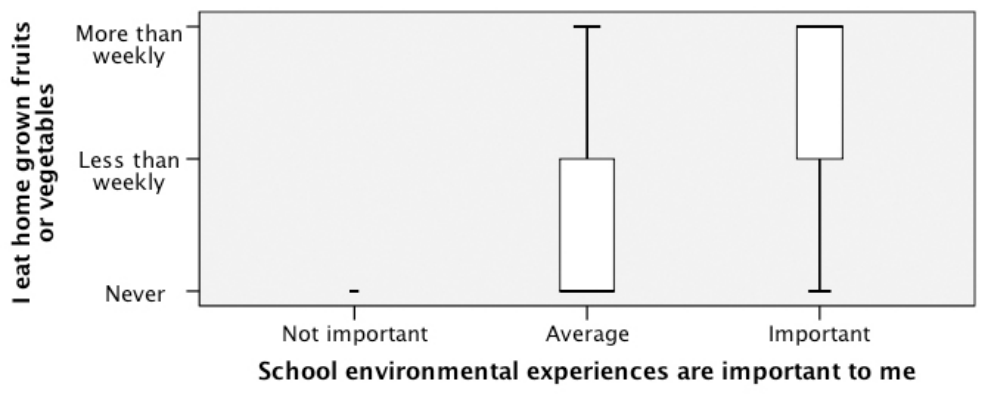

Appendix 6.6. Variable width box plots of students' self-reported frequency of eating home grown fruits or vegetables ( $\mathrm{y}$ axis) and students' importance of school environmental experiences (x axis). 2009 ( $\left.n_{\text {not important }}=2, n_{\text {average }}=13, n_{\text {important }}=11\right)$.

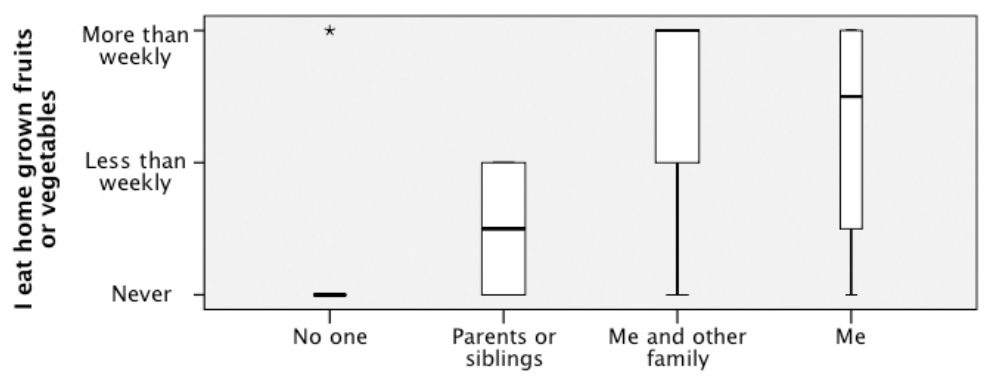

Family member/s who eat home grown fruits or vegetables most often

Appendix 6.7. Variable width box plots of students' self-reported frequency of eating home grown fruits or vegetables (y axis) and students' degree of participation in eating home grown fruits or vegetables (x axis). 2009 ( $n_{n o}$ one $=4, n_{\text {parents or siblings }}=8, n_{\text {me and other family }}=8, n_{\text {me }}=6$ ).

Maintaining organic waste. Putting food scraps into a worm farm or compost bin was practiced on a greater than weekly basis by 15 percent of upper-primary students at Fertile Ground Primary School in 2009 and 85 percent of students indicated that they never worm farmed or composted at home (Figure 6.9). Chi-square results indicate that maintaining organic waste processes at home was not related to any of the three comparison variables, Learning, Importance or Participation. Box plots are not shown because there were no relationships. Consequently, if students were doing this 
Appendix 6 - Detailed Student Behaviour Results from Fertile Ground Primary School behaviour weekly they did it regardless of how often they learned about waste minimisation, how important school environmental experiences were to them and which family members were most proactive. 
THIS PAGE HAS PURPOSELY BEEN LEFT BLANK 


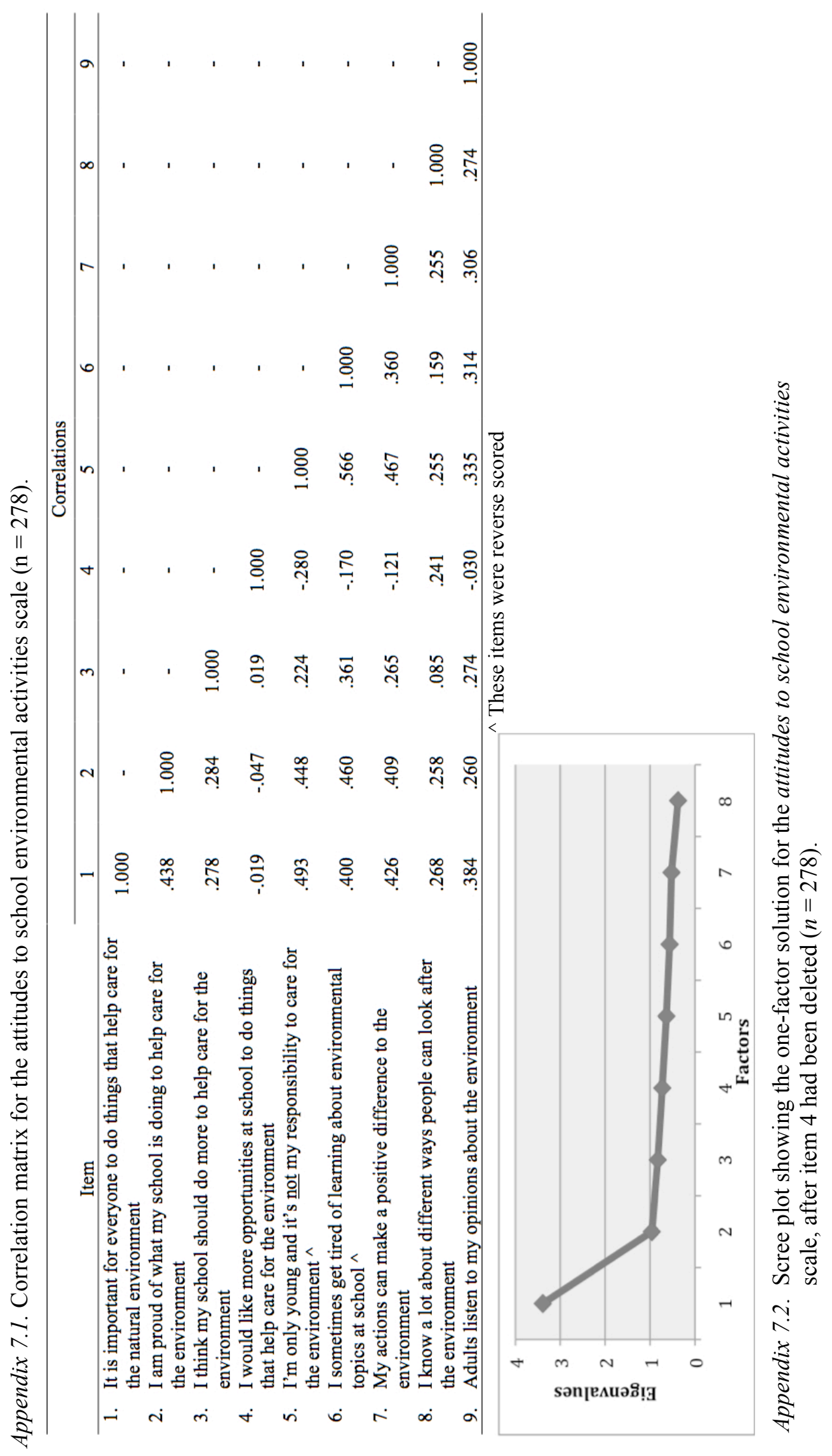




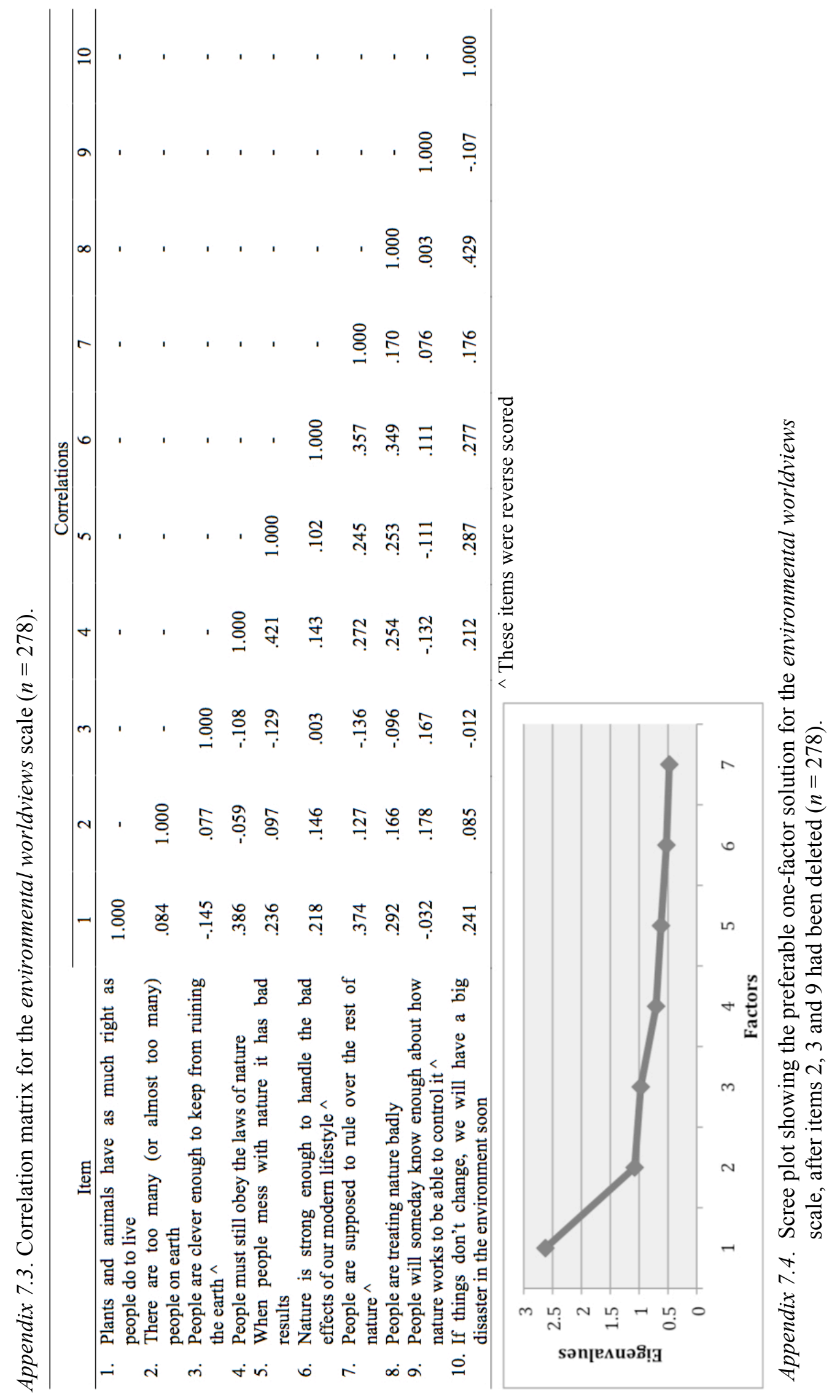




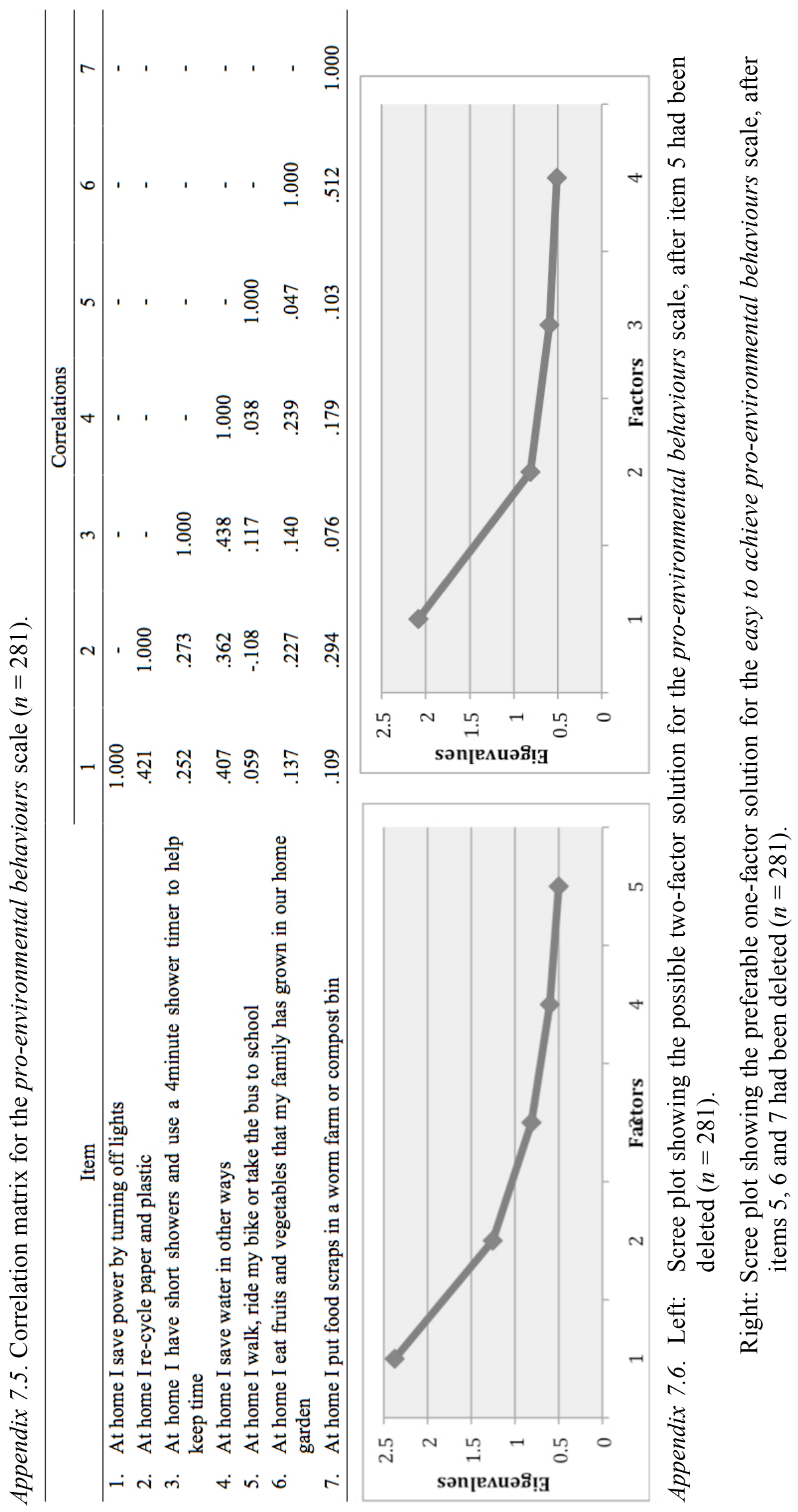




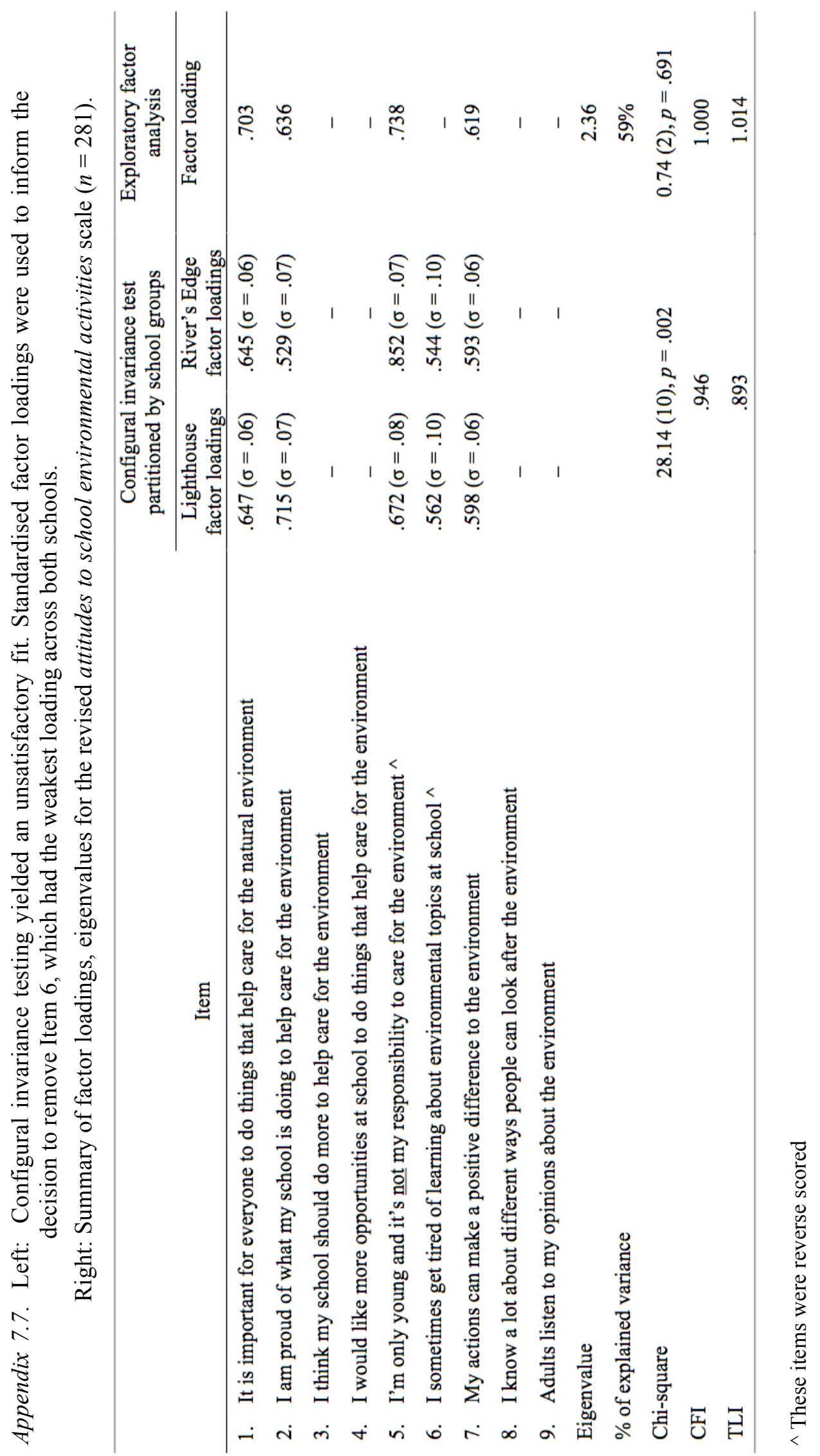


THIS PAGE HAS PURPOSELY BEEN LEFT BLANK 